\title{
Core-Concrete Interactions Using Molten Urania With Zirconium on a Limestone Concrete Basemat
}

The SURC-1 Experiment

Manuscript Completed: August 1992

Date Published: September 1992

Prepared by

E. R. Copus, R. E. Blose*, J. E. Brockmann,

R. B. Simpson, D. A. Lucero

Sandia National Laboratories

Albuquerque, NM 87185

Prepared for

Division of Systems Research

Office of Nuclear Regulatory Research

U.S. Nuclear Regulatory Commission

Washington, DC 20555

NRC FIN A1218

${ }^{*}$ Ktech Corporation, Albuquerque, NM 87185 


\section{DISCLAIMER}

This report was prepared as an account of work sponsored by an agency of the United States Government. Neither the United States Government nor any agency Thereof, nor any of their employees, makes any warranty, express or implied, or assumes any legal liability or responsibility for the accuracy, completeness, or usefulness of any information, apparatus, product, or process disclosed, or represents that its use would not infringe privately owned rights. Reference herein to any specific commercial product, process, or service by trade name, trademark, manufacturer, or otherwise does not necessarily constitute or imply its endorsement, recommendation, or favoring by the United States Government or any agency thereof. The views and opinions of authors expressed herein do not necessarily state or reflect those of the United States Government or any agency thereof. 


\section{DISCLAIMER}

Portions of this document may be illegible in electronic image products. Images are produced from the best available original document. 


\begin{abstract}
An inductively heated experiment SURC-1, using $\mathrm{UO}_{2}-\mathrm{ZrO}_{2}$ material, was executed to measure and assess the thermal, gas, and aerosol source terms produced during core debris/concrete interactions. The SURC-1 experiment eroded a total of $27 \mathrm{~cm}$ of limestone concrete during 130 minutes of sustained interaction using $204.2 \mathrm{~kg}$ of molten prototypic $\mathrm{UO}_{2}-\mathrm{ZrO}_{2}$ core debris material that included $18 \mathrm{~kg}$ of $\mathrm{Zr}$ metal and $3.4 \mathrm{~kg}$ of fission product simulants. The melt pool temperature ranged from 2100 to $2400^{\circ} \mathrm{C}$ during the first 50 minutes of the test, followed by steady temperatures of 2000 to $2100^{\circ} \mathrm{C}$ during the middle portion of the test and temperatures of 1800 to $2000^{\circ} \mathrm{C}$ during the final 50 minutes of testing. The total erosion during the first 50 minutes was $16 \mathrm{~cm}$ with an additional $2 \mathrm{~cm}$ during the middle part of the test and $9 \mathrm{~cm}$ of ablation during the final 50 minutes. Aerosols were continuously released in concentrations ranging from 30 to $200 \mathrm{~g} / \mathrm{m}^{3}$. Comprehensive gas flow rates, gas compositions, and aerosol compositions were also measured during the SURC-1 test.
\end{abstract}




\section{Contents}

Section

Executive Summary $\ldots \ldots \ldots \ldots \ldots \ldots \ldots \ldots \ldots \ldots \ldots \ldots \ldots$

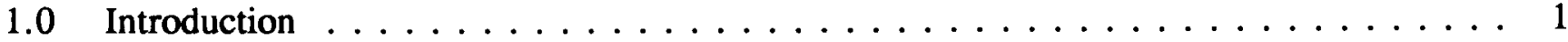

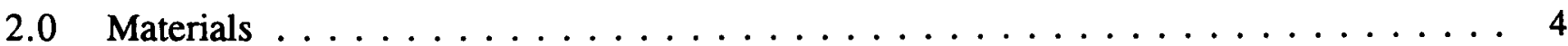

2.1 Magnesium Oxide $(\mathrm{MgO})$ Castable Refractory . . . . . . . . . . . . . . . . 4

2.2 Concrete Material . . . . . . . . . . . . . . . . . . . . 9

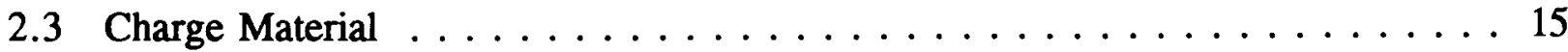

2.4 Fission Product Simulants ....................... 15

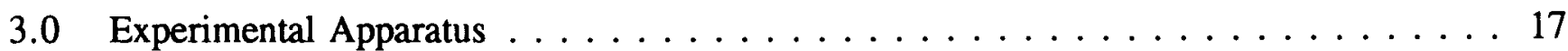

3.1 Containment Vessel $\ldots \ldots \ldots \ldots \ldots \ldots \ldots \ldots$

3.2 Interaction Crucible $\ldots \ldots \ldots \ldots \ldots \ldots \ldots \ldots \ldots$

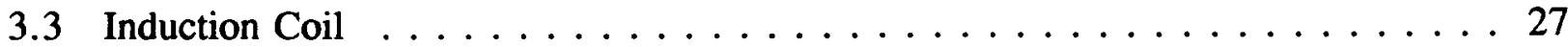

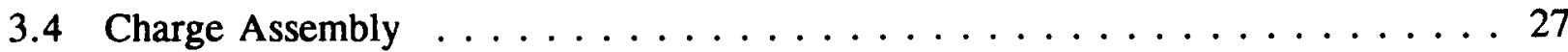

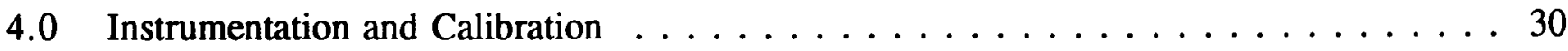

4.1 Thermocouple and Pyrometer Instrumentation . . . . . . . . . . . . 30

4.2 Gas Analysis Instrumentation . . . . . . . . . . . . . . . . . . 31

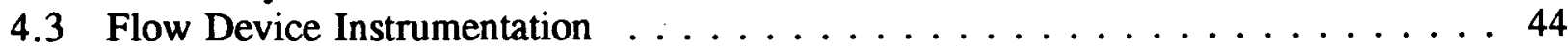

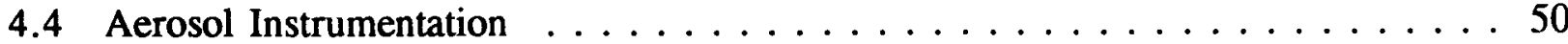

4.5 Induction Power Instrumentation $\ldots \ldots \ldots \ldots \ldots \ldots$

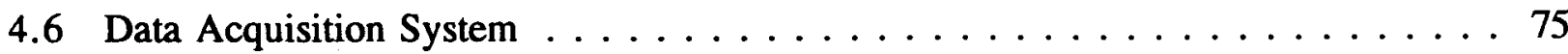

4.7 Video Monitoring Instrumentation . . . . . . . . . . . . . . . . 80

5.0 Test Procedure and Posttest Observations $\ldots \ldots \ldots \ldots \ldots$

5.1 Operational Procedure $\ldots \ldots \ldots \ldots \ldots \ldots$

5.2 Posttest Observations ........................ 81

6.0 Data Presentation and Results ... . . . . . . . . . . . . . . . . . 94

6.1 Temperature Data . . . . . . . . . . . . . . . . . . . . . 94

6.2 Gas Composition Data Presentation . . . . . . . . . . . . . . . . 112

6.3 Flow Data Presentation . . . . . . . . . . . . . . . . . . . 117

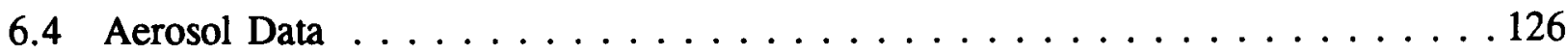

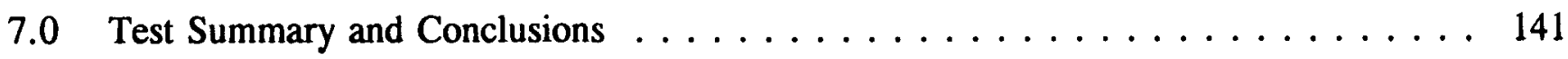

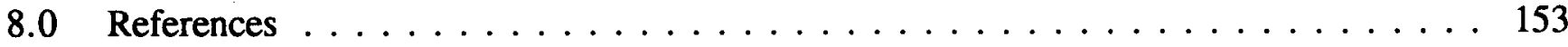




\section{Contents (continued)}

$\underline{\text { Section }}$

Page

Appendix A: Calorimetric Test Data . . . . . . . . . . . . . . A A-1

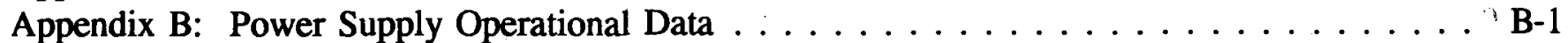

Appendix C: Crucible Thermocouple Profiles $\ldots \ldots \ldots \ldots \ldots \ldots \ldots \ldots$ C-1

Appendix D: Melt Temperature and Pyrometer Data $\ldots \ldots \ldots \ldots \ldots \ldots \ldots \ldots$ D-1

Appendix E: Calculated Sidewall Heat Flux Data $\ldots \ldots \ldots \ldots \ldots \ldots \ldots$ E-1

Appendix F: Pressure Transducer and Flow Device Calibration Data $\ldots \ldots \ldots \ldots \ldots$ F-1

Appendix G: Gas Composition, Flow Rate, and Aerosol Data . . . . . . . . . . G-1 
Figure

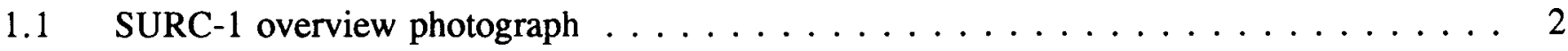

2.1 Interaction crucible, SURC-1 experiment $\ldots \ldots \ldots \ldots \ldots$

2.2 Elevated temperature cure for the annulus of the lower crucible $\ldots \ldots \ldots \ldots$

2.3 Thermogram (TGA) of the cured and baked K/R Cast 98; bottom of lower crucible . . 7

2.4 Thermogram (TGA) of the cured and baked K/R Cast 98; top of lower crucible . . . . 8

2.5 Compressive strength versus time of cure for limestone concrete . . . . . . . . . . 13

2.6 Thermogram (TGA) of limestone concrete used in the SURC-1 experiment . . . . . . 14

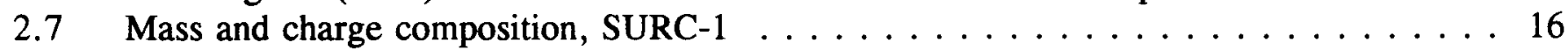

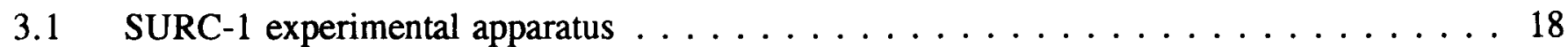

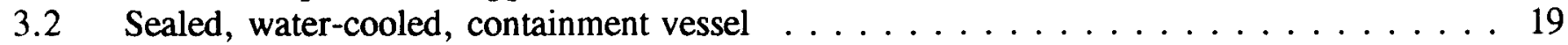

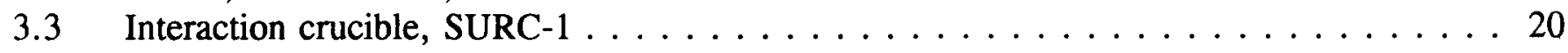

3.4 Relative thermocouple locations, SURC-1 crucible . . . . . . . . . . . . . . 22

3.5 Typical thermocouple arrays cast into the concrete . . . . . . . . . . . . . . 25

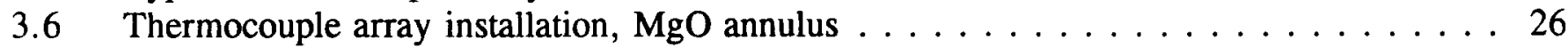

4.1 .1 Schematic of fiber optic pyrotube assembly . . . . . . . . . . . . . . . 32

4.1.2 Photograph showing the position of tungsten pyrotubes installed

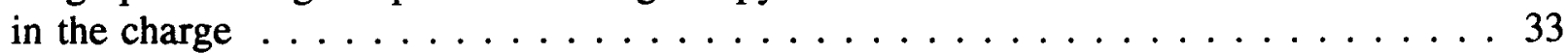

4.1.3 Photograph of the stainless steel adapters used to connect the tungsten

pyrotubes to the pyrometer head adapter . . . . . . . . . . . . . . . 34

4.1.4 Photograph of the fiber optic pyrometer assembly installed on the

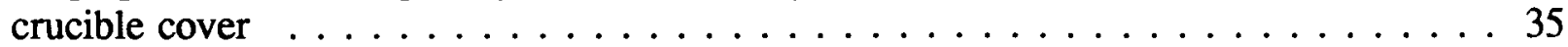

4.1.5 Micron fiber optic pyrometer calibration, pyrotube elevation $\mathrm{z}=0 \mathrm{~cm} \ldots \ldots 36$

4.1.6 Micron fiber optic pyrometer calibration, pyrotube elevation $z=+10 \mathrm{~cm} \ldots \ldots 37$

4.1.7 Micron fiber optic pyrometer calibration, pyrotube elevation $z=+20 \mathrm{~cm} \ldots \ldots 38$

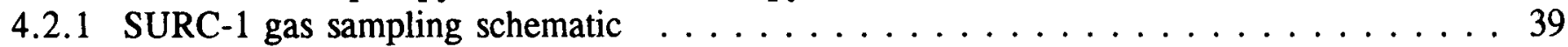

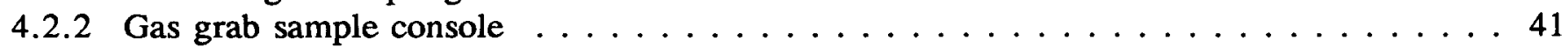

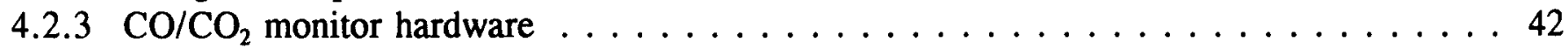

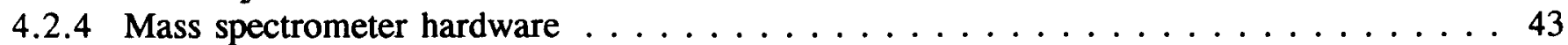

4.3 .1 Flow train schematic . . . . . . . . . . . . . . . . . . . . . 46

4.3.2 ASME sharp edge orifice calibration, $1 \mathrm{~cm}$ diameter . . . . . . . . . . . . . 48

4.3 .3 Laminar flow element calibration . . . . . . . . . . . . . . . . . . . 49

4.3 .4 Turbine flowmeter calibration ....................... 51

4.3.5 Rockwell 415 positive displacement gas meter calibration . . . . . . . . . . . . . 52

4.3.6 Rockwell 750 positive displacement gas meter calibration . . . . . . . . . . . . . 53

4.4.1 Flow chart illustrating how the source term parameters are determined from measurements made in the SURC-1 melt/concrete interaction test . . . . . . . 56

4.4.2 Photograph of the aerosol sampling instrumentation connected to the flow line . . . . . . . . . . . . . . . . . . . . . . . . 57

4.4.3 Schematic diagram of the sample extraction dilution system (SEDS) showing the locations of pressure transducers, thermocouples, and flow controlling orifices. 


\section{Figures (continued)}

Figure

Page

4.4.4 Schematic diagram of flow diluter used in the sample extraction

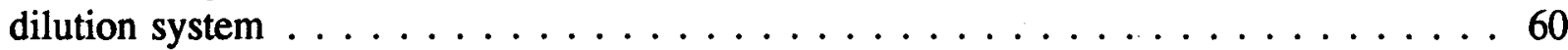

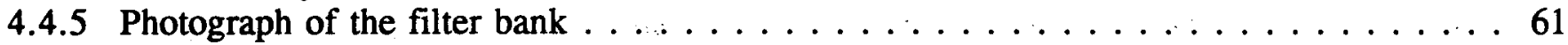

4.4.6 The Gelman high pressure filter holder shown disassembled with filter substrate support and filter substrate and supports in place . . . . . . . . . . 63

4.4.7 Photograph of the impactor bank showing the impactors and by-pass filter . . . . . . . . 64

4.4.8 Photograph showing the assembled Anderson Mark III impactor-preseparator

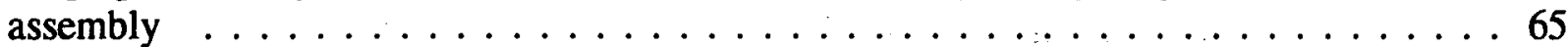

4.4.9 Photograph showing the disassembled Anderson Mark III impactor-preseparator

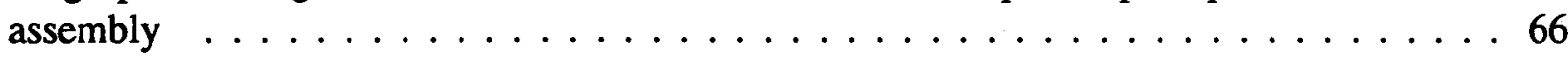

4.4.10 Sierra cascade cyclone shown assembled with its six constituent cyclones

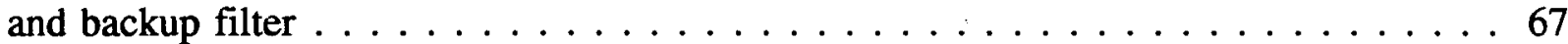

4.4.11 Sierra cascade cyclone shown disassembled into its six constituent cyclones

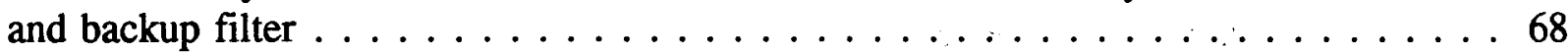

4.4.12 Schematic diagram of the opacity meter used on the SURC-1 test showing how it was installed behind gas purged windows in the exhaust gas line . . . . . . . . 70

4.4.13 Experimental results and theory for particle penetration through a $90^{\circ}$ bend as a function of Stokes number $\ldots \ldots \ldots \ldots \ldots$

4.4.14 Penetration efficiency as a function of particle aerodynamic diameter predicted by theory and measured for a $4.56 \mu \mathrm{m}$ particle from the SEDS inlet at diluter 1 to the filter sample point

4.4.15 Penetration efficiency as a function of particle aerodynamic diameter predicted by theory and measured for a $4.56 \mu \mathrm{m}$ particle from the SEDS inlet at diluter 1 to the impactor sample point $\ldots \ldots \ldots \ldots \ldots$

4.5 .1 Inductotherm power supply . . . . . . . . . . . . . . . . . . 79

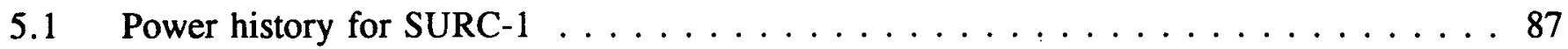

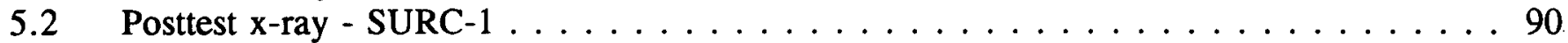

5.3 Photograph showing a section of the third tungsten ring on top of a crust overlying the solidified meltpool surface $\ldots \ldots \ldots \ldots \ldots$

5.4. Photograph showing a sectional view of the crucible exposing the configuration of the meltpool and the crust material above . . . . . . . . . . . . . . 92

5.5 Photograph showing a section of the crucible revealing the meltpool/concrete interface . 93

6.1.1 Three regions for analyzing melt concrete interactions $\ldots \ldots \ldots \ldots \ldots \ldots$

6.1.2 Typical thermal response of the concrete for the SURC-1 experiment . . . . . . . . 96

6.1 .3 Location of the SURC-1 $400 \mathrm{~K}$ isotherm $\ldots \ldots \ldots \ldots \ldots$

6.1 .4 Location of the SURC-1 erosion front . . . . . . . . . . . . . . . . . . . 99

6.1.5 Initial thermal response of the concrete during the onset of ablation for the center axis array $\ldots \ldots \ldots \ldots \ldots \ldots$

6.1.6 Comparison of the $400 \mathrm{~K}$ and $1600 \mathrm{~K}$ isotherms in SURC $-1 \ldots \ldots \ldots$ 


\section{Figures (continued)}

Figure

Page

6.1.7 Thermal response indicated by type $C$ and $S$ thermocouples installed

in alumina tubes and cast into the concrete . . . . . . . . . . . . . . . . 103

6.1.8 Peak meltpool temperature measured as a function of time for the alumina

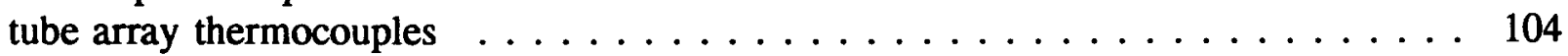

6.1.9 Thermal response of type $\mathrm{C}$ thermocouples installed in the tungsten pyrotubes $\ldots \ldots 5$

6.1.10 Comparison of temperatures indicated by the fiber optic pyrometers and the type $\mathbf{C}$ thermocouples installed at the base of each pyrotube $\ldots \ldots \ldots 6$

6.1.11 Typical thermal response from thermocouples installed in the $\mathrm{MgO}$ annulus . . . . . . 108

6.1.12 Sidewall heat flux profile initially below the melt, SURC-1 . . . . . . . . . . . . . 109

6.1 .13 Sidewall heat flux profile initially adjacent to melt, SURC-1 . . . . . . . . . . . 110

6.1.14 Sidewall heat flux profile initially above the melt, SURC-1 . . . . . . . . . . . 111

6.1.15 Typical thermal response from thermocouples installed in the $\mathrm{MgO}$ cover $\ldots \ldots$. . . . 113

6.1.16 Upward heat flux calculated from thermocouples data located in the MgO cover . . . 114

6.2.1 Plot of the pressure inside the containment as a function of time . . . . . . . . . 116

6.2 .2 SURC-1 $\mathrm{CO} / \mathrm{CO}_{2}$ monitor data . . . . . . . . . . . . . . . . . . . 119

6.3 .1 Temperature distribution in the SURC-1 flow system . . . . . . . . . . . . . . . 121

6.3 .2 Pressure history in the SURC-1 flow system . . . . . . . . . . . . . . . . . . . 122

6.3.3 SURC-1 total flow - gas clock data . . . . . . . . . . . . . . . . . . . . . . . 124

6.3.4 SURC-1 total gas flow rate indicated by the orifice plate data . . . . . . . . . . . . . 125

6.3.5 SURC-1 total gas flow rate indicated by the laminar flow element . . . . . . . . . . 127

6.4 .1 Opacity meter output for SURC-1 test . . . . . . . . . . . . . . . . . . . . . 132

6.4.2 SURC-1 aerosol size distribution. Normalized aerosol mass distributions from impactors $\mathrm{E}$ and $\mathrm{F}$ taken at 154 minutes $\ldots \ldots \ldots \ldots$

6.4.3 SURC-1 aerosol size distribution. Normalized aerosol mass distributions from impactors $\mathrm{G}$ and $\mathrm{H}$ taken at 159 minutes . . . . . . . . . . . . . . . . . 134

6.4.4 SURC-1 aerosol size distribution. Normalized aerosol mass distributions from impactors $\mathrm{J}$ and $\mathrm{K}$ taken at 173 minutes $\ldots \ldots \ldots \ldots$

6.4.5 SURC-1 aerosol size distribution. Normalized aerosol mass distributions from impactors $\mathrm{N}$ and $\mathrm{O}$ taken at 260 minutes . . . . . . . . . . . . . . 136

6.4.6 SURC-1 aerosol size distribution. Normalized aerosol mass distribution from cyclone taken from 153 to 162 minutes . . . . . . . . . . . . . . 138

6.4 .7 SURC-1 elemental aerosol source term . . . . . . . . . . . . . . . . . . . . . . 139

6.4 .8 SURC-1 elemental aerosol source term . . . . . . . . . . . . . . . . . . . . . . . 140

7.1 Total and net power histories for SURC-1 . . . . . . . . . . . . . . . . . . . 142

7.2 Thermal response of the charge measured by type $C$ thermocouples installed in the tungsten pyrotubes . . . . . . . . . . . . . . . . . . . 143

7.3 Location of the dehydration front for SURC-1 . . . . . . . . . . . . . . . . . . 144

7.4 Total volume and gas flow rate (alpm) indicated by the 415 gas clock . . . . . . . . 145

7.5 Comparison of charge temperatures measured by the fiber optic pyrometers and the type $\mathrm{C}$ thermocouples installed in the tungsten pyrotubes $\ldots \ldots \ldots$ 
Figures (continued)

Figure

Page

7.6 Location of the ablation front and average ablation rates during different periods of the SURC-1 experiment . . . . . . . . . . . . . . . 148

7.7 Pressure history inside the containment vessel $\ldots \ldots \ldots \ldots \ldots \ldots \ldots$ 


\section{Tables}

Table

Page

$2.1 \quad$ Chemical composition of $\mathrm{K} / \mathrm{R}$ Cast-98 $\mathrm{MgO}$ castable refractory $\ldots \ldots \ldots \ldots$

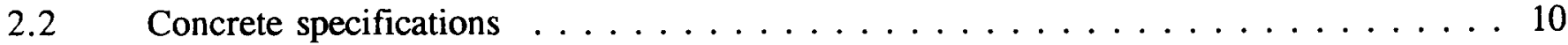

2.3 Engineering composition of limestone concrete $\ldots \ldots \ldots \ldots \ldots \ldots$

2.4 Chemical composition of limestone concrete constituents . . . . . . . . . . . . 11

2.5 Comparison of specified and actual size distributions for the fine and coarse

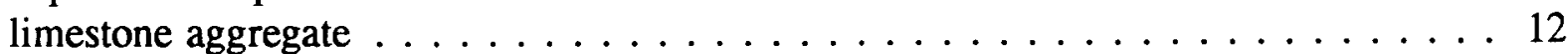

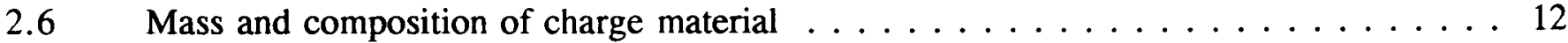

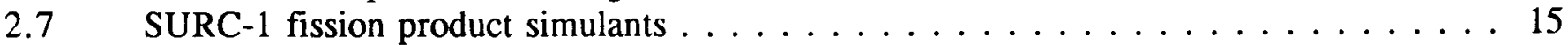

3.1 Location of thermocouples cast within the concrete cylinder, SURC-1 . . . . . . . 23

3.2 Location of thermocouples installed in the alumina tubes and cast into the

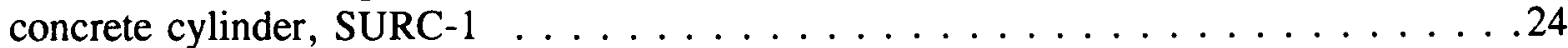

3.3 Location of thermocouples cast within the $\mathrm{MgO}$ sidewall, SURC-1 . . . . . . . . 28

3.4 Location of thermocouples cast within the crucible cover, SURC-1 _ . . . . . . . 29

4.2.1 Results of grab sample analysis on calibrated gas using gas chromatography . . . . . 45

4.3 .1 In-situ calibration for SURC-1 flow devices . . . . . . . . . . . . . . . . 54

4.3.2 Pre-test pressure decay and leak rate for SURC-1 containment vessel and flow train . 54

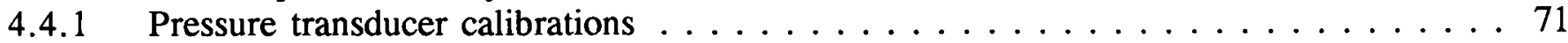

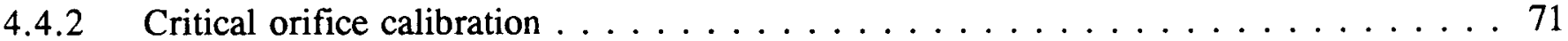

4.4.3 Anderson Mark III impactor cut points . . . . . . . . . . . . . . . . 73

4.4.4 Sierra cascade cyclone cut points supplied by manufacturer . . . . . . . . . . 73

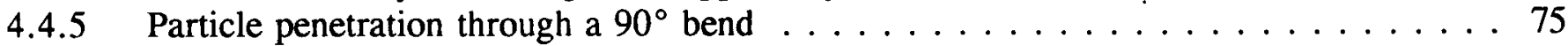

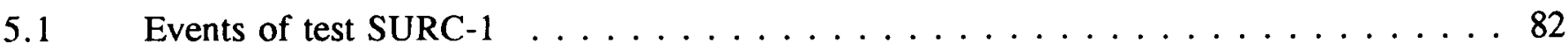

$5.2 \quad$ Elemental analysis of gravel filter aerosols $\ldots \ldots \ldots \ldots \ldots$

6.2.1 SURC-1 mass spectrometer data raw data - volume percent . . . . . . . . . . . . 118

6.2.2 SURC-1 mass spectrometer results normalized data - volume percent . . . . . . . 118

6.2.3 SURC-1 grab sample analysis raw data in volume (mole) percent . . . . . . . . . 120

6.3 .1 SURC-1 flow rates from gas clock data . . . . . . . . . . . . . . . . 126

$6.4 .1 \quad$ SURC-1 filter data . . . . . . . . . . . . . . . . . . . . . . . . . . . . . . 129

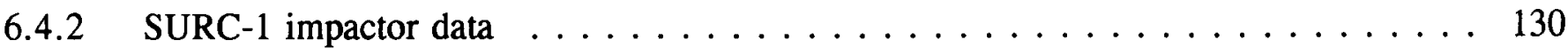

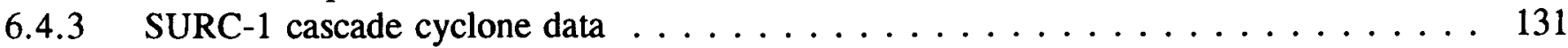

6.4.4 Elemental analysis of SURC-1 aerosol weight percent of element in sample . . . . 137

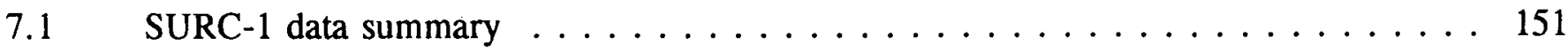




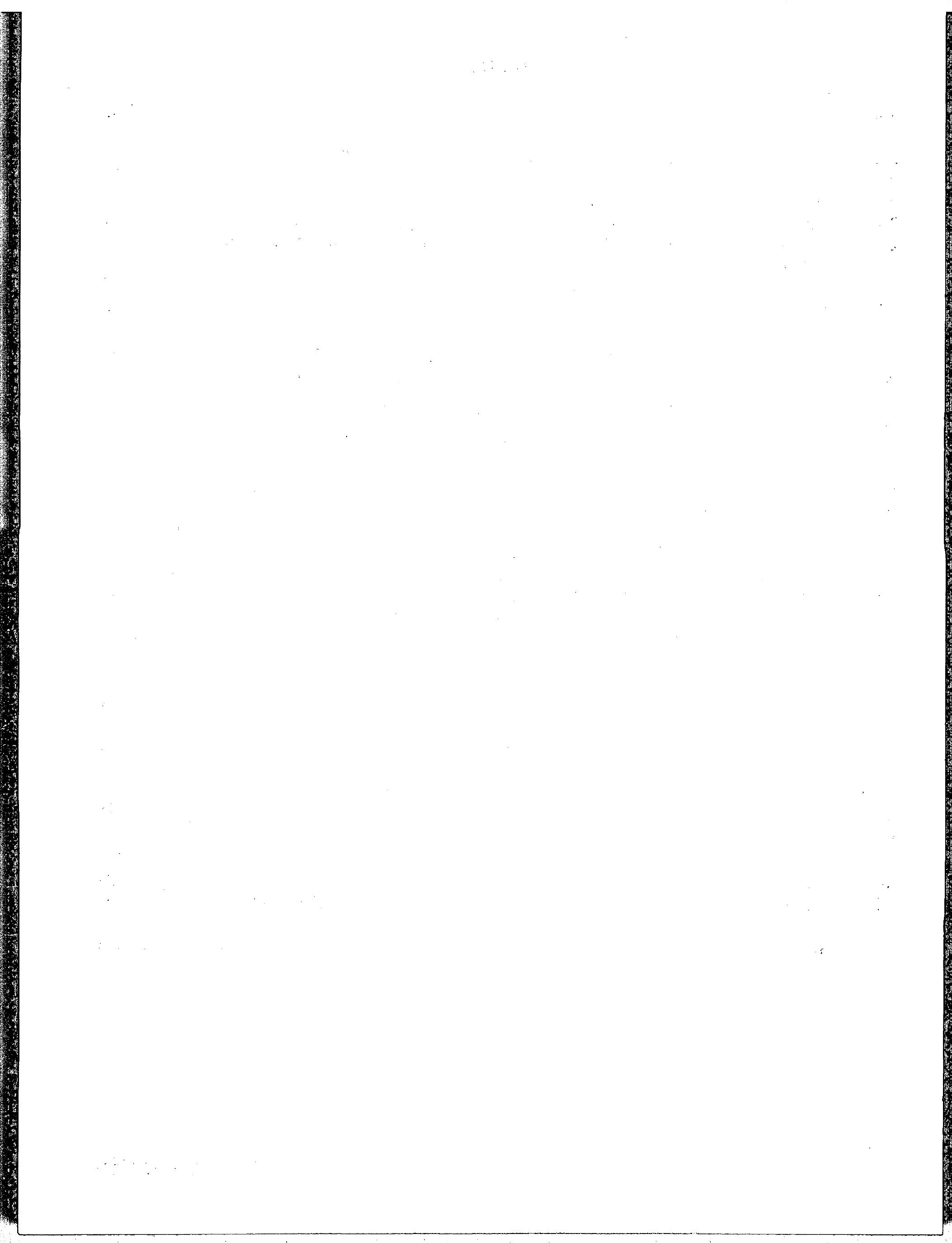

. 


\section{Executive Summary}

The SURC-1 and SURC-2 experiments form a major part of the core debris-concrete interactions data base. These tests were designed to measure, model, and assess the range of responses which are most likely during the initial 2 to 10 hours of these ex-vessel events. The range of response was measured using an oxide debris of $\mathrm{UO}_{2}-\mathrm{ZrO}_{2}$ on both limestone and siliceous concretes. Also included were a $\mathrm{Zr}$ metallic component and a limited number of fission product simulants. Both tests sustained the core debris-concrete interaction for over 2 hours using an identical power input history of 0.2 to $0.3 \mathrm{~W} / \mathrm{g}$.

The purpose of the SURC-1 experiment was to measure and assess the source terms produced during core debris/concrete interactions. These source terms include thermal energy released to both the reactor basemat and the containment environment, as well as flammable gas, condensible vapor, and toxic or radioactive aerosols generated during the course of a severe nuclear reactor accident. The SURC-1 experiment was an integral effects test conducted as part of the Core Debris Interactions program and used the same geometry and instrumentation scheme as was used in the SURC-2 and SURC-4 tests. The basic geometry was a $40 \mathrm{~cm}$ diameter limestone concrete basemat surrounded by an $\mathrm{MgO}$ annulus. A $280 \mathrm{~kW}$ induction power supply was used to heat a series of tungsten rings which were embedded in the oxide charge material. After 120 minutes of heating, the $204 \mathrm{~kg}$ oxide charge $\left(67 \% \mathrm{UO}_{2}-22 \% \mathrm{ZrO}_{2}-9 \% \mathrm{Zr}\right)$ became molten and began to attack the underlying concrete basemat. A total of $27 \mathrm{~cm}$ of limestone concrete were then eroded during the following 150 minutes. During the first 100 minutes of erosion a net power of $76 \mathrm{~kW}$ was applied to the tungsten susceptors to sustain the interaction. After 100 minutes, the power was increased to a net power of $100 \mathrm{~kW}$ for the final 50 minutes. Comprehensive measurements of meltpool temperature, erosion distance, sidewall heat losses, total gas production, total aerosol production, gas composition, and aerosol composition were taken throughout the test using a computerized data acquisition system.

Four time periods during the test were of particular interest. These were the onset of gas release prior to melting, a period of rapid erosion following initial melt-concrete contact, slowed erosion after the $\mathrm{Zr}$ metal in the charge was chemically consumed, and increased erosion when the power was increased towards the end of test. During the 50 minutes prior to melt, the temperature of the oxide charge increased from $1300 \mathrm{~K}$ to $2600 \mathrm{~K}$. The concrete basemat started to dehydrate during this time at an average rate of 4 to $5 \mathrm{~cm} / \mathrm{hr}$ producing a reaction gas flow rate of $29 \mathrm{slpm}$. The composition of this initial effluent gas was $50 \% \mathrm{H}_{2}-20 \% \mathrm{H}_{2} \mathrm{O}-20 \% \mathrm{CO}-10 \% \mathrm{CO}_{2}$ and only light aerosols were present at levels less then $1 \mathrm{~g} / \mathrm{m}^{3}$. Concrete erosion began when the oxide charge became completely molten, and a protective $\mathrm{ZrO}_{2}$ insulator board was breached. Meltpool temperatures at the onset of concrete attack were approximately $2700 \mathrm{~K}$. These temperatures decreased to $2400 \mathrm{~K}$ as $16 \mathrm{~cm}$ of concrete were eroded over a period of 50 to 60 minutes. The reaction gas flow increased to $150 \mathrm{slpm}$ and had a composition of $5 \% \mathrm{H}_{2}-5 \% \mathrm{H}_{2} \mathrm{O}-85 \% \mathrm{CO}-5 \% \mathrm{CO}_{2}$. Large amounts of aerosol were also produced at concentrations of 30 to $200 \mathrm{~g} / \mathrm{m}^{3}$ which had a composition rich in silicon, sodium, potassium, barium, molybdenum, and cerium. The size distribution of these aerosols ranged from 0.5 to 25 microns with a mass mean diameter at 3 microns. After 50 to 60 minutes of erosion the erosion rate slowed from $15 \mathrm{~cm} / \mathrm{hr}$ to $2 \mathrm{~cm} / \mathrm{hr}$ after all of the $\mathrm{Zr}$ metal became oxidized. The meltpool temperatures dropped from $2400 \mathrm{~K}$ to $2200 \mathrm{~K}$ as an additional 2 to $3 \mathrm{~cm}$ of concrete were eroded over a period of 30 minutes. The reaction gas flow rate decreased to 40 slpm and had a composition of $7 \% \mathrm{H}_{2}-8 \% \mathrm{H}_{2} \mathrm{O}-75 \%$ $\mathrm{CO}-10 \% \mathrm{CO}_{2}$. No aerosols were collected during this period despite the indication that concentrations were still quite high. After 90 to 100 minutes, the net power was increased to the charge material from 67 to $91 \mathrm{~kW}$. This resulted in increased erosion rates, increased gas release rates, and increased aerosol release rates. The meltpool temperature was 2050 to $2150 \mathrm{~K}$ during these final 50 to 60 minutes of the test as an additional 7 to $9 \mathrm{~cm}$ of concrete were eroded. The reaction gas flow rate increased from 40 
Executive

to 80 slpm and the gas composition was $5 \% \mathrm{H}_{2}-5 \% \mathrm{H}_{2} \mathrm{O}-80 \% \mathrm{CO}-10 \% \mathrm{CO}_{2}$. Aerosols averaged $60 \mathrm{~g} / \mathrm{m}^{3}$ and had a mean mass diameter of 2 microns.

After 287 minutes of heating and 160 minutes of continuous erosion, the gravel filter bed in the SURC-1 exit flow stream became plugged causing significant overpressures in the containment vessel. Power to the test was shut down at this point and the test was terminated. The test was excellent in all respects and successfully met all of the test goals.

The results of the SURC-1 test with limestone concrete generally confirm the observations made in the SURC-2 test with basaltic concrete. Both tests had very similar charge compositions and nearly identical power histories. The key observations made during the tests were: (1) high initial temperatures and erosion rates, (2) sustained interaction temperatures in excess of $2000 \mathrm{~K}$, and (3) continuous release of gas and aerosols in large amounts. This test should provide comprehensive, redundant, and well-characterized information on molten oxide interactions with limestone concrete that is well-suited for code validation efforts.

The major conclusions from the tests are that interaction temperatures remain well above the concrete melting point, that zirconium chemistry drastically affects the ablation rate and the gas composition, and that fission product materials can be released in significant amounts. The results of the SURC tests provide a substantial base for validation of the heat transfer, gas chemistry, and aerosol release models such as those found in the CORCON code and indicate that a relatively complete understanding now exists concerning the initial phases of core debris interactions with concrete when liquid water is not present. We feel that the understanding derived from the combined oxide and metal data base is reasonably adequate for current regulatory purposes. Future regulations or new reactor design efforts will be able to tap this technology base but may also suggest a new range of responses that need definition. 


\subsection{Introduction}

The Core Debris Interactions Program is intended to measure, model, and assess the thermal, gas evolution, and aerosol source terms produced during core debris-concrete interactions that might occur following a severe nuclear reactor accident. These source terms are the governing phenomena in any postaccident containment integrity analysis or risk evaluation. A matrix of tests is being conducted as part of the program. This matrix is designated as the SURC test series.

In addition to extending the existing data base to include more prototypic core debris-concrete interactions, the SURC experiments are designed to provide information necessary to validate three important aspects of ex-vessel core debrisconcrete interactions models. These are (1) heat transfer mechanisms, (2) gas release chemistry, and (3) vaporization release of aerosols. Both integral tests using $\mathrm{UO}_{2}-\mathrm{ZrO}_{2}$ materials (SURC-1, SURC-2 [Copus et al., 1992]), as well as separate effects tests using Fe-Zr (SURC-3, SURC-4 [Copus et al., 1989]) have been conducted.

The SURC-1 and SURC-2 tests in the SURC series were designed to be integral tests using a $200 \mathrm{~kg}$ mixture of 63 w/o $\mathrm{UO}_{2}-27$ w/o $\mathrm{ZrO}_{2}-10$ w/o $\mathrm{Zr}$ over a $40 \mathrm{~cm}$ diameter concrete basemat formed from either limestone concrete (SURC-1) or basaltic concrete (SURC-2). The purpose of these tests was to study the protracted interaction of an oxidic meltpool on a range of concrete basemat materials. Before these tests were conducted the bulk of data available for evaluating the ex-vessel core concrete interaction was either from tests using metallic iron as the core debris simulant or from tests which lasted only a few minutes. The SURC- 1 test sustained the oxide-concrete reaction for over 130 minutes and the SURC-2 experiment 180 minutes. During the course of these tests it was our goal to measure all of the essential aspects of the coreconcrete interaction, namely; melt temperatures, erosion rates, overall heat balance, thermal conduction into the concrete, gas release rates, gas release chemistry, aerosol release rates and aerosol chemistry. The data return from both tests was excellent and provides comprehensive, redundant, and well characterized information on the oxide-concrete interaction which should be well suited for code validation efforts [Bradley et al., 1992].

The SURC-1 experiment was conducted using the same geometry and instrumentation scheme as was used in SURC-2 and in SURC-4. The basic geometry consisted of a $60 \mathrm{~cm}$ diameter interaction crucible with a $40 \mathrm{~cm}$ diameter limestone concrete cylinder in the base of a magnesium oxide $(\mathrm{MgO})$ annulus. A $10 \mathrm{~cm}$ thick, circular cover of $\mathrm{MgO}$ was fabricated and placed on top of the crucible. The interaction crucible and induction coil were housed in a sealed, water cooled, aluminum containment vessel. A picture of this vessel and some of the rest of the test apparatus is shown in Figure 1.1. The vessel was $180 \mathrm{~cm}$ high, $120 \mathrm{~cm}$ in diameter and contained feedthroughs for the induction power leads, instrumentation leads, and an exhaust gas port connected to the flow and aerosol sampling instrumentation. The interaction crucible was instrumented with numerous thermocouple arrays cast into the concrete cylinder, $\mathrm{MgO}$ annulus and $\mathrm{MgO}$ cover. A $280 \mathrm{~kW}$ induction power supply and coil were used to heat and melt the $200.8 \mathrm{~kg}$ charge within the test article and to sustain the interaction for the duration of the experiment. Additionally, 3.4 $\mathrm{kg}$ of fission product simulants were added into the melt to study fission product release. Flow rates of generated gases were measured using a sharp edge concentric orifice, a laminar flow device and two dry gas clocks. Gaseous effluents produced during the experiment were monitored and sampled using an infrared gas analyzer, a mass spectrometer, and by an integral grab sample technique. Aerosols were captured on filters, cascade impactors and a cascade cyclone. Erosion characteristics were measured using type $\mathrm{K}, \mathrm{S}$, and $\mathrm{C}$ thermocouples. Three tungsten thermowells containing optical pyrometers were embedded in the charge in order to define the 


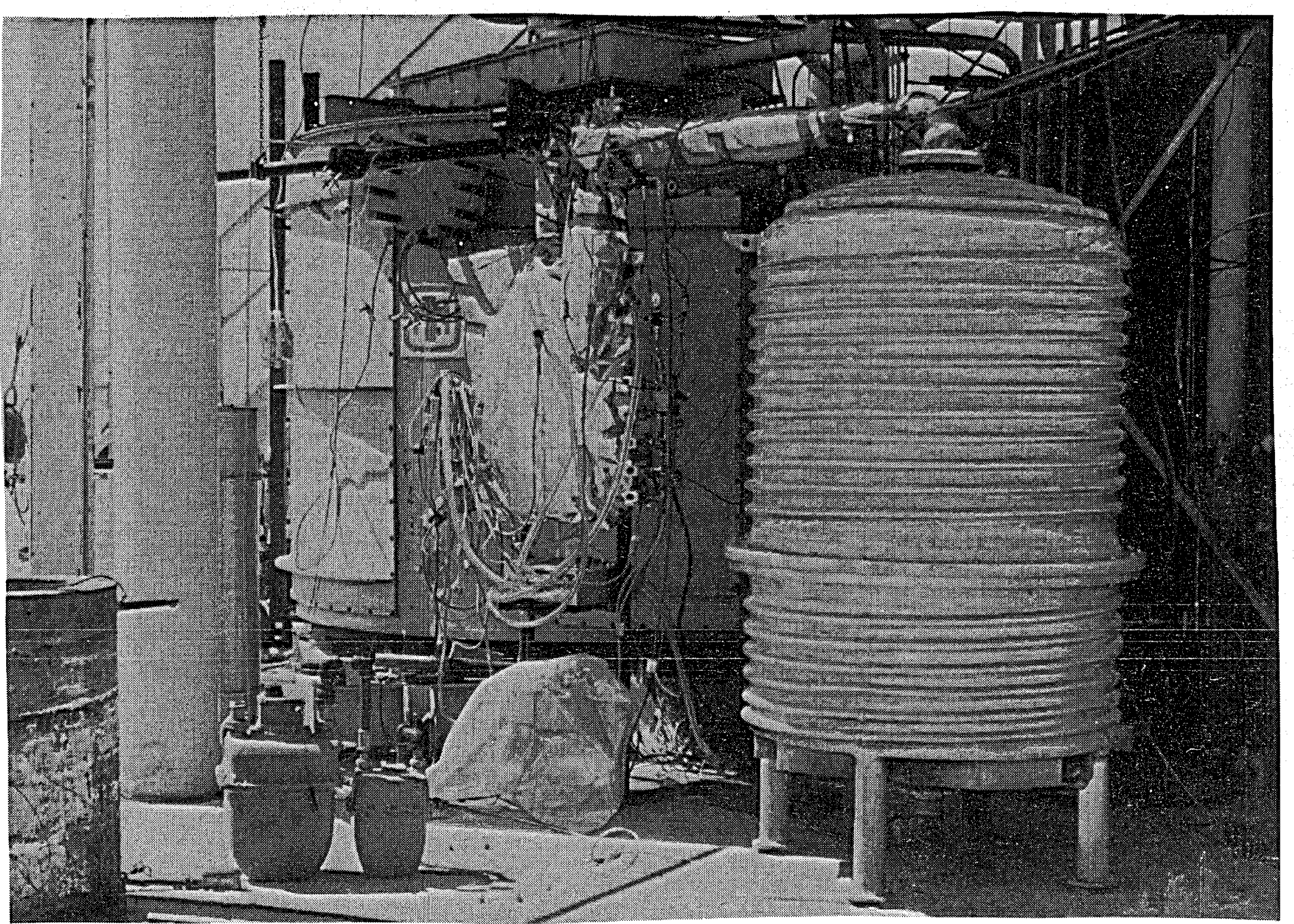


Introduction

meltpool temperature and overall heat balance. The apparatus was sealed and purged with argon gas in order to direct the majority of the reaction gas and aerosol effluents through a $5 \mathrm{~cm}$ diameter flow pipe. The SURC-1 test was run at local atmospheric pressure $(0.83 \mathrm{~atm})$ and at an ambient temperature of $25^{\circ} \mathrm{C}$. 


\subsection{Materials}

The interaction crucible used in the SURC-1 experiment is of cylindrical geometry and is shown in Figure 2.1. The crucible consists of three major components; the lower crucible, upper crucible and cover. The annulus of the upper and lower crucible and the cover are cast using a $\mathrm{MgO}$ castable refractory material. Limestone concrete is cast into the base of the lower crucible. A detailed description of the interaction crucible including dimensions and thermocouple locations will be given later in Section 3.2.

\subsection{Magnesium Oxide (MgO) Castable Refractory}

The annulus of the crucible was cast using an $\mathrm{MgO}$ castable material manufactured by Kaiser Refractories called K/R Cast-98. This material is a superior $\mathrm{MgO}$ castable produced from critically sized $98+$ percent $\mathrm{MgO}$ periclase and bonded with a special chromate composition. K/R Cast -98 can be vibrated to exceptionally high densities. This material resists melt penetration and provides outstanding resistance to highly basic slags. This material also has excellent volume stability and is commonly used for crucibles in the steel industry. The chemical composition of K/R Cast-98 taken from manufacturers specifications is shown in Table 2.1 .

The $\mathrm{MgO}$ castable was mixed by placing a known mass of dry material into a clean paddle-type mixer. Water was then added 5 percent by weight to the castable material and mixed for at least two minutes. Once a homogeneous mixture was achieved, the mix was carefully placed into the casting forms with small scoops and shovels. Two types of vibrators, operating at 10,000 to 12,000 vibrations/minute were used to densify the mix and remove entrained air. A pneumatically operated eccentric vibrator was attached to the brackets mounted to the steel casting forms.
Table 2.1 Chemical composition of $K / R$ Cast $-98^{*} \mathrm{MgO}$ castable refractory

\begin{tabular}{lc}
\hline Oxide & Weight \% \\
\hline $\mathrm{MgO}$ & 97.1 \\
$\mathrm{SiO}_{2}$ & 0.4 \\
$\mathrm{Al}_{2} \mathrm{O}_{3}$ & 0.1 \\
$\mathrm{Fe}_{2} \mathrm{O}_{3}$ & 0.3 \\
$\mathrm{CaO}$ & 1.0 \\
$\mathrm{Cr}_{2} \mathrm{O}_{3}$ & 1.1 \\
\hline${ }^{*} \mathrm{~K} / \mathrm{R} \mathrm{Cast-98}$ is a product of Kaiser Refractories, \\
300 Lakeside Drive, Oakland, CA 94643. \\
\multicolumn{2}{c}{ Data obtained from Basic Ramming and Casting } \\
Mixes Bulletin Published by Kaiser Refractories. \\
\hline
\end{tabular}

Another mechanical vibrator called a "stinger" was inserted directly into the mix to enhance densification.

After casting, the mix was cured at ambient temperature $\left(15\right.$ to $\left.35^{\circ} \mathrm{C}\right)$ for 24 hours. Then the casting and forms were placed into an oven and initially heated at a rate of $30^{\circ} \mathrm{C} /$ hour to $490^{\circ} \mathrm{C}$. The casting was held at $490^{\circ} \mathrm{C}$ for 12 hours. The total curing cycle took 32 hours. During the baking period, two K-type thermocouples were connected to a strip chart recorder to monitor the curing temperature. One thermocouple measured the ambient oven temperature, the other thermocouple was cast into the annulus and measured the actual temperature of the castable. The data from these thermocouples are presented in Figure 2.2. The annulus temperature lags the oven temperature as shown in the figure.

The thermal behavior of the K/R Cast-98 was characterized by thermal gravimetric analysis (TGA), shown in Figures 2.3 and 2.4. This analysis was performed with a Dupont 790 thermal analysis apparatus with a $1870 \mathrm{~K}$ DTA cell and Model 950 TGA attachment. 


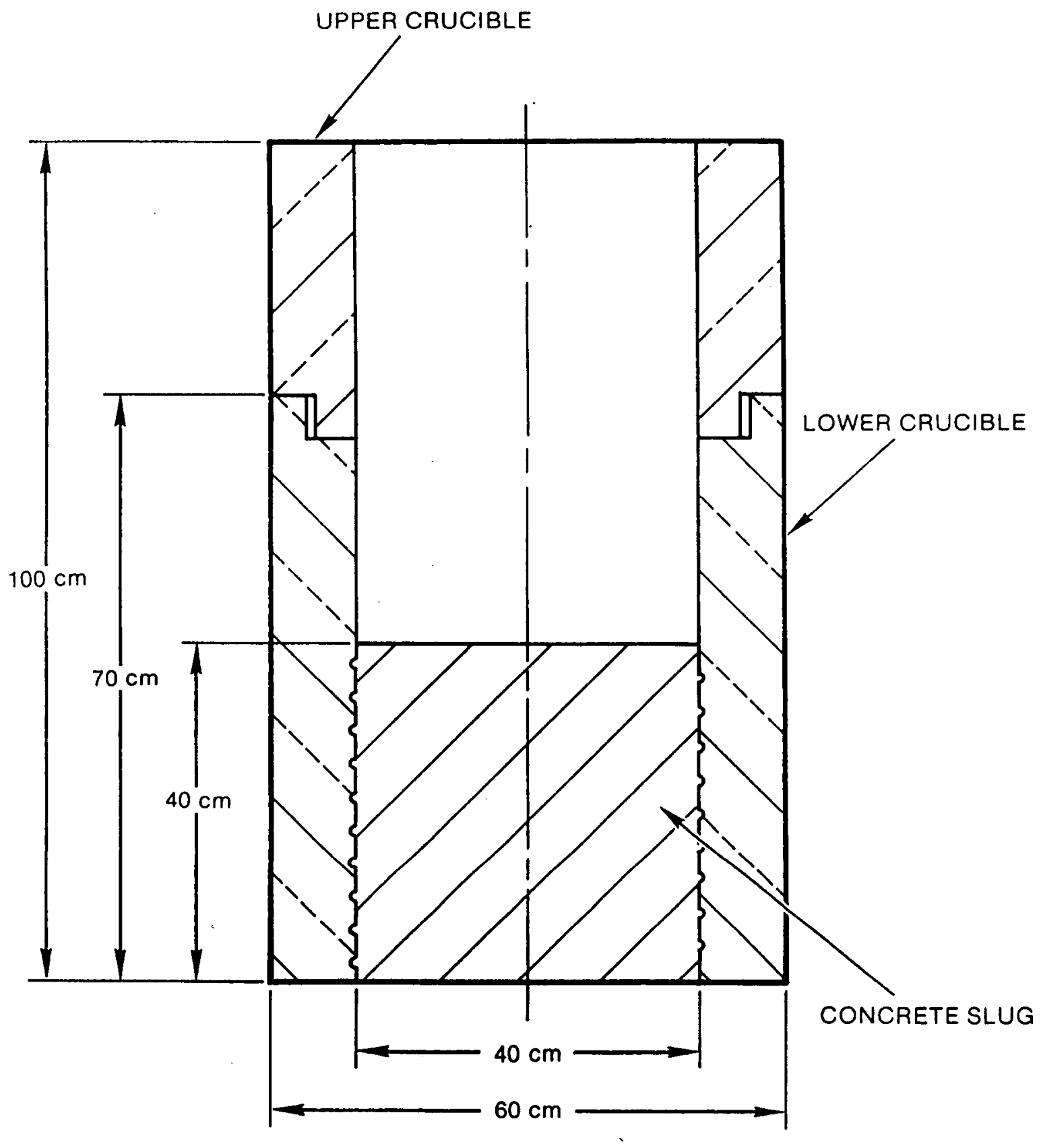

Figure 2.1 Interaction crucible, SURC-1 experiment 
$a$

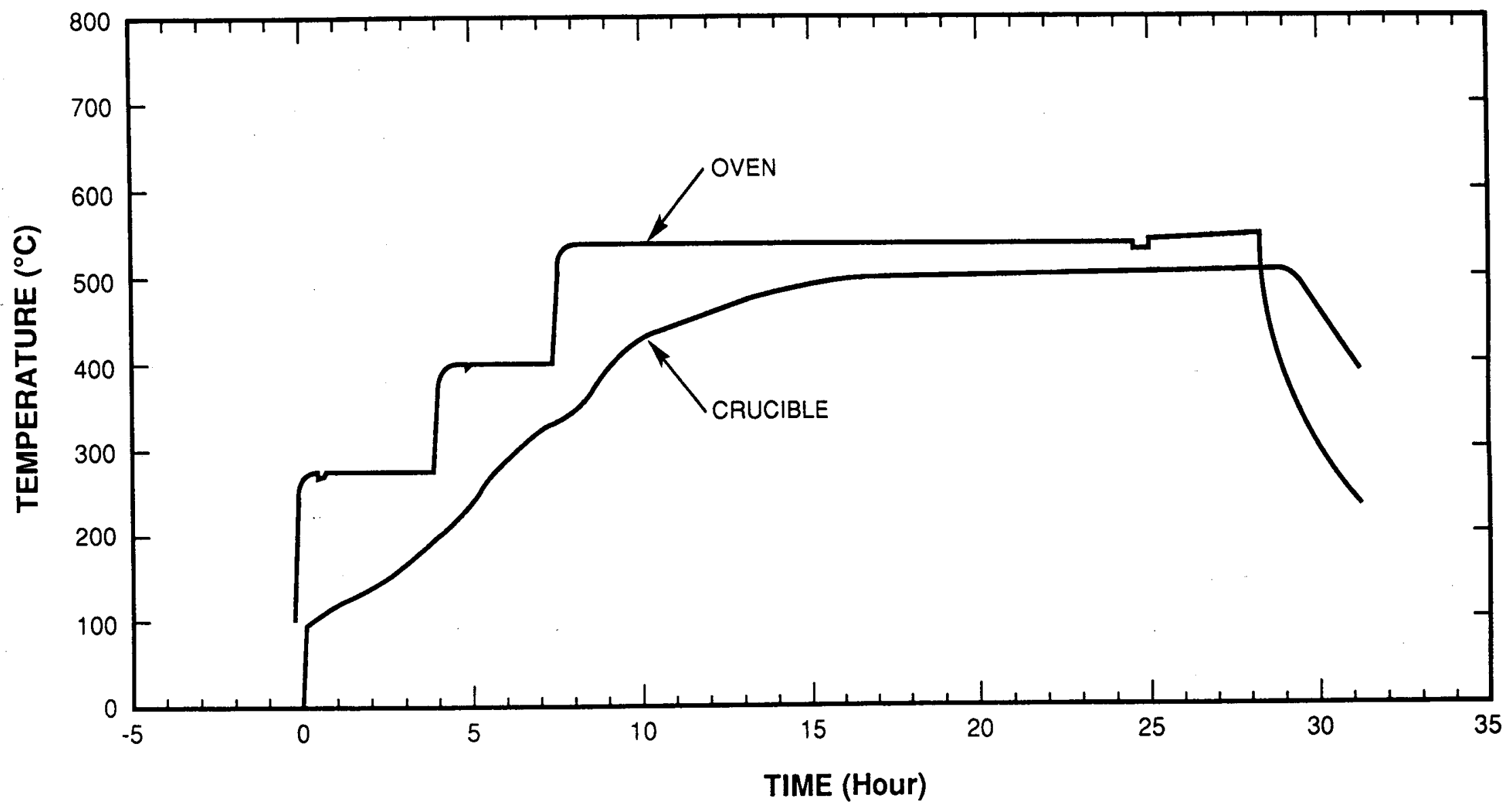

Figure 2.2 Elevated temperature cure for the annulus of the lower crucible 


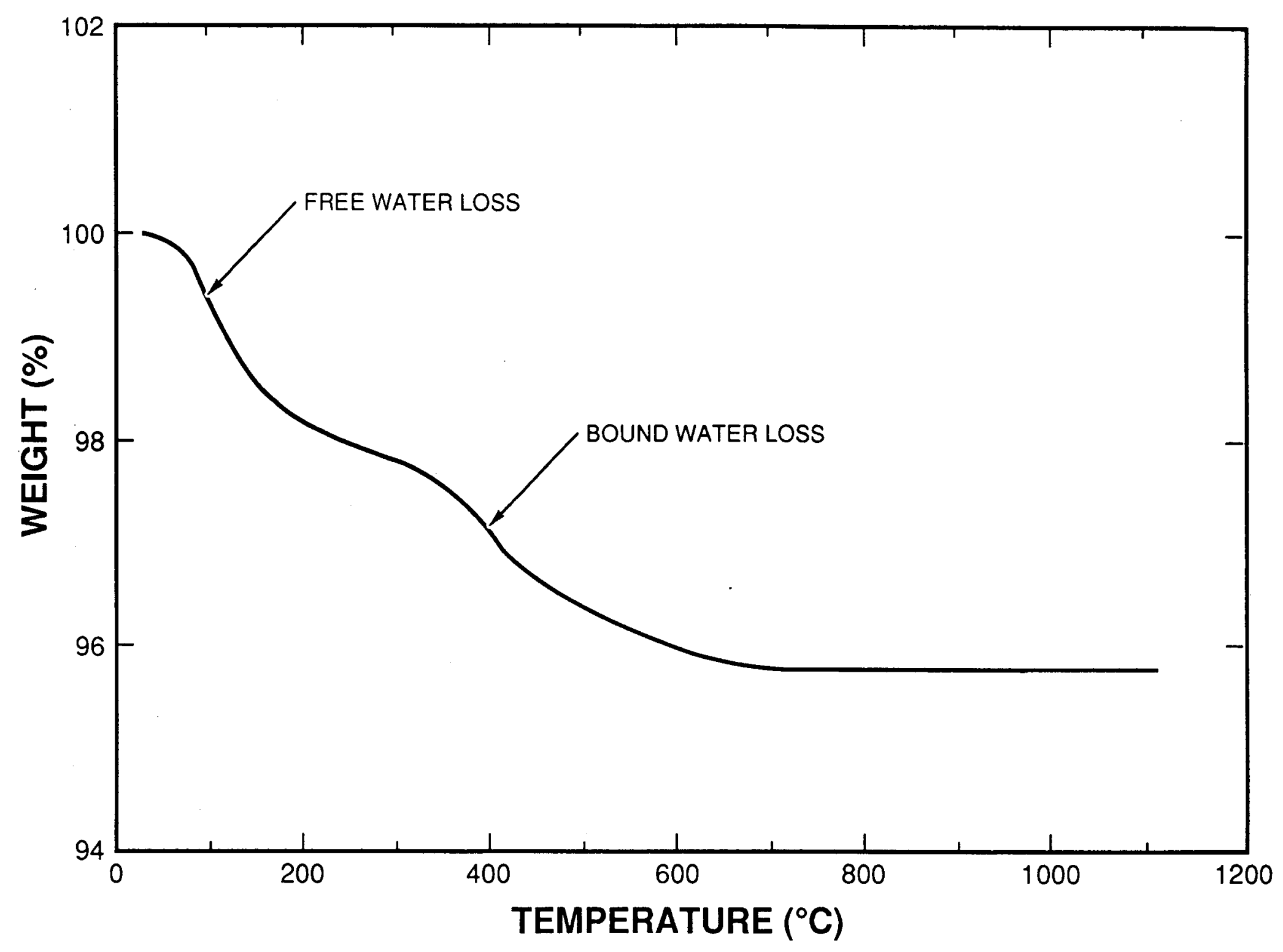

Figure 2.3 Thermogram (TGA) of the cured and baked K/R Cast 98; bottom of the lower crucible. 


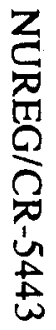

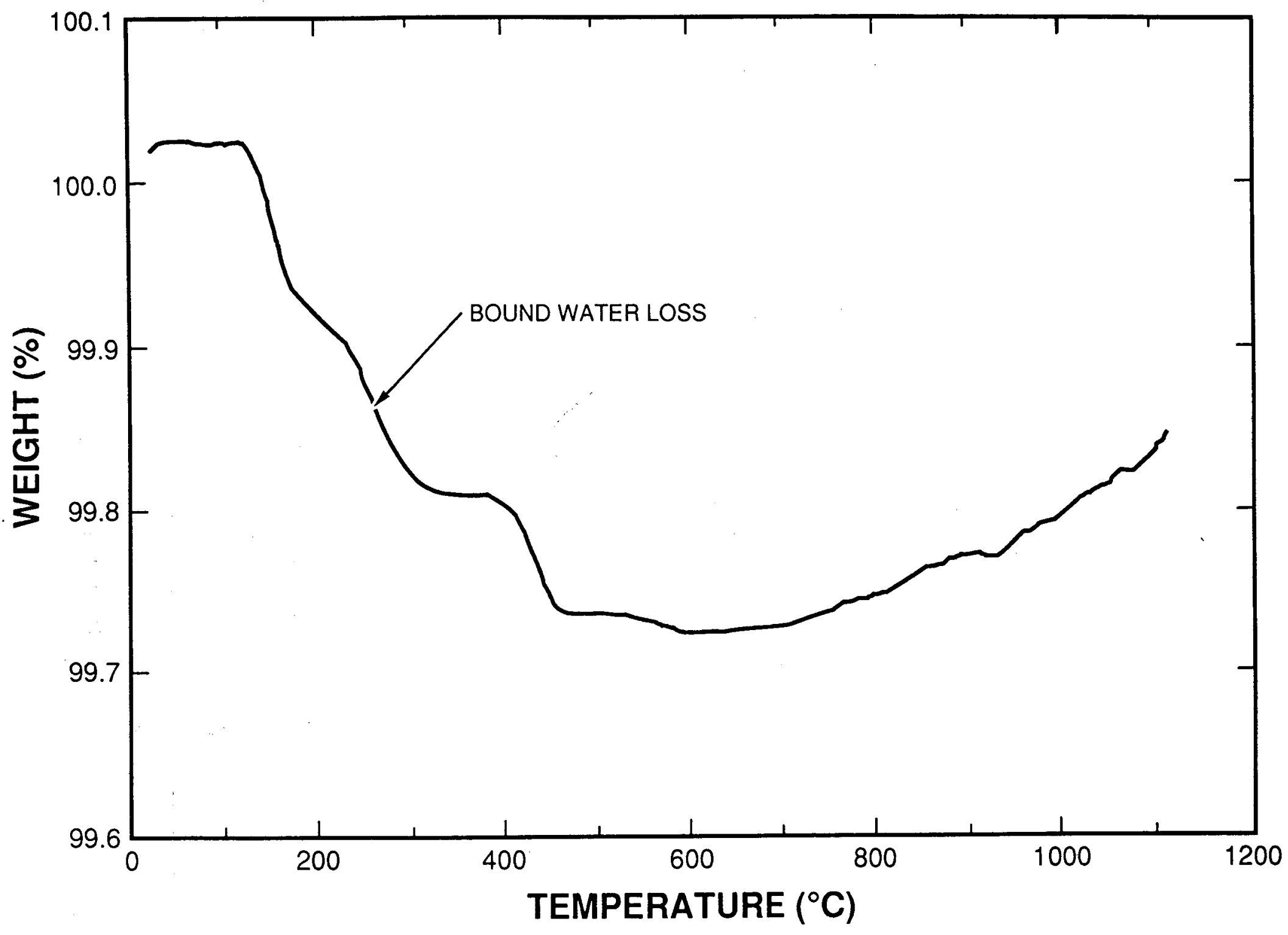

恣

$\infty$

Figure 2.4 Thermogram (TGA) of the cured and baked K/R Cast 98; top of the lower crucible. 
The TGA for each sample was performed in dry air with a flow rate of $50 \mathrm{~cm}^{3} / \mathrm{min}$. The heating was $10^{\circ} \mathrm{C} / \mathrm{min}$ from room temperature to $1100^{\circ} \mathrm{C}$. The data in Figure 2.3 was produced from a sample extracted from the base of the lower crucible adjacent to the concrete. The data in Figure 2.4 was produced from a sample taken at the top of the lower crucible $30 \mathrm{~cm}$ above the surface of the concrete. Comparing the data between the two samples the $\mathrm{MgO}$ castable adjacent to the concrete has 5 percent more water than the sample taken above the concrete. This is caused by the rehydration of the $\mathrm{MgO}$ castable when the concrete basemat is cast. The water content in the sample taken above the concrete is indicative of temperature cured material. Weight losses indicated in both thermograms are attributed to the release of free and chemically bound water between 20 and $700^{\circ} \mathrm{C}$. The thermograms show that the water content in the annulus above the concrete is approximately 0.3 percent and adjacent to the concrete is 4.2 percent.

The thermal properties of the castable K/R Cast98 have been extensively investigated. In addition to industry data, experiments were conducted at Sandia to study the thermal response of the $\mathrm{MgO}$ to intense heating conditions similar to those expected during an experiment. The results of these tests yield a value of specific heat and temperature-dependent values of thermal conductivity and are presented in Section 2.1 of the SURC-4 document [Copus et al., 1989]. Another determination of the thermal physical properties and density of $K / R$ Cast-98 was performed by Purdue University and is described in Appendix A of the SURC-4 report [Copus et al., 1989].

\subsection{Concrete Material}

The base of the interaction crucible was constructed of limestone concrete. This concrete was used because it is typical of that used in the construction of nuclear power plants. Materials making up this type of calcareous concrete are found throughout the United States. This concrete melts over a range of 1653 to $1873 \mathrm{~K}$ and typically liberates 30 to 35 weight-percent $\mathrm{CO}_{2}$ gas and 4 to 5 weight-percent $\mathrm{H}_{2} \mathrm{O}$ vapor when heated to melting [Powers et al., 1982].

The casting of the concrete was performed by mixing the concrete constituents with water in a clean paddle mixer. Once a homogeneous mixture had been achieved, the mix was carefully placed into the casting forms and vibrated as previously described in Section 2.1 for the $\mathrm{MgO}$ castable material.

Specifications for the concrete are listed in Table 2.2. Tables 2.3 and 2.4 summarize the engineering and chemical composition of the limestone concrete. Table 2.5 shows comparisons of the size specifications and the distribution of sizes for the course and fine aggregate actually used for the concrete [Powers et al., 1982].

Four $10.2 \mathrm{~cm}$ diameter $\times 20.3 \mathrm{~cm}$ long test cylinders were cast with the concrete slug to measure the compressive strength after $7,14,28$, and 1080 (day of the experiment) days. The concrete was cured at ambient temperature conditions nominally $20 \pm 10^{\circ} \mathrm{C}$. Compressive strengths for this concrete are compared to strengths measured for other samples tested in the past as a function of cure time in days in Figure 2.5. The strength for the cylinder tested at 1080 days (not shown in the figure) was $25.4 \mathrm{MPa}$ (3680 psi). The strength of this cylinder is 2.1 MPa (350 psi) below specifications for the concrete presented in Table 2.2. Even though this value is low it is within acceptable limits for conducting the experiment.

The thermal behavior of the concrete can be characterized by thermal gravimetric analysis (TGA), derivative thermogravimetric analysis (DTGA), and differential thermal analysis (DTA). Figure 2.6 shows a typical thermogram produced by TGA for limestone concrete. Between ambient temperature and $100^{\circ} \mathrm{C}$ there is 
1. Compressive strength after 90 cure $=27.5 \mathrm{MPa}$ minimum $(3990 \mathrm{psi})$

2. Slump $=5 \mathrm{~cm}$

3. Cement $=$ American Type II Portland Cement

4. Air content $=3$ to 5 percent by volume

5. Air entraining agent per reference (a) below

6. Composition per reference (b) below

7. Aggregate size and size distribution per reference (c) below

8. Water reducing agent per reference (a) below

9. Mixing, forming, and placing per references $(b, c, d, e)$ below

a. ASTM C-494-71, Standard Specification for Chemical Admixtures for Concrete, American Society for Testing and Materials, Philadelphia, PA.

b. ACTI 211. 1-74, Recommended Practices for Normal and Heavy Concrete, American Concrete Institute, Detroit, MI.

c. ASTM 33-74., Standard Specification for Concrete Aggregates, American Society for Testing and Materials, Philadelphia, PA.

d. ACI 347-68, Recommended Practice for Working Concrete, American Concrete Institute, Detroit, MI.

e. ACI 315-74, Detailing Manual, American Concrete Institute, Detroit, MI. 
Table 2.3 Engineering composition of limestone concrete

\begin{tabular}{lcc}
\hline Constituents $^{b}$ & Mass & Weight \% \\
\hline Aggregate, Coarse $^{\mathrm{c}}$ & $165.2 \mathrm{~kg}$ & 46.3 \\
Aggregate, Fine $^{\mathrm{c}}$ & $118.0 \mathrm{~kg}$ & 33.0 \\
Sand & 0.0 & 0.0 \\
Cement & $42.6 \mathrm{~kg}$ & 11.9 \\
Water & $24.0 \mathrm{~kg}$ & 6.7 \\
Fly Ash & $7.3 \mathrm{~kg}$ & 2.0 \\
"AEA & $82.0 \mathrm{ml}$ & - \\
+WRA & $83.0 \mathrm{ml}$ & - \\
\hline * Air Entraining Agent & & \\
+Water Reducing Agent & & \\
a. ASTM C-494-71, Standard Specification for Chemical Admixtures for \\
Concrete, American Society for Testing and Materials, Philadelphia, PA. \\
b. ACTI 211. 1-74, Recommended Practices for Normal and Heavy \\
Concrete, American Concrete Institute, Detroit, MI. \\
c. ASTM 33-74., Standard Specifications for Concrete Aggregates, \\
American Society for Testing and Materials, Philadelphia, PA.
\end{tabular}

Table 2.4 Chemical composition of limestone concrete constituents

\begin{tabular}{|c|c|c|c|c|c|}
\hline Oxide & $\begin{array}{c}\text { Cement } \\
(\%)\end{array}$ & $\begin{array}{c}\text { Limestone } \\
\text { Aggregate } \\
(\%)\end{array}$ & $\begin{array}{c}\text { Fly Ash } \\
(\%)\end{array}$ & $\begin{array}{c}\text { Limestone } \\
\text { Concrete } \\
(\%)\end{array}$ & $\begin{array}{c}\text { Expected } \\
\text { Error } \\
(\%)\end{array}$ \\
\hline $\mathrm{Fe}_{2} \mathrm{O}_{3}$ & 4.11 & 0.38 & 11.7 & 1.2 & 0.3 \\
\hline $\mathrm{Cr}_{2} \mathrm{O}_{3}$ & 0.011 & 0.12 & 0.022 & 0.004 & 0.01 \\
\hline $\mathrm{MnO}$ & 0.08 & 0.04 & 0.02 & 0.01 & 0.02 \\
\hline $\mathrm{TiO}_{2}$ & 0.2 & 0.04 & 2.24 & 0.12 & 0.04 \\
\hline $\mathrm{K}_{2} \mathrm{O}$ & 0.54 & 0.36 & 3.5 & 0.68 & 0.4 \\
\hline $\mathrm{Na}_{2} \mathrm{O}$ & 0.27 & 0.16 & 0.34 & 0.08 & 0.2 \\
\hline $\mathrm{CaO}$ & 63.5 & 47.2 & 1.3 & 45.4 & 1.0 \\
\hline $\mathrm{MgO}$ & 1.53 & 0.6 & 1.14 & 5.67 & 0.5 \\
\hline $\mathrm{SiO}_{2}$ & 20.1 & 8.0 & 51.2 & 3.6 & 1.5 \\
\hline $\mathrm{Al}_{2} \mathrm{O}_{3}$ & 4.2 & 1.2 & 24.5 & 1.6 & 0.2 \\
\hline $\mathrm{CO}_{2}$ & ND & 38.0 & ND & 35.7 & 1.0 \\
\hline $\mathrm{H}_{2} \mathrm{O}$ & ND & ND & 0.3 & 4.1 & 0.5 \\
\hline $\mathrm{SO}_{2}$ & 1.0 & ND & ND & $<0.02$ & 0.2 \\
\hline \multicolumn{6}{|c|}{ ND $=$ Not determined. } \\
\hline
\end{tabular}


Table 2.5 Comparison of specified and actual size distributions for the fine and coarse limestone aggregate

\begin{tabular}{lcc}
\hline $\begin{array}{l}\text { Screen } \\
\text { Opening (cm) }\end{array}$ & $\begin{array}{c}\text { Specified Weight \% } \\
\text { Passing Through the } \\
\text { Screen }\end{array}$ & $\begin{array}{c}\text { Observed Weight \% Passing } \\
\text { Through the Screen }\end{array}$ \\
\hline A) Coarse Aggregate & & \\
2.5 & $95-100$ & 100 \\
1.9 & $90-100$ & 96.3 \\
1.3 & $25-60$ & 54.7 \\
0.95 & $20-55$ & 25.2 \\
0.48 & $0-10$ & 5.6 \\
0.23 & $0-5$ & not measured \\
B) Fine Aggregate & & 100 \\
1.3 & 100 & 98.9 \\
0.95 & $85-100$ & 96.8 \\
0.48 & $10-30$ & 84.4 \\
0.23 & $0-10$ & 59.7 \\
0.12 & $0-5$ & \\
\hline
\end{tabular}

Table 2.6 Mass and composition of charge material

\begin{tabular}{lllc}
\hline Material & Composition (w/o) & Mass (kg) \\
\hline Crushed Isostatic & & \\
Pressed Cylinders & $63 \mathrm{UO}_{2}$ & 164.1 \\
& $27 \mathrm{ZrO}_{2}$ & \\
& $10 \mathrm{Zr}$ & \\
$\mathrm{ZrO}_{2}$ Board & $100 \mathrm{ZrO}_{2}$ & & 1.7 \\
Insulation Powder & $100 \mathrm{UO}_{2}$ & & $\underline{35.0}$ \\
& & Total & 200.8 \\
\hline
\end{tabular}




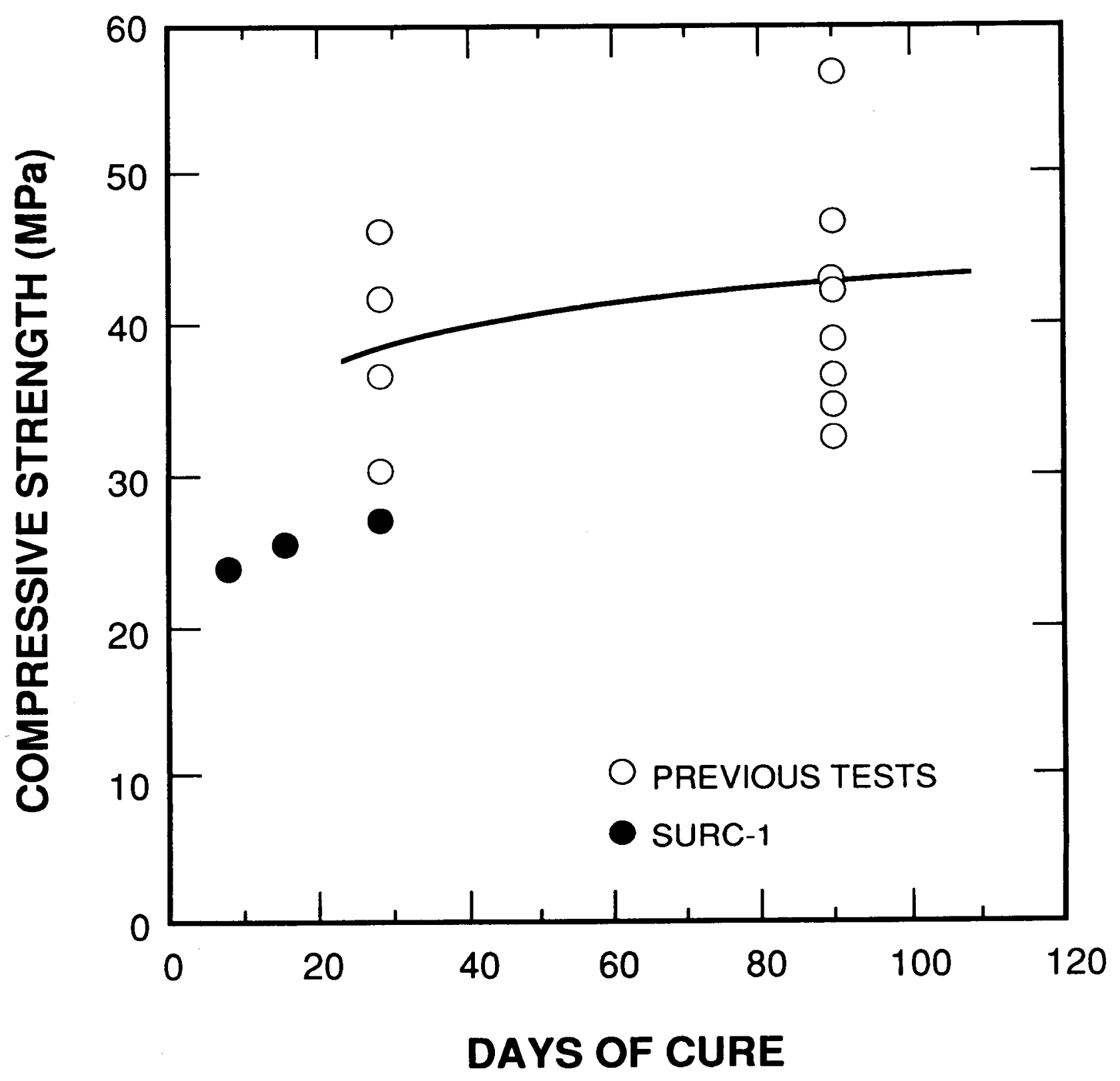

Figure 2.5 Compressive strength versus time of cure for limestone concrete 


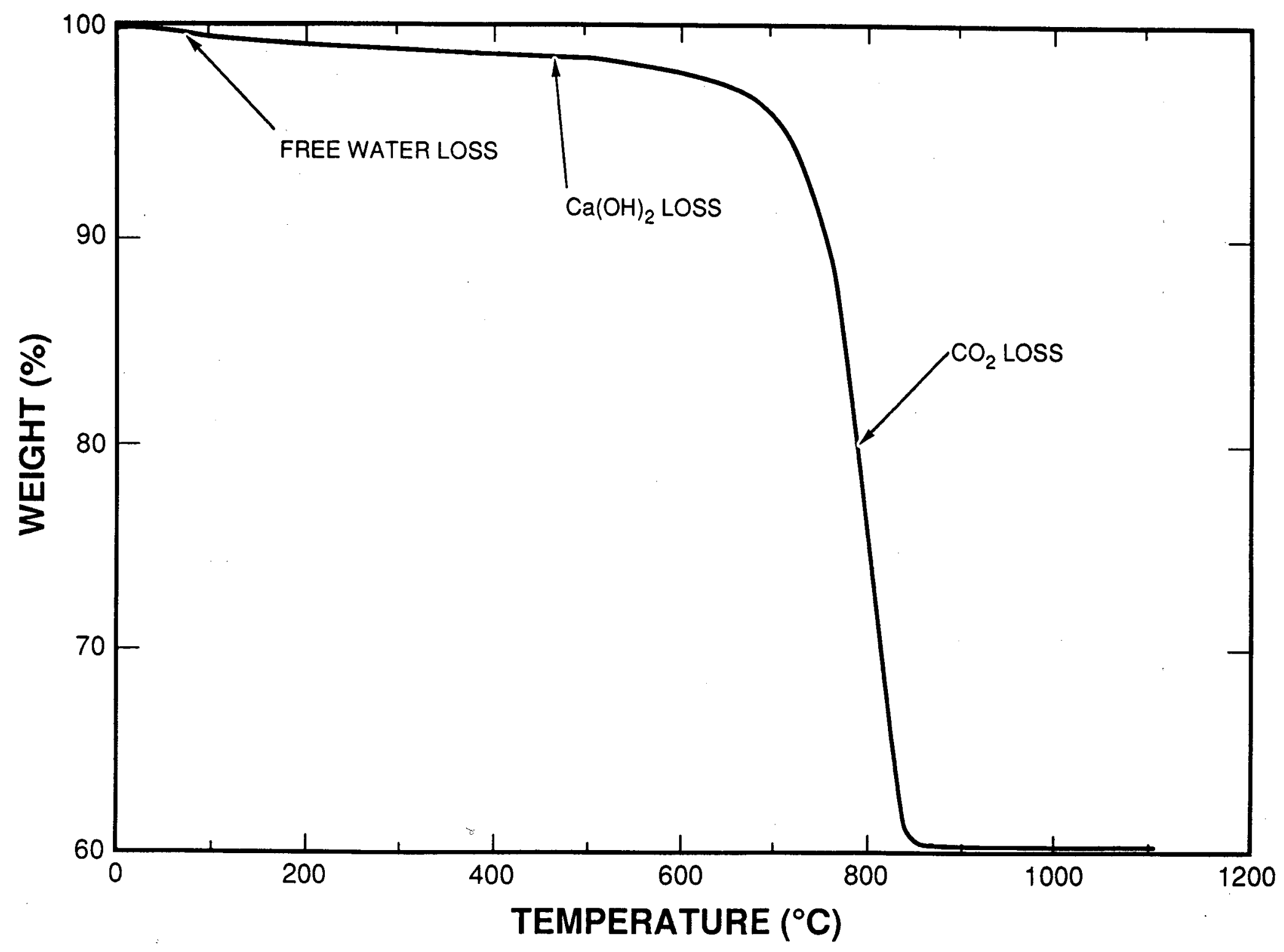

录

E

Figure 2.6 Thermogram (TGA) of limestone concrete used in the SURC-1 experiment 
a 2.5 weight-percent loss due to the release of free water. There is a 1 weight-percent loss between 400 and $450^{\circ} \mathrm{C}$. This is attributed to the release of $\mathrm{Ca}(\mathrm{OH})_{2}$. A significant weight loss (34 weight-percent) is observed between 600 and $850^{\circ} \mathrm{C}$. This is due to the release of $\mathrm{CO}_{2}$.

\subsection{Charge Material}

The charge material consisted of $200.8 \mathrm{~kg}$ of $\mathrm{UO}_{2}-\mathrm{ZrO}_{2}$ and $\mathrm{Zr}$ metal in the form of powder, crushed isostatic pressed cylinders and metal chips. The total mass and w/o of constituents in each of the material forms is presented in Table 2.6 previously. The relative weight percentages of the individual constituents for the total charge was calculated to be $63 \mathrm{w} / \mathrm{o} \mathrm{UO}_{2}, 27$ w/o $\mathrm{ZrO}_{2}$, and $10 \mathrm{w} / \mathrm{o} \mathrm{Zr}$ metal. In order to produce a homogeneous mix, $\mathrm{Zr}$ metal chips were added to the crushed $\mathrm{UO}_{2}-\mathrm{ZrO}_{2}$ cylinder material to produce the desired ratios. Five tungsten plates were placed within the charge material to serve as susceptors to heat the material. The plates were spaced approximately $10 \mathrm{~cm}$ apart within the charge. A detailed description of the charge assembly is discussed in Section 3.4. The mass and ratio of charge constituents placed between the tungsten plates is shown in Figure 2.7. The density of the charge was calculated to be $3.6 \mathrm{~g} / \mathrm{cm}^{3}$.

\subsection{Fission Product Simulants}

In order to evaluate the transport of fission products during the melt-concrete interaction, various chemical species, listed in Table 2.7, were added to the charge prior to heating. These materials were added to the charge material as a homogeneous powdered mixture just below the third tungsten plate. The placement of the simulants corresponds to a location 54 percent of the charge height.

Table 2.7 SURC-1 fission product simulants

\begin{tabular}{lcc}
\hline Fission Product & Chemical Formula & Quantity (g) \\
\hline Barium Molybdate & $\mathrm{BaMoO}_{4}$ & 1000 \\
Lanthanum Oxide & $\mathrm{La}_{2} \mathrm{O}_{3}$ & 750 \\
Cerium Oxide & $\mathrm{CeO}_{2}$ & 750 \\
Niobium Oxide & $\mathrm{Nb}_{2} \mathrm{O}_{5}$ & 864 \\
\multicolumn{1}{c}{ TOTAL } & & $3364 \mathrm{~g}$ \\
\hline
\end{tabular}


Materials

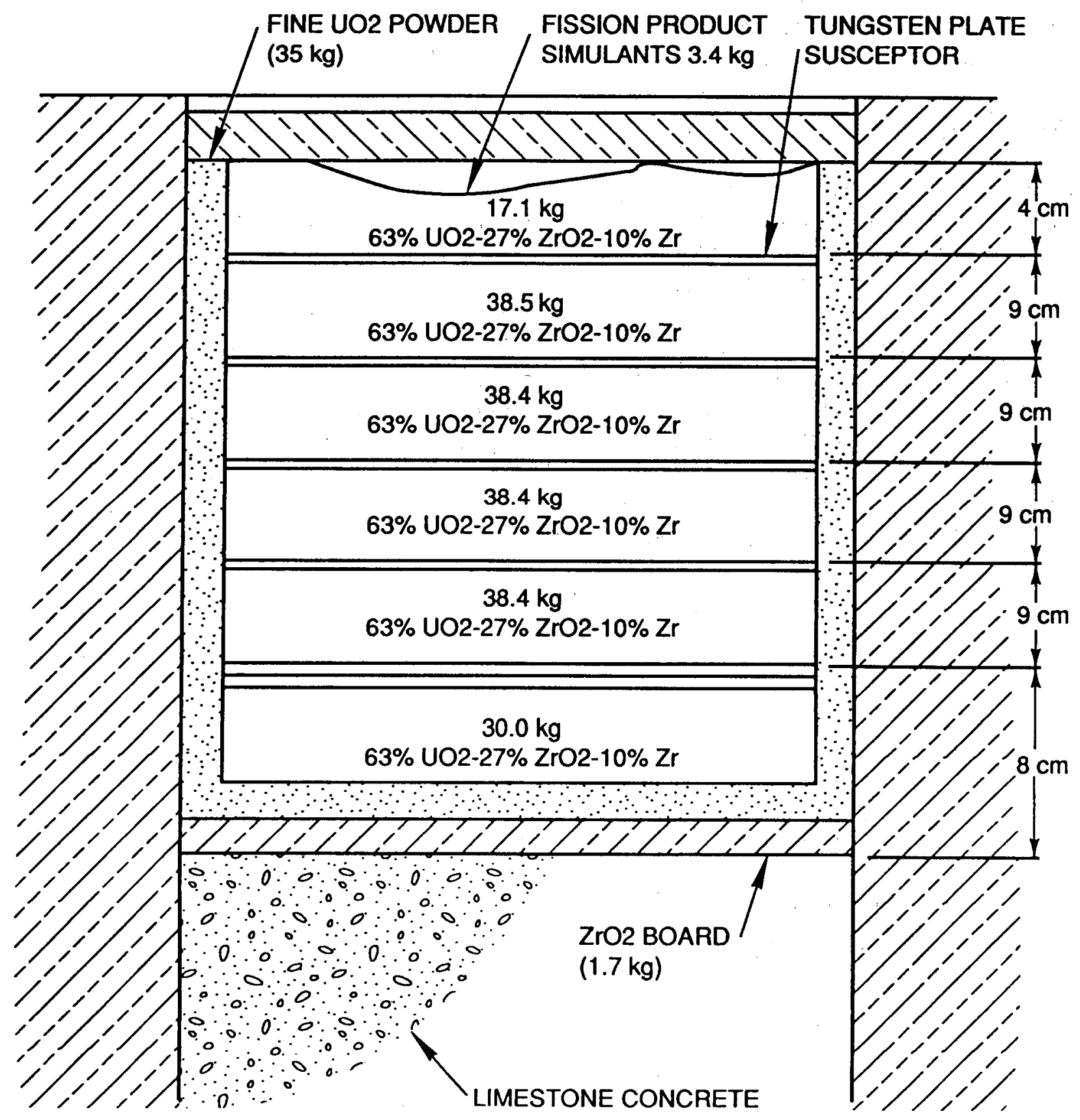

Figure 2.7 Mass and charge composition, SURC-1 


\subsection{Experimental Apparatus}

The major components of the SURC-1 experimental apparatus are shown in Figure 3.1 and include a sealed, water-cooled, containment vessel, interaction crucible, and induction coil. These components are described in the following sections. The remainder of the SURC-1 apparatus including the exit flow piping and the gravel bed filter are described in Section 4.3.

\subsection{Containment Vessel}

A containment vessel was used in SURC-1 to ensure that nearly all of the reaction products would pass through the instrumented exit flow piping. A sectional view of the water cooled containment vessel is shown in Figure 3.2. The vessel was fabricated in two sections using $2.5 \mathrm{~cm}$ thick, weldable 6061-T6 aluminum alloy. The two sections were assembled using 24, $1.4 \mathrm{~cm}$ diameter hex head bolts and nuts securing the mating flanges. The flange of the lower section incorporated a double O-ring for sealing. The vessel was supported by four $10 \mathrm{~cm}$ diameter $x 45.7 \mathrm{~cm}$ long legs welded to the bottom of the lower section. Basic dimensions of the vessel are shown in Figure 3.2. The internal volume of the vessel was calculated to be approximately $2.0 \mathrm{~m}^{3}$.

Aluminum (6061-T6) tubing $2.5 \mathrm{~cm}$ in diameter was welded to the outside and top of the vessel at a pitch of approximately $10 \mathrm{~cm}$. This tubing was used to circulate a mixture of 30 percent by volume ethylene glycol in water used to cool the vessel during the experiment. The bottom of the vessel was cooled by means of three large reservoirs welded to the bottom of the vessel. The tubing and reservoirs were connected in series to form a single cooling circuit.

Bolted, flanged ports located in the lower section of the vessel were used to provide feedthroughs for power and instrumentation leads and for mounting fittings to connect a pressure transducer and tubing for supplying argon purge gas. Another port was fitted with a spring-loaded safety diaphragm calibrated to open at 15 psig to eliminate the potential for over-pressurization of the vessel. A 3-in.-diameter flange port located in the base of the vessel was used as a feedthrough for all crucible thermocouple terminations. The sheaths and/or extension wires for all the thermocouples were pulled through a mating $90^{\circ}$ flanged elbow. The elbow was filled with epoxy and allowed to cure, encapsulating the instrumentation leads and thermocouple sheaths. The elbow was then bolted to the flanged port, sealing the instrumentation cabling. A flanged port in the top of the vessel was fitted with a 2 -in. O.D. $\times 0.062$ in. wall $\times 12$ in. long, stainless steel tube. This tube connected the containment vessel with the flow system instrumented for sampling evolved gas and aerosols and measuring gas flow rate.

The inside floor of the lower vessel was lined with 6 in. of standard refractory $\mathrm{MgO}$ brick and backfilled with fine $\mathrm{MgO}$ powder. The perimeter of the floor was built-up with an extra layer of bricks 6 in. high and 2 in. thick. This was done to protect the vessel from melt attack should any molten material breach the interaction crucible during the experiment.

The vessel was pressure tested and certified to operate either in a partial vacuum or up to 20 psig.

\subsection{Interaction Crucible}

The interaction crucible for SURC-1 was designed to limit concrete erosion to the downward or axial direction [Blose et al., 1987]. The materials used in the construction of the interaction crucible have been discussed in detail in Sections 2.1 and 2.2. The crucible used in SURC-1 was of cylindrical geometry and is shown in Figure 3.3. The main body of the crucible was cast in two sections--namely the upper and lower crucible. The overall dimensions of the crucible are $60 \mathrm{~cm}$ diameter $\mathrm{x}$ $100.0 \mathrm{~cm}$ high with a $40.0 \mathrm{~cm}$ diameter cavity $60.0 \mathrm{~cm}$ deep. Cast into the bottom of the lower 


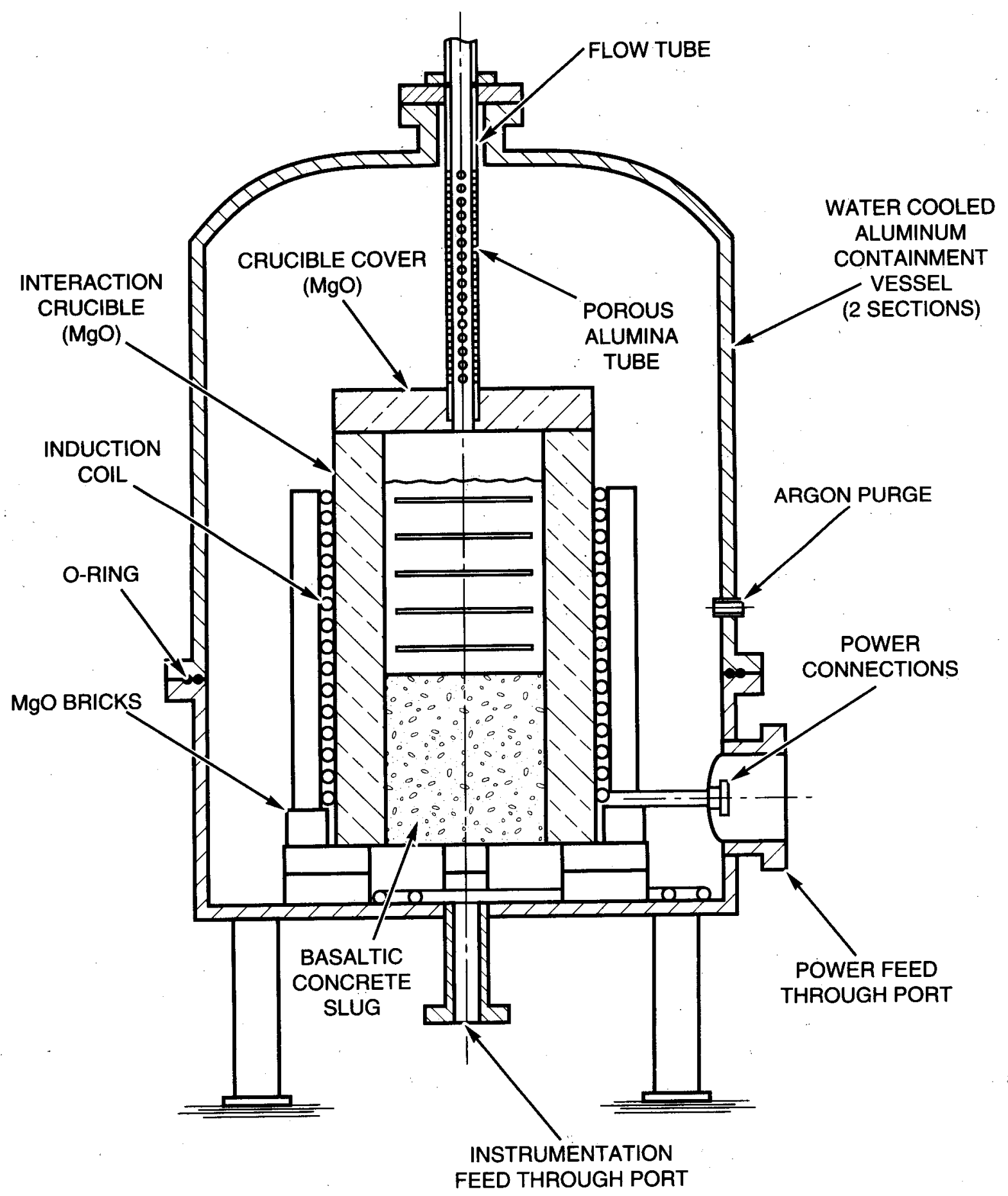

Figure 3.1 SURC-1 experimental apparatus 


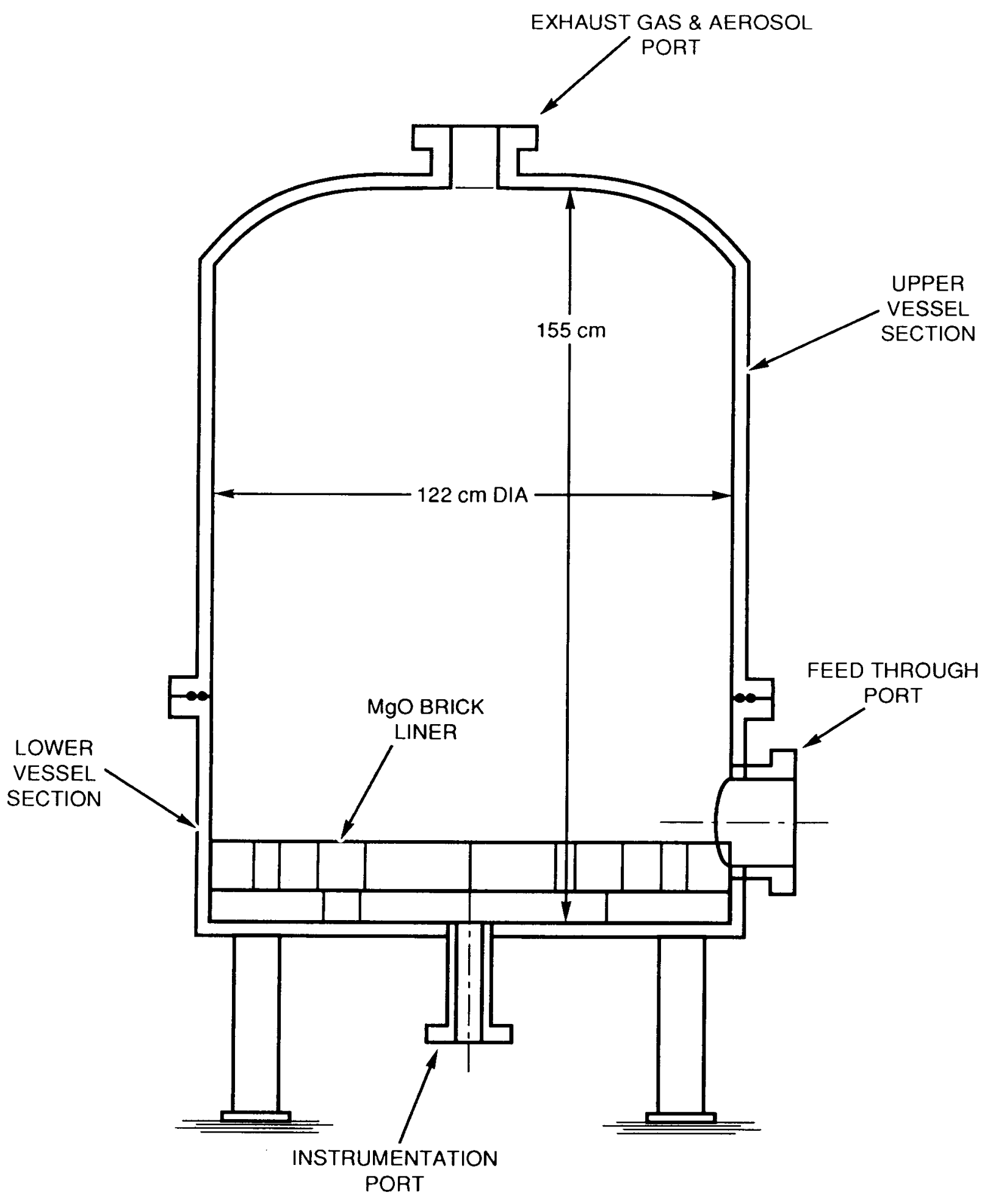

Figure 3.2 Sealed, water-cooled, containment vessel 


\section{Experimental}

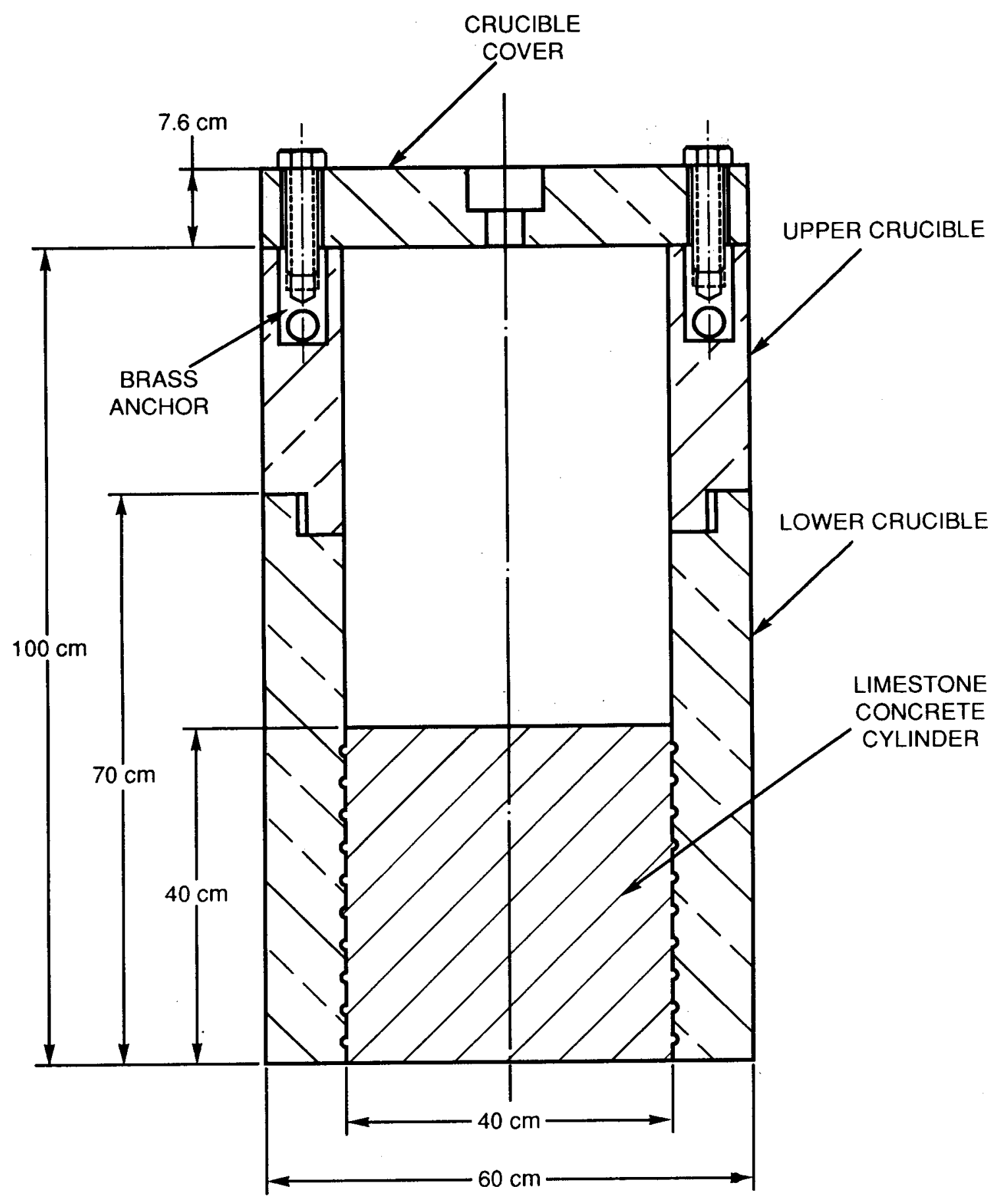

Figure 3.3 Interaction crucible, SURC-1 
crucible was an instrumented limestone concrete cylinder $40.0 \mathrm{~cm}$ diameter $\times 40.0 \mathrm{~cm}$ thick. The upper crucible was cast with an annular step and the lower crucible with a mating annular recess. The two crucible sections were assembled and sealed with Saureisen Cement No. 31.

The annulus of the upper and lower crucible and cover were cast using a reusable steel casting form constructed in a clam shell arrangement. Bolts were placed through the crucible cover and threaded into brass anchors cast into the upper crucible securing the cover. A detailed description of the casting forms and fabrication procedures is presented in Appendix B of the SURC-4 report [Copus et al., 1989].

Approximately $0.18 \mathrm{~m}^{3}$ of $\mathrm{MgO}$ castible ceramic and $0.05 \mathrm{~m}^{3}$ of limestone concrete were required per crucible cast. The total estimated mass of the crucible was:

Annulus - MgO Castible

$$
\text { Volume-0.15 } \mathrm{m}^{3} @ 2680 \mathrm{~kg} / \mathrm{m}^{3}=402 \mathrm{~kg}
$$

Cover - $\mathrm{MgO}$ Castible

Volume-0.03 $\mathrm{m}^{3} @ 2680 \mathrm{~kg} / \mathrm{m}^{3}=80 \mathrm{~kg}$

Concrete Cylinder - Limestone Concrete

Volume-0.05 m @2400 kg/m $\mathrm{m}^{3}=120 \mathrm{~kg}$

$$
\text { TOTAL MASS } \quad 602 \mathrm{~kg}
$$

The annulus, concrete cylinder and crucible cover were instrumented with 117 type $\mathrm{K}$ thermocouples cast into the crucible in 16 arrays to measure the thermal response. Figure 3.4 shows the relative thermocouple locations and the various arrays cast into the crucible. This figure also shows the nomenclature used to describe the locations of the thermocouples in cylindrical coordinates, specifically $\mathrm{r}, \boldsymbol{\theta}, \mathrm{z}$ and $\mathrm{t}$. Additionally, six type $S$ and six type $C$ thermocouples installed into six alumina tubes were cast into the limestone concrete cylinder to measure melt temperature.
Sixty thermocouples were cast into the concrete in three arrays. The array containing thermocouples designated $\mathrm{Cl}$ through $\mathbf{C} 20$ was located on the axial centerline at odd $(0,1,3,5$, etc.) centimeter depths. The array containing thermocouples designated $\mathrm{C} 21$ through $\mathrm{C} 40$ was located on a line parallel to the center axis at a radial distance of $10.0 \mathrm{~cm}$ at even $(0,2,4,6$ etc.) centimeter depths. The third array designated by thermocouples $\mathrm{C} 41$ through $\mathrm{C} 60$ was located near the perimeter of the concrete cylinder at a radial distance of $18.0 \mathrm{~cm}$. The depth of the thermocouples in this array was identical to the axial centerline array. The locations of the thermocouples cast into the concrete cylinder are tabulated in Table 3.1. The sheath of each thermocouple was bent at an angle of $90^{\circ}$ ten sheath diameters from the tip. This was done to minimize the errors caused by heat conduction down the metal sheath. Installation of a typical thermocouple array is shown in Figure 3.5.

Six four-hole alumina tubes were cast into the concrete slug parallel to the axial centerline, $60^{\circ}$ apart at a radial distance of $14 \mathrm{~cm}$. Installed in each tube were type $S$ and type $C$ thermocouples located at various depths from the surface of the concrete cylinder. These thermocouples were used to measure melt temperature and their locations are tabulated in Table 3.2. Figure 3.5 shows an installation of a typical concrete and alumina tube array with the type $S$ and type $C$ thermocouples.

Thermocouples used to monitor sidewall temperatures in the $\mathrm{MgO}$ annulus of the crucible were installed into pre-cast $\mathrm{MgO}$ cylinders prior to casting as shown in Figure 3.6. The ends of the cylinders conformed to the curvature of the annulus of the casting forms providing a good fit. The cylinders were bolted to the inside diameter of the outer steel crucible form by threading a small hex head bolt into a small brass anchor cast into the $\mathrm{MgO}$ cylinders. This method for installation of sidewall thermocouples accurately positions the thermocouples, which is critical for 


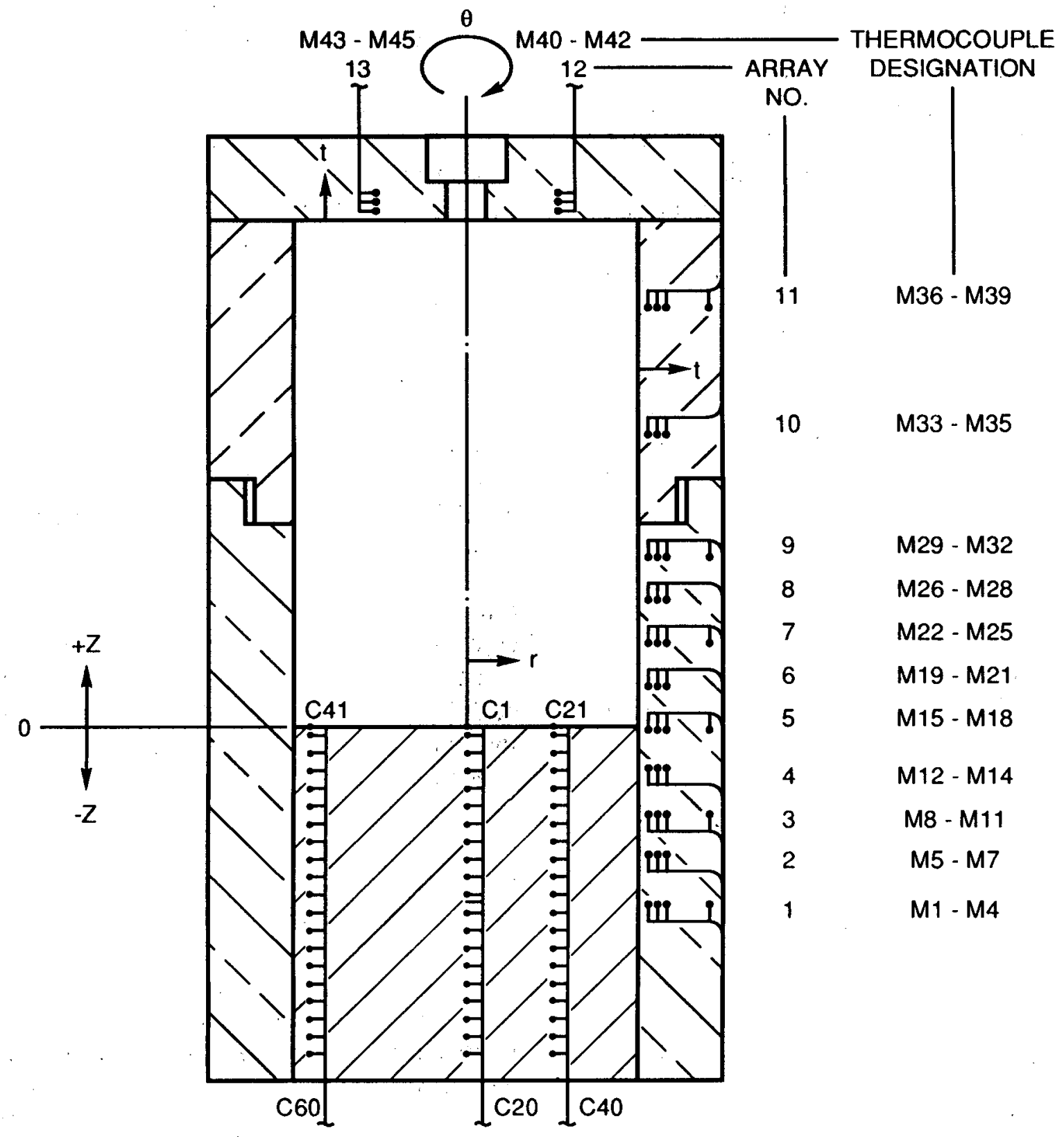

Figure 3.4 Relative thermocouple locations, SURC-1 crucible 
Table 3.1 Location of thermocouples cast within the concrete cylinder, SURC-1 (See Figure 3.4)

\begin{tabular}{|c|c|c|c|}
\hline Thermocouple No. & $\begin{array}{c}\mathbf{r} \\
(\mathrm{cm})\end{array}$ & $\begin{array}{c}\theta \\
\text { (degree) }\end{array}$ & $\begin{array}{c}-\mathrm{z} \\
(\mathrm{cm})\end{array}$ \\
\hline $\mathrm{Cl}$ & 0 & 0 & 0 \\
\hline $\mathrm{C} 2$ & 0 & 0 & 1.0 \\
\hline C3 & 0 & 0 & 3.0 \\
\hline $\mathrm{C} 4$ & 0 & 0 & 5.0 \\
\hline C5 & 0 & 0 & 7.0 \\
\hline C6 & 0 & 0 & 9.0 \\
\hline C7 & 0 & 0 & 11.0 \\
\hline $\mathrm{C} 8$ & 0 & 0 & 13.0 \\
\hline C9 & 0 & 0 & 15.0 \\
\hline $\mathrm{C} 10$ & 0 & 0 & 17.0 \\
\hline $\mathrm{C} 11$ & 0 & 0 & 19.0 \\
\hline $\mathrm{C} 12$ & 0 & 0 & 21.0 \\
\hline $\mathrm{C} 13$ & 0 & 0 & 23.0 \\
\hline $\mathrm{C} 14$ & 0 & 0 & 25.0 \\
\hline C15 & 0 & 0 & 27.0 \\
\hline C16 & 0 & 0 & 29.0 \\
\hline $\mathrm{C} 17$ & 0 & 0 & 31.0 \\
\hline $\mathrm{C} 18$ & 0 & 0 & 33.0 \\
\hline C19 & 0 & 0 & 35.0 \\
\hline $\mathrm{C} 20$ & 0 & 0 & 37.0 \\
\hline $\mathrm{C} 21$ & 10.0 & 0 & 0.0 \\
\hline $\mathrm{C} 22$ & 10.0 & 0 & 2.0 \\
\hline $\mathrm{C} 23$ & 10.0 & 0 & 4.0 \\
\hline $\mathrm{C} 24$ & 10.0 & 0 & 6.0 \\
\hline $\mathrm{C} 25$ & 10.0 & 0 & 8.0 \\
\hline $\mathrm{C} 26$ & 10.0 & 0 & 10.0 \\
\hline $\mathrm{C} 27$ & 10.0 & 0 & 12.0 \\
\hline C28 & 10.0 & 0 & 14.0 \\
\hline C29 & 10.0 & 0 & 16.0 \\
\hline C30 & 10.0 & 0 & 18.0 \\
\hline C31 & 10.0 & 0 & 20.0 \\
\hline C32 & 10.0 & 0 & 22.0 \\
\hline C33 & 10.0 & 0 & 24.0 \\
\hline C34 & 10.0 & 0 & 26.0 \\
\hline C35 & 10.0 & 0 & 28.0 \\
\hline C36 & 10.0 & 0 & 30.0 \\
\hline C37 & 10.0 & 0 & 32.0 \\
\hline C38 & 10.0 & 0 & 34.0 \\
\hline C39 & 10.0 & 0 & 36.0 \\
\hline
\end{tabular}


Table 3.1 Location of thermocouples cast within the concrete cylinder, SURC-1 (See Figure 3.4) (Continued)

\begin{tabular}{cccc}
\hline Thermocouple No. & $\begin{array}{c}\mathbf{r} \\
(\mathbf{c m})\end{array}$ & $\begin{array}{c}\boldsymbol{\theta} \\
\text { (degree) }\end{array}$ & $\begin{array}{c}\mathbf{- z} \\
(\mathbf{c m})\end{array}$ \\
\hline C40 & 10.0 & 0 & 38.0 \\
C41 & 18.0 & 180 & 0.0 \\
C42 & 18.0 & 180 & 1.0 \\
C43 & 18.0 & 180 & 3.0 \\
C44 & 18.0 & 180 & 5.0 \\
C45 & 18.0 & 180 & 7.0 \\
C46 & 18.0 & 180 & 9.0 \\
C47 & 18.0 & 180 & 11.0 \\
C48 & 18.0 & 180 & 13.0 \\
C49 & 18.0 & 180 & 15.0 \\
C50 & 18.0 & 180 & 17.0 \\
C51 & 18.0 & 180 & 19.0 \\
C52 & 18.0 & 180 & 21.0 \\
C53 & 18.0 & 180 & 23.0 \\
C54 & 18.0 & 180 & 25.0 \\
C55 & 18.0 & 180 & 27.0 \\
C56 & 18.0 & 180 & 29.0 \\
C57 & 18.0 & 180 & 31.0 \\
C58 & 18.0 & 180 & 33.0 \\
C59 & 18.0 & 180 & 35.0 \\
C60 & 18.0 & 180 & 37.0 \\
\hline
\end{tabular}

Table 3.2 Location of thermocouples installed in the alumina tubes and cast into the concrete cylinder, SURC-1

\begin{tabular}{cccccc}
\hline $\begin{array}{c}\text { Tube } \\
\text { Number }\end{array}$ & $\begin{array}{c}\text { Thermocouple } \\
\text { No. }\end{array}$ & $\begin{array}{c}\text { Thermocouple } \\
\text { Type }\end{array}$ & $\begin{array}{c}\mathbf{r} \\
\text { (cm) }\end{array}$ & $\begin{array}{c}\boldsymbol{\theta} \\
\text { (degree) }\end{array}$ & $\begin{array}{c}\mathbf{- z} \\
(\mathbf{c m})\end{array}$ \\
\hline 1 & A1 & S & 14 & 30 & 1 \\
4 & A2 & C & 14 & 210 & 3 \\
3 & A3 & S & 14 & 150 & 5 \\
6 & A4 & C & 14 & 330 & 7 \\
5 & A5 & S & 14 & 270 & 9 \\
2 & A6 & C & 14 & 90 & 11 \\
1 & A7 & S & 14 & 30 & 14 \\
4 & A8 & C & 14 & 210 & 17 \\
3 & A9 & S & 14 & 150 & 20 \\
6 & A10 & C & 14 & 330 & 23 \\
5 & A11 & S & 14 & 270 & 26 \\
2 & A12 & C & 14 & 90 & 29 \\
\hline
\end{tabular}




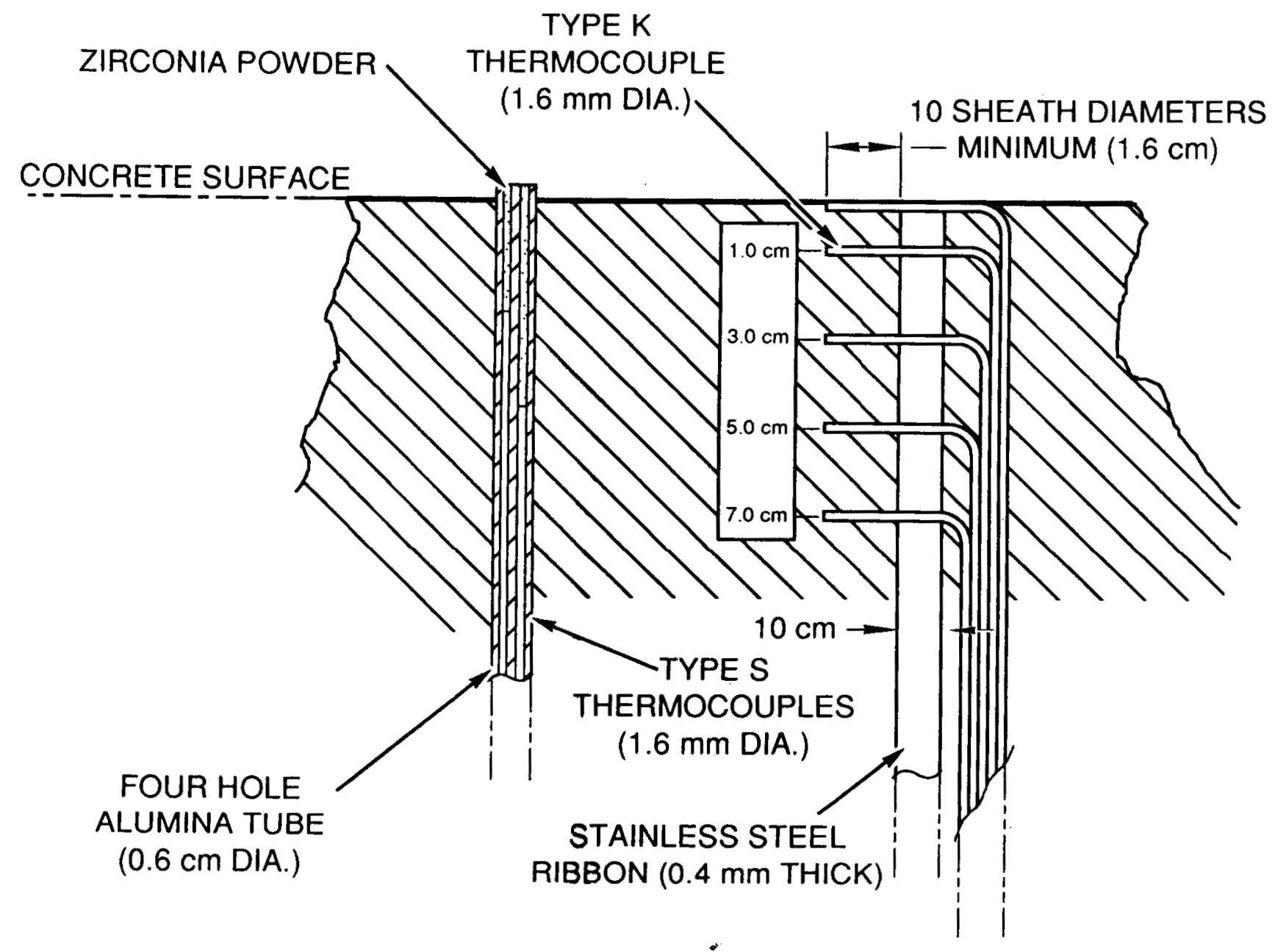

Figure 3.5 Typics.l thermocouple arrays cast into the concrete 


\section{Experimental}

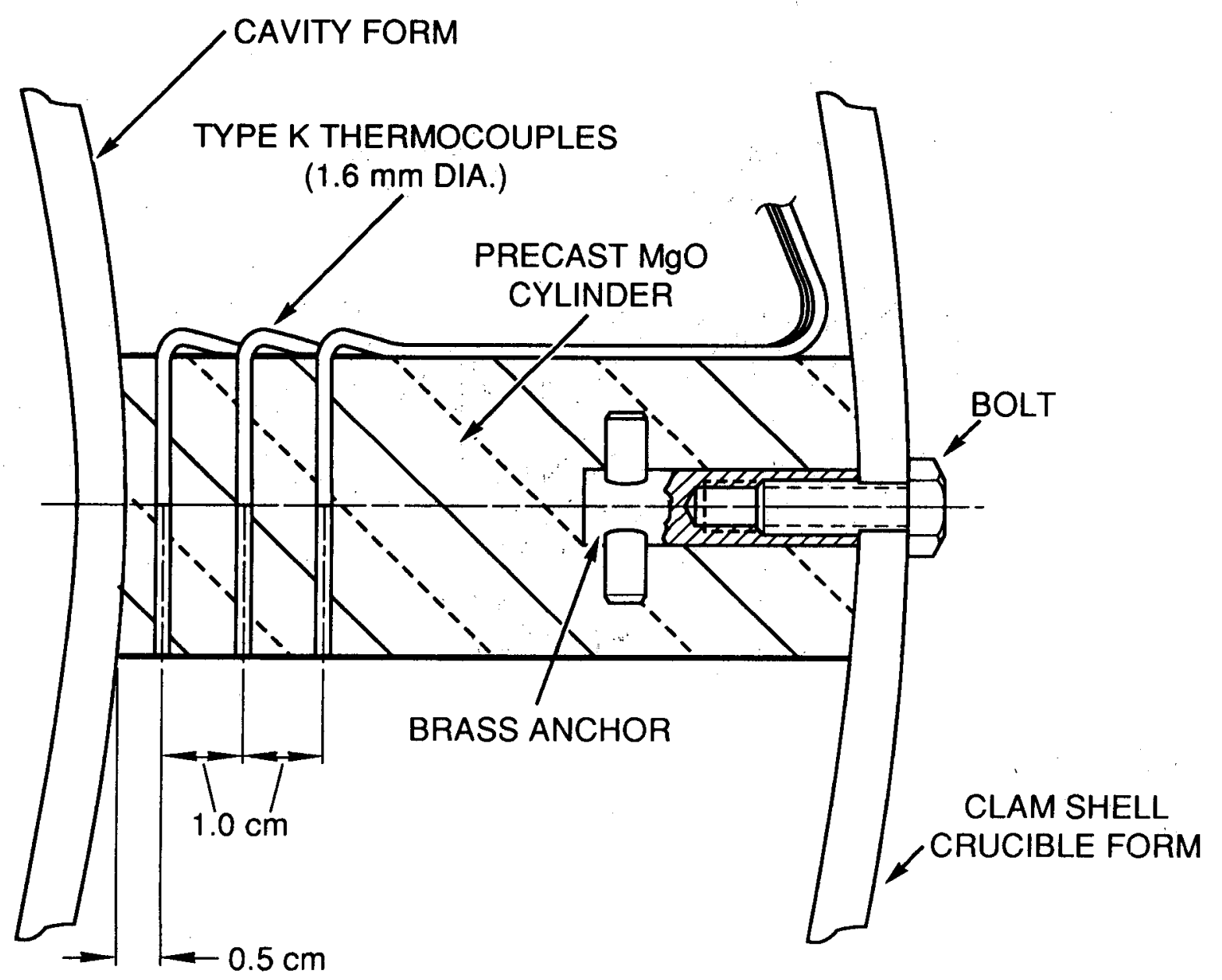

Figure 3.6. Thermocouple array installation, $\mathrm{MgO}$ annulus 
heat flux calculations. The thermocouple tips were oriented in a horizontal plane parallel to the base of the crucible and perpendicular to the thermal front. The specific locations of the sidewall thermocouples are tabulated in Table 3.3.

Two thermocouple arrays were cast into the crucible cover. Like the arrays cast into the annulus, the thermocouples were installed into pre-cast $\mathrm{MgO}$ cylinders. The locations of these thermocouples are listed in Table 3.4. The $\mathrm{t}$ dimension given in the table is referenced from the bottom face of the crucible cover.

\subsection{Induction Coil}

The induction coil used in the SURC-1 experiment was designed and built by Inductotherm Corporation. The coil was fabricated with $3.8 \mathrm{~cm}$ O.D. copper tubing having 20 turns with a pitch of $4.2 \mathrm{~cm}$. The coil was supported by six equally spaced hard rock maple columns $7.5 \mathrm{~cm} \times 5.5 \mathrm{~cm} \times 100 \mathrm{~cm}$ long attached to the outside of the coil. The dimensions of the coil were $61 \mathrm{~cm}$ I.D. $\times 71 \mathrm{~cm}$ high. After the coil was placed around the crucible and centered on the stainless charge inside the aluminum containment vessel, fiber glass cloth was attached to the outside of the support columns. Fine MgO powder was placed between the crucible and coil and dry $K / R$ Cast-98 was placed between the coil and fiber glass shroud. This was done to protect the coil from contact with debris, should the crucible fail.

\subsection{Charge Assembly}

The inductive ring susceptor technique was used to melt and sustain the molten state of the oxide meltpool. Basically, this technique uses embedded tungsten susceptors which are inductively heated using an external coil. The susceptor assemblies draw power from the magnetic induction field. This energy heats the metallic susceptors which in turn heats the oxide charge materials via conduction and radiation heat transfer. The number and size of the susceptors determine the boundaries of the meltpool and the material and shape of the susceptors determine the heating efficiency. This technique was developed by Copus [1983] at Sandia National Laboratories and has been used to melt $\mathrm{SiO}_{2}, \mathrm{Al}_{2} \mathrm{O}_{3}, \mathrm{UO}_{2}$, and $\mathrm{UO}_{2}-\mathrm{ZrO}_{2}$ materials. Detailed information on the development of the inductive ring susceptor technique is reported by Copus [1983] and experimental efforts using the technique are described in Bradley and Copus [1986] and Gronager et al. [1986].

The charge assembly for the SURC-1 test consisted of 3 elements: (1) the oxide melt material, (2) the ring susceptor assembly, and (3) the boundary insulation layer. A schematic depicting the layout of the charge assembly was previously shown in Figure 2.7. The oxide melt material in the SURC-1 experiment was formed from isostatically pressed cylinders of 63 w/o $\mathrm{UO}_{2}-27 \mathrm{w} / \mathrm{o} \mathrm{ZrO}_{2}-10 \mathrm{w} / \mathrm{o} \mathrm{Zr}$. These cylinders were crushed into particulate form just prior to the execution of SURC-1. The particulate material was evenly distributed within the central charge volume which had dimensions of $47 \mathrm{~cm}$ (height) $\times 35.6 \mathrm{~cm}$ (diameter). The oxide melt material weighed $164.1 \mathrm{~kg}$ and had an approximate density of $3.5 \mathrm{~g} / \mathrm{cm}^{3}$.

The ring susceptor assembly for SURC-1 consisted of 5 tungsten rings, three tungsten guide rods, and fifteen tungsten spacers. All of the tungsten rings were $35.6 \mathrm{~cm}$ in diameter and had a central hole diameter of $7.6 \mathrm{~cm}$. The top four rings had a thickness of $0.32 \mathrm{~cm}$ and were spaced at $9 \mathrm{~cm}$ intervals while the bottom ring had a thickness of $0.64 \mathrm{~cm}$ and was spaced $7 \mathrm{~cm}$ above the zirconia board insulation layer. Three guide rods were used to prevent skewed collapse during the melting and interaction phase of the experiment. These rods were $1.3 \mathrm{~cm}$ in diameter and $40 \mathrm{~cm}$ in length. The tungsten spacers were $0.64 \mathrm{~cm}$ in diameter and $2.5 \mathrm{~cm}$ in length. Five spacers were placed in the bottom, middle, and top rings with $1 \mathrm{~cm}$ above and $1 \mathrm{~cm}$ below each ring so that none of the rings would touch each other during the test. The total tungsten ring 
Experimental

Table 3.3 Location of thermocouples cast within the MgO sidewall, SURC-1 (See Figure 3.4)

\begin{tabular}{|c|c|c|c|c|}
\hline $\begin{array}{l}\text { Array } \\
\text { No. }\end{array}$ & $\begin{array}{c}\text { Thermocouple } \\
\text { No. }\end{array}$ & $\begin{array}{c}\mathrm{t} \\
(\mathrm{cm})\end{array}$ & $\begin{array}{c}\theta \\
\text { (degree) }\end{array}$ & $\begin{array}{c}z \\
(\mathrm{~cm})\end{array}$ \\
\hline \multirow[t]{4}{*}{1} & M1 & 0.5 & 0 & -20.0 \\
\hline & M2 & 1.5 & 0 & -20.0 \\
\hline & M3 & 2.5 & 0 & -20.0 \\
\hline & M4 & 9.0 & 0 & -20.0 \\
\hline \multirow[t]{3}{*}{2} & M5 & 0.5 & 0 & -15.0 \\
\hline & M6 & 1.5 & 0 & -15.0 \\
\hline & M7 & 2.5 & 0 & -15.0 \\
\hline \multirow[t]{4}{*}{3} & M8 & 0.5 & 0 & -10.0 \\
\hline & M9 & 1.5 & 0 & -10.0 \\
\hline & M10 & 2.5 & 0 & -10.0 \\
\hline & M11 & 9.0 & 0 & -10.0 \\
\hline \multirow[t]{3}{*}{4} & M12 & 0.5 & 90 & -5.0 \\
\hline & M13 & 1.5 & 90 & -5.0 \\
\hline & M14 & 2.5 & 90 & -5.0 \\
\hline \multirow[t]{4}{*}{5} & M15 & 0.5 & 90 & 0.0 \\
\hline & M16 & 1.5 & 90 & 0.0 \\
\hline & M17 & 2.5 & 90 & 0.0 \\
\hline & M18 & 9.0 & 90 & 0.0 \\
\hline \multirow[t]{3}{*}{6} & M19 & 0.5 & 165 & +5.0 \\
\hline & M20 & 1.5 & 165 & +5.0 \\
\hline & M21 & 2.5 & 165 & +5.0 \\
\hline \multirow[t]{4}{*}{7} & M22 & 0.5 & 165 & +10.0 \\
\hline & M23 & 1.5 & 165 & +10.0 \\
\hline & M24 & 2.5 & 165 & +10.0 \\
\hline & M25 & 9.0 & 165 & +10.0 \\
\hline \multirow[t]{3}{*}{8} & M26 & 0.5 & 270 & +15.0 \\
\hline & M27 & 1.5 & 270 & +15.0 \\
\hline & M28 & 2.5 & 270 & +15.0 \\
\hline \multirow[t]{4}{*}{9} & M29 & 0.5 & 270 & +20.0 \\
\hline & M30 & 1.5 & 270 & +20.0 \\
\hline & M31 & 2.5 & 270 & +20.0 \\
\hline & M32 & 9.0 & 270 & +20.0 \\
\hline \multirow[t]{3}{*}{10} & M33 & 0.5 & 0 & +35.0 \\
\hline & M34 & 1.5 & 0 & +35.0 \\
\hline & M35 & 2.5 & 0 & +35.0 \\
\hline \multirow[t]{4}{*}{11} & M36 & 0.5 & 0 & +50.0 \\
\hline & M37 & 1.5 & 0 & +50.0 \\
\hline & M38 & 2.5 & 0 & +50.0 \\
\hline & M39 & 9.0 & 0 & +50.0 \\
\hline
\end{tabular}


Table 3.4 Location of thermocouples cast within the crucible cover, SURC-1 (See Figure 3.4)

\begin{tabular}{ccccc}
\hline $\begin{array}{c}\text { Array } \\
\text { No. }\end{array}$ & $\begin{array}{c}\text { Thermocouple } \\
\text { No. }\end{array}$ & $\begin{array}{c}\mathbf{t} \\
(\mathbf{c m})\end{array}$ & $\begin{array}{c}\boldsymbol{\theta} \\
\text { (degree) }\end{array}$ & $\begin{array}{c}\mathbf{z} \\
(\mathbf{c m})\end{array}$ \\
\hline \multirow{2}{*}{12} & M40 & 10.0 & 0 & 0.5 \\
& M41 & 10.0 & 0 & 1.5 \\
& M42 & 10.0 & 0 & 2.5 \\
13 & M43 & 10.0 & 180 & 0.5 \\
& M44 & 10.0 & 180 & 1.5 \\
& M45 & 10.0 & 180 & 2.5 \\
\hline
\end{tabular}

assembly weighed approximately $50 \mathrm{~kg}$.

The boundary insulation layer of the charge consisted of a zirconia insulating board placed on top and at the base of the charge and an annulus of fine uranium dioxide powder. The zirconia boards were $40 \mathrm{~cm}$ in diameter. A $1.3-\mathrm{cm}$-thick board was placed on top of the concrete cylinder. This was followed by a $1.3-\mathrm{cm}$-thick layer of fine $\mathrm{UO}_{2}$ powder. The base of the charge was configured in this manner to minimize concrete dehydration during initial heating and prior to melt attack. As the charge was built up within the crucible, fine $\mathrm{UO}_{2}$ powder was used between the crucible sidewall and charge material. The annular thickness of the powder was $2.5 \mathrm{~cm}$ and spanned the height of the charge of $47 \mathrm{~cm}$. The average density of the $\mathrm{UO}_{2}$ insulation boundary layer was $4.9 \mathrm{~g} / \mathrm{cm}^{3}$ and its total weight was 35.0 $\mathrm{kg}$. The powder at the sidewalls sintered during the experiment providing an insulating skull preventing melt contact with the $\mathrm{MgO}$ crucible. A $2.5 \mathrm{~cm}$ zirconia board was placed on top of the charge. This was done to prevent heat losses. The total mass of the two zirconia boards used in the charge was $1.7 \mathrm{~kg}$. The total mass of the charge including $3.4 \mathrm{~kg}$ of fission product simulants previously described in Section 2.4 was $204.2 \mathrm{~kg}$. 


\subsection{Instrumentation and Calibration}

The HP 1000 acquisition system used 171 data channels to record the results of the SURC-1 test. Of these, 140 were thermocouple channels. Sixty thermocouple channels were used to monitor axial erosion in the concrete. An additional 45 thermocouple channels were used to record temperatures in the crucible sidewalls and lid. Fourteen thermocouples were located in the system to monitor the temperature of power supply water and effluent gases. Six more thermocouples were used to monitor the temperature within the aerosol collection system, and the last 15 thermocouple channels were used to record the meltpool temperature.

Thirty-one data channels were voltage channels. Ten of these were used to monitor pressure and flow through the system. One was used to record the relative opacity of the gas stream. Six more were used to measure the induction coil power and coolant flow levels. Three channels were used to record the output from the optical pyrometers. Three were used to monitor the composition of the effluent gas and the last eight were used to record aerosol data.

In addition to the HP 1000 data system, data were sampled and stored with the aerosol sample system ( 23 channels), the gas grab sample system (seven channels), the Inficon Mass Spectrometer (nine channels), and a video camera/recorder system.

\subsection{Thermocouple and Pyrometer Instrumentation}

Sixty thermocouples divided into three groups were cast into the concrete cylinder of the interaction crucible. The relative locations of the thermocouples were discussed in Section 3.2. One typical array of 20 type $K$ thermocouples was located on the axial centerline. Thermocouples in this array were spaced $2 \mathrm{~cm}$ apart. These thermocouples had a $0.16 \mathrm{~cm}$ diameter, 304 stainless steel, ungrounded sheaths.
The sheath of each thermocouple in the axial array was bent at an angle of 90 degrees at a minimum of 10 sheath diameters from the tip. The bent tip of the thermocouple was located in a plane parallel to the concrete surface and thus parallel to the propagating isotherm. This was done to minimize the errors caused by heat conduction down the metal sheaths. Six sets of two type $S$ or two type $C$ (tungsten - 5 percent rhenium versus tungsten 26 percent rhenium) thermocouples were mounted in alumina tubes and cast into the concrete. The alumina tubes were $0.64 \mathrm{~cm}$ in diameter and contained four $0.2 \mathrm{~cm}$ diameter holes in which the two thermocouples were installed. The type $S$ thermocouples installed in the alumina tubes were $0.16 \mathrm{~cm}$ diameter, and had ungrounded, tantalum sheaths. The type $\mathrm{C}$ thermocouples also had a $0.16 \mathrm{~cm}$, ungrounded, tantalum sheath. These alumina tube arrays were cast into the concrete cylinder on a radius of $14 \mathrm{~cm}$ from the axis and $60^{\circ}$ apart. Theta for the angular orientation of these arrays is taken to be zero relative to the side wall array located at $z=-20 \mathrm{~cm}$. Positive theta is clockwise looking down on the crucible from the top. The type $\mathrm{S}$ and the type $\mathrm{C}$ thermocouples were installed for measuring melt temperatures. These thermocouples also provided some data on the concrete thermal response prior to ablation which complemented data from the arrays of type $\mathrm{K}$ thermocouples.

An additional 45 thermocouples were used to monitor the $\mathrm{MgO}$ sidewall and lid temperatures. Locations for these K-type devices are also described in Section 3.2. These type $\mathrm{K}$ thermocouples were identical in sheath material and diameter as those cast in the concrete.

In addition to the thermocouples, three fiber optic pyrometers manufactured by Micron Incorporated were used to measure the temperature of the oxidic debris. Fiber optic pyrometers were used because the focusing head and lense assembly were very compact and the fiber optic signal transmitted to the signal conditioner was not affected by the electric field generated by the 
induction power supply. These pyrometers provided virtually a noise-free output signal proportional to the temperature measured at their focal point. A schematic showing the hardware and instrumentation used in the pyrotube assembly is shown in Figure 4.1.1. Each of the pyrometers were attached to a closed-end, thick-walled tungsten pyrotube measuring $2.5 \mathrm{~cm}$ O.D. and $1.3 \mathrm{~cm} \mathrm{I.D.} \mathrm{The} \mathrm{lengths} \mathrm{varied} \mathrm{so} \mathrm{that}$ the debris temperature could be measured at three different elevations. The lengths of the pyrotubes were 61,71 , and $81 \mathrm{~cm}$ long. The bottoms of the pyrotubes were located at 0,10 , and $20 \mathrm{~cm}$ above the $1.3-\mathrm{cm}$-thick zirconia insulating board placed directly on the concrete. The three pyrotubes were precisely located in the center of the charge equally spaced 120 degrees apart on a $5.4 \mathrm{~cm}$ diameter bolt circle as shown in Figure 4.1.2. The tungsten tubes were connected to a 304 stainless steel adapter using a stainless tube-to-pipe adapter as shown in Figure 4.1.3.

Each of the three stainless adapters were threaded into a water-cooled copper plate. This plate served to support the pyrotube assemblies and keep the pyrometer heads cool during the experiment. Installed into each adapter was a type $\mathrm{K}$ thermocouple to monitor pyrometer head temperature and a type $\mathrm{C}$ thermocouple installed inside a thin-walled tantalum tube measuring $0.32 \mathrm{~cm}$ OD $\times 0.25 \mathrm{~cm} \mathrm{I.D.} \mathrm{The} \mathrm{tantalum} \mathrm{tube}$ with the type $C$ thermocouple installed was routed through a stainless Swagelok tube to pipe adapter located on the pyrotube adapter down to the bottom of the closed-end tungsten pyrotube. The base of the tantalum tube (not including the thermocouple sheath) was bent at a right angle to keep the assembly adjacent to the inside diameter of the tungsten tube so as not to obstruct the focal area of the pyrometer. In order to keep the tantalum thermocouple sheaths from oxidizing during the experiment, argon was purged into the assembly very close to the lense of the pyrometer head. The tantalum tube served as the exhaust for the argon purge gas, thereby consistently flooding the tungsten pyrotube and sheaths of the type $\mathrm{C}$ thermocouples with a flow of argon. This minimized the potential for oxidation and ultimate failure: The head of each pyrometer was threaded into the stainless adapter and secured with a lock nut. The $4 \mathrm{~m}$ fiber optic extension leads were routed to their respective electronic modules through a feed-through located in the side of the aluminum containment vessel. Figure 4.1.4 shows the installation of the pyro head assembly on the crucible cover.

Each pyrometer was calibrated prior to the experiment with a black body source and calibration standard. The calibration curves showing a plot of temperature as a function of voltage and resulting least squares fit are shown in Figures 4.1.5, 4.1.6, and 4.1.7. The heads were calibrated at a focal distance of $76 \mathrm{~cm}$. Deviation from this focal length only affected the spot size measuring $0.64 \mathrm{~cm}$ in diameter. For the differences in focal lengths discussed the change in spot size is negligible and well within the diameter of the tungsten pyrotubes.

\subsection{Gas Analysis Instrumentation}

Gas composition analysis for the SURC-1 test was performed using three techniques: An Inficon Model IQ200 mass spectrometer, an Infrared Industries Series $700 \mathrm{CO} / \mathrm{CO}_{2}$ detector, and integral grab samples. The first two techniques yield real-time data which is viewed on-line and stored on computer disks. The grab samples are stored and analyzed posttest using both gas chromatography and mass spectrometry. A schematic layout of the SURC-1 gas composition sampling apparatus is shown in Figure 4.2.1.

Three different sampling locations were utilized. Location No. 1 was downstream of the main exhaustline gravel filter. Location No. 2 was between the containment vessel and the gravel filter and location No. 3 was inside the aluminum containment vessel. All sample lines for gas collection were $6.4 \mathrm{~mm}(0.250 \mathrm{in}$.$) O.D.$ stainless steel with Swagelok stainless steel fittings and Nupro plug valves. Inline filters 
Instrumentation

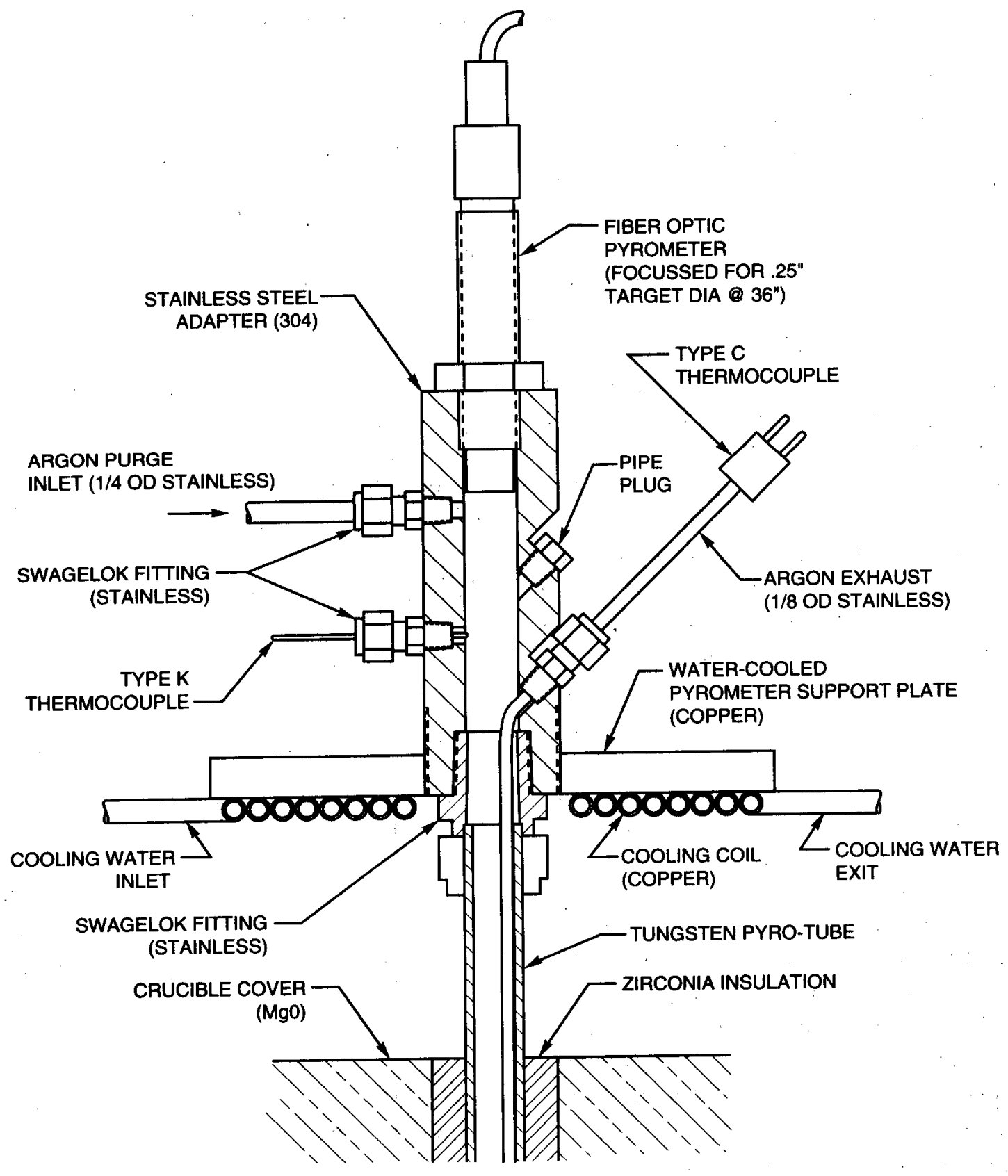

Figure 4.1.1 Schematic of fiber optic pyrotube assembly 


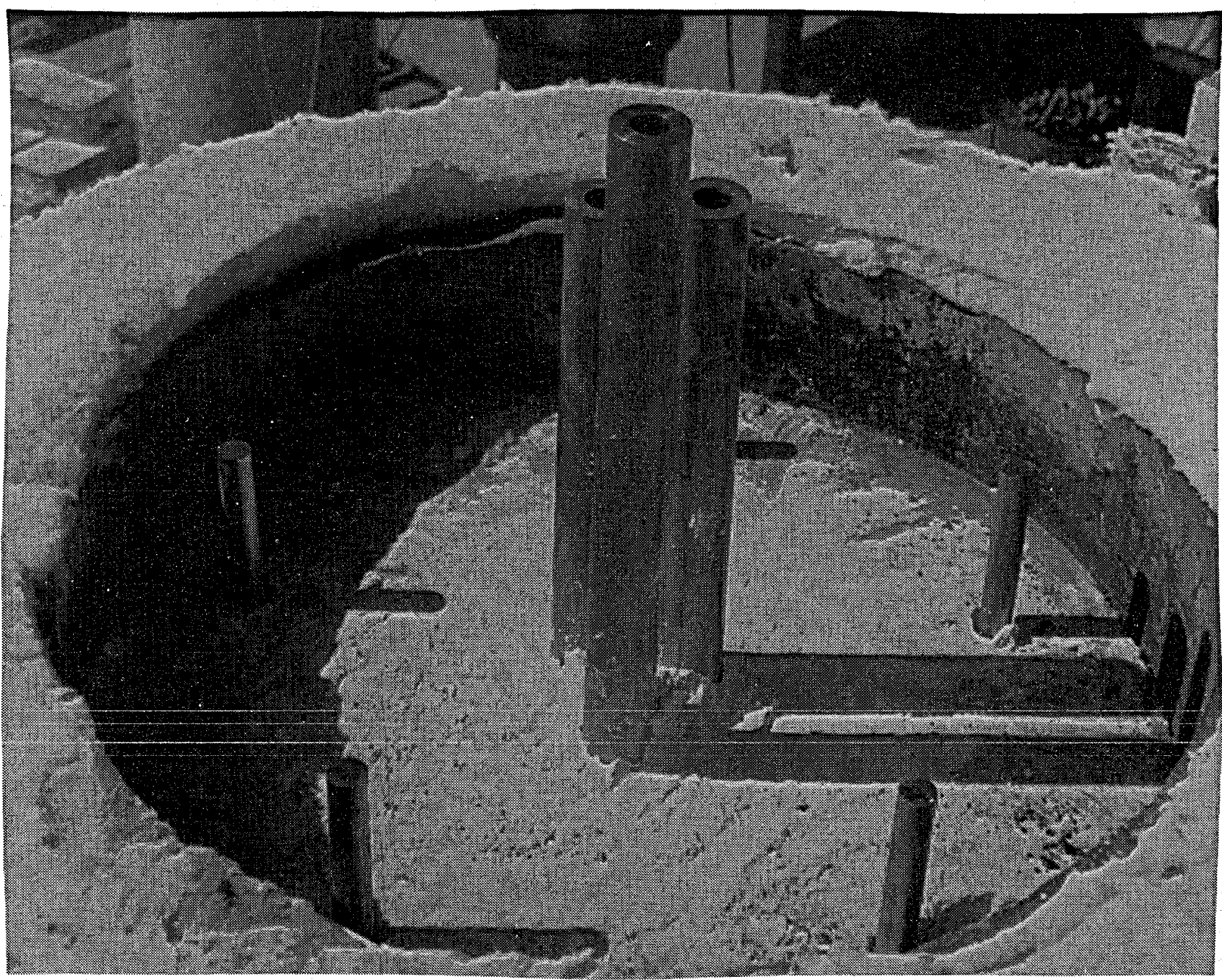

Figure 4.1.2 Photograph showing the position of tungsten pyrotubes installed in the charge 


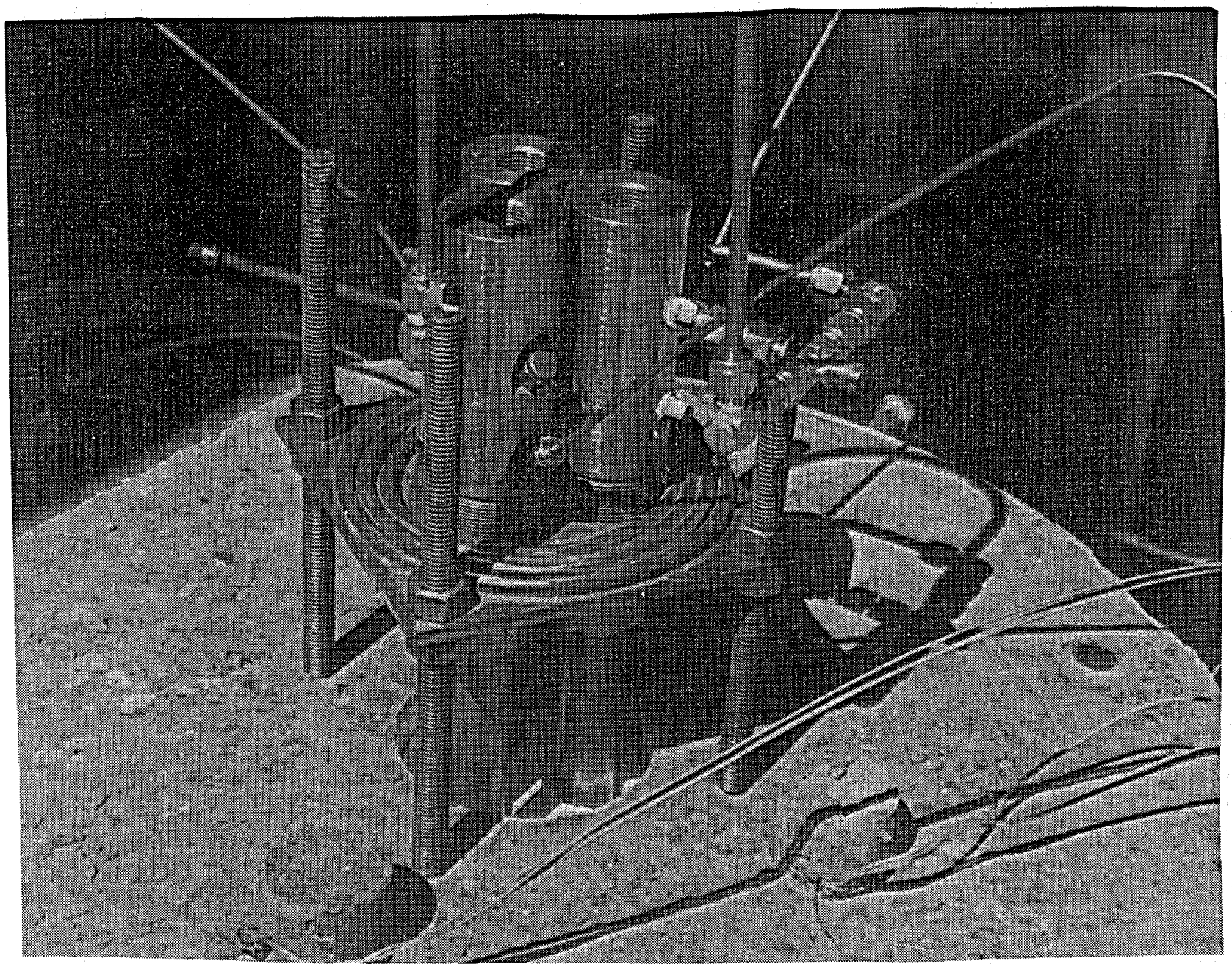

Figure 4.1.3 Photograph of the stainless steel adapters used to connect the tungsten pyrotubes to the pyrometer head adapter 


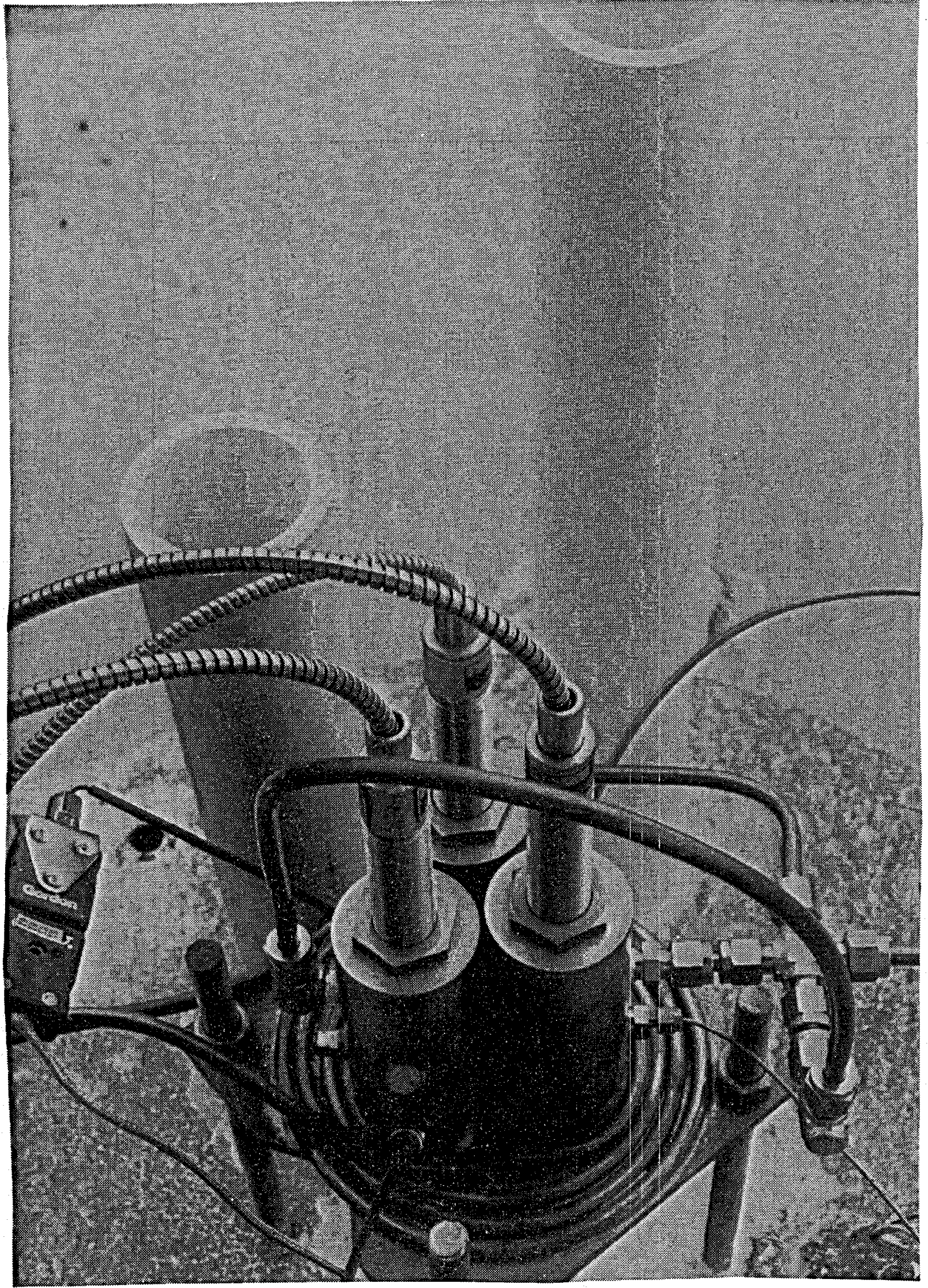

Figure 4.1.4 Photograph of the fiber optic pyrometer assembly installed on the crucible cover 


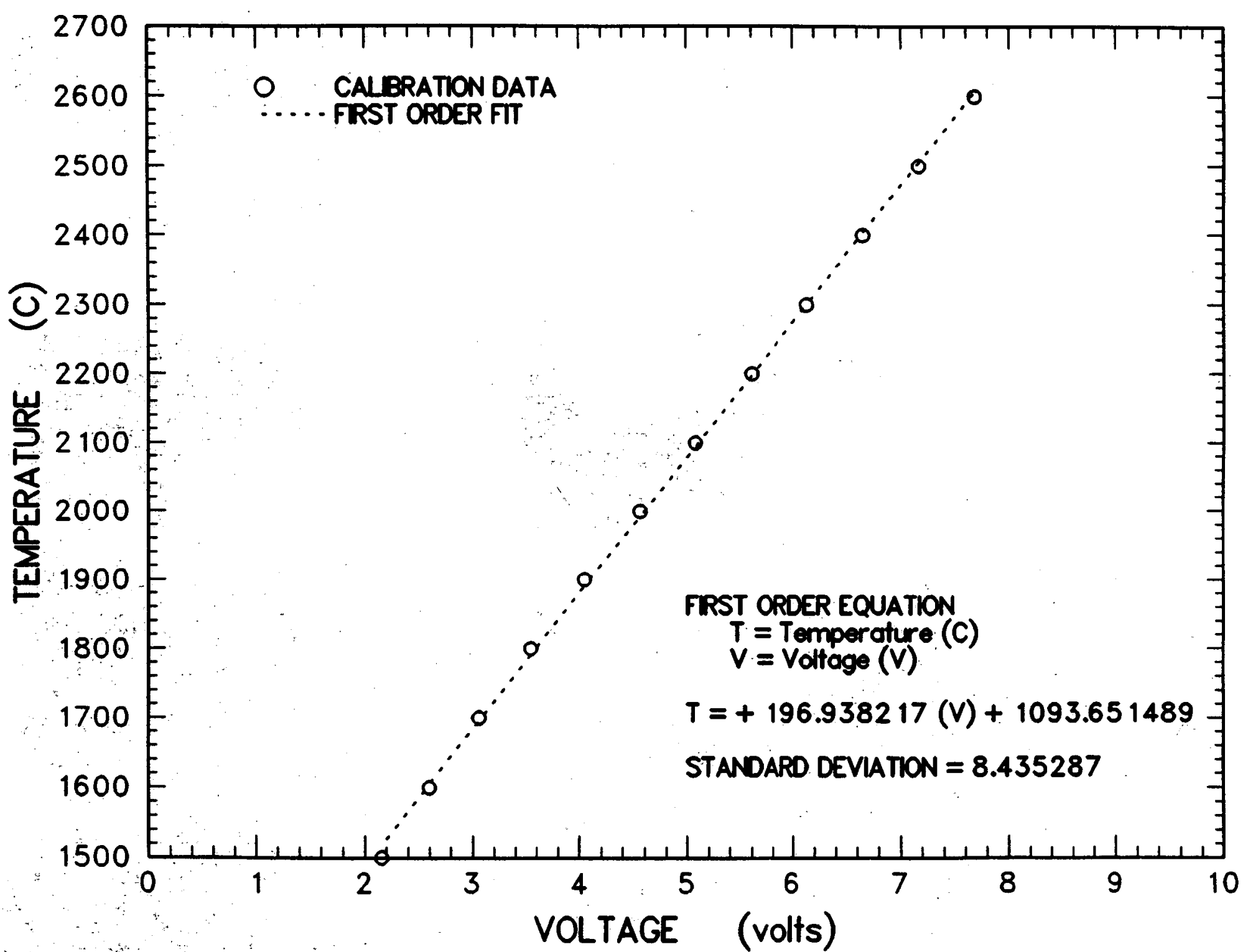

Figure 4.1.5 Micron fiber optic pyrometer calibration, pyrotube elevation $z=0 \mathrm{~cm}$ 


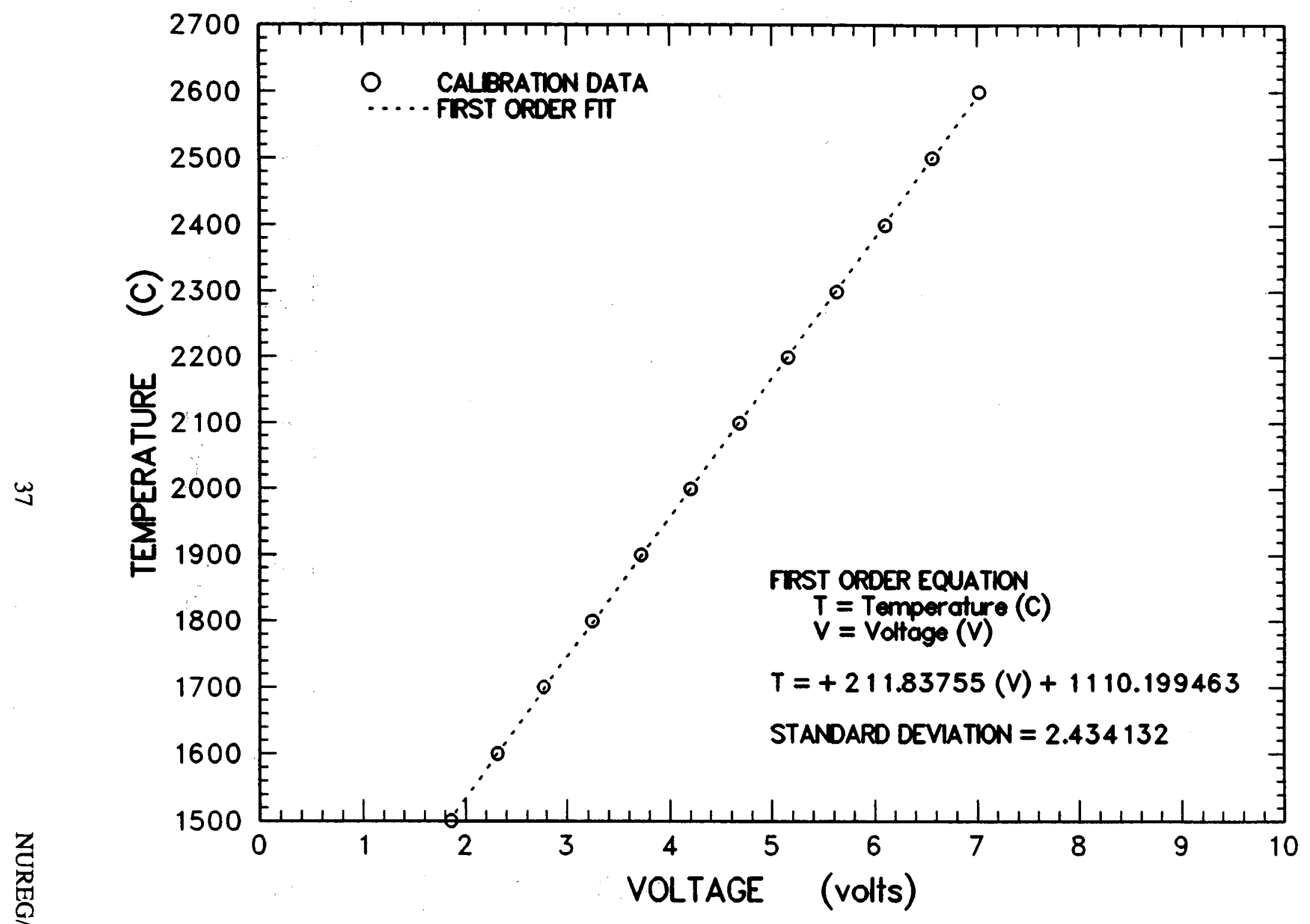

Figure 4.1.6 Micron fiber optic pyrometer calibration, pyrotube elevation $z=+10 \mathrm{~cm}$ 


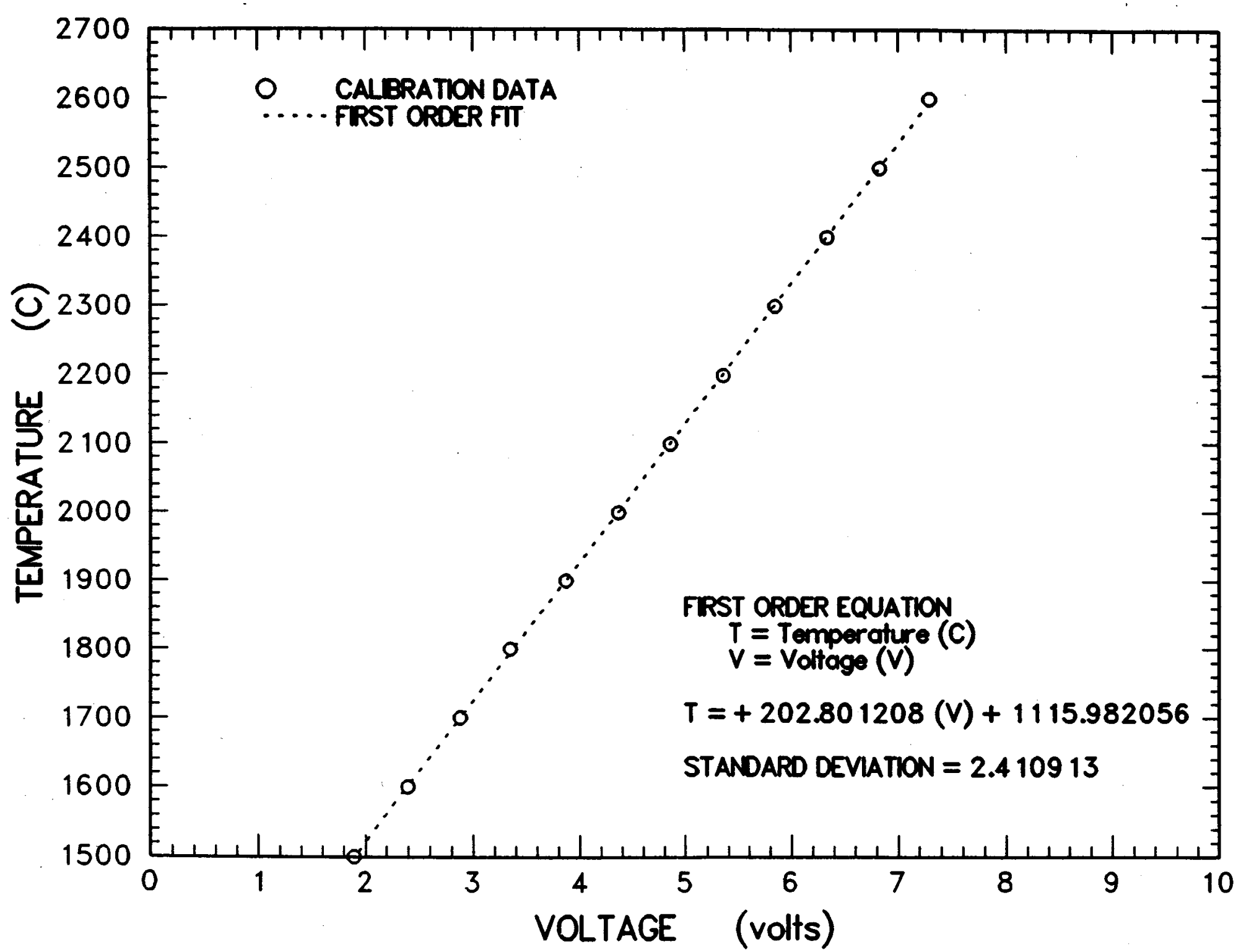

Figure 4.1.7 Micron fiber optic pyrometer calibration, pyrotube elevation $z=+20 \mathrm{~cm}$ 
Instrumentation

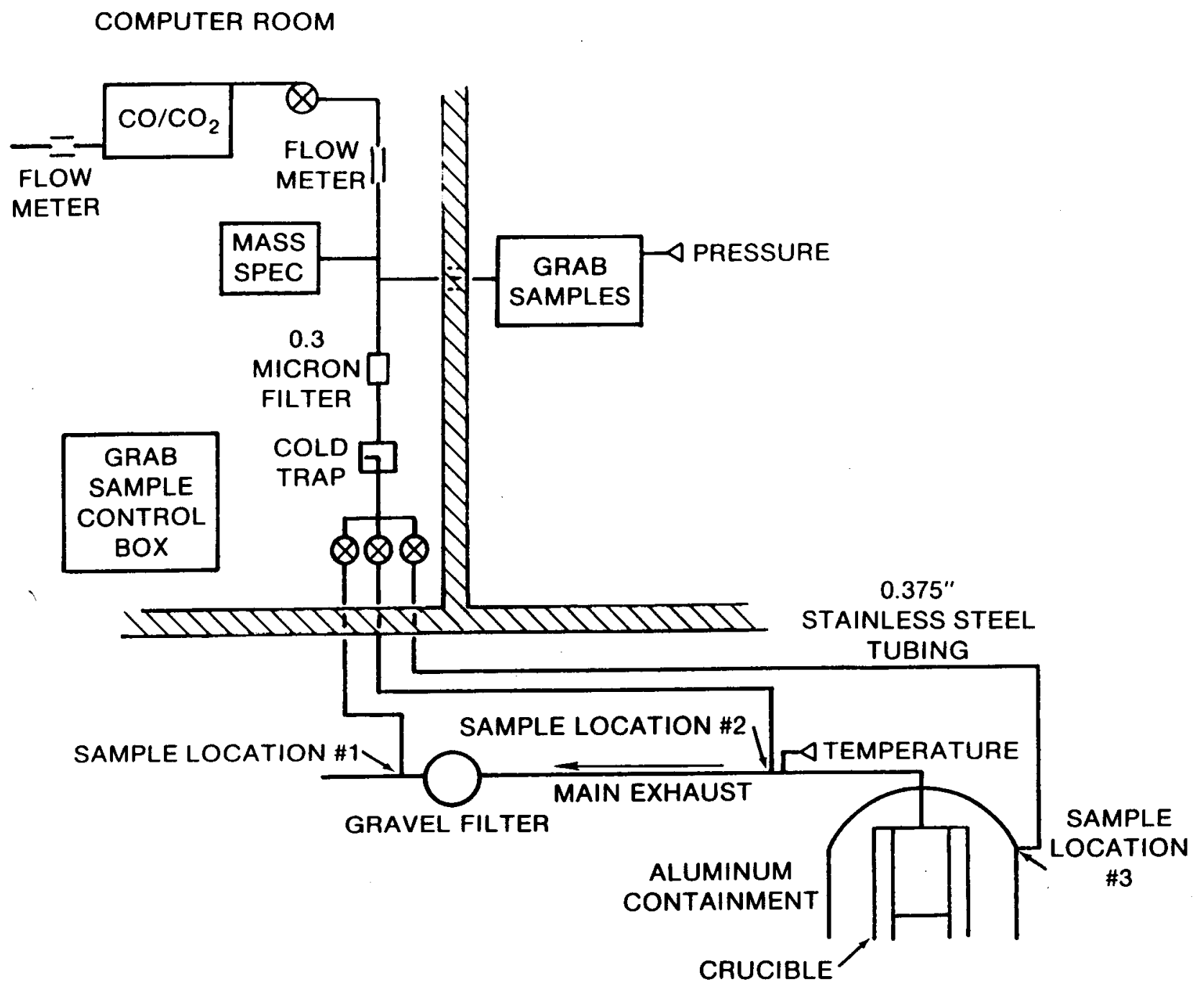

Figure 4.2.1 SURC-1 gas sampling schematic 
used for SURC-1 were 0.3 micron Gelman HEPA filters with an element of acrylic copolymer.

Type $\mathbf{K}$ thermocouples were used to monitor sample gas temperatures at the flow pipe sample port and at the $\mathrm{CO} / \mathrm{CO}_{2}$ monitor. A stainless steel cold trap with a volume of $75 \mathrm{~cm}^{3}$ and cooled with liquid nitrogen was used to prevent large amounts of water from fouling the analysis equipment. A single Gast diaphragm-type air pump was used to provide flow for the gas analysis system. Flow indication for the system was measured by self-indicating rotameters. The $\mathrm{CO} / \mathrm{CO}_{2}$ supply was also monitored with a Dwyer 0 to $10 \mathrm{scfh}$ air rotameter. The flow rate indicated by these rotameters was viewed remotely with a video camera and monitor.

Samples from the grab sample system were analyzed by gas chromatography and mass spectrometry using a Tracor MT-150 gas chromatograph and a Finnigan Mat 271/45 mass spectrometer. The samples were contained in either $75 \mathrm{~cm}^{3}$ or $500 \mathrm{~cm}^{3}$ stainless steel bottles with Nupro JB series regulating valves for closure. A Validyne absolute pressure transducer with a range of 1 to 1000 torr and a 0 to 10 VDC output was used to indicate the timing of sampling events by monitoring manifold pressure. Vacuum in the bottles was maintained prior to sampling by a Welch two-stage belt drive vacuum pump with $175 \mathrm{lpm}$ free air capacity. Grab samples were taken by manually operating a selector switch which remotely actuated an electrically controlled multiport ball valve. This valve connected the evacuated bottle to the gas sample line. The grab sample console is shown in Figure 4.2 .2 with $75 \mathrm{~cm}^{3}$ stainless steel bottles installed. For the SURC-1 test five of these bottles were replaced with $500 \mathrm{~cm}^{3}$ bottles.

The $\mathrm{CO} / \mathrm{CO}_{2}$ analyzer operates on an infrared absorption technique using. Infrared Industries Model 702 and 703 detectors (Figure 4.2.3). Carbon monoxide is monitored over a range of 0 to 50 percent and carbon dioxide is monitored over a range of 0 to 20 percent. Response time is 5 seconds for 90 percent of the reading with a sensitivity of \pm 2 percent. Output for the detectors to the data acquisition system is 0 to 5 volts full scale.

Another diagnostic tool for gas data used for the SURC-1 test was a quadrupole residual gas analyzer, Inficon model IQ200 (Figure 4.2.4). This instrument was set up in the table display mode and controlled automatically with a Hewlett Packard 9826 computer for scanning specifically selected masses corresponding to the gas species of interest: $\mathrm{H}_{2}, \mathrm{H}_{2} \mathrm{O}, \mathrm{CO}, \mathrm{O}_{2}, \mathrm{Ar}$, and $\mathrm{CO}_{2}$. A pressure converter manifold with a 10-torr orifice, $27 \mathrm{lpm}$ vacuum pump, and $0.5 \mathrm{~mm}$ $(0.020$ in.) I.D. capillary tube provided the ability for continuous sampling from a pressure of up to 2 atmospheres at the sample source down to 10 torr at the analyzer supply where the associated $150 \mathrm{lps}$ turbo pump could maintain $10^{-6}$ torr at the analyzer head. A Faraday cup detector was used to produce the currents for analysis.

For data acquisition, a Hewlett Packard 1000 (right side, Figure 4.2.3) series computer system was used with acquisition rates of 15 seconds for the duration of the experiment. Inputs from gas composition data were: temperature from the containment chamber thermocouple; temperature from the $\mathrm{CO} / \mathrm{CO}_{2}$ monitor thermocouple; percent $\mathrm{CO}, 0$ to 5 volts per 0 to 50 percent; and percent $\mathrm{CO}_{2}, 0$ to 5 volts per 0 to 20 percent.

\section{Layout and Location}

The relative location of the various support components and analysis equipment can be seen in Figure 4.2.1. The HEPA filter for the gas system, cold trap, rotometer, and solenoid valves were located $3 \mathrm{~m}$ upstream of the gas sampling devices and $9.5 \mathrm{~m}(31.5 \mathrm{ft})$ down stream from the aluminum containment vessel. The sample lines connected to the containment vessel and exhaust line just downstream from the outlet of 
Instrumentation

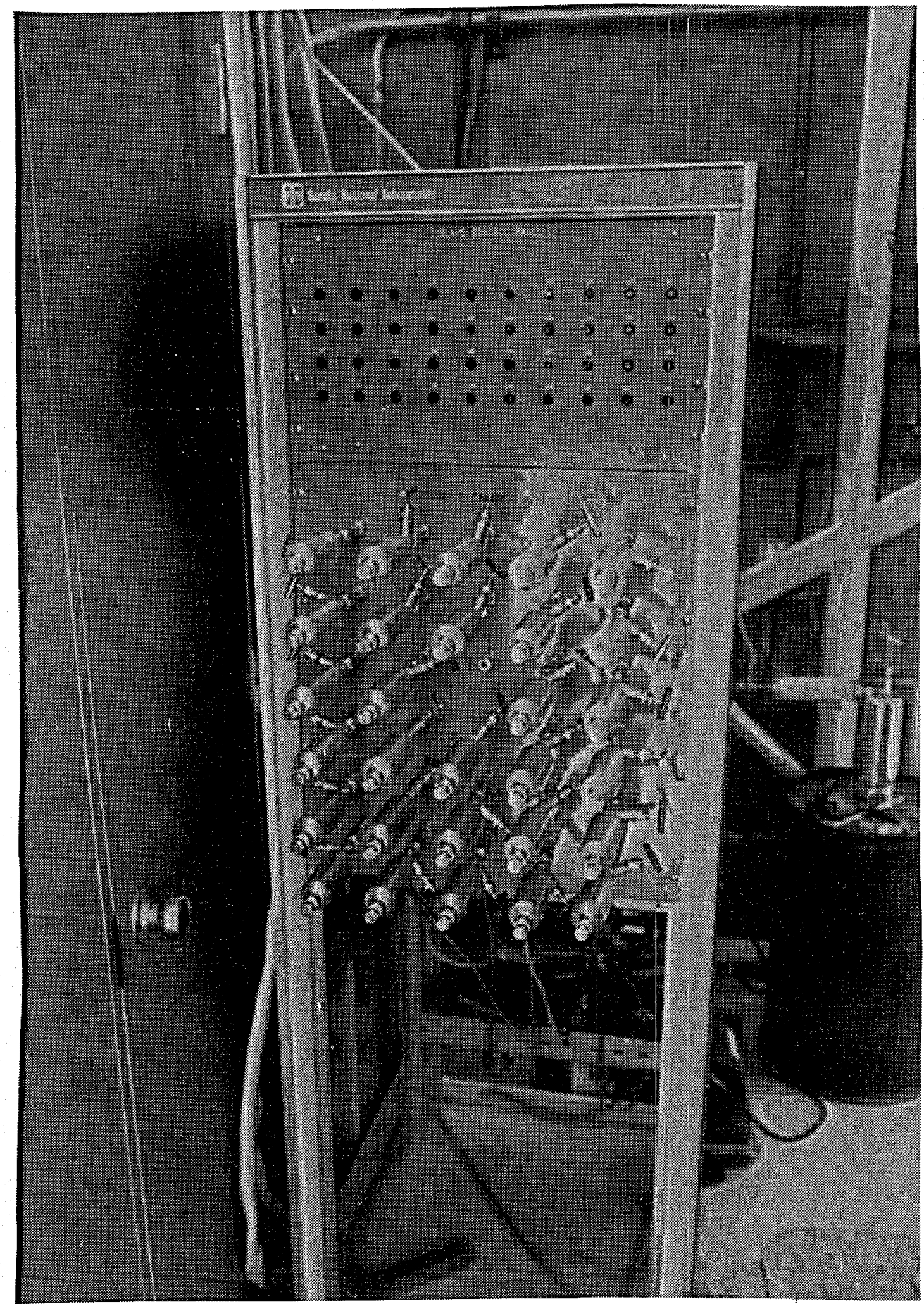

Figure 4.2.2 Gas grab sample console 
Instrumentation

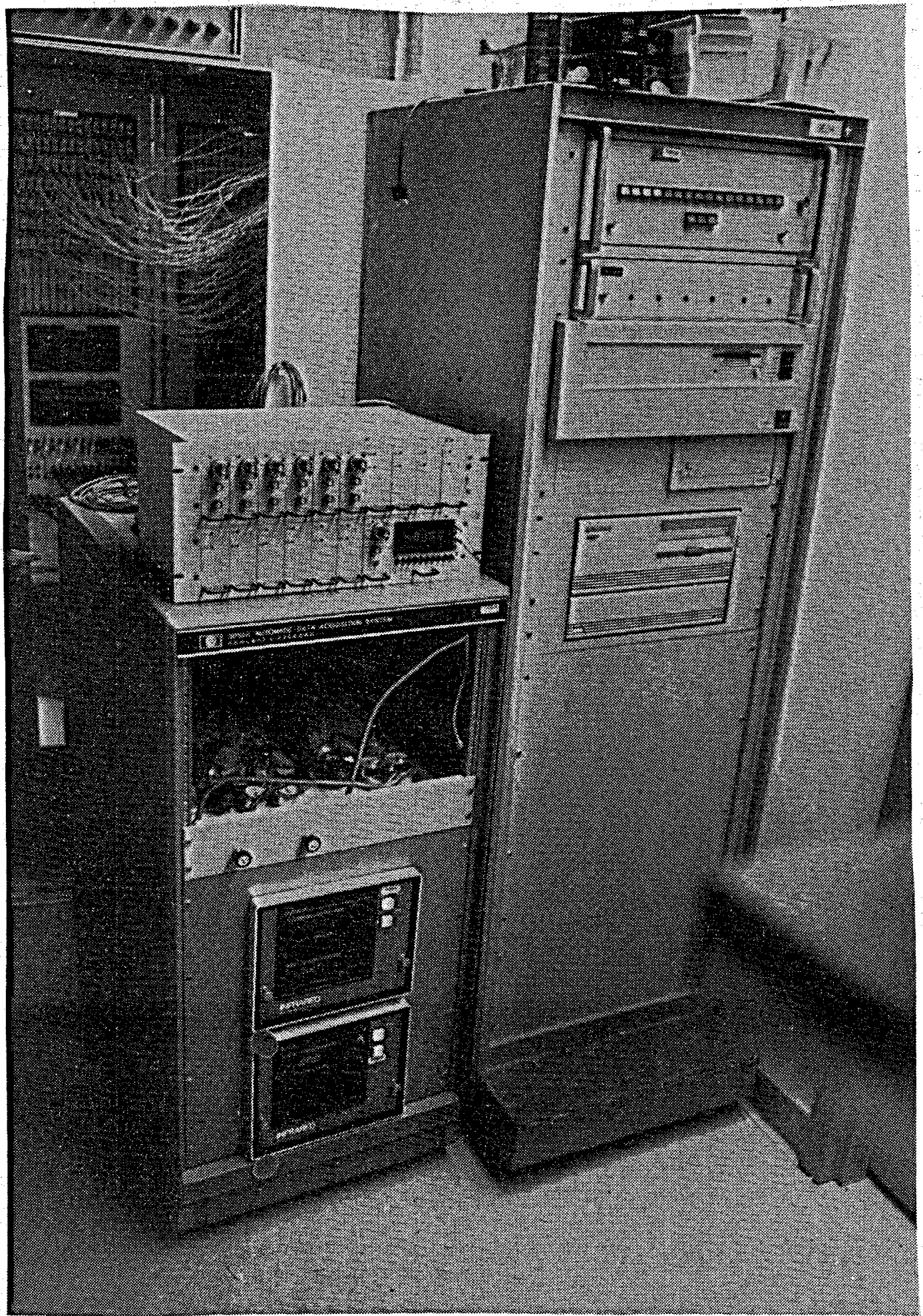

Figure 4.2.3 $\mathrm{CO} / \mathrm{CO}_{2}$ monitor hardware 


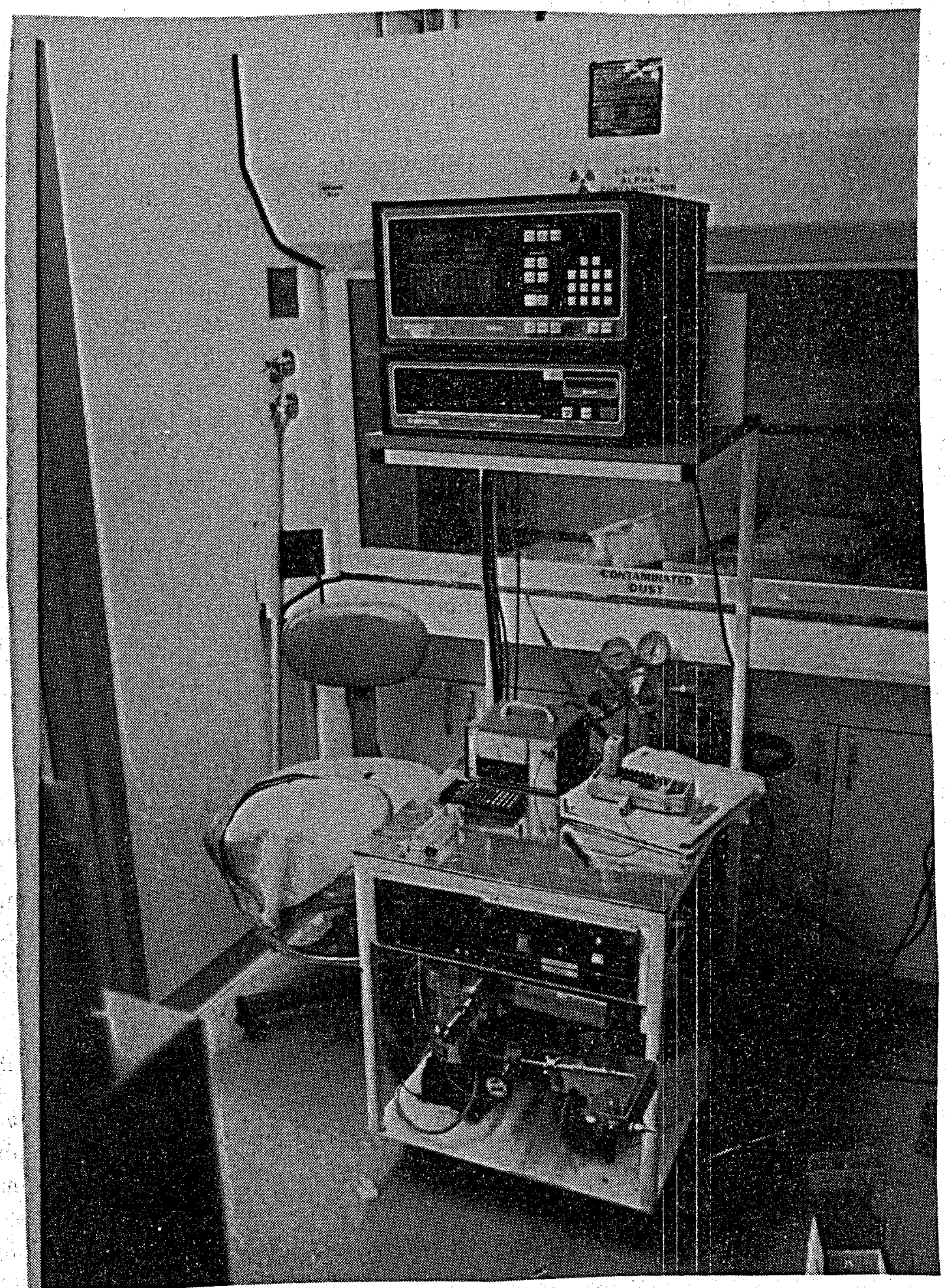

Figure 4.2.4 Mass spectrometer hardware 
the gravel filter contained an in-line, ambient temperature, condensate trap followed by a stainless steel wool rough particulate filter. The locations of these devices were $1.5 \mathrm{~m}(5 \mathrm{ft})$ and $4.5 \mathrm{~m}(15 \mathrm{ft})$ from the containment vessel, respectively. The condensate trap consisted of a $75 \mathrm{~cm}^{3}$ stainless steel bottle. Temperature inside the containment vessel was measured using a type $\mathrm{K}$ thermocouple.

The grab sample system tied into the main gas line using $6.4 \mathrm{~mm}$ (0.25 in.) O.D. stainless steel tube. The tube connecting the sample system with the flow line had a dead volume of $50 \mathrm{~cm}^{3}$. The grab sample console was located adjacent to the $\mathrm{CO} / \mathrm{CO}_{2}$ monitor and mass spectrometer approximately $10 \mathrm{~m}$ from the containment vessel. The control panel for manual grab sample acquisition was located in the remote control center along with other instrumentation.

The $\mathrm{CO} / \mathrm{CO}_{2}$ monitor was located in the shielded computer room where it was connected to the main gas line by a $6.4 \mathrm{~mm}(0.250$ in.) O.D. stainless steel tube. A diaphragm pump and flowmeter supplied the sample gas from the main gas stream for the infrared detectors. The distance upstream to the SURC-1 test article was $12 \mathrm{~m}(39 \mathrm{ft})$.

The Inficon mass spectrometer was also located in the shielded computer room and was connected to the main gas stream by a $0.5 \mathrm{~mm}(0.020 \mathrm{in}$.) I.D. capillary tube and was situated approximately $12.5 \mathrm{~m}(41 \mathrm{ft})$ from the test vessel.

\section{Calibrations}

In-situ calibrations for the different gas sampling equipment were accomplished with primary standard calibration gas mixtures from Alphagaz. For the analysis, mixtures of 2.0 percent $\mathrm{H}_{2}$, 25.1 percent $\mathrm{CO}, 10.0$ percent $\mathrm{CO}_{2}, 62.9$ percent Ar (Alphagaz Mix 1) and 45.0 percent $\mathrm{CO}$, 15.0 percent $\mathrm{CO}_{2}, 40$ percent $\mathrm{N}_{2}$ (Alphagaz Mix 2) were analyzed in addition to the SURC-1 test samples. Results from these calibrations are listed in Table 4.2.1.

The $\mathrm{CO} / \mathrm{CO}_{2}$ analyzer was calibrated according to the operating reference manual using gas mixture Alphagaz Mix 1 as well as pure nitrogen. This calibration procedure was accomplished pre-test. Following the test completion, the zero and full range were again checked to ensure that there was no significant drift.

After the test, the calibration procedure for the mass spectrometer was completed again and showed no significant drift. Operational checks of the support components included response of the thermocouples from below ambient to above ambient as compared with other type $\mathrm{K}$ thermocouples in the same environment. Flow measurements through the self-indicating rotameters were matched with several other similar flowmeters. Output from the pressure transducer was monitored while changing the grab sample manifold configuration from pressure to vacuum conditions.

\subsection{Flow Device Instrumentation}

Five different devices were used to measure the gas flow rate in SURC-1: A $1.02 \mathrm{~cm}$ orifice plate, a laminar flow element, a turbine meter, a Rockwell 415 gas clock, and a Rockwell 750 gas clock. Figure 4.3.1 shows a flow train schematic of the hardware for SURC-1.

The flow system consisted of a series of piping, tubing, and a gravel filter instrumented with a variety of devices for measuring gas flow rates. The flow system starts with an exhaust tube that is fit into the crucible cover. The tube material was porous alumina, having dimensions of $5.1 \mathrm{~cm}$ O.D. $\mathrm{x} 0.6 \mathrm{~cm}$ wall $\mathrm{x} 1.2 \mathrm{~m}$ long. A $5.1 \mathrm{~cm}$ diameter stainless steel vacuum $90^{\circ}$ elbow was attached to a $5.1 \mathrm{~cm}$ O.D. $x$ $25 \mathrm{~cm}$ long stainless steel tube mounted to the flange port located on top of the aluminum containment vessel. The horizontal flange of the 
Table 4.2.1 Results of grab sample analysis on calibrated gas using gas chromatography

\begin{tabular}{lccccc}
\hline Sample \# & $\mathbf{C O}(\%)$ & $\mathbf{C O}_{\mathbf{2}}(\%)$ & $\mathbf{N}_{\mathbf{2}}(\%)$ & $\mathbf{A r}(\%)$ & $\mathbf{H}_{\mathbf{2}}(\%)$ \\
\hline Alphagaz Mix 1 & 25.1 & 10.0 & 0. & 62.9 & 2.0 \\
Mass Spectrometer & 20 & $\mathbf{8}$ & $\mathrm{ND}$ & 70 & 2 \\
Grab Sample & 21.5 & 6.6 & 3.7 & 44.1 & 1.8 \\
CO/CO 2 Monitor & 21.3 & 9.2 & $\mathrm{ND}$ & $\mathrm{ND}$ & $\mathrm{ND}$ \\
Alphagaz Mix 2 & 45.0 & 15.0 & 40.0 & 0. & 0. \\
Mass Spectrometer & 42 & 15 & 40 & Trace & Trace \\
\hline ND = Not detected. & & & & & \\
\hline
\end{tabular}

elbow was connected to a $5.1 \mathrm{~cm}$ O.D. $x$ $0.17 \mathrm{~cm}$ wall $\times 1.8 \mathrm{~m}$ long length of stainless tubing. The end of this tubing was fitted with a $5.1 \mathrm{~cm} \mathrm{O.D.,} \mathrm{stainless} \mathrm{flanged} \mathrm{cross.} \mathrm{The}$ centerline of all the flange ports on the cross were positioned in a horizontal plane. The cross was used to mount an opacity meter and a nozzle for sampling the aerosol. The cross was adapted to a $2.0 \mathrm{~m}$ section of $5.1-\mathrm{cm}$ diameter, $150-\mathrm{lb}$, schedule-40 black steel pipe via a $5.1 \mathrm{~cm}$ bolted flange. A $1.02 \mathrm{~cm}$ diameter, sharp-edge, concentric orifice was mounted between two flanges $1.0 \mathrm{~m}$ from the stainless steel cross. Two Validyne pressure transducers were connected in parallel across pressure taps machined in the flanges. Another pressure transducer was mounted to the black pipe $5 \mathrm{~cm}$ upstream of the orifice to measure gas flow pressure.

The section of pipe containing the orifice was connected to the inlet of a gravel filter with a $1.1 \mathrm{~m}$ length of $5.1 \mathrm{~cm}$ black steel pipe using a combination of flanges and fittings. The gravel filter had an inside diameter of $25.4 \mathrm{~cm}$ and was filled with sand to a depth of $1 \mathrm{~m}$. The gravel filter was used to filter aerosols, preventing them from entering the laminar flow device and the two gas clocks located downstream. The filter was designed and tested to remove 99 percent of the aerosols at flow rates of $10 \mathrm{scfm}$ (300 slpm) with a backpressure of less than 0.25 psig. Connected to the outlet of the gravel filter were two lengths of $2.5 \mathrm{~cm}$, schedule-40 black steel pipe, $50.8 \mathrm{~cm}$ long. A laminar flow element (LFE) was installed between the two pipe sections. The LFE was instrumented with a Validyne differential pressure transducer. The end of the flow train was terminated by two Rockwell gas clocks mounted in series. The gas clocks were connected using $2.5 \mathrm{~cm}$ schedule -40 black steel pipe fittings.

The principles of operation and pertinent equations for orifice plate flowmeters may be found in Baker and Pouchot [1983]. The orifice plate flowmeter is probably the most widely used flowmeter in service today. It is found mostly in field use and is simple, rugged, reliable, accurate, and inexpensive. Orifice plates used for gas measurement are considered to be accurate to 1 to 2 percent based on physical dimensions and published correction factors. It should be noted, however, that uncertainties in differential pressure (the measured parameter), temperature, line pressure, and gas density can easily overwhelm the uncertainty from the laboratory calibration. One disadvantage of the orifice plate is that a 10:1 change in differential pressure results from only a 3:1 change in flow due to the square root relationship between 


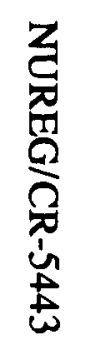

TO AEROSOL SAMPLING

INSTRUMENTATION

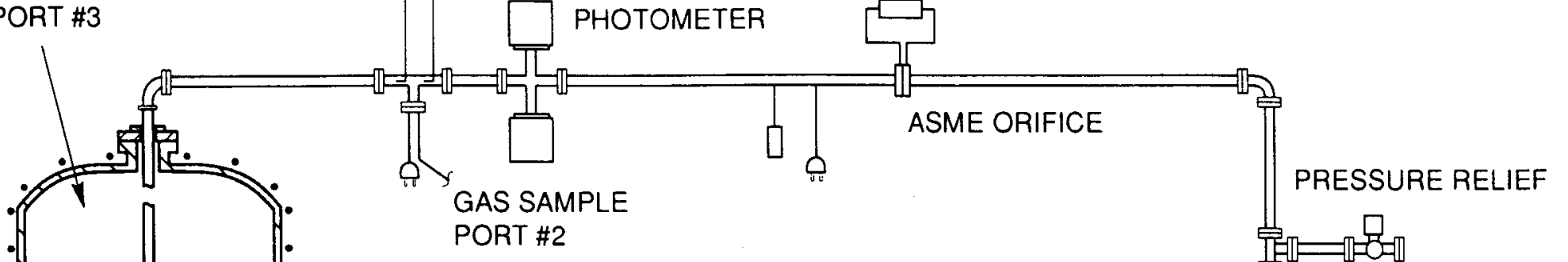

TURBINE METER

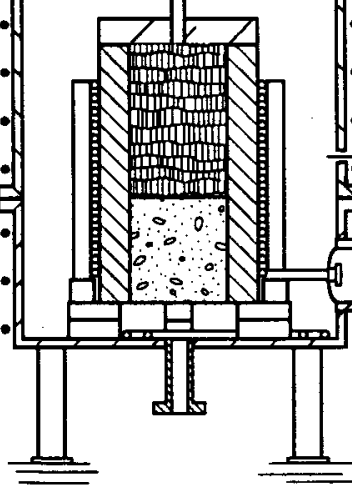

EXHAUST

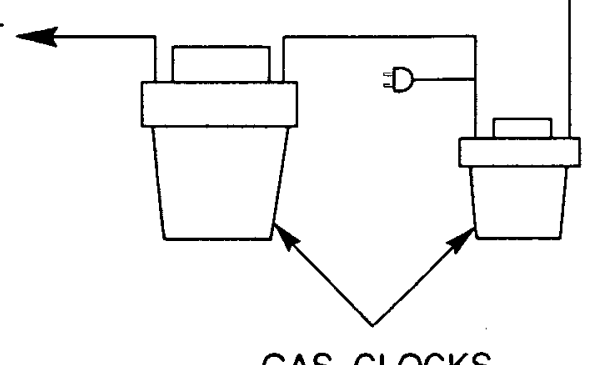

LAMINAR FLOW ELEMENT

Figure 4.3.1 Flow train schematic 
differential pressure and flow. Hence, 50 percent of expected full flow is measured in 20 percent of expected differential pressure. This makes low flow rates difficult to measure accurately.

The orifice flowmeter used in the SURC-1 experiment had an opening of $1.02 \mathrm{~cm}$ and was mounted between flanges in a $5 \mathrm{~cm}$ I.D. pipe. This pipe was mounted to the SURC-1 expansion chamber so that $100 \mathrm{~cm}$ of straight pipe preceded the flow device and $100 \mathrm{~cm}$ of straight pipe followed the device. Three Validyne pressure transducers were used in conjunction with the orifice plate. Two of these were used to record the differential pressures across the plate and had operational ranges of 0 to 2 psid and 0 to 5 psid. The third pressure transducer was used to measure the system pressure and had a range of 0 to $10 \mathrm{psig}$. The orifice plate was calibrated in the laboratory using air, helium, and argon at several different flow rates ranging from 0 to $18 \mathrm{cfm}(509 \mathrm{lpm})$. A pre-test flow calibration was performed on the test apparatus in-situ with argon. This was done to correlate the flow rate indicated by all the flow devices in the system. Results of the laboratory calibration for the ASME sharp edge orifice are shown graphically in Figure 4.3.2. Calibration data for the pressure transducers used with the orifice plate are presented in Appendix F.

The laminar flow element (LFE) is a group of capillary tubes bundled together to form a matrix such that the flow through each passage is laminar, even though the total flow upstream of the device may be turbulent. The LFE is not as sensitive to piping configuration as an orifice plate so that an inlet pipe length of one or two pipe diameters (instead of five or ten) is usually sufficient to provide a satisfactory flow pattern. The equations governing the operation of LFE devices are given in Baker and Pouchot [1983]. One advantage of an LFE is that the relationship between differential pressure (the measured parameter) and flow is linear for the range of flows for which it is designed. Calibration of the device should be done against a primary standard and is a function of gas viscosity which is itself a function of gas composition. A potential disadvantage is that the small passages in the flow matrix are susceptible to plugging when the gas contains aerosols or water vapor.

The LFE used in the SURC-1 experiment was designed and built by Calibrating and Measuring Equipment (CME) and has a nameplate flow range of 0 to $10 \mathrm{scfm}(0$ to $300 \mathrm{lpm})$ for air at standard conditions. The LFE is contained in a $100 \mathrm{~cm}$ section of schedule 40 black pipe with an O.D. of $3.3 \mathrm{~cm}$. Differential pressure is measured using a Validyne differential transducer with a range of 0 to 2 psid. The LFE was calibrated both in the laboratory and at the test site as described above. Laboratory calibration (Figure 4.3.3) was done using a variety of gases using NBS-traceable critical orifices, flow nozzles, and hot wire anemometer as the primary standards. The calibration of the differential pressure transducer used with the LFE is presented in Appendix F.

The turbine flowmeter [Baker and Pouchot, 1983] consists of a freely rotating propeller mounted concentrically in a pipe. The force of the gas striking the propeller blades causes them to rotate at an angular velocity proportional to the gas velocity so that the volumetric gas flow is directly proportional to the rotational speed of the propeller. A magnetic pickup in the rotor causes a voltage to be generated in an external electrical coil. The magnitude of the voltage is then directly proportional to the volumetric flow rate for the designated flow range of the device. The output of the device is in actual liters per minute (alpm) and must be corrected to standard conditions. Turbine flowmeters must be calibrated to determine the coefficient of discharge but once this is done are considered to be accurate to about 1 percent. Some advantages of the turbine flowmeter are that it is insensitive to gas composition and that it produces a linear response over its design flow range. Some disadvantages are that it is susceptible to drag if the gas contains aerosols or water and that the magnetic 


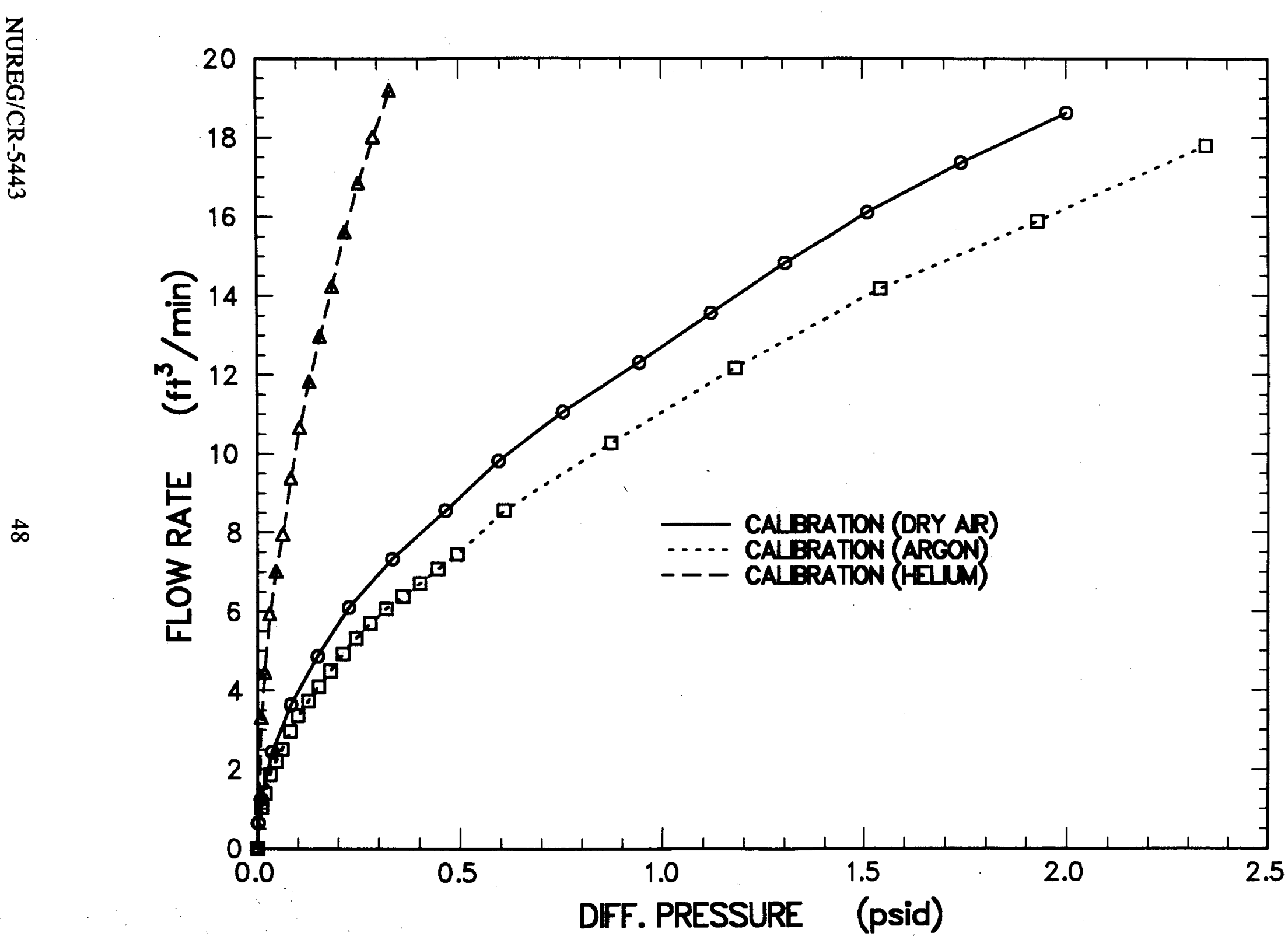

蛋

Figure 4.3.2 ASME sharp edge orifice calibration, $1 \mathrm{~cm}$ diameter 


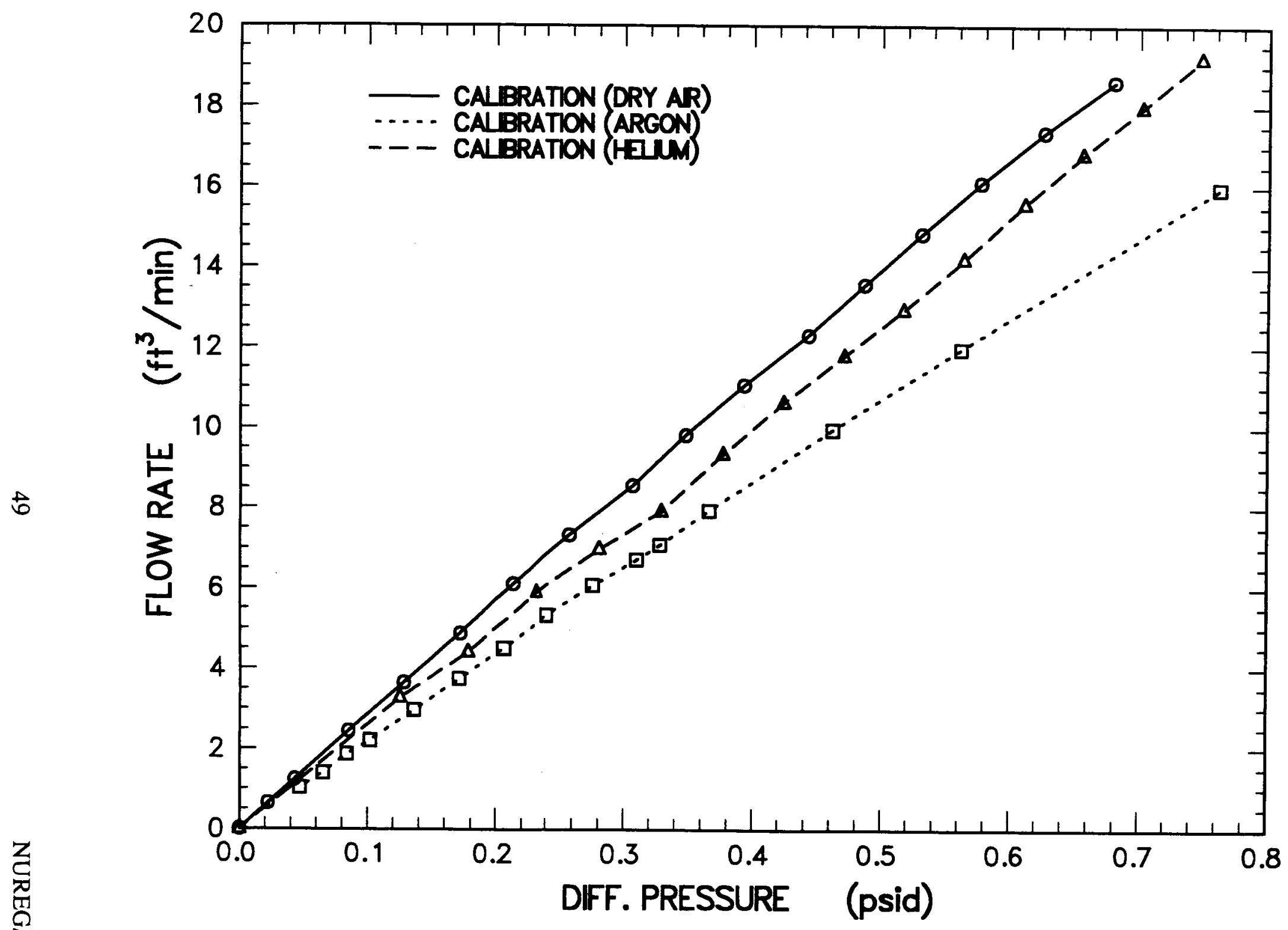

Figure 4.3.3 Laminar flow element calibration 
pickup can be affected by an induction or electrical field.

The turbine meter used in SURC-1 was made by Flow Technology Inc. This device was located in a $50 \mathrm{~cm}$ long section of $1.3 \mathrm{~cm} \mathrm{O.D.} \mathrm{stainless}$ steel tubing connected to the aluminum containment vessel. This meter was used to indicate the flow rate of argon gas used to purge the apparatus. The operating range of the device is $10 \mathrm{cfm}(280 \mathrm{lpm})$ as indicated by a voltage output of $0-10$ volts dc. The turbine meter was calibrated in the laboratory using air, helium, and argon. Results of the laboratory calibration are shown in Figure 4.3.4.

The Rockwell gas clocks used in SURC-1 are dry gas meters. These devices have four bellows-type chambers that alternately fill and empty known volumes of gas. The slide valves that control the cycle are attached to mechanical counters that totalize the volume of gas that passes through the meter. These devices are very rugged and bulky and register the total volume in actual cubic feet per minute (acfm). They are impervious to the aerosol or water content in the gas and measure total volume independently without corrections for density or viscosity. Once the volume of the bellows is known, the accuracy of the gas clocks is within 1 percent. The major disadvantages of the dry gas meter are its size and lack of sensitivity to transient flow perturbations.

The Rockwell 415 gas clock has a stated operational range of 0 to $7 \mathrm{cfm}(0$ to $200 \mathrm{lpm})$ at STP. The device has a sensitivity of 1.0 cubic foot (28.3 liters) per cycle. The Rockwell 750 was also manufactured by Rockwell and has an operational range of 0 to $12.5 \mathrm{cfm}(0$ to $350 \mathrm{lpm})$ at STP. The Rockwell 750 gas clock has a sensitivity of 10 cubic feet (283 liters) per cycle. Both devices were calibrated in the laboratory with dry air and at the test site with argon gas and a range of flow rates. The laboratory calibrations are shown in Figures 4.3.5 and 4.3.6.

After the experimental setup was completed for the SURC-1 test, an in-situ calibration was performed using argon. This was done to ensure that the laboratory calibrations were still valid, to evaluate the entire flow system, and to determine the system pressure as a function of flow rate. Results of the in-situ calibration for the orifice flowmeter, LFE, turbine meter, gas clock, and system pressure are given in Table 4.3.1. In addition, a systems leak test was performed by valving off the flow train and pressurizing the expansion chamber and flow circuit. A pressure decay chart for this procedure is given in Table 4.3.2. Based on the in-situ checks, the initial leak rate from the crucible was calculated to be $0.7 \mathrm{scfm}(20 \mathrm{lpm})$ at a system pressure of 1.0 psig or 12 percent at the 165 slpm flow rate.

\subsection{Aerosol Instrumentation}

The interaction of molten material with concrete produces an aerosol. In the context of nuclear reactor accidents, the aerosol produced by the interaction of molten core debris with concrete basemat material is a potential source of radionuclide release [Brockmann, 1987].

It is, therefore, important to characterize this aerosol with respect to its mass source rate, concentration, composition, and transport properties. The aerosol source term is defined as the mass source rate of aerosol generation, its composition, and its size distribution, as well as additional parameters such as the dynamic shape factor which aids in the description of the aerosol's transport behavior and the agglomeration shape factor which aids in the description of the aerosol's coagulation behavior. Measurements of the aerosol source term resulting from the melt/concrete interaction experiments provide a data base against which to test predictive models of aerosol release and formation [Powers et al., 1986]. 


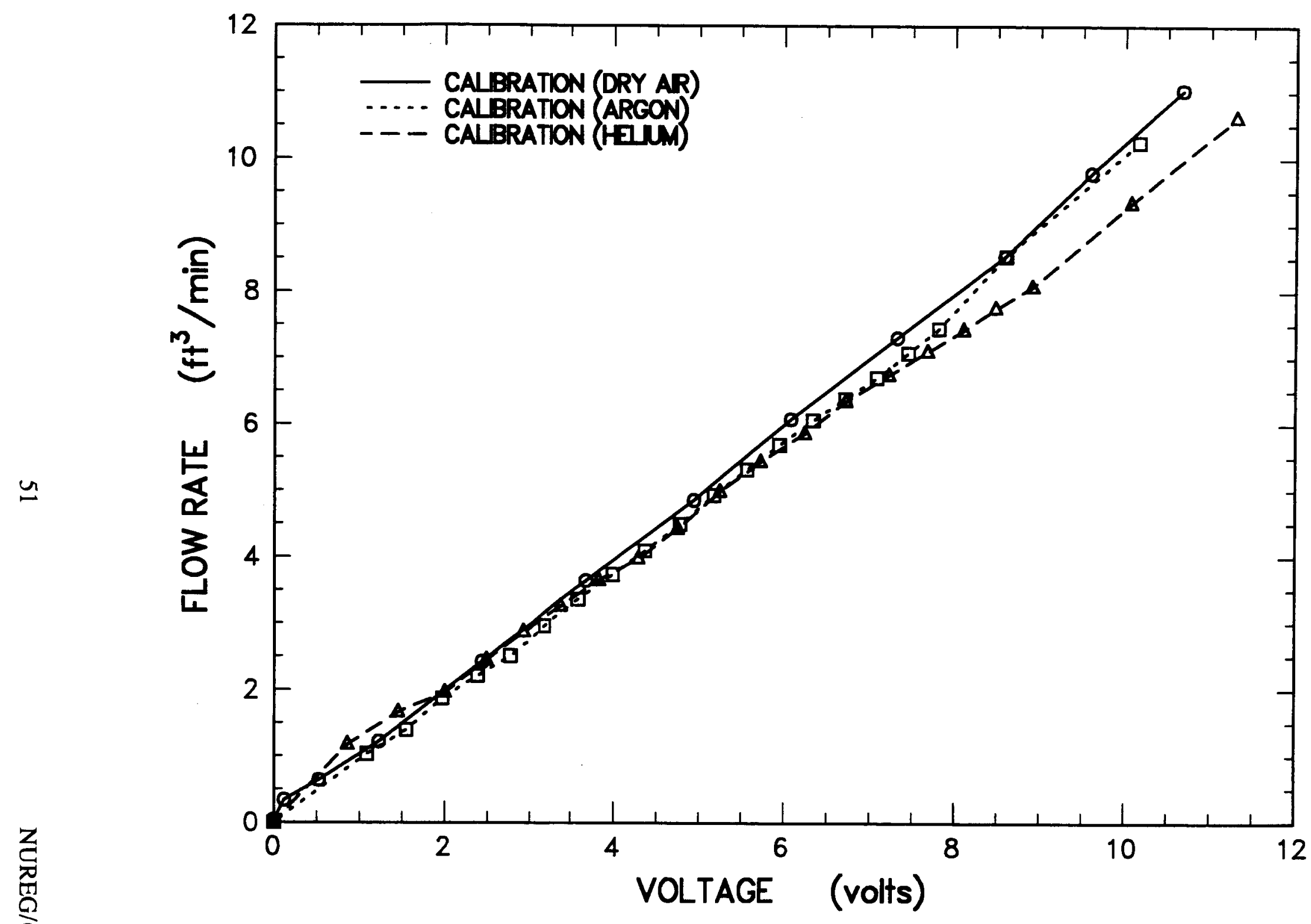

Figure 4.3.4 Turbine flowmeter calibration 


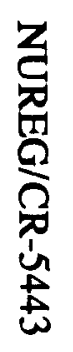

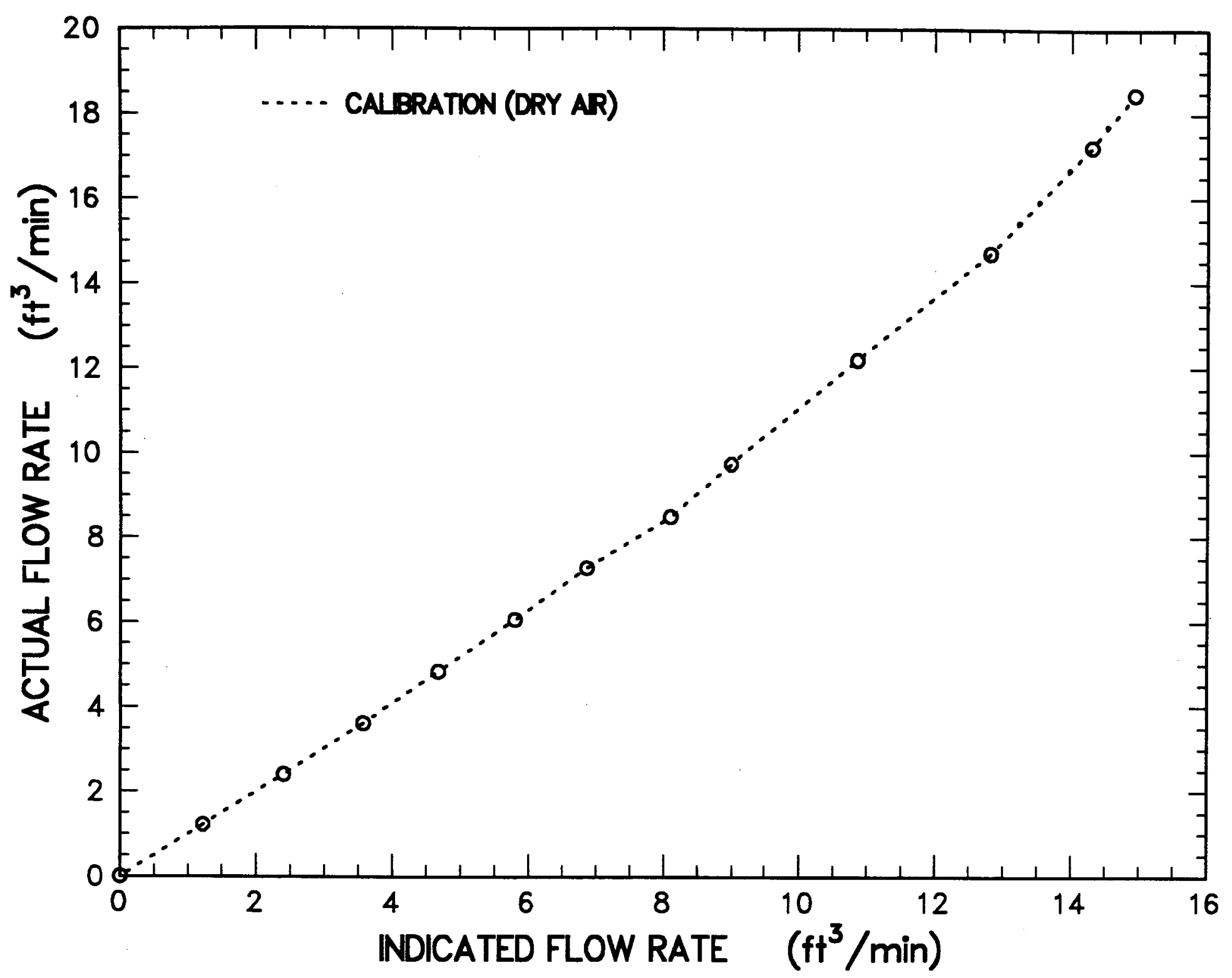

志

N

Figure 4.3.5 Rockwell $\mathbf{4 1 5}$ positive displacement gas meter calibration 


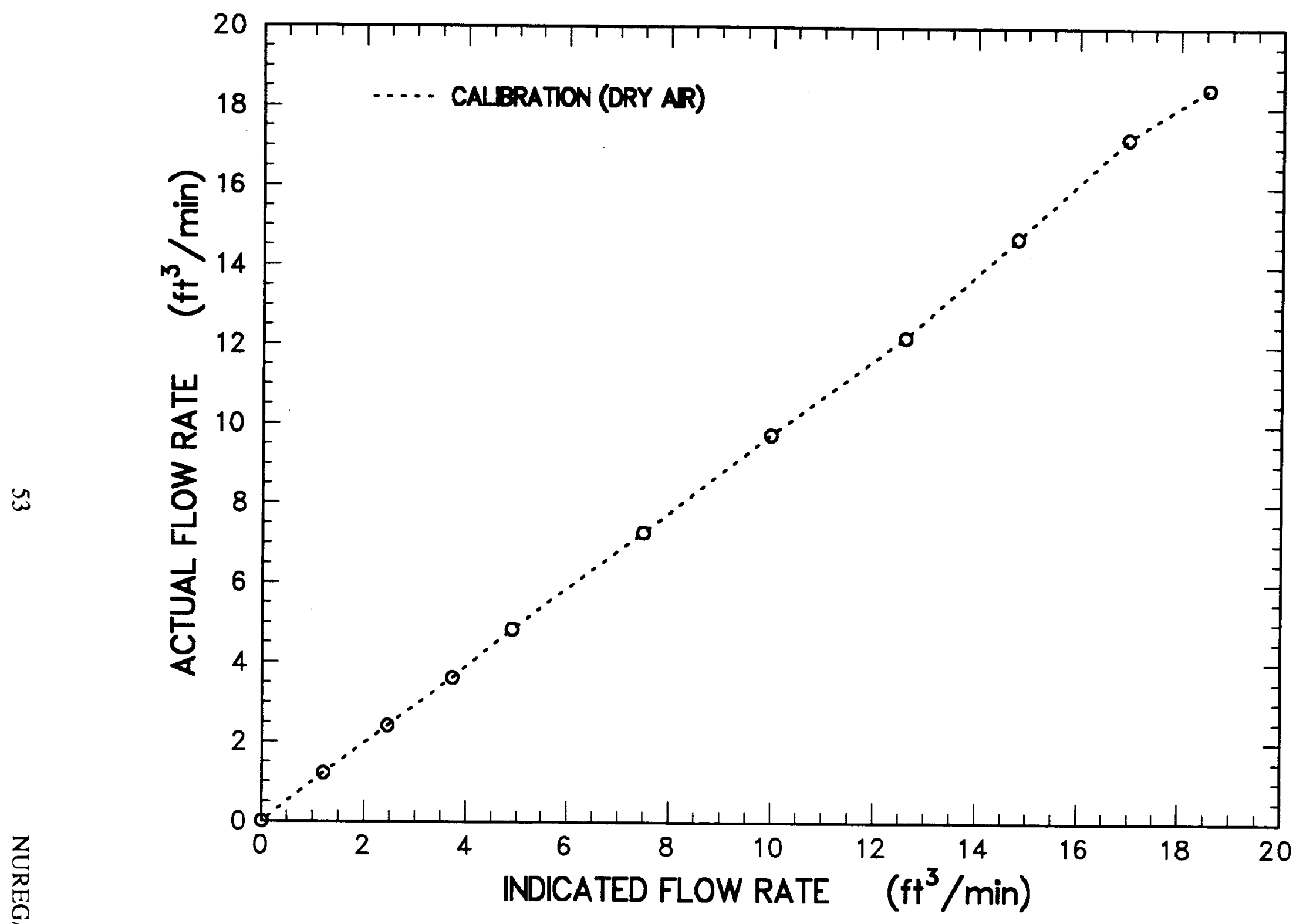

Figure 4.3.6 Rockwell 750 positive displacement gas meter calibration 
Instrumentation

Table 4.3.1 In-situ calibration for SURC-1 flow devices

\begin{tabular}{ccccc}
\hline $\begin{array}{c}\text { Inlet } \\
\text { Turbine } \\
\text { Flow } \\
\text { (alpm) }\end{array}$ & $\begin{array}{c}\text { Gas } \\
\text { Clock } \\
\text { Flow } \\
\text { (alpm) }\end{array}$ & $\begin{array}{c}\text { Orifice } \\
\text { Plate } \\
\text { Flow } \\
\text { (alpm) }\end{array}$ & $\begin{array}{c}\text { LFE } \\
\text { Flow } \\
\text { (alpm) }\end{array}$ & $\begin{array}{c}\text { System } \\
\text { Pressure } \\
\text { (psig) }\end{array}$ \\
\hline 283 & 280 & 265 & 275 & 1.5 \\
226 & 212 & 214 & 218 & 1.1 \\
170 & 156 & 155 & 153 & .7 \\
133 & 119 & 121 & 124 & .5 \\
91 & 85 & 83 & 86 & .3 \\
33 & -- & 32 & 35 & .1 \\
\hline \multicolumn{2}{c}{ "Calibration done with argon gas. } & & & \\
\hline
\end{tabular}

Table 4.3.2 Pre-test pressure decay and leak rate for SURC-1 containment vessel and flow train*

\begin{tabular}{cc}
\hline Time (min) & Pressure (psig) \\
\hline 0. & 1.28 \\
1.0 & .91 \\
2.0 & .64 \\
3.0 & .44 \\
5.0 & .20 \\
\hline "Calibration with argon gas. & \\
\hline
\end{tabular}


The SURC-1 test contained aerosol instrumentation designed to provide data which would allow calculation of the aerosol source term. Specific measurements were made in order to determine the aerosol mass generation rate, aerosol size distribution, and aerosol composition. Figure 4.4.1 is a flow chart illustrating how each of the three source term parameters mentioned above is determined. The aerosol mass generation source rate is the product of the melt/concrete gas evolution rate and the aerosol mass concentration in the evolved gas. The gas flow train described in Section 4.3 measures the gas evolution rate. The aerosol mass concentration is measured primarily by filter samples; however, impactor samples and an opacity meter provide additional means of aerosol mass concentration measurement. The size distribution of the sampled aerosol is primarily determined by cascade impactor samples. The cascade cyclone gives an additional means of determining the integral aerosol size distribution over an extended sampling time.

Aerosol composition is determined from elemental analysis of the aerosol collected on the filters. A size dependent aerosol composition is obtained from analysis of the aerosol collected by the cascade cyclone.

The sample extraction dilution system (SEDS) comprised of the filters, cascade impactors, cascade cyclone, and the necessary dilution systems and flow control is shown in the photograph in Figure 4.4.2. An aerosol sample is drawn into the SEDS through a gooseneck sample probe (from Anderson, Inc.). The probe has a nozzle with a $0.32 \mathrm{~cm}$. inside diameter opening located coaxially in the center of the exhaust line. The nozzle expands into a $1.6 \mathrm{~cm}$. inside diameter tube. The cyclone samples the undiluted aerosol. The primary dilution is performed on the sample and this is sampled by the filters. A secondary dilution is performed and this aerosol is sampled by the impactors.
Figure 4.4.3 shows a detailed schematic diagram of the SEDS showing the locations and connections of the dilution and gas flow control systems. The locations of the flow controlling orifices, pressure transducers, and thermocouples are shown. Their alpha-numeric identifications are also listed on the figure.

The flows are controlled by critical orifices manufactured by Millipore and calibrated at Sandia's Primary Standards Laboratory. Critical flow occurs when the ratio of upstream to downstream absolute pressure exceeds two. The equations governing flow through a critical orifice are [Holman, 1966]:

$$
\begin{aligned}
\mathrm{Q} & =\mathrm{Q}_{\mathrm{c}}\left[\frac{\mathrm{T}}{\mathrm{T}_{\mathrm{c}}} \cdot \frac{\mathrm{MW}}{\mathrm{MW}}\right]^{1 / 2} \\
\dot{\mathrm{n}} & =\frac{\mathrm{PQ}}{\mathrm{RT}} \\
& =\frac{\mathrm{PQ}_{\mathrm{c}}}{\mathrm{RT}_{\mathrm{c}}{ }^{1 / 2} \mathrm{~T}^{1 / 2}}\left[\frac{\mathrm{MW}}{\mathrm{MW}}\right]^{1 / 2}
\end{aligned}
$$

where $Q$ is the volumetric flow rate of gas upstream of the orifice, $\mathrm{T}$ is the upstream temperature, $\mathrm{P}$ is the upstream pressure, $\mathrm{MW}$ is the molecular weight of the gas, $n$ is the molar flow rate, $R$ is the universal gas constant, and the subscript $c$ refers to the calibration conditions.

As shown in Figure 4.4.3, temperature and pressure upstream of the orifices are measured. Where the critical orifices are located away from any heated sections of the test apparatus, such as the cyclone and dilution gas supply system, ambient temperature is assumed.

The dilution flows and sample flows are turned on and off by remotely actuated valves manufactured by ASCO. The remotely actuated valves for the samplers are operated by a Modicon Micro 84 programmable controller. 
Instrumentation

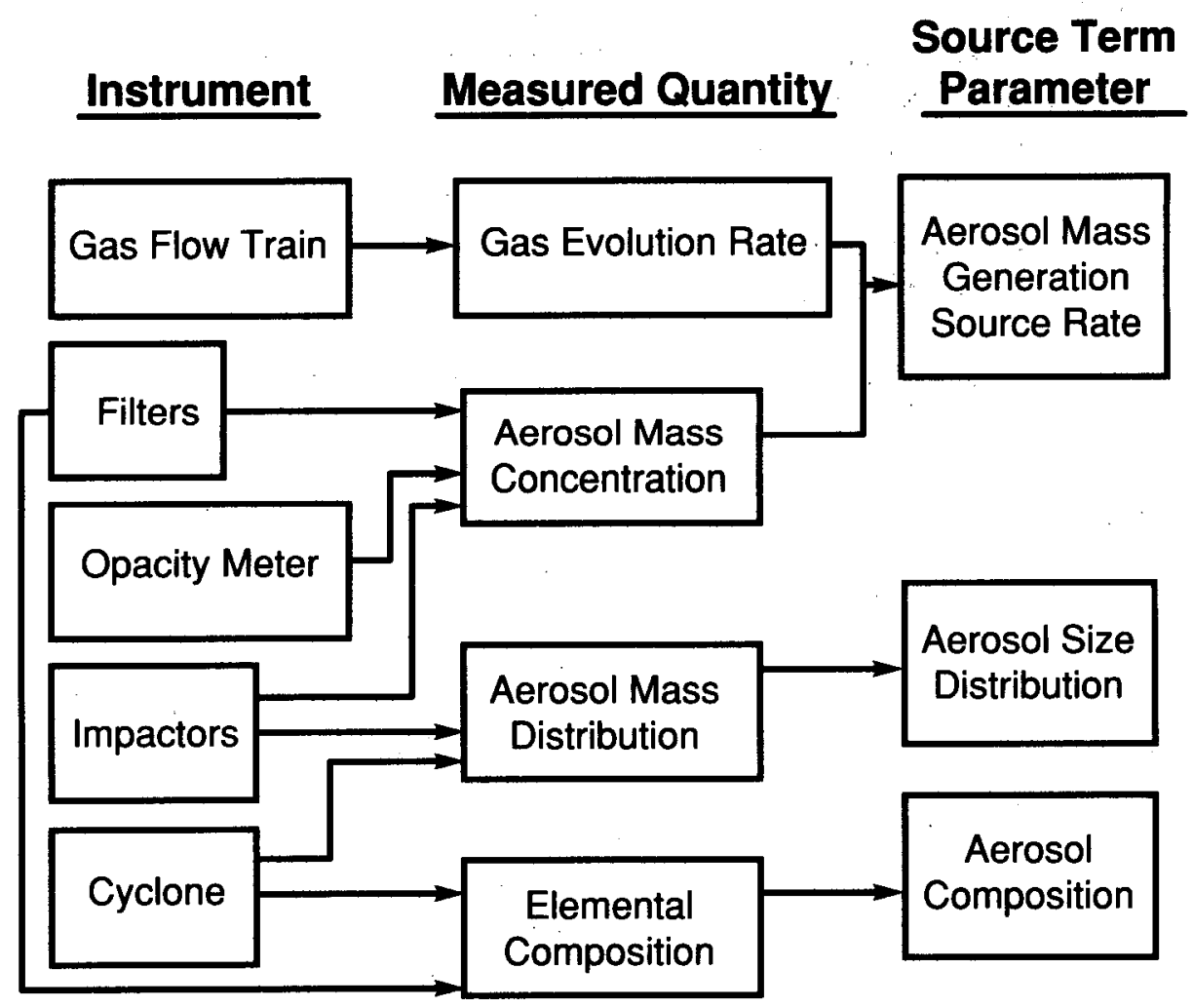

Figure 4.4.1 Flow chart illustrating how the source term parameters are determined from measurements made in the SURC-1 melt/concrete interaction test 
Instrumentation

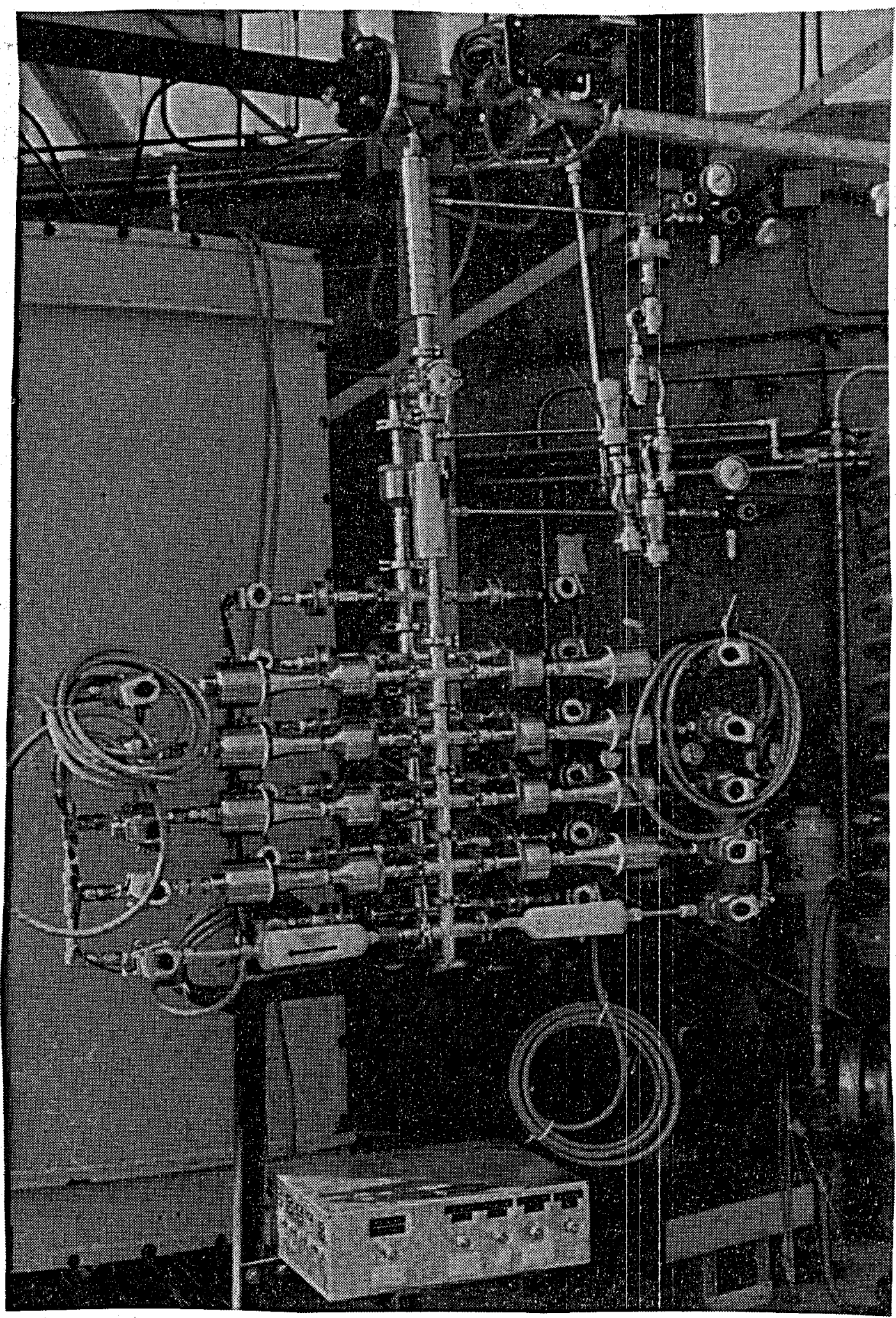

Figure 4.4.2 Photograph of the aerosol sampling instrumentation connected to the flow line 
Instrumentation

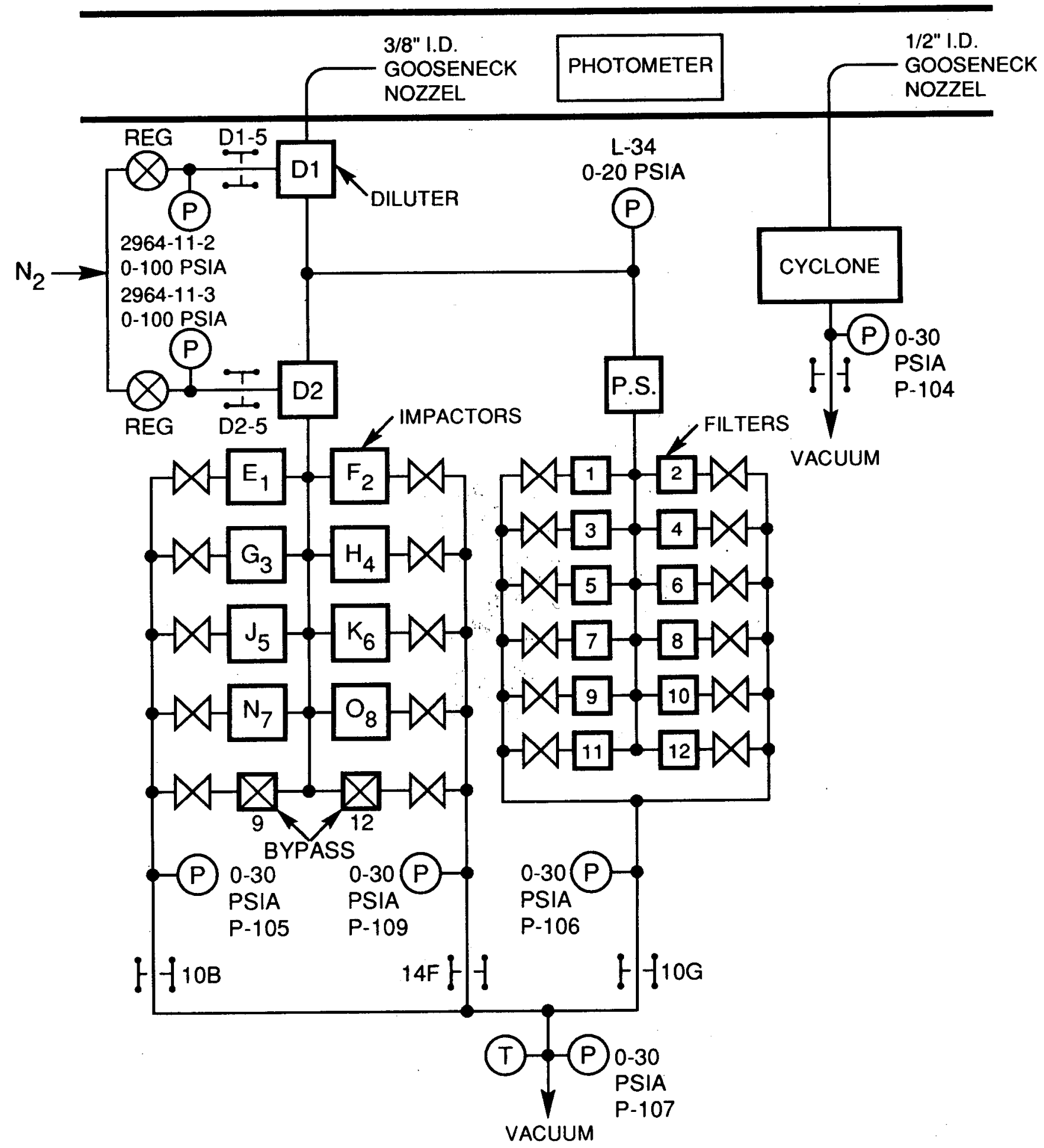

Figure 4.4.3 Schematic diagram of the sample extraction dilution system (SEDS) showing the locations of pressure transducers, thermocouples, and flow controlling orifices. The identifying designations of the orifices and thermocouples are also shown. 
Dilution of the sample by the diluters D1 and D2 serves three purposes. The first is to reduce the high aerosol concentration to a level that is within the measurement range of the instrumentation (less than about $20 \mathrm{~g} / \mathrm{m}^{3}$ for the filters and less than about $5 \mathrm{~g} / \mathrm{m}^{3}$ for the impactors). The second is to cool the flow and to reduce the temperature variation of gas passing through the SEDS by the addition of the cooler dilution gas. The third is to reduce the variation in gas properties by the addition of a known dilution gas in high enough amounts to dominate the gas properties. Dilution can be used to inhibit further evolution of an aerosol size distribution resulting from coagulation and condensation [Brockmann et al., 1984]. In this application, however, the aerosol size distribution has evolved during transport through the crucible and exhaust line and is likely to have reached a point where the time scale of evolution is large compared to that of transport through the SEDS.

Figure 4.4.4 is a schematic diagram of the flow diluter designed for this test series. The diluter consists of an aluminum outer tube $15 \mathrm{~cm}$ long and $6.35 \mathrm{~cm}$ in outside diameter and a $1.9 \mathrm{~cm}$ outside diameter sintered stainless inner tube. End caps hold the tubes in place. Dry dilution gas passed through a $0.64 \mathrm{~cm}$. Swagelok fitting in the outer tube to the annular plenum region between the two tubes. Gas passes through the porous walls of the inner tube diluting the aerosol sample flowing through it.

The total flow out of the diluter, $Q_{T}$, was measured and the dilution flow into the diluter, $Q_{D}$, was measured. The dilution ratio $D R$ is then defined as $\mathrm{Q}_{\mathrm{T}}$ divided by the difference between $Q_{T}$ and $Q_{D}$. Some care in the magnitude of the dilution is necessary. The dilution ratio is calculated using the difference between two numbers and when those numbers are close, the error in the difference can become large. For example, if the uncertainty in the flows $Q_{T}$ and $Q_{D}$ is \pm 5 percent for each, the resulting uncertainty in dilution ratio is \pm 36 percent for a nominal dilution ratio of 5 . This magnification of the flow uncertainties in the calculation of the dilution ratio places a practical upper limit on dilution ratio of about 5 . For this test, nominal dilution ratios were about 3 for each of the two diluters.

Because the system pressure in the SEDS is the same as that of the experimental apparatus, the SEDS can become pressurized (at higher gas evolution rates, the evolution gas flow train causes some back pressure in the apparatus). Each orifice controlling the dilution gas flow delivers a fixed molar flow of dilution gas by virtue of its fixed upstream temperature and pressure. The orifices controlling the sample flow draw at a fixed volumetric flow rate. The fixed volumetric flow rate yields a molar flow rate directly proportional to the system pressure. Consequently, if the dilution flow is unchanged, the dilution ratio will decrease with increasing system pressure. To maintain a consistent level of dilution in the face of a pressurizing system, the molar flow of dilution gas must be increased in proportion to the increase in molar flow of the sample produced by the increase in system pressure. This increase in dilution molar flow was accomplished in diluter 1 by selecting combinations of three orifices as shown in Figure 4.4.3. These orifices were switched in and out by actuating remotely controlled valves controlling each orifice. This feature was not included in diluter 2 .

Figure 4.4.5 shows a photograph of a typical filter bank of 10 filter samples on the SEDS. A bank of 12 filters was used on the SURC-1 experiment. The flow through each filter was controlled by a remotely actuated valve. The 12 valves were plumbed to a single critical orifice giving a nominal filter sample flow rate of $10 \mathrm{lpm}$. The filter bank consists of 12 Gelman in-line stainless steel filter holders. These stainless steel, $5.9 \mathrm{~cm}$ diameter, $5.7 \mathrm{~cm}$ long filter holders (Gelman catalog number 2220) are designed for pressure applications of up to 200 psig. They use $47 \mathrm{~mm}$ diameter Durapore Membrane filtration media from Millipore 


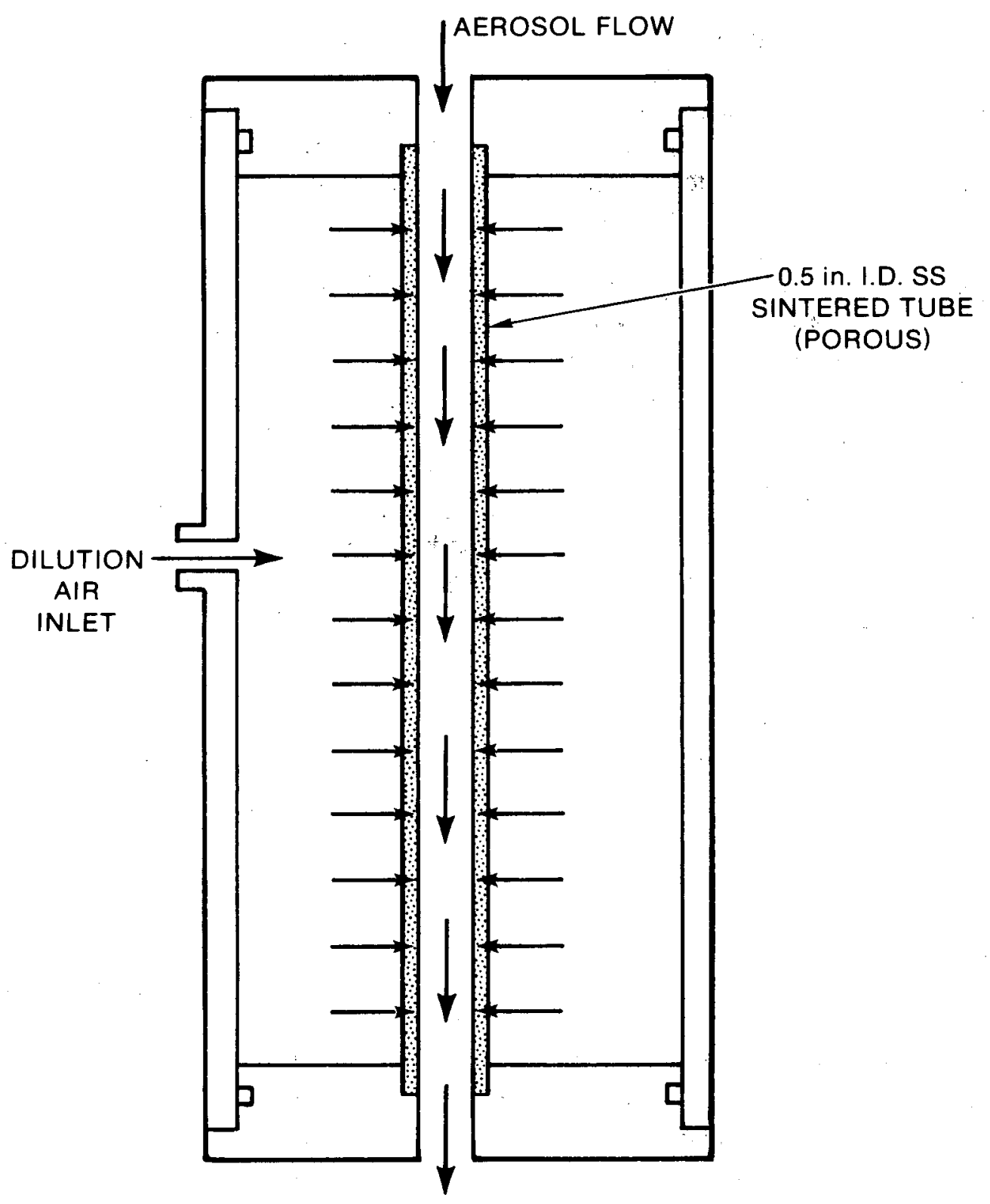

Figure 4.4.4 Schematic diagram of flow diluter used in the sample extraction dilution system 


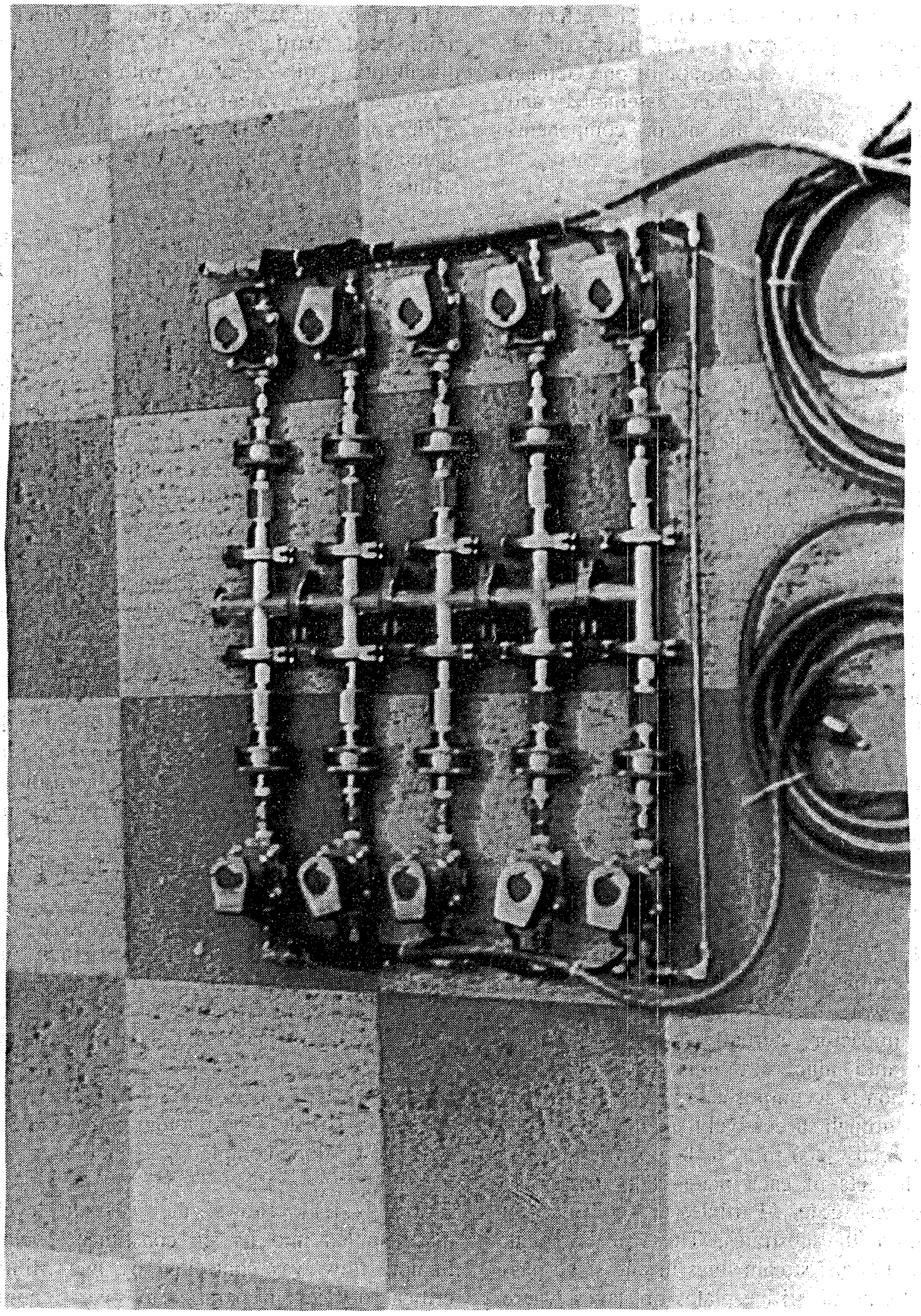

Figure 4.4.5 Photograph of the filter bank 
(catalog designation HVLP 047). The effective filtration area is $9.67 \mathrm{~cm}^{2}$ for each filter sample. Figure 4.4.6 shows a photograph of one Gelman high pressure filter holder assembled and disassembled showing the major components including filter and substrates.

The inlet to the filter sample section was connected to a preseparator which removes particles larger than 10 to 15 micrometers aerodynamic equivalent diameter. This preseparator is manufactured by Anderson and is of stainless steel construction, $8: 2 \mathrm{~cm}$ in diameter and $12.8 \mathrm{~cm}$ long. The preseparator collects coarse material in an impaction cup, passing on the finer aerosol to the filter sample section.

Each filter sample provides a collected mass of aerosol with aerodynamic equivalent particle diameter less than 10 to 15 micrometers. This sample allows calculation of the aerosol mass concentration of these smaller particles. The collected material can also be chemically analyzed. The filter sample is the principal measurement in determining aerosol mass source rate and elemental composition.

The filter sample section was mounted in an insulated box and electrically heated to avoid water condensation. The heaters were controlled by an Omega Model 920 temperature controller with a type $\mathrm{K}$ thermocouple.

Figure 4.4.7 shows a photograph of the impactor sample section. Anderson Mark IIII cascade impactors were used. An Anderson Mark III cascade impactor inertially classifies aerosol particles into nine size bins. This inertial classification is accomplished by accelerating the particles through successively smaller holes (and higher velocity jets) in a stack of orifice plates. Under the jets of each plate is a glass fiber collection substrate. Particles are collected by impaction on the substrates. Those small enough to follow the gas stream lines in one stage pass on to subsequent orifice plates or stages where they may be collected. The impactor consists of eight stages and a backup filter to collect any unimpacted particles. It yields a mass distribution of aerosol with respect to aerodynamic equivalent particle diameter. The Anderson Mark III cascade impactor is $8.2 \mathrm{~cm}$ in diameter and $18 \mathrm{~cm}$ long and is constructed of stainless steel.

A preseparator (shown in Figure 4.4.8), which removes particles nominally larger than 10 to 15 micrometers aerodynamic diameter, was used to avoid overloading (more than $\sim 25 \mathrm{mg}$ of material on any one stage) of the impactor by these larger particles. It effectively collects material which would otherwise be collected on the first two stages of the impactor. The preseparator collects material in an impaction cup, which is brushed out to retrieve the collected sample. The preseparator is of stainless steel construction, $8: 2 \mathrm{~cm}$ in diameter and $12.8 \mathrm{~cm}$ long. It threads into the front of the impactor. The assembled preseparator-impactor is $8.2 \mathrm{~cm}$ in diameter and $29.8 \mathrm{~cm}$ long.

Two impactor samples were taken simultaneously, one at a nominal $10 \mathrm{lpm}$ and the other at a nominal $15 \mathrm{lpm}$. This provides a more detailed measurement of the aerosol size distribution and will be discussed further in the section on impactor calibration. The box containing the impactor bank is heated in the same way as the filter sample box.

Figures 4.4 .8 and 4.4 .9 show photographs of the assembled and disassembled Anderson Mark III impactor and preseparator, respectively. Also shown are the jet plates and glass fiber collection substrates.

Figure 4.4.10 shows a photograph of the Sierra Cascade Cyclone completely assembled.

Figure 4.4.11 shows the cascade cyclone disassembled into its six constituênt cyclones. Sample flow was controlled by two Millipore critical orifices in parallel to give a nominal sample flow of $24 \mathrm{lpm}$. A remotely actuated 


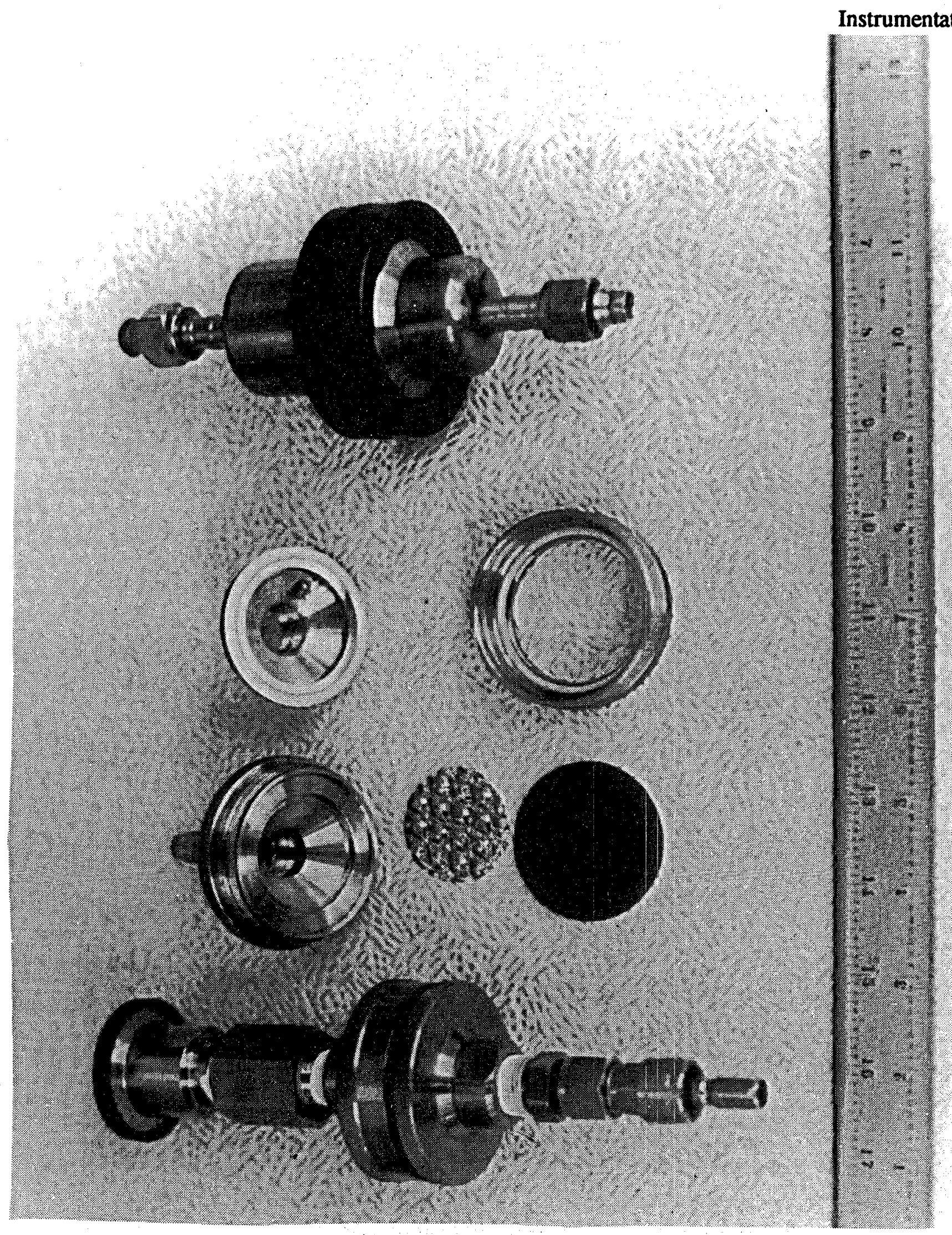

Figure 4.4.6 The Gelman high pressure filter holder shown disassembled with filter substrate support (left) and filter substrate and supports in place (right). The assembled filter holder is shown at the top in each photograph. 


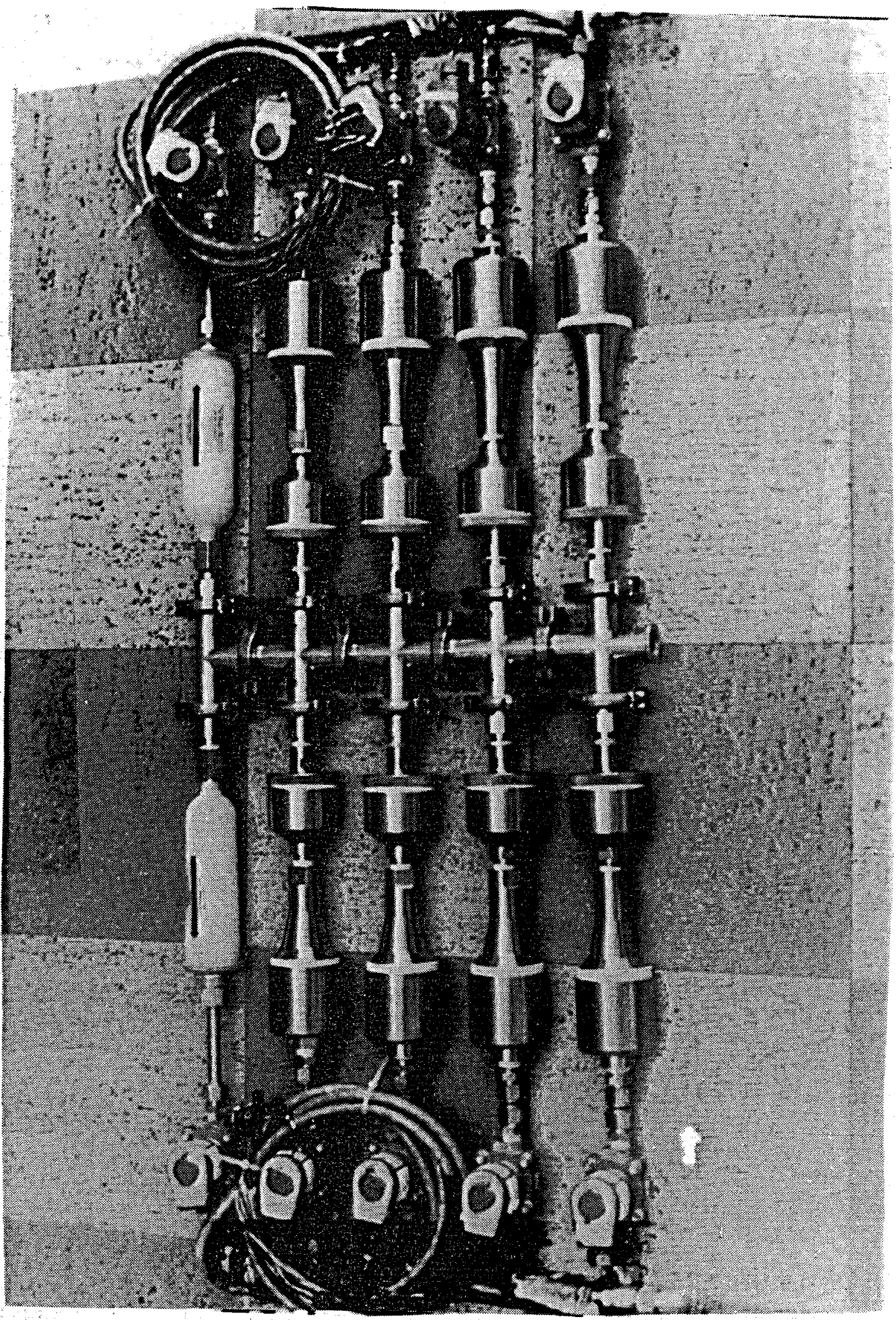

Figure 4.4.7 Photograph of the impactor bank showing the impactors and by-pass filter 
Instrumentation

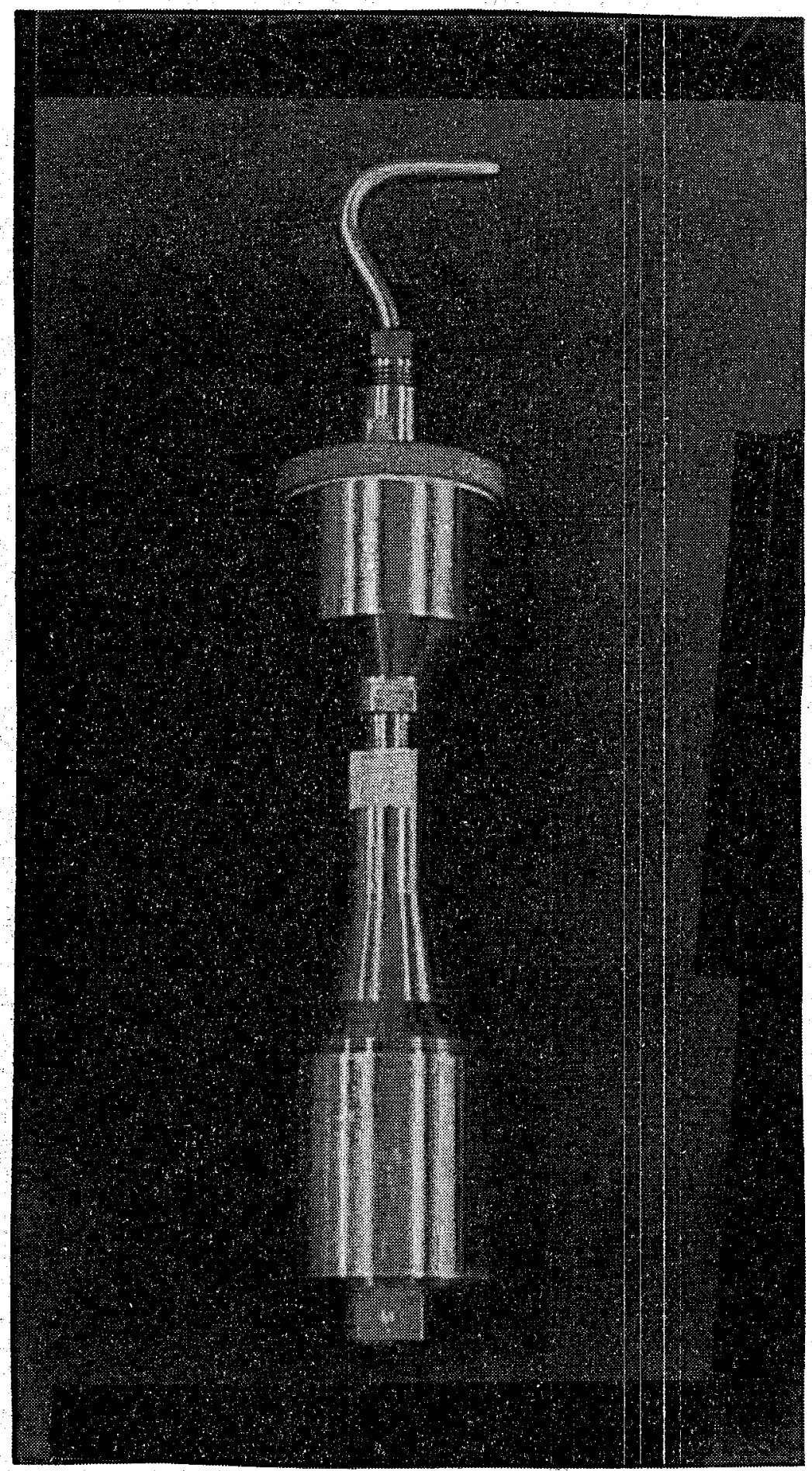

Figure 4.4.8 Photograph showing the assembled Anderson Mark III impactor-preseparator assembly 


\section{Instrumentation}

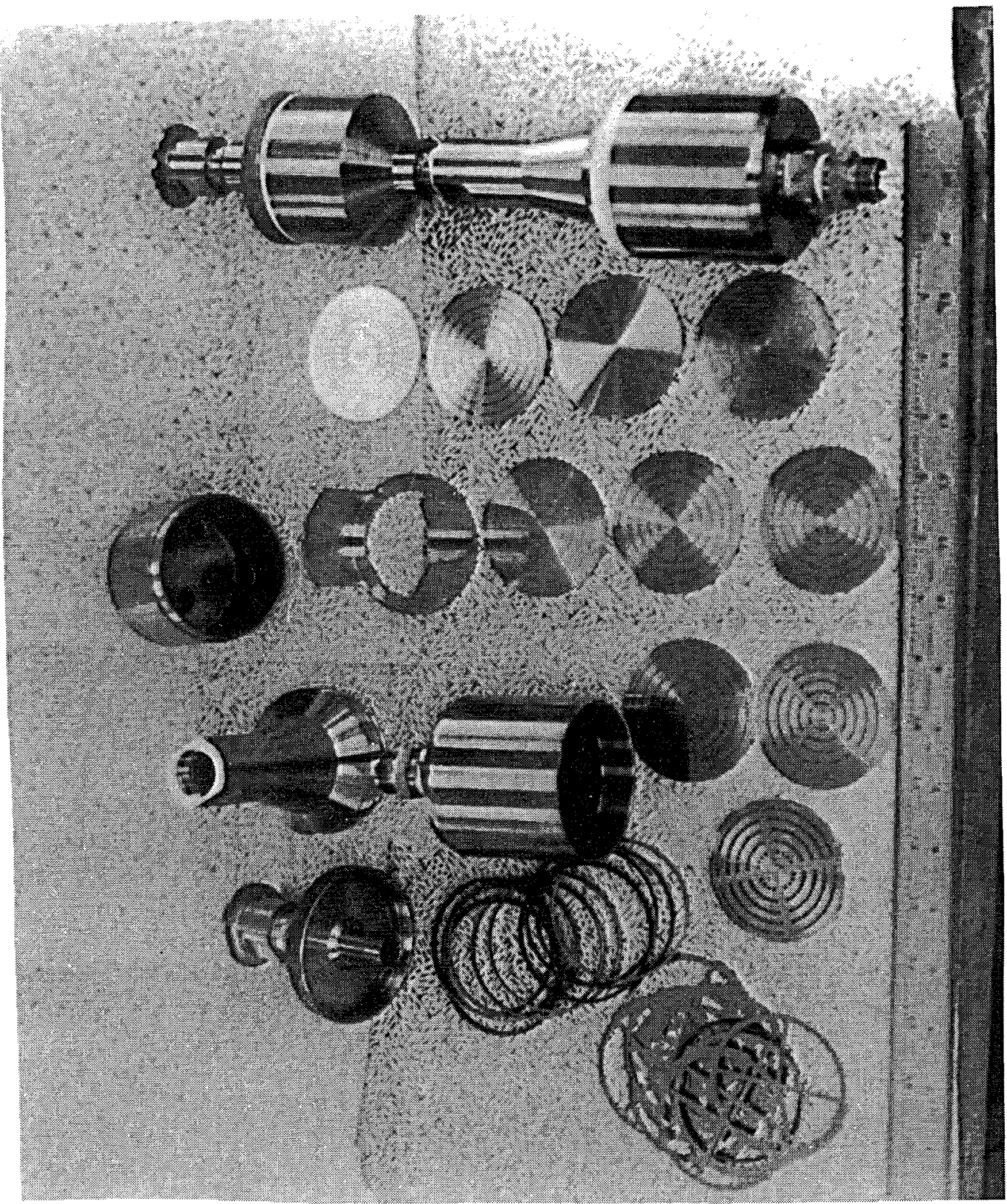

Figure 4.4.9 Photograph showing the disassembled Anderson Mark III impactor-preseparator assembly 


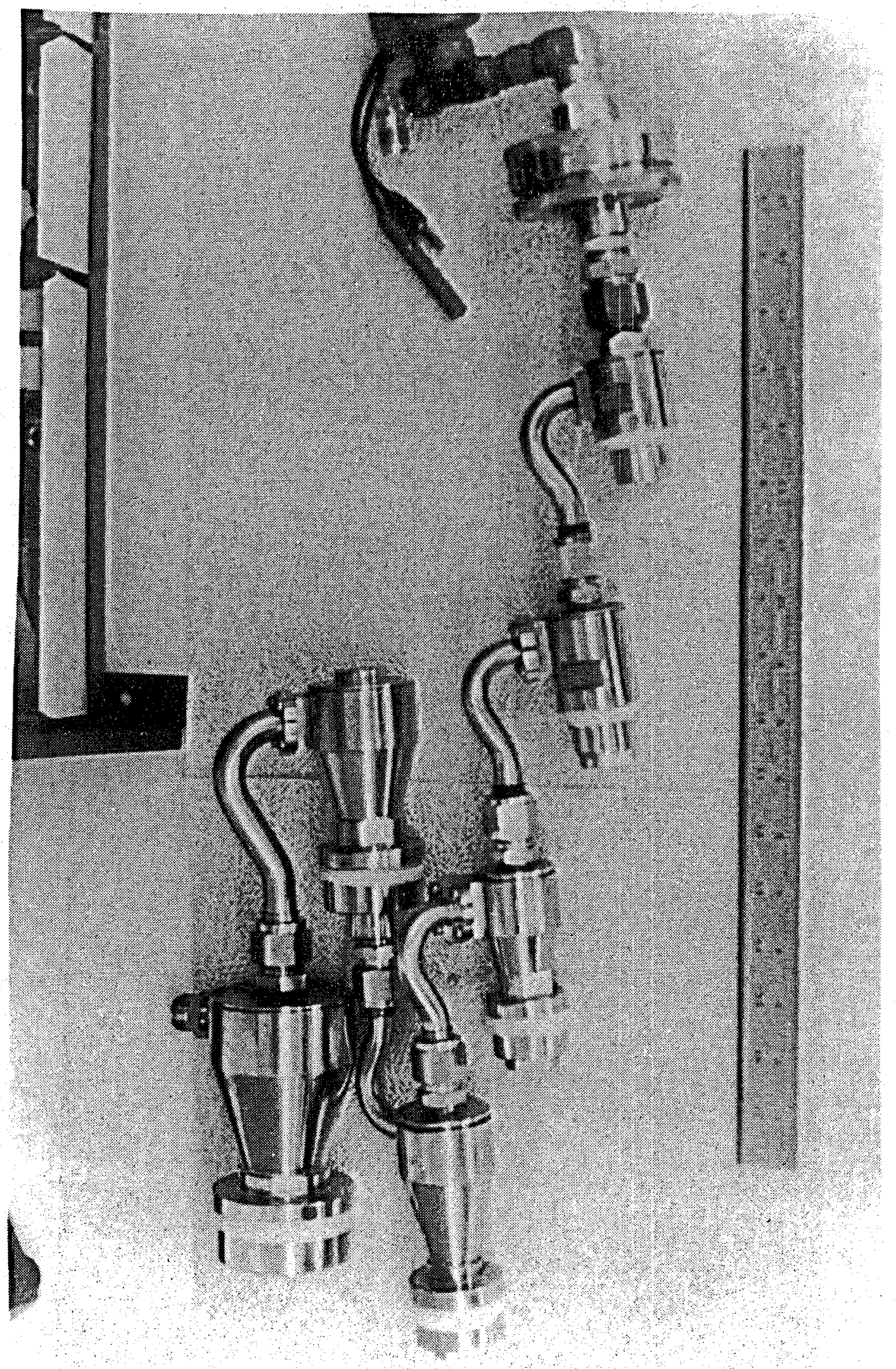

Figure 4.4.10 Sierra cascade cyclone shown assembled with its six constituent cyclones and backup filter 
Instrumentation

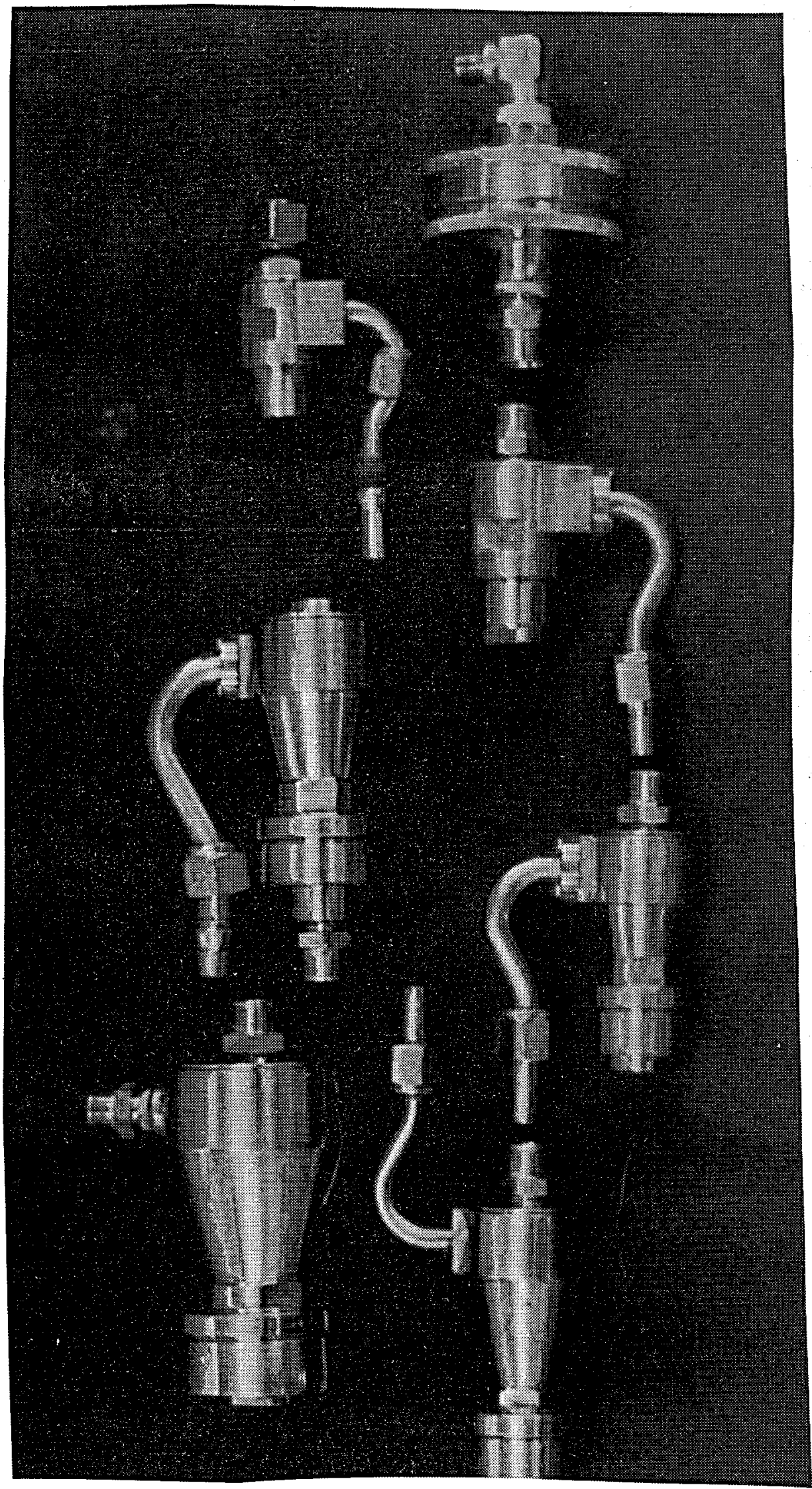

Figure 4.4.11 Sierra cascade cyclone shown disassembled into its six constituent cyclones and backup filter 
valve manufactured by ASCO was used to take the sample.

The cascade cyclone is manufactured by Sierra. This device inertially classifies aerosol particles and yields a mass distribution with respect to aerodynamic equivalent particle diameter. This classification is accomplished by flowing the aerosol sample through a succession of smaller cyclones. The flow is introduced tangentially into the circular body of the cyclone where the circulating swirling flow causes larger particles to move by centrifugal force to the walls where they are collected. The smaller particles are withdrawn through the center and passed on to subsequent cyclones where they may be collected. Particles too small to be collected by the cyclones are collected by a backup filter. A cyclone is capable of collecting much more material than an impactor and can be used to collect size classified material for bulk analyses.

The Sierra cascade cyclone is a series of six cyclones of increasing capability to collect smaller particles followed by a glass fiber backup filter. The aerosol sample was brushed out of the collection cup of each cyclone for weighing. The cascade cyclone is of stainless steel construction and when assembled is $12.7 \mathrm{~cm}$ in diameter at the widest point and about $60 \mathrm{~cm}$ in length.

Figure 4.4.12 is a schematic diagram of the Dynatron Model 301 opacity meter placed in the exhaust line of the test article upstream of the gravel filter and flow measurement devices. This device measures the attenuation of a light beam as it travels through an aerosol. Light attenuation correlates with aerosol mass concentration. Posttest correlation of the opacity meter output with the mass measured by the filter samples provided a continuous record of mass concentration in the pipe exhausting gas and aerosol from the interaction crucible in the SURC test. The windows allowing light transmission were kept clean and free of aerosol deposition by a purge gas flow.

\section{Pressure Transducer Calibration}

Kulite 0 to 100 psia pressure transducers were used to monitor the pressure of the gas upstream of the orifices in the diluters and the pressures in the sample extraction-dilution system. The calibration data for the pressure transducers is given in Table 4.4.1. The locations of the pressure transducers and the flow controlling critical orifices in the SEDS are shown in Figure 4.4.3.

From the pressure transducers located upstream and downstream of the flow-controlling orifices, critical flow determination is made.

\section{Orifice Calibration}

The sample flows are controlled by critical orifices from Millipore. These orifices have been calibrated in Sandia National Laboratories' primary standards lab. The orifice calibration flow rates are given in Table 4.4.2. The orifice location and designation are shown in Figure 4.4 .3 of the SEDS.

\section{Impactor Calibration}

The Anderson Mark III cascade impactor has been calibrated by Cushing et al. [1976]. We have employed their experimentally determined calibration in the reduction of data taken with the Anderson Mark III impactors.

Each impactor stage is assumed to collect all particles larger than some characteristic size and pass along all particles smaller than that size. This characteristic size is called the cut point. Thus, in a cascade impactor (an impactor 


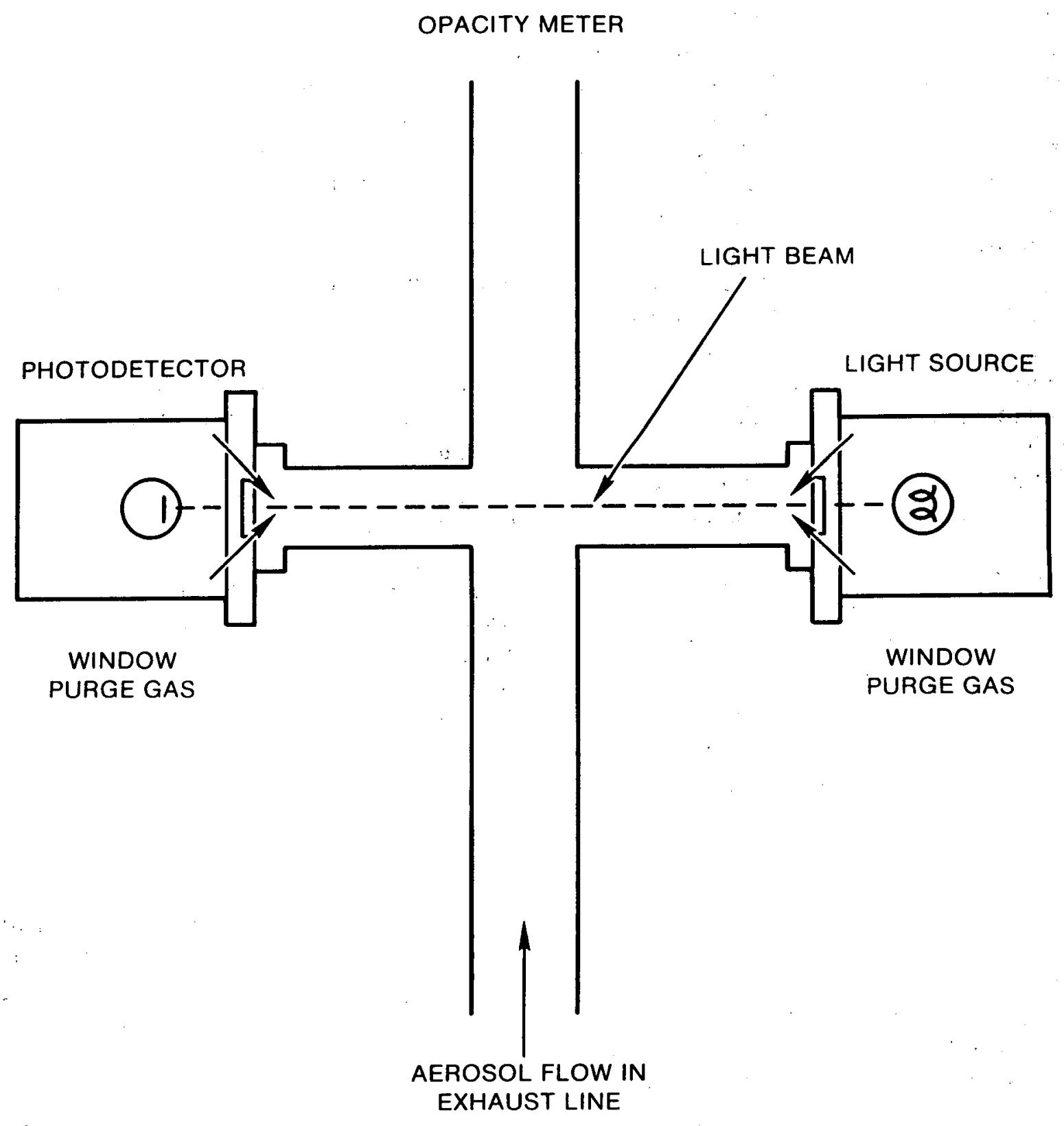

Figure 4.4.12 Schematic diagram of the opacity meter used on the SURC-1 test showing how it was installed behind gas purged windows in the exhaust gas line 
Table 4.4.1 Pressure transducer calibrations

\begin{tabular}{|c|c|c|c|c|c|c|c|c|}
\hline \multirow[b]{2}{*}{ Pressure } & \multicolumn{8}{|c|}{ Orifice I.D., Range (PSIA), and Output in Volts } \\
\hline & $\begin{array}{c}11-2 \\
0-100 \\
\text { (V) }\end{array}$ & $\begin{array}{c}11-3 \\
0-100 \\
\text { (V) }\end{array}$ & $\begin{array}{c}\text { P104 } \\
0-30 \\
\text { (V) }\end{array}$ & $\begin{array}{c}\text { P105 } \\
0-30 \\
\text { (V) }\end{array}$ & $\begin{array}{c}\text { P106 } \\
0-30 \\
\text { (V) }\end{array}$ & $\begin{array}{l}\text { P107 } \\
0-30 \\
\text { (V) }\end{array}$ & $\begin{array}{c}\text { P109 } \\
0-30 \\
\text { (V) }\end{array}$ & $\begin{array}{c}\text { L34 } \\
0-20 \\
\text { (V) }\end{array}$ \\
\hline 12.15 & 0.814 & 0.806 & 2.552 & 2.520 & 2.508 & 2.370 & 2.035 & 0.094 \\
\hline 15.00 & 0.950 & 0.945 & 3.103 & 3.077 & 3.056 & 2.985 & 2.611 & 0.129 \\
\hline 20.00 & 1.193 & 1.193 & 4.080 & 4.061 & 4.046 & 4.063 & 3.639 & 0.191 \\
\hline 30.00 & 1.672 & 1.675 & 5.916 & 5.910 & 5.870 & 6.070 & 5.550 & \\
\hline 40.00 & 2.154 & 2.159 & & & & & & \\
\hline 50.00 & 2.614 & 2.644 & & & & & & \\
\hline 60.00 & 3.104 & 3.120 & & & & & & \\
\hline 70.00 & 2.565 & 3.603 & & & & & & \\
\hline 80.00 & 4.053 & 4.080 & & & & & & \\
\hline 90.00 & 4.514 & 4.560 & & & & & & \\
\hline 100.00 & 4.992 & 5.030 & & & & & & \\
\hline
\end{tabular}

Table 4.4.2 Critical orifice calibration

\begin{tabular}{cc}
\hline Orifice I.D. & $\begin{array}{c}\text { Critical Calibration } \\
\text { Flow }\left(\mathbf{c m}^{3} / \mathbf{s e c}\right)\end{array}$ \\
\hline 10B & 176.7 \\
14F & 222.3 \\
10G & 158.3 \\
25 & 379.3 \\
D51 & 69.8 \\
D52 & 83.8 \\
\hline
\end{tabular}


composed of a series of stages with successively smaller cut points) each stage collects particles of a size between the cut point of that stage and that of the previous stage. The impactor yields a distribution of aerosol mass as mass between successive cut points.

The cut point of an impactor can be expressed as a Stokes number:

$$
\text { Stk }=\frac{\rho_{\mathrm{o}} \mathrm{D}_{\mathrm{ac}}^{2} \mathrm{U}}{18 \mathrm{~L} \mu}
$$

where $\rho_{\mathrm{o}}$ is the reference density of $1 \mathrm{~g} / \mathrm{cm}^{3}, D_{\mathrm{ae}}$ is the aerodynamic equivalent diameter, $U$ is the velocity through the orifice, $\mu$ is the absolute viscosity of the gas, and $\mathrm{L}$ is the diameter of the orifice. Impactor theory holds that for a given stage, the characteristic Stokes number is constant [Marple and Willeke, 1979]. Thus, changing the flow (or $U$ ) through the impactor changes the cut point for that stage. The aerodynamic equivalent diameter corresponding to the cut point for each stage for impactors operating at 10 and $15 \mathrm{lpm}$ are given in Table 4.4.3.

The preseparator used on the impactors has been calibrated by McFarland et al. [1978] and their calibration is used in the work presented here. Table 4.4.3 gives the cut points for the preseparator-impactor combination at the two nominal flow rates of 10 and $15 \mathrm{lpm}$.

The cut points for the two flow rates were staggered. A simultaneous sample taken by two such impactors will give the same distribution but with different cut points. Combination of the two distribution measurements gives a distribution with a finer definition than either measurement alone.

\section{Cyclone Calibration}

The cyclone exhibits the same general cut point behavior as an impactor, but there is no corresponding theory of cyclones as there is for impactors. The cyclone must be calibrated and operated at the same conditions. The manufacturer's calibration (Table 4.4.4) is used in the work presented here. Since the cyclone was used to collect bulk aerosol material over an extended period of the test, this calibration is reasonably accurate.

\section{Aerosol Transport Calibration}

The relationship between the sampled aerosol and the aerosol actually evolved from the test crucible must be understood. This relationship is defined by the efficiencies of aerosol extraction and transport. These efficiencies are calculated with an aerosol sampling efficiency model and an aerosol penetration model of the sampling system.

The extraction of the aerosol sample from the exhaust line through the gooseneck sampling probe is subject to the inefficiencies of anisokinetic sampling. Models describing the sampling efficiency exist in the literature [Davies and Subari, 1982; Jayasekera and Davies, 1980] and are used to calculate the probe performance.

The aerosol penetration model employed is described more fully in Gronager et al. [1986]. In this model, particle losses have been estimated for inertial deposition, diffusive deposition, and particle settling. The source term at the sampling point and sampling times can be adjusted for estimated loss and delay time.

Aerosol transport through the sample extraction and dilution system (SEDS) is not universally efficient. It is dependent upon particle size and 
Table 4.4.3 Anderson Mark III impactor cut points

\begin{tabular}{ccc}
\hline & \multicolumn{2}{c}{$\begin{array}{c}\text { 50\% Cut Points (Particle Diameter in } \\
\text { Micrometers) for Two Flow Rates }\end{array}$} \\
\cline { 2 - 3 } Stage & 10 LPM & 15 LPM \\
\hline Preseparator & 10.5 & 10.0 \\
1 & - & - \\
2 & - & - \\
3 & 7.6 & 6.3 \\
4 & 5.1 & 4.3 \\
5 & 2.8 & 2.4 \\
6 & 1.3 & 1.1 \\
7 & 0.84 & 0.70 \\
8 & 0.49 & 0.41 \\
\hline
\end{tabular}

Table 4.4.4 Sierra cascade cyclone cut points supplied by manufacturer. Flow nominally at $0.8 \mathrm{scfm}$ and temperature at $23^{\circ} \mathrm{C}$

\begin{tabular}{cc}
\hline $\begin{array}{c}\text { Cyclone } \\
\text { Stage }\end{array}$ & $\begin{array}{c}\text { Cut Point } \\
(\boldsymbol{\mu} \mathbf{m})\end{array}$ \\
\hline 1 & Not supplied at these conditions \\
2 & 6.2 \\
3 & 2.65 \\
4 & 1.55 \\
5 & 0.84 \\
6 & 0.54 \\
\hline
\end{tabular}


flow conditions. Transport data for the SEDS system have been taken to test the transport model. These data are highly limited comprising only a portion of the desired calibration work. Exacting test schedules and limited resources prevented the in-depth testing desired. Further calibration of the system is under way.

The aerosol mass source rates are calculated by multiplying the measured aerosol concentration by the exhaust gas flow rates. Delay times for the aerosol to flow from the crucible volume to the sampling point are taken into account by calculating the time to flow through the intervening volume.

Experimental measurements of penetration through a series of $90^{\circ}$ bends and through the SEDS plumbing from inlet to filter sample point and to impactor sample point have been made. The calibration aerosol was monodisperse oleic acid particles generated with the vibrating orifice generator manufactured by TSI, Inc. [Berglund and Liu, 1973]. Measurements of the aerosol concentration were made with a TSI aerodynamic particle sizer (APS-33). Aerosol concentration measurements were made upstream and downstream of the test section to obtain the penetration efficiency. Table 4.4 .5 gives the results for the $90^{\circ}$ bend and Figure 4.4.13 shows these results as penetration efficiency plotted against Stokes number along with the theoretical curve. For these high levels of penetration, the theory and data match well; however, for larger particles or higher flows resulting in lower penetration, the theory may be in some error.

Figure 4.4.14 is the room temperature penetration of a 4.56 micrometer diameter particle through the SEDS plumbing to the filter sample point. The curve is the theoretical penetration calculated by the model discussed above. Figure 4.4.15 is the penetration of a 4.56 micrometer particle through the plumbing to the impactor sample point along with the theoretical penetration.
In both cases, the experiment gave lower penetration than the model calculated: about 30 percent low for the filters and 15 percent low for the impactors. The cause of these differences is not known, and further calibration and verification of models are required.

Aerosol data from previous tests [Brockmann, 1987] have indicated that aerosols produced during melt interactions with concrete are typically on the order of one micrometer aerodynamic equivalent diameter. Penetration of this size to the samplers is seen from Figures 4.4.14 and 4.4.15 to be high.

\subsection{Induction Power Instrumentation}

The $204.2 \mathrm{~kg}$ of $\mathrm{UO}_{2}-\mathrm{ZrO}_{2}-\mathrm{Zr}$ core debris was melted and sustained using an Inductotherm $250 \mathrm{~kW}, 1 \mathrm{kHz}$ induction power supply, shown in Figure 4.5.1. Power was delivered to the coils via remote control using a pair of No. 16 high current, water-cooled, flexible leads. During the melting process, the induction power supply automatically controlled voltage and frequency to deliver the desired power. Maximum efficiency was maintained throughout the experiment without the need to switch capacitors or voltage taps. The power at the buss bars was measured using a power transducer manufactured by Research Incorporated. This device converted the current and voltage measured at the buss bars inside the power supply into a voltage equivalent of power.

In order to conduct a posttest power balance, the flow rate and differential temperature of the cooling fluid across the power supply and coil were both measured during the experiment. The cooling fluid was a mixture of 30 percent ethylene glycol/70 percent water. The flow rate of the cooling fluid flowing through the coil and power supply (separate circuits) was measured using a turbine flowmeter installed in line. The meter was manufactured by Signet Scientific and included a power supply and signal conditioner. 
Table 4.4.5 Particle penetration through a $90^{\circ}$ bend

\begin{tabular}{cccccc}
\hline $\begin{array}{c}\text { Dp } \\
(\boldsymbol{\mu m})\end{array}$ & $\begin{array}{c}\mathbf{Q} \\
\left(\mathbf{c m}^{3} / \mathbf{s e c}\right)\end{array}$ & $\begin{array}{c}\text { Tube I.D. } \\
(\mathbf{c m})\end{array}$ & \multicolumn{1}{c}{ Stk } & $\begin{array}{c}\text { Experimental } \\
\text { Penetration }\end{array}$ & $\begin{array}{c}\text { Model } \\
\text { Predicted } \\
\text { Penetration }\end{array}$ \\
\hline 4.56 & 136 & 1.092 & $8.3 \cdot 10^{-3}$ & $0.978-0.987$ & 0.987 \\
4.56 & 208 & 1.092 & $1.26 \bullet 10^{-2}$ & $0.961-0.972$ & 0.980 \\
4.56 & 136 & 1.727 & $2.1 \cdot 10^{-3}$ & $0.972-1.00$ & 0.997 \\
4.56 & 208 & 1.727 & $3.2 \cdot 10^{-3}$ & $0.981-1.00$ & 0.995 \\
7.24 & 136 & 1.727 & $5.2 \bullet 10^{-3}$ & $0.945-0.985$ & 0.992 \\
9.12 & 136 & 1.727 & $8.3 \cdot 10^{-3}$ & $0.942-0.967$ & 0.987 \\
\hline
\end{tabular}

Net power to the tungsten susceptors was calculated to be 50 percent of the gross power. This ratio is determined using calorimetric methods and is detailed in Appendix A.

The differential temperature across the power supply was measured across the inlet and exit using two Omega ON-970-44008, 33,000 ohm thermistors arranged in a half bridge circuit. The differential temperature across the coil was measured using a differential temperature transducer manufactured by Delta-T Co. Type K thermocouples were installed at the inlet and exit of both the power supply and coil for redundant temperature measurement.

\subsection{Data Acquisition System}

All 171 instrument channels were recorded every 15 seconds for the entire experiment. Two-hundred-ten channels of data may be acquired during an experiment. Of the 210 channels, 150 are for type $\mathrm{K}$ thermocouples, 20 are for either type $S$ or type $C$ thermocouples and the remaining 40 are dc voltage channels. A patch panel routes all the analog data channels from the test location to the Hewlett-Packard Model 2250 Measurement and Control Unit. This unit houses an analog to digital converter capable of multiplexing the 210 data channels. The voltage range of the data acquisition unit is \pm 10 volts $\mathrm{dc}$, with a programmable gain to increase sensitivity if the expected signal is small. A Hewlett-Packard Model 1000 series A-600 minicomputer is used to control all remote devices and manipulate the data received from the Measurement and Control Unit. Data are stored on a Hewlett-Packard Model 7946, 15 megabyte hard disk. A Hewlett-Packard Model 2623 terminal is used to command the minicomputer during test and to display real-time data in a tabular format as data acquisition progresses. A desk-top terminal Hewlett-Packard Model 9836 is used to display real-time data in both graphic and numeric format as well as to provide interrupt control over the minicomputer during a test. A Hewlett-Packard Model 9872 four-color plotter and nine-track magnetic tape are used for posttest data plotting and transfer.

The measurement accuracy of the 14-bit analogto-digital converter is 1.56 microvolts in the most sensitive range and 1.25 millivolts at the highest range $(-10$ to +10 volts). With the appropriate range setting, the resolution for a $K$ type thermocouple is $\pm 1^{\circ} \mathrm{C}$, and for a type $\mathrm{S}$ or a type $\mathrm{C}$ thermocouple, the resolution is $\pm 1.1^{\circ} \mathrm{C}$.

The data acquisition speed can be selected from 1.25 seconds per point upward for 210 channels. The sample rate can be increased by reducing the number of channels sampled. For the SURC-1 



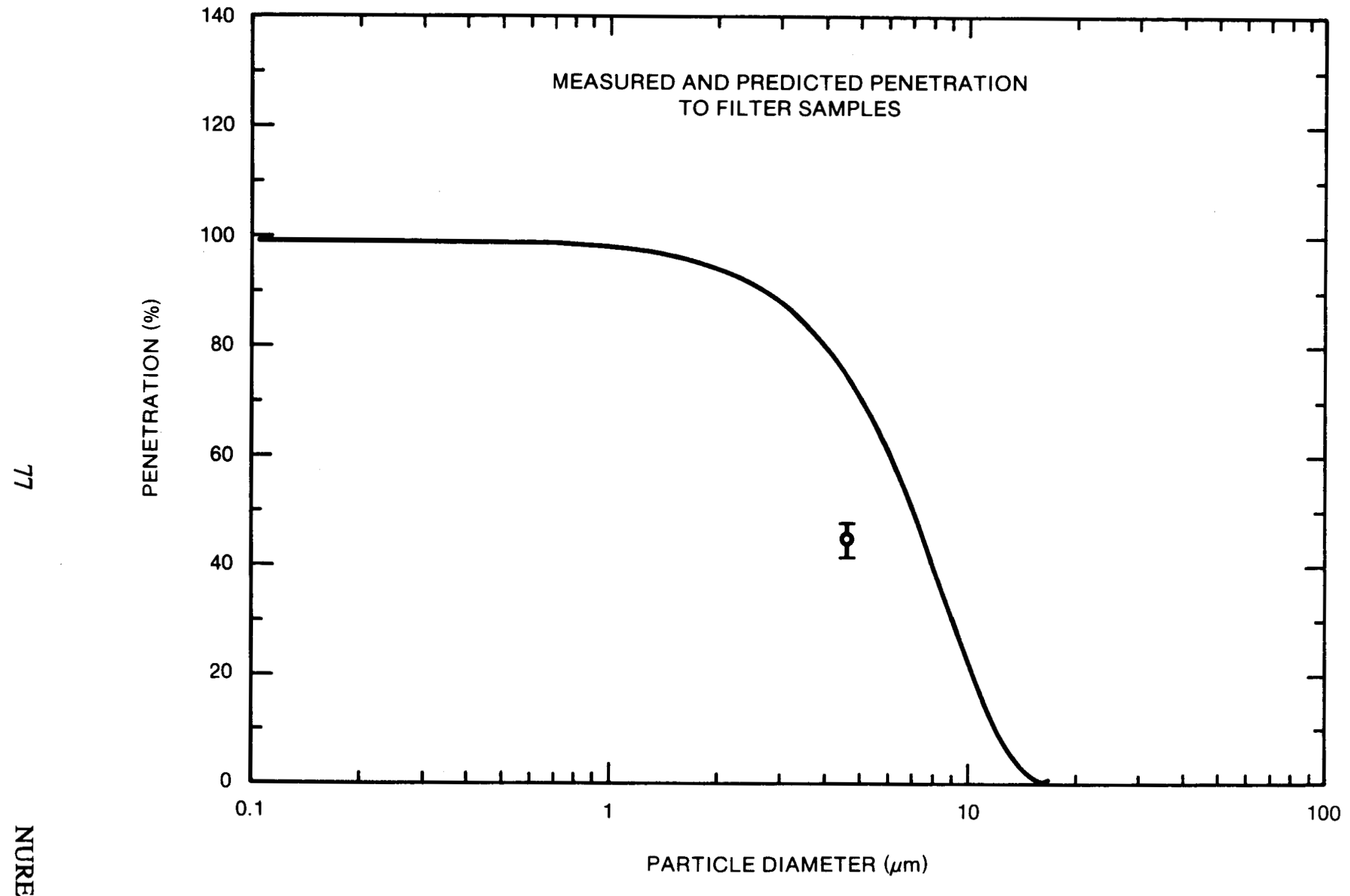

Figure 4.4.14 Penetration efficiency as a function of particle aerodynamic diameter predicted by theory and measured for a $4.56 \mu \mathrm{m}$ particle from the SEDS inlet at diluter 1 to the filter sample point 


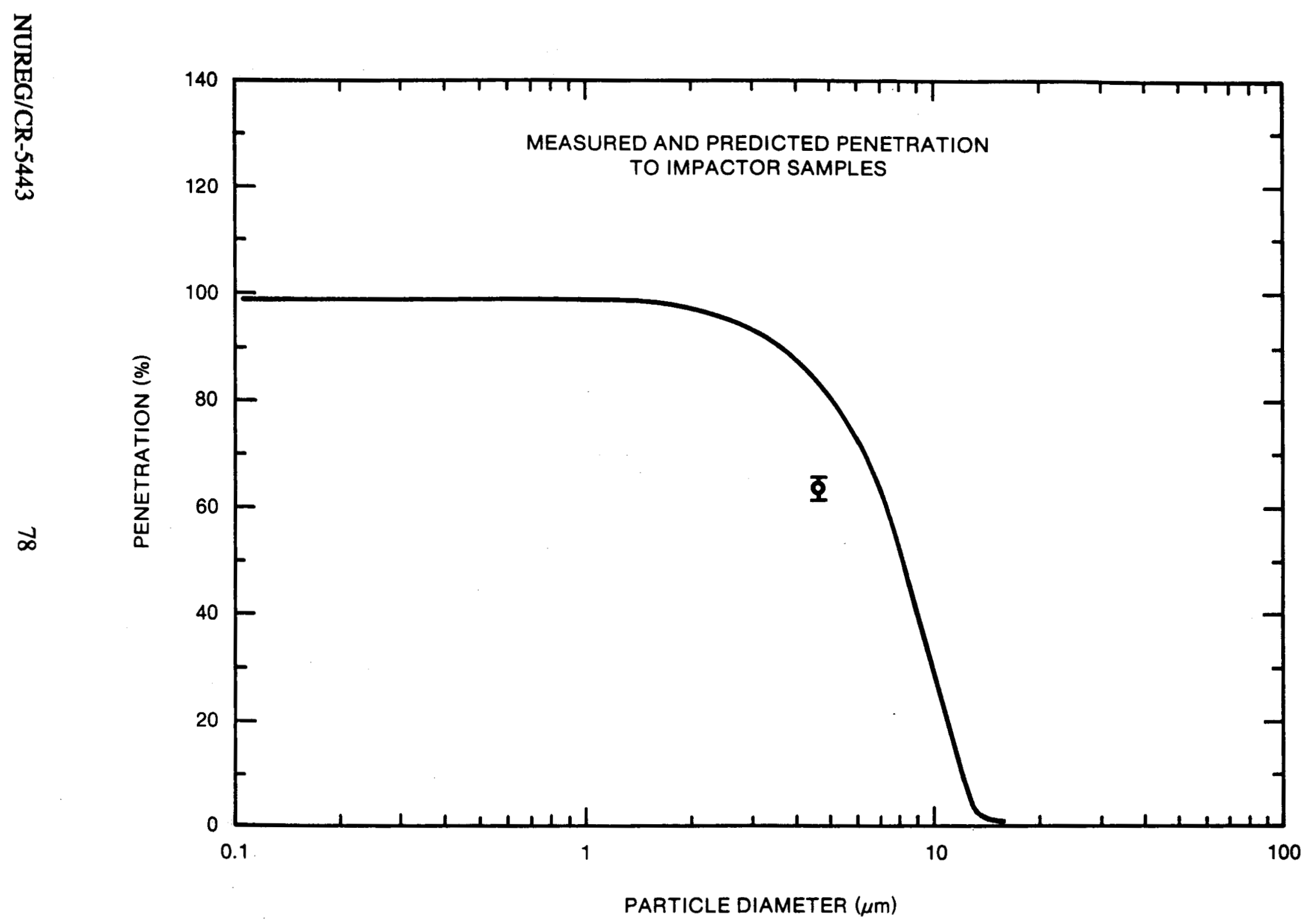

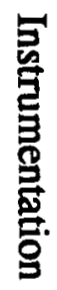

Figure 4.4.15 Penetration efficiency as a function of particle aerodynamic diameter predicted by theory and measured for a $4.56 \mu \mathrm{m}$ particle from the SEDS inlet at diluter 1 to the impactor sample point 


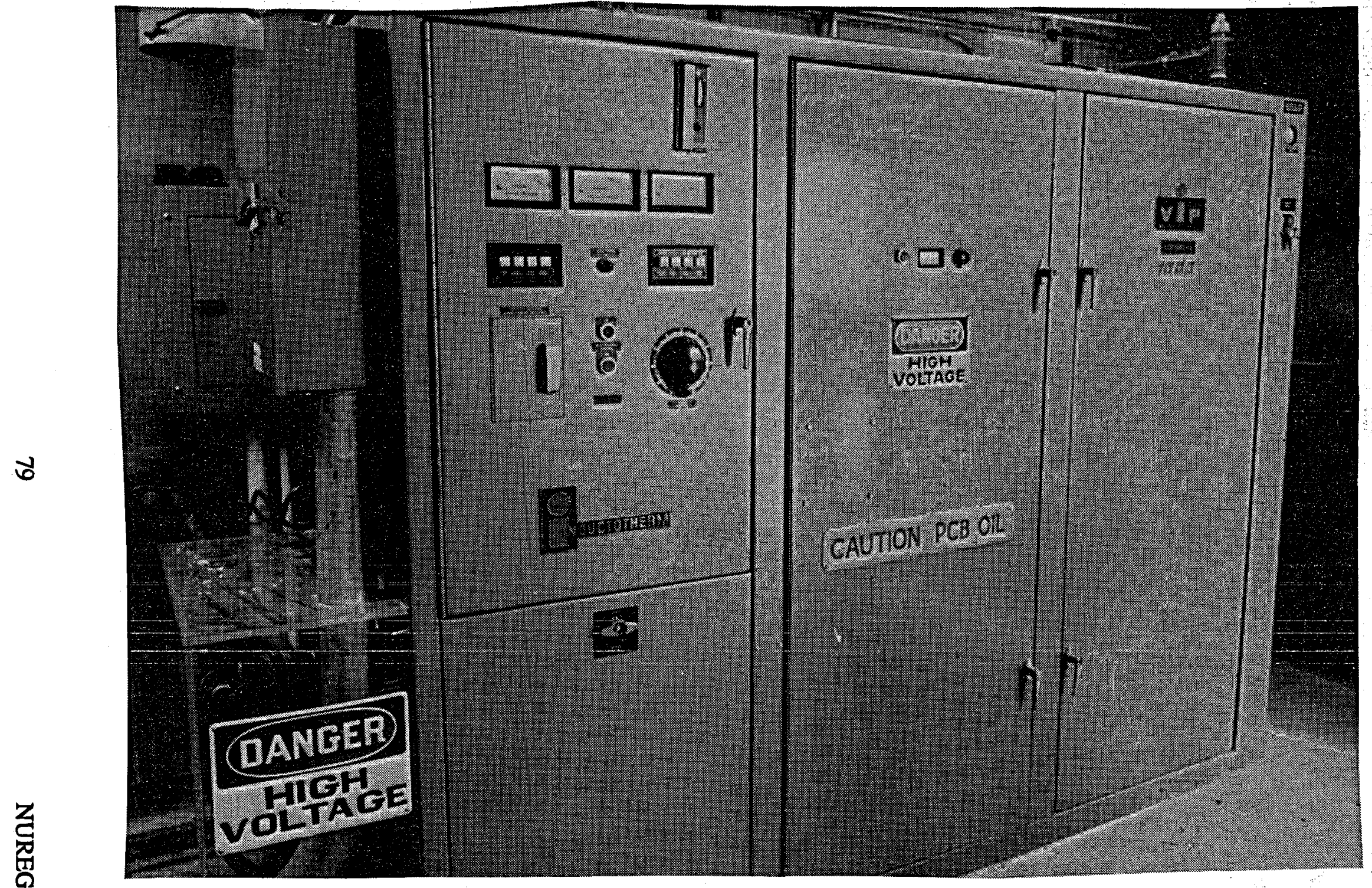

Figure 4.5.1 Inductotherm power supply 
Instrumentation

test, data for the channels were sampled at 15 second intervals.

\subsection{Video Monitoring Instrumentation}

The experiment was monitored remotely using a Sony Beta Model HVC 2200 video camera connected to a Sony Model SL 2000 portable Beta recorder and Model TT 2000 Tuner/Timer. The real-time camera image was displayed on a 19-in. Sony model CVM 1900 color monitor. The image was passed between the video recorder and color monitor via a RG-59 coax cable. 


\subsection{Test Procedure and Posttest Observations}

\subsection{Operational Procedure}

On the day of the test, the SURC-1 assembly was leak tested. Results of the leak tests using argon gas as the flow medium indicated a cold leak rate of $20 \mathrm{alpm}$ at an inlet flow rate of $165 \mathrm{alpm}(12$ percent losses) and an overpressure of 1 psig in the SURC-1 containment vessel. After final calibration and pretest checkouts were performed, the data acquisition system was started. Power was then applied to the coil at a rate of $50 \mathrm{~kW}$ at time $=14$ minutes, thus constituting the start of SURC-1.

A summary of the events in the SURC-1 test is presented in Table 5.1. Power increases were effected to a level of $99 \mathrm{~kW}$ (gross) at 48 minutes, to a level of $154 \mathrm{~kW}$ at 126 minutes, and to a level of $200 \mathrm{~kW}$ at 222 minutes. A plot of the power history showing both the total and net power is presented in Figure 5.1. The charge became molten at times after 120 minutes and concrete attack began at 135 minutes when the zirconia insulator board at the bottom of the charge was dissolved into the melt. Aerosol samples were taken at 153 minutes as the optical pyrometer started to indicate large amounts of aerosol production. Gas composition grab samples were also taken at this time.

Additional gas samples were taken at 162,190 , 218 , and 248 minutes and supplementary aerosol samples were taken at regular intervals between 160 and 260 minutes. The data acquisition system was set to take data every 15 seconds. Significant flow blockage and a large back pressure were noted in the containment vessel at 287 minutes and the power supply was turned off, thus terminating the test.

\subsection{Posttest Observations}

The SURC-1 gravel filter, aluminum vessel, and crucible assembly were disassembled and inspected after the test. These inspections showed that large amounts of aerosol material had been generated and transported throughout the containment and along the flow paths and that the $\mathrm{MgO}$ crucible assembly had successfully contained the $\mathrm{UO}_{2}$-concrete interactions with little or no evidence of meltpool-sidewall interaction other than thermal dehydration.

The gravel filter was disassembled at the inlet plenum to reveal a fairly thick layer of packed fine particulate completely covering the $1 \mathrm{~mm}$ alumina gravel which served as the filter media. The aerosol material was uniformly $0.65 \mathrm{~cm}$ thick and filled the $30 \mathrm{~cm}$ diameter of the gravel filter. There were three distinct layers of material which had the appearance of very fine cracked grey mud. The top layer was $0.05 \mathrm{~cm}$ thick and had relatively large amounts of tungsten material in it in addition to $\mathrm{Mg}, \mathrm{Zr}$, and $\mathrm{Si}$ materials. The middle layer was $0.17 \mathrm{~cm}$ thick and had smaller amounts of tungsten material and increased relative amounts of $\mathrm{Mg}, \mathrm{Zr}$, and $\mathrm{Si}$ material. The bottom layer was $0.42 \mathrm{~cm}$ thick and had the lowest relative amount of tungsten in it and the highest concentrations of $\mathrm{Mg}, \mathrm{Zr}$, and Si. The total weight of all three layers was 186 g. The results of an elemental analysis of the gravel filter material using inductively coupled mass spectroscopy are shown in Table 5.2.

These results show that the aerosol was rich in sodium and potassium and also had significant amounts of cerium, barium, molybdenum and uranium in it, in addition to the $\mathrm{W}, \mathrm{Mg}, \mathrm{Zr}$, and Si materials.

The containment bell was opened to reveal the internals. The inside of the bell was coated with flaky grey aerosol and had streaks of evaporated liquid (probably $\mathrm{H}_{2} \mathrm{O}$ ) running down the sides. A fine grey aerosol also covered the crucible, coil, and pyrometer assemblies. This material resembled dried grey mud in most places and was several millimeters deep. The alumina exhaust tubes installed in the crucible cover were severely deformed but a clear flow path to the former meltpool still existed. The lid and sides of the $\mathrm{MgO}$ crucible were cracked in several places but 


\begin{tabular}{|c|c|}
\hline Time (min) & Event \\
\hline 0.0 & Start of data acquisition system, 15 second scanning intervals \\
\hline 14.0 & Power supply turned on power meter reading $50 \mathrm{~kW}$, \\
\hline 48.0 & Power increased to $99 \mathrm{~kW}$ \\
\hline 50.0 & Charge temperature (measured by pyro thermocouple at $\mathrm{z}=+10 \mathrm{~cm}$ ) $722 \mathrm{~K}$ \\
\hline 68.0 & First detection of aerosols by photometer \\
\hline $76: 0$ & Onset of the dehydration front (rate nearly constant for next $70 \mathrm{~min}$ ) \\
\hline 78.0 & Photometer reading maximum 0.96 \\
\hline 100.0 & $\begin{array}{l}\text { Photometer reading } 0.64 \\
\text { Charge temperature } 1906 \mathrm{~K}\end{array}$ \\
\hline 126.0 & Power increased to $154 \mathrm{~kW}$. \\
\hline 135.0 & $\begin{array}{l}\text { Midradius surface thermocouple } C 21(\mathrm{z}=0.0 \mathrm{~cm} \text { ) failed } \\
\text { Onset of ablation (dehydration depth } 6 \mathrm{~cm} \text { ) } \\
\text { Charge temperature } 2577 \mathrm{~K}\end{array}$ \\
\hline 136.0 & Photometer reading maximum 0.98 (remains maximum for remainder of test) \\
\hline 136.3 & Midradius thermocouple $\mathrm{C} 22(\mathrm{z}=-2.0 \mathrm{~cm})$ failed \\
\hline 138.9 & Midradius thermocouple $\mathrm{C} 23(\mathrm{z}=-4.0 \mathrm{~cm})$ failed \\
\hline 141.0 & Alumina tube $S$ type thermocouple A1 $(z=-1.0 \mathrm{~cm})$ failed \\
\hline 143.5 & Midradius thermocouple $\mathrm{C} 24(\mathrm{z}=-6.0 \mathrm{~cm})$ failed \\
\hline 145.5 & $\begin{array}{l}\text { Midradius thermocouple } \mathrm{C} 25(\mathrm{z}=-8.0 \mathrm{~cm}) \text { failed } \\
\text { Dehydration rate increases }\end{array}$ \\
\hline $147: 5$ & $\begin{array}{l}\text { Axial surface thermocouple } \mathrm{Cl}(\mathrm{z}=0.0 \mathrm{~cm}) \text { failed } \\
\text { Charge temperature } 2611 \mathrm{~K}\end{array}$ \\
\hline 148.5 & Axial thermocouple $\mathrm{C} 2(\mathrm{z}=-1.0 \mathrm{~cm})$ failed \\
\hline 149.5 & Axial thermocouple $\mathrm{C} 3(\mathrm{z}=-3.0 \mathrm{~cm})$ failed \\
\hline
\end{tabular}


Table 5.1 Events of test SURC-1 (Continued)

\begin{tabular}{|c|c|}
\hline Time (min) & Event \\
\hline 150.3 & Axial thermocouple $\mathrm{C} 4(\mathrm{z}=-7.0 \mathrm{~cm})$ failed \\
\hline 151.3 & Axial thermocouple $C 5(\mathrm{z}=-7.0 \mathrm{~cm})$ failed \\
\hline 152.3 & Axial thermocouple $\mathrm{C} 6(\mathrm{z}=-9.0 \mathrm{~cm})$ failed \\
\hline 153.0 & $\begin{array}{l}\text { Grab sample \#1 } \\
\text { Filter sample \#1 taken }(60 \mathrm{sec}) \\
\text { Peak charge temperature } 2650 \mathrm{~K}\end{array}$ \\
\hline 154.0 & $\begin{array}{l}\text { Cascade Cyclone Sample (9 min) } \\
\text { Filter sample \#2 taken }(60 \mathrm{sec}) \\
\text { Impactor E sample }(60 \mathrm{sec}) \\
\text { Impactor F sample }(60 \mathrm{sec}) \\
\text { Gas grab sample \#1 }\end{array}$ \\
\hline 155.0 & Filter sample \#3 (60 sec) \\
\hline 158.0 & $\begin{array}{l}\text { Sidewall array thermocouple } M 33(\mathrm{z}=+35.0 \mathrm{~cm}, \mathrm{t}=0.5 \mathrm{~cm}) \text { failed } \\
\text { Filter sample } \# 4(60 \mathrm{sec})\end{array}$ \\
\hline 158.3 & Axial array thermocouple $C 7(z=-11.0 \mathrm{~cm})$ failed \\
\hline 159.0 & $\begin{array}{l}\text { Impactor G sample }(60 \mathrm{sec}) \\
\text { Impactor } \mathrm{H} \text { sample }(60 \mathrm{sec}) \\
\text { Filter sample } \# 5(60 \mathrm{sec})\end{array}$ \\
\hline 160.0 & Filter sample \#6 (60 sec) \\
\hline 161.0 & Alumina tube type $C$ thermocouple $A 2(z=-3.0 \mathrm{~cm})$ failed \\
\hline 162.3 & Axial array thermocouple $C 8(z=-13.0 \mathrm{~cm})$ failed \\
\hline 162.5 & Gas grab sample \#2 \\
\hline 168.3 & Midradius array thermocouple $\mathrm{C} 26(\mathrm{z}=-10.0 \mathrm{~cm})$ failed \\
\hline 168.5 & Alumina tube $S$ type thermocouple A3 $(\mathrm{z}=-5.0 \mathrm{~cm})$ failed \\
\hline 171.5 & $\begin{array}{l}\text { Perimeter array surface thermocouple } \mathrm{C} 41(\mathrm{z}=0.0 \mathrm{~cm}) \text { failed } \\
\text { Perimeter array thermocouple } \mathrm{C} 42(\mathrm{z}=-1.0 \mathrm{~cm}) \text { failed } \\
\text { Charge temperature } 2543 \mathrm{~K}\end{array}$ \\
\hline
\end{tabular}


Test

Table 5.1 Events of test SURC-1 (Continued)

\begin{tabular}{ll} 
Time (min) & Event \\
\hline 172.0 & Perimeter array thermocouple C43 $(\mathrm{z}=-3.0 \mathrm{~cm})$ failed \\
& Perimeter array thermocouple C44 $(\mathrm{z}=-5.0 \mathrm{~cm})$ failed \\
& Opened ball valve, vessel pressure $9.2 \mathrm{psig}$
\end{tabular}

$172.5 \quad$ Filter sample \#7 $(60 \mathrm{sec})$

173.5 Perimeter array thermocouple C45 $(\mathrm{z}=-7.0 \mathrm{~cm})$ failed Filter sample \#8 $(60 \mathrm{sec})$

Impactor J sample

Impactor K sample

173.8 Midradius array thermocouple C27 $(z=-12.0 \mathrm{~cm})$

174.5 Filter sample \#9

Axial array thermocouple $C 9(\mathrm{z}=-15.0 \mathrm{~cm})$ failed

176.3 Perimeter array thermocouple C46 $(z=-9.0 \mathrm{~cm})$ failed

177.0 Ball valve closed

178.3 Perimeter array thermocouple C47 $(\mathrm{z}=-11.0 \mathrm{~cm})$ failed

179.5 Midradius array thermocouple C28 $(z=-14.0 \mathrm{~cm})$ failed

180.3 Aluminum tube type $S$ thermocouple A5 $(\mathrm{z}=-9.0 \mathrm{~cm})$ failed Start of 50 min period of slow concrete ablation

Charge temperature $2456 \mathrm{~K}$

181.0 Alumina tube type $C$ thermocouple A4 $(z=-7.0 \mathrm{~cm})$ failed

181.5 Axial array thermocouple $\mathrm{C} 10(\mathrm{z}=-17.0 \mathrm{~cm})$ failed

181.8 Perimeter array thermocouple C48 $(\mathrm{z}=-13.0 \mathrm{~cm})$ failed

186.3 Alumina tube type $C$ thermocouple A6 $(\mathrm{z}=-11.0 \mathrm{~cm})$ failed

186.5 Midradius array thermocouple C29 $(\mathrm{z}=-16.0 \mathrm{~cm})$ failed

188.0 Sidewall array thermocouple M34 $(\mathrm{z}=+35.0 \mathrm{~cm}, \mathrm{t}=1.5 \mathrm{~cm})$ failed

$190.5 \quad$ Gas grab sample \#3 
Table 5.1 Events of test SURC-1 (Continued)

\begin{tabular}{|c|c|}
\hline Time (min) & Event \\
\hline 200.0 & Charge temperature $2308 \mathrm{~K}$ \\
\hline 206.0 & Sidewall array thermocouple $M 8(\mathrm{z}=-10 \mathrm{~cm}, \mathrm{t}=0.5 \mathrm{~cm})$ failed \\
\hline 212.5 & Alumina tube type $S$ thermocouple $A 7(z=-14.0 \mathrm{~cm})$ failed \\
\hline 214.0 & Midradius array thermocouple $\mathrm{C} 30(\mathrm{z}=-18.0 \mathrm{~cm})$ failed \\
\hline 216.0 & Sidewall array thermocouple $\mathrm{M} 9(\mathrm{z}=-10.0 \mathrm{~cm}, \mathrm{t}=1.5 \mathrm{~cm})$ failed \\
\hline 218.0 & $\begin{array}{l}\text { Midradius array thermocouple } C 31(\mathrm{z}=-20.0 \mathrm{~cm}) \text { failed } \\
\text { Gas grab sample } \# 4\end{array}$ \\
\hline 222.0 & $\begin{array}{l}\text { Power increased to } 200 \mathrm{~kW} \\
\text { Charge temperature } 2177 \mathrm{~K}\end{array}$ \\
\hline 224.0 & Sidewall array thermocouple $M 35(\mathrm{z}=+35.0 \mathrm{~cm}, \mathrm{t}=2.5 \mathrm{~cm})$ failed \\
\hline 230.8 & Axial array thermocouple $\mathrm{C} 11(\mathrm{z}=-19.0 \mathrm{~cm})$ failed \\
\hline 235.8 & $\begin{array}{l}\text { Axial array thermocouple } \mathrm{C} 12(\mathrm{z}=-21.0 \mathrm{~cm}) \text { failed } \\
\text { Dehydration rate nearly constant for remainder of test }\end{array}$ \\
\hline 236.0 & Sidewall thermocouple M29 $(\mathrm{z}=+2.0 \mathrm{~cm}, \mathrm{t}=0.5 \mathrm{~cm})$ failed \\
\hline 237.5 & Midradius array thermocouple $\mathrm{C} 32(\mathrm{z}=-22.0 \mathrm{~cm})$ failed \\
\hline 243.5 & Midradius array thermocouple $\mathrm{C} 33(\mathrm{z}=-24.0 \mathrm{~cm})$ failed \\
\hline 248.0 & $\begin{array}{l}\text { Sidewall array thermocouple } \mathrm{M} 36(\mathrm{z}=+50.0 \mathrm{~cm}, \mathrm{t}=0.5 \mathrm{~cm}) \text { failed } \\
\text { Open ball valve vessel pressure } 8.9 \mathrm{psig}\end{array}$ \\
\hline 248.3 & Gas grab sample \#5 \\
\hline 250.0 & $\begin{array}{l}\text { Perimeter array thermocouple } \mathrm{C} 50(\mathrm{z}=-17.0 \mathrm{~cm}) \text { failed } \\
\text { Charge temperature } 1874 \mathrm{~K}\end{array}$ \\
\hline 250.5 & Axial array thermocouple $\mathrm{C} 13(\mathrm{z}=-23.0 \mathrm{~cm})$ failed \\
\hline 251.0 & Perimeter array thermocouple C51 $(\mathrm{z}=-19.0 \mathrm{~cm})$ failed \\
\hline
\end{tabular}


Test

Table 5.1 Events of test SURC-1 (Concluded)

\begin{tabular}{|c|c|}
\hline Time (min) & Event \\
\hline 259.5 & $\begin{array}{l}\text { Filter sample } \# 10(60 \mathrm{sec}) \\
\text { Axial array thermocouple } \mathrm{C} 14(\mathrm{z}=-25.0 \mathrm{~cm}) \text { failed }\end{array}$ \\
\hline 259.8 & Alumina tube type $C$ thermocouple $A 8(z=-17.0 \mathrm{~cm})$ failed \\
\hline 260.0 & Sidewall array thermocouple M26 $(\mathrm{z}=+15 \mathrm{~cm} \mathrm{t}=0.5 \mathrm{~cm})$ failed \\
\hline 260.3 & Perimeter thermocouple C52 $(\mathrm{z}=-21.0 \mathrm{~cm})$ failed \\
\hline 260.5 & $\begin{array}{l}\text { Filter sample \#11 }(60 \mathrm{sec}) \\
\text { Impactor } \mathrm{N} \text { sample }(60 \mathrm{sec}) \\
\text { Impactor O sample }(60 \mathrm{sec})\end{array}$ \\
\hline 261.5 & Filter sample \#12 (60 sec) \\
\hline 262.0 & Sidewall array thermocouple $\mathrm{M} 30(\mathrm{z}=+20.0 \mathrm{~cm}, \mathrm{t}=1.5 \mathrm{~cm})$ failed \\
\hline 262.8 & Alumina tube $S$ type thermocouple $A 9(z=-20.0 \mathrm{~cm})$ failed \\
\hline 264.0 & Perimeter array thermocouple C53 $(\mathrm{z}=-23.0 \mathrm{~cm})$ failed \\
\hline 265.0 & Termination of ablation \\
\hline 265.8 & Axial array thermocouple $\mathrm{C} 15(\mathrm{z}=-27.0 \mathrm{~cm})$ failed \\
\hline 272.0 & Sidewall array thermocouple M37 $(\mathrm{z}=+50.0 \mathrm{~cm}, \mathrm{t}=1.5 \mathrm{~cm})$ failed \\
\hline 273.8 & Grab sample \#6 \\
\hline 287.5 & $\begin{array}{l}\text { Power supply turned off, test terminated } \\
\text { Charge temperature } 1782 \mathrm{~K} \\
\text { Dehydration depth } \mathrm{z}=-35 \mathrm{~cm}\end{array}$ \\
\hline
\end{tabular}




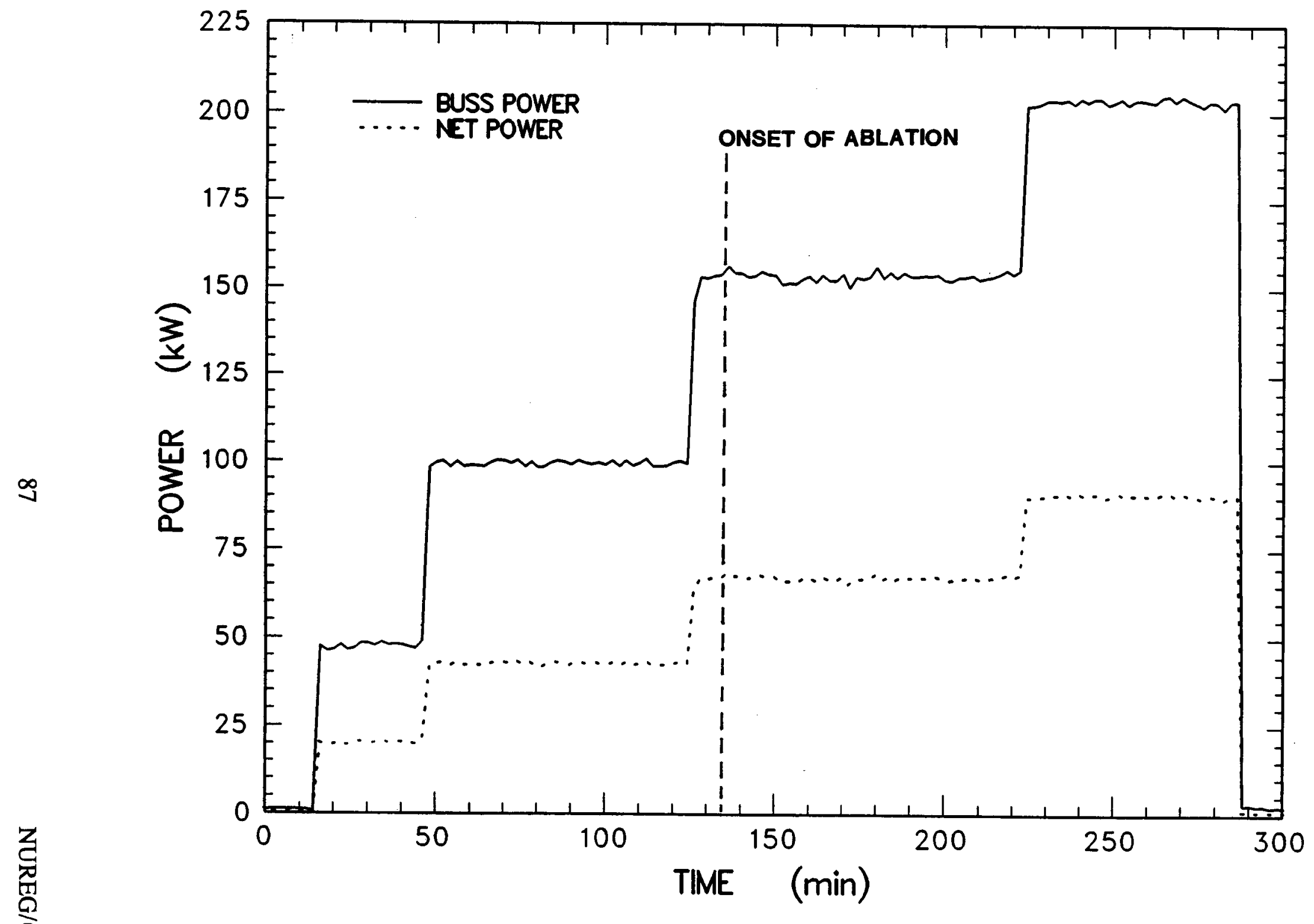

Figure 5.1 Power history for SURC-1 
Table 5.2 Elemental analysis of gravel filter aerosols

\begin{tabular}{|c|c|c|c|c|c|c|c|c|c|c|c|c|c|c|}
\hline Description & $\mathbf{B a}$ & $\mathbf{C a}$ & Ce & $\mathbf{C l}$ & $\mathbf{K}$ & $\mathbf{L a}$ & $\mathbf{M g}$ & Mo & $\mathbf{N a}$ & $\mathbf{N b}$ & Si & $\mathbf{U}$ & $\mathbf{W}$ & $\mathbf{Z r}$ \\
\hline $\begin{array}{l}\text { Gravel Filter } \\
\text { - Top }\end{array}$ & 0.14 & 0.54 & 0.022 & 0.55 & 16.4 & -- & 11.5 & 0.026 & 1.6 & -- & 12.0 & 0.05 & 9.0 & 0.17 \\
\hline $\begin{array}{l}\text { Gravel Filter } \\
\text { - Center }\end{array}$ & 0.35 & 0.80 & 0.048 & 0.53 & 14.3 & -- & 17.1 & 0.037 & 1.6 & -- & 18.2 & 0.05 & 2.2 & 0.07 \\
\hline $\begin{array}{l}\text { Gravel Filter } \\
\text { - Bottom }\end{array}$ & 0.23 & 0.40 & 0.11 & 1.40 & 8.8 & -- & 34.4 & 0.042 & 0.82 & -- & 32.8 & 0.10 & 0.66 & 0.26 \\
\hline
\end{tabular}


remained intact and there were no signs of anomalous attack or melt-through. The pyrometer head assemblies had become disconnected from the tungsten thermowells and the tubes had dropped down into the melt some 6 to $17 \mathrm{~cm}$. This drop probably caused a loss of the "line of sight" to the pyroheads at times after 165 minutes. The C-type thermocouples in the tungsten thermowells were badly oxidized but appeared to be intact. Additional samples of aerosol material were taken from the flow line at the ball valve and at the orifice plate. These materials were also analyzed and the results are shown in Table 6.4.4.

A posttest $\mathrm{x}$-ray was taken of the $\mathrm{MgO}$ crucible and is shown in Figure 5.2. The $x$-ray showed a large, dense meltpool in the bottom of the crucible and there were no indications of $\mathrm{MgO}$ sidewall attack. The meltpool extended uniformly across the entire diameter $(40 \mathrm{~cm})$ of the $\mathrm{MgO}$ annulus and was approximately $25 \mathrm{~cm}$ deep. The tungsten pyrotubes appeared intact and there were remains of two of the five tungsten susceptor rings in the area above the meltpool with a third ring just at the top of the meltpool. The crucible was sectioned with a ceramic saw to examine the internals. The upper section of the crucible had the remains of two of the collapsed tungsten rings. These were bronze in color, very thin, and warped but still intact. The third ring in a similar condition was found on top of a crust overlying the meltpool surface (Figure 5.3). A contraction zone gap $(7 \mathrm{~cm})$ separated the ring/crust from the remainder of the solidified meltpool. The meltpool material was dense, brittle, and grey to black in color. Density measurements found this material to be 4.2 to $5.2 \mathrm{~g} / \mathrm{cm}^{3}$. No signs of the other two rings were found in the meltpool although at least one tungsten spacer was removed from the bottom of the pool at the concrete interface. The meltpool extended uniformly to the $\mathrm{MgO}$ walls of the crucible and showed no signs of interaction with the sidewall other than dehydration (Figure 5.4). Approximately $11 \mathrm{~cm}$ of concrete were left in the bottom of the crucible with the concrete at the interface being chalky white and crumbly as shown in Figure 5.5. There were no signs of any slag material on the pool side of the interface. 


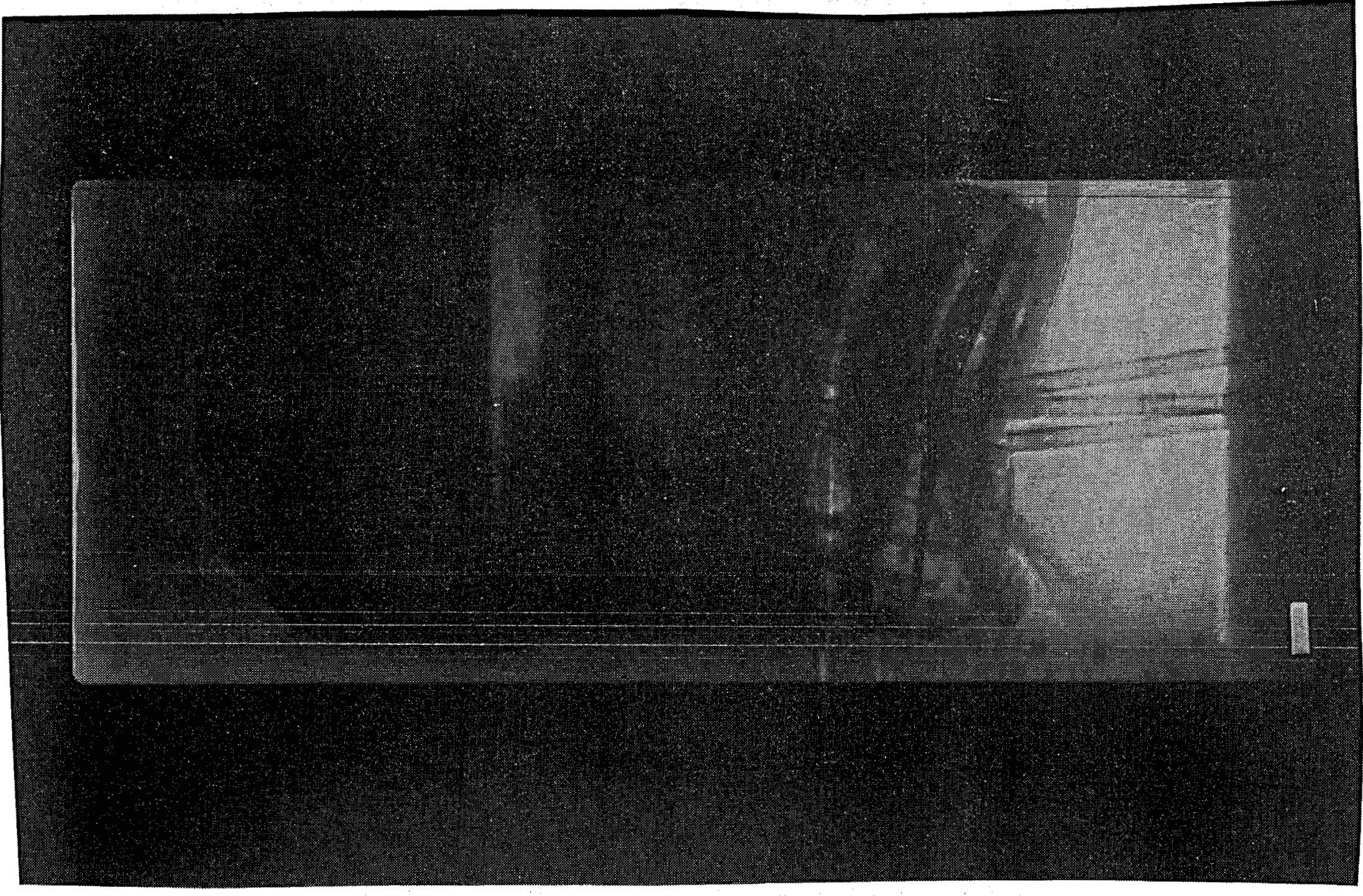

Figure 5.2 Posttest X-ray - SURC-1 


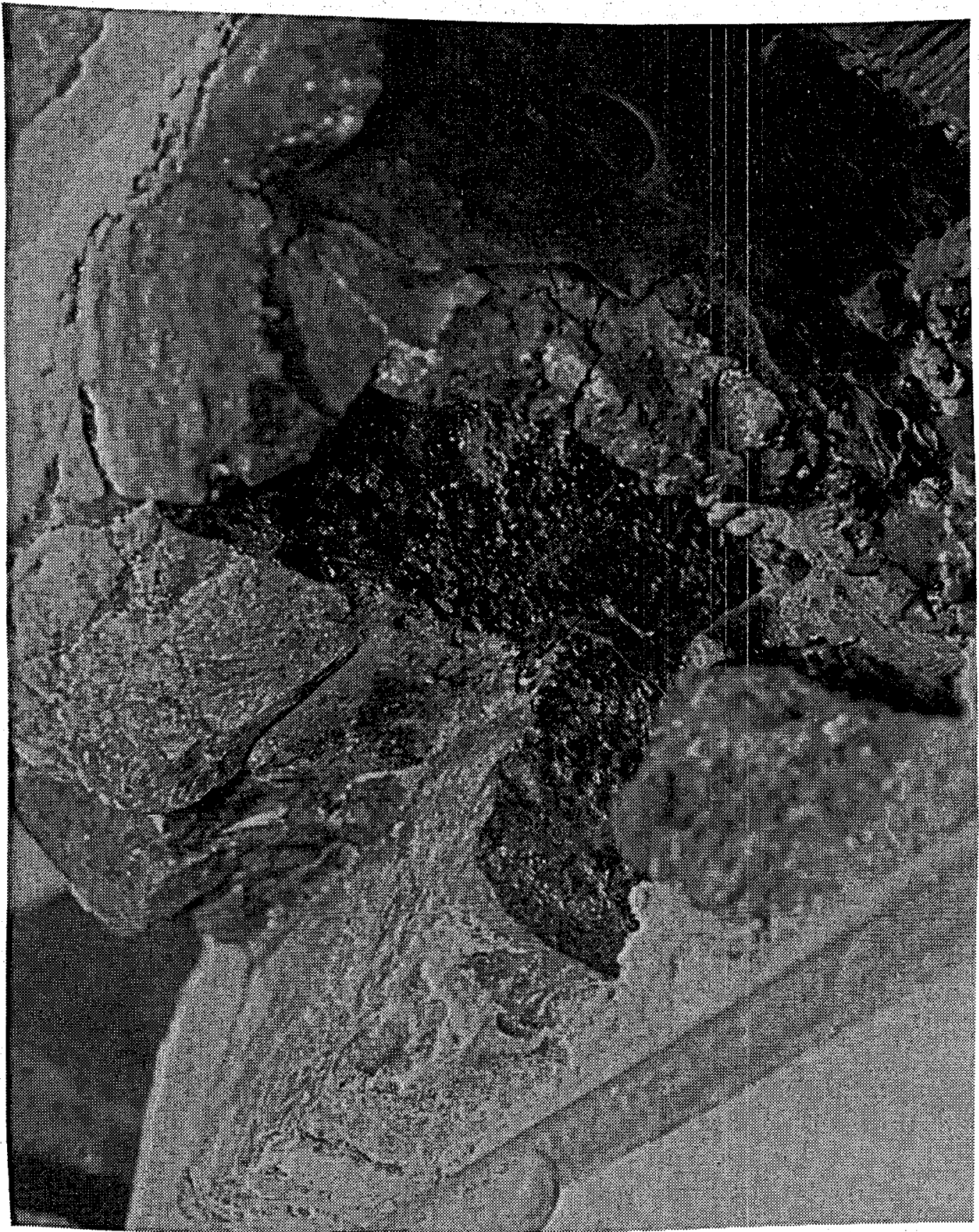

Figure 5.3 Photograph showing a section of the third tungsten ring on top of a crust overlying the solidified meltpool surface 
Test

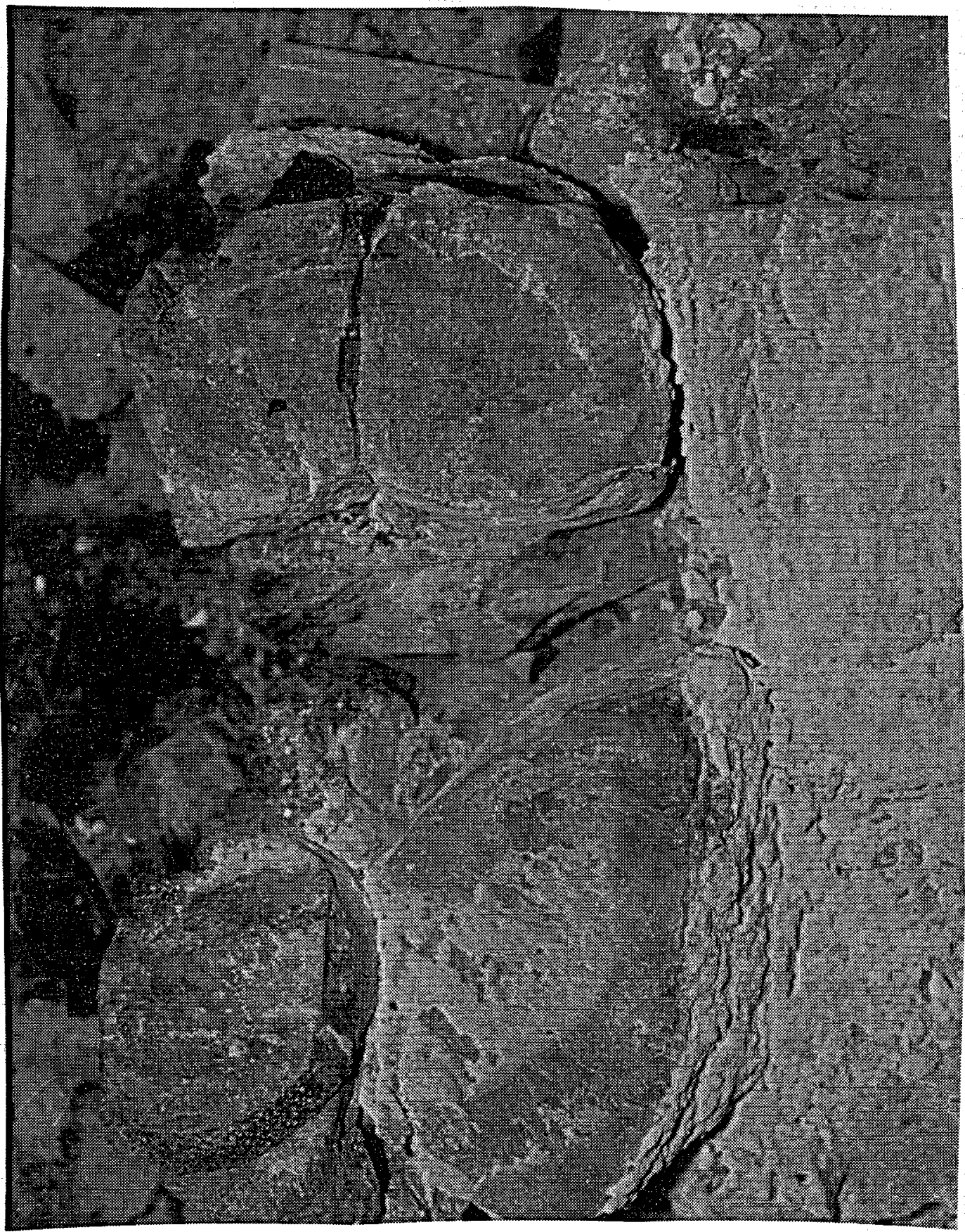

Figure 5.4 Photograph showing a sectional view of the crucible exposing the configuration of the meltpool and the crust material above 


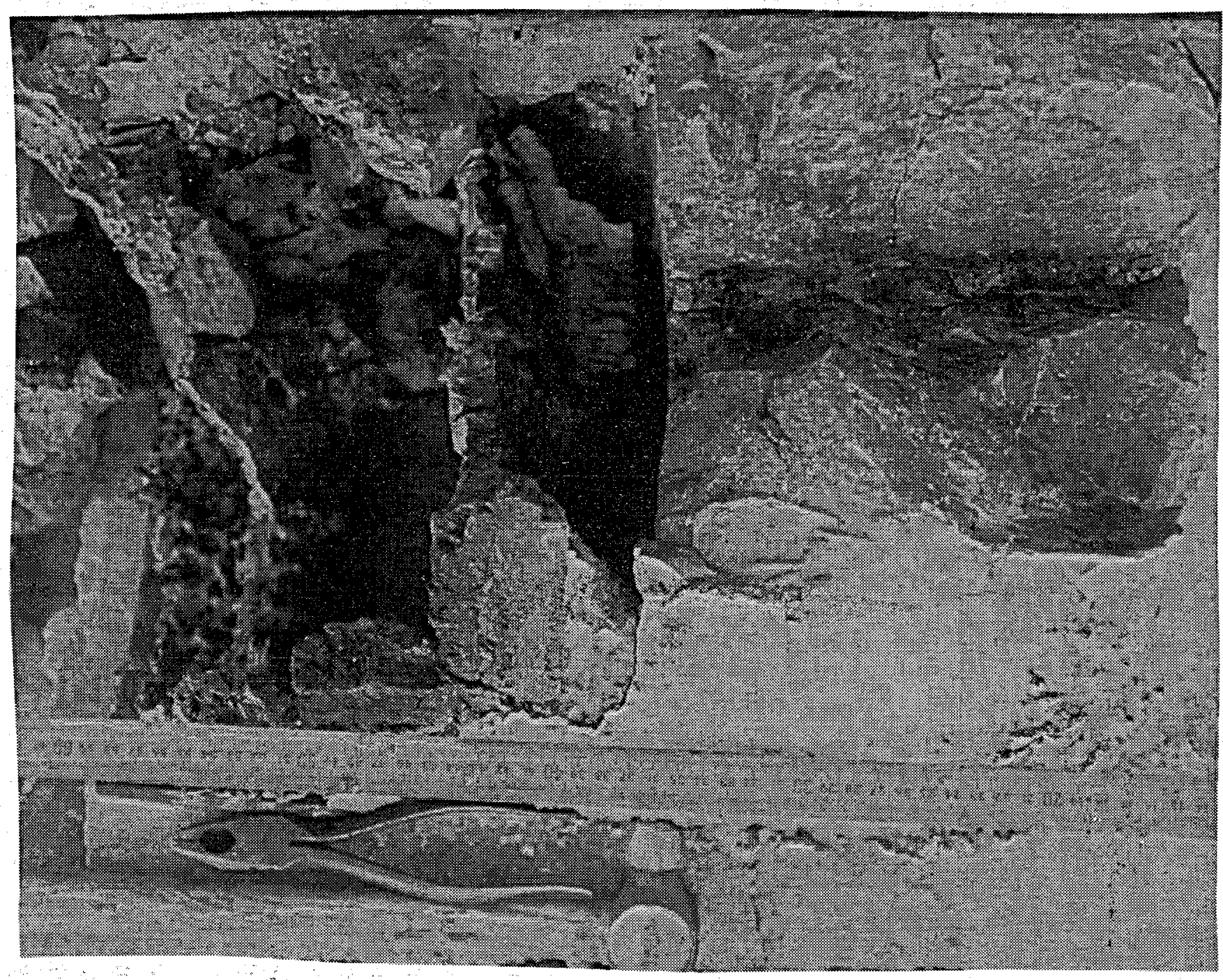

Figure 5.5 Photograph showing a section of the crucible revealing the meltpool/concrete interface 


\subsection{Data Presentation and Results}

The $204.2 \mathrm{~kg}$ charge of $\mathrm{UO}_{2}-\mathrm{Zr}_{2}-\mathrm{Zr}$ material was heated for 135 minutes prior to the onset of concrete erosion. Interactions then proceeded in three stages. First came rapid erosion enhanced by $\mathrm{Zr}$ oxidation lasting 35 minutes. Then came slower erosion at lower temperatures for 50 minutes. Finally, there was an increased erosion period when power was increased by 33 percent at 222 minutes. At 287 . minutes the power supply was shut off due to significant overpressures generated in the containment vessel caused by aerosol plugging of the gravel filter. A total of $27 \mathrm{~cm}$ of limestone concrete had been eroded over an interaction period of 130 minutes.

\subsection{Temperature Data}

The temperature data from SURC-1 are used to determine concrete erosion and the crucible thermal response. Three regions of the melt/ concrete interaction are shown in Figure 6.1.1. The pool consists primarily of uranium dioxide, but it may also contain zirconium metal and zirconium oxide as well as condensed products of concrete decomposition and fission product compounds. The "dry" region consists of the concrete that is dehydrated, decomposing, and beginning to melt. The "wet" region is the concrete that still contains water of hydration and water in the concrete pores. The transition between the "wet" and the "Iry" region is taken here to be the point at which hydration and pore water undergo the phase change to vapor.

Surrounding the three important regions of the melt/concrete interaction in the SURC-1 test, is the magnesium oxide annulus. In an ideal circumstance, the confining annulus of the test would be totally inert. That is, it would neither conduct heat nor mechanically degrade or chemically interact. Clearly, no such totally inert material exists and it is necessary to consider how the magnesia annulus affects the melt/ concrete interaction.
In this section, the temperature data obtained in the SURC-1 experiment will be used to describe the thermal response of the three regions of melt/ concrete interactions, the magnesium oxide annulus and crucible cover.

\section{Concrete Response}

The dehydration front of the concrete defined by the $400 \mathrm{~K}$ isotherm began to propagate through the concrete slug at approximately $t=75$ minutes. Concrete ablation began between $t=$ 135 and 172 minutes depending on the location of the concrete thermocouple array considered. The ablation front was defined by the failure of the type $\mathrm{K}$ thermocouples embedded in the concrete. The failure temperature for type $\mathbf{K}$ thermocouples is approximately $1645 \mathrm{~K}$. Twenty-seven centimeters of concrete were eroded over a period of 130 minutes. Melt temperatures as high as $2620 \mathrm{~K}$ were measured by the fiber optic pyrometers and confirmed by type $\mathrm{C}$ thermocouples. Side wall heat fluxes calculated from thermocouple data adjacent to the melt ranged between $5 \times 10^{4}$ and $2.2 \times 10^{5} \mathrm{~W} / \mathrm{m}^{2}$. The peak upward heat flux imparted to the crucible cover was calculated to be $1 \times 10^{5} \mathrm{~W} / \mathrm{m}^{2}$.

Figure 6.1.2 shows a typical temperature versus time profile indicated by thermocouples embedded in the concrete slug during a period of steady state ablation. The figure shows the response of five thermocouples located in the axial array at depths between $z=-19$ and $-27 \mathrm{~cm}$. The temperature histories for other thermocouples cast into the concrete slug in various arrays are presented in Appendix C. Temperatures rise slowly between 300 and $400 \mathrm{~K}$ as the concrete dehydrates. This is followed by a rapid increase in temperature to failure (indicated by the vertical lines going off-scale) caused by contact with the meltpool.

The axial centerline array has been chosen to characterize the position of the dehydration front with respect to time. This is shown by the solid 


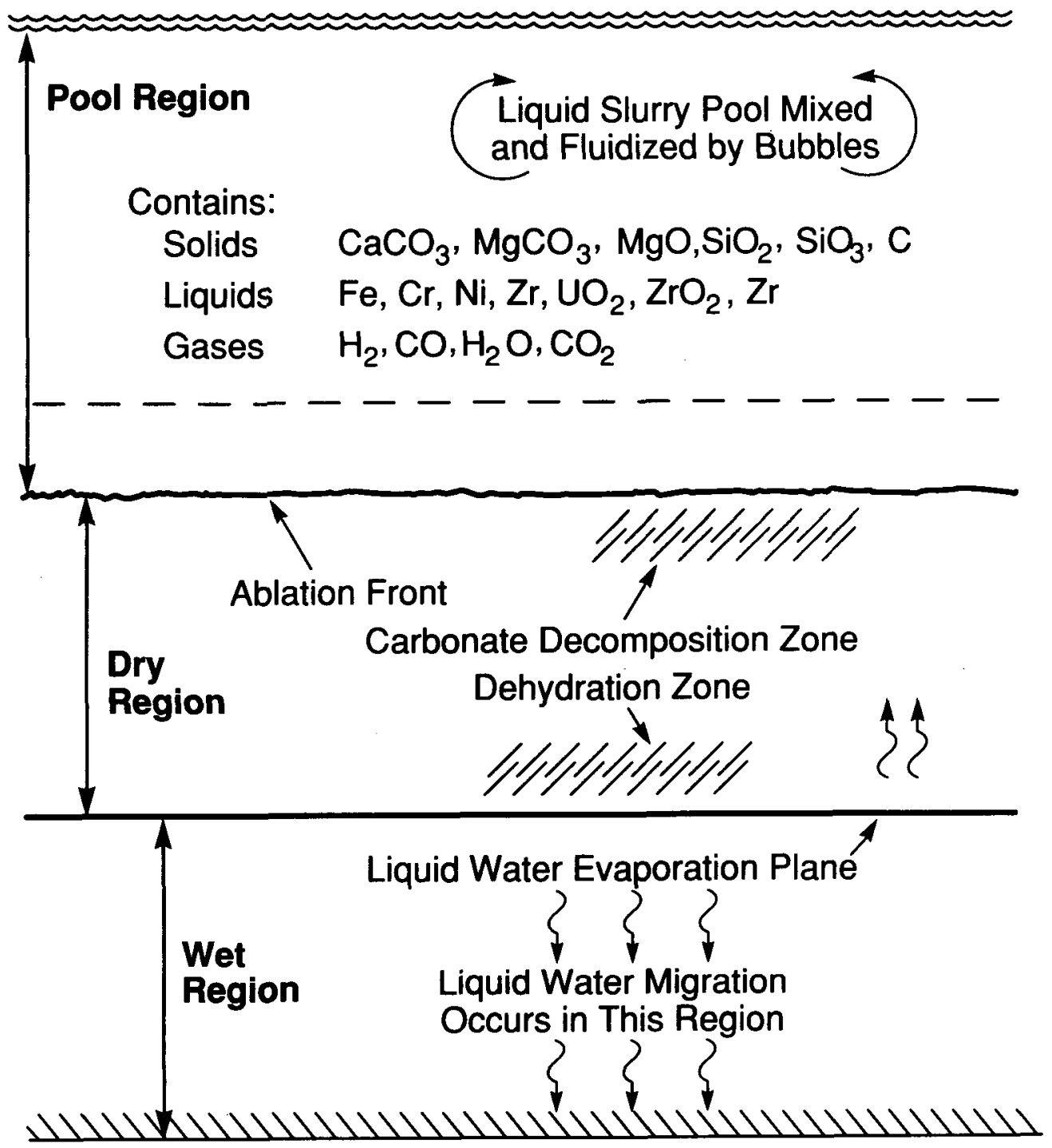

Figure 6.1.1 Three regions for analyzing melt concrete interactions 


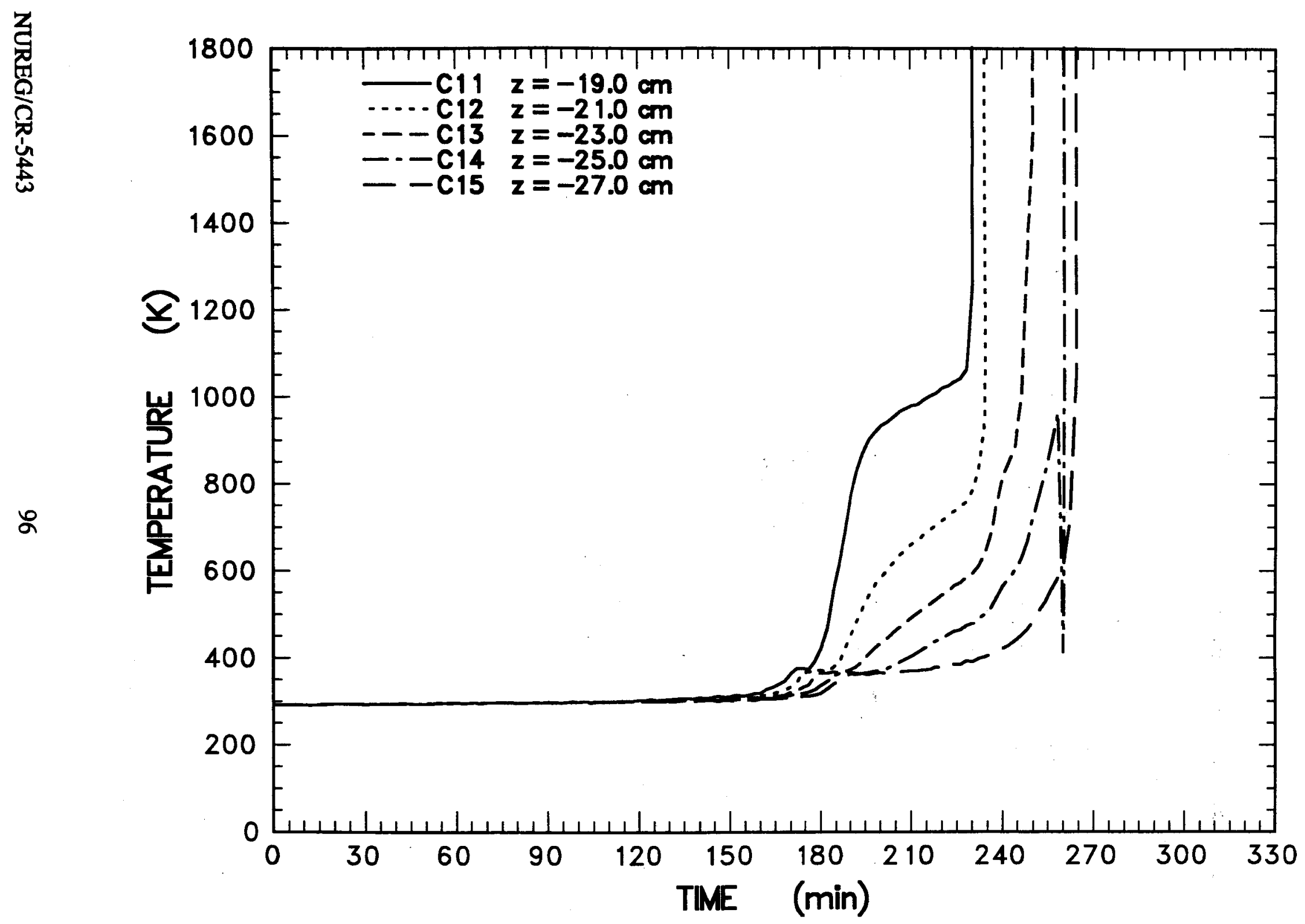

Figure 6.1.2 Typical thermal response of the concrete for the SURC-1 experiment 
line connecting the circles in Figure 6.1.3. There are three periods of interest; the initial heating period between $t=75$ and 147 minutes, the period during the onset of concrete ablation (taken as 147 minutes for the axial centerline array) between $t=147$ and 195 minutes, and the period late in the test where the propagation of the 400 isotherm is nearly constant between $t=$ 195 and 320 minutes. A linear regression routine was used to calculate the velocity of the dehydration front for the various time periods mentioned above. During the initial heating period of the $\mathrm{UO}_{2}-\mathrm{ZrO}_{2}-\mathrm{Zr}$ charge material the velocity of the $400 \mathrm{~K}$ isotherm was calculated to be $5.6 \pm 0.4 \mathrm{~cm} / \mathrm{hr}$. At the onset of concrete ablation at $\mathrm{t}=147$ and through 195 minutes the rate was calculated to be $19.7 \pm 0.8 \mathrm{~cm} / \mathrm{hr}$. This is over three times greater than the initial rate. Late in the test, the wet/dry front moves through the concrete at nearly a constant rate calculated to be $7.4 \pm 0.4 \mathrm{~cm} / \mathrm{hr}$. This is approximately $2 \mathrm{~cm} / \mathrm{hr}$ greater than the initial rate of $5.6 \mathrm{~cm} / \mathrm{hr}$.

The limestone concrete used in the SURC-1 experiment melts over the temperature range of 1635 to $1873 \mathrm{~K}$. The temperature at which physical ablation of the melting concrete occurs is not precisely known. Here it is assumed ablation occurs at $1600 \mathrm{~K}$ for the purpose of measuring the propagation of the erosion front. The position of the $1600 \mathrm{~K}$ isotherm plotted as a function of time is shown in Figure 6.1.4. Based on the data shown in the figure, concrete ablation began between $t=135$ at 172 minutes depending on the thermocouple array being considered. The test was terminated at $t=287.5$ minutes when the power supply was turned off after eroding $27 \mathrm{~cm}$ of concrete.

After the melt penetrated the zirconia insulating board it eroded $9 \mathrm{~cm}$ of concrete in 4.8 minutes. Figure 6.1 .5 shows the temperature profiles for the first five thermocouples in the axial array embedded in the concrete at depths between $\mathrm{z}=$ 0.0 and $-7 \mathrm{~cm}$. The figure shows that the thermocouples in this array fail at nearly the same time. The data in Figure 6.1.4 shows an offset when comparing individual arrays during the early period of erosion. This is due to the insulating effect of the zirconia board separating the melt from the concrete. In an ideal case the melt would uniformly take the zirconia board into solution and spread over the concrete surface uniformly. This was not the case however. Even though the time periods for the onset of ablation vary between the arrays, their slopes are nearly the same, thereby verifying the consistency in the velocity of the ablation front. Late in the test the greatest difference in the location of the erosion front when comparing these concrete arrays was approximately $6 \mathrm{~cm}$. Taking the axial centerline array as being representative of the position of the erosion front, linear regression calculations were conducted to determine ablation rates during specific time periods.

There are four periods of interest identifying ablation rates: the initial period just after the melt penetrated the zirconia board between 147 and 152 minutes; the period between $t=152$ and 182 minutes when the rate decreases; a transition period between $\mathrm{t}=182$ and 231 minutes; and the late period of increased erosion between 231 and 266 minutes after increasing the input power from 150 to $200 \mathrm{~kW}$.

The rate calculated for the initial period of rapid ablation was $118.8 \pm 0.4 \mathrm{~cm} / \mathrm{hr}$. The rate decreases between 152 and 182 minutes as the concrete was taken into solution with the charge material. The rate for this time period was calculated to be $14.2 \pm 0.6 \mathrm{~cm} / \mathrm{hr}$. During the transition period between 182 and 231 minutes the rate was $2.5 \mathrm{~cm} / \mathrm{hr}$. After the power was increased the propagation of the ablation was calculated to be $12.5 \pm 0.6 \mathrm{~cm} / \mathrm{hr}$. This was similar to that calculated for the period following the initial period of ablation.

The depth to which the concrete was dehydrated prior to the onset of ablation can be determined by comparing the position of the $400 \mathrm{~K}$ (wet/dry interface) and $1600 \mathrm{~K}$ (ablation front) isotherm at 


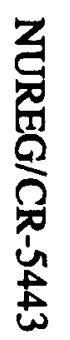

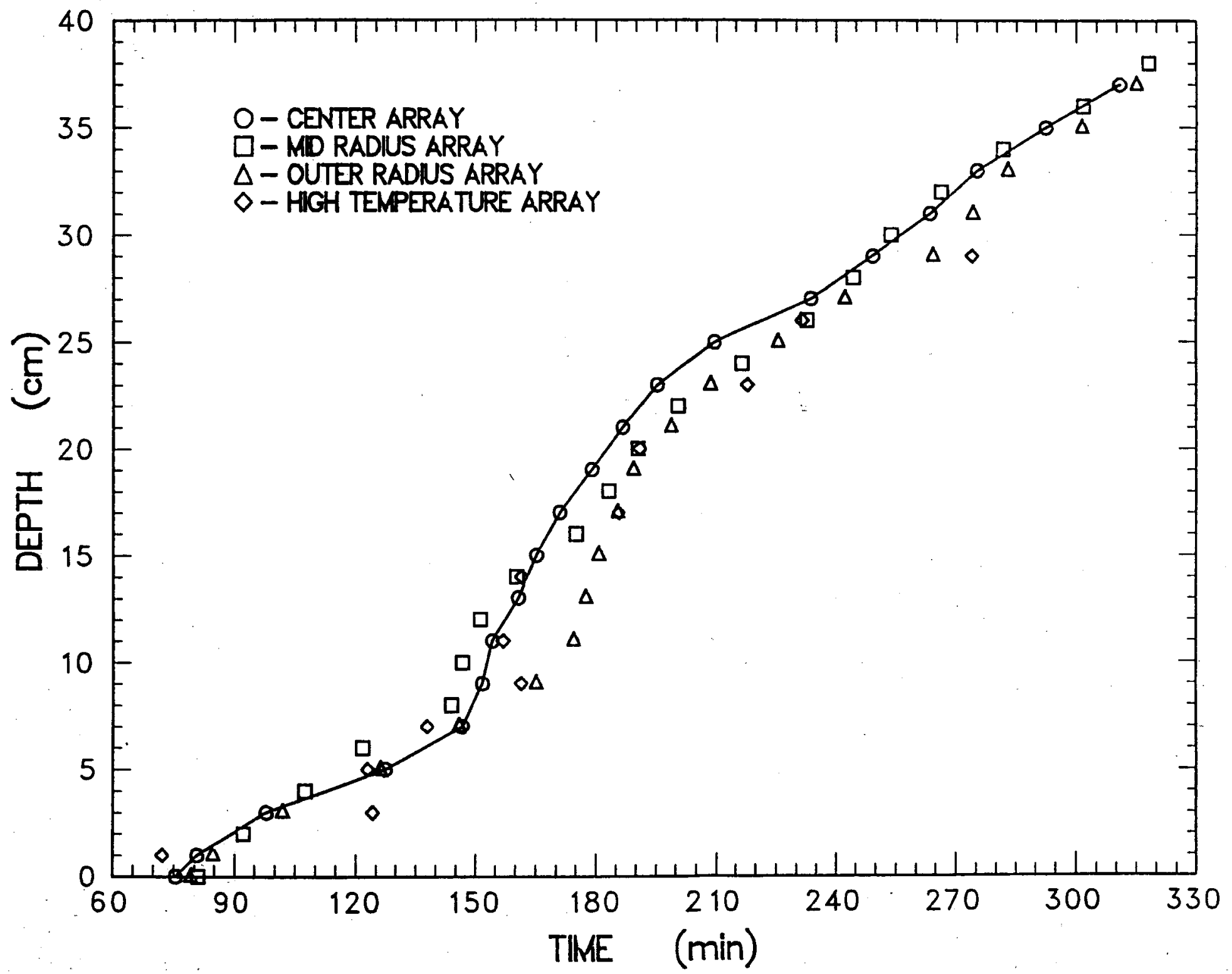

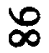

Figure 6.1.3 Location of the SURC-1 $400 \mathrm{~K}$ isotherm 


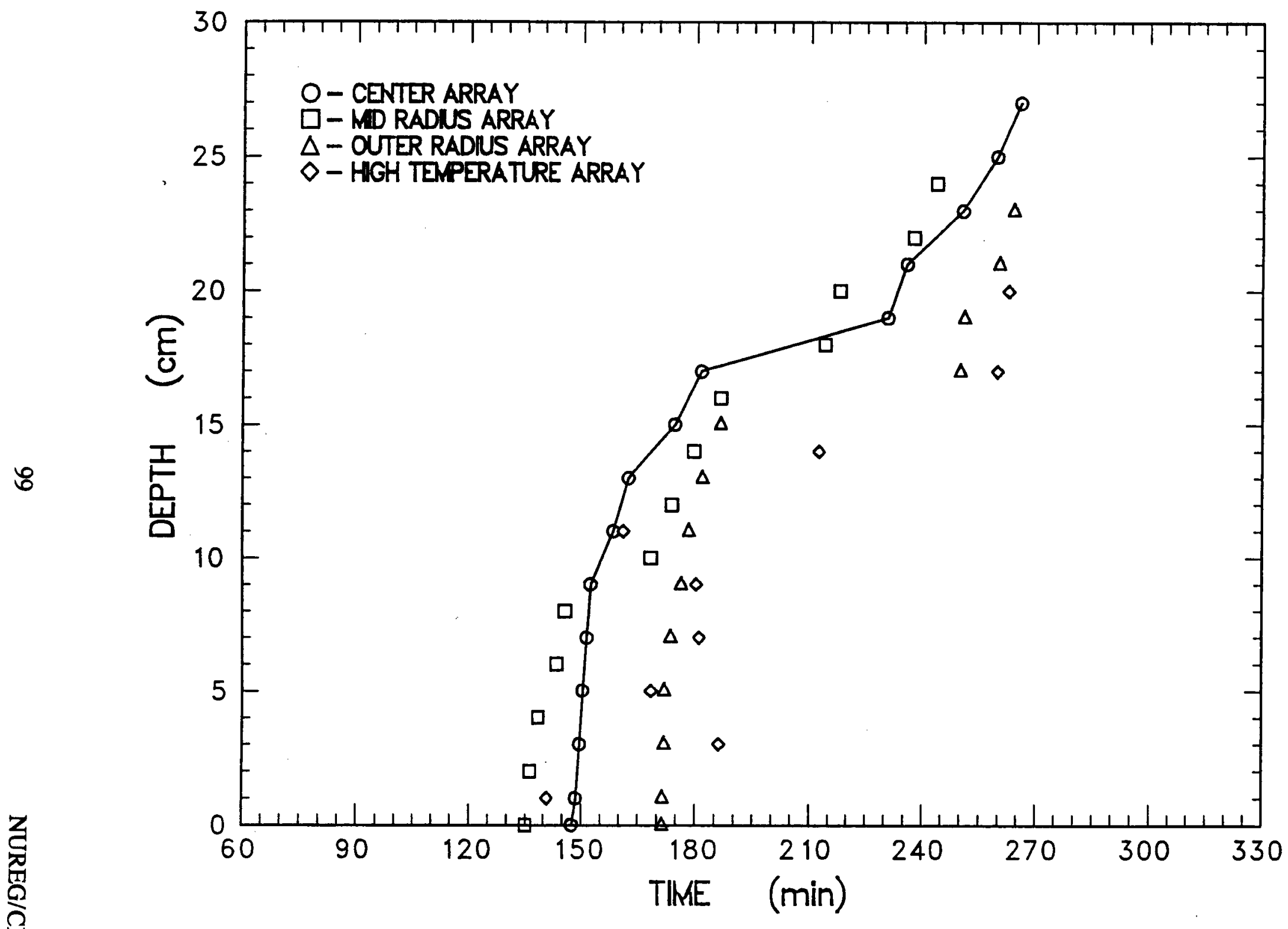

Figure 6.1.4 Location of the SURC-1 erosion front 


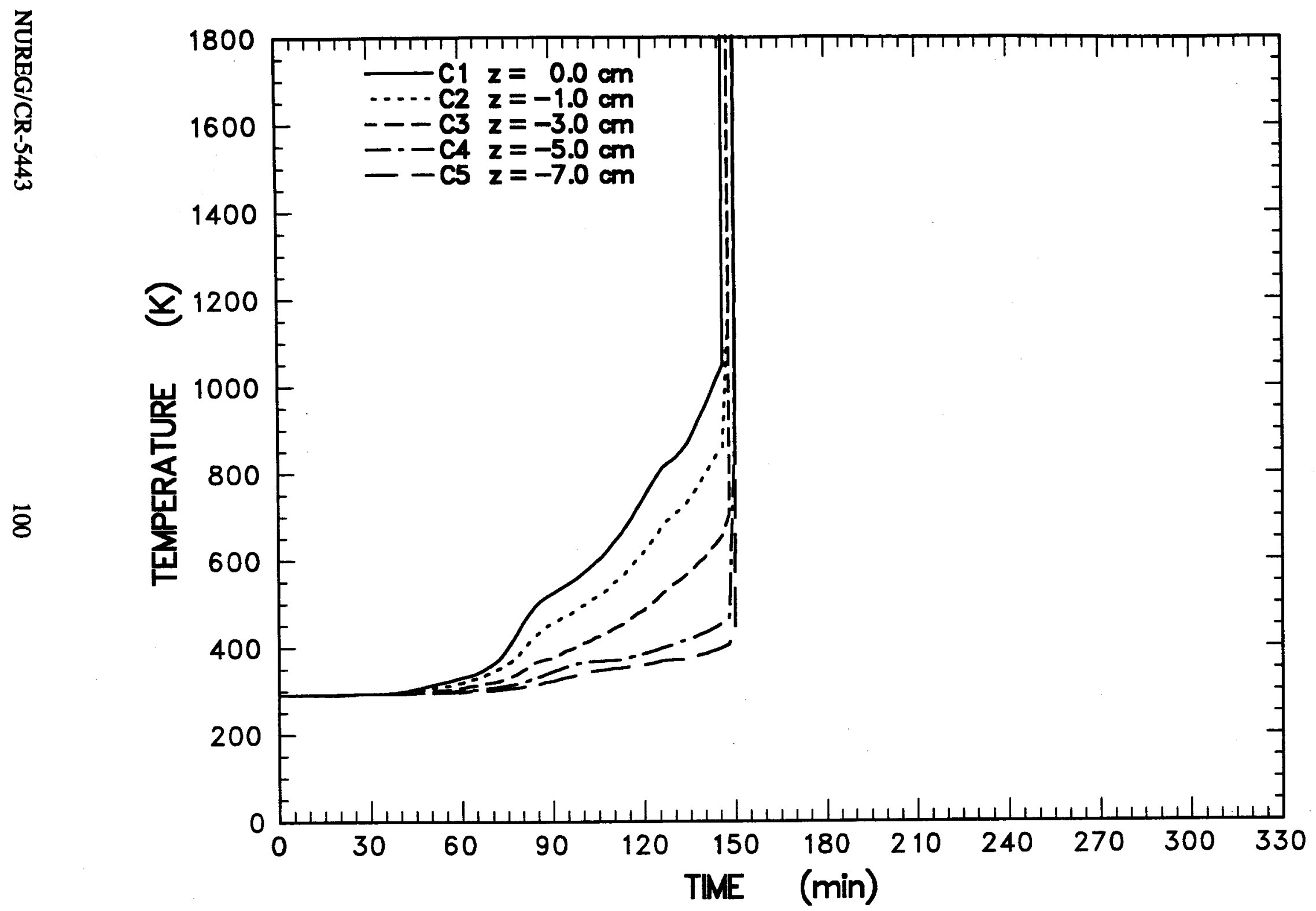

몷

Figure 6.1.5 Initial thermal response of the concrete during the onset of ablation for the center axis array 
a specific time. Figure 6.1.6 shows a plot comparing data representing the 400 and $1600 \mathrm{~K}$ isotherms. The depth of the dehydrated concrete at the onset of ablation is initially $7 \mathrm{~cm}$ at 147 minutes considering the center axial array. The $1600 \mathrm{~K}$ isotherm converges and overlaps the $400 \mathrm{~K}$ isotherm near 152 minutes. After this time the $400 \mathrm{~K}$ isotherm precedes the ablation front by approximately 1 to $8 \mathrm{~cm}$ for the remainder of the test.

\section{Meltpool Temperature}

Melt temperatures were measured during the experiment with six type $C$ and six type $S$ thermocouples installed in alumina tubes and cast into the concrete at various depths within the concrete slug. The debris temperature was also measured using three fiber optic pyrometers focused at the base of a thick walled closed end tungsten tube embedded into the melt charge. In addition to the pyrometers a $\mathrm{C}$ type thermocouple was installed in the base of each tungsten pyrotube to measure temperatures.

Figure 6.1.7 shows a typical thermal response of the type $\mathrm{C}$ and $\mathrm{S}$ thermocouples installed in alumina tubes. Other individual plots of melt temperature indicated by these thermocouples can be found in Appendix D. A1 and A3 are S type thermocouples and $\mathrm{A} 2$ and $\mathrm{A} 4$ are $\mathrm{C}$ type. These thermocouples behaved erratically throughout the test. The reason for this is unknown. In previous tests with metallic debris eroding concrete the thermocouples exposed to the melt front usually give a consistent temperature for 1 to 2 minutes prior to failing. The response of these thermocouples did not produce the sustained temperature plateau observed in other experiments prior to failure.

The data obtained from these thermocouples was the peak temperature indicated prior to failure. This data is presented in Figure 6.1.8 plotted as a function of time. The failure temperature of the type $S$ and $C$ thermocouples under ideal conditions in a non-oxidizing atmosphere is 2041 and $2589 \mathrm{~K}$, respectively. The $\mathrm{S}$ and $\mathrm{C}$ thermocouples were installed in the alumina tubes at alternating depths. It is obvious that the melt temperatures indicated by the type $\mathrm{C}$ thermocouples are not in fact the actual melt temperatures of the debris but the failure temperature of the thermocouple itself. The melt temperature is several hundred degrees greater than the temperatures measured by these thermocouples. This will be shown to be true in the presentation of the pyrometer data that follows. Note in Figure 6.1.8 the type $\mathrm{S}$ thermocouples fail between 1826 and $1944 \mathrm{~K}$. The $\mathrm{C}$ types read nearly $400 \mathrm{~K}$ higher and fail between 2181 and $2290 \mathrm{~K}$.

In addition to the thermocouples described above, three fiber optic pyrometers focused at the bottom of a thick wall, closed end, tungsten tube embedded in the center of the oxidic debris were also used. To verify the temperatures indicated by the pyrometers a type $\mathrm{C}$ thermocouple was installed at the base of each of the three tubes. Figure 6.1.9 shows a plot of the temperature indicated by the type $\mathrm{C}$ thermocouple plotted as a function of time. The three agree extremely well throughout the test. The thermocouple located in the pyrotube at $z=+20 \mathrm{~cm}$ failed at $t=240$ minutes. There is never greater than $250 \mathrm{~K}$ difference between the three thermocouples and often their curves are coincident with each other. The peak temperature indicated by these thermocouples is $2625 \mathrm{~K}$ near 150 minutes. After this period the temperature declines as the concrete goes into solution with the melt decreasing the temperature.

Figure 6.1.10 shows the temperature histories measured by the three fiber optic pyrometers overlayed with the type $C$ thermocouples for comparison. The data agree to better than $150 \mathrm{~K}$ of the temperatures indicated by the two devices in each case. At $t=172$ minutes the pressure in the containment vessel reached $9.2 \mathrm{psig}$. To relieve this pressure a ball valve was remotely actuated to vent the pressure safely. The moment the ball valve was actuated the pyrometers 


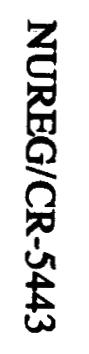

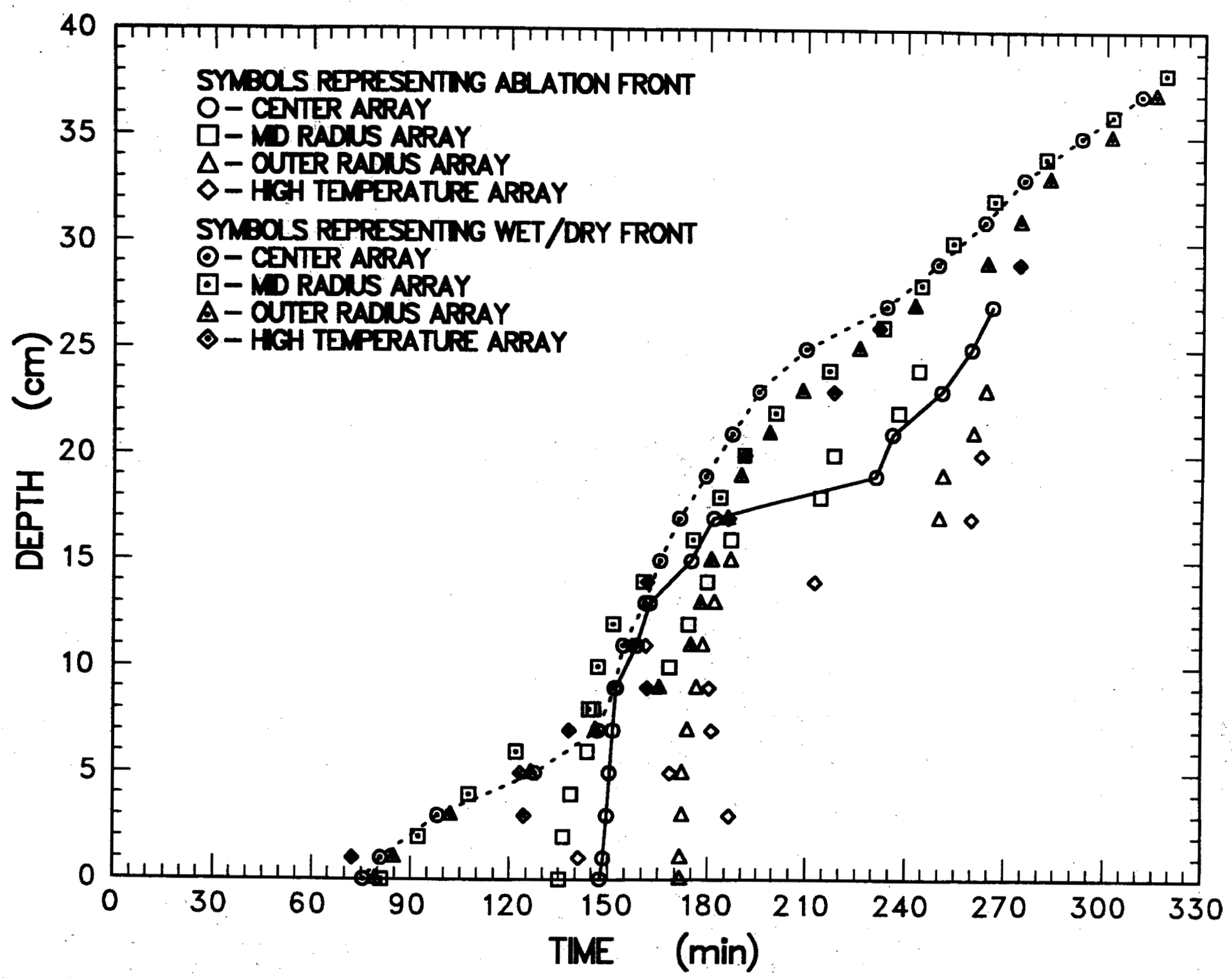

Figure 6.1.6 Comparison of the $400 \mathrm{~K}$ and $1600 \mathrm{~K}$ isotherms in SURC-1 


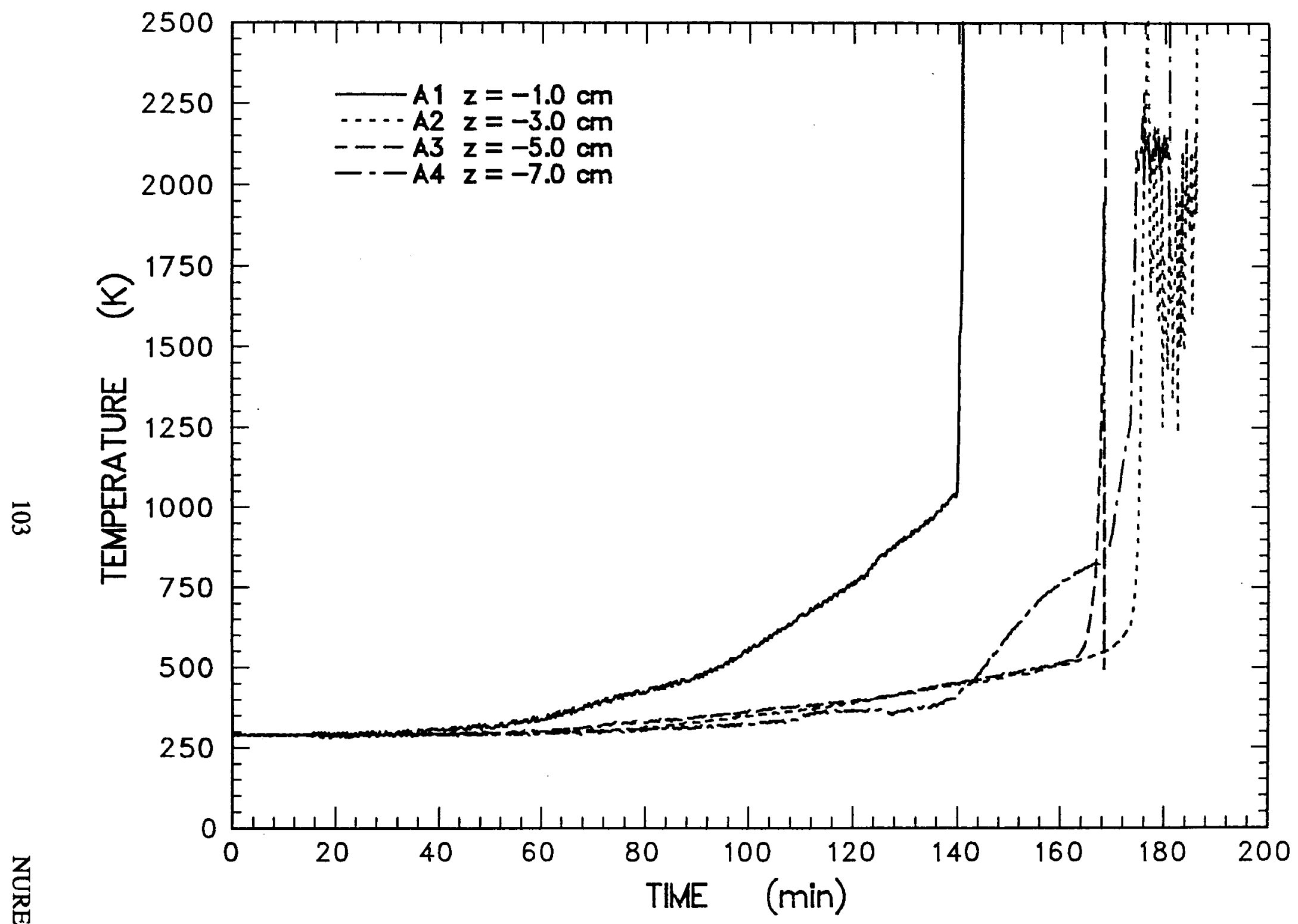

Figure 6.1.7 Thermal response indicated by type $C$ and $S$ thermocouples installed in alumina tubes and cast into the concrete 


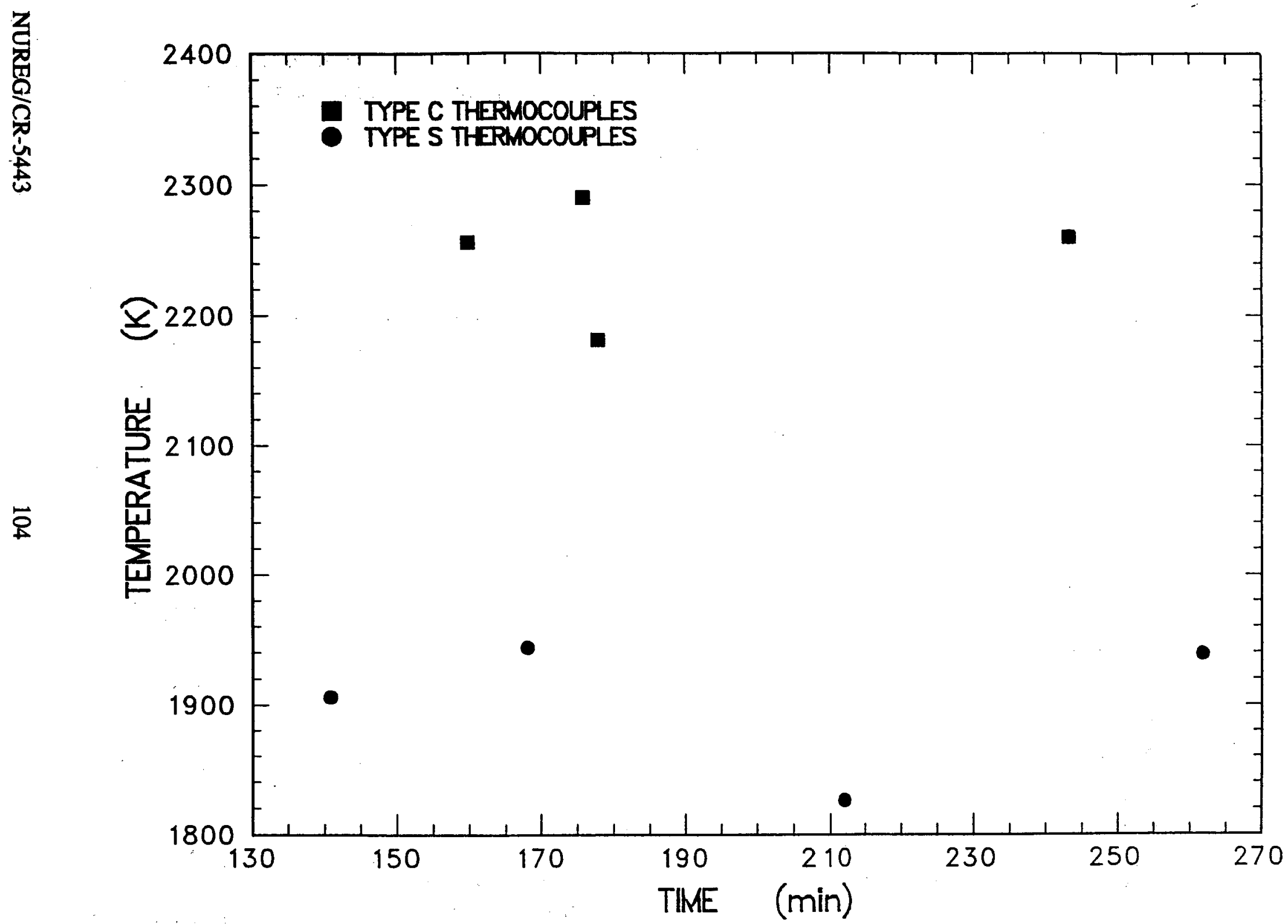

Figure 6.1.8 Peak meltpool temperature measured as a function of time for the alumina tube array thermocouples 


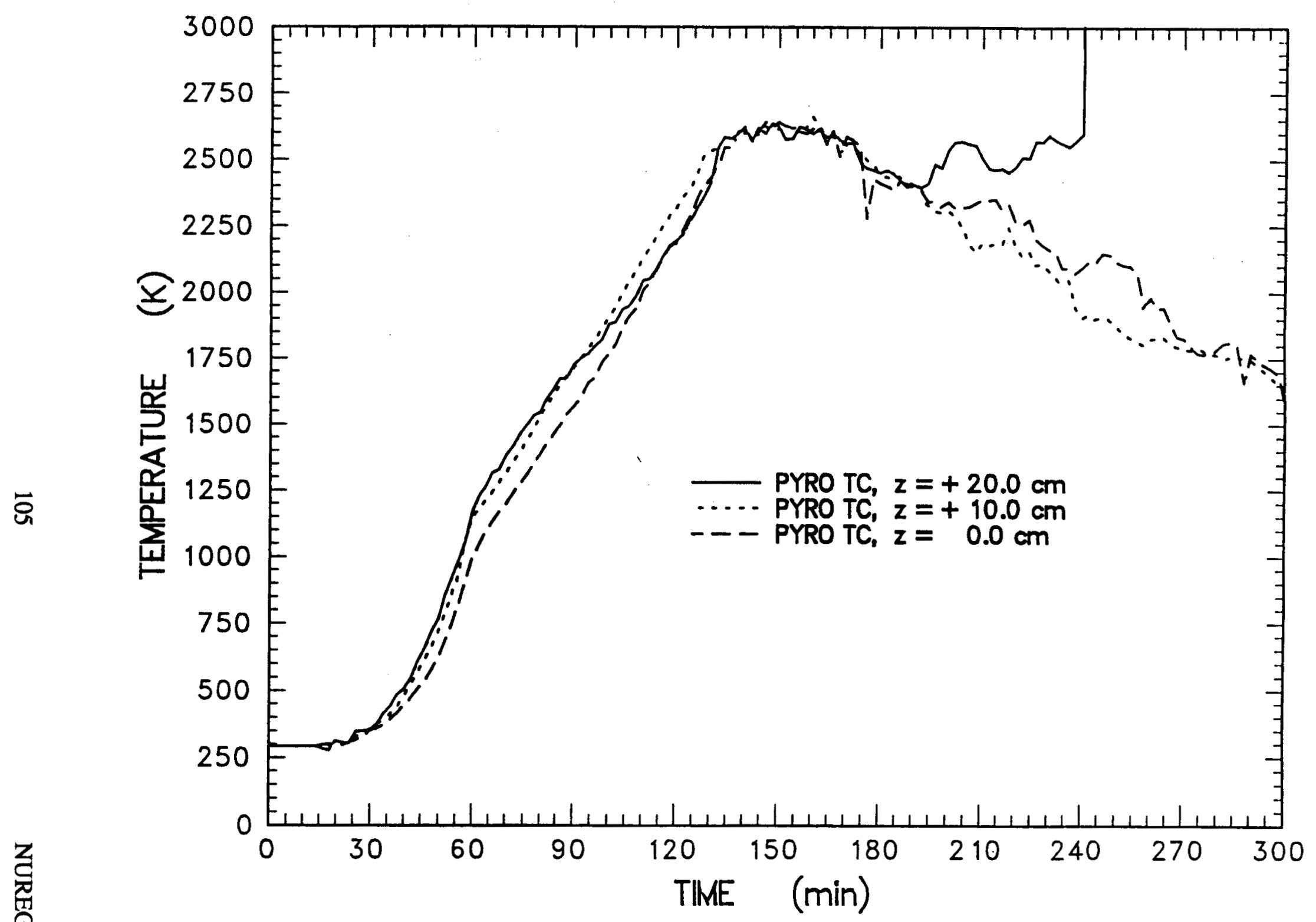

Figure 6.1.9 Thermal response of type $\mathbf{C}$ thermocouples installed in the tungsten pyrotubes 


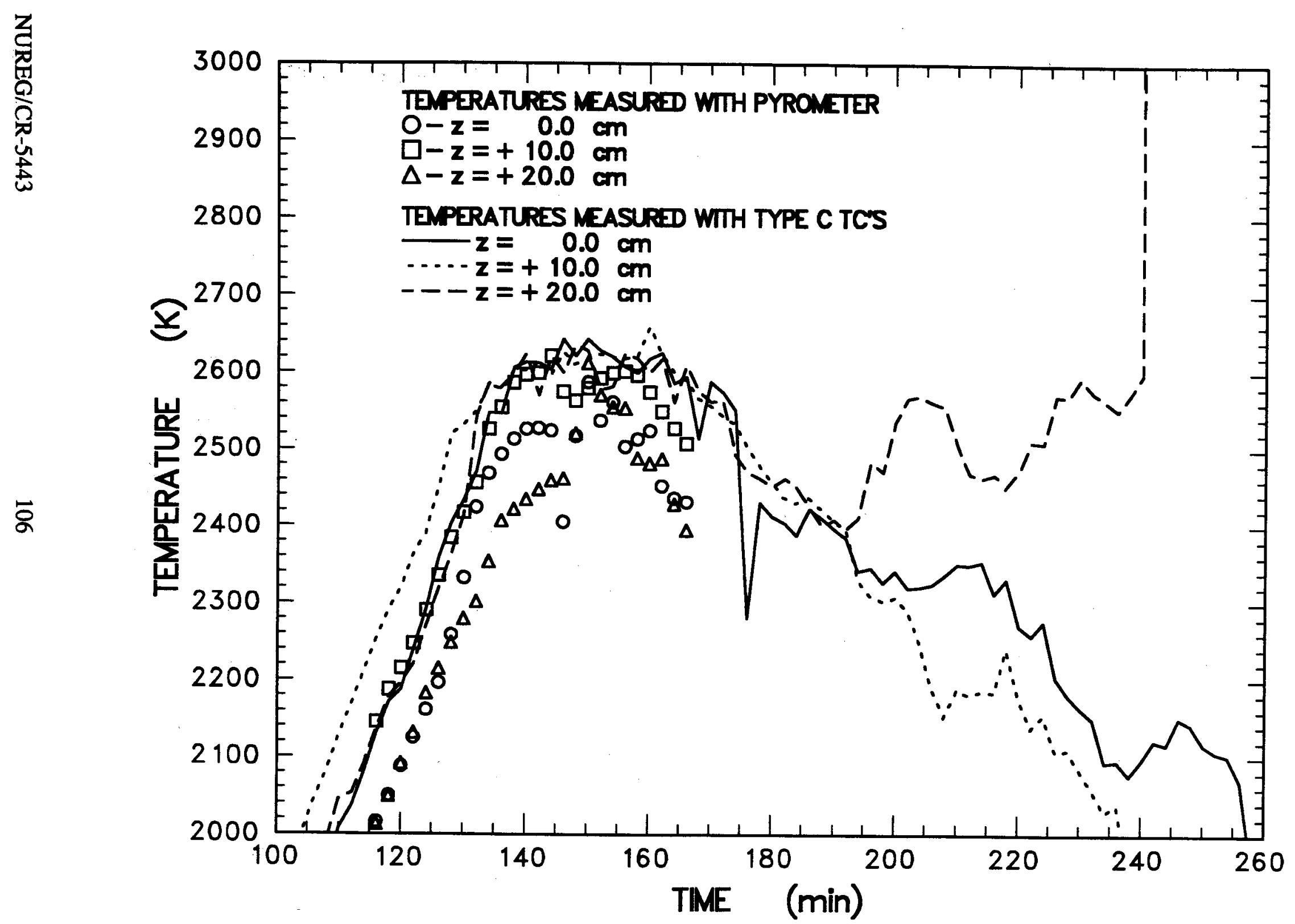

Figure 6.1.10 Comparison of temperatures indicated by the fiber optic pyrometers and the type $C$ thermocouples installed at the base of each pyrotube 
stopped registering but the thermocouples installed in the base of the pyrotubes continued reading. Posttest examination showed that the tungsten thermowells became disconnected from the pyrometer head assemblies. This caused a loss in the "line of sight" and thus loss of signal. Redundancy in meltpool measuring techniques provided for a reliable pool temperature to be measured throughout the experiment.

\section{MgO Sidewalls}

The heat transfer to the $\mathrm{MgO}$ sidewalls during the interaction has a global effect on the energy balance and therefore, the heat transfer to the concrete. As discussed in Section 3.2 thermocouple arrays were installed at various locations within the $\mathrm{MgO}$ annulus to determine the thermal response of the sidewalls. A typical temperature history is shown in Figure 6.1.11 for the sidewall array located adjacent to the melt at an elevation of $\mathrm{z}=+10 \mathrm{~cm}$.

The temperatures indicated by thermocouples located at depths of $0.5,1.5,2.5$, and $9.0 \mathrm{~cm}$ rise gradually peaking near the termination of the test. The temperature gradient in the $\mathrm{MgO}$ wall at this location at the end of the test was $400 \mathrm{~K}$. The temperature histories measured by thermocouples in other arrays, cast into the $\mathrm{MgO}$ sidewall, are presented in Appendix C.

The calculation of heat flux to the $\mathrm{MgO}$ walls is a classic example of an "inverse" heat conduction problem (IHCP) where the boundary condition (e.g., heat flux) is determined from known interior temperatures. Of the available methods for solving the IHCP, one that appears to be successful for a wide variety of applications is a nonlinear estimation technique. In this method, the value of the calculated heat flux minimizes the square of the difference between the calculated and the experimental temperatures. A computer code, IHCP, has been written based on Beck's methods [Beck, 1985]. The code was tested using a variety of exact solution problems and was found to perform excellently. In general, it was found that the greater the number of thermocouples utilized in the analysis, the greater the accuracy of the solution. However, Bradley found that beyond three thermocouples, the improvement in accuracy was not sufficient to justify additional instrumentation. The experimental data utilized in the IHCP consisted of at least two thermocouples at depths from the surface of 0.5 to $2.5 \mathrm{~cm}$ into the $\mathrm{MgO}$ sidewall. A typical IHCP solution was calculated for each array of the thermocouples that was embedded in the $\mathrm{MgO}$ sidewall at various locations above and below $0 \mathrm{~cm}$. Here the $0 \mathrm{~cm}$ location is taken as the original location of the concrete surface.

The thermal properties used to calculate the sidewall heat fluxes are presented in Section 2.1.

Shown in Figures 6.1.12, 6.1.13, and 6.1.14 are the heat flux histories for the sidewall arrays initially below the melt, adjacent to the melt, and above the melt, respectively. Heat flux histories for other sidewall arrays are shown in Appendix E. Figure 6.1.12 shows the heat flux at $\mathrm{z}=-20.0 \mathrm{~cm}$. The heat flux shown slowly increases from a value of $1 \times 10^{3} \mathrm{~W} / \mathrm{m}^{2}$ at 100 minutes to $7 \times 10^{4} \mathrm{~W} / \mathrm{m}^{2}$ at $\mathrm{t}=255$ minutes when the melt becomes adjacent to the thermocouple array.

The thermocouples in the array located at $z=+10.0 \mathrm{~cm}$ (Figure 6.1.13) were directly adjacent to the stainless steel during initial heating, melting and the early period of erosion. The heat flux increases as the melt temperature increases and rises to a maximum of $7 \times 10^{4}$ $\mathrm{W} / \mathrm{m}^{2}$ at $\mathrm{t}=140$ minutes, 7 minutes prior to concrete erosion for the center axis array. The heat flux maintains a value between $7 \times 10^{4}$ and $9 \times 10^{4} \mathrm{~W} / \mathrm{m}^{2}$ for the remainder of the test.

Thermocouples in the sidewall array at $\mathbf{z}=$ $+50.0 \mathrm{~cm}$ (Figure 6.1.11) were above the melt after the debris became molten and became redistributed in the crucible. The heat flux reaches a peak value at this elevation of $1.01 \mathrm{x}$ $10^{5} \mathrm{~W} / \mathrm{m}^{2}$ at $\mathrm{t}=250$ minutes. The heat flux 


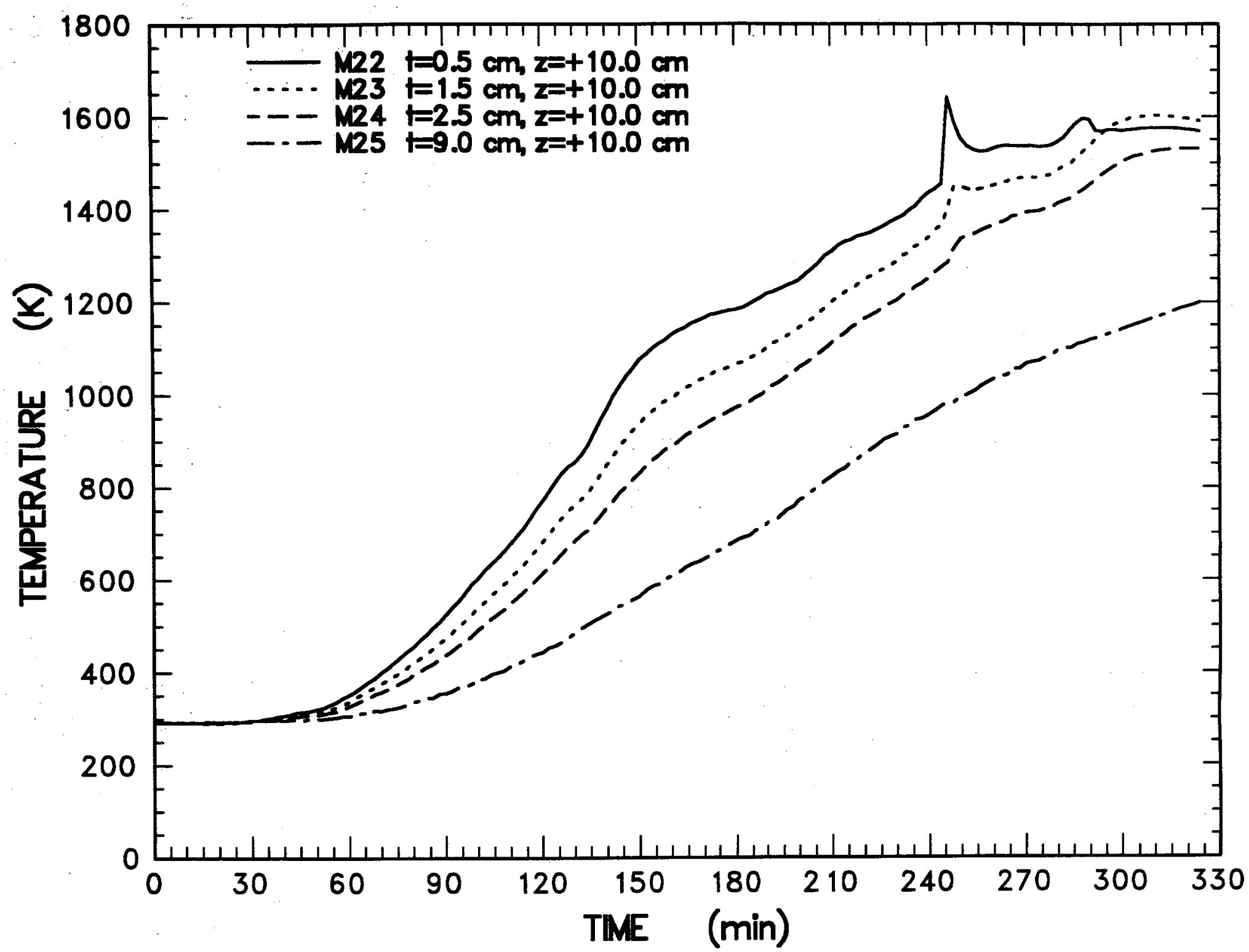




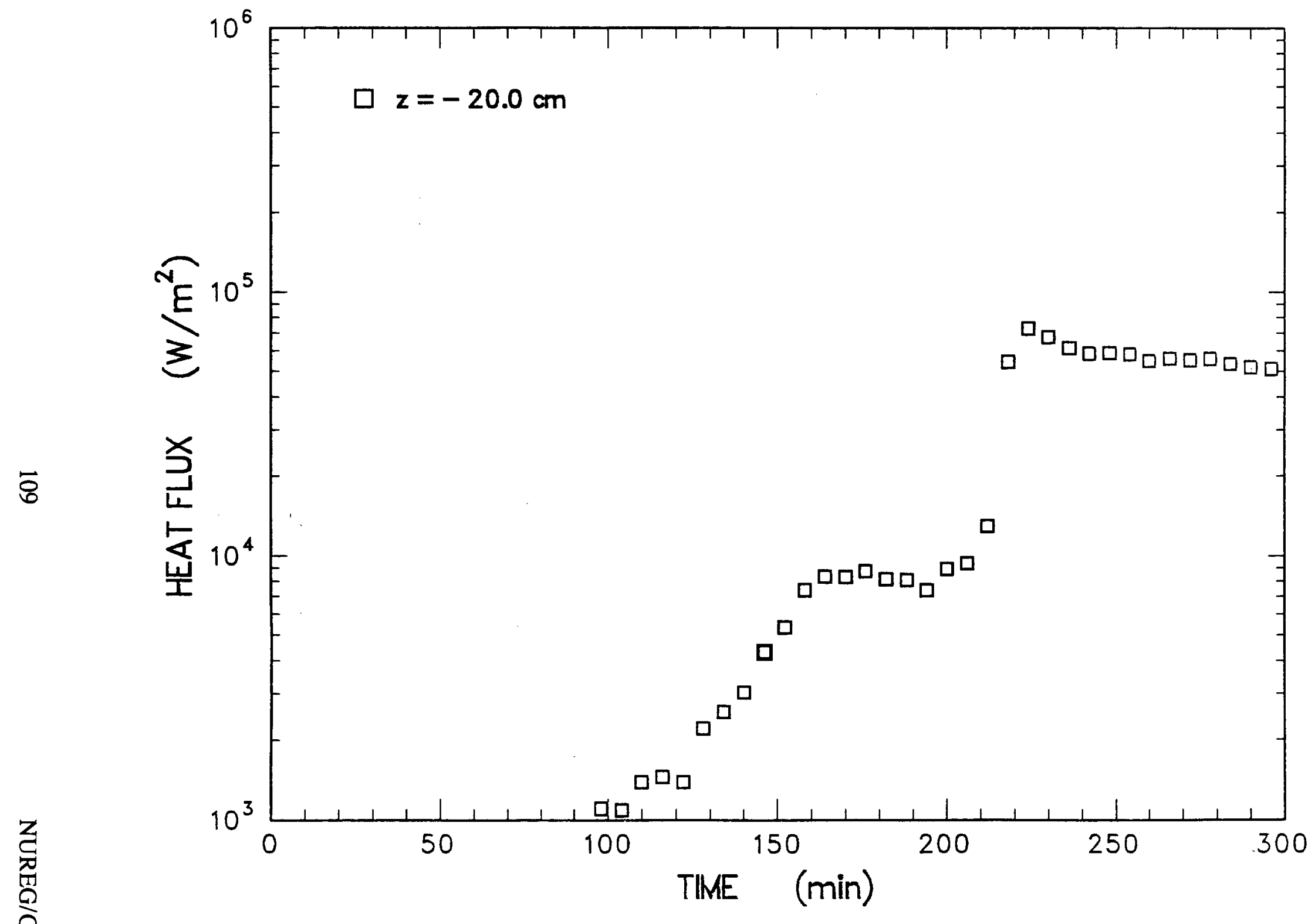

Figure 6.1.12 Sidewall heat flux profile initially below the melt, SURC-1 


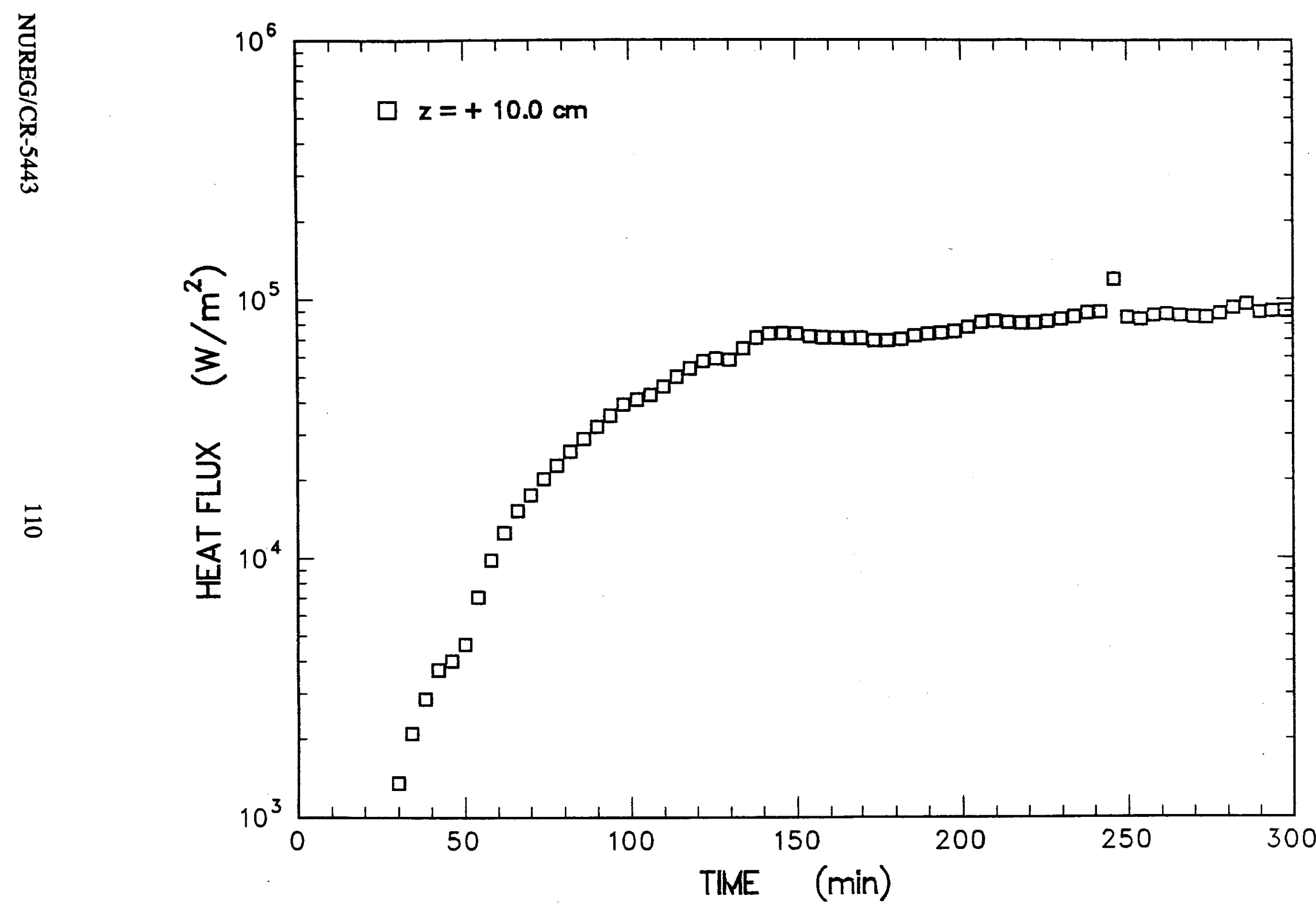

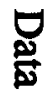

Figure 6.1.13 Sidewall heat flux profile initially adjacent to melt, SURC-1 


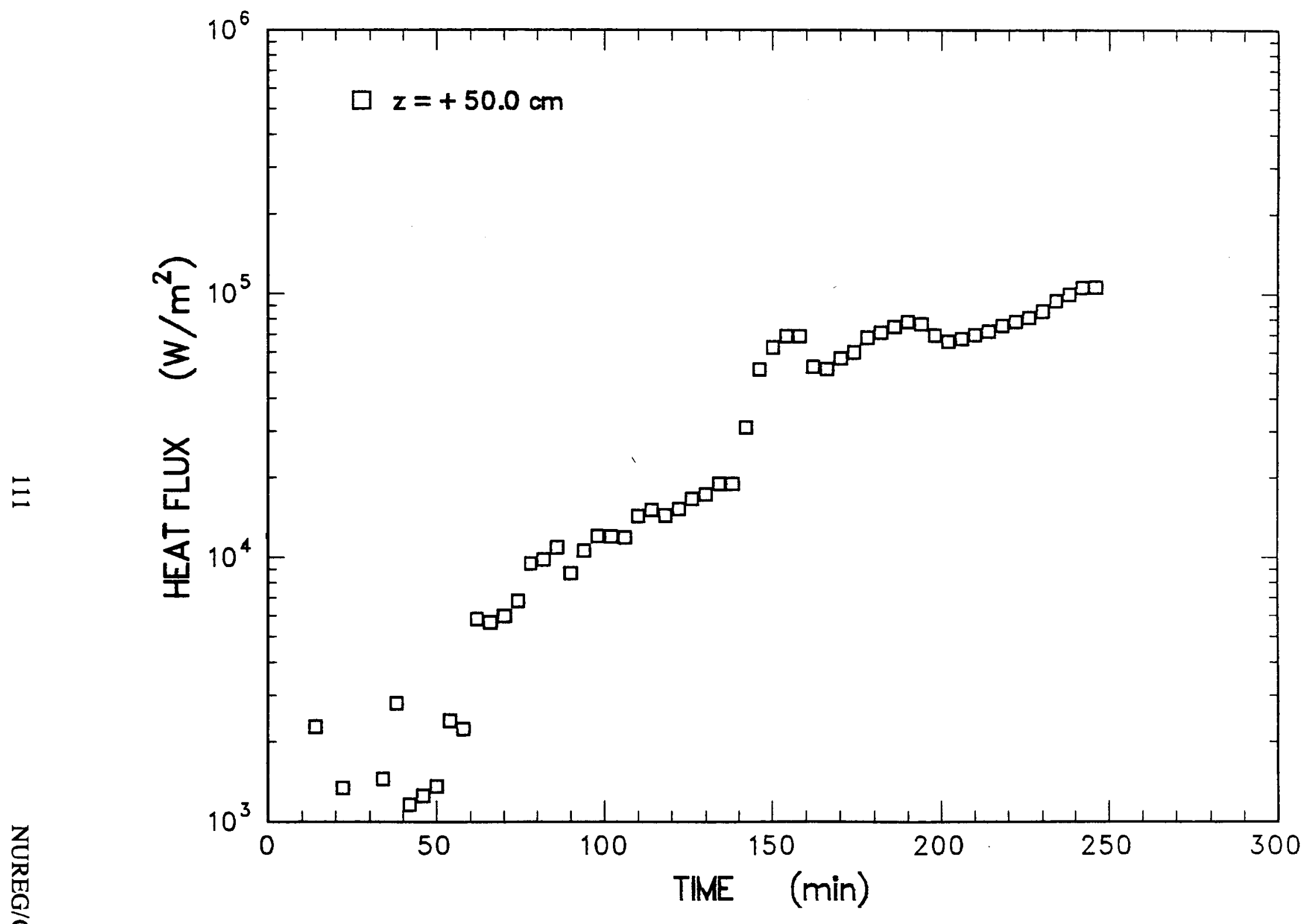

Figure 6.1.14 Sidewall heat flux profile initially above the melt, SURC-1 
increases rapidly from $2 \times 10^{4} \mathrm{~W} / \mathrm{m}^{2}$ to $7 \times$ $10^{4} \mathrm{~W} / \mathrm{m}^{2}$ between $\mathrm{t}=140$ and 150 minutes. This is the period indicated by the onset of concrete ablation.

In summary, the heat flux when the melt was adjacent to the $\mathrm{MgO}$ sidewall arrays was calculated to average between $5 \times 10^{4}$ and $2.1 \times 10^{5} \mathrm{~W} / \mathrm{m}^{2}$. The array located above the melt inferred heat fluxes in the range of $5.0 \times 10^{4}$ to $1.01 \times 10^{5} \mathrm{~W} / \mathrm{m}^{2}$. Heat fluxes indicated by the array embedded in the sidewalls below the concrete surface increased to a value near $2.02 \mathrm{x}$ $10^{5} \mathrm{~W} / \mathrm{m}^{2}$ when the melt was directly adjacent to the array. This value decreased to a value $5 \mathrm{x}$ $10^{4} \mathrm{~W} / \mathrm{m}^{2}$ as the melt continued to penetrate the concrete and pass the array.

\section{Crucible Cover}

Two duplicate arrays of three thermocouples each were cast into the $\mathrm{MgO}$ cover to infer upward heat flux. The temperatures indicated by type $\mathrm{K}$ thermocouples cast in one of the arrays is shown in Figure 6.1.15. The temperature response of the second array is nearly identical as seen in Appendix E. The specific location of these thermocouples with respect to the crucible geometry can be found in Table 3.4. Figure 6.1.15 shows the temperature profile of the three type $K$ thermocouples cast at depths of $0.5,1.5$, and $2.5 \mathrm{~cm}$ in the crucible cover. At the onset of erosion the temperature indicated by the thermocouples increases rapidly at $\mathrm{t}=135$ minutes. The temperature declines after the initial peak and steadily increases until the power supply is shut off at $\mathbf{2 8 7 . 5}$ minutes.

Figure 6.1.16 shows the heat flux calculated from the temperatures measured by the thermocouples. The figure indicates that the heat flux steadily increases to a value of $6 \times 10^{4} \mathrm{~W} / \mathrm{m}^{2}$ at $t=157$ minutes. The heat flux holds at this value for 53 minutes. The heat flux then increases from $6 \mathrm{x}$ $10^{4}$ to $1 \times 10^{5} \mathrm{~W} / \mathrm{m}^{2}$ because of power increases from 150 to $200 \mathrm{~kW}$ at $\mathrm{t}=222$ minutes.

\subsection{Gas Composition Data Presentation}

Gas sampling for the SURC-1 test was done using three techniques: an Inficon Model IQ200 mass spectrometer, an Infrared Industries Model $700 \mathrm{CO} / \mathrm{CO}_{2}$ detector, and integral grab samples. The first two techniques yield real-time data which are viewed on-line and stored on computer disks. The grab samples are stored and analyzed posttest using both gas chromatography and mass spectrometry. Additional information on these systems is detailed in Section 4.2.

\section{Test Procedures}

Operational procedures for the gas analysis equipment and support components were accomplished in the following manner:

The output from the K-type thermocouples installed in the flow stream $3 \mathrm{~m}$ downstream from the crucible was continuously monitored and recorded by the data acquisition system as was the output from the other K-type thermocouple mounted at the actual sampling location. Although the temperature in the flow line ranged from 300 to $600 \mathrm{~K}$, the conditions at the actual sampling point were very constant at $300 \pm 3 \mathrm{~K}$ throughout the test.

Gas flow through the sample line was established 30 minutes before the test by energizing the diaphragm pump. The flow was manually regulated to provide a $3 \mathrm{lpm}$ flow rate. Monitoring of the sample line flow rate was done continuously. No substantial fluctuations were indicated.

The grab sample bottles were evacuated before the test and then individually subjected to vacuum just prior to sample collection. All six samples were taken manually. Times for the samples were recorded on computer disk as pressure spikes indicated by an absolute pressure transducer connected to the sampling manifold. To minimize dead volume effect in the gas 


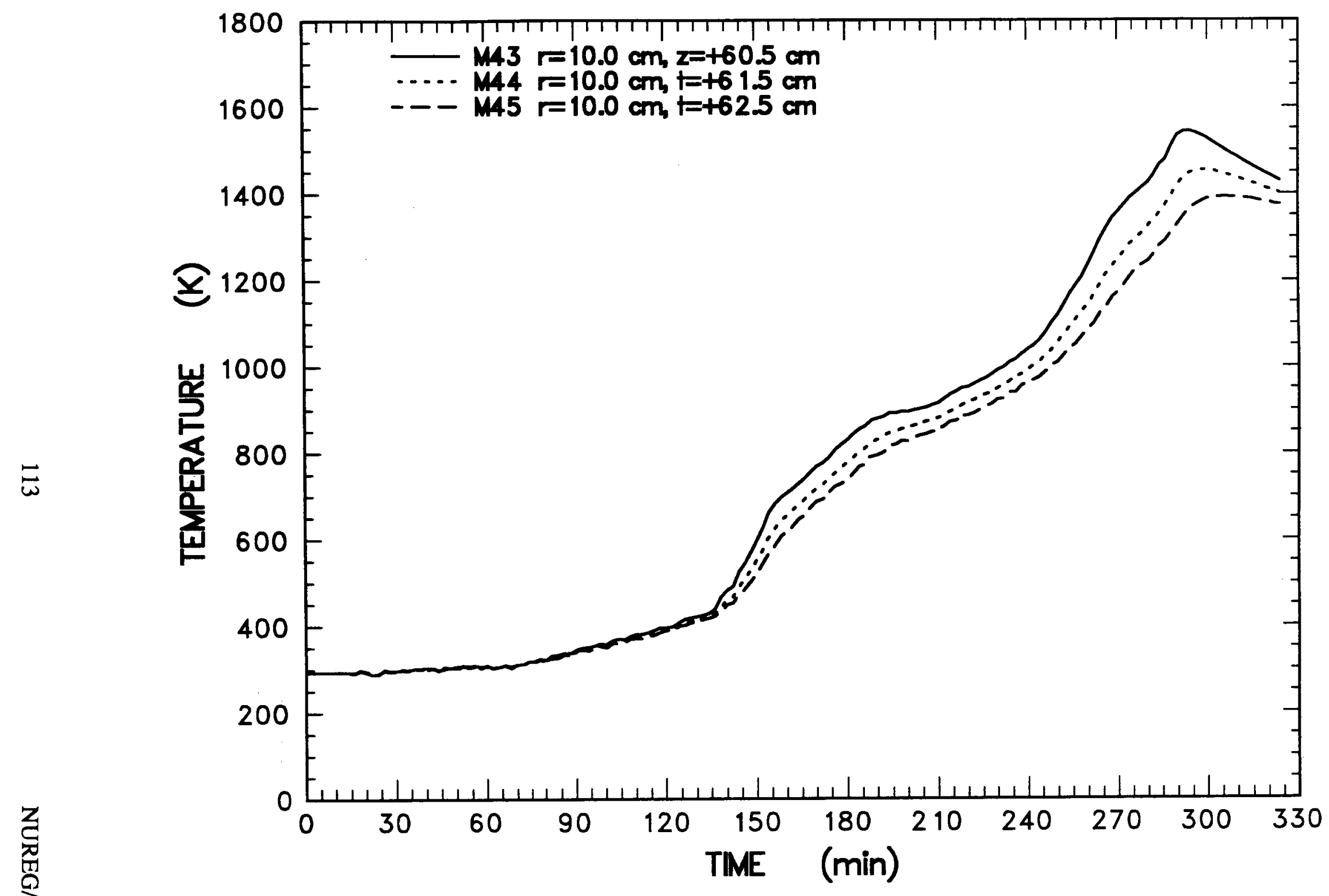

Figure 6.1.15 Typical thermal response from thermocouples installed in the MgO cover 


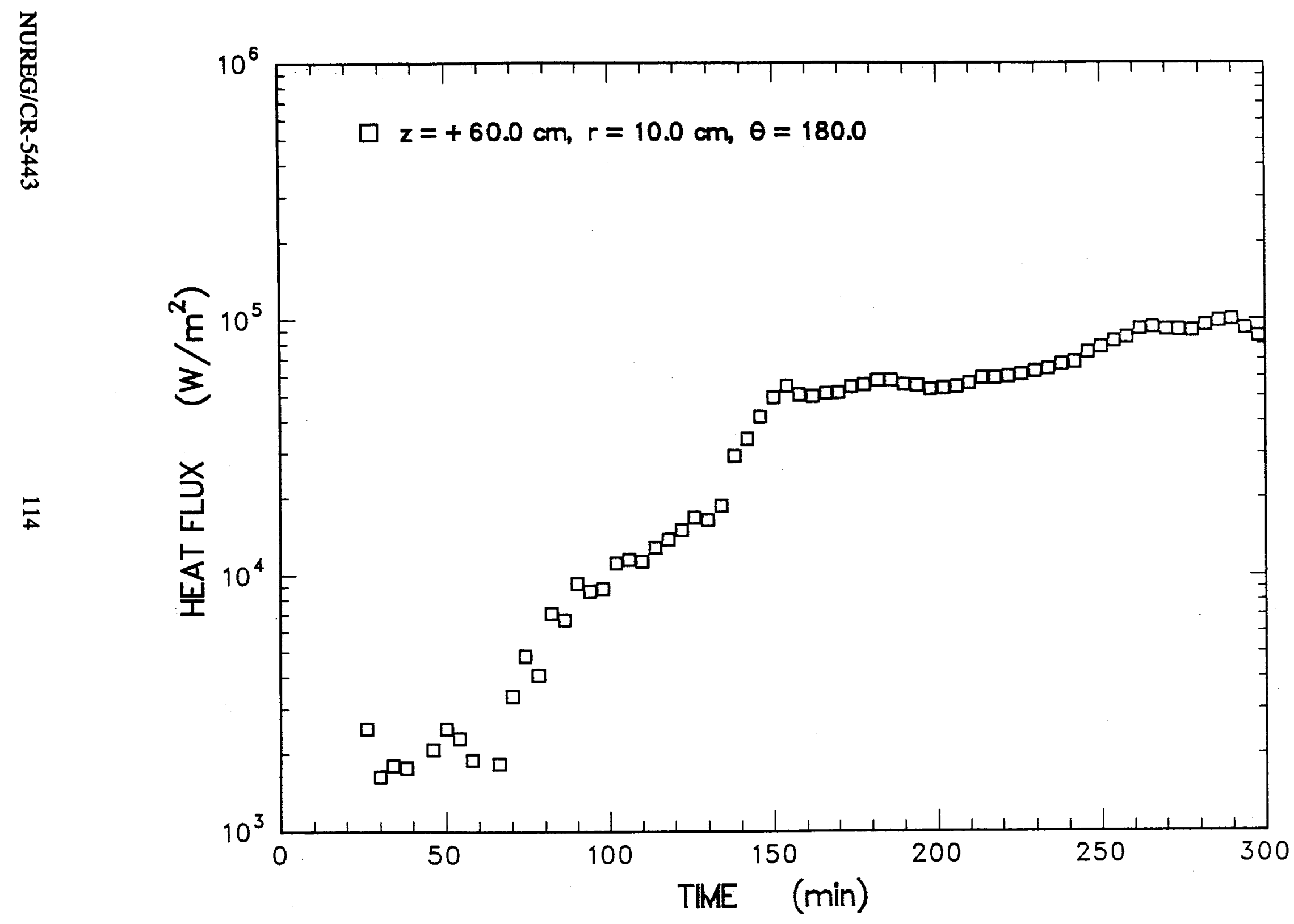

Figure 6.1.16 Upward heat flux calculated from thermocouples data located in the MgO cover 
sample line, three samples were taken per sampling event. Two $75 \mathrm{~cm}^{3}$ samples were followed by a $500 \mathrm{~cm}^{3}$ sample. Each sample bottle filled within 1 second following the opening of the control valve. After the test three additional sample bottles were filled with calibration gas.

The $\mathrm{CO} / \mathrm{CO}_{2}$ monitor was warmed up at least 30 minutes before the test. A pretest calibration was performed prior to start-up of the data acquisition system and no irregularities were noted. The $\mathrm{CO} / \mathrm{CO}_{2}$ data were automatically recorded by the data acquisition system throughout the test. Following the test, another calibration run was performed on the monitor to verify measurement accuracy and operational stability.

The mass spectrometer system was in operation under a low vacuum of 100 millitorr for one week prior to establishing a vacuum of $10^{-6}$ torr for three days before the test date. The analysis display was continuously monitored and several hundred discrete samples were recorded during the test. On-line data were recorded every 10 to 20 seconds throughout the test.

\section{$\underline{\text { Results }}$}

Four periods of time are of interest for the SURC-1 gas composition data: the onset of gas production between 50 and 135 minutes, the rapid erosion between 135 and 185 minutes, the slow erosion period after $\mathrm{Zr}$ depletion between 185 and 230 minutes, and the increased erosion following the power increase from 150 to $200 \mathrm{~kW}$ at 222 minutes through the end of the test at 287 minutes. Notable events which affected the gas composition data were pressurization of the containment vessel and formation of an ice plug in the water trap. Shortly after the onset of concrete ablation at 135 minutes the containment vessel pressurized to a value of 9.2 psig between 135 and 172 minutes, as shown in Figure 6.2.1. At 172 minutes a ball valve located upstream of the gravel filter was actuated relieving the pressure in the containment vessel. The valve was closed at 177 minutes. At approximately 210 minutes the vessel began to pressurize again peaking at approximately 8.9 psig when the ball valve was opened at 248 minutes to relieve the pressure. The valve was closed at 258 minutes. This last pressure excursion caused a leak in a stainless steel rough particulate filter. The gas data after this time is swamped by the air molecules. Posttest disassembly of the gravel filter showed that a significant layer of aerosol had built up across the surface of the gravel blocking the flow of gases. This will be discussed further in Section 6.4, Aerosol Data. Pressurization of the containment vessel also caused the Infrared $\mathrm{CO} / \mathrm{CO}_{2}$ Monitor to deviate from the original calibration setting.

At 122.7 minutes the flow to the gas sampling instrumentation dropped off due to the formation of an ice plug in the water trap. This was corrected and gas flow was restored at 144.7 minutes.

Although water vapor is present in the reaction gas, it cannot be measured in large amounts by the gas analysis system without ruining the equipment. Consequently, water vapor traps are installed in the gas analysis flow lines. A total of $4.8 \mathrm{ml}$ of water was recovered from the liquid nitrogen cooled cold trap. This would have added 6 liters of $\mathrm{H}_{2} \mathrm{O}$ vapor to the 200 liters of collected $\mathrm{H}_{2}, \mathrm{CO}$, and $\mathrm{CO}_{2}$ yielding an estimated water content of 3 to 5 percent in addition to the reported gas compositions for $\mathrm{H}_{2}, \mathrm{CO}$, and $\mathrm{CO}_{2}$.

The results from the mass spectrometer are shown in Table 6.2.1 and in Appendix G. This table lists the raw data as volume (mole) percent along with the time for the sampled gas species. The mass spectrometer data is characterized by large amounts of argon purge gas between 0 to 60 minutes and large amounts of air due to leakage from 190 to 280 minutes. There is an increase in $\mathrm{H}_{2}, \mathrm{H}_{2} \mathrm{O}, \mathrm{CO}$, and $\mathrm{CO}_{2}$ reaction gas production at 135 minutes just as the rapid concrete erosion begins. This increased 


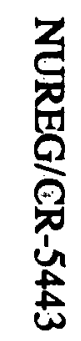

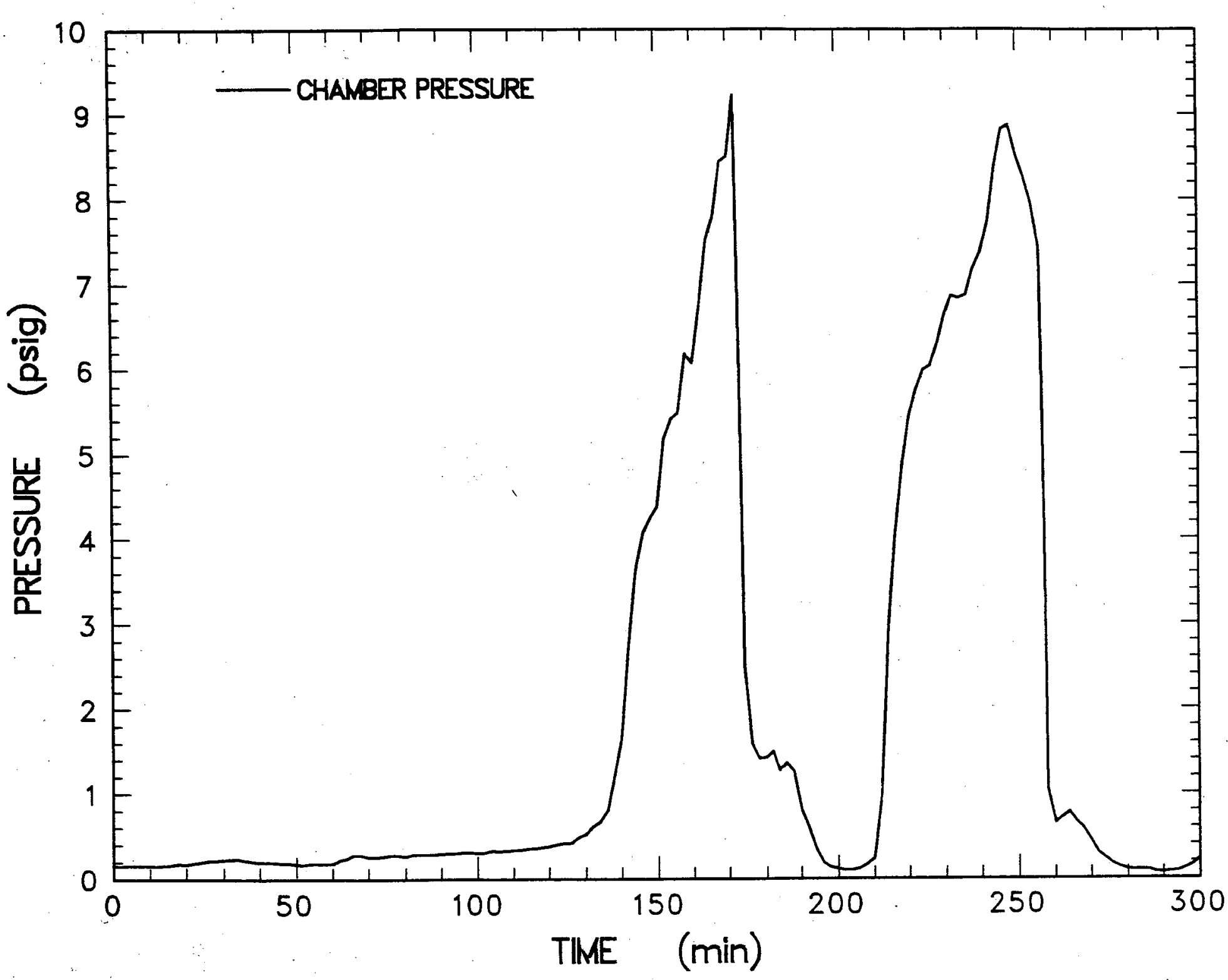

井

Figure 6.2.1 Plot of the pressure inside the containment as a function of time 
production lasted until 190 minutes after which the gas analysis system became plugged from extensive aerosol production which created air leakage into the system. The ratio of $\mathrm{H}_{2}$ to $\mathrm{H}_{2} \mathrm{O}$ production is seen to be approximately $1: 1$ during the early portion of the test between 0 to 50 minutes. This ratio increases to $2: 1$ as ablation begins at 80 minutes and peaks at 8:1 at 100 minutes, followed by a decrease back to $2: 1$ at 140 minutes and 1:1 thereafter. Similar results are seen for the $\mathrm{CO} / \mathrm{CO}_{2}$ ratios during the test. Initially the $\mathrm{CO} / \mathrm{CO}_{2}$ ratio is $1: 1$ between 0 to 50 minutes followed by an increase to 1.7 to 1 as dehydration begins at 80 minutes. The peak ratio of 30 to 1 is during rapid erosion at 160 minutes followed by a decrease to a $\mathrm{CO} / \mathrm{CO}_{2}$ ratio of 15 to 1 at 190 minutes as the $\mathrm{Zr}$ metal in the meltpool is depleted. Normalized results are shown in Table 6.2.2. The effluent gas is initially high in hydrogen as the concrete dehydrates between 60 to 120 minutes. Carbon monoxide production then dominates as the meltpool rapidly erodes the limestone concrete between 135 to 190 minutes. Air and aerosols contaminated the system after 190 minutes making that data unreliable. Continuous plots of the partial pressure of each gas species are shown in Appendix G.

The results from the $\mathrm{CO} / \mathrm{CO}_{2}$ monitor are shown in Figure 6.2.2. The raw data, shown here as percent $\mathrm{CO}$ and percent $\mathrm{CO}_{2}$ in the sampling flow line, indicate the onset of increased gas release between 135 to 190 minutes into the test. Both $\mathrm{CO}$ and $\mathrm{CO}_{2}$ content rise from the onset of gas release when erosion begins at around time $=$ 135 minutes with the $\mathrm{CO}_{2}$ content being lower than the $\mathrm{CO}$ content. When concrete erosion begins at time $=135$ minutes, the $\mathrm{CO} / \mathrm{CO}_{2}$ ratio steadily increases from 1:1 to 5:1. After 190 minutes the aerosol gravel filter became plugged and both $\mathrm{CO}$ and $\mathrm{CO}_{2}$ values dropped to background levels.

The grab sample results for SURC- 1 are shown in Table 6.2.3. The carrier gas for these samples included argon in total amounts ranging from 1 to
18 percent. A total of six samples were taken in which no other gases besides $\mathrm{H}_{2}, \mathrm{O}_{2}, \mathrm{CO}_{2}, \mathrm{~N}_{2}$, $\mathrm{CO}$, or Ar were detected. Normalized results for the samples taken during the erosion phase of the test between times 135 and 190 minutes are also shown in Table 6.2.3. These samples have an average $\mathrm{H}_{2}$ concentration of 20 percent with 75 percent $\mathrm{CO}$ and 5 percent $\mathrm{CO}_{2}$. As with the mass spectrometer results, these concentrations do not include $\mathrm{H}_{2} \mathrm{O}$ vapor which averaged 3 to 5 percent over the entire test.

\subsection{Flow Data Presentation}

Four different devices were used to measure the reaction gas flow rate in SURC-1: $1.02 \mathrm{~cm}$ orifice plate, a laminar flow element, a Rockwell 415 gas clock, and a Rockwell 750 gas clock. A flow train schematic for these devices is shown in Figure 4.3.1 and information regarding the description, operation, and calibration of the flow equipment is detailed in Section 4.3.

\section{Procedures}

All of the flow devices were operated continuously throughout the test. Data from the devices in the form of voltage outputs from either pressure transducers or a summing transmitter were recorded at 15 second intervals on computer disk using the HP1000 data acquisition system. Initial flow for the system was established and maintained using argon carrier gas. Argon was introduced into the apparatus at two locations. The first location was into the water cooled aluminum containment vessel. The total flow rate of argon was monitored at this position using a turbine meter. Argon was also used to purge a window protecting the opacity meter. The opacity meter was located in the flow tube approximately $3 \mathrm{~m}$ downstream from the crucible. The flow of argon at this position was monitored using a Kulite 100 psi pressure transducer upstream of a Millipore $1.1 \mathrm{~mm}(5 \mathrm{lpm})$ diameter critical orifice. The turbine meter registered a flow rate of $44 \pm 2 \mathrm{lpm}$ throughout the test. The pressure transducer recorded a 
Data

Table 6.2.1 SURC-1 mass spectrometer data

raw data - volume percent

\begin{tabular}{ccccccccc}
\hline $\begin{array}{c}\text { Run Time } \\
\text { (min) }\end{array}$ & $\begin{array}{c}\text { Sample } \\
\text { Port }\end{array}$ & $\mathbf{H}_{\mathbf{2}}$ & $\mathbf{H}_{\mathbf{2}} \mathbf{O}$ & $\mathbf{C O}$ & $\mathbf{O}_{\mathbf{2}}$ & $\mathbf{A r}$ & $\mathbf{C O}_{\mathbf{2}}$ & Notes \\
\hline 0 & 3 & 0.7 & 1.6 & 0.9 & - & 94 & 0.7 & Background \\
20 & 3 & 0.8 & 1.6 & 0.9 & - & 97 & 0.7 & \\
40 & 3 & 1.0 & 1.7 & 1.0 & - & 95 & 0.7 & \\
60 & 2 & 1.6 & 1.8 & 1.6 & - & 94 & 0.9 & \\
80 & 2 & 7.3 & 3.6 & 4.5 & 14 & 55 & 2.7 & Dehydration Begins \\
100 & 2 & 18.7 & 2.1 & 2.7 & 0.5 & 75 & 1.6 & \\
120 & 3 & 6.3 & 2.0 & 2.4 & 0.5 & 88 & 1.0 & \\
140 & 3 & 6.3 & 2.5 & 51 & 0.5 & 38 & 1.9 & Start of Rapid Erosion \\
160 & 1 & 3.5 & 2.8 & 70 & 7.0 & 21 & 2.1 & \\
170 & 1 & 2.7 & 3.7 & 75 & 0.5 & 15 & 3.0 & \\
180 & 1 & 3.3 & 3.7 & 74 & 7.4 & 7.4 & 3.7 & \\
190 & 1 & 3.0 & 3.7 & 74 & 0.5 & 15 & 4.4 & \\
200 & All & - & - & - & - & - & - & Air Leak in Gas System \\
*Sample Port Locations & & & & & & & \\
1 Gravel Filter & & & & & & & \\
2 Flow Line & & & & & & & & \\
3 Aluminum & Containment & Vessel & & & &
\end{tabular}

Table 6.2.2 SURC-1 mass spectrometer results normalized data - volume percent

\begin{tabular}{cccccc}
\hline Run Time (min) & $\mathbf{H}_{\mathbf{2}}$ & $\mathbf{H}_{\mathbf{2}} \mathbf{O}$ & $\mathbf{C O}$ & $\mathbf{C O}_{\mathbf{2}}$ & Notes \\
\hline 0 & -- & -- & - & -- & \\
20 & -- & -- & - & -- & \\
40 & -- & - & - & -- & Mostly Argon \\
60 & 27 & 31 & 27 & 15 & \\
80 & 40 & 20 & 25 & 15 & Dehydration Begins \\
100 & 75 & 8 & 11 & 6 & \\
120 & 54 & 17 & 21 & 9 & \\
140 & 10 & 4 & 83 & 3 & Rapid Erosion \\
160 & 4 & 4 & 89 & 3 & \\
170 & 4 & 4 & 88 & 4 & \\
180 & 4 & 4 & 87 & 5 & \\
190 & 3 & 4 & 87 & 6 & Zr Depletion \\
\hline
\end{tabular}




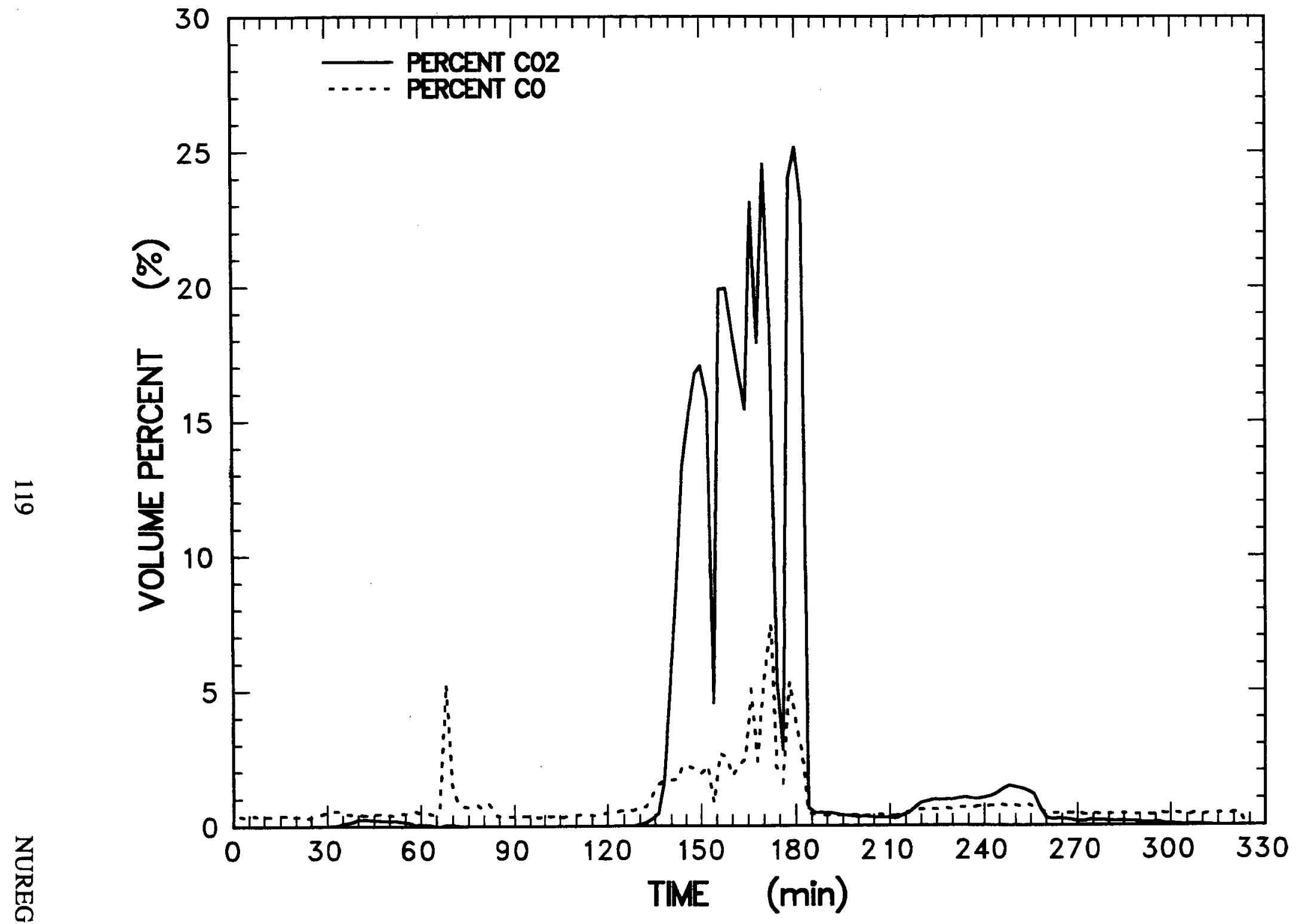

Figure 6.2.2 SURC-1 $\mathrm{CO} / \mathrm{CO}_{2}$ monitor data 
Data

Table 6.2.3 SURC-1 grab sample analysis

raw data in volume (mole) percent

\begin{tabular}{crrrrr}
\hline Run Time (min) & $\mathbf{H}_{2}$ & $\mathbf{C O}$ & $\mathbf{O}_{2}$ & $\mathbf{A r}$ & $\mathbf{C O}_{2}$ \\
\hline 150 & 15.0 & 51.4 & 2.5 & 18.5 & 1.0 \\
161 & 8.0 & 53.0 & 3.6 & 15.9 & 1.2 \\
192 & 0.1 & 0.8 & 19.4 & 1.1 & 0.1 \\
220 & 0.3 & 2.5 & 19.1 & 2.0 & 0.3 \\
250 & 0.1 & 0.7 & 20.6 & 1.2 & 0.2 \\
273 & 0.1 & 0.5 & 18.9 & 1.1 & 0.2
\end{tabular}

Normalized Data in Volume (Mole) Percent

\begin{tabular}{clll} 
Run Time (min) & $\mathbf{H}_{\mathbf{2}}$ & $\mathbf{C O}$ & $\mathbf{C O}_{\mathbf{2}}$ \\
\hline 150 & 22.2 & 76.3 & 1.5 \\
161 & 12.9 & 85.2 & 1.9 \\
192 & 10 & 80 & 10 \\
220 & 10 & 80 & 10 \\
250 & 10 & 70 & 20 \\
273 & 13 & 63 & 24
\end{tabular}

constant gauge pressure of $26 \pm 1$ psi. The flow rate to the opacity meter based on the pressure and orifice calibration was calculated to be $16 \pm 1 \mathrm{lpm}$.

The temperature of the gas in the flow system was measured at three locations: $3 \mathrm{~m}$ downstream from the crucible at the second gas sampling pickoff point; $4 \mathrm{~m}$ downstream from the crucible at the orifice plate flow device; and $7 \mathrm{~m}$ downstream from the crucible at the flow system exhaust. A plot of the flow system temperatures at these locations is shown in Figure 6.3.1. Although the reaction gases generated in the crucible can have initial temperatures in excess of $2000 \mathrm{~K}$, these gases cool quickly and were mixed with argon at ambient conditions so that the temperatures at the flow measurement devices were generally less than $400 \mathrm{~K}$. The system pressure was also monitored and is shown in Figure 6.3.2. This pressure was recorded at a position $4 \mathrm{~m}$ downstream from the crucible and $10 \mathrm{~cm}$ upstream from the orifice flowmeter. This location represents the highest pressures achieved in the flow system during the SURC-1 test at which the measured values ranged from 0.1 to 9.0 psig.

\section{$\underline{\text { Results }}$}

As with the crucible temperature and gas composition data, four time periods are of interest for the SURC-1 flow data. These are the onset of gas release from concrete between 80 to 135 minutes, the gas release associated with initial rapid concrete erosion between 135 and 190 minutes, the decrease in gas evolution due to the cessation of $\mathrm{Zr}$ interactions at times after 190 minutes, and the increased gas flow resulting from a power increase at 220 minutes and lasting until test termination at 287 minutes. Events during the SURC-1 test which caused fluctuations in the data are between 172 and 211 minutes and again after 257 minutes when the gravel filter became plugged with aerosols. 


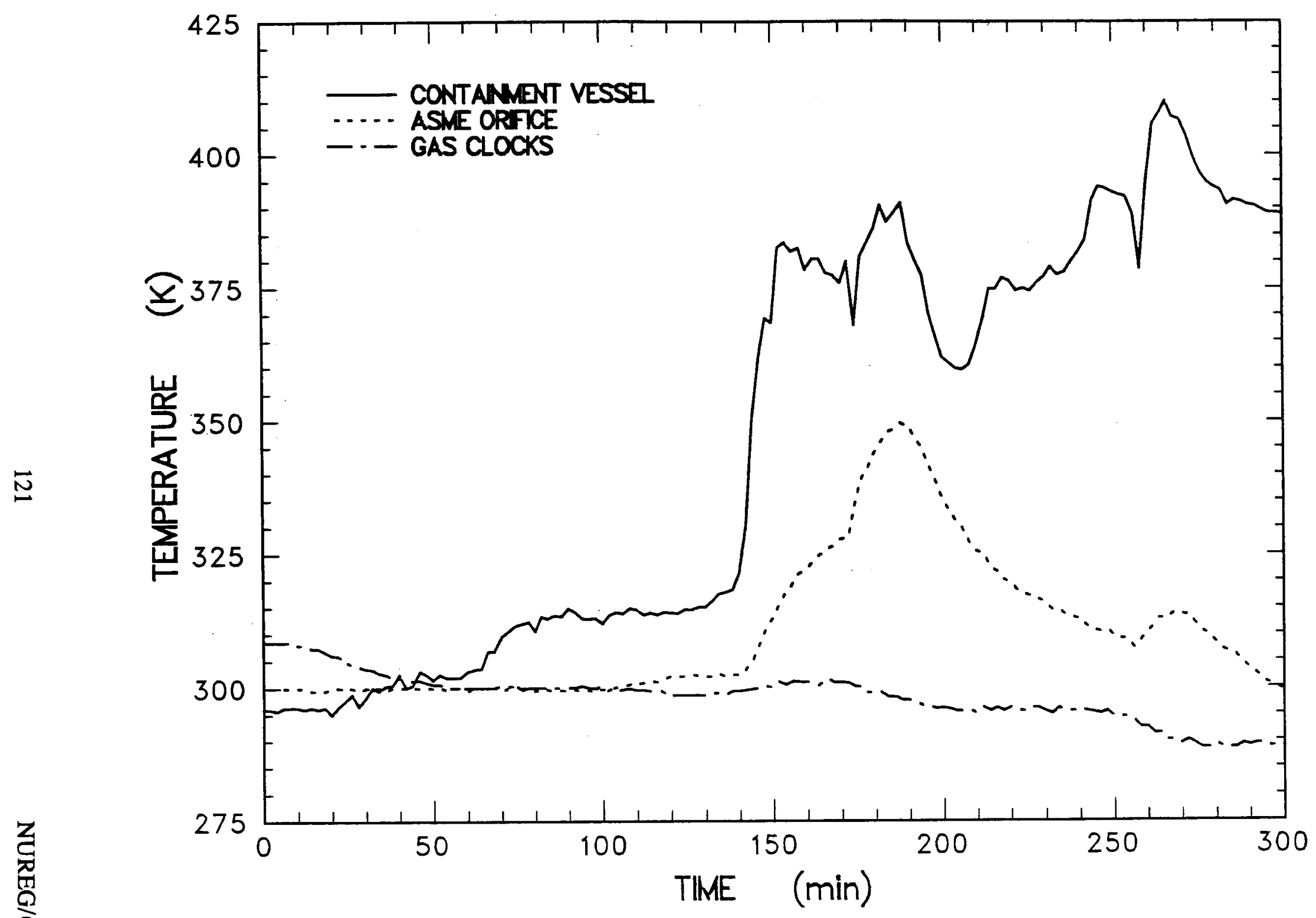

Figure 6.3.1 Temperature distribution in the SURC-1 flow system 


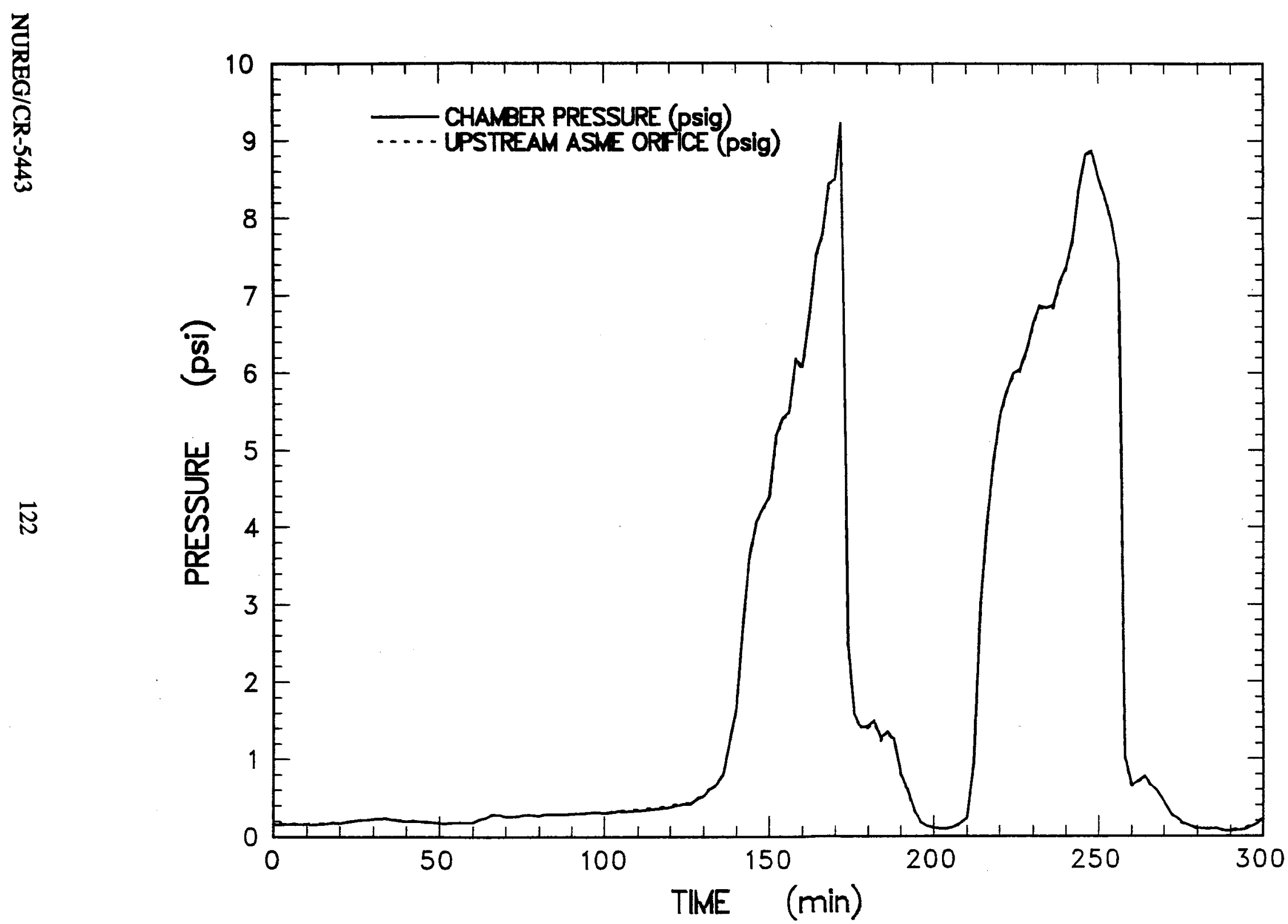

$\underset{\mathrm{E}}{\stackrel{0}{5}}$

Figure 6.3.2 Pressure history in the SURC-1 flow system 
The raw data for the 415 gas clock is shown in Figure 6.3.3. Here the total volume is in actual cubic meters of gas collected at the ambient conditions of 12.2 psia and $295 \mathrm{~K}$. As seen by Figure 6.3.3, the two gas clocks measured virtually identical volumes of gas throughout the experiment. A total of 20,100 liters of gas were collected before the gravel filter plugged in SURC-1. Based on a constant argon input flow of 45 alpm and the temperature profiles for the crucible materials, approximately 10,000 liters of this total were due to the argon carrier gas, 1500 liters were due to the dehydration of the $\mathrm{MgO}$, and 8500 liters were due to the decomposition of the limestone concrete basemat. Average flow rates for discrete periods of time during the test have been calculated using the gas clock data and are presented in Table 6.3.1.

The actual flow rate has been corrected in the final column of Table 6.3.1 to account for leakage from the system (12 percent at full flow) and non-STP conditions. These data indicate that the initial argon flow was 37 slpm. When the initial argon flow of 37 slpm is subtracted from the values shown in the final column of Table 6.3.1, it can been seen that significant offgassing of the concrete basemat began between 50 and 135 minutes at an average rate of $29 \mathrm{slpm}$. This is the characteristic flow rate for the period prior to the onset of ablation. After ablation began at 135 minutes the flow rate increased to 119 slpm between 135 and 160 minutes and to a rate of 170 slpm at 172 minutes, followed by a decrease to 51 slpm at times 210 to 240 minutes. Flow then increases to 79 slpm at times after 240 minutes.

The reduced flow rate data for the orifice plate flowmeter are shown in Figure 6.3.4. Argon was used to calibrate the flow devices and the results are calculated from the pressure transducer data. A summation of the flow rate yields a total volume of 25,000 liters of gas as compared to a total of 20,100 liters measured by the gas clocks. As discussed in Section 4.3, the actual flow rate measured by the orifice plate device is strongly dependent on the density of the reaction gas and is highly affected by the large quantities of $\mathrm{H}_{2}$ produced in the test. The "argon" result represents a lower bound for an arbitrary SURC-1 gas mixture of 50 percent $\begin{array}{lllll}\text { argon-35\% } & \mathrm{CO}-5 \% & \mathrm{CO}_{2}-5 \% & \mathrm{H}_{2} \mathrm{O}-5 \% & \mathrm{H}_{2} \text {. }\end{array}$ Examination of the total flow rate at the orifice plate in Figure 6.3.4 shows that the initial argon input flow was $50 \mathrm{lpm}$. Initial offgassing begins between 70 to 135 minutes and the total flow rate increases to a plateau of 70 to $80 \mathrm{lpm}$ during the period before ablation begins. After 130 minutes, the total flow jumps to 200 to $300 \mathrm{lpm}$ then decreases to $150 \mathrm{lpm}$ for the middle portion of the test. During the final period of the test between 240 to 280 minutes the flow rate was observed to rise again to a peak of $250 \mathrm{lpm}$.

Similar results are shown in Figure 6.3.5 for the laminar flow element. This device also is sensitive to gas composition and a range of output is shown using both argon and nitrogen as a basis for data reduction. Figure 6.3.5 illustrates the total flow rate during the SURC-1 test for the period identical to that for the orifice plate and the gas clocks. The argon inlet flow is established at $48 \mathrm{lpm}$ between 0 and 40 minutes. Offgassing begins between 40 and 50 minutes and the flow rate increases to a plateau of $70 \mathrm{lpm}$ between 85 and 135 minutes. After concrete erosion begins at 135 minutes the flow rate increases to a rate of 200 to $2251 \mathrm{pm}$. Flow then decreases to $100 \mathrm{lpm}$ followed by an increase to $130 \mathrm{lpm}$. Reaction gas can be calculated after corrections are made for leakage, temperature, pressure, and the argon carrier gas flow. The initial flow begins at 30 minutes, and increases gradually to 25 to $30 \mathrm{lpm}$ at 85 minutes. When concrete ablation begins at 135 minutes the flow rate increases to 185 to $200 \mathrm{lpm}$. After ablation slows the reaction gas flow rate decreases to $50 \mathrm{lpm}$ between 200 to 240 minutes followed by an increase to $100 \mathrm{lpm}$ for the duration of the test.

The results from the orifice plate and laminar flow element compare well with the results of the 
Z⿱

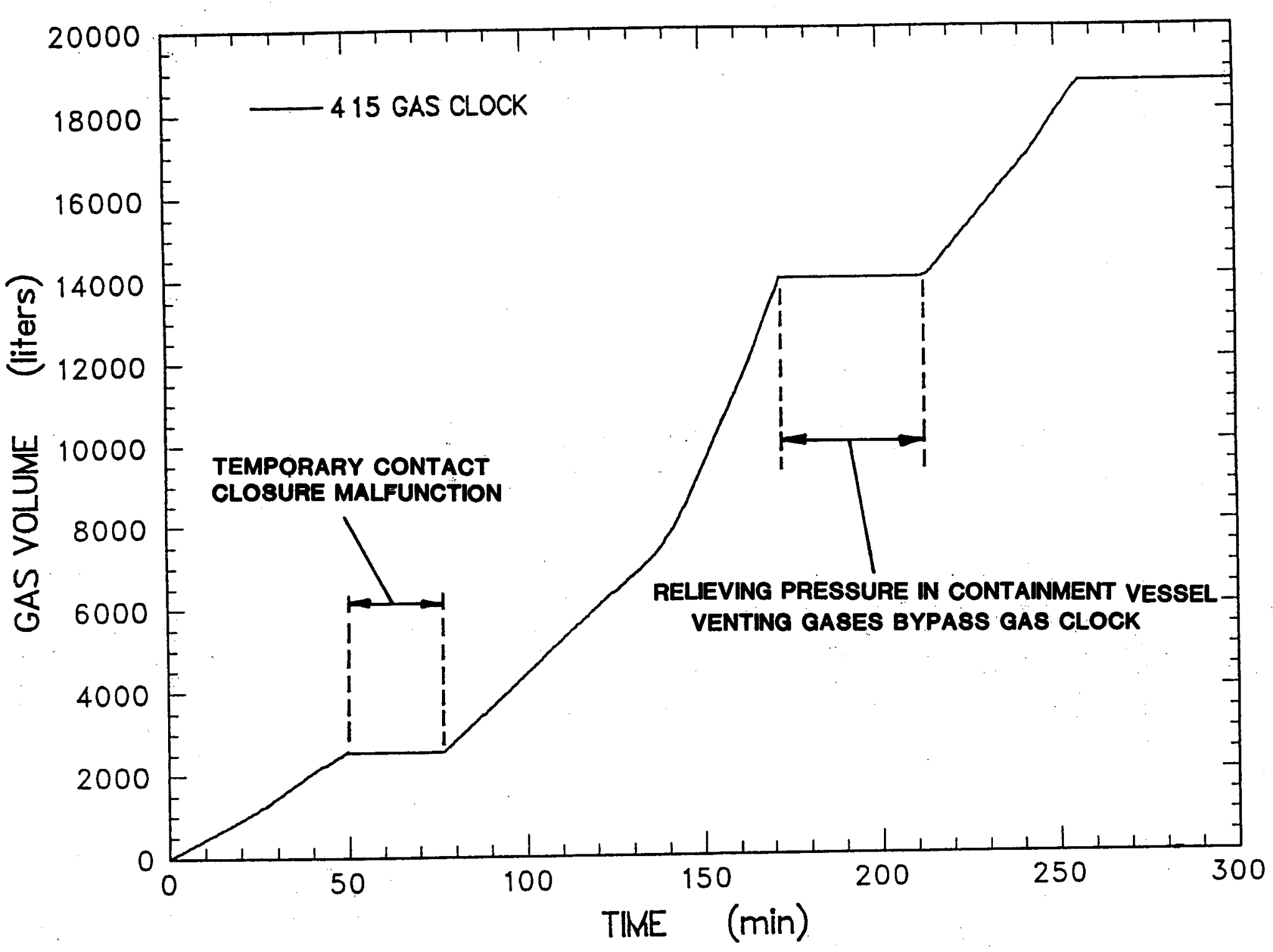

Figure 6.3.3 SURC-1 total flow - gas clock data 


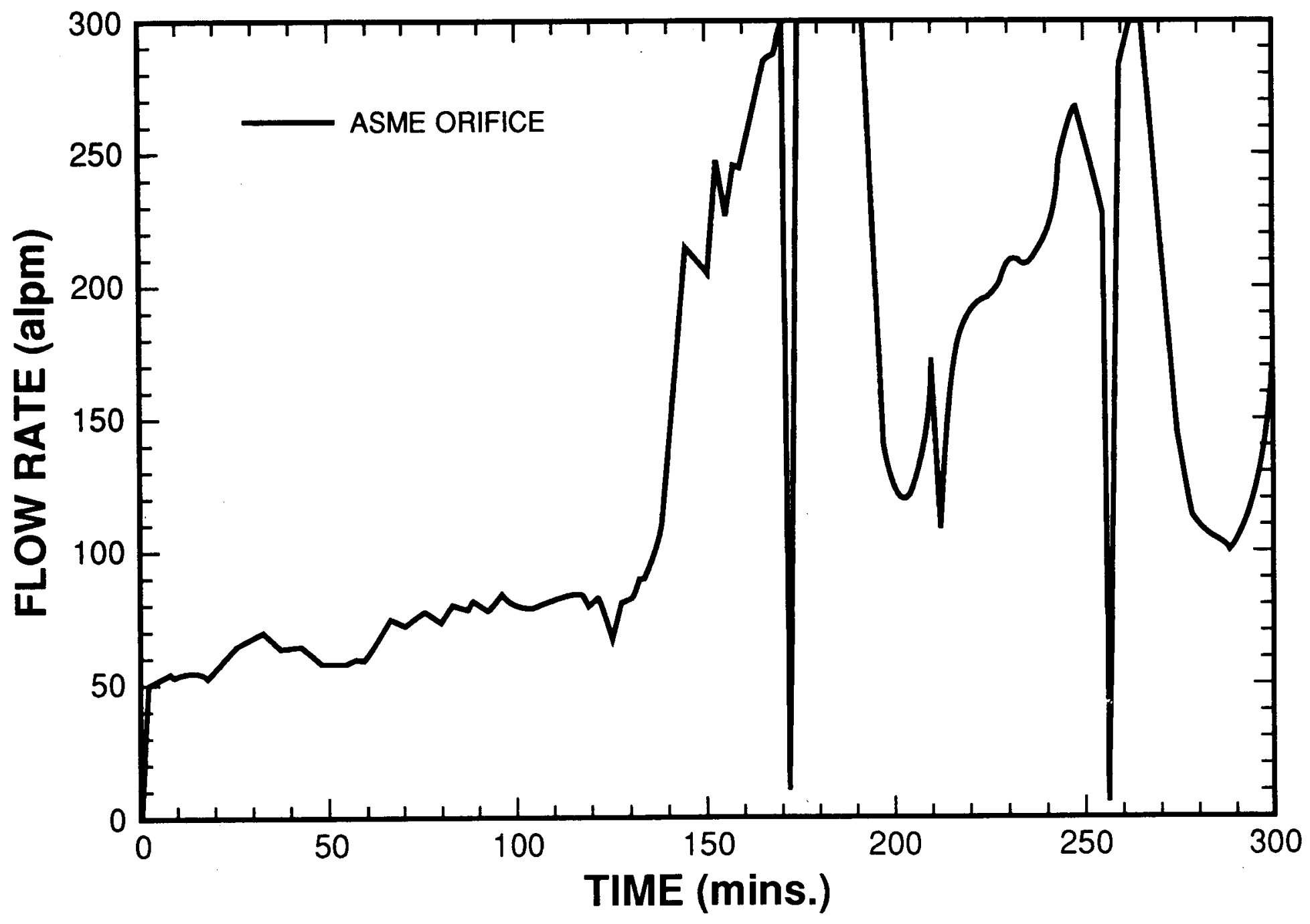

Figure 6.3.4 SURC-1 total gas flow rate indicated by the orifice plate data 
Table 6.3.1 SURC-1 flow rates from gas clock data

\begin{tabular}{cccc}
\hline $\begin{array}{c}\text { Time } \\
(\mathbf{m i n})\end{array}$ & $\begin{array}{c}\text { Total Flow } \\
\text { (Actual Liters) }\end{array}$ & $\begin{array}{c}\text { Avg. Flow Rate } \\
\text { (alpm) }\end{array}$ & $\begin{array}{c}\text { Corrected Flow Rate } \\
\text { (slpm) }\end{array}$ \\
\hline $0-24$ & 1075 & 45 & 37 \\
$24-49$ & 2519 & 58 & 49 \\
$49-78$ & 1972 & 68 & 57 \\
$78-134$ & 4387 & 78 & 66 \\
$134-153$ & 2830 & 156 & 140 \\
$153-172$ & 4245 & 223 & 207 \\
$211-240$ & 2972 & 102 & 88 \\
$240-257$ & 2236 & 132 & 116 \\
\hline
\end{tabular}

gas clocks with regard to the timing and relative magnitudes of the initial gas release, the gas release associated with steady state concrete erosion, and the increased release associated with the $\mathrm{Zr}$ metal in the initial melt. The absolute flow rates for these events, however, are most accurately represented by the gas clocks (Table 6.3.1) since no corrections are required to account for significant flow blockage or fluctuations in gas density or gas viscosity as are required for the orifice plate and laminar flow element. A detailed listing of the gas clock results is included in Appendix G.

\subsection{Aerosol Data}

A total of 2 to $4 \mathrm{~kg}$ of aerosol material was produced during the SURC-1 experiment with $1 / 3$ to $1 / 2$ of that material being accounted for by the aerosol measurement techniques. A large quantity of material was deposited in the containment vessel and was never transported to the measurement system. In addition, large diameter materials which can account for a large fraction of the aerosol mass cannot be sampled efficiently.

Aerosols were collected and measured using Gelman filters, Anderson Impactors, cyclones, and an opacity meter. These instruments are described in Section 4.4. The SURC-1 aerosol was found to be broadly distributed between about 0.5 to 20 micrometers aerodynamic particle diameter with a peak ranging from 0.5 to 4 micrometer. Its composition was dominated by sodium, potassium, and silicon from the concrete along with barium, molybdenum, and cerium from the charge materials. Electron micrographs showed the particles to have the agglomerate morphology expected of a vapor condensation aerosol. There was also evidence of spherical particles likely produced by liquid entrainment of melt. The aerosol concentrations measured during SURC-1 ranged from on the order of 30 to $200 \mathrm{~g} / \mathrm{m}^{3}$ STP.

\section{Procedure}

Sample gangs were initiated manually at the Modicon controller during the concrete erosion at 154 minutes, 159 minutes, 173 minutes, and near the end of the test at 260 minutes. Each sample gang consisted of three sequential 1 minute filter samples along with two 1 minute impactor samples (one at $10 \mathrm{lpm}$ and one at $15 \mathrm{lpm}$ nominal flows) beginning at the second minute of the sequence. The output of the pressure transducers giving flow indication was monitored at the control site and recorded on the data acquisition system. A cyclone sample was taken for a total of 9 minutes from 153 to 162 minutes.

The opacity meter operated for the duration of the test. Its output was monitored on the meter 


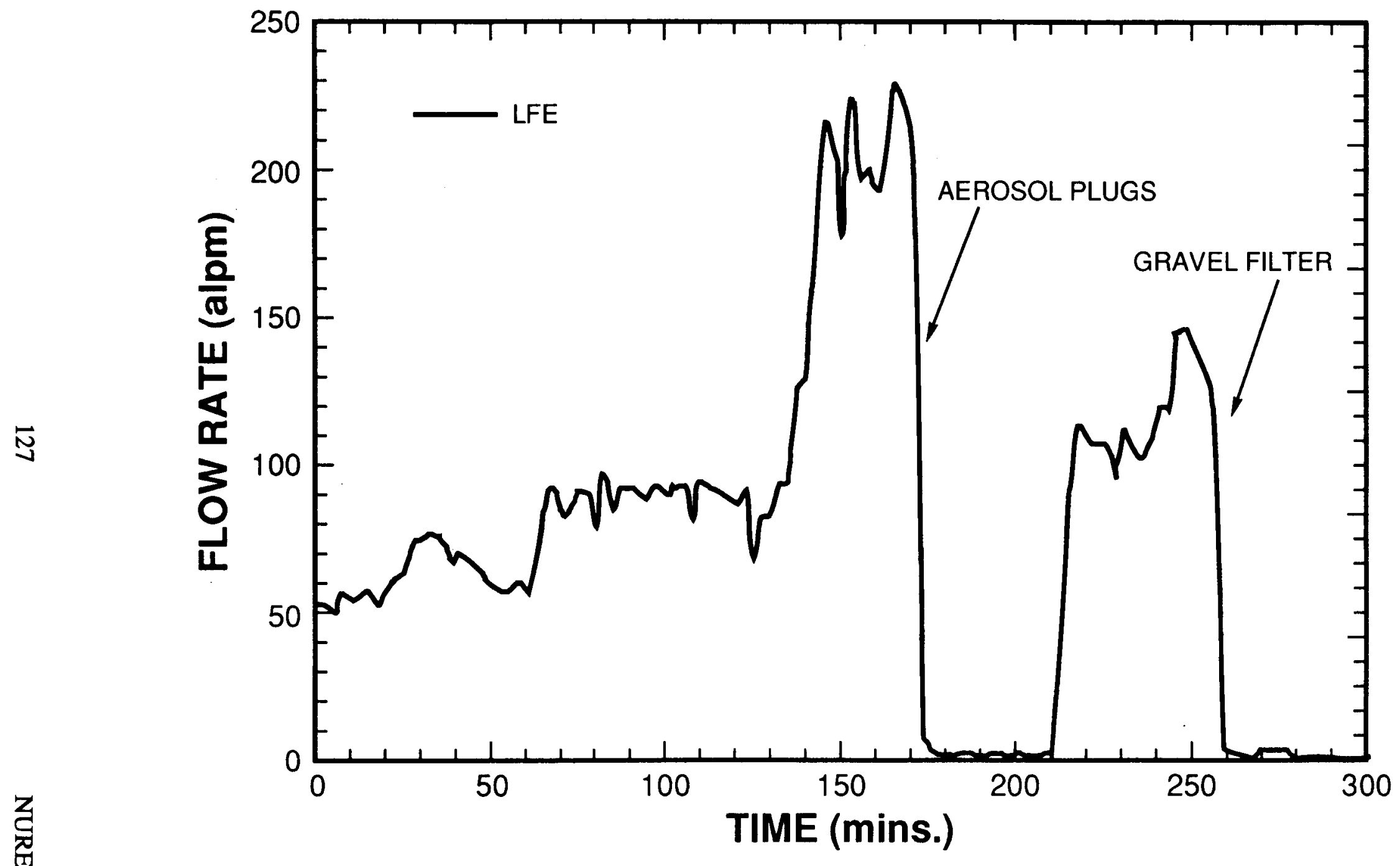

Figure 6.3.5 SURC-1 total gas flow rate indicated by the laminar flow element 
at the control site and recorded on the data acquisition system.

Pressure transducer outputs and thermocouple readings were recorded on the data acquisition system. The instrumentation and its calibration and operation has been discussed in Section 4.4. The aerosol mass was collected on filters, on impactor collection surfaces and in the cyclone. These masses were recovered and weighed after the test using procedures described in Section 4.4.

Selected filter, impactor, and cyclone samples were submitted for elemental analysis using inductively coupled plasma spectroscopy. Electron micrographs were taken of some of the samples for morphological analysis.

\section{$\underline{\text { Results }}$}

The sample times, sample flows, collected masses, dilution rates and calculated concentrations for the filter samples are given in Table 6.4.1. The same information for the impactors is given in Table 6.4.2. This information for the cyclone is given in Table 6.4.3. The flow was calculated from the system temperature and pressure and the flow control orifice calibration.

The voltage output from the opacity meter is plotted as a function of time in Figure 6.4.1. Here voltage is used as an indicator of relative aerosol density. The higher the voltage, the greater the opacity and the higher the aerosol concentration.

The filter samples 1,2 , and 3 (153 to 155 minutes) give good agreement on an aerosol concentration between 195 and 76 STP. The impactor samples taken at this time ( $E$ and F, 154 minutes) are in close agreement with each other at about $120 \mathrm{~g} / \mathrm{m}^{3}$ STP but are higher than the filter sample concentrations. This may be attributed to a smeared average in sampling or transport efficiency. An average concentration of $120 \mathrm{~g} / \mathrm{m}^{3}$ STP with a standard deviation of
$25 \mathrm{~g} / \mathrm{m}^{3}$ STP is calculated using all five results. The sizes of the aerosols sampled during this time period are shown in Figure 6.4.2. The particle diameters range from 0.4 to 25 microns with a mean size of 3.0 microns.

The filter samples 4,5 , and 6 (158 to 160 minutes) show consistent results at slightly lower concentrations. These filters indicate concentrations ranging from 47 to $61 \mathrm{~g} / \mathrm{m}^{3}$ STP. The concentrations indicated by the impactor samples (G and H, 159 minutes) are 67 and $78 \mathrm{~g} / \mathrm{m}^{3}$ STP. The sizes of these aerosols again range from 0.4 to 20 microns with a mean size of 2.5 microns. The size distribution is shown in Figure 6.4.3.

The filter samples 7, 8, and 9 (172 to 175 minutes) show lower concentrations ranging from 32 to $36 \mathrm{~g} / \mathrm{m}^{3}$. The impactors $\mathrm{J}$ and $\mathrm{K}(173$ minutes) indicate concentrations of 49 and $53 \mathrm{~g} / \mathrm{m}^{3}$. System flow at this time is at its highest at 200 to $250 \mathrm{lpm}$. The size distribution is shown in Figure 6.4.4 and has a slightly smaller mass mean at 1.0 micron.

The last filter samples, 10,11 , and 12 , were taken at 259 to 262 minutes. Concentrations at these times remain high at 37 to $43 \mathrm{~g} / \mathrm{m}^{3}$. The impactor samples $\mathrm{N}$ and $\mathrm{O}$ were taken at 260 minutes and indicate higher concentrations of 82 to $130 \mathrm{~g} / \mathrm{m}^{3}$. The size distribution is shown in Figure 6.4.5 and has a mass median of 2 microns.

The cyclone gives an average aerosol concentration of $51 \mathrm{~g} / \mathrm{m}^{3}$ STP over a period of time from 153 to 162 minutes. This includes the period of activity on the opacity monitor as well as the sampling times for filter samples 1 through 6. The size distribution for aerosols collected in the cyclone are presented in Figure 6:4.6. They are consistent with the impactor samples ranging from 0.5 to 25 microns with a mean of about 2 microns.

Elemental analysis was performed on filter samples, $2,5,8$, and 11 by inductively coupled 
Table 6.4.1 SURC-1 filter data

\begin{tabular}{|c|c|c|c|c|c|c|c|c|c|c|}
\hline $\begin{array}{l}\text { Filter } \\
\text { Sample }\end{array}$ & $\begin{array}{c}\text { On Time } \\
\text { (min) }\end{array}$ & $\begin{array}{c}\text { Duration } \\
\text { (sec) }\end{array}$ & $\begin{array}{c}\text { Orifice } \\
\text { Pressure } \\
\text { (psia) }\end{array}$ & $\begin{array}{l}\text { Orifice } \\
\text { Temp } \\
\text { (K) }\end{array}$ & $\begin{array}{c}\text { Orifice } \\
\text { Flow } \\
\text { (alpm) }\end{array}$ & $\begin{array}{c}\text { System } \\
\text { Pressure } \\
\text { (psia) }\end{array}$ & $\begin{array}{c}\text { Diluter } \\
\text { Gas } \\
\text { Flow } \\
\text { (alpm) }\end{array}$ & $\begin{array}{c}\text { Dilution } \\
\text { Ratio }\end{array}$ & $\begin{array}{l}\text { Total } \\
\text { Mass } \\
\text { (gm) }\end{array}$ & $\begin{array}{c}\text { Mass Conc } \\
\left(\mathrm{g} / \mathrm{m}^{3}\right)\end{array}$ \\
\hline 1 & 153.0 & 60.0 & 11.00 & 298.0 & 6.99 & 17.00 & 10.49 & 2.13 & 0.64216 & 195.59 \\
\hline 2 & 154.5 & 60.0 & 12.50 & 298.0 & 7.94 & 17.00 & 10.49 & 1.02 & 0.39079 & 99.62 \\
\hline 3 & 155.0 & 60.0 & 13.75 & 298.0 & 8.73 & 17.00 & 10.49 & 1.95 & 0.34401 & 76.84 \\
\hline 4 & 158.0 & 60.0 & 15.00 & 298.0 & 9.00 & 18.00 & 9.91 & 1.78 & 0.28468 & 56.34 \\
\hline 5 & 159.0 & 60.0 & 15.00 & 298.0 & 9.00 & 18.00 & 9.91 & 1.78 & 0.30591 & 60.54 \\
\hline 6 & 160.0 & 60.0 & 15.00 & 298.0 & 9.00 & 18.00 & 9.91 & 1.78 & 0.23803 & 47.10 \\
\hline 7 & 172.5 & 60.0 & 15.00 & 298.0 & 9.26 & 17.50 & 10.19 & 1.83 & 0.17973 & 35.52 \\
\hline 8 & 173.5 & 60.0 & 13.00 & 298.0 & 9.36 & 15.00 & 11.89 & 2.35 & 0.12662 & 31.80 \\
\hline 9 & 174.5 & 60.0 & 11.75 & 298.0 & 8.46 & 15.00 & 11.89 & 2.51 & 0.11202 & 33.17 \\
\hline 10 & 259.5 & 60.0 & 12.10 & 298.0 & 10.54 & 12.50 & 14.48 & 4.09 & 0.09456 & 36.67 \\
\hline 11 & 260.5 & 60.0 & 12.10 & 298.0 & 10.54 & 12.50 & 14.48 & 4.09 & 0.09544 & 37.01 \\
\hline 12 & 261.5 & 60.0 & 12.10 & 298.0 & 10.54 & 12.50 & 14.48 & 4.09 & 0.11001 & 42.66 \\
\hline \multicolumn{11}{|c|}{$\begin{array}{l}\text { Preseparator } 0.35861 \text {. } \\
\text { Total Mass }(\mathrm{gm})\end{array}$} \\
\hline \multicolumn{11}{|c|}{ Dilution Gas N2. } \\
\hline
\end{tabular}




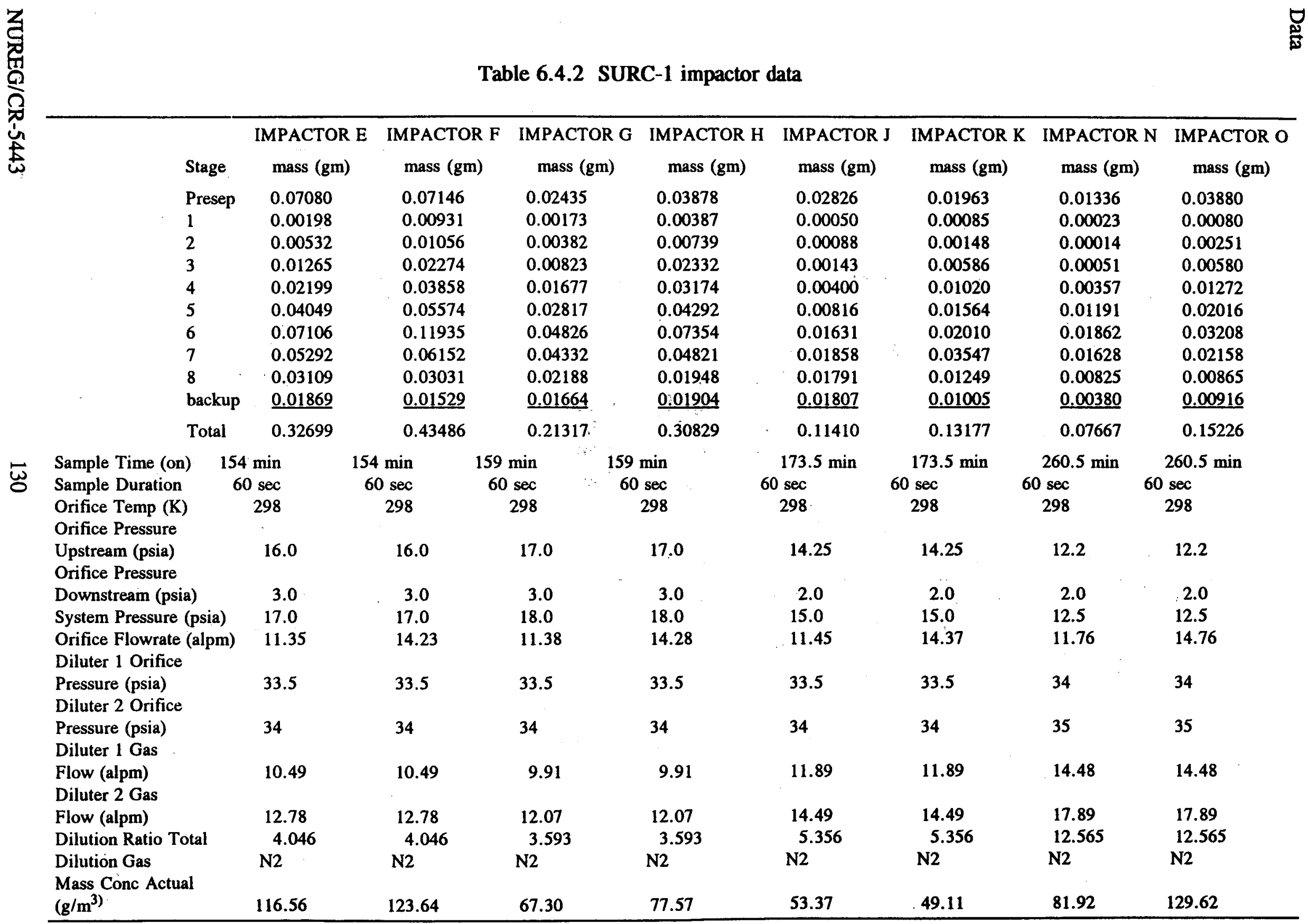


Table 6.4.3 SURC-1 cascade cyclone data

\begin{tabular}{lc}
\hline Cyclone Type & Cyclade Six Stage \\
\hline Orifice Temp (K) & 298.0 \\
Orifice Pressure & $12.5 \mathrm{psia}$ \\
Sampler Flowrate & $22.8 \mathrm{lpm}$ \\
Sample Duration & $9.0 \mathrm{~min}$ \\
Sample Time (on) & $153.5 \mathrm{~min}$ \\
Stage & Mass (gm) \\
1 & 4.92374 \\
2 & 0.67258 \\
3 & 1.34738 \\
4 & 1.35912 \\
5 & 0.76812 \\
6 & 0.89123 \\
Backup Filter & $\underline{0.44495}$ \\
Total & 10.40712 \\
Mass Concentration & $50.80609 \mathrm{gm} / \mathrm{m}^{3}$ \\
\hline
\end{tabular}

plasma spectroscopy. Table 6.4 .4 gives the results for these samples. Gross material samples of aerosols deposited at the orifice plate and at the ball valve in the flow train are also included. All of the samples show large amounts of $\mathrm{Mg}$, $\mathrm{Na}, \mathrm{Si}$, and $\mathrm{Na}$ from the concrete and crucible materials. The fission product simulants of $\mathrm{Ba}$, $\mathrm{Ce}$, and $\mathrm{Mo}$ are present in significant quantities but no traces of niobium or lanthanum aerosols were detected. The charge materials of tungsten and uranium were also present in sufficient quantities to be important. Where no element was detected, the result is given as less than the detectable threshold for the element on that sample. An elemental distribution with respect to time for the combined aerosol source term is given in Figures 6.4.7 and 6.4.8. 


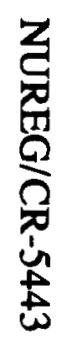

$\vec{\omega}$

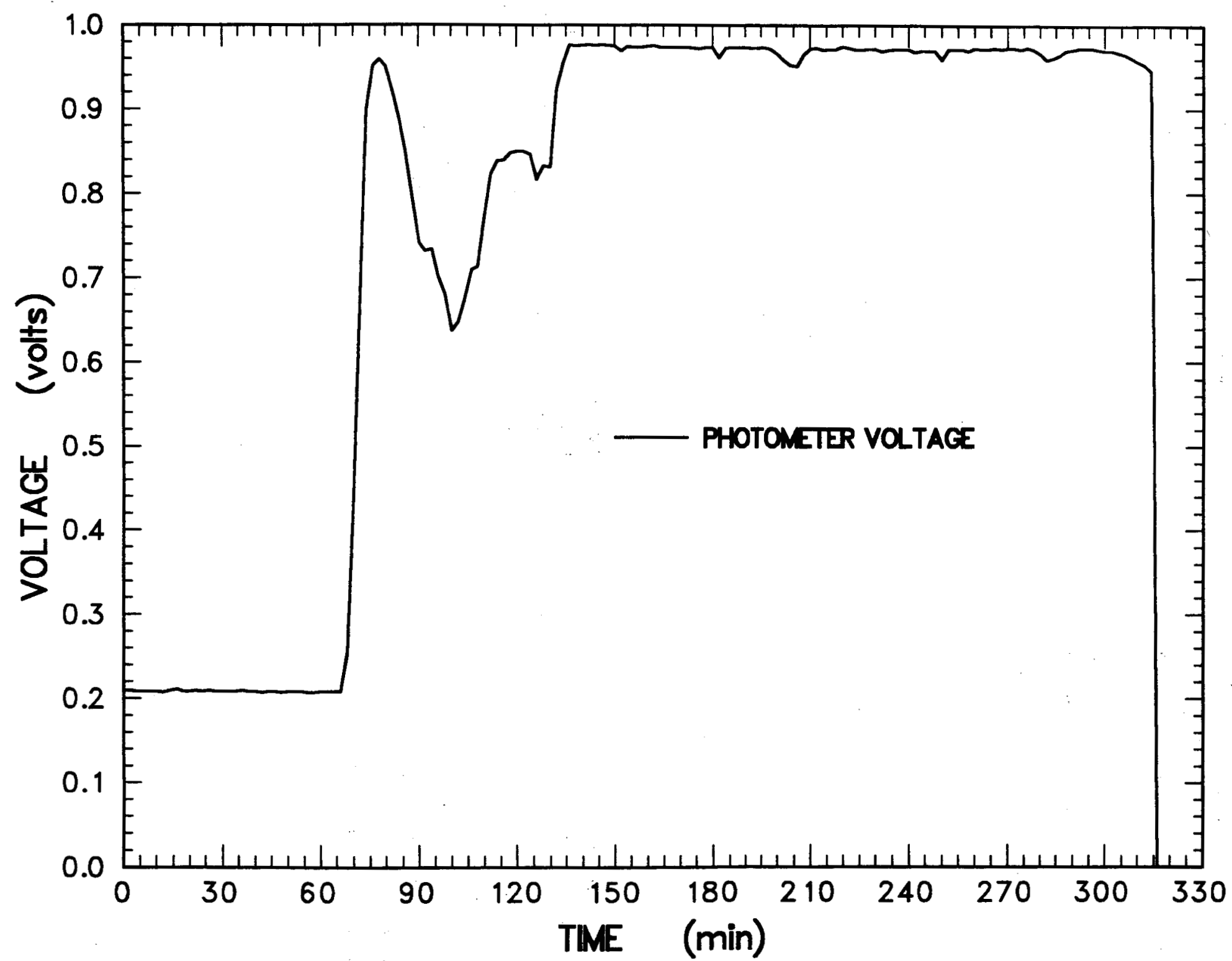

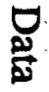

Figure 6.4.1 Opacity meter output for SURC-1 test. Voltage level is directly proportional to aerosol concentration. 


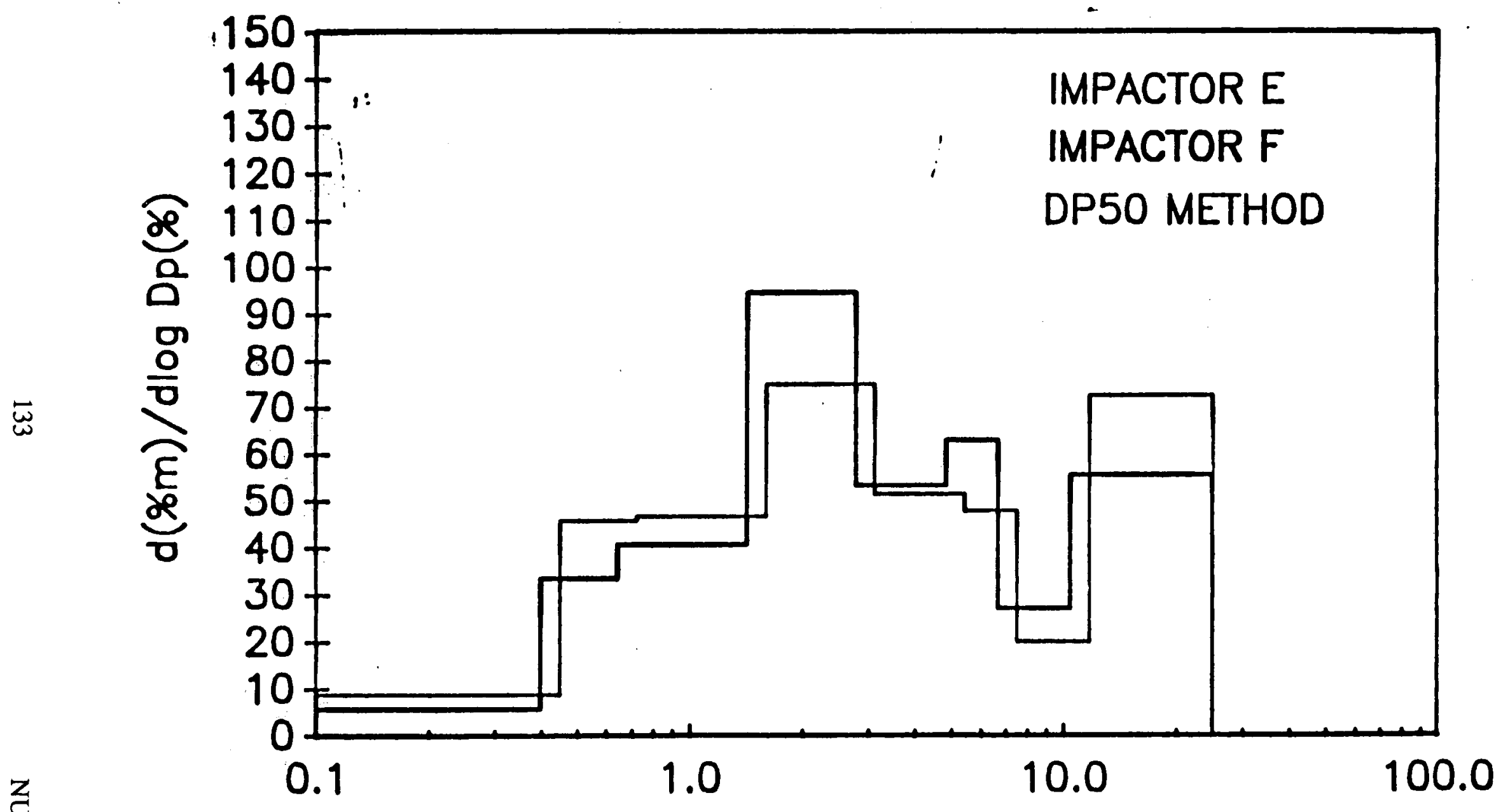

Figure 6.4.2 SURC-1 aerosol size distribution. Normalized aerosol mass distributions from impactors $E$ and F taken at 154 minutes. 


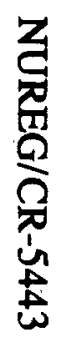

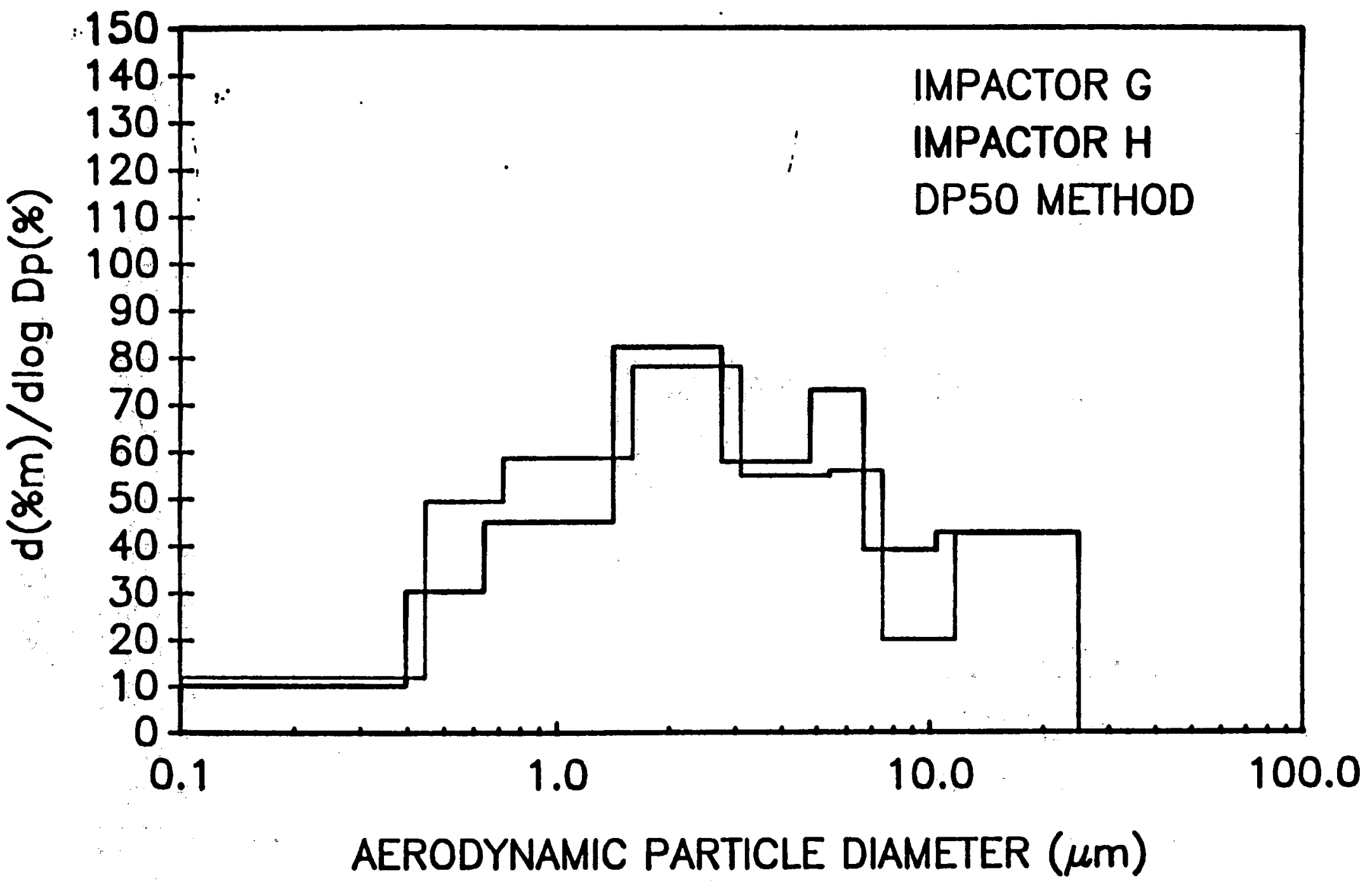

Figure 6.4.3 SURC-1 aerosol size distribution. Normalized aerosol mass distributions from impactors G and $\mathbf{H}$ taken at 159 minutes. 


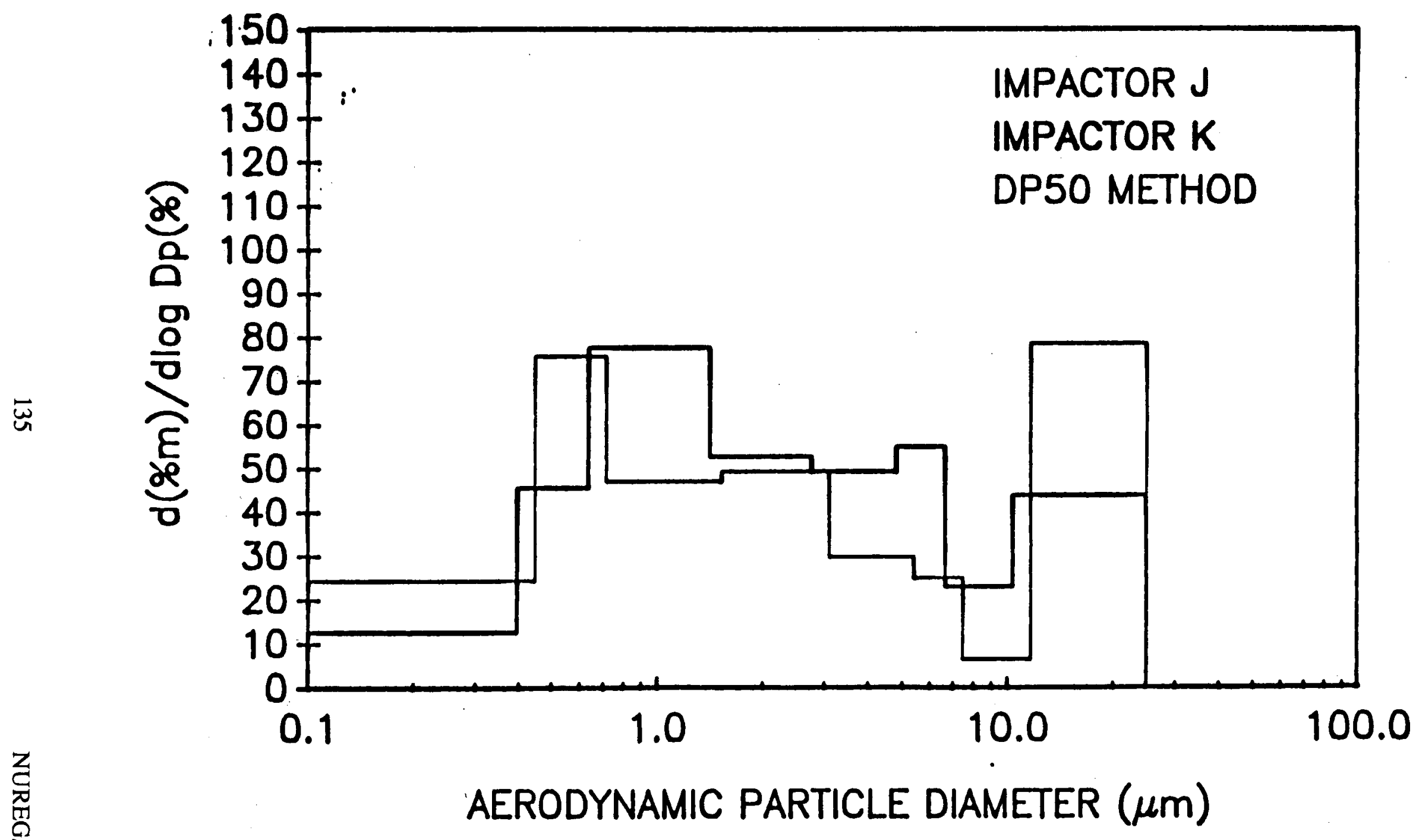

Figure 6.4.4 SURC-1 aerosol size distribution. Normalized aerosol mass distributions from impactors $J$ and $K$ taken at 173 minutes. 


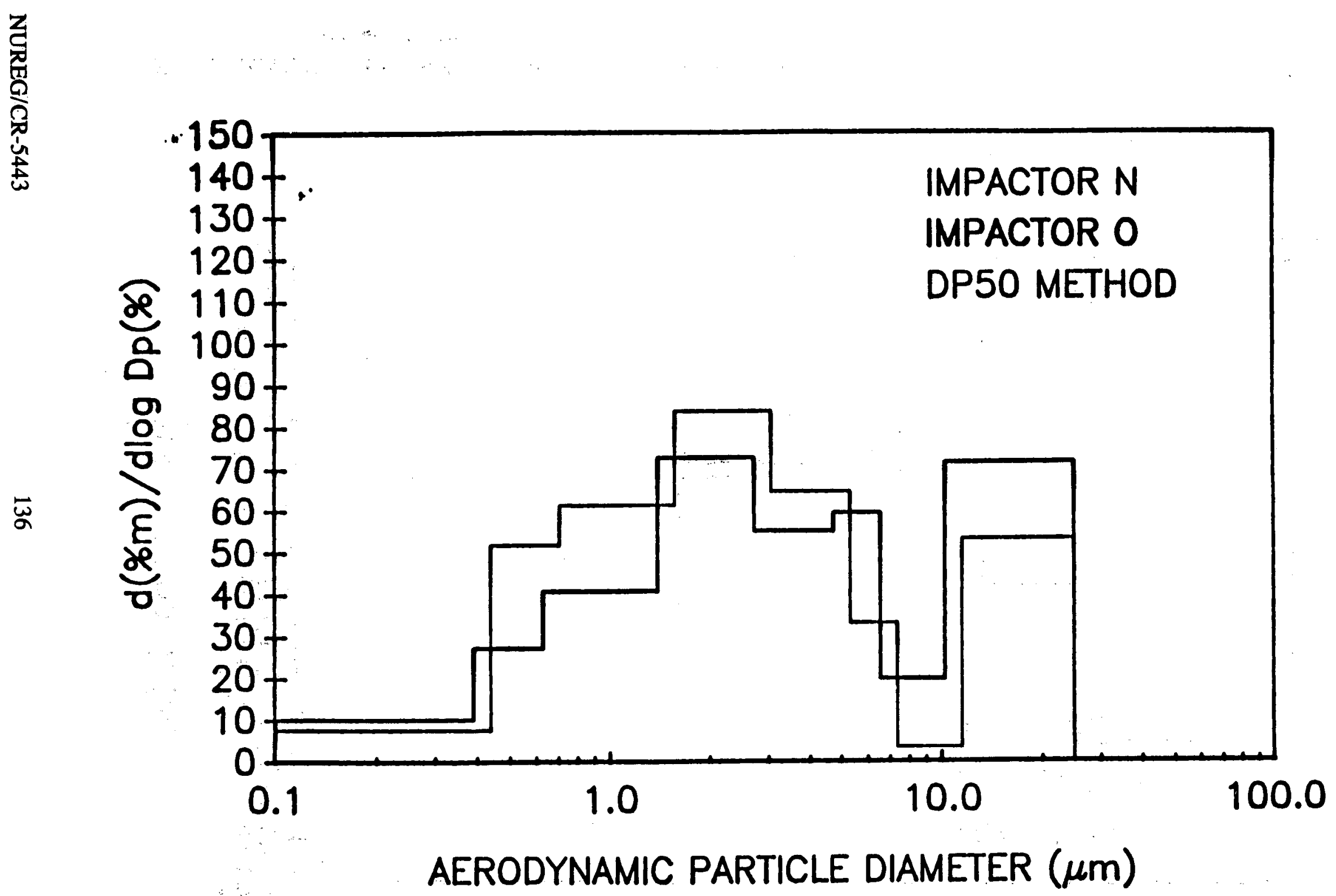

Figure 6.4.5 SURC-1 aerosol size distribution. Normalized aerosol mass distributions from impactors $\mathrm{N}$ and $\mathrm{O}$ taken at 260 minutes. 
Table 6.4.4 Elemental analysis of SURC-1 aerosol weight percent of element in sample

\begin{tabular}{lccccccccccccccc}
\hline \multicolumn{1}{c}{ Sample } & $\mathrm{Ba}$ & $\mathbf{C a}$ & $\mathbf{C e}$ & $\mathbf{C l}$ & $\mathbf{K}$ & $\mathbf{L a}$ & $\mathbf{M g}$ & $\mathbf{M o}$ & $\mathbf{N a}$ & $\mathbf{N b}$ & $\mathbf{S i}$ & $\mathbf{U}$ & $\mathbf{W}$ & $\mathbf{Z r}$ & Moisture \\
\hline Filter 2 & .28 & .54 & .051 & 1.14 & $\mathbf{5 . 9}$ & $<.01$ & 33.7 & $<.005$ & .68 & $<.05$ & 32.9 & $<.1$ & $<.05$ & .070 & .56 \\
Filter 5 & .56 & 1.0 & .080 & 1.71 & 12.8 & $<.01$ & 29.0 & .024 & 1.4 & $<.05$ & 30.6 & $<.1$ & .06 & .076 & .38 \\
Filter 8 & .46 & 1.2 & .063 & 1.91 & 22.7 & $<.01$ & 19.3 & .081 & 2.4 & $<.05$ & 22.5 & .2 & 2.2 & .16 & 1.22 \\
Filter 11 & .07 & .35 & .01 & 3.24 & 25.2 & $<.01$ & 8.0 & .07 & 1.8 & $<.05$ & 7.6 & $<.1$ & 1.5 & .05 & 4.27 \\
Orifice & .34 & .84 & .038 & .30 & 15.0 & $<.01$ & 14.4 & .11 & 2.2 & $<.05$ & 16.9 & .1 & 7.9 & .26 & - \\
Ball Value & .23 & .61 & .072 & .66 & 11.4 & $<.01$ & 20.2 & .098 & 1.4 & $<.05$ & 21.2 & .2 & 5.0 & .23 & - \\
\hline
\end{tabular}




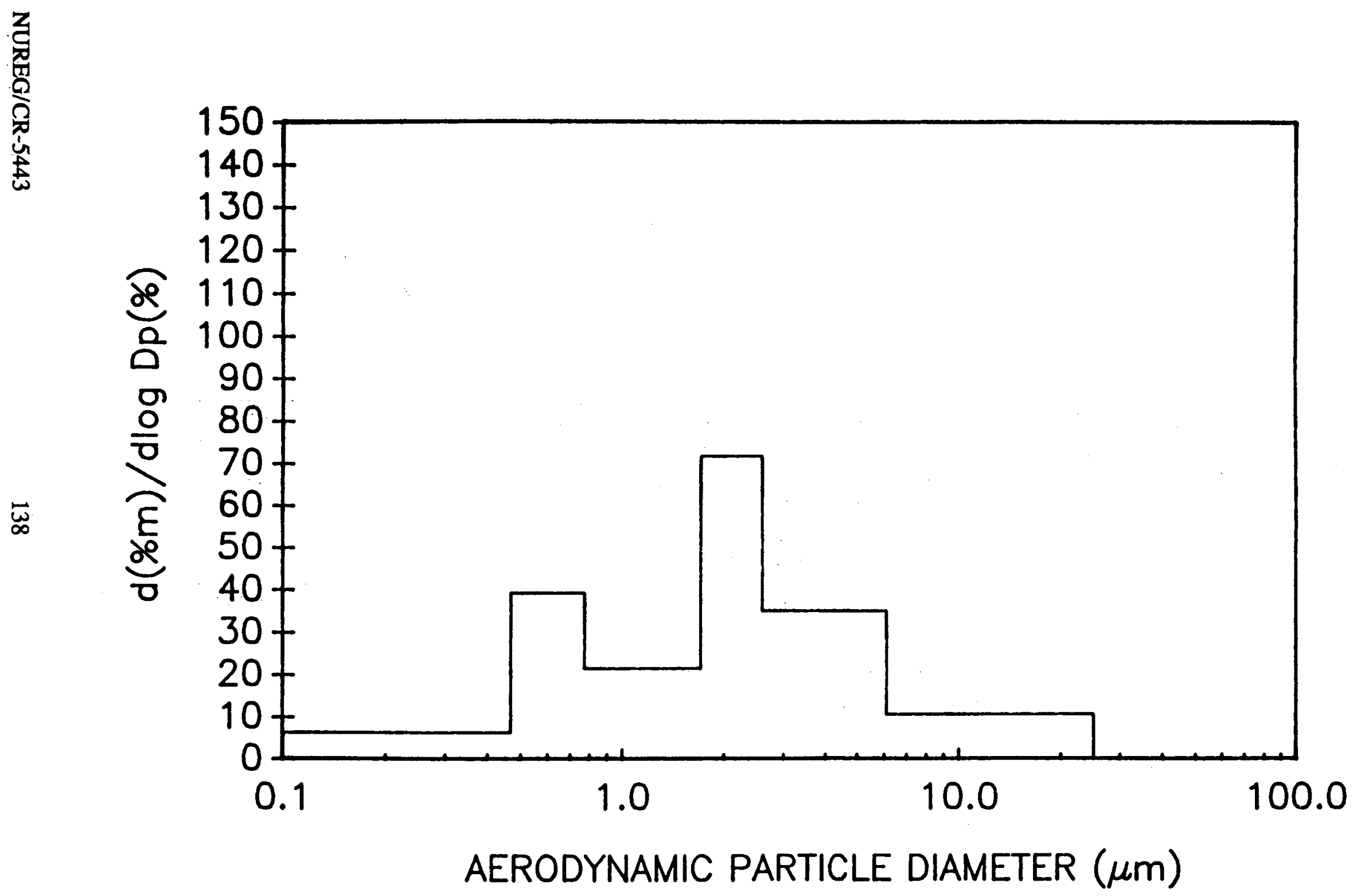

Figure 6.4.6 SURC-1 aerosol size distribution. Normalized aerosol mass distribution from cyclone taken from 153 to 162 minutes. 
Data

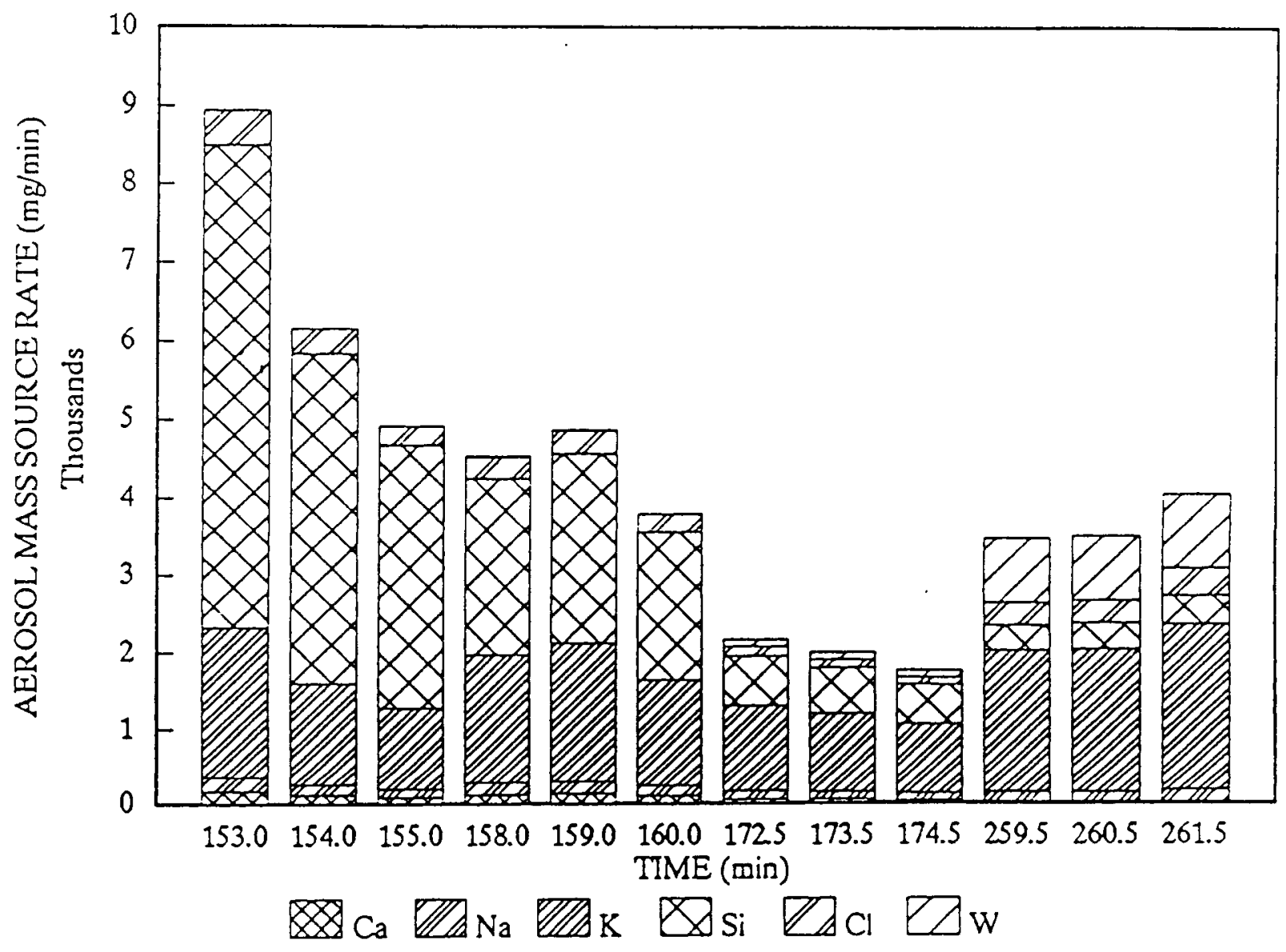

Figure 6.4.7 SURC-1 elemental aerosol source term 
Data

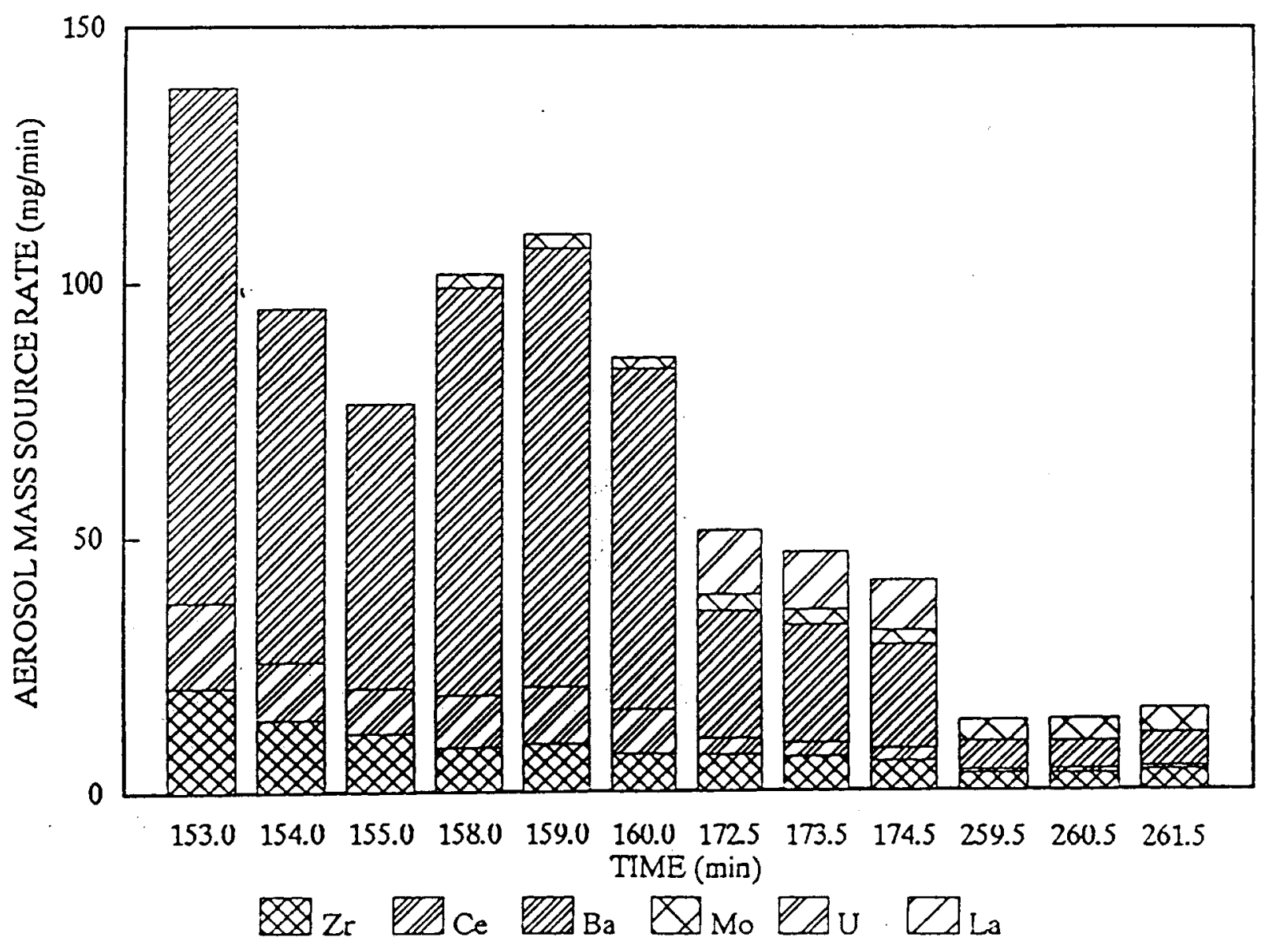

Figure 6.4.8 SURC-1 elemental aerosol source term 


\subsection{Test Summary and Conclusions}

The SURC-1 experiment was a molten core debris concrete interaction test designed to sustain a melt of $204.2 \mathrm{~kg}$ of depleted uranium oxide, zirconium metal and zirconium oxide in a magnesium oxide crucible with a limestone concrete bottom. The goals of the experiment were to measure in detail the gas evolution, aerosol generation, and erosion characteristics associated with molten oxide-concrete interactions.

The charge material in SURC-1 was a mixture of 69 w/o $\mathrm{UO}_{2}-22$ w/o $\mathrm{ZrO}_{2}-9$ w/o $\mathrm{Zr}$. Additionally, $3.3 \mathrm{~kg}$ of fission product simulants were added to the melt to study fission product release. The SURC-1 experiment was conducted in a $60 \mathrm{~cm}$ diameter interaction crucible constructed with a $40 \mathrm{~cm}$ limestone concrete cylinder in the base of a magnesium oxide (MgO) annulus. A $10-\mathrm{cm}$-thick cover of $\mathrm{MgO}$ was placed on top of the crucible. The interaction crucible and an induction coil were housed in a sealed, water-cooled, aluminum containment vessel that was $180 \mathrm{~cm}$ high and $120 \mathrm{~cm}$ in diameter. Exhaust ports in the crucible and in the containment vessel directed the reaction products through flow and aerosol sampling instrumentation. The interaction crucible was instrumented with thermocouple arrays cast into the concrete cylinder, $\mathrm{MgO}$ annulus, and $\mathrm{MgO}$ cover. A $280 \mathrm{~kW}$ induction power supply was used to heat tungsten rings placed in the charge which in turn heated, melted, and sustained the oxide-concrete interaction. Flow rates of generated gases were measured using a sharp-edged orifice, a laminar flow element, a turbine meter, and two dry gas clocks. Gaseous effluents produced during the experiment were monitored and sampled using an infrared gas analyzer, a mass spectrometer, and by an integral grab sample technique. Aerosols were captured on filters, cascade impactors, and a cascade cyclone. Erosion characteristics were measured using type $\mathrm{K}, \mathrm{S}$, and $\mathrm{C}$ thermocouples. Three tungsten thermowells containing optical pyrometers were embedded in the charge in order to define the meltpool temperature. The apparatus was purged with argon gas in order to direct the majority of the reaction gas and aerosol effluents through a $5 \mathrm{~cm}$ diameter flow pipe. The SURC-1 test was run at local atmospheric pressure $(0.83 \mathrm{~atm})$ and at an ambient temperature of $25^{\circ} \mathrm{C}$.

The SURC-1 test ran for a total of 287 minutes. A total of $27 \mathrm{~cm}$ of limestone concrete was eroded during the final 150 minutes of the experiment. Figure 7.1 shows a net power of $67 \mathrm{~kW}$ was applied to the tungsten susceptors to sustain the initial interaction (120 to $220 \mathrm{~min}$ ). This was increased to a net power of $91 \mathrm{~kW}$ for the final portion (220 to 287 minutes) of the test.

Four time periods during the test are of particular interest. These are the onset of gas release from the concrete between 80 to 135 minutes, the initial rapid erosion period between 135 and 190 minutes, the slowed erosion period after $\mathrm{Zr}$ depletion between 190 and 220 minutes, and the increased erosion following the power increase from $150 \mathrm{~kW}$ (gross) to $200 \mathrm{~kW}$ at 220 minutes which lasted until the termination of the test at 287 minutes.

During the initial heatup period between 80 and 135 minutes, the temperature of the oxide charge, as shown in Figure 7.2, increases from $1300 \mathrm{~K}$ to $2600 \mathrm{~K}$ and began to melt. Figure 7.3 shows that the concrete basemat started to dehydrate during this time at an average rate of $5.6 \pm$ $0.4 \mathrm{~cm} / \mathrm{hr}$ producing a reaction gas flow rate of 29 slpm (35 alpm) as shown in Figure 7.4. The composition of this initial effluent gas was $50 \%$ $\mathrm{H}_{2}-20 \% \mathrm{H}_{2} \mathrm{O}-20 \% \mathrm{CO}-10 \% \mathrm{CO}_{2}$ as shown in Table 6.2.2. No aerosol samples were taken during this period and the opacity meter registered an aerosol density well below its threshold of $1 \mathrm{~g} / \mathrm{m}^{3}$.

Concrete erosion began after 135 minutes when the oxide charge became completely molten. The $\mathrm{ZrO}_{2}$ insulator board separating the $\mathrm{UO}_{2}-\mathrm{ZrO} \mathrm{Z}_{2}-\mathrm{Zr}$ material from the charge was incorporated into the melt between 135 to 140 minutes, thus 


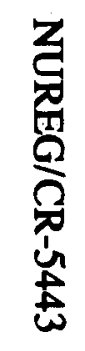

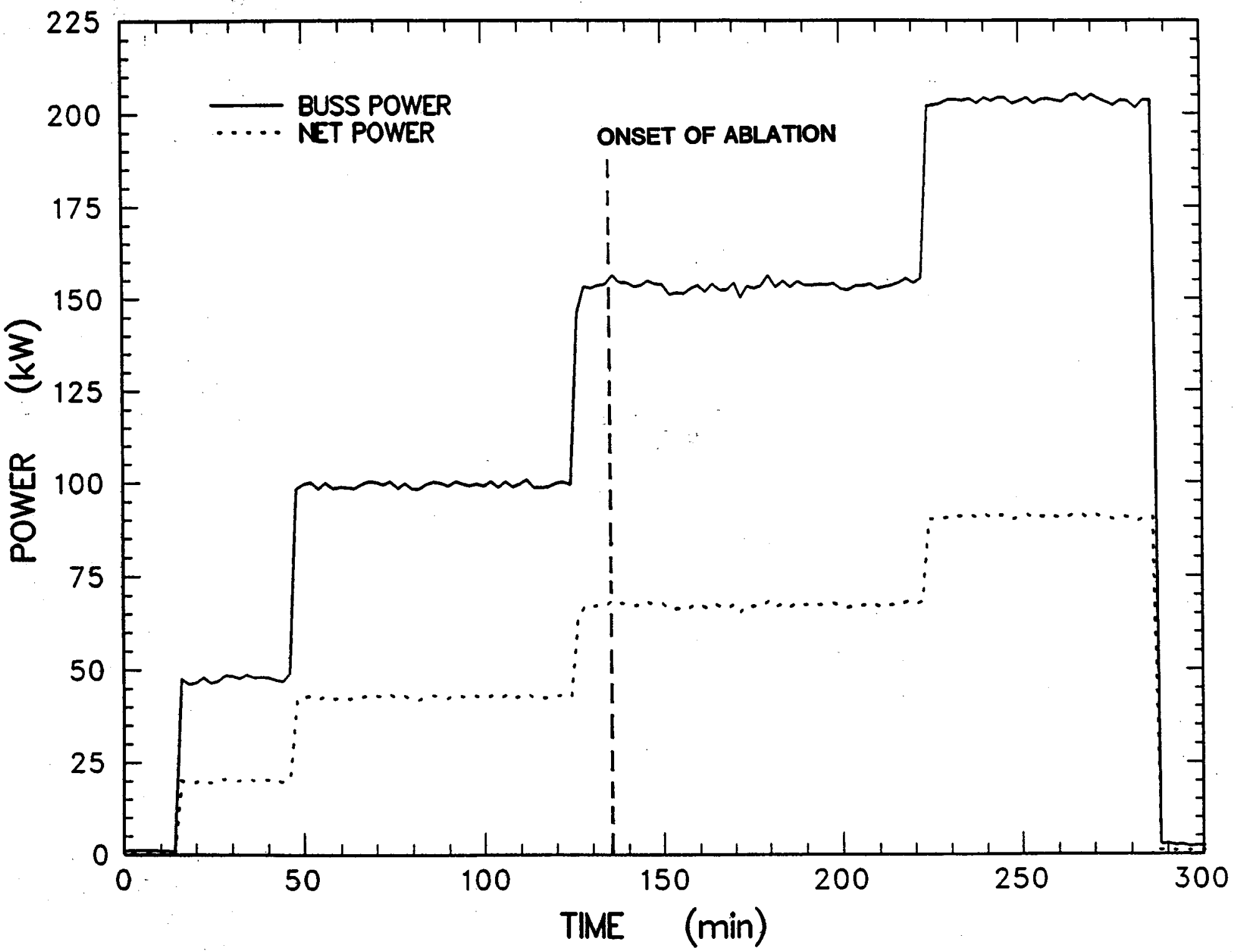

Figure 7.1 Total and net power histories for SURC-1 


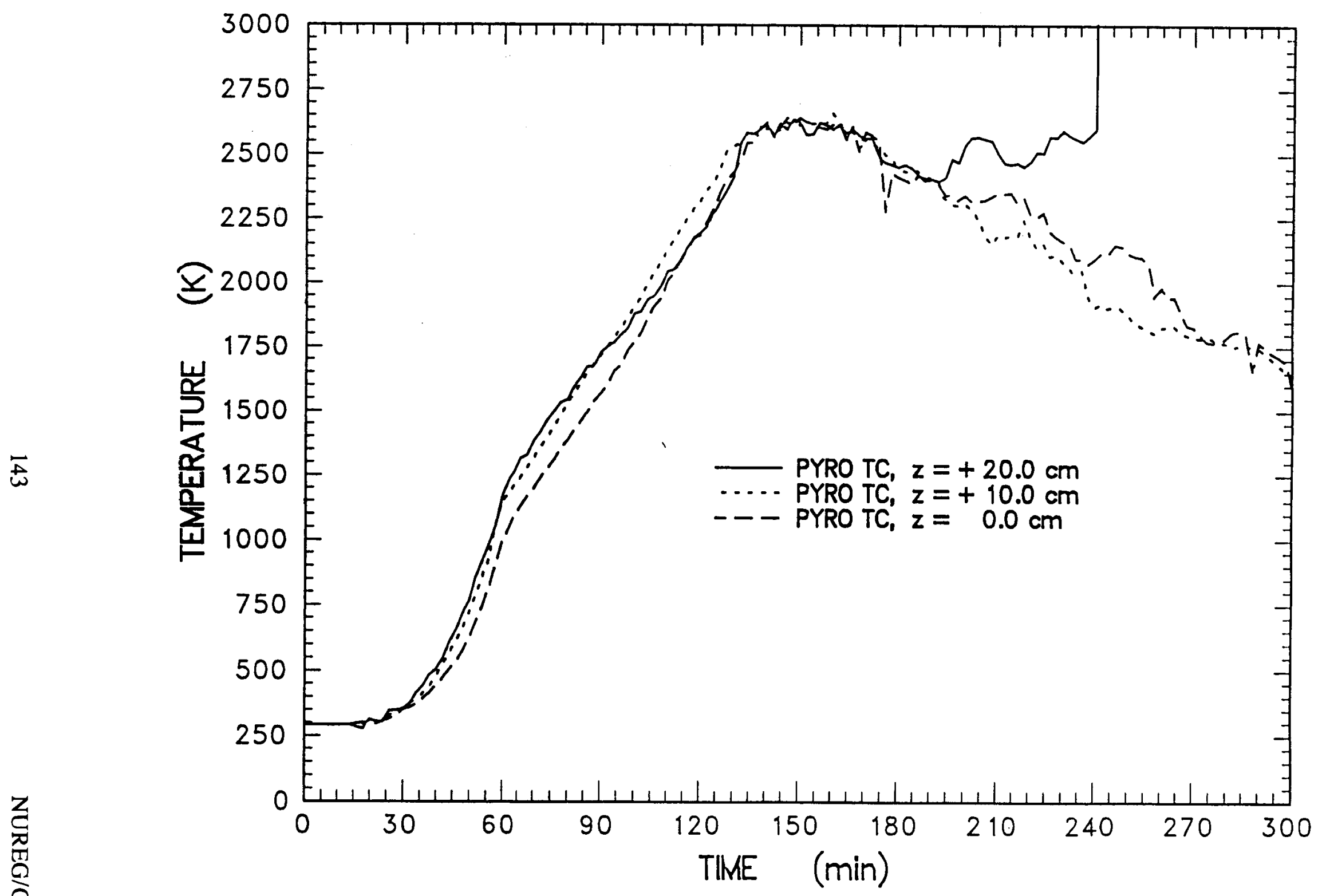

Figure 7.2 Thermal response of the charge measured by type $\mathrm{C}$ thermocouples installed in the tungsten pyrotubes 
孞

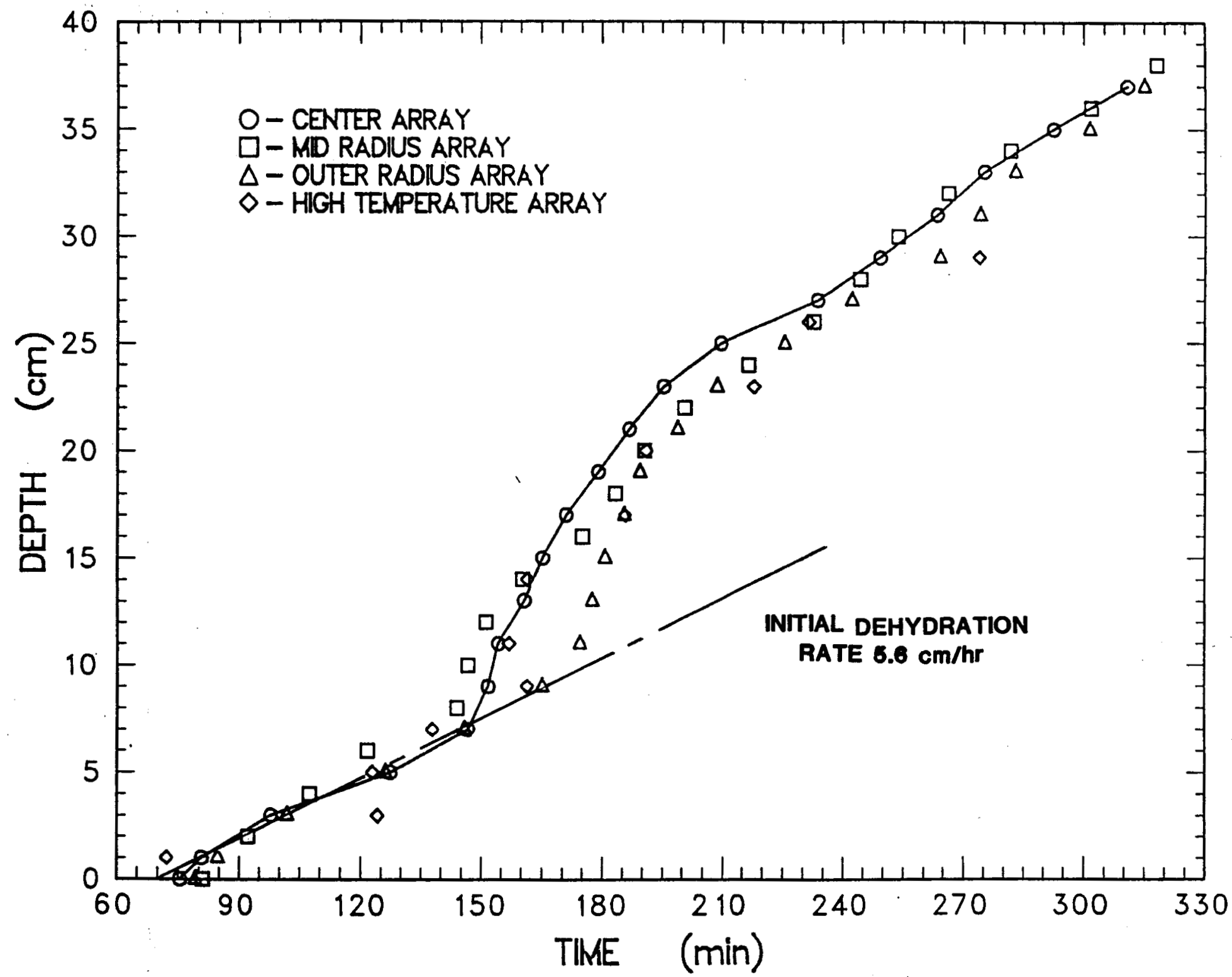

$\overrightarrow{8}$

Figure 7.3 Location of the dehydration front for SURC-1 


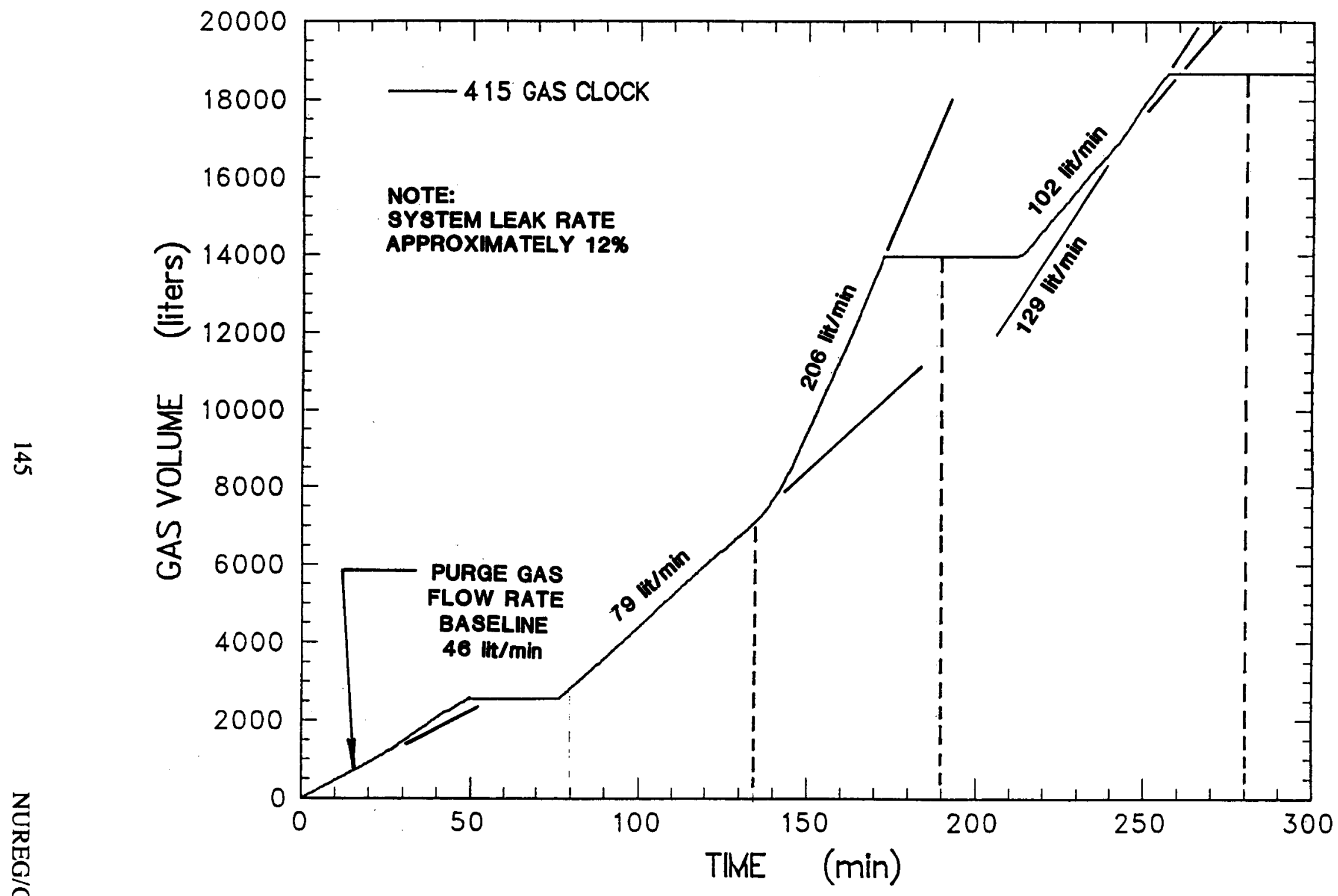

Figure 7.4 Total volume and gas flow rate (alpm) indicated by the $\mathbf{4 1 5}$ gas clock 
initiating the attack. The meltpool temperatures at 135 minutes were 2400 to $2580 \mathrm{~K}$. The peak meltpool temperature measured by the type $\mathrm{C}$ thermocouple installed in the pyrotube at $\mathrm{z}=$ $+10 \mathrm{~cm}$ was $2660 \mathrm{~K}$ at 160 minutes (see Figure 7.5). These temperatures decreased to $2400 \mathrm{~K}$ at 190 minutes as $17 \mathrm{~cm}$ of concrete were eroded at a rate of $14.2 \mathrm{~cm} / \mathrm{hr}$ as shown in Figure 7.6. The reaction gas flow rate between 135 and 190 minutes averaged 150 slpm (180 alpm)and had a typical composition of $5 \% \mathrm{H}_{2}-5 \%$ $\mathrm{H}_{2} \mathrm{O}-85 \% \mathrm{CO}-5 \% \mathrm{CO}_{2}$ (Table 6.2.2). Twelve aerosol filter samples (Table 6.4.1), eight impactor samples ( Table 6.4.2), and a cyclone sample (Table 6.4.3) were taken during this period. These samples indicated aerosol densities ranging from 30 to $200 \mathrm{~g} / \mathrm{m}^{3}$ and were rich in silicon, potassium, and barium, with trace amounts of tungsten, cerium, molybdenum, and uranium (Tables 6.4.7 and 6.4.8). The size distribution of these aerosols ranged from 0.4 to 25 microns with a mass mean diameter of 3 microns as shown in Figures 6.4.2 through 6.4.6.

Between 190 and 220 minutes the erosion rate dropped from $14.2 \mathrm{~cm} / \mathrm{hr}$ to $2.5 \mathrm{~cm} / \mathrm{hr}$ after all of the $\mathrm{Zr}$ metal had been oxidized. The meltpool temperatures during this period ranged from 2400 to $2150 \mathrm{~K}$ as an additional $2 \mathrm{~cm}$ of concrete were eroded. The reaction gas flow rate decreased to 40 slpm (48 alpm). (Figure 7.4) and had a typical composition of $7 \% \quad \mathrm{H}_{2}-8 \% \quad \mathrm{H}_{2} \mathrm{O}-75 \% \mathrm{CO}-10 \%$ $\mathrm{CO}_{2}$ (Table 6.2.2). No aerosol impactor samples or filter samples were taken during this period. Aerosols collected from the gravel filter had traces of calcium and tungsten in addition to abundant amounts of uranium, molybdenum, silicon, sodium, and potassium.

At 220 minutes, the gross power to the charge was increased from $150 \mathrm{~kW}$ to $200 \mathrm{~kW}$ (Figure 7.1). This resulted in higher erosion rates, higher gas release rates, and higher aerosol release rates. The meltpool temperature was $1750 \mathrm{~K}$ to $2250 \mathrm{~K}$ (Figure 7.2) during the final 60 minutes of the test. The erosion rate increased from $2.5 \mathrm{~cm} / \mathrm{hr}$ to $12.5 \mathrm{~cm} / \mathrm{hr}$ (Figure 7.6) as an additional $9 \mathrm{~cm}$ of concrete were eroded bringing the total erosion to $27 \mathrm{~cm}$ (Figure 7.6). The reaction gas flow rate went from 40 to 80 slpm (48 to 96 alpm) (Figure 7.4) and the gas composition was $5 \% \mathrm{H}_{2}-5 \%$ $\mathrm{H}_{2} \mathrm{O}-80 \% \mathrm{CO}-10 \% \mathrm{CO}_{2}$ (Table 6.2.2). Aerosol samples were taken during this period which averaged $60 \mathrm{~g} / \mathrm{m}^{3}$ and had a mean mass diameter of 2 microns.

After 287 minutes of heating and 160 minutes of continuous concrete erosion, the gravel filter bed in SURC-1 became plugged causing significant overpressures in the containment vessel as shown in Figure 7.7. Power to the test was shut down at this point and the test was terminated. Posttest examination of the crucible and vessel indicated three distinct layers of fine aerosol deposition in the gravel filter bed. Analysis of these layers indicated high concentrations of tungsten in the top layer and much lower amounts in the middle and bottom layers. Significant amounts of cerium, barium, molybdenum, and uranium were also recorded. The crucible materials were intact after the experiment and little or no sidewall attack was noted in posttest $\mathrm{x}$-ray examinations. A large solidified meltpool was found in the bottom of the SURC-1 crucible which extended all the way across its diameter and $27 \mathrm{~cm}$ below the original concrete interface. There were no observed anomalies in the final erosion pattern.

The initial temperatures in the SURC-1 test were in excess of $2500 \mathrm{~K}$ and erosion rates for the first 5 minutes were as high as $119 \mathrm{~cm} / \mathrm{hr}$. Both chemical energy and decay heat power appear to contribute to these observed phenomena. As the $\mathrm{Zr}$ content of the melt is depleted by oxidation and concrete byproducts are incorporated into the meltpool both temperatures and erosion rates are seen to decrease.

The sustained temperatures of 2400 to $2150 \mathrm{~K}$ are observed for over 100 minutes following the initial rapid erosion period. This is well above the liquidus temperature of limestone concrete 


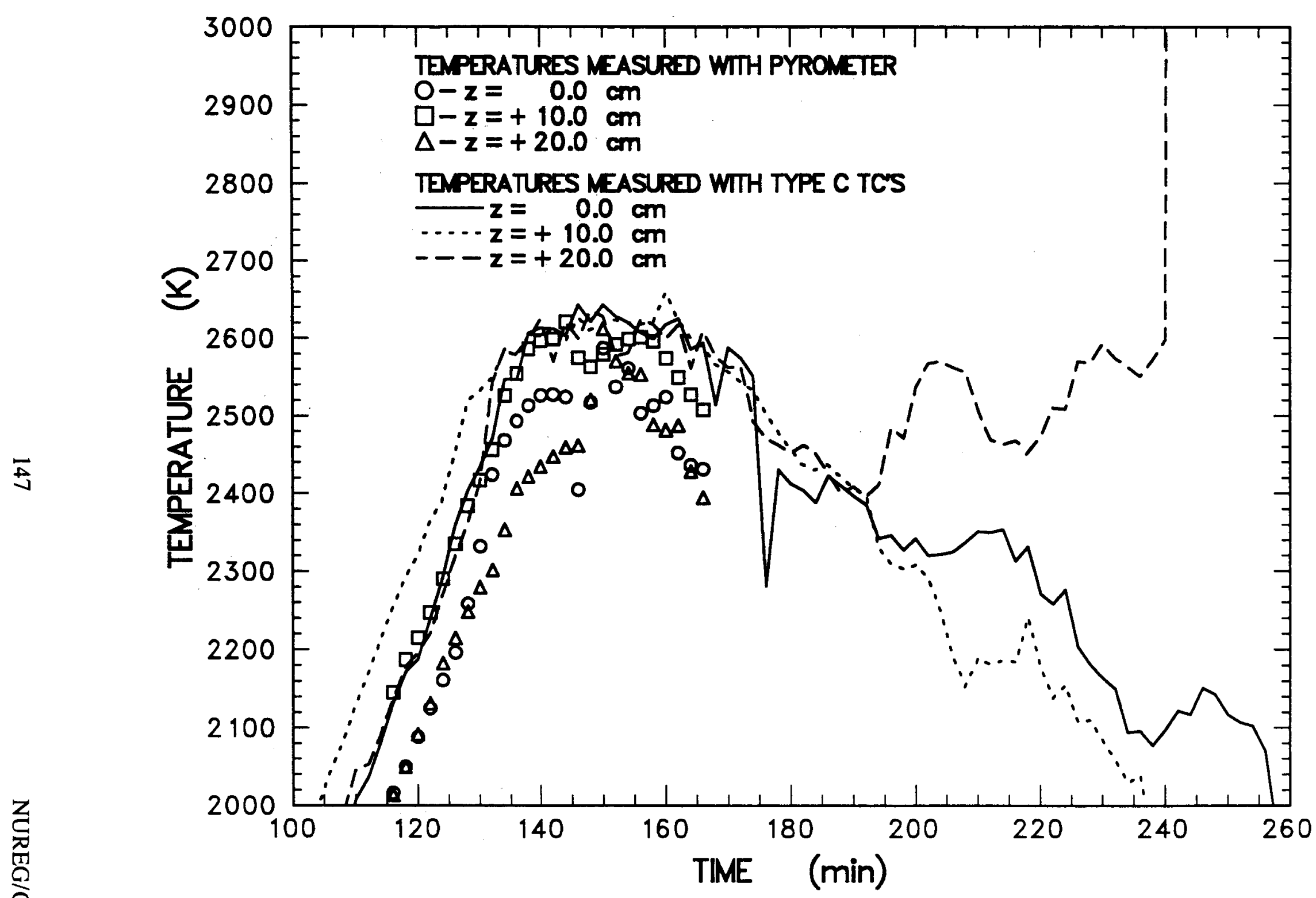

Figure 7.5 Comparison of charge temperatures measured by the fiber optic pyrometers and the type $\mathbf{C}$ thermocouples installed in the tungsten pyrotubes 


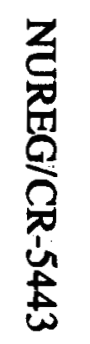

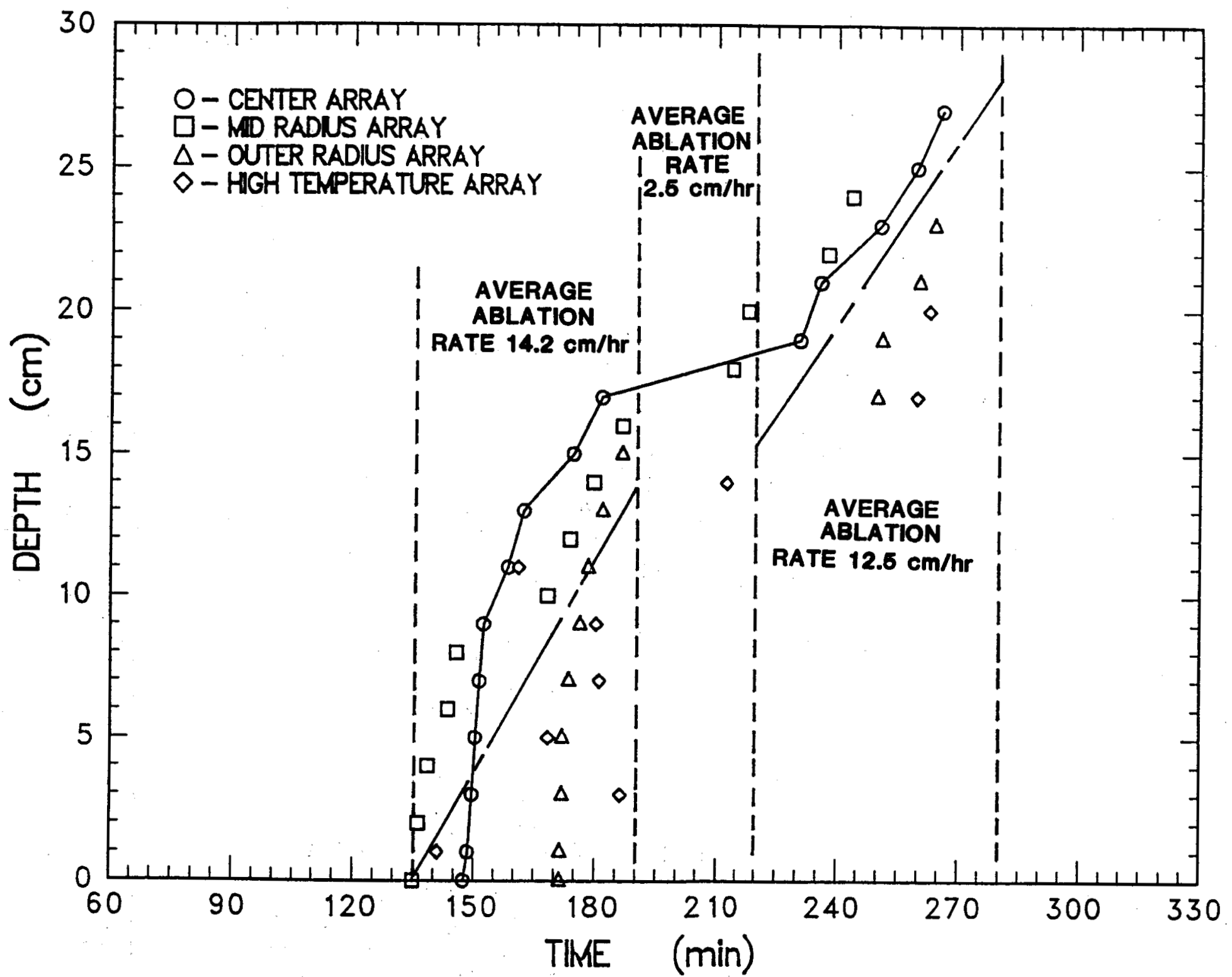

$\vec{\Phi}$

$\vec{\infty}$

Figure 7.6 Location of the ablation front and average ablation rates during different periods of the SURC-1 experiment 


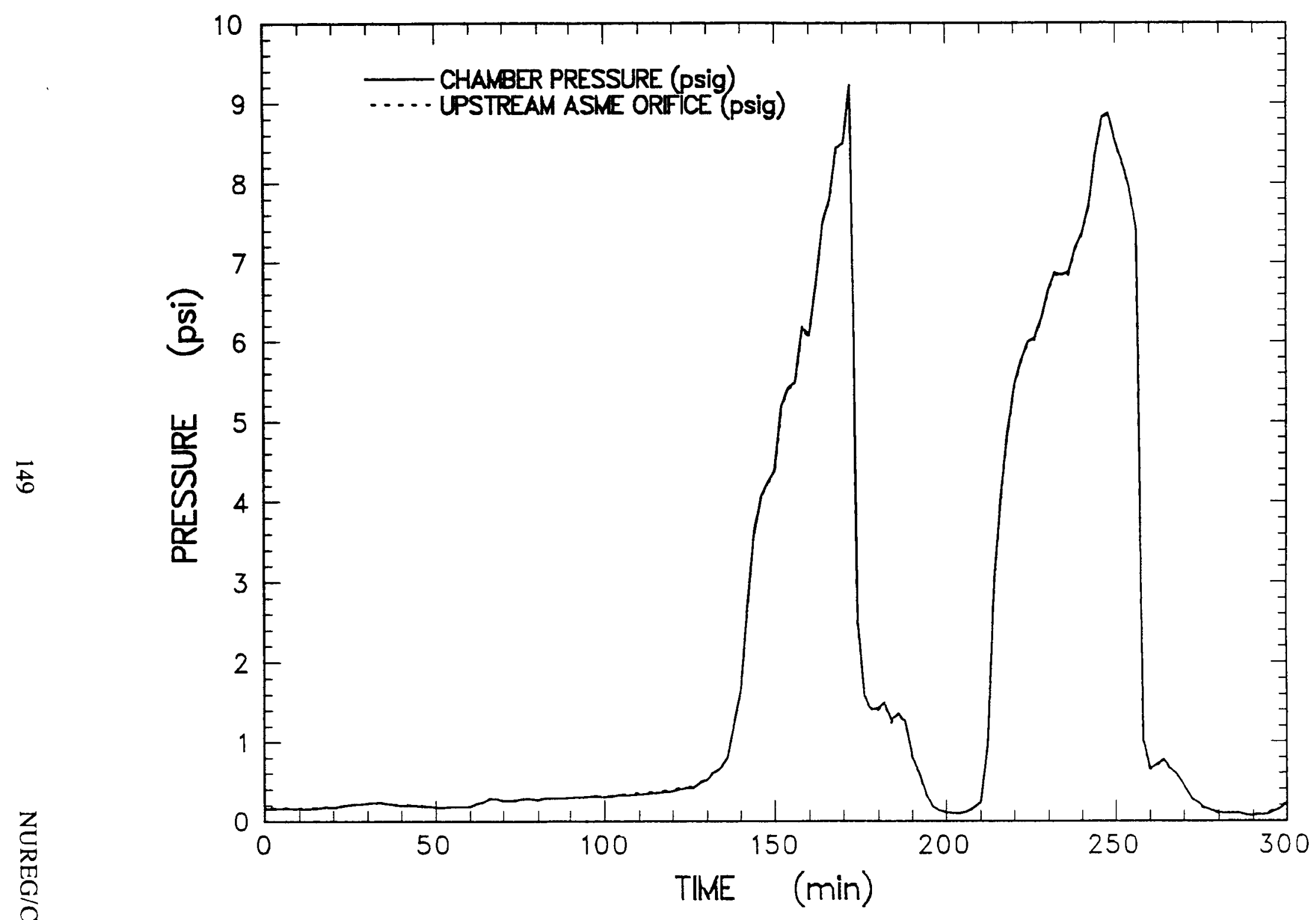

Figure 7.7 Pressure history inside the containment vessel 
$(1653-1873 \mathrm{~K})$ and implies that there is a significant thermal resistance between the molten oxide pool and the concrete. An increase in power to the oxide pool also increases the oxide pool temperature as well as the erosion rate.

Aerosols are continuously released in concentrations ranging from 30 to $200 \mathrm{~g} / \mathrm{m}^{3}$. Although the composition of these aerosols is mostly concrete materials, significant amounts of barium and small amounts of cerium, molybdenum, and uranium are also found. These amounts are orders of magnitude higher than would be predicted from mechanical release mechanisms. This implies that the aerosol release is predominantly vaporization driven and would be expected to continue as long as significant amounts of gas generation continued.

The aerosols changed in composition and release rate over the course of the test. Generally, high melt temperatures and high gas evolution rates produce high aerosol releases. The melt chemistry will influence the type of materials released. Early in the test, there was zirconium metal present which produced a chemically reducing environment in the melt. Later after the zirconium had been oxidized, a more oxidizing environment was seen in the melt. The zirconium metal appeared to be present during the initial rapid erosion from 130 to 190 minutes. The aerosol composition during this time period is high in barium; barium oxide was reduced to the more volatile barium during this initial part of the test as seen in Figure 6.4.8. At later times after the zirconium has been oxidized and the melt has a more oxidizing environment, molybydenum is oxidized to a more volatile oxide and released (Figure 6.4.8). Tungsten from the susceptor plates is also seen to be released at these later times; it also has a volatile oxide as seen in Figure 6.4.7. Higher silicon release is also seen during the early part of the test as shown in Figure 6.4.7. This illustrates the importance of melt chemistry on release.
The results of the SURC- 1 test generally confirm the observations made in the SURC-2 test with basaltic concrete. Both tests had very similar charge compositions and nearly identical power histories. The key observations made during the tests were (1) high initial temperatures and erosion rates, (2) sustained interaction temperatures in excess of $2000 \mathrm{~K}$, and (3) continuous release of gas and aerosols in large amounts. Table 7.1 provides a summary of the primary data during the early, middle, and late stages of the experiment.

The concrete dehydration history for each experiment was very similar when comparing dehydration depth with time. The limestone concrete in SURC-1 began dehydrating at about 75 minutes and the basalt concrete in SURC-2 began near 55 minutes.

The onset of ablation occurred at about 150 minutes in SURC-1 and 135 minutes in SURC-2. The ablation rate for the two experiments was initially high for the first 2 to 5 minutes calculating to be $119 \mathrm{~cm} / \mathrm{hr}$ for SURC-1 and 150 $\mathrm{cm} / \mathrm{hr}$ for SURC-2. This was followed by an order of magnitude decrease in ablation for the remainder of the experiment in both cases.

The meltpool temperatures increased and peaked at about $2650 \mathrm{~K}$ for SURC-1 and 2720 for SURC-2. The meltpool temperatures then declined as concrete was taken into solution with the $\mathrm{UO}_{2}$.

A comparison of sidewall heat flux profiles calculated at various elevations, for the two experiments, were very similar. The steady state values calculated for each of the locations at the end of the experiment (300 minutes) ranged between $4.5 \times 10^{4} \mathrm{~W} / \mathrm{m}^{2}$ and $1.0 \times 10^{5} \mathrm{~W} / \mathrm{m}^{2}$ in both experiments.

The gas flow rates measured in SURC-1 were generally higher than in SURC-2 because of the composition of the concrete. During the high ablation period, gas flow rates averaged 150 slpm 
Table 7.1 SURC-1 data summary

\begin{tabular}{llll}
\hline & Early (with Zr) & Mid (without Zr) & Late (without Zr) \\
\cline { 2 - 4 } Time & $135-190 \mathrm{~min}$ & $190-220 \mathrm{~min}$ & $220-280 \mathrm{~min}$ \\
Melt Temperature & $2650-2400 \mathrm{~K}$ & $2400-2150 \mathrm{~K}$ & $2250-1750 \mathrm{~K}$ \\
Erosion Rate & $14.2 \mathrm{~cm} / \mathrm{hr}$ & $2.5 \mathrm{~cm} / \mathrm{hr}$ & $12.5 \mathrm{~cm} / \mathrm{hr}$ \\
Gas Flow & $150 \mathrm{slpm}$ & $40 \mathrm{slpm}$ & $80 \mathrm{slpm}$ \\
Gas Composition & $5 \% \mathrm{H}_{2}-5 \% \mathrm{H}_{2} \mathrm{O}$ & $7 \% \mathrm{H}_{2}-8 \% \mathrm{H}_{2} \mathrm{O}$ & $5 \% \mathrm{H}_{2}-5 \% \mathrm{H}_{2} \mathrm{O}$ \\
& $84 \% \mathrm{CO}-6 \% \mathrm{CO}_{2}$ & $75 \% \mathrm{CO}-10 \% \mathrm{CO}_{2}$ & $80 \% \mathrm{CO}-10 \% \mathrm{CO}_{2}$ \\
Aerosol Density & $50 \mathrm{~g} / \mathrm{m}^{3}$ & $30 \mathrm{~g} / \mathrm{m}^{3}$ & $60 \mathrm{~g} / \mathrm{m}^{3}$ \\
\hline
\end{tabular}


for SURC-1 and $110 \mathrm{slpm}$ for SURC-2. In the mid to later stages of the experiments, gas flow rates averaged between $40-80 \mathrm{slpm}$ and $20-60$ slpm for SURC-1 and SURC-2 respectively.

Aerosol concentrations in the early and middle stages of SURC-1 were lower than for the same period in SURC-2. In the later stage the opposite was true. The aerosol concentration in SURC-1 was higher than SURC-2. For SURC-1, the initial and middle stage concentrations measured $50 \mathrm{~g} / \mathrm{m}^{3}$ and $30 \mathrm{~g} / \mathrm{m}^{3}$ respectively. For the same period in SURC-2, concentrations measured 90 $\mathrm{g} / \mathrm{m}^{3}$ and $50 \mathrm{~g} / \mathrm{m}^{3}$. In the later stages of the experiments SURC-1 averaged a slightly higher concentration which measured $60 \mathrm{~g} / \mathrm{m}^{3}$ when compared to SURC-2 which measured $40 \mathrm{~g} / \mathrm{m}^{3}$.

The aerosol particulate size is nearly the same for both experiments with each exhibiting particle diameters ranging from 0.4 to 25 microns. Both experiemtns indicated a mean particle size of 2 3 microns with a peak between 10 and 25 microns.

The SURC-1 test was excellent in all respects and successfully met all of the test goals. This test should provide comprehensive, redundant, and well-characterized information on molten oxide interactions with limestone concrete which is well-suited for code validation efforts. 


\subsection{References}

Baker, W. C., and J. F. Pouchot, "The Measurement of Gas Flow," Control Technology News, Vol. 33, No. 1, 1983.

Beck, J. V., B. Blackwell, and C. R. St. Clair, Jr., Inverse Heat Conduction, New York, NY, Wiley Interscience, 1985.

Berglund, R. N., and B. Y. H. Liu, "Generation of Monodisperse Aerosol Standards," Environmental Science Technology, Vol. 7, p. 147-153, 1973.

Blose, R. E., J. E. Gronager, A. J. Suo-Antilla, and J. E. Brockmann, SWISS: Sustained Heated Metallic Melt/Concrete Interactions with Overlying Water Pools, NUREG/CR-4727, SAND85-1546, Sandia National Laboratories, Albuquerque, NM, 1987.

Bradley, D. R., and E. R. Copus, Interaction of Hot Solid Core Debris with Concrete, NUREG/CR-4558, SAND85-1739, Sandia National Laboratories, Albuquerque, NM, 1986.

Brockmann, J. E., "Ex-Vessel Releases: Aerosol Source Terms in Reactor Accidents," Progress in Nuclear Energy, Vol. 19, p. 17-68, 1987.

Brockmann, J. E., B. Y. H. Liu, and P. H. McMurry, "A Sample Extraction Diluter for Ultra Fine Aerosol Sampling," Aerosol Science and Technology, Vol. 3, Number 4, pp. 441-451, 1984.

Bradley, D. R., Jr. and D.R. Gardner, CORCON-MOD3: An Integrated Computer Model for Analysis of Molten-Core Concrete Interactions. Users Manual, NUREG/CR-5843, SAND92-0167, Sandia National Laboratories, Albuquerque, NM, 1992.
Copus, E. R., Development of the Inductive Ring Susceptor Technique for Sustaining Oxide Melts, NUREG/CR-3043, SAND82-2546, Sandia National Laboratories, Albuquerque, NM 1983.

Copus, E. R., R. E. Blose, J. E. Brockmann, R. B. Simpson, and D. A. Lucero, CoreConcrete Interactions Using Molten $\mathrm{UO}_{2}$ with Zirconium on a Basaltic Basemat: The SURC-2 Experiment, NUREG/CR-5564, SAND90-1022, Sandia National Laboratories, Albuquerque, NM, 1992.

Copus, E. R., R. E. Blose et al., Core-Concrete Interactions Using Molten Steel with Zirconium on a Basaltic Basemat: The SURC-4 Experiment, NUREG/CR-4994, SAND87-2008, Sandia National Laboratories, Albuquerque, NM, 1989.

Cushing, K. E., G. E. Lacey, J. D. McCain, and W. B. Smith, Particulate Sizing Techniques for Control Device Evaluation: Cascade Impactor Calibrations, EPA-600/2-76-280, U.S. Environmental Protection Agency, 1976.

Davies, C. N., and M. Subari, "Aspiration Above Wind Velocity of Aerosols with Thin-Walled Nozzles Facing and at Right Angles to the Wind Direction," J. Aerosol Sci., Vol. 13, Number 1, pp. 59-71, 1982.

Gronager, J. E., A. J. Suo-Antilla, and J. E. Brockmann, TURC2 and 3: Large Scale $\mathrm{UO} 2 / \mathrm{ZrO} 2 / \mathrm{Zr}$ Melt-Concrete Interaction Experiments and Analysis, NUREG/CR-4521, SAND86-0318, Sandia National Laboratories, Albuquerque, NM, 1986.

Holman, J. P., Experimental Methods for Engineers, New York, NY, McGraw-Hill, Inc., 1966. 
Jayasekera, P. N., and C. N. Davies, "Aspiration Below Wind Velocity of Aerosols with Sharp Edged Nozzles Facing the Wind," J. Aerosol Sci., Vol. 11, pp. 535-547, 1980.

Marple, V. A., and Willeke, K., Inertial Impactors in Aerosol Measurement, Gainesville, FL, University Presses of Florida, pp. 90-107, 1979.

McFarland, A. R., C. A. Ortiz, and R. W. Bertch Jr., "A High Capacity Preseparator for Collecting Large Particles," AIHA Paper No. 80, Texas A\&M University, Civil Engineering Department, Air Quality Lab Publication 3718/04/78/ARM, 1978.
Powers, D. A., J. E. Brockmann, and A. W. Shiver, VANESA: A Mechanistic Model of Radionuclide Release and Aerosol Generation During Core Debris Interactions with Concrete, NUREG/CR-4308, SAND85-1370, Sandia National Laboratories, Albuquerque, NM, 1986.

Powers, D. A., and Arellano, F. E., LargeScale, Transient Tests of the Interaction of Molten Steel with Concrete, NUREG/CR-2282, SAND81-1753, Sandia National Laboratories, Albuquerque, NM, 1982.

The Temperature Handbook, Volume 28, Omega Engineering Inc., P.O. Box 2284, Stamford, CT, 1992. 
APPENDIX A

\section{CALORIMETRIC TEST DATA}


Appendix A

In this appendix data are presented for calorimetry tests conducted on an array of stainless steel susceptor plates simulating the tungsten plates in the charge.
Calculations were made using the data from these tests to calculate the coupling efficiency of the induction power supply to the charge. 


\section{Power Based on Calorimetry Calculations}

Three calibration tests were performed at input powers of 100,175 , and $300 \mathrm{~kW}$, based on power meter readings on the control console of the power supply. The output of the power transducer connected to the buss bars, the thermocouples and flow meter were connected to a Hewlett-Packard HP-1000 data acquisition system for collection and posttest plotting and analysis.

The setup for the calorimetric tests is shown in Figure A-1. The calorimetric test was initiated by starting the data acquisition system, establishing base line data for the instrumentation. The water was turned on and the flow was regulated by a gate valve. After a few minutes of base line data was taken and induction power supply was started and a constant input power was applied to the stainless steel plates. The power supply was run until the differential temperature in the water pool and in the aluminum containment vessel reached a steady state condition.

The power imparted to the stainless steel susceptor plates was calculated using the common energy equation

$$
P_{\text {susceptor }}=\dot{m} C_{p}\left(T_{\text {out }}-T_{\text {in }}\right)
$$

where

$$
\begin{aligned}
\mathrm{P}_{\text {susceptor }}= & \text { Power deposited into the susceptor } \\
& \text { plates } \mathrm{j} / \mathrm{sec} \\
\mathrm{m}= & \text { mass flow of cooling water }(\mathrm{kg} / \mathrm{sec}) \\
\mathrm{C}_{\mathrm{p}}= & \text { specific heat of water }(\mathrm{j} / \mathrm{kg} \bullet \mathrm{K}) \\
\mathrm{T}_{\text {out }}= & \text { temperature of the water flowing out } \\
& \text { of the crucible }(\mathrm{K}) \\
\mathrm{T}_{\mathrm{in}}= & \text { temperature of the water flowing } \\
& \text { into the crucible }(\mathrm{K})
\end{aligned}
$$

The specific heat for water is taken at the mean temperature of the water pool $\left(\left(\mathrm{T}_{\text {out }}-\mathrm{T}_{\text {in }}\right) / 2\right)$.
The fraction of power deposited in the aluminum containment vessel is found similarly. The only difference is that the cooling fluid was a 50/50 mixture of ethylene glycol and water.

For the initial test the input power was $101.7 \mathrm{~kW}$. The output from the power transducer is shown in Figure A-2. The flow rate of water and ethylene glycol/water mixture is shown in Figure A-3 plotted as function of time. The flow rate of water to the crucible and through the containment vessel was 3.6 and 8.8 gallons/minute respectively. The steady state differential temperature measured for the crucible pool and containment vessel was $45.8^{\circ} \mathrm{C}$ and $5.1^{\circ} \mathrm{C}$, respectively. The plot of differential temperature for the crucible pool and aluminum containment vessel is shown in Figures A-4 and A-5, respectively. Converting units and substituting and appropriate values into equation A-1 for the water pool and containment vessel yields $43.5 \mathrm{~kW}$ of power imparted to the tungsten susceptor plates and $10.2 \mathrm{~kW}$ to the aluminum containment vessel.

The coupling efficiency is then defined by the ratio of the power imparted to the plate divided by the total power measured by the power transducer at the buss bars.

$$
\% \text { eff }=P_{\text {plares }} / P_{\text {total }} \times 100
$$

The coupling efficiency of the containment vessel is found likewise.

Power, differential temperature, and flow rate profiles plotted as a function of time for the 175 and $300 \mathrm{~kW}$ calorimetry are shown in Figures A-6 through A-9.

Based on these data, the coupling efficiency for the 175 and $300 \mathrm{~kW}$ power levels were calculated as well as the coupling to the containment vessel. The results of all three calorimetry tests for the susceptor assembly are presented in Table A-1. 
Appendix A

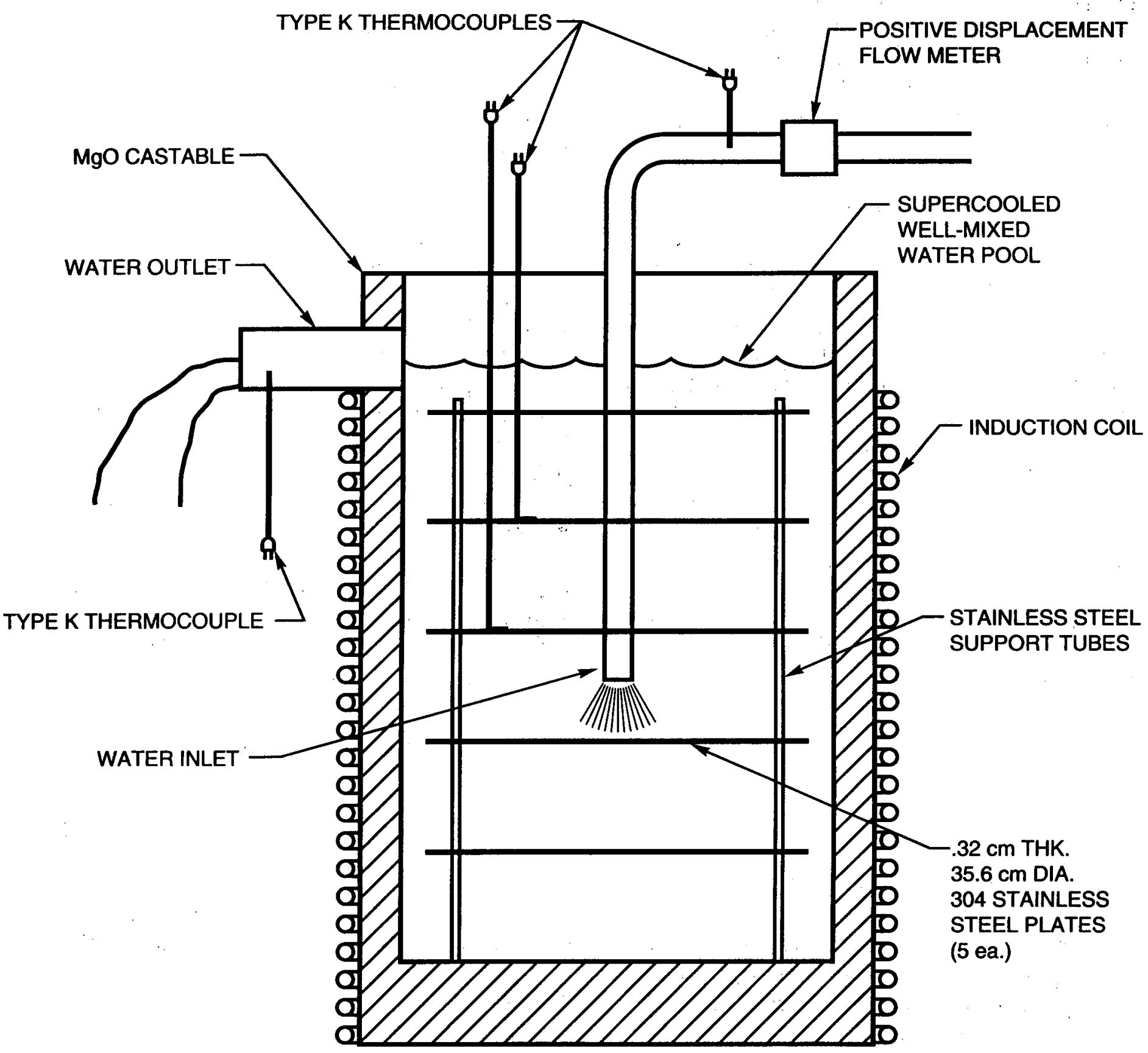

Figure A-1 Crucible, power calibration, SURC experiments 1 and 2 


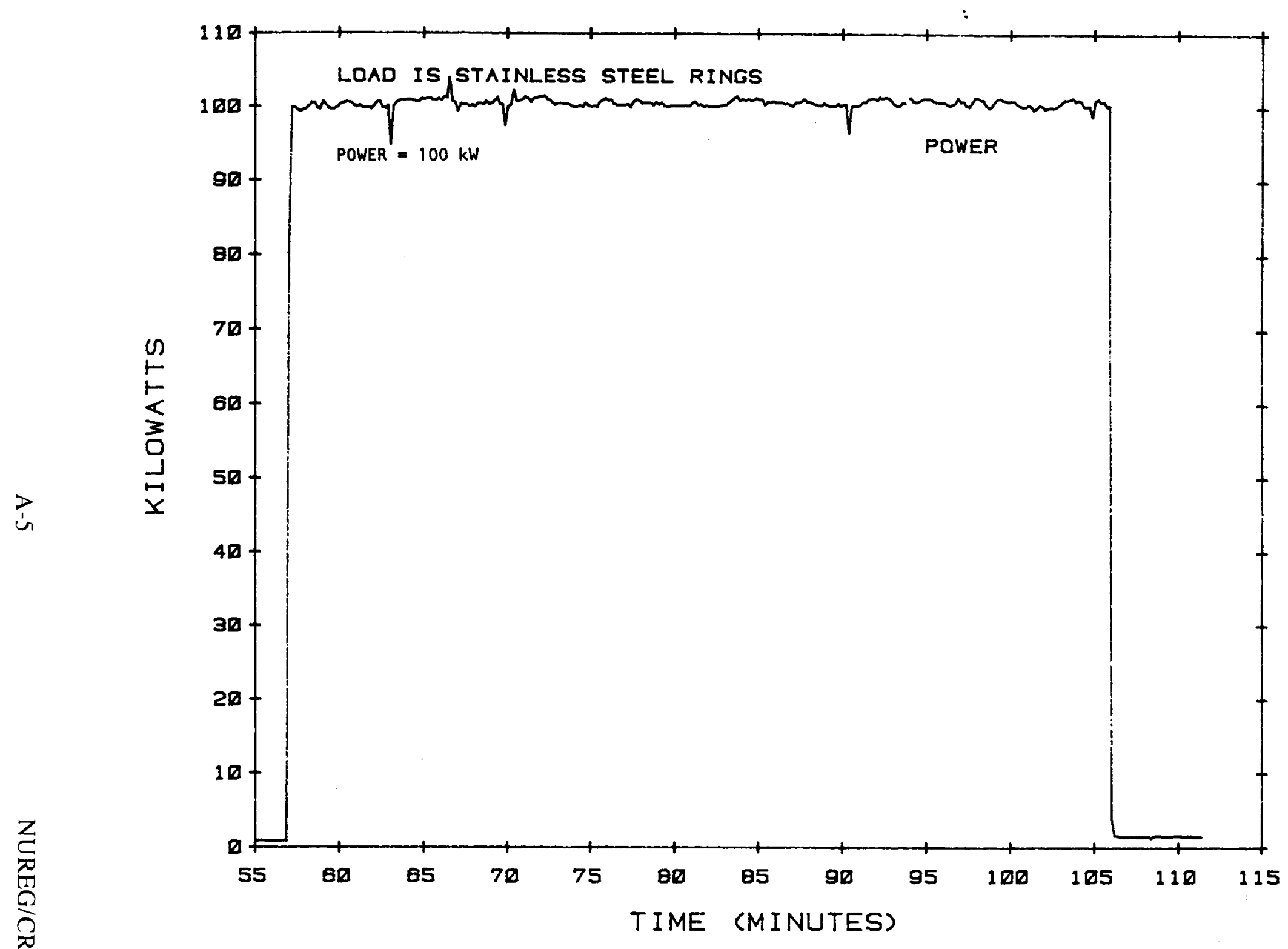

Figure A-2 Plot of total power plotted as a function of time, $100 \mathrm{~kW}$ calorimetric test 


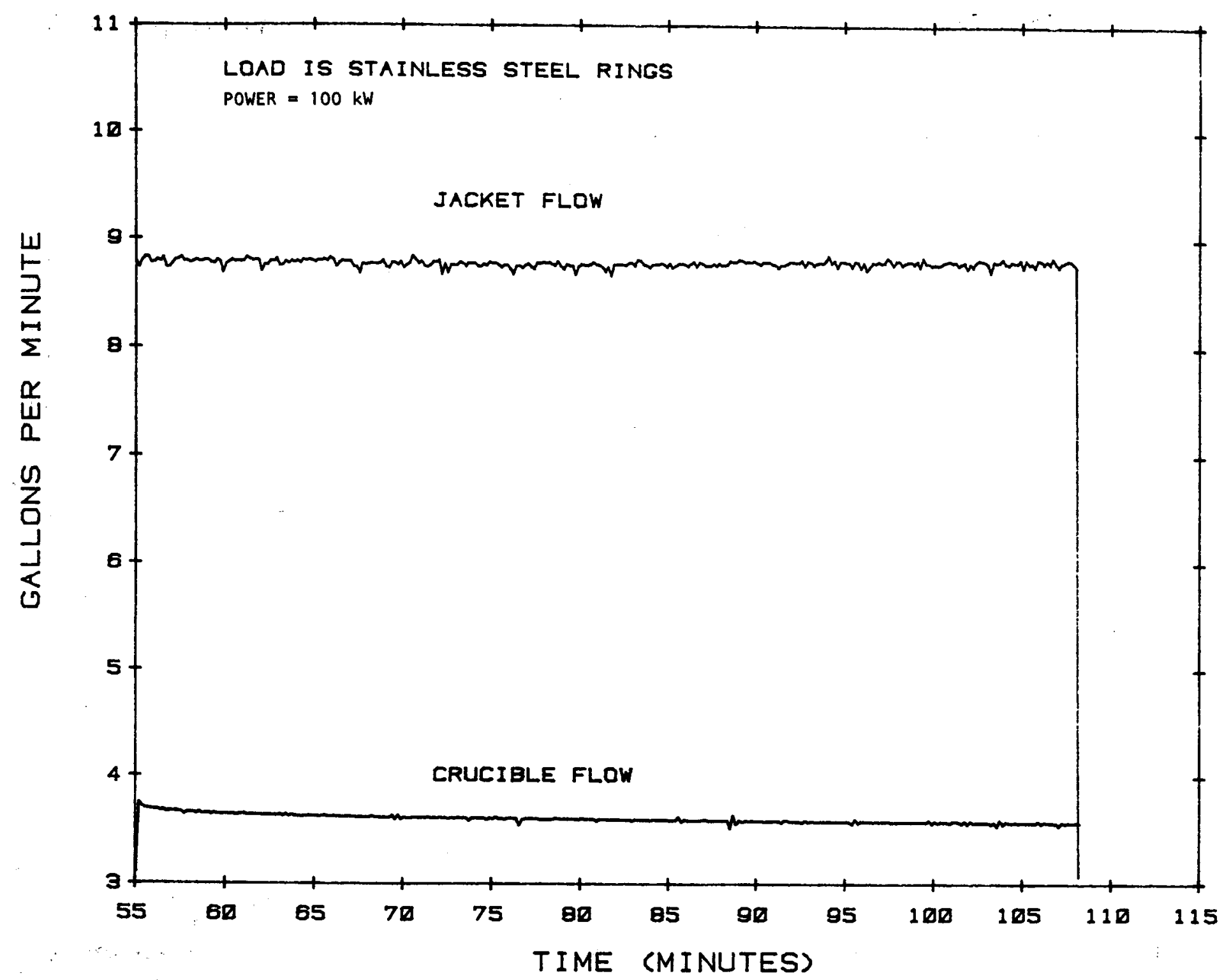

Figure A-3 Flow rate of cooling fluid through the crucible and containment vessel, $100 \mathrm{~kW}$ calorimetric test 


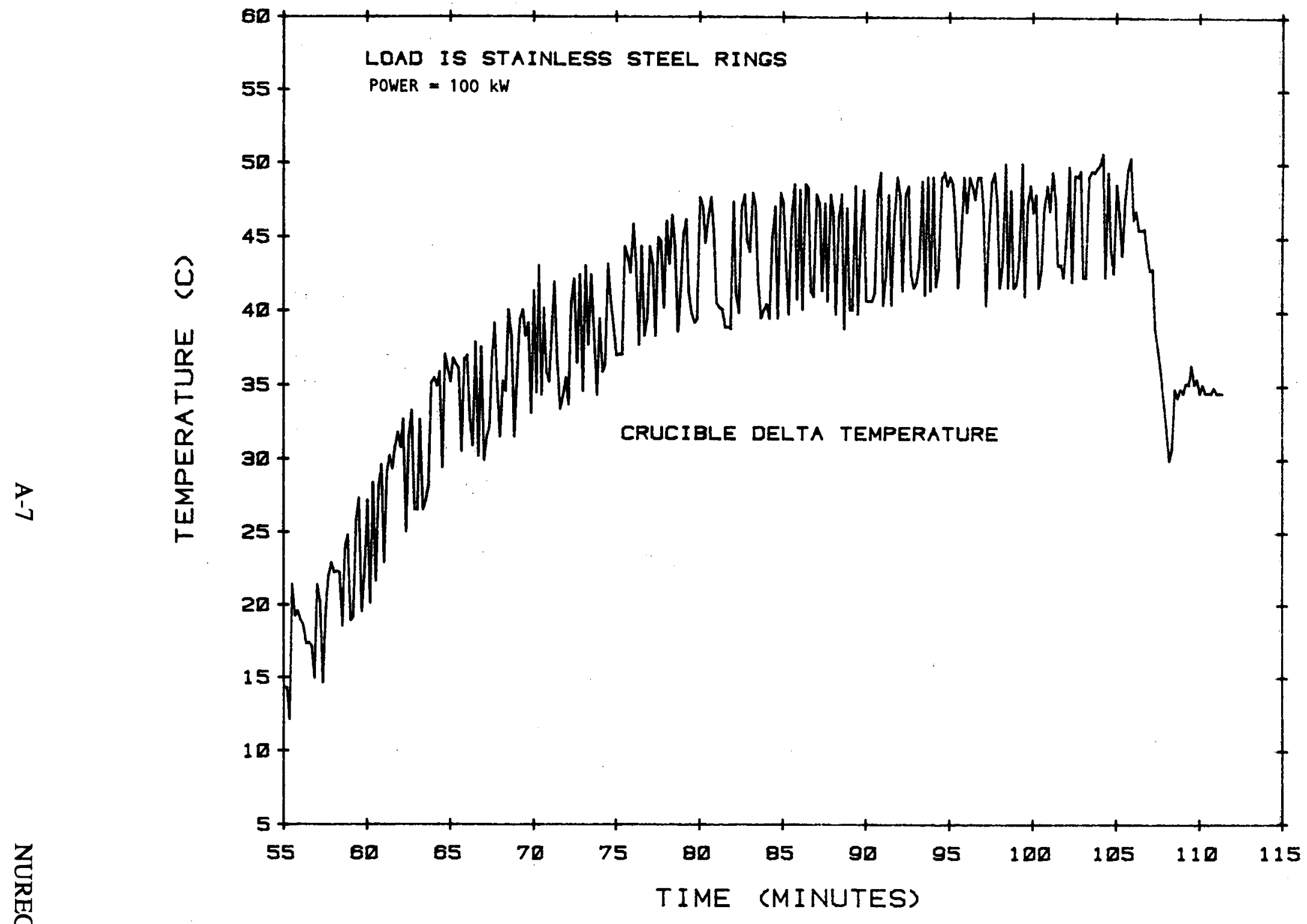

Figure A-4 Differential temperature of the water flowing through the crucible, $100 \mathrm{~kW}$ calorimetric test 


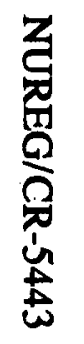

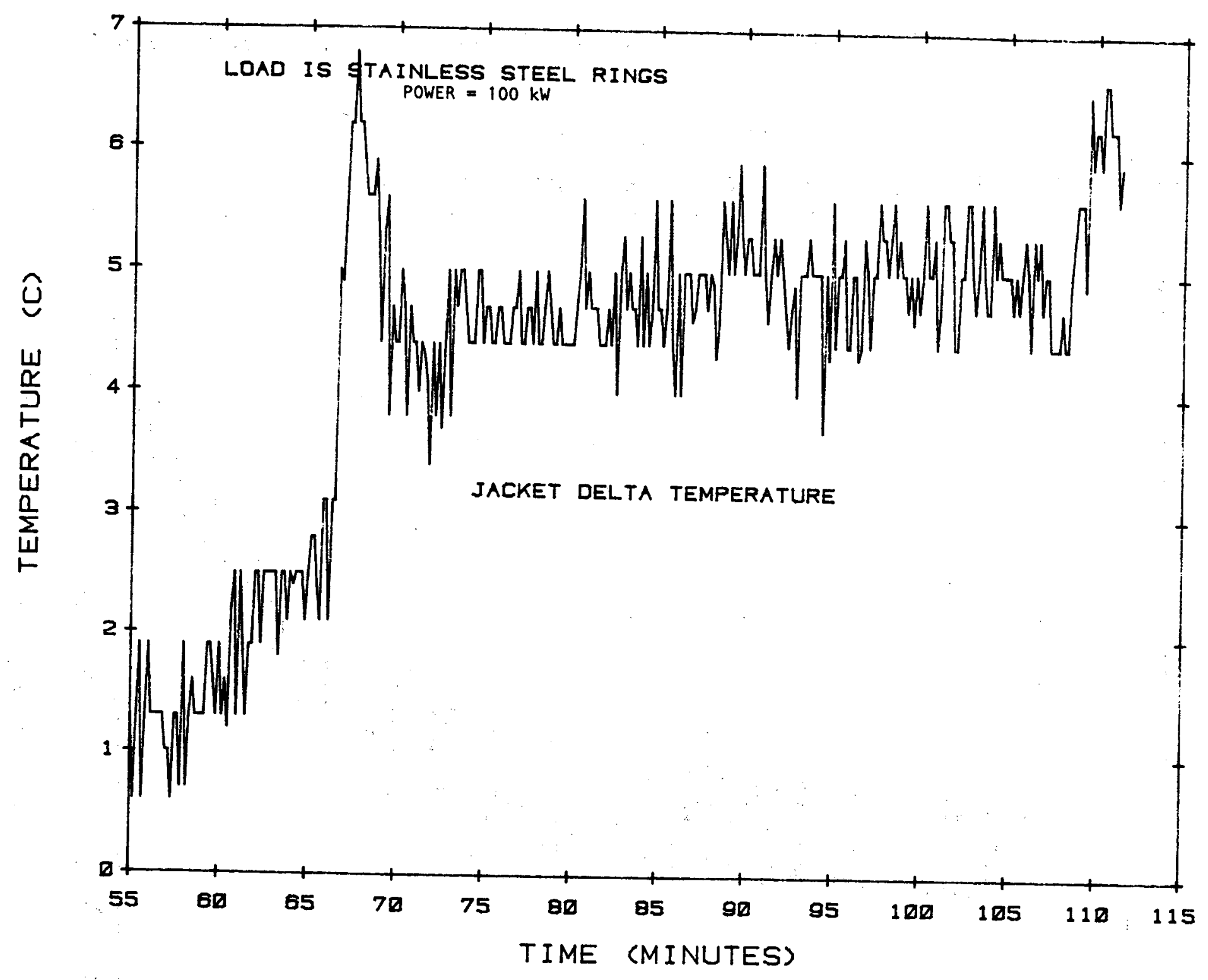

Figure A-5 Differential temperature of the cooling fluid flowing through the aluminum containment vessel, $100 \mathrm{~kW}$ calorimetric test 


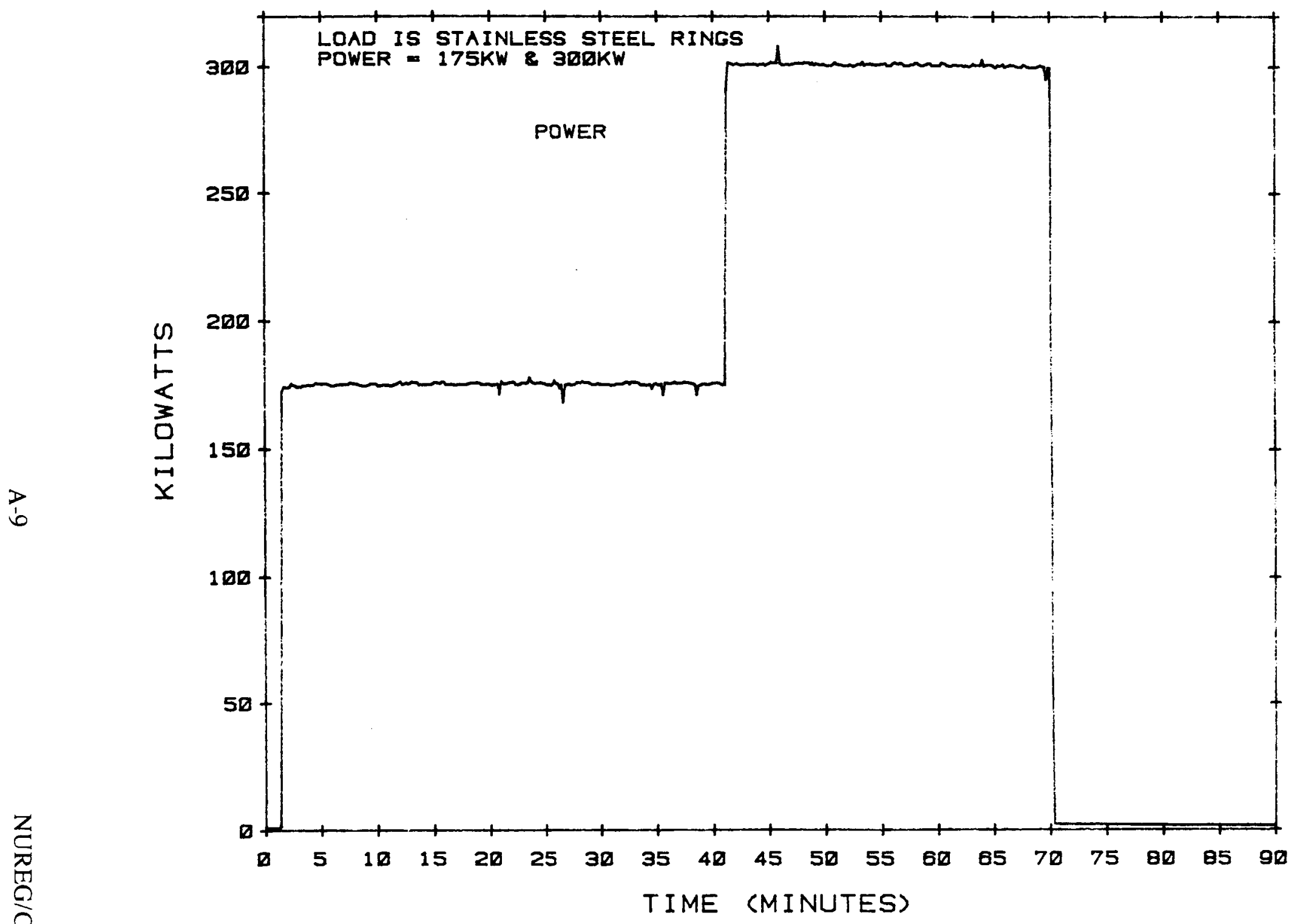

Figure A-6 Plot of total power plotted as a function of time, 175 and $300 \mathrm{~kW}$ calorimetric tests 
Zる.

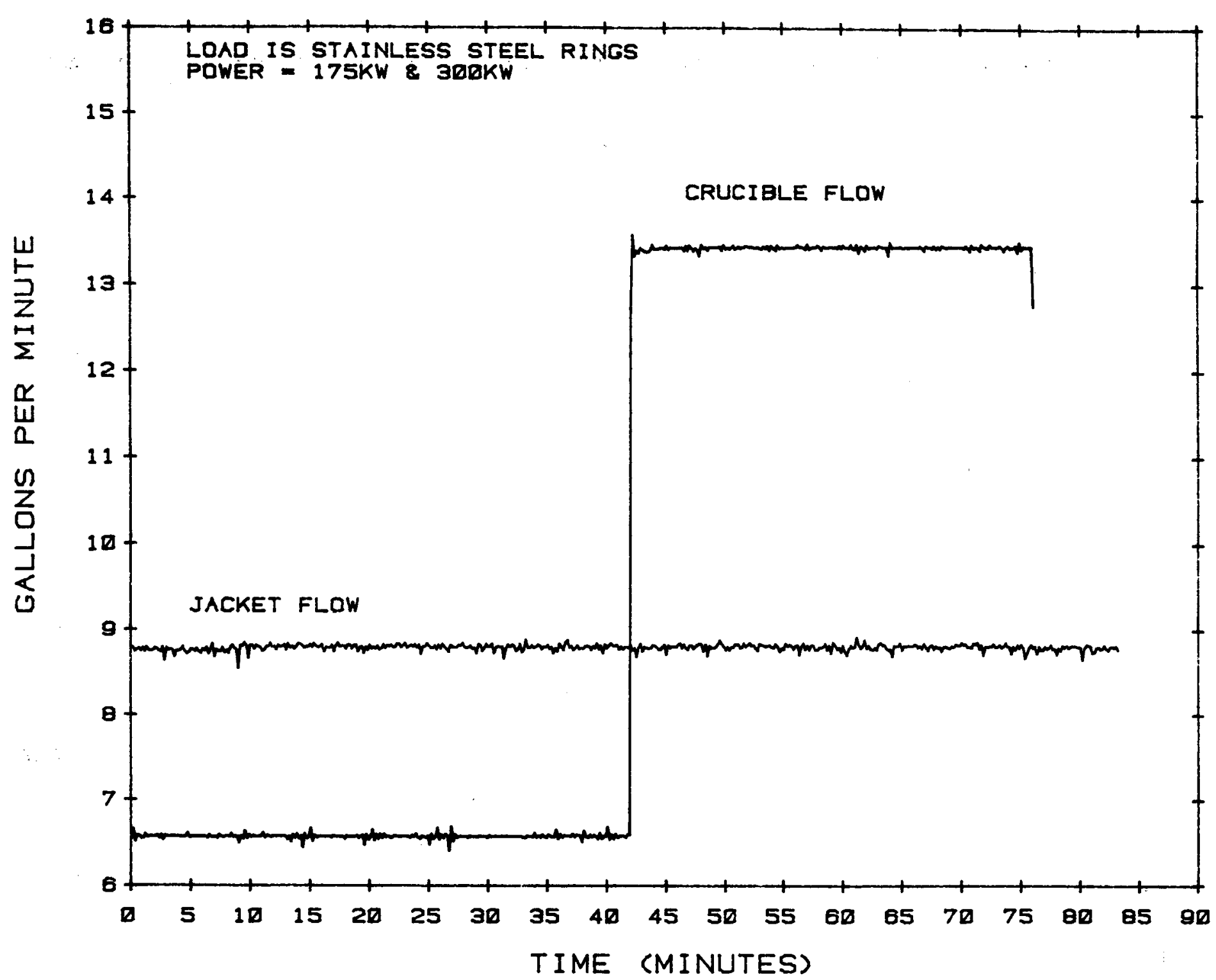

Figure A-7. Flow rate of cooling fluid through the crucible and containment vessel, 175 and $300 \mathrm{~kW}$ calorimetric tests 


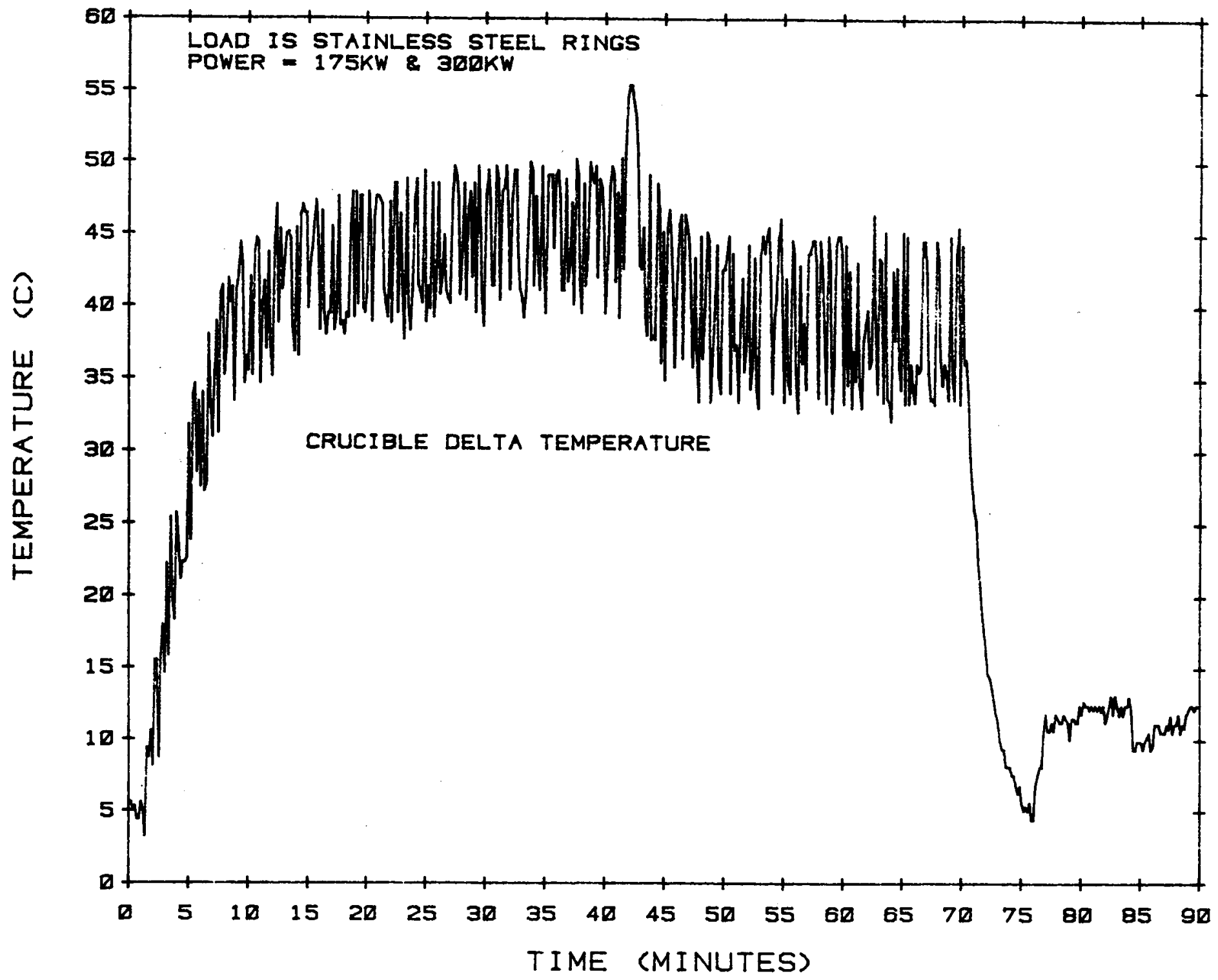

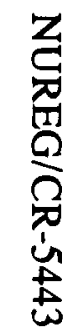




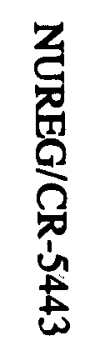

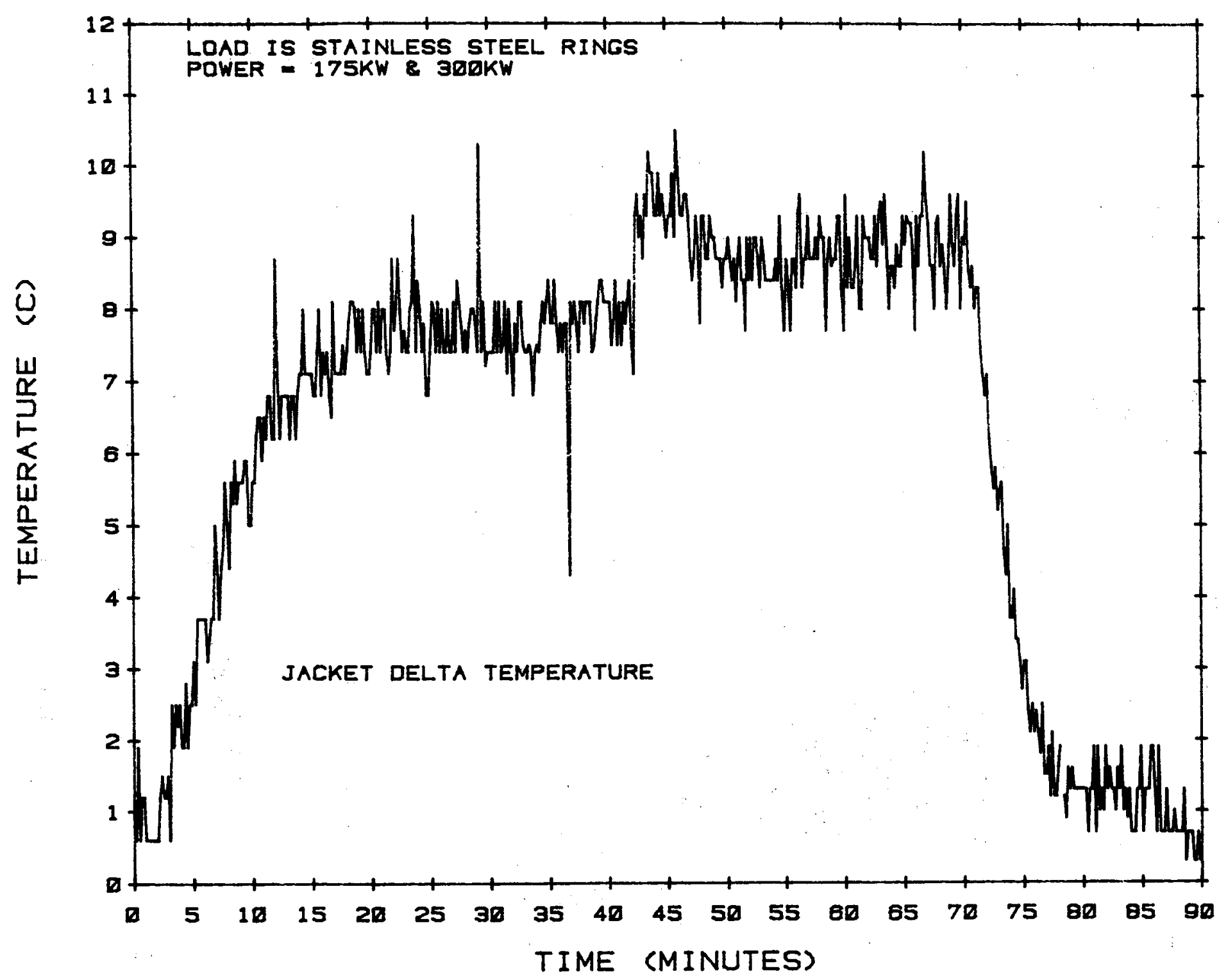

Figure A-9 Differential temperature of the cooling fluid flowing through the containment vessel, 175 and $300 \mathrm{~kW}$ calorimetric tests 
The power imparted to the aluminum containment is presented Table A-2. Included in this table is a calculation of the power applied to the vessel with the power supply operating without the susceptor assembly in place. The power supply essentially operated in a no-load condition.

The calculated coupling efficiencies for the susceptor plate assembly ranged between 42.8 and 45.8 percent for buss power between 101.7 and $301 \mathrm{~kW}$. The efficiency increases slightly with the increase of buss power.
The fraction of total power coupled to the containment vessel ranged between 10.0 and 4.8 percent for the same buss powers described above. As the buss power is increased the power to the vessel remains about the same thus reducing the coupling efficiency. The power coupled to the containment vessel for the no load case is about 3.2 percent higher than the loaded case when the induction power supply operated at essentially the same peak power. 
Appendix A

Table A-1 Susceptor assembly coupling efficiency

\begin{tabular}{cccc}
\hline $\begin{array}{c}\text { Input Power } \\
\text { Console Power } \\
\text { Meter (kw) }\end{array}$ & $\begin{array}{c}\text { Power Measured } \\
\text { at Buss Bars } \\
\text { (kw) }\end{array}$ & $\begin{array}{c}\text { Power Deposited } \\
\text { in Susceptor } \\
\text { Plates (kw) }\end{array}$ & $\begin{array}{c}\text { Coupling } \\
\text { Efficiency }\end{array}$ \\
\hline 100 & 101.7 & 43.5 & $42.8 \%$ \\
175 & 175.5 & 77.5 & 44.2 \\
300 & 301.0 & 137.9 & $45.8 \%$ \\
\hline
\end{tabular}

Table A-2 Aluminum containment vessel coupling efficiency

\begin{tabular}{cccc}
\hline $\begin{array}{c}\text { Input Power } \\
\text { Console Power } \\
\text { Meter (kw) }\end{array}$ & $\begin{array}{c}\text { Power Measured } \\
\text { at Buss Bars } \\
\text { (kw) }\end{array}$ & $\begin{array}{c}\text { Power Deposited } \\
\text { in Susceptor } \\
\text { Plates (kw) }\end{array}$ & $\begin{array}{c}\text { Coupling } \\
\text { Efficiency }\end{array}$ \\
\hline 100 & 101.7 & 10.2 & $10.0 \%$ \\
175 & 175.5 & 15.5 & $8.8 \%$ \\
300 & 301.0 & 14.4 & $4.8 \%$ \\
\hline
\end{tabular}


APPENDIX B

POWER SUPPLY OPERATIONAL DATA 


\section{Appendix B}

In this appendix data is presented related to the operation of the induction power supply. This data includes buss power, flow rate and temperature data for the cooling fluid flowing through the power supply, induction coil and containment vessel. 


\section{Appendix B}

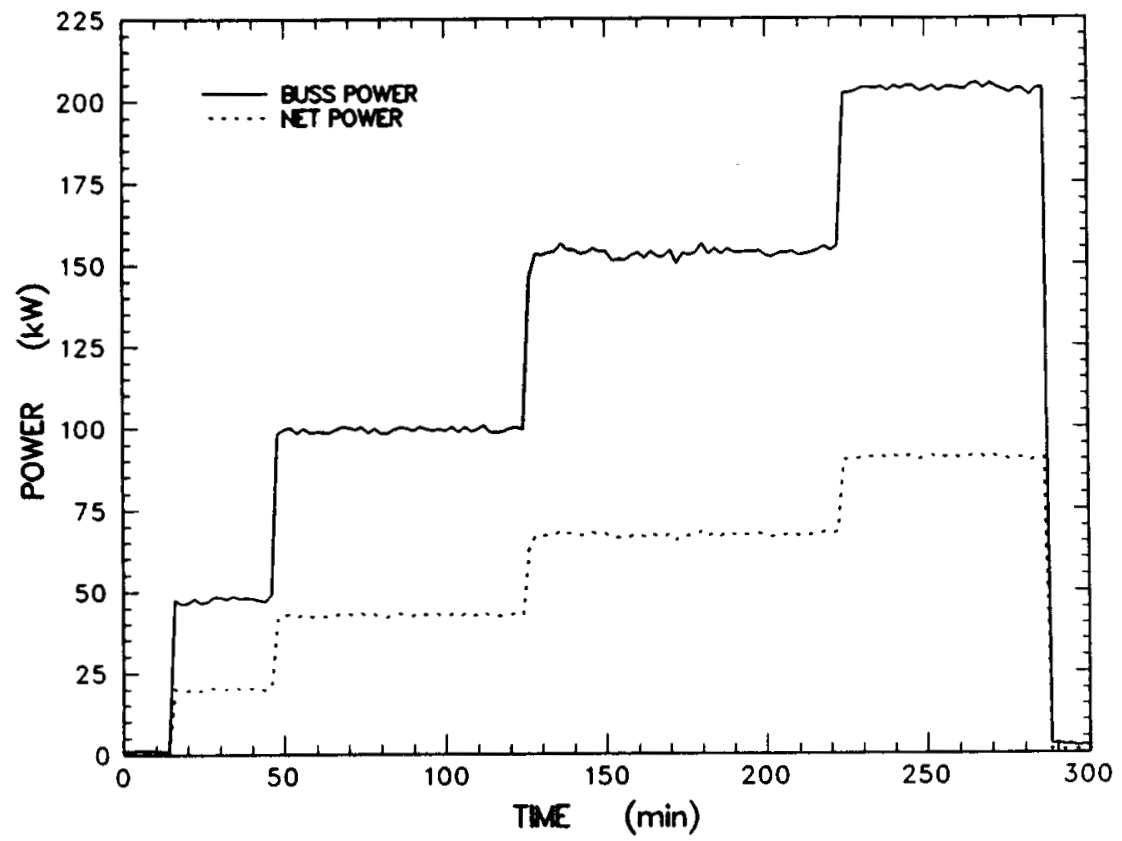

Figure B-1 Power applied at the buss bars during the SURC-1 experiment

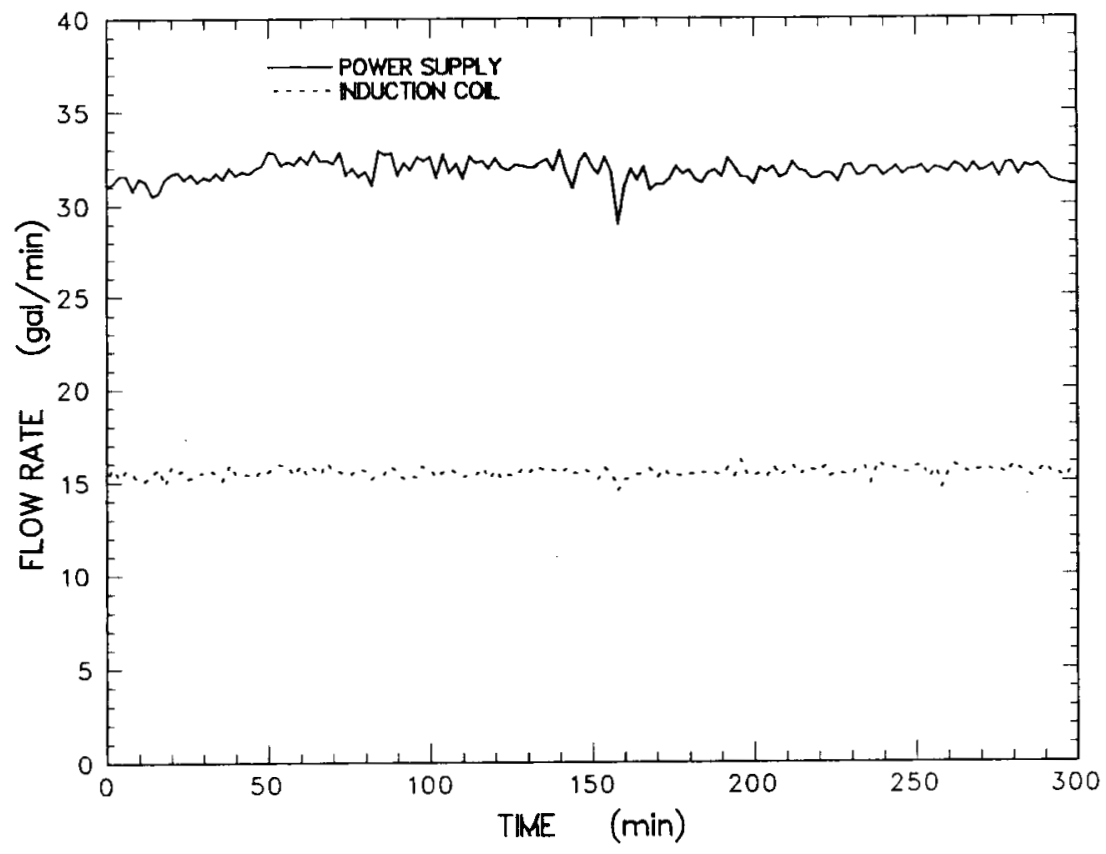

Figure B-2 Flow rate of cooling fluid flowing through the power supply and induction coil 
Appendix B

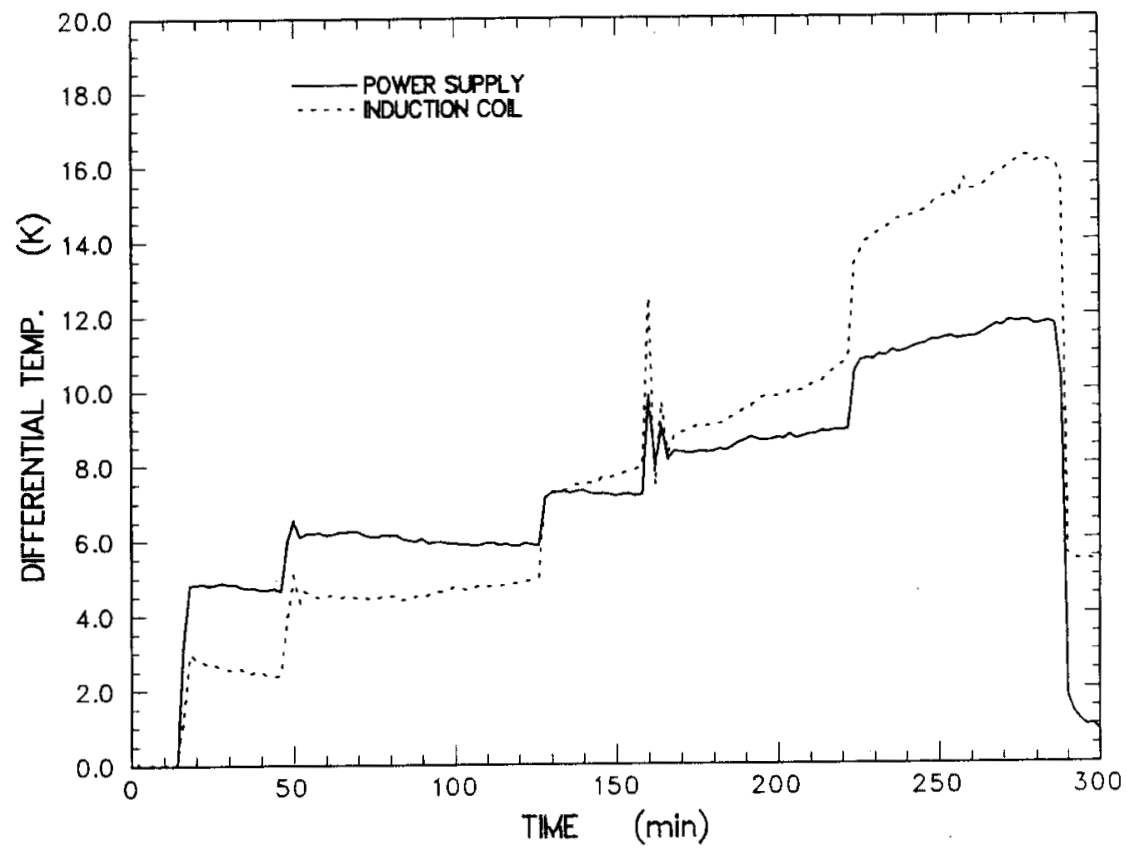

Figure B-3 Differential temperature of the cooling fluid flowing through the power supply and induction coil

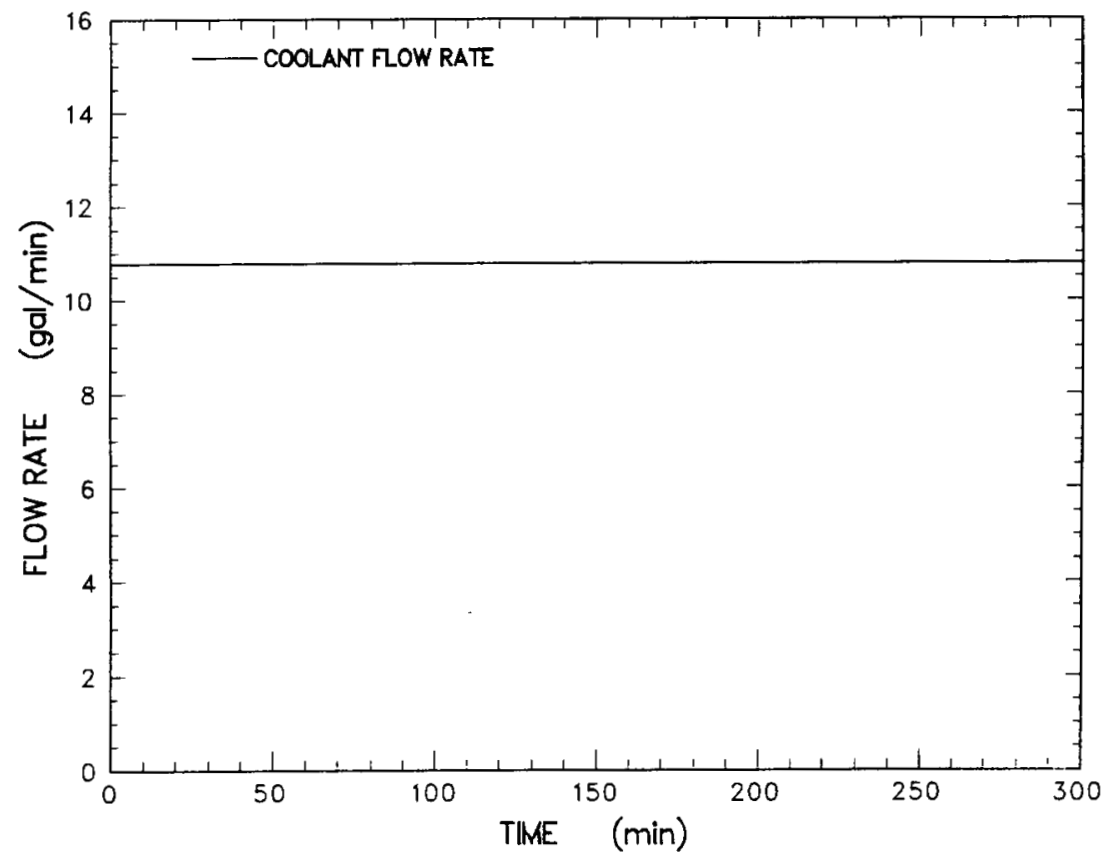

Figure B-4 Flow rate of cooling fluid flowing through the containment vessel 
Appendix B

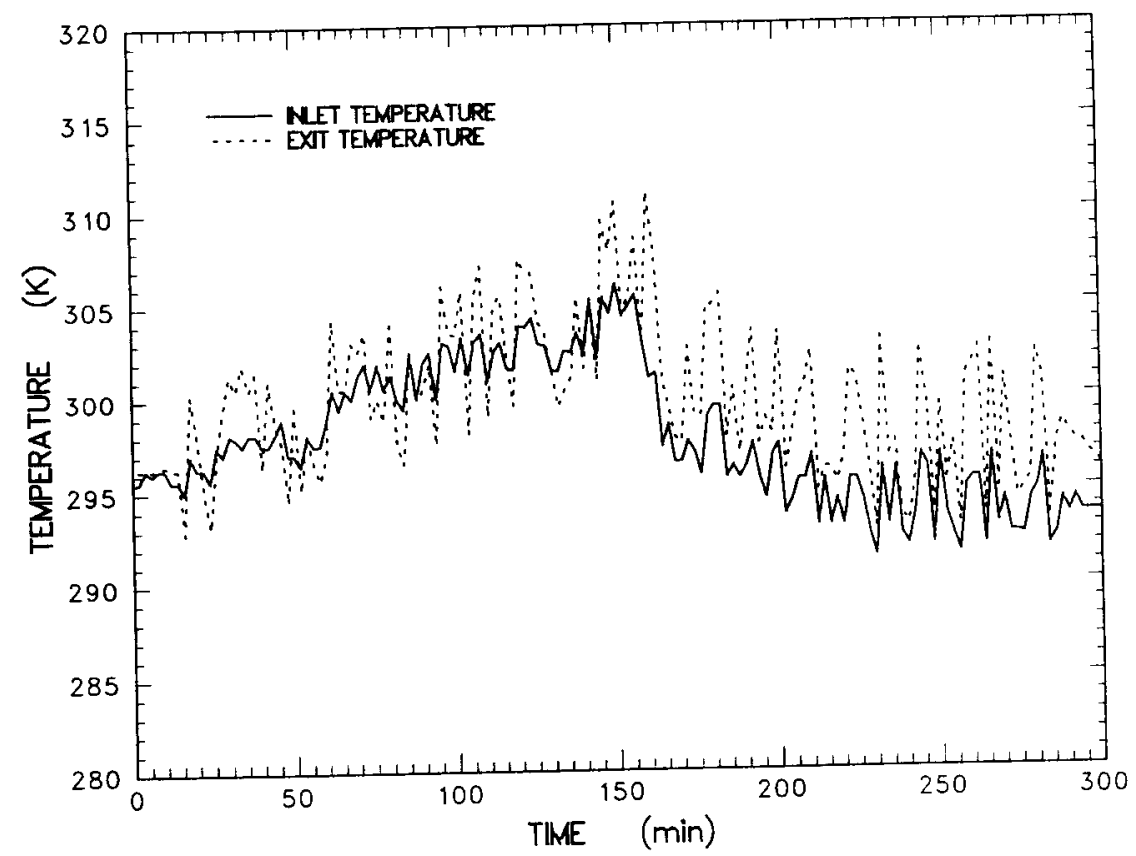

Figure B-5 Inlet/exit temperature of the cooling fluid flowing through the containment vessel 


\section{APPENDIX C \\ CRUCIBLE THERMOCOUPLE PROFILES}

C-1 


\section{Appendix C}

Presented in this appendix are the temperature profiles produced from the type $\mathrm{K}$ thermocouples embedded in the concrete, $\mathrm{MgO}$ castable sidewall and $\mathrm{MgO}$ cover. Also presented is the location of the dehydration and erosion front of the concrete plotted as a function of time. 
Appendix C

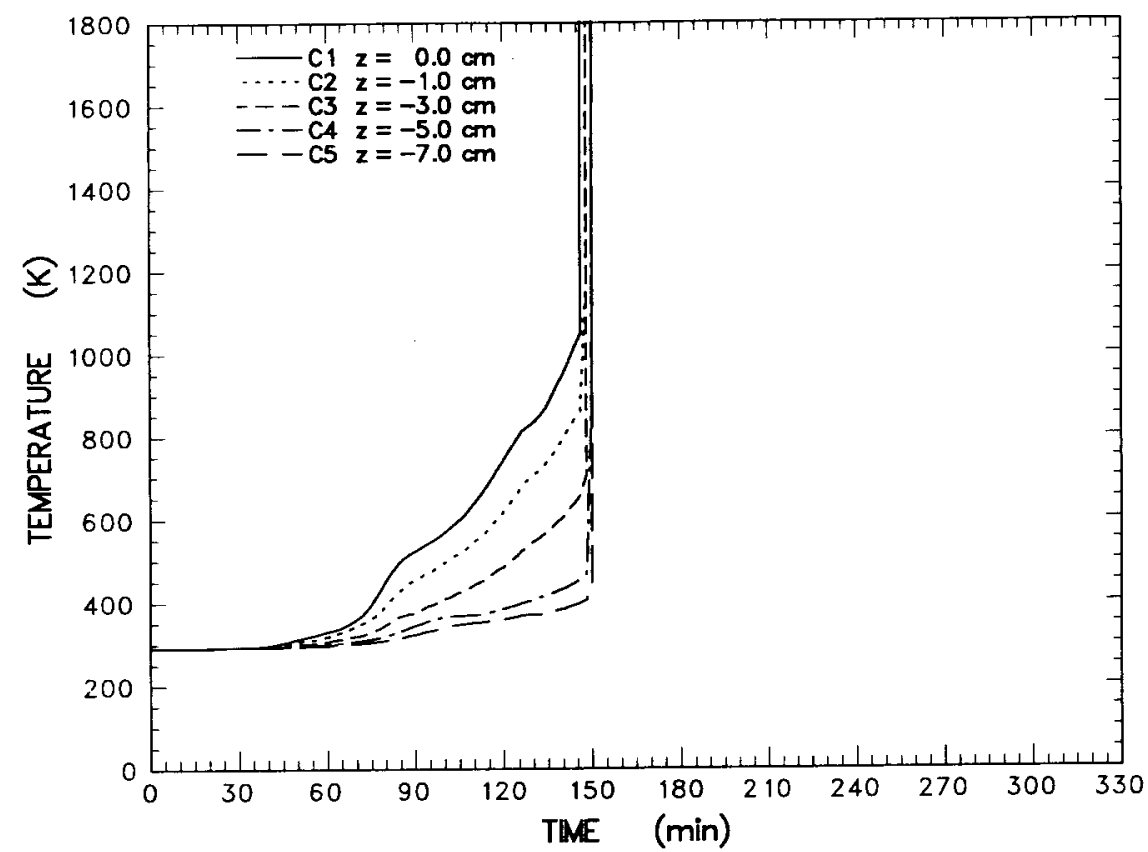

Figure C-1 Concrete temperature data measured by thermocouples located in the axial centerline array between $\mathrm{z}=0.0$ and $-7.0 \mathrm{~cm}$

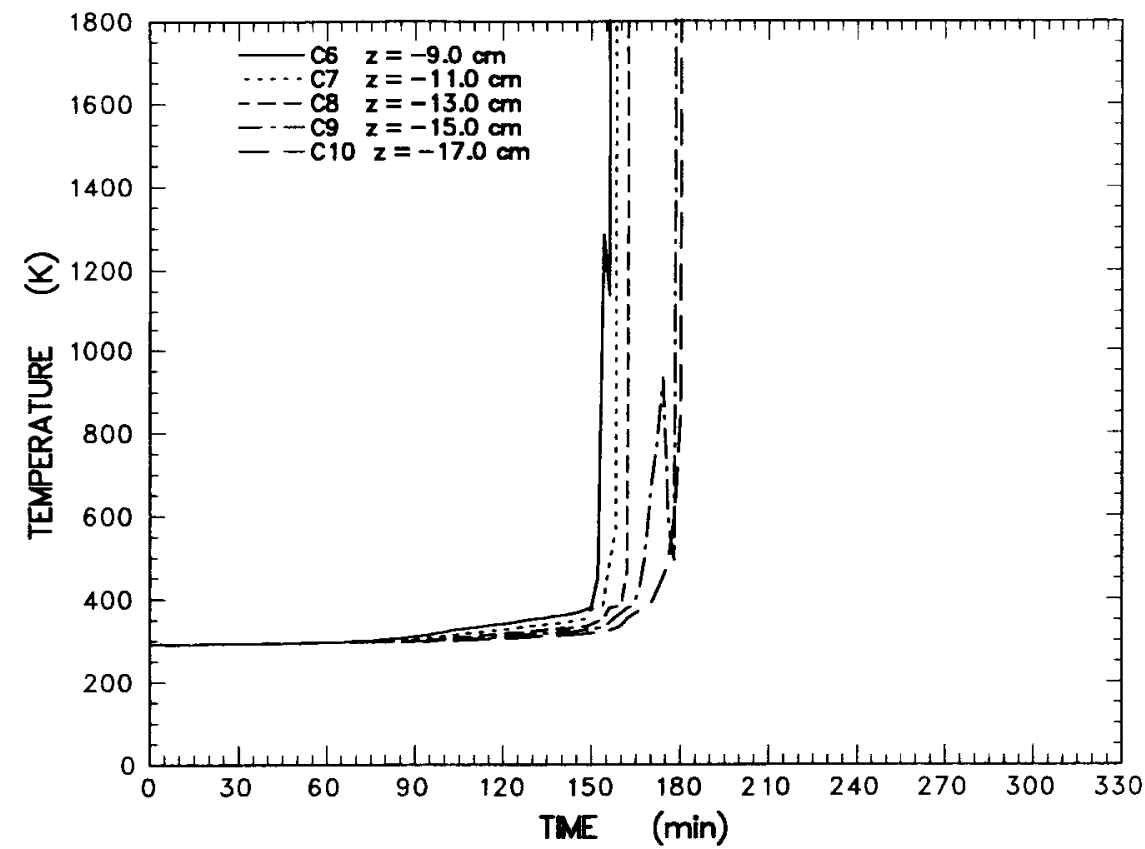

Figure C-2 Concrete temperature data measured by thermocouples located in the axial centerline array between $\mathrm{z}=-9.0$ and $-17.0 \mathrm{~cm}$ 
Appendix C

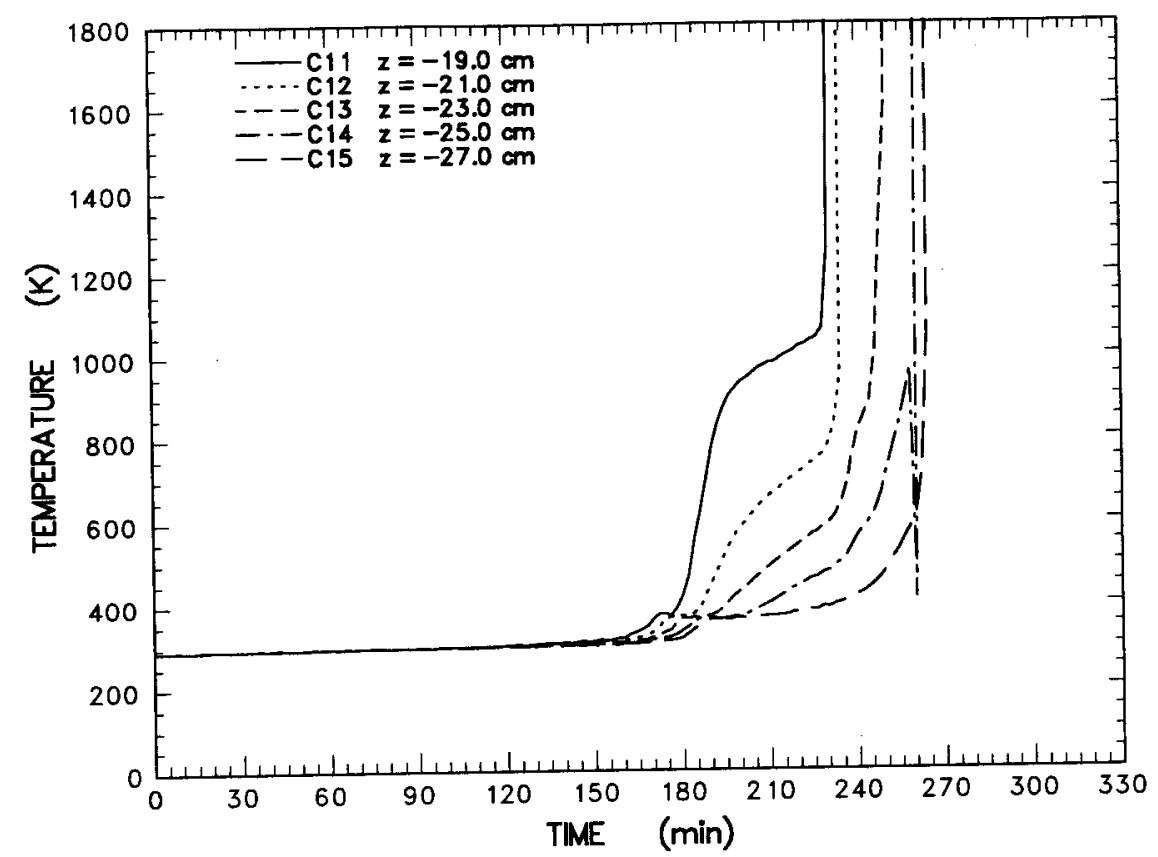

Figure C-3 Concrete temperature data measured by thermocouples located in the axial centerline array between $z=-19.0$ and $-27.0 \mathrm{~cm}$

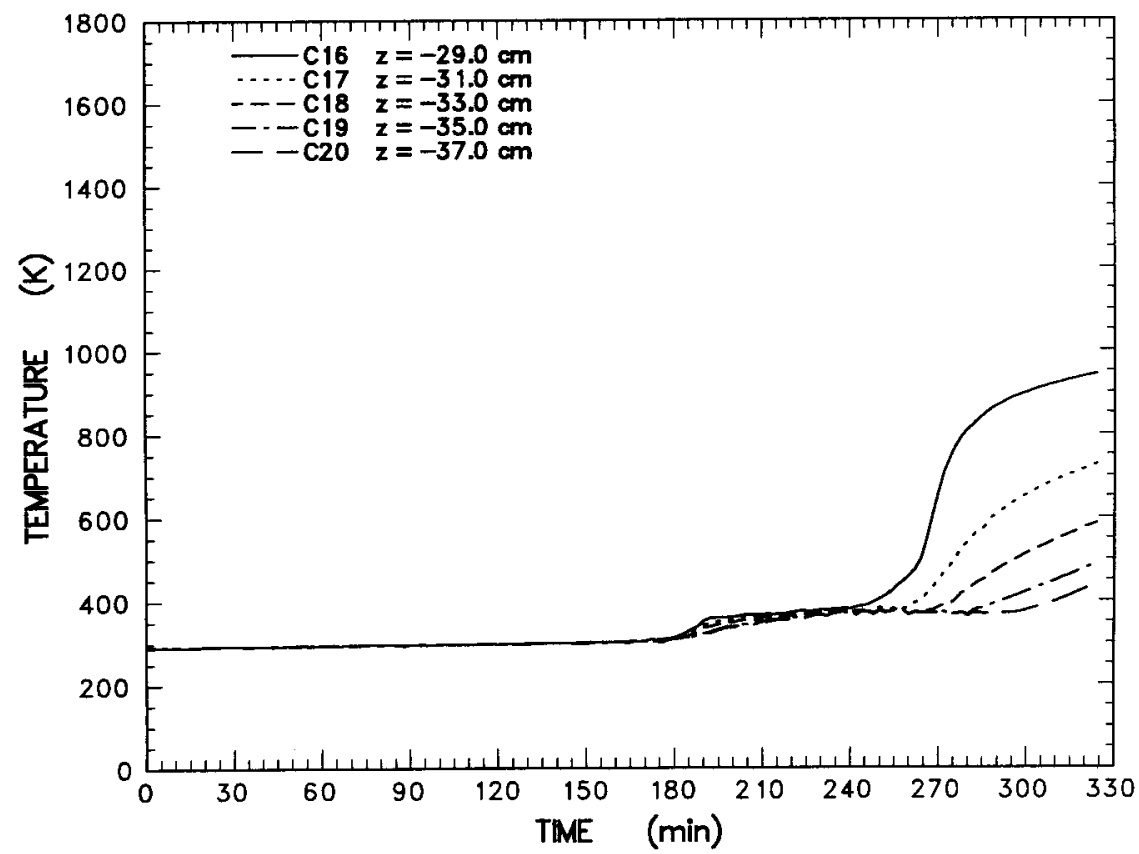

Figure $\mathrm{C}-4$ Concrete temperature data measured by thermocouples located in the axial centerline array between $\mathrm{z}=-29.0$ and $-37.0 \mathrm{~cm}$ 


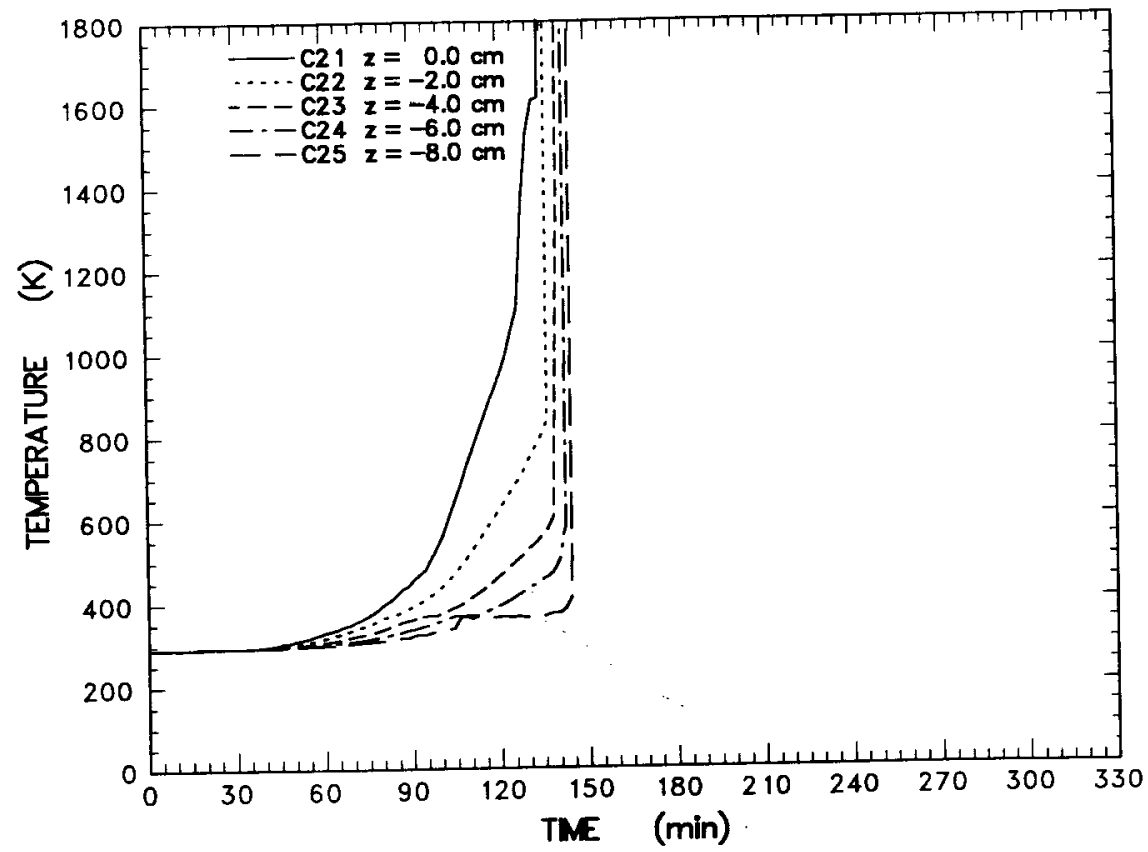

Figure C-5 Concrete temperature data measured by thermocouples located in the midradius array between $\mathrm{z}=0.0$ and $-8.0 \mathrm{~cm}$

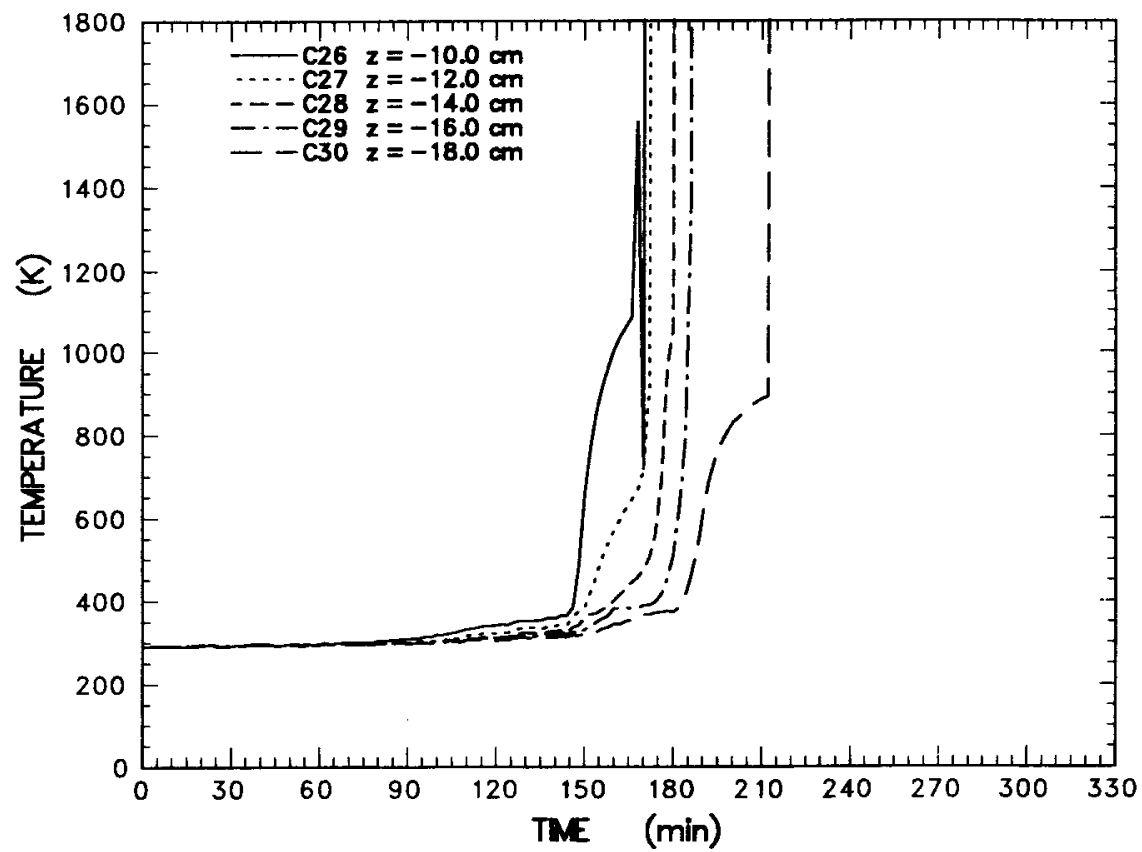

Figure C-6 Concrete temperature data measured by thermocouples located in the midradius array between $z=-10.0$ and $-18.0 \mathrm{~cm}$ 


\section{Appendix C}

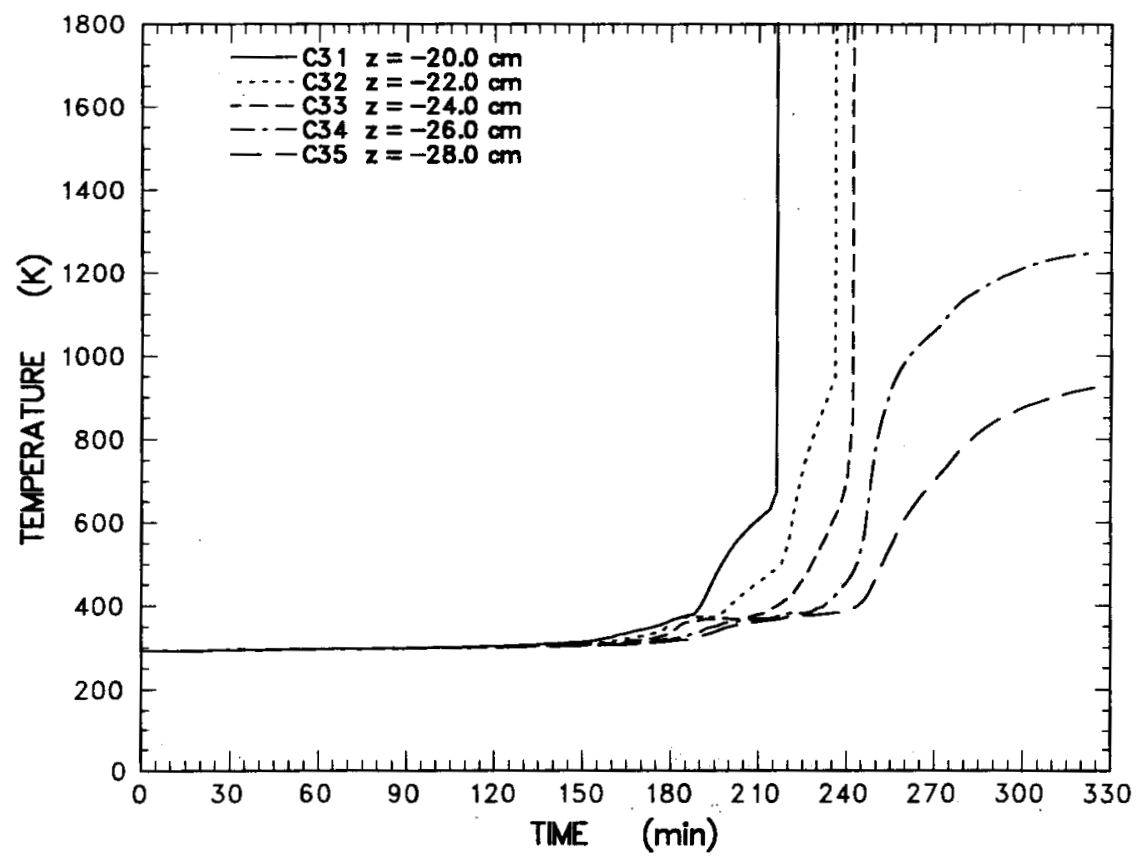

Figure C-7 Concrete temperature data measured by thermocouples located in the midradius array between $\mathrm{z}=-20.0$ and $-28.0 \mathrm{~cm}$

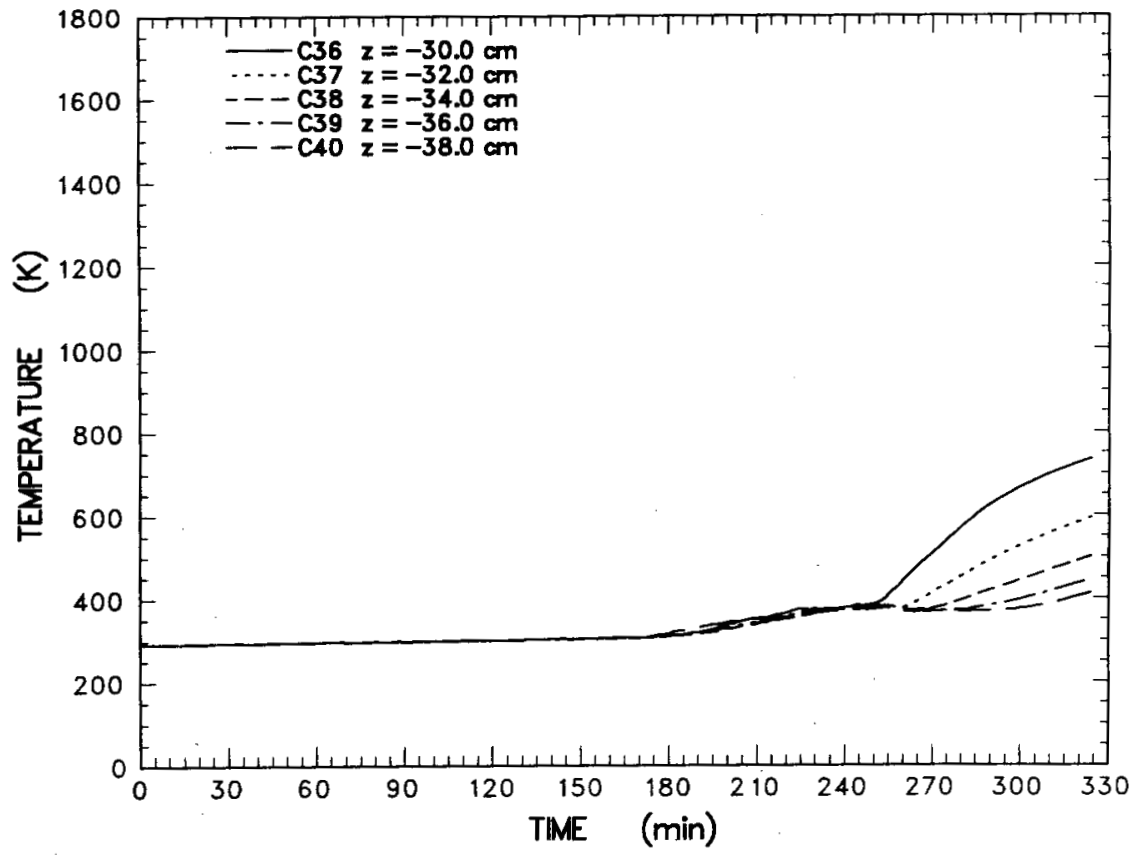

Figure C-8 Concrete temperature data measured by thermocouples located in the midradius array between $\mathrm{z}=-30.0$ and $-38.0 \mathrm{~cm}$ 
Appendix C

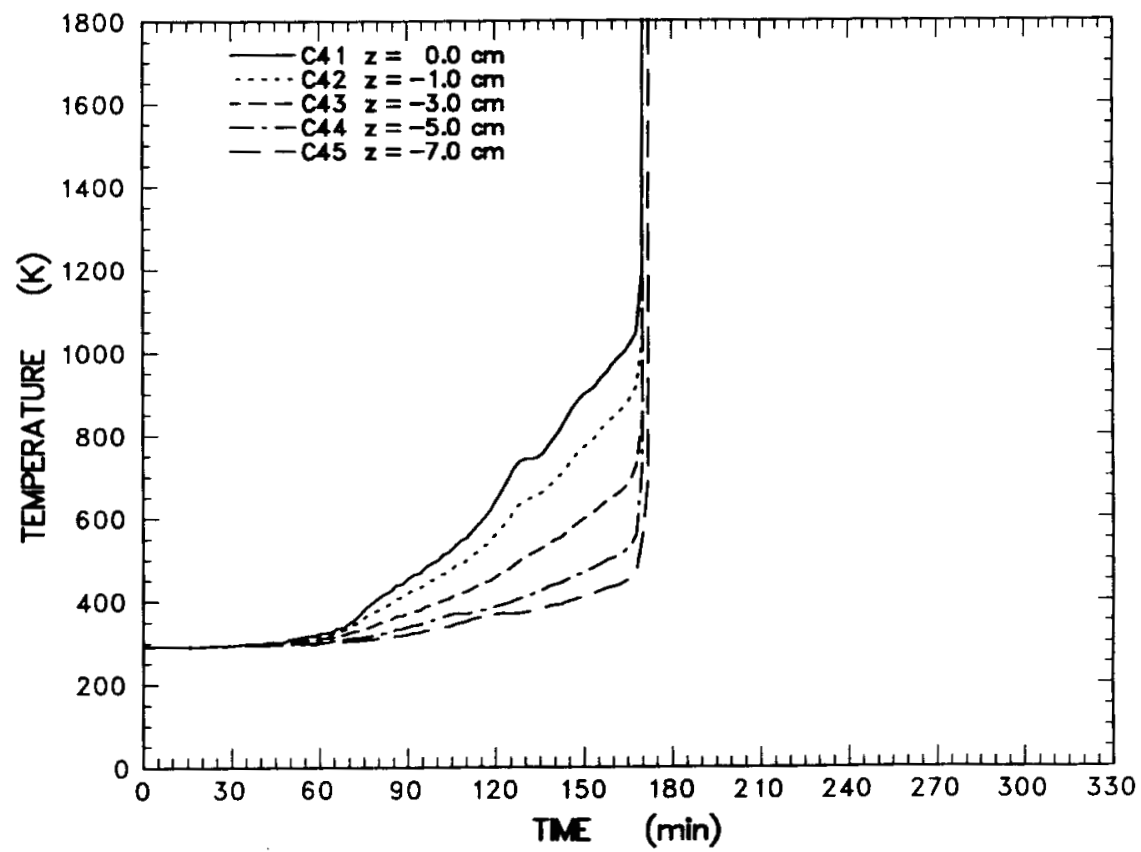

Figure C-9 Concrete temperature data measured by thermocouples located in the perimeter array between $\mathrm{z}=0.0$ and $-7.0 \mathrm{~cm}$

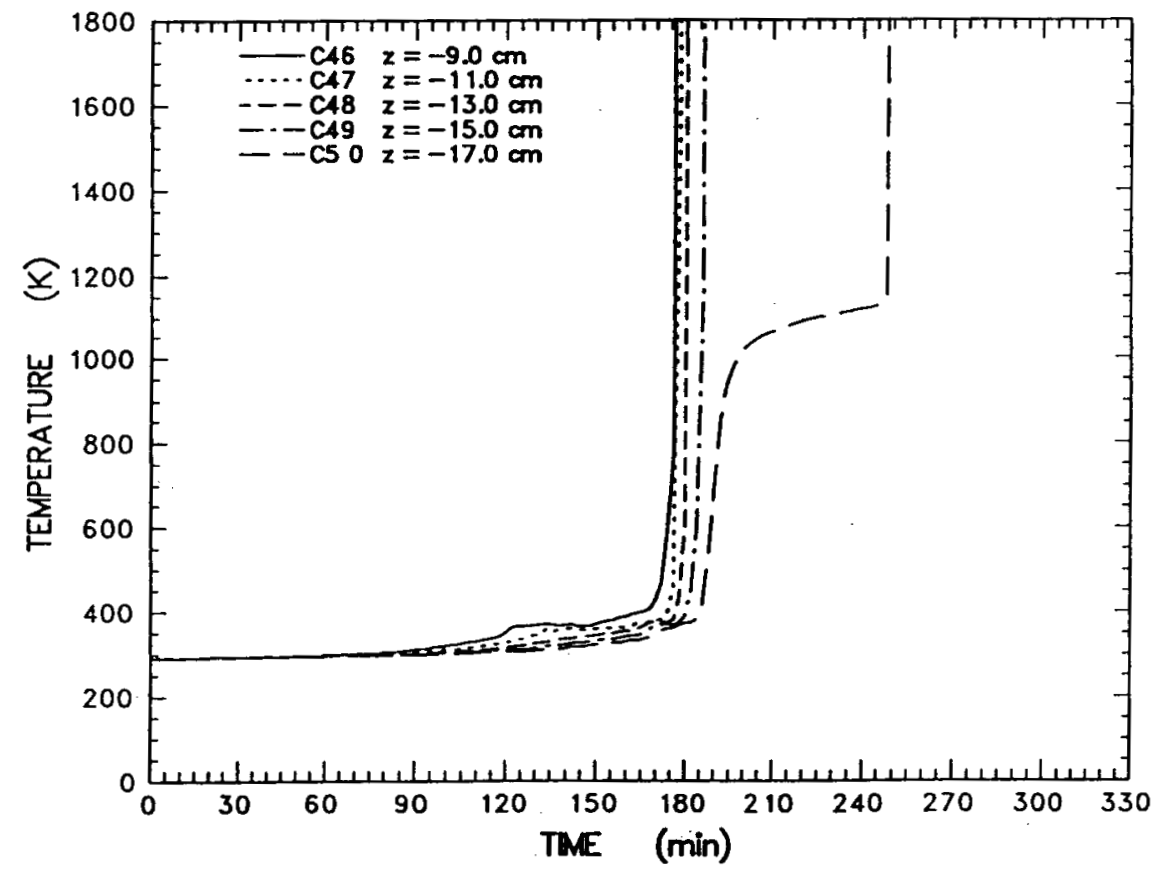

Figure C-10 Concrete temperature data measured by thermocouples located in the perimeter array between $z=-9.0$ and $-17.0 \mathrm{~cm}$ 


\section{Appendix C}

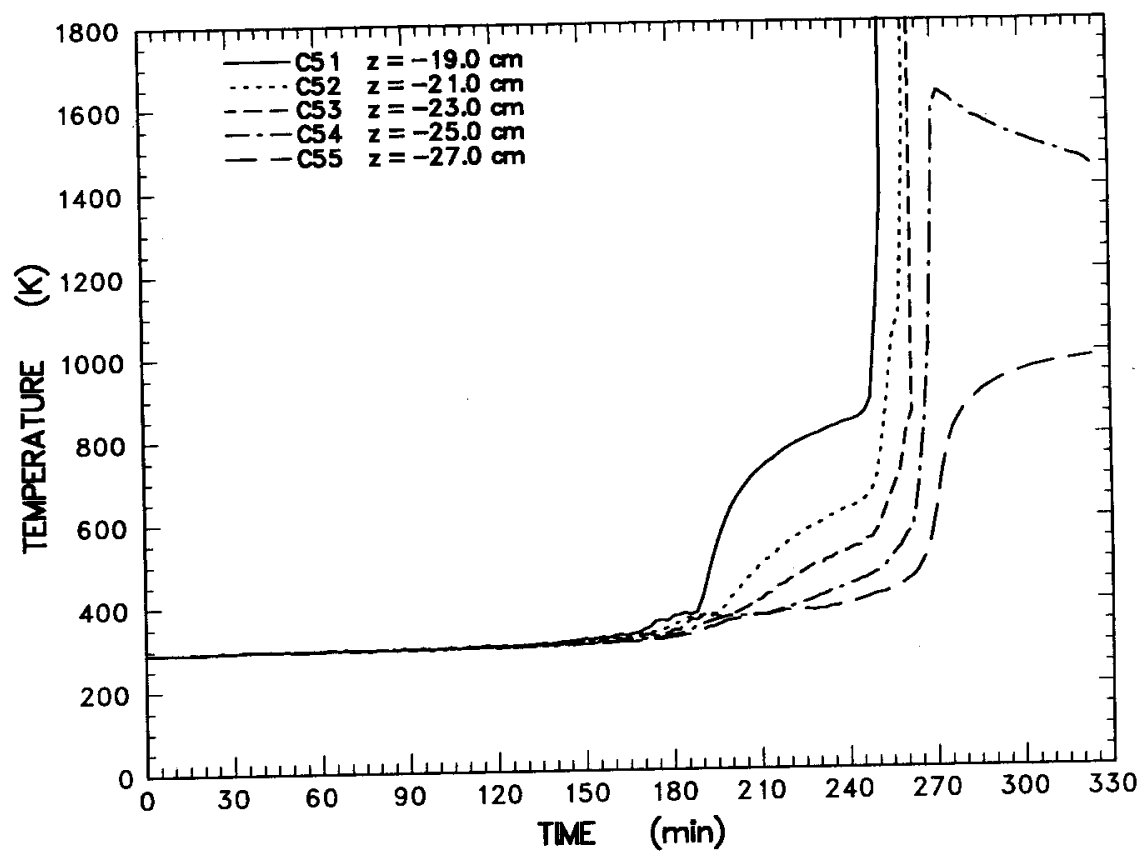

Figure C-11 Concrete temperature data measured by thermocouples located in the perimeter array between $z=-19.0$ and $-27.0 \mathrm{~cm}$

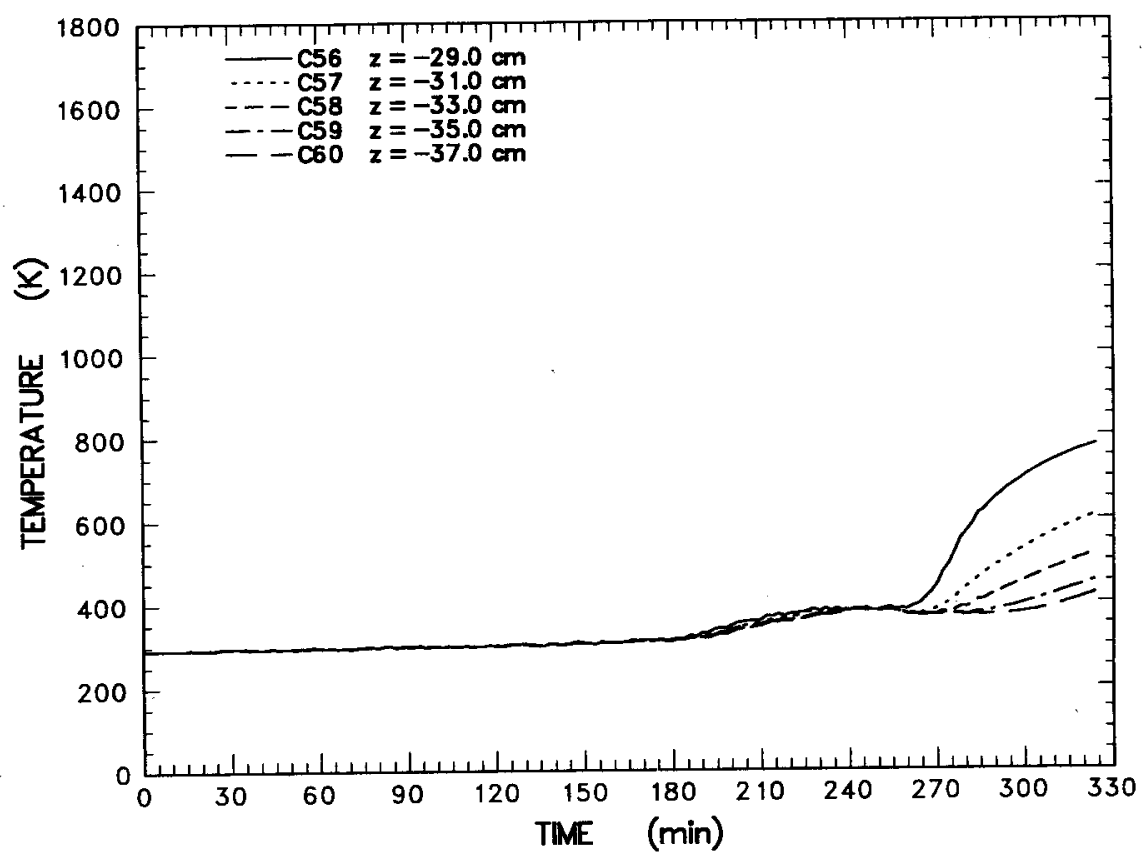

Figure C-12 Concrete temperature data measured by thermocouples located in the perimeter array between $z=-29.0$ and $-37.0 \mathrm{~cm}$ 


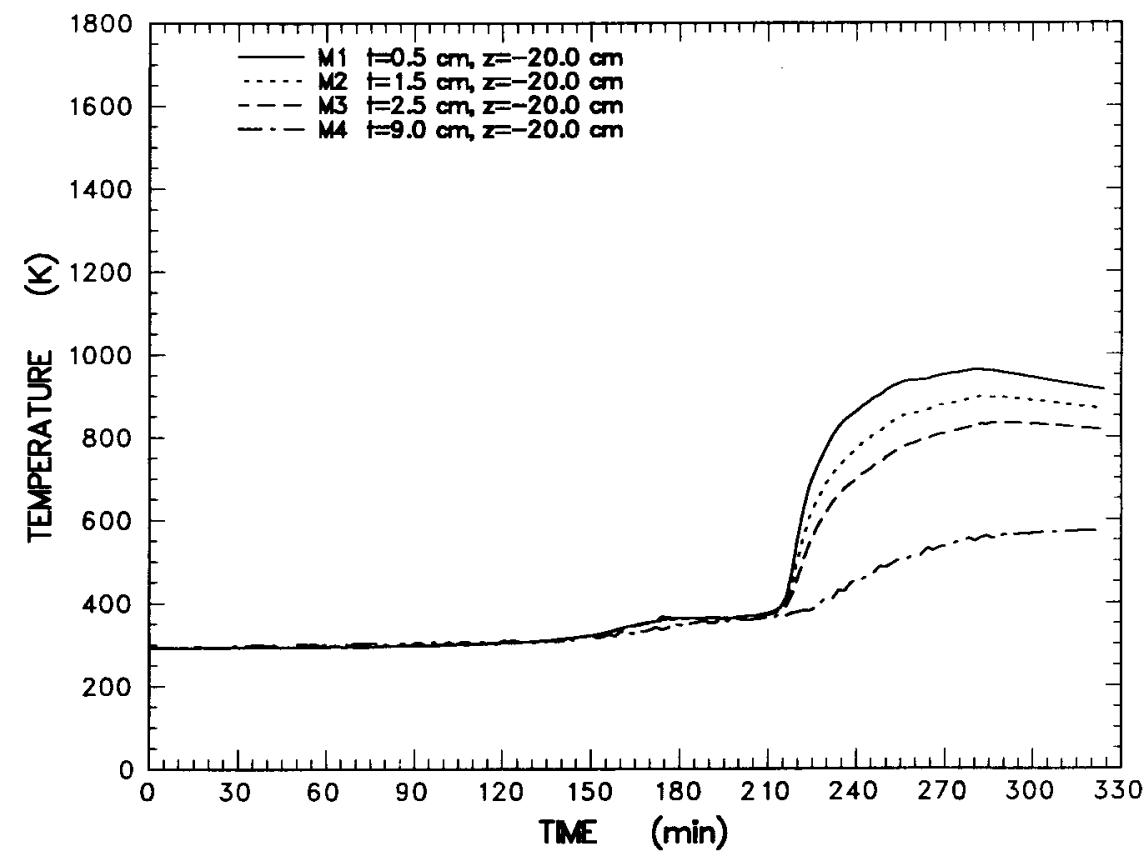

Figure C-13 MgO sidewall temperature data measured by thermocouples in the array located at $\mathrm{z}=-20.0 \mathrm{~cm}$

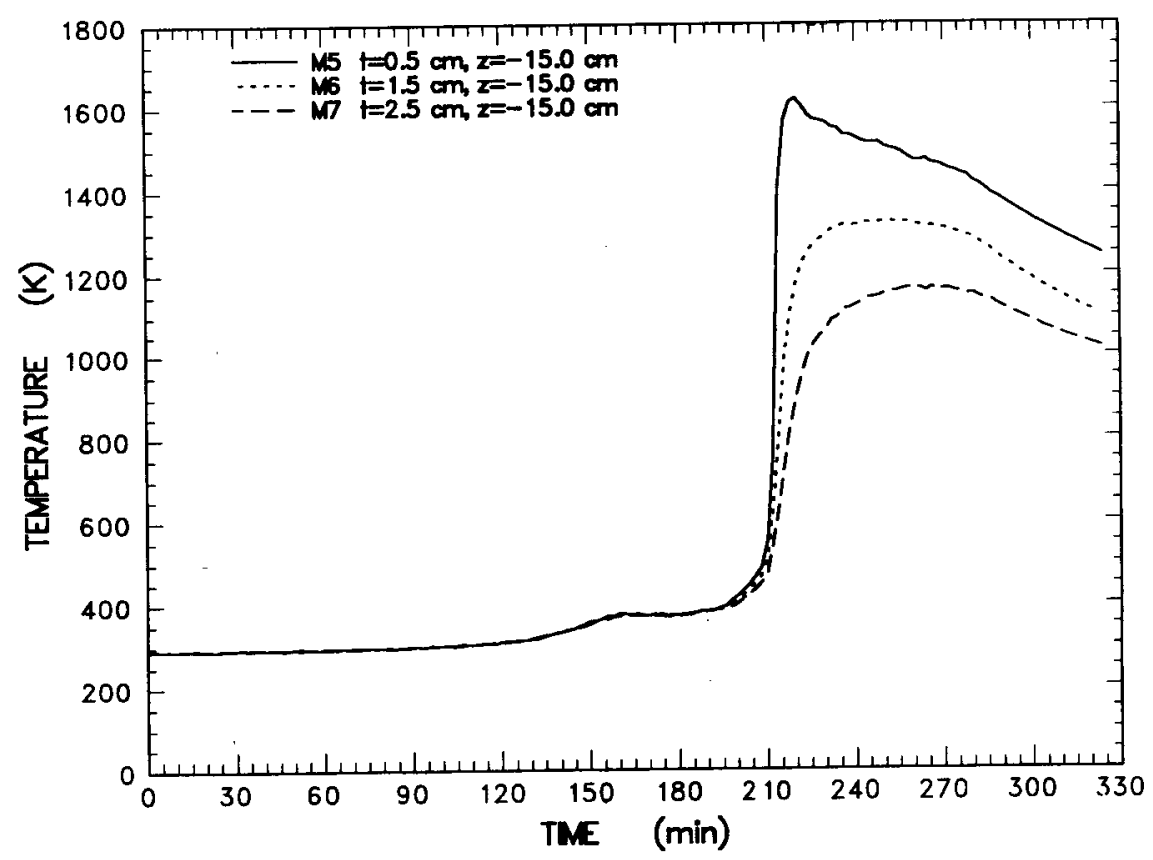

Figure C-14 MgO sidewall temperature data measured by thermocouples in the array located at $\mathrm{z}=-15.0 \mathrm{~cm}$ 
Appendix C

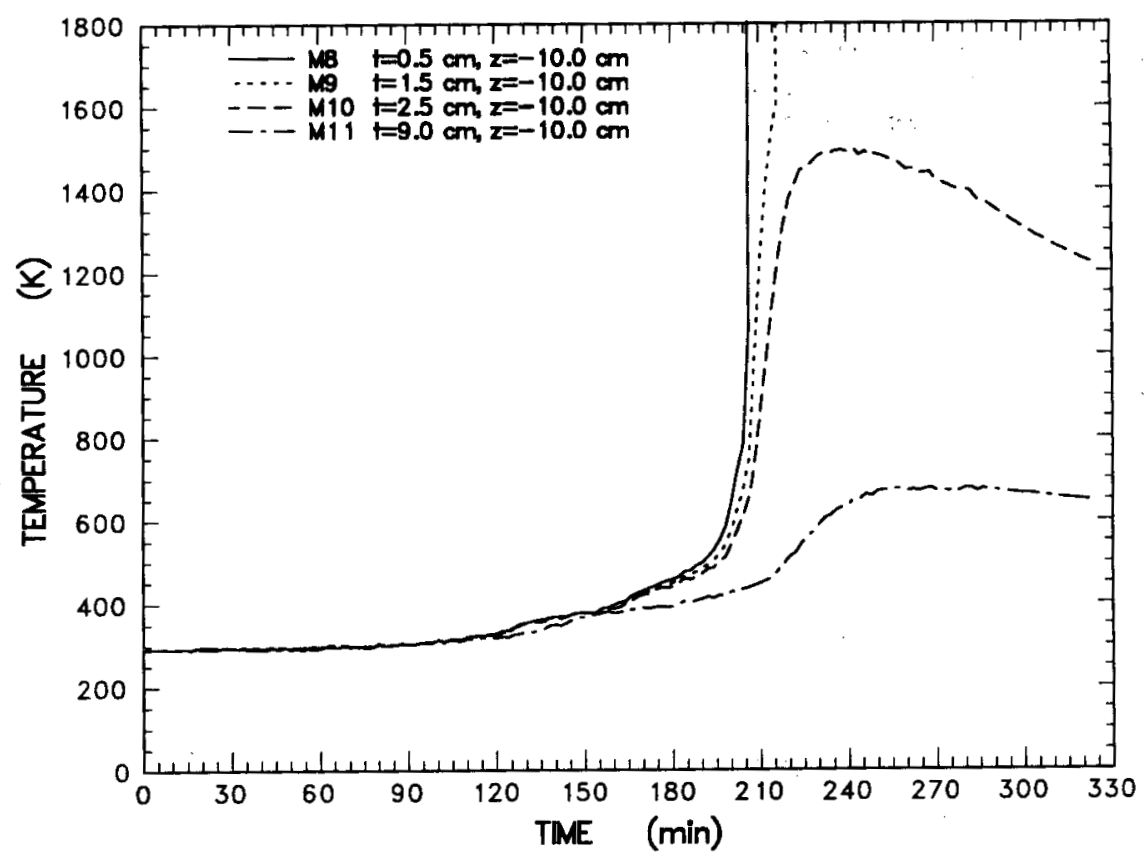

Figure C-15 $\mathrm{MgO}$ sidewall temperature data measured by thermocouples in the array located at $\mathrm{z}=-10.0 \mathrm{~cm}$

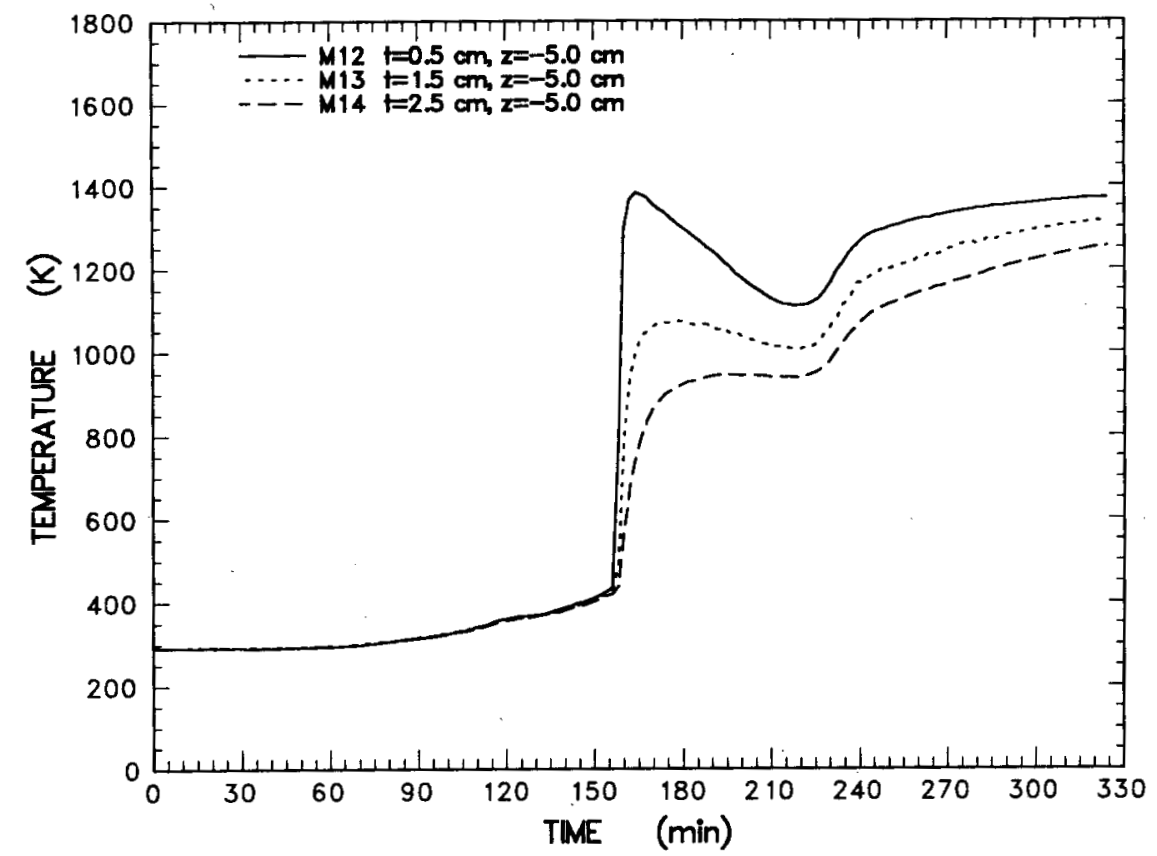

Figure C-16 MgO sidewall temperature data measured by thermocouples in the array located at $\mathrm{z}=-5.0 \mathrm{~cm}$ 


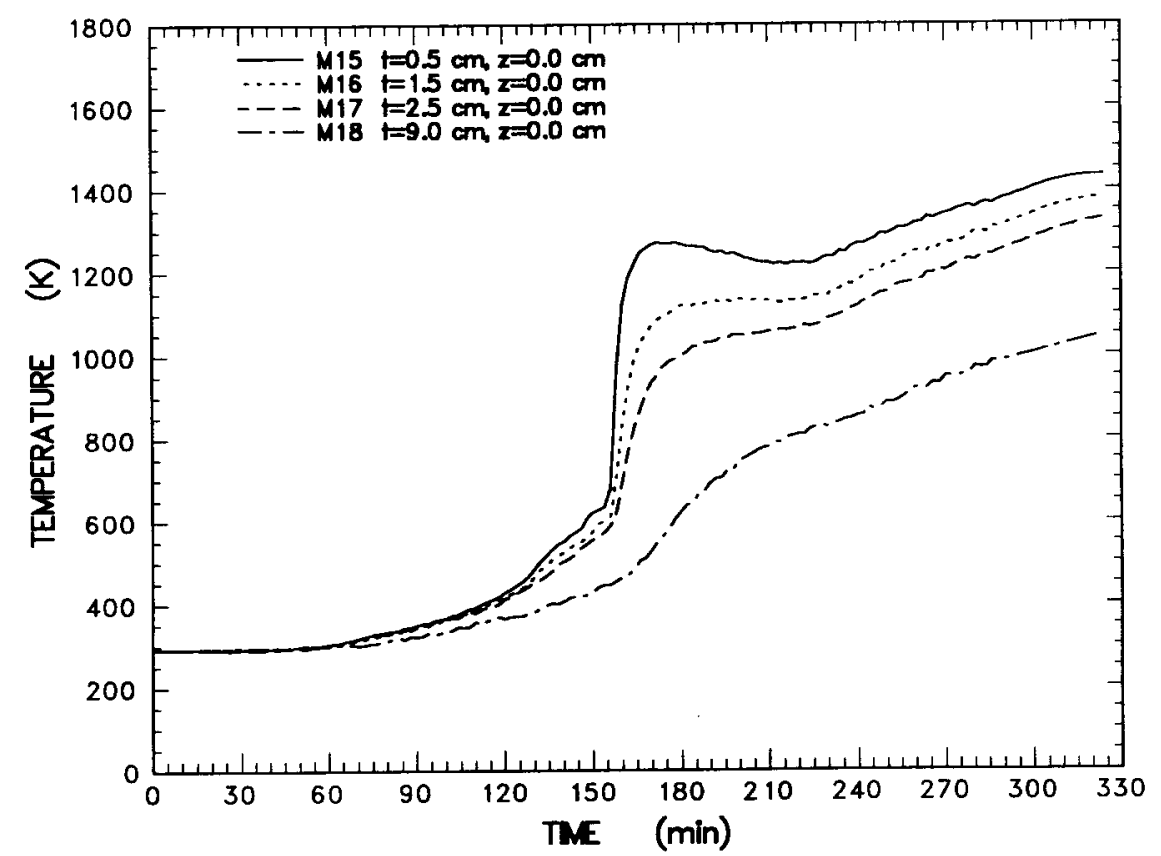

Figure C-17 $\mathrm{MgO}$ sidewall temperature data measured by thermocouples in the array located at $\mathrm{z}=0.0 \mathrm{~cm}$

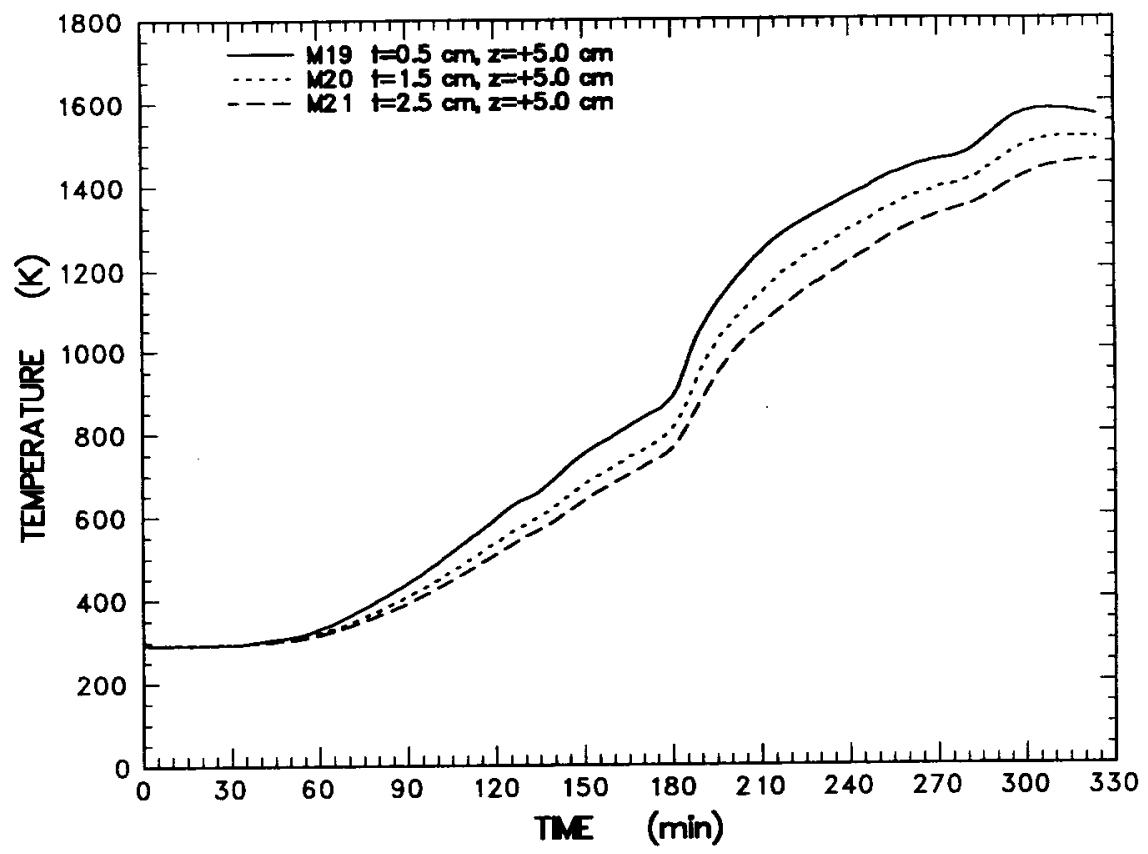

Figure C-18 $\mathrm{MgO}$ sidewall temperature data measured by thermocouples in the array located at $z=+5.0 \mathrm{~cm}$ 
Appendix C

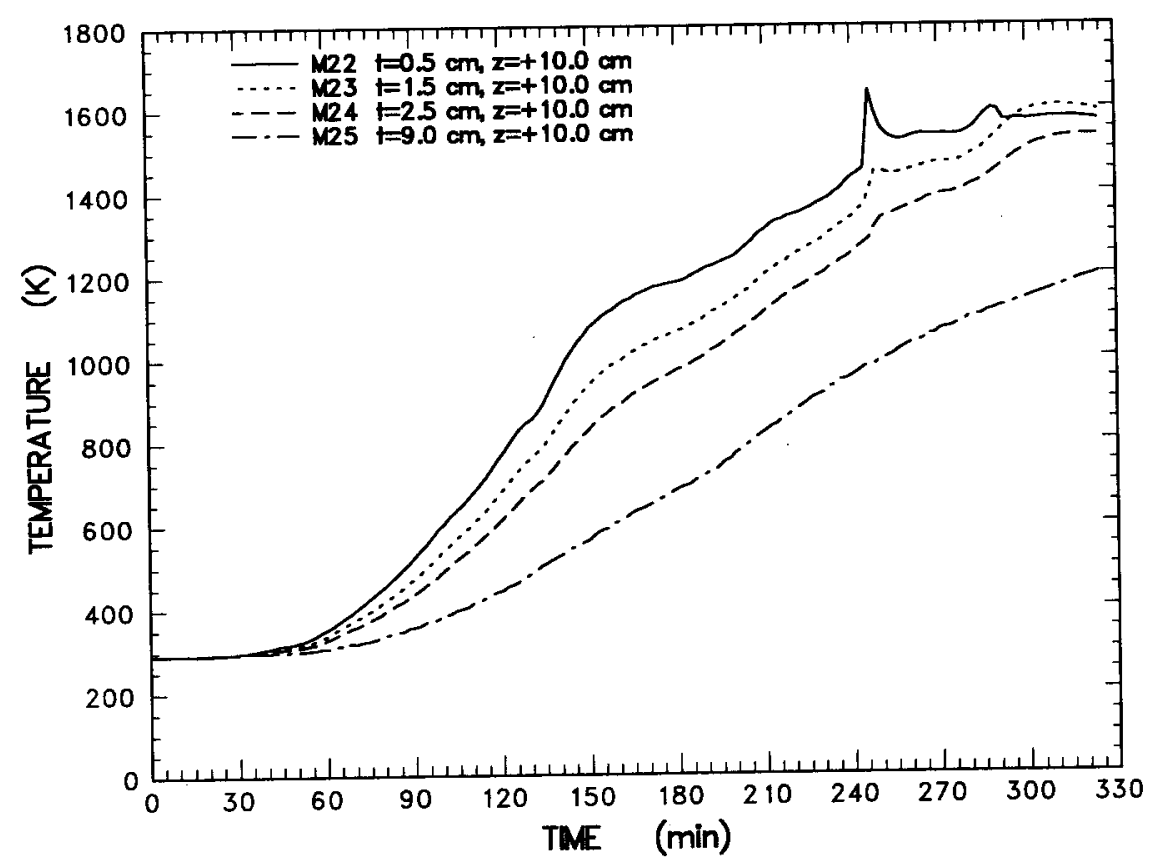

Figure C-19 MgO sidewall temperature data measured by thermocouples in the array located at $\mathrm{z}=+10.0 \mathrm{~cm}$

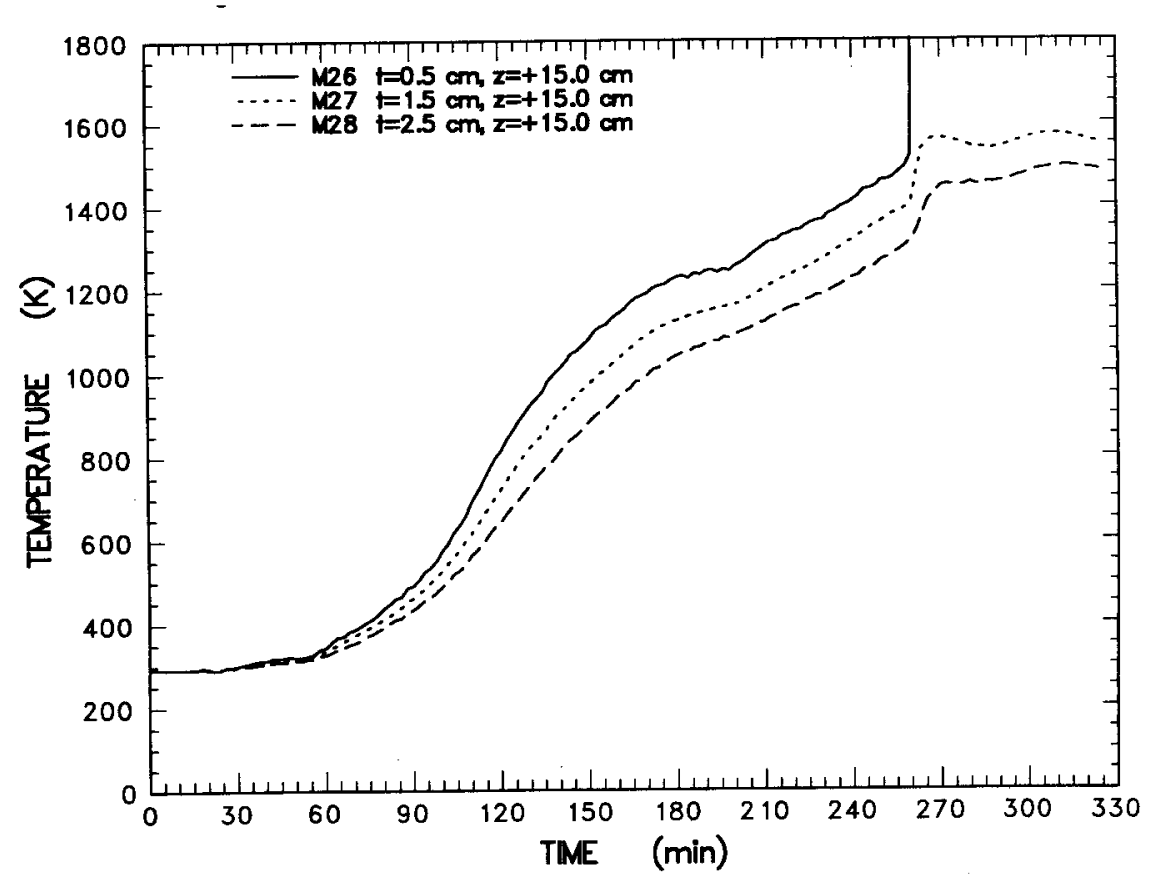

Figure C-20 MgO sidewall temperature data measured by thermocouples in the array located at $\mathrm{z}=+15.0 \mathrm{~cm}$ 


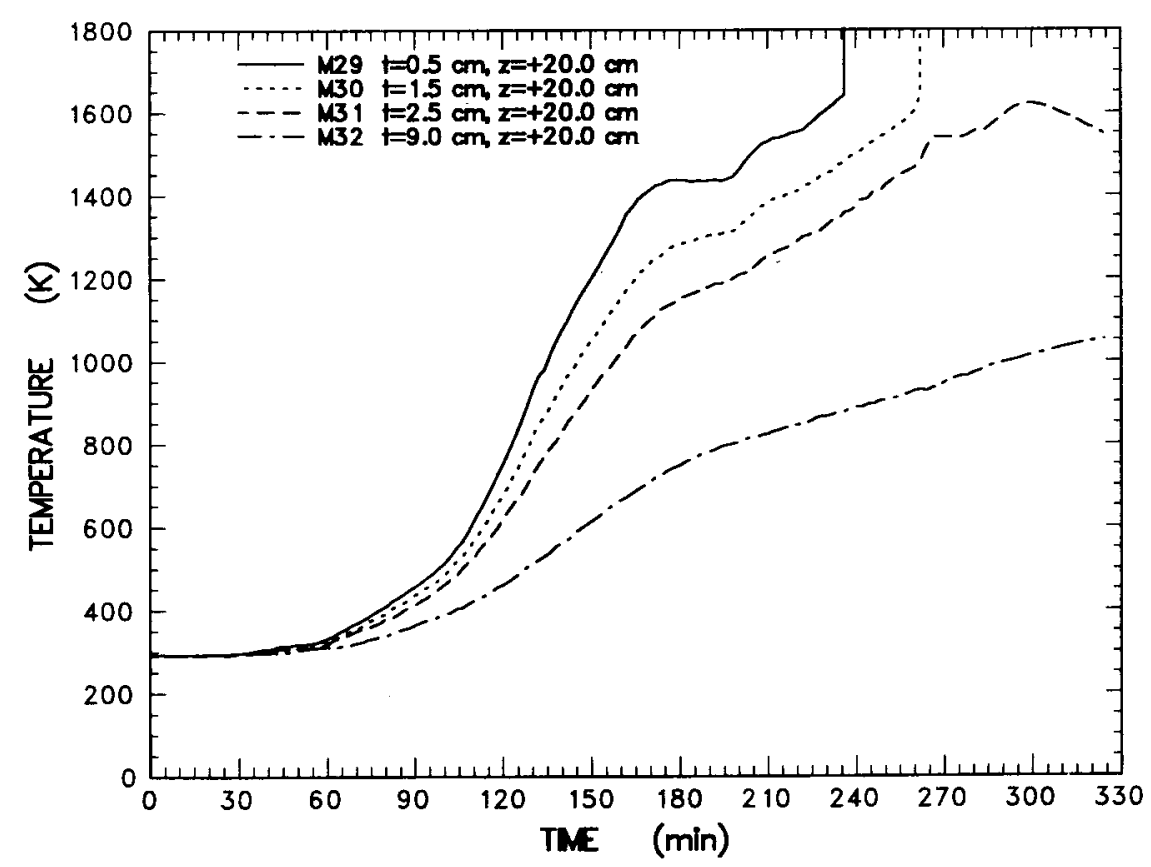

Figure C-21 MgO sidewall temperature data measured by thermocouples in the array located at $\mathrm{z}=+20.0 \mathrm{~cm}$

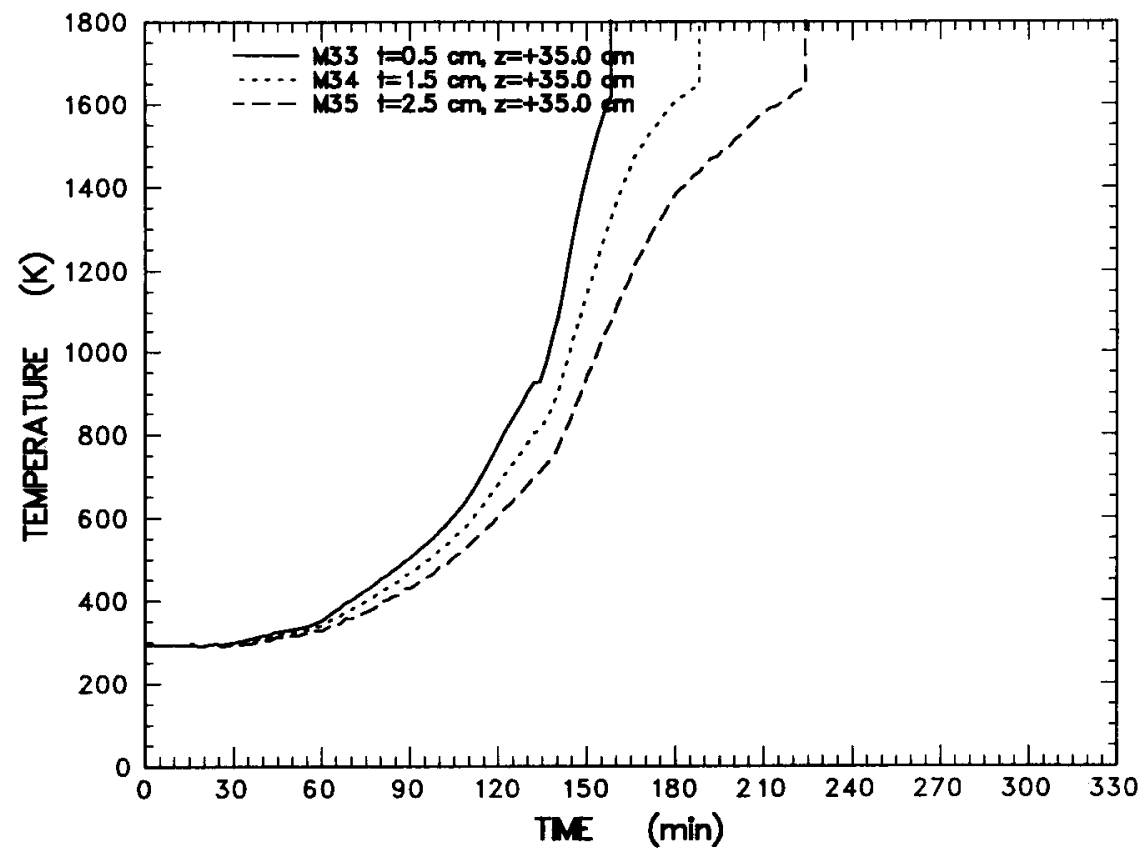

Figure C-22 $\mathrm{MgO}$ sidewall temperature data measured by thermocouples in the array located at $\mathrm{z}=+35.0 \mathrm{~cm}$ 
Appendix C

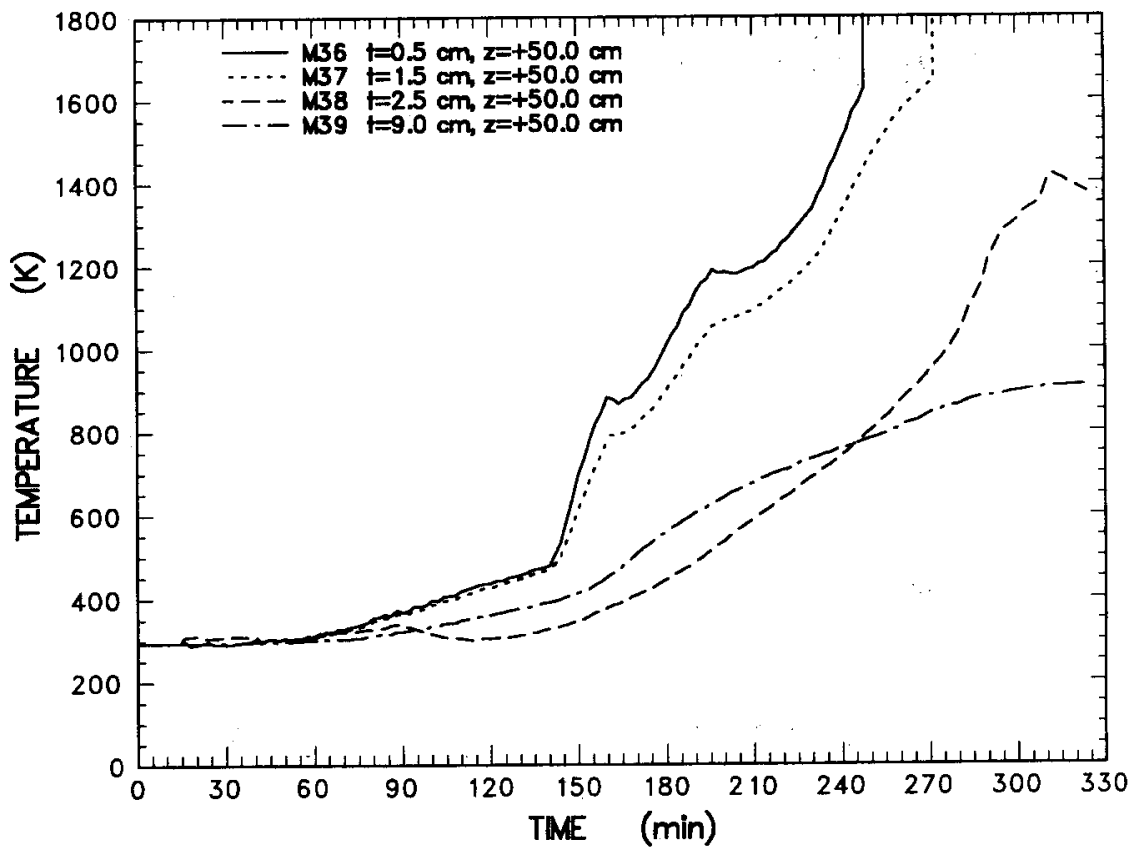

Figure C-23 MgO sidewall temperature data measured by thermocouples in the array located at $\mathrm{z}=+50.0 \mathrm{~cm}$

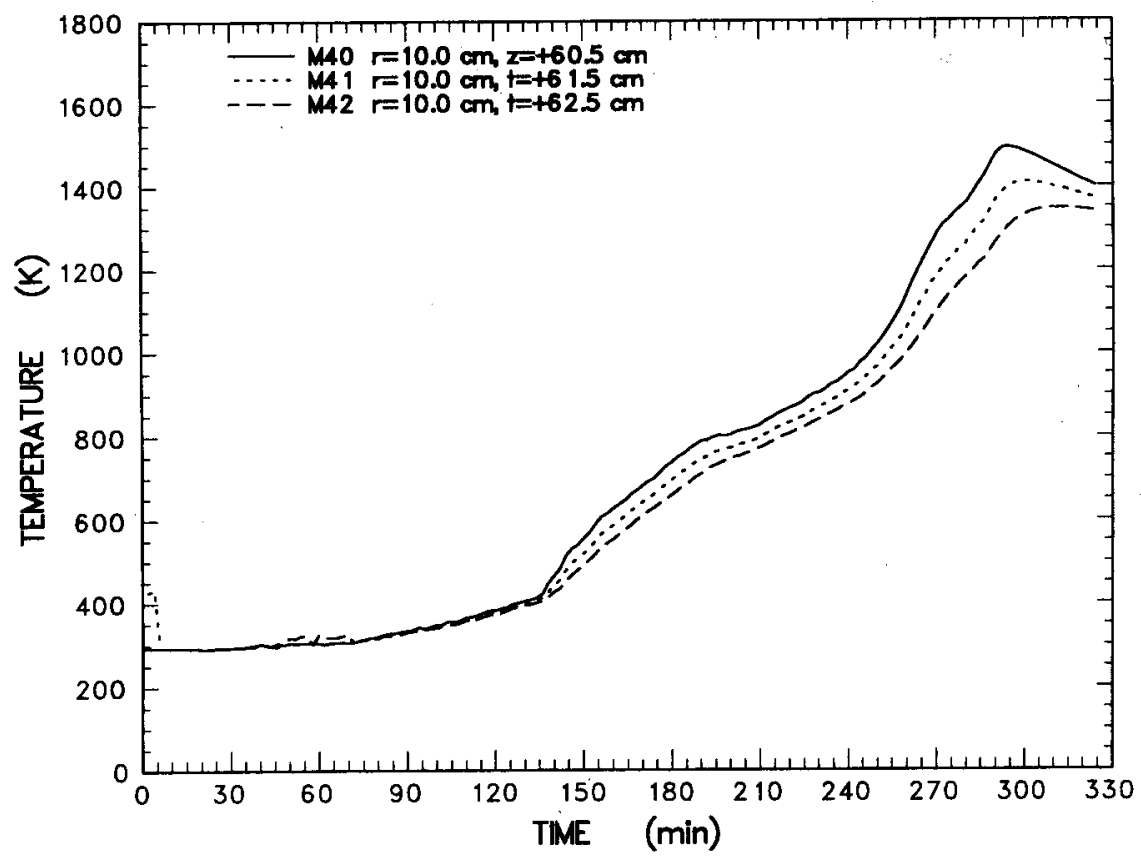

Figure C-24 MgO cover temperature data measured by thermocouples in the array located at $\mathrm{r}=10.0 \mathrm{~cm}, \theta=0$, and $\mathrm{z}=+60.0 \mathrm{~cm}$ 


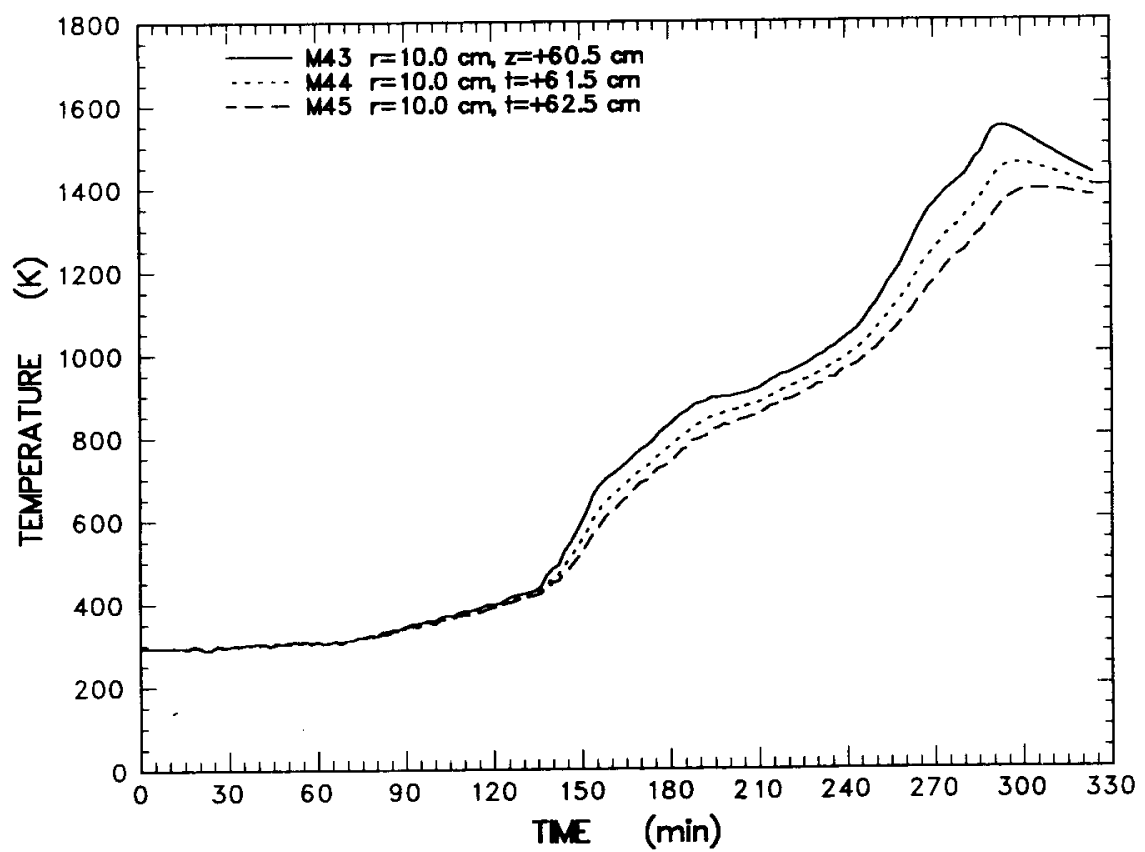

Figure C-25 MgO cover temperature data measured by thermocouples in the array located at $r=10.0 \mathrm{~cm}, \theta=180$, and $\mathrm{z}=+60.0 \mathrm{~cm}$

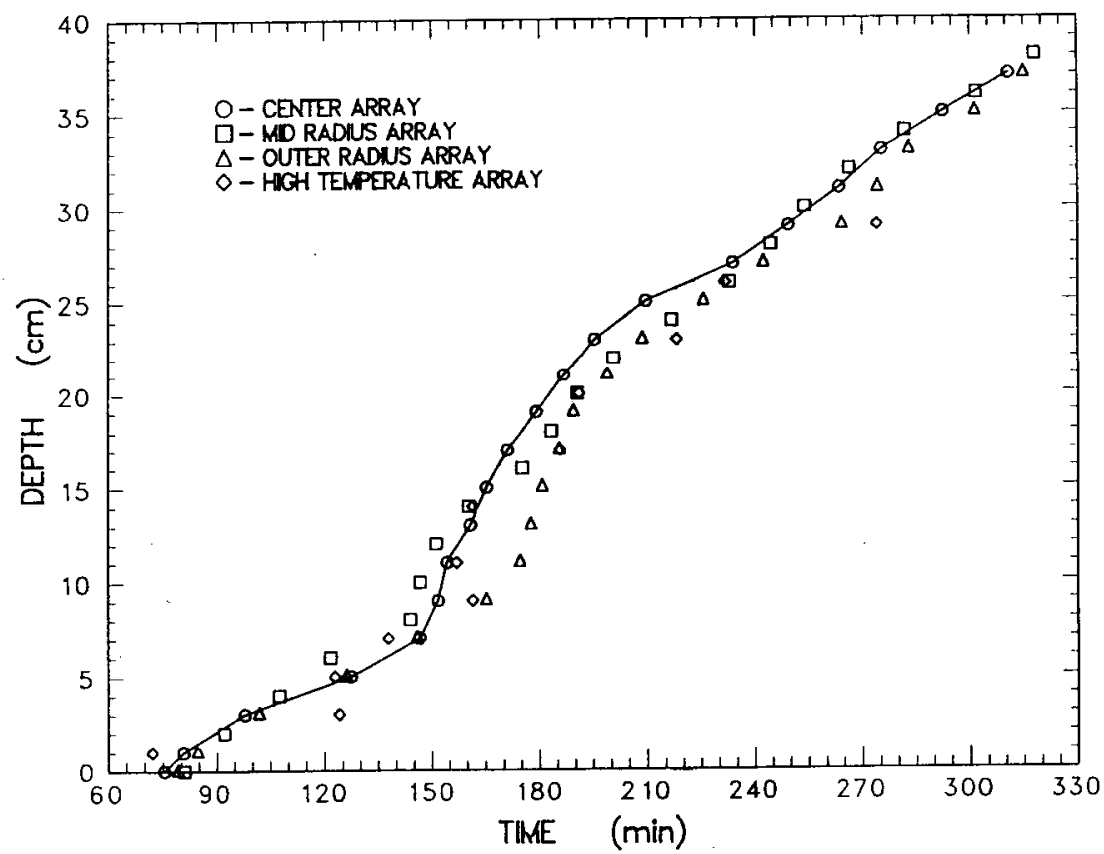

Figure C-26 Position of the $400 \mathrm{~K}$ isotherm plotted as a function of time 


\section{Appendix C}

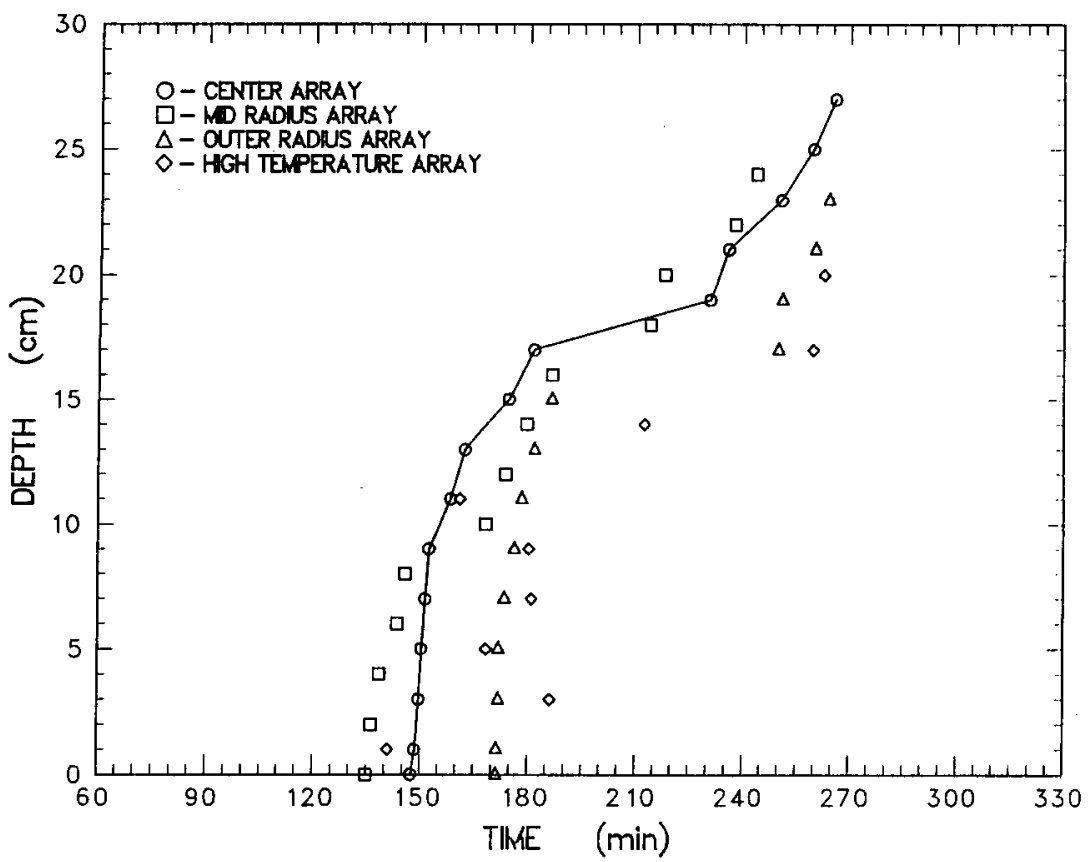

Figure C-27 Position of the concrete erosion plotted as a function of time

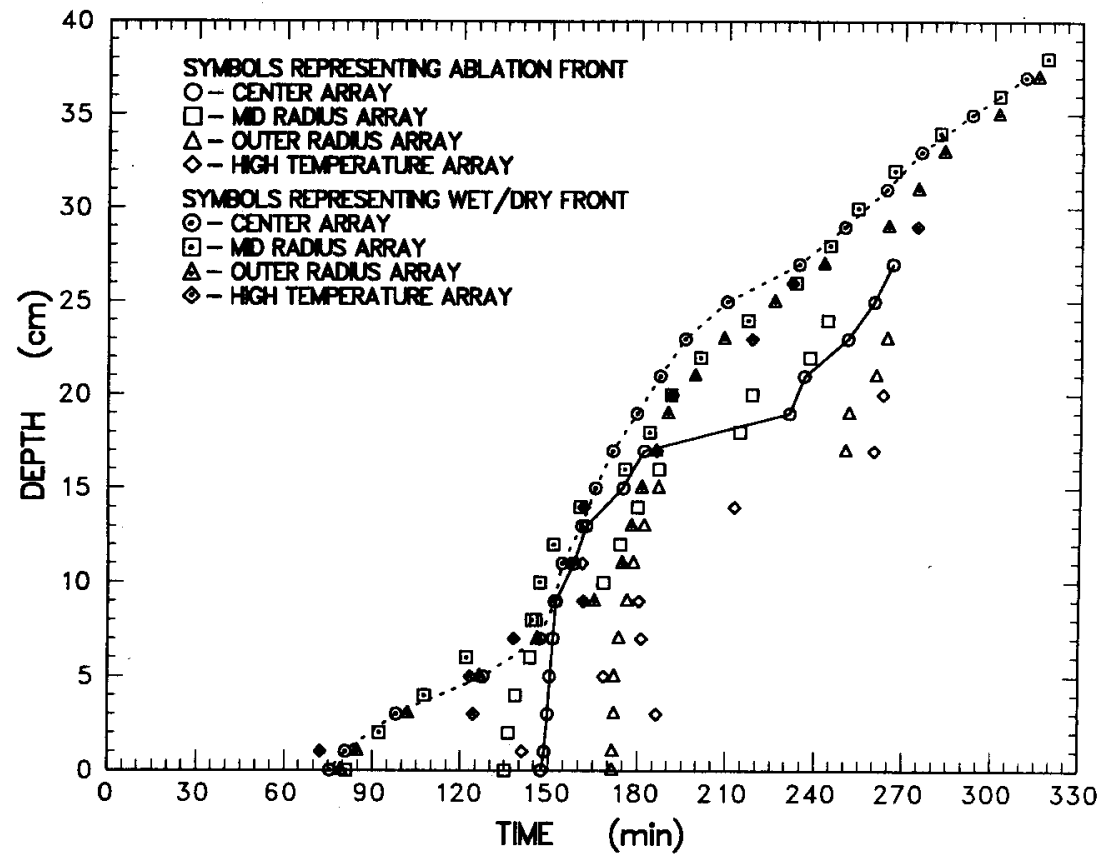

Figure C-28 Comparison of the position of the $400 \mathrm{~K}$ isotherm and the concrete erosion front 


\section{APPENDIX D \\ MELT TEMPERATURE AND PYROMETER DATA}

D-1

NUREG/CR-5443 


\section{Appendix D}

In this appendix charge temperature data is presented for type $C$ and $S$ thermocouples installed in alumina tubes and cast into the concrete cylinder. Pyrometer data is presented for three fiber optic pyrometers each focused at the base of a thick walled, closed end tungsten tube. Also presented, are the temperature profiles for the $\mathrm{C}$ type thermocouples installed at the base of each of the tungsten tubes. The tubes were purged with argon to minimize oxidation. 


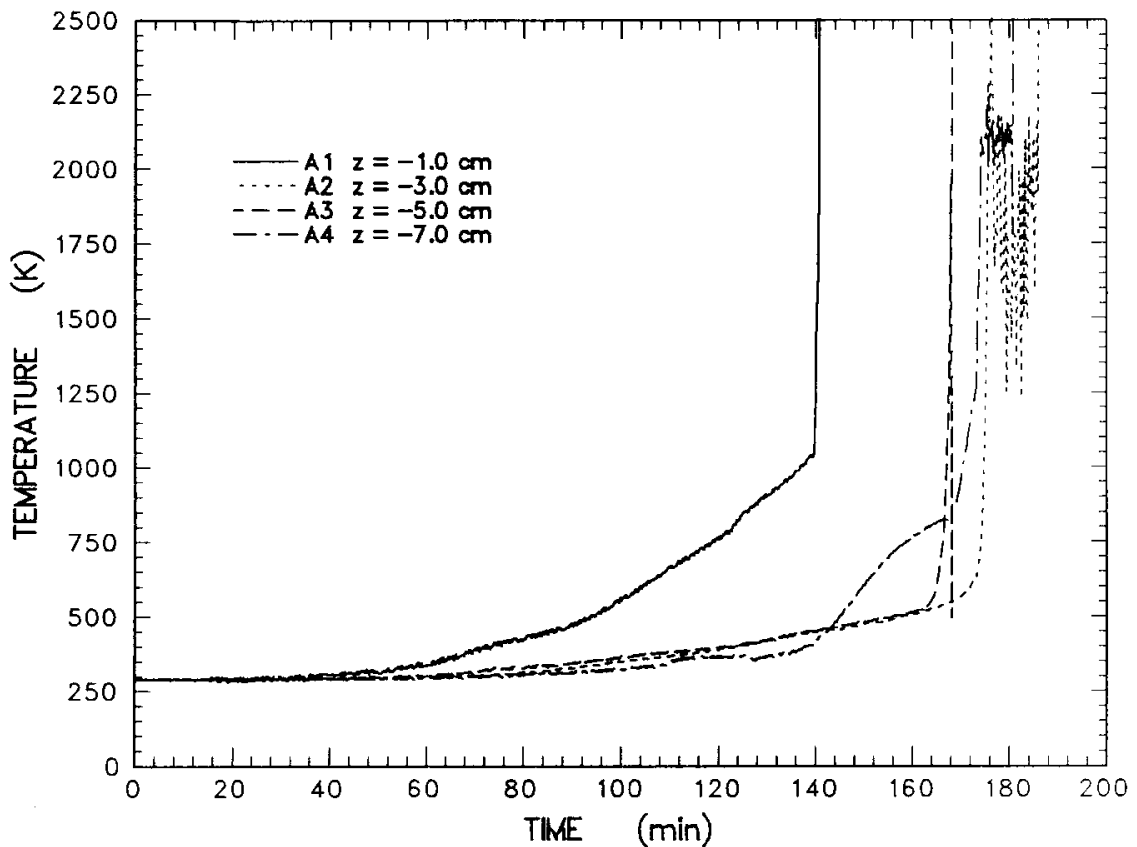

Figure D-1 Meltpool temperature data measured by Type $\mathbf{C}$ and $\mathbf{S}$ thermocouple installed in alumina tubes cast into the concrete between $z=-1.0$ and $-7.0 \mathrm{~cm}$

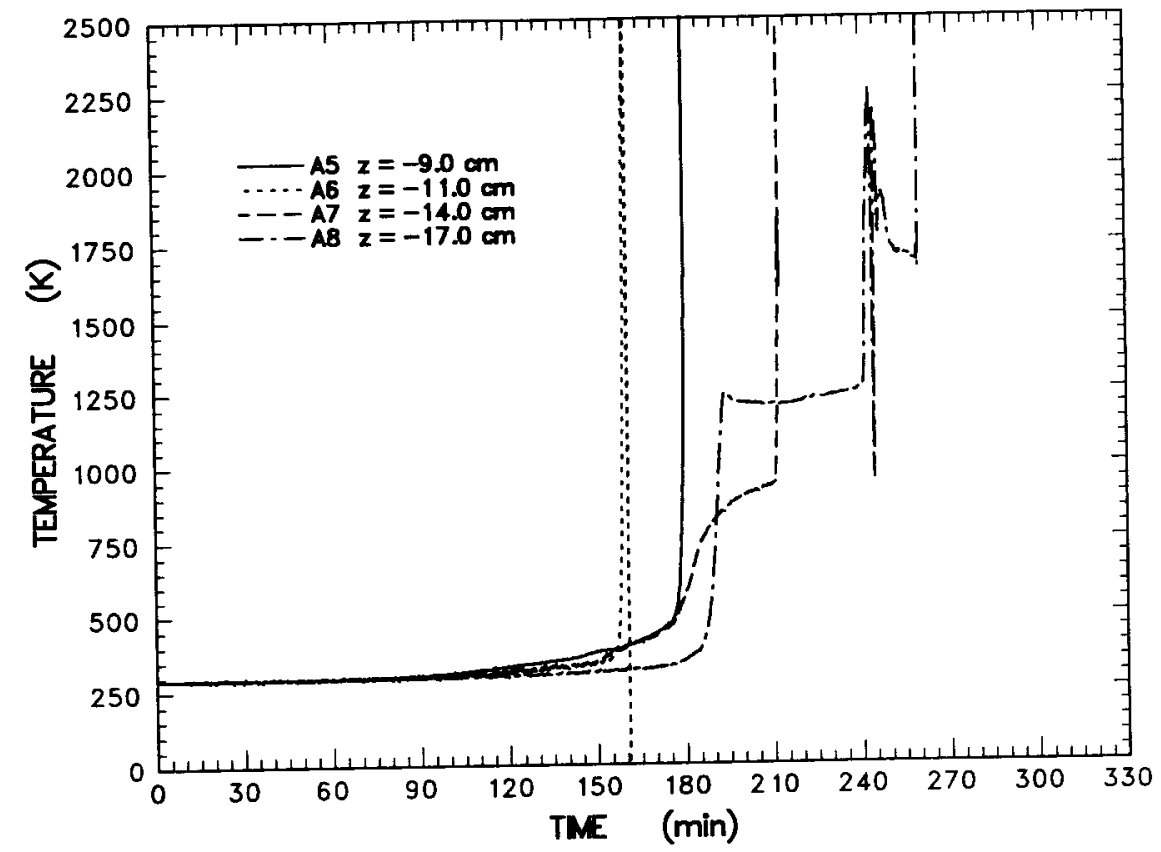

Figure D-2 Meltpool temperature data measured by Type $\mathbf{C}$ and $\mathbf{S}$ thermocouple installed in alumina tubes cast into the concrete between $z=-9.0$ and $-17.0 \mathrm{~cm}$ 
Appendix D

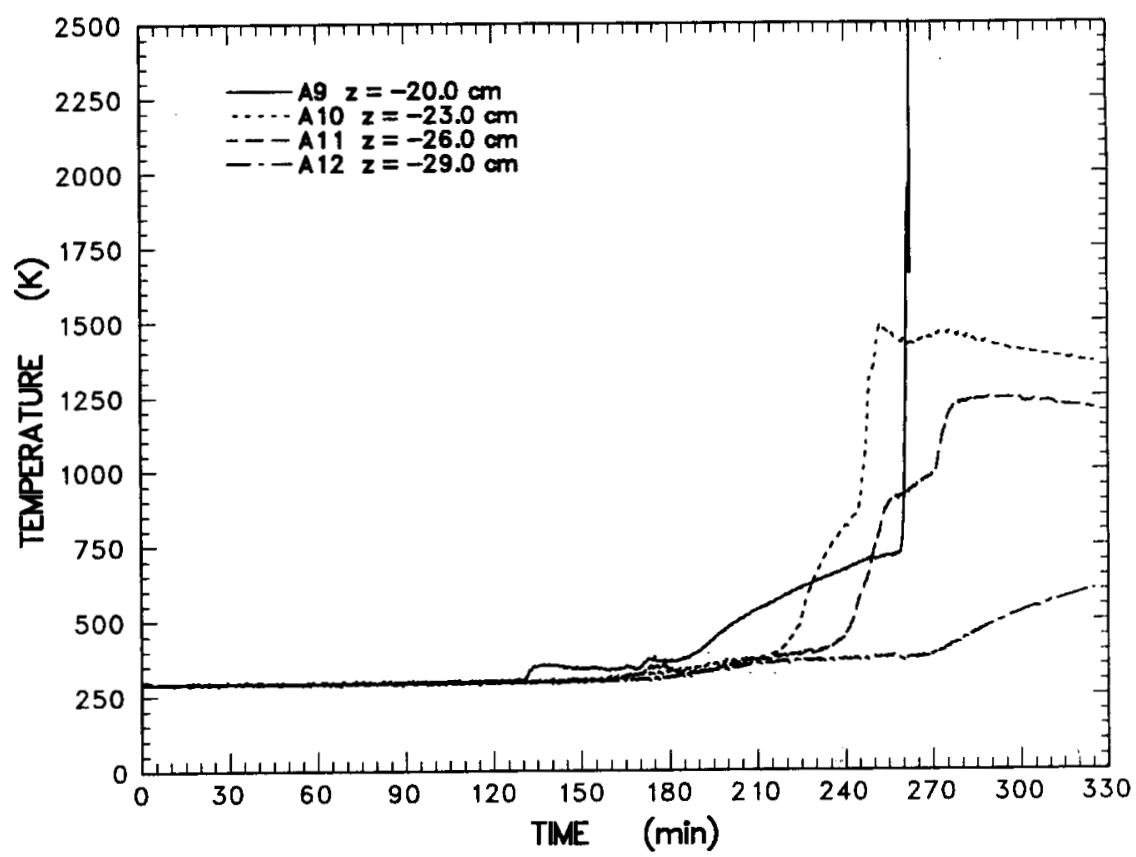

Figure D-3 Meltpool temperature data measured by Type $\mathbf{C}$ and $\mathbf{S}$ thermocouple installed in alumina tubes cast into the concrete between $\mathrm{z}=-20.0$ and $-29.0 \mathrm{~cm}$

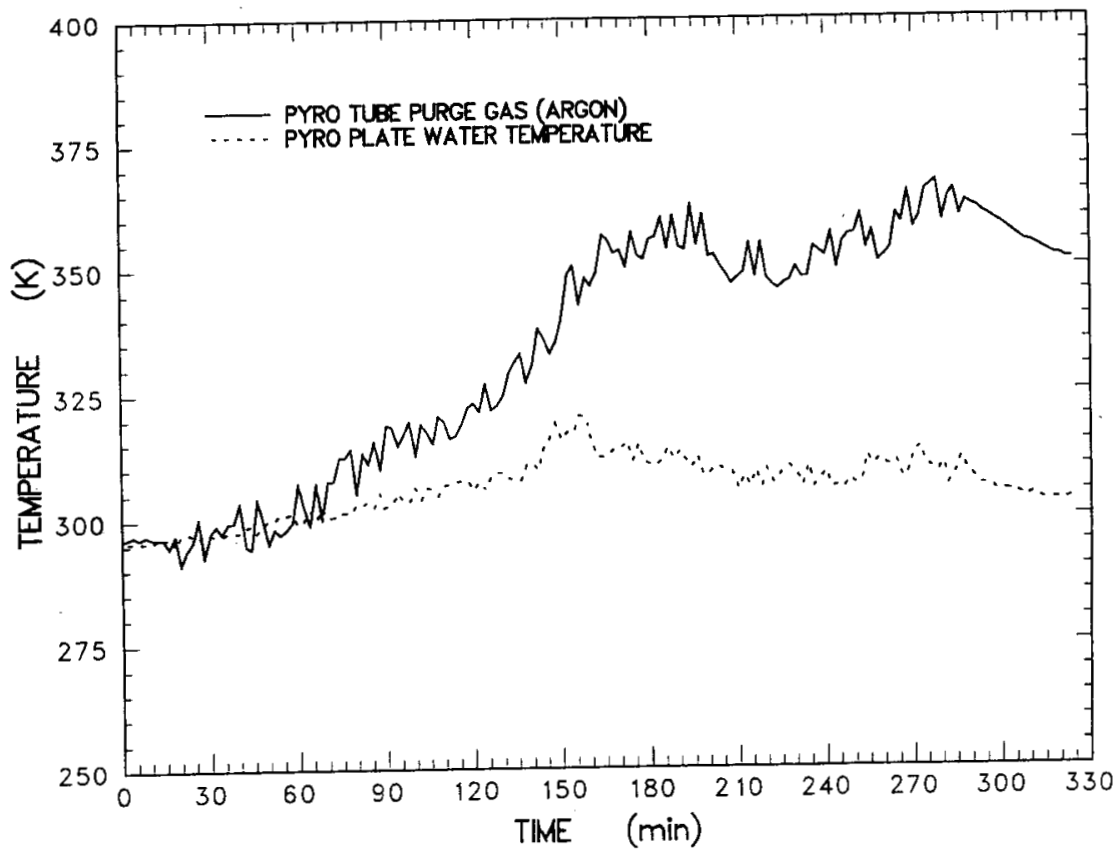

Figure D-4 Temperature at the pyrometer head and exit temperature of the cooling fluid flowing through the pyrometer adapter/support plate 


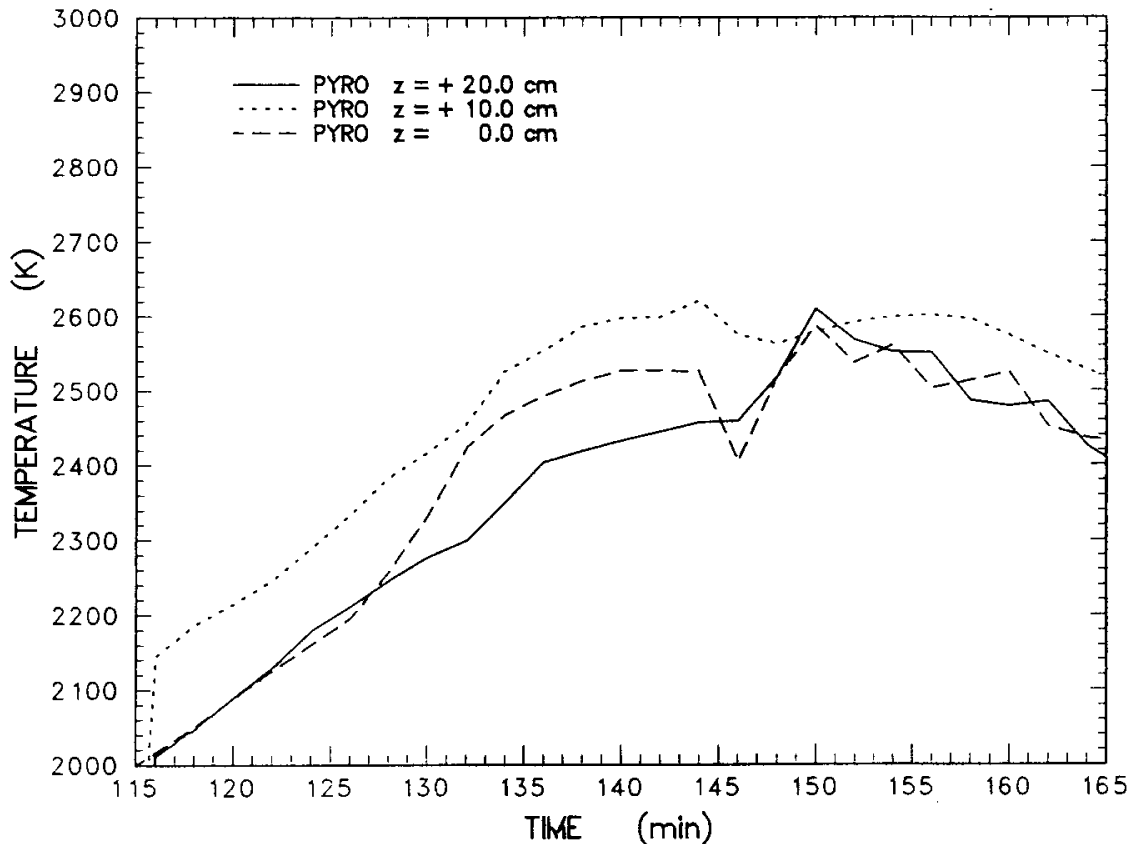

Figure D-5 Temperatures measured by the micron fiber optic pyrometers

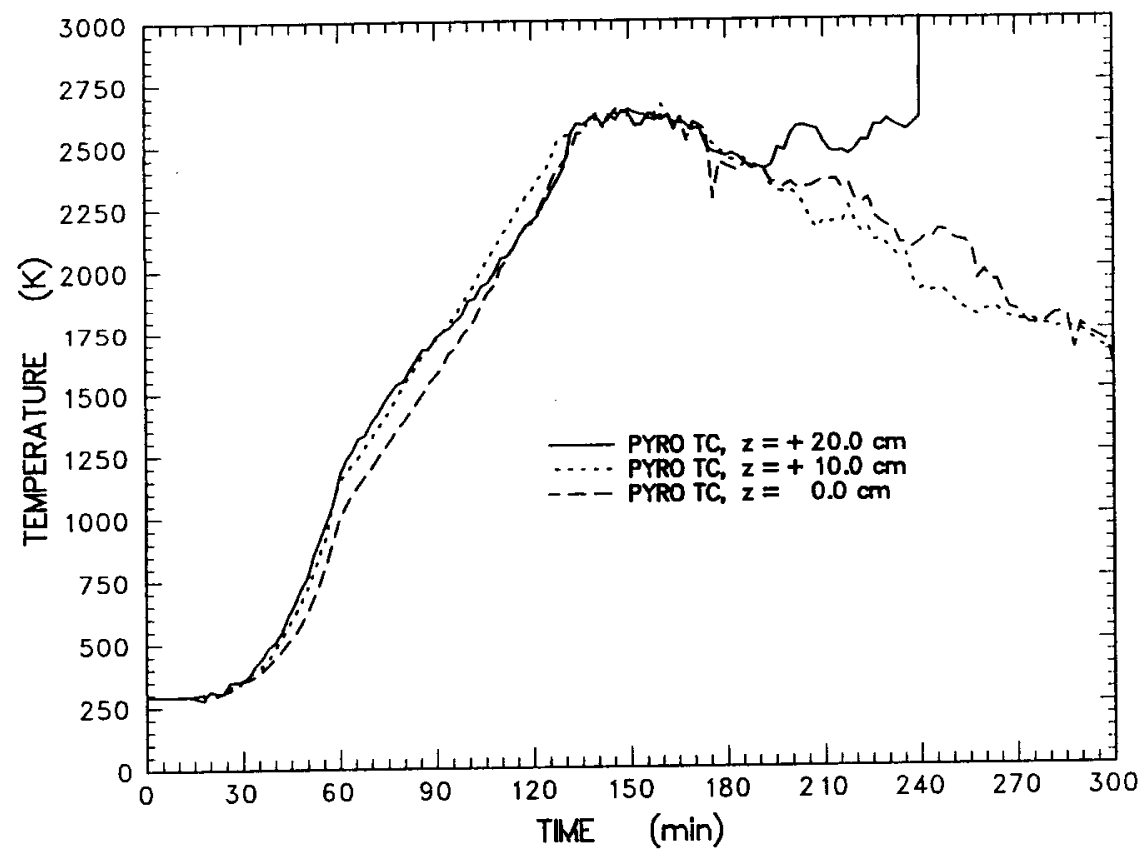

Figure D-6 Temperatures measured by the Type C thermocouples installed at the base of the tungsten pyrotubes 
Appendix D

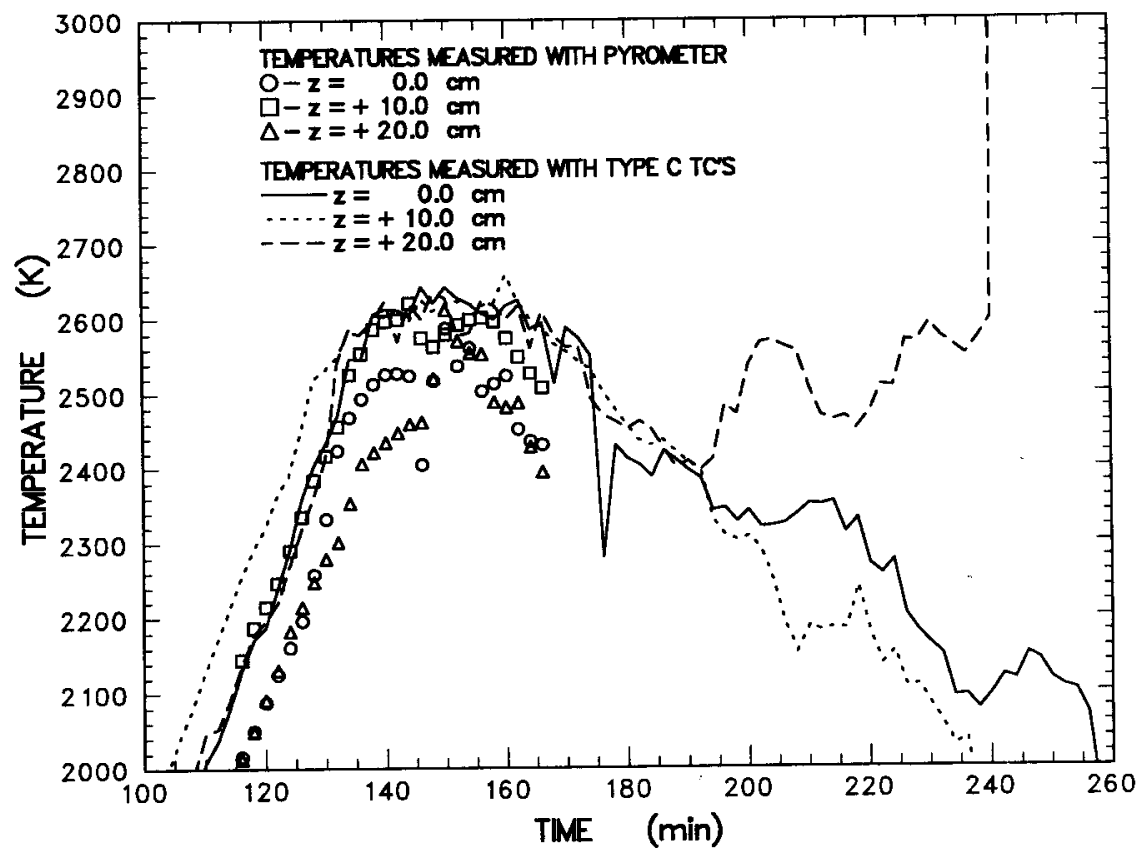

Figure D-7 Comparison of temperatures measured by the pyrometers and the Type $\mathrm{C}$ thermocouple installed in the tungsten pyrotubes located between $\mathrm{z}=0.0$ and $\mathrm{z}=+20.0 \mathrm{~cm}$

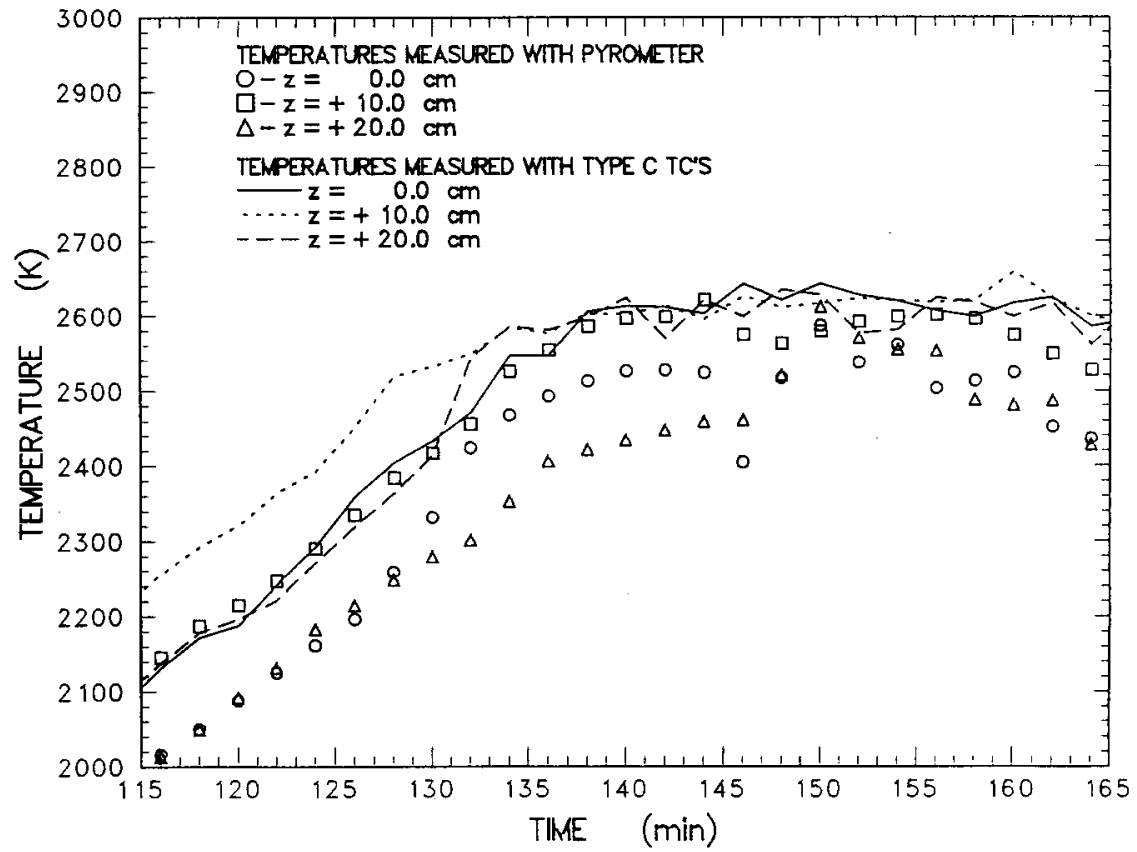

Figure D-8 Expansion of temperature data measured by the pyrometers and the Type $\mathbf{C}$ thermocouple installed in the tungsten pyrotubes located between $\mathrm{z}=0.0$ and $\mathrm{z}=+20.0 \mathrm{~cm}$ 


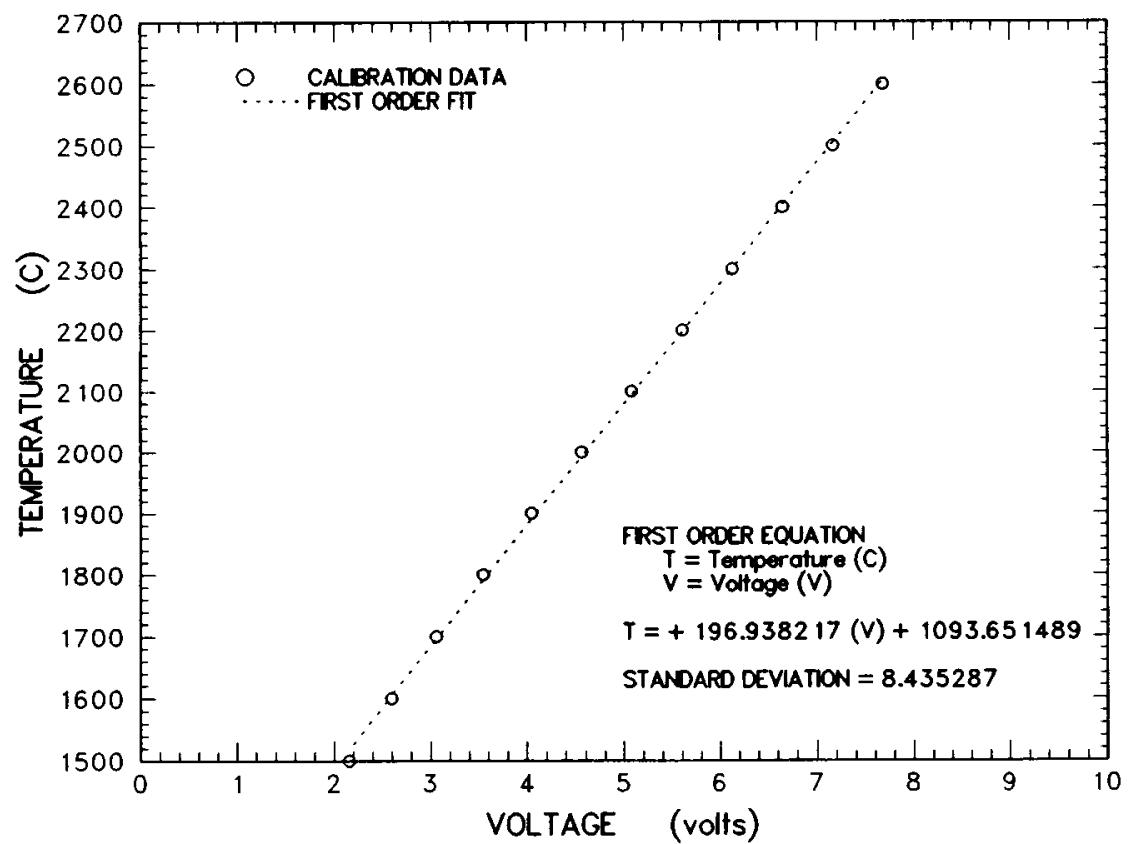

Figure D-9 Calibration data for the micron fiber optic pyrometer focused at the base of the pyrotube located at $z=+0.0 \mathrm{~cm}$

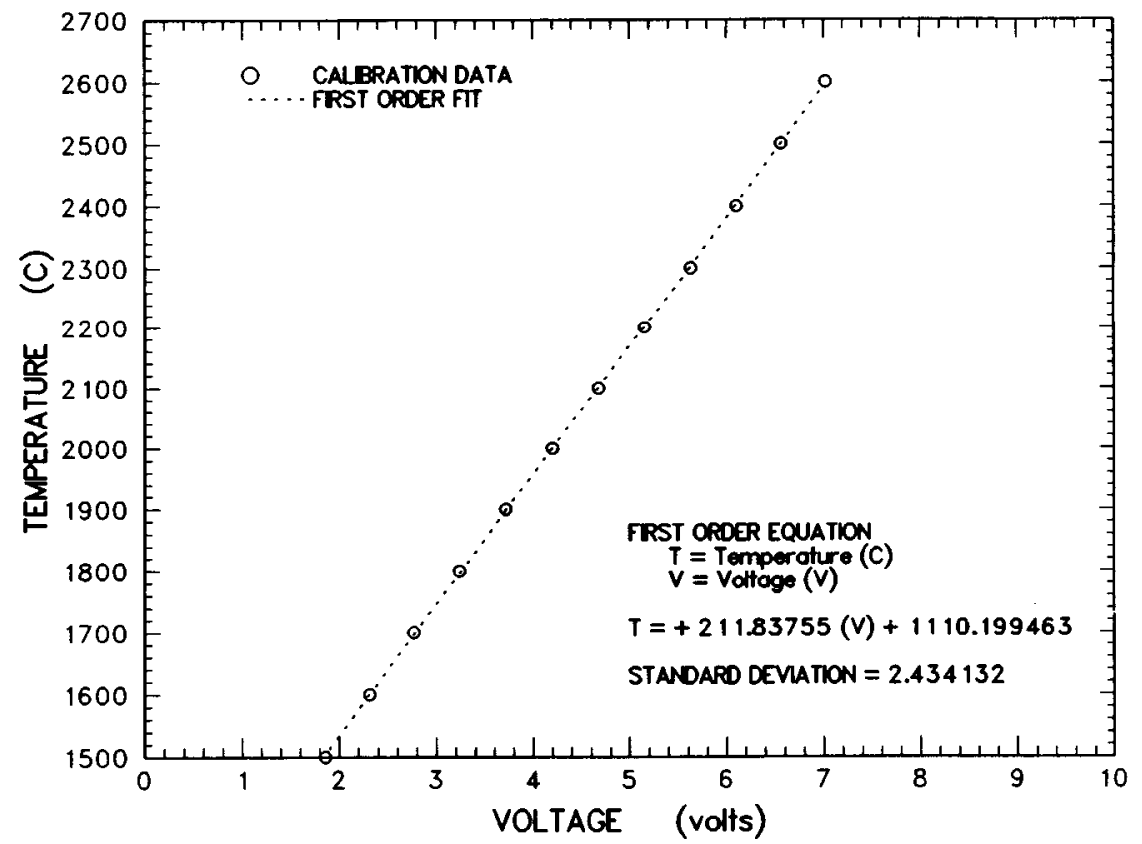

Figure D-10 Calibration data for the micron fiber optic pyrometer focused at the base of the pyrotube located at $\mathrm{z}=+10.0 \mathrm{~cm}$ 


\section{Appendix D}

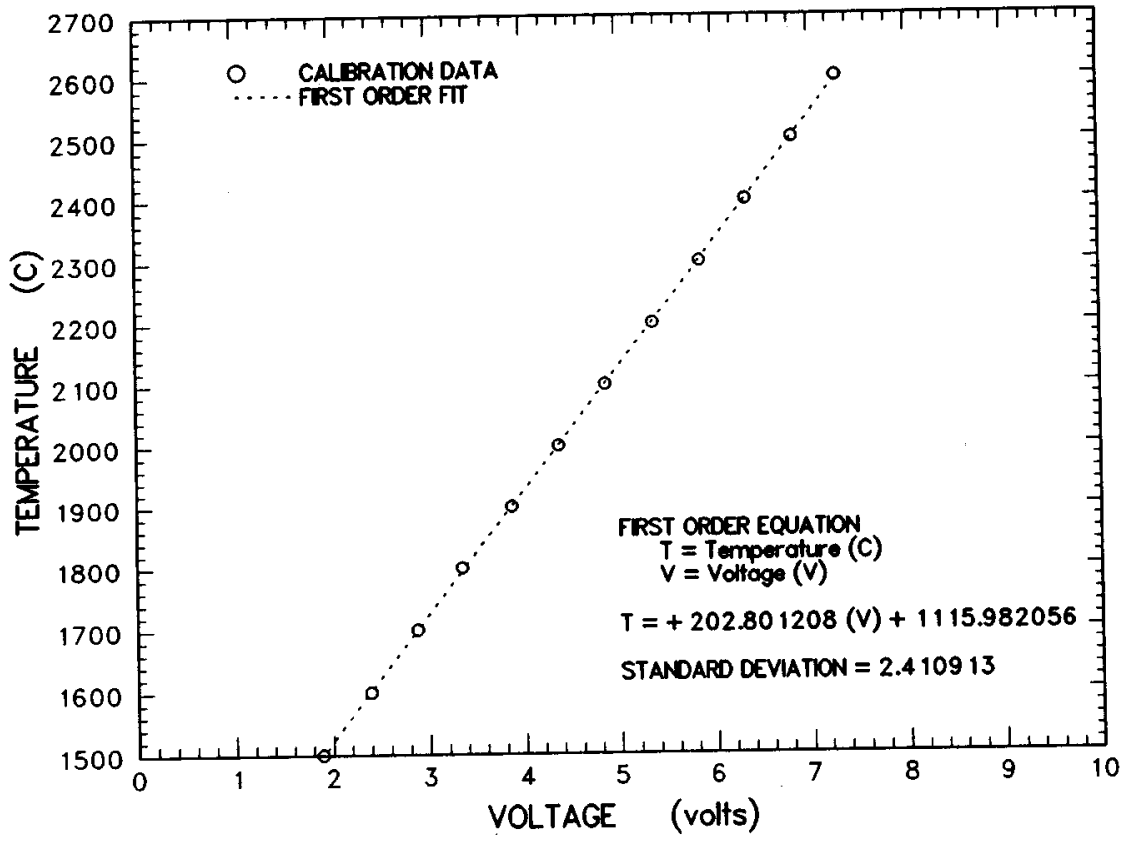

Figure D-11 Calibration data for the micron fiber optic pyrometer focused at the base of the pyrotube located at $\mathrm{z}=+20.0 \mathrm{~cm}$

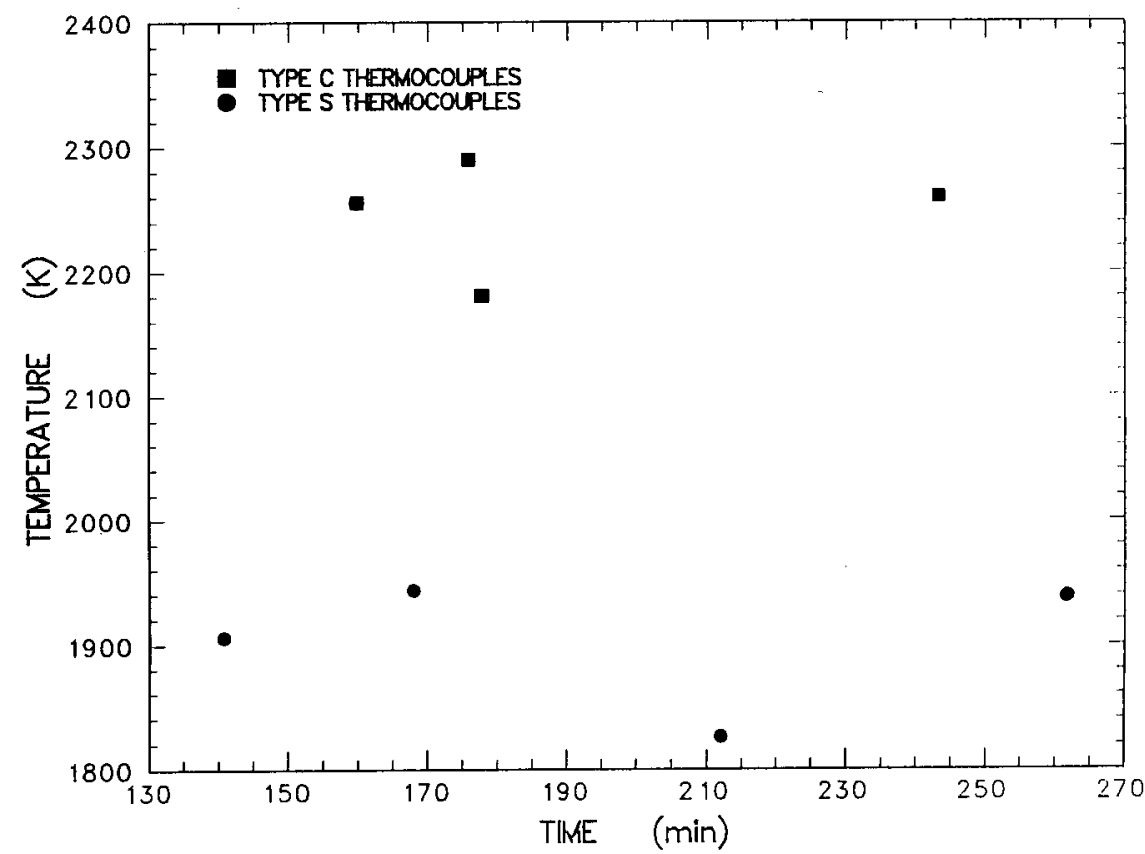

Figure D-12 Peak meltpool temperatures indicated by Type C and S thermocouples installed in alumina tubes cast into the concrete just prior to failure 
APPENDIX E

\section{CALCULATED SIDEWALL HEAT FLUX DATA}


Appendix E

Presented in this appendix are the sidewall and upward heat fluxes calculated using an inverse heat conduction code. Calculations were made based on temperature data produced from type $K$ thermocouple arrays embedded in the $\mathrm{MgO}$

annulus and crucible cover. Additionally, plots are presented comparing sidewall temperatures measured during the experiment and calculated from the inverse heat conduction code. 
Appendix E

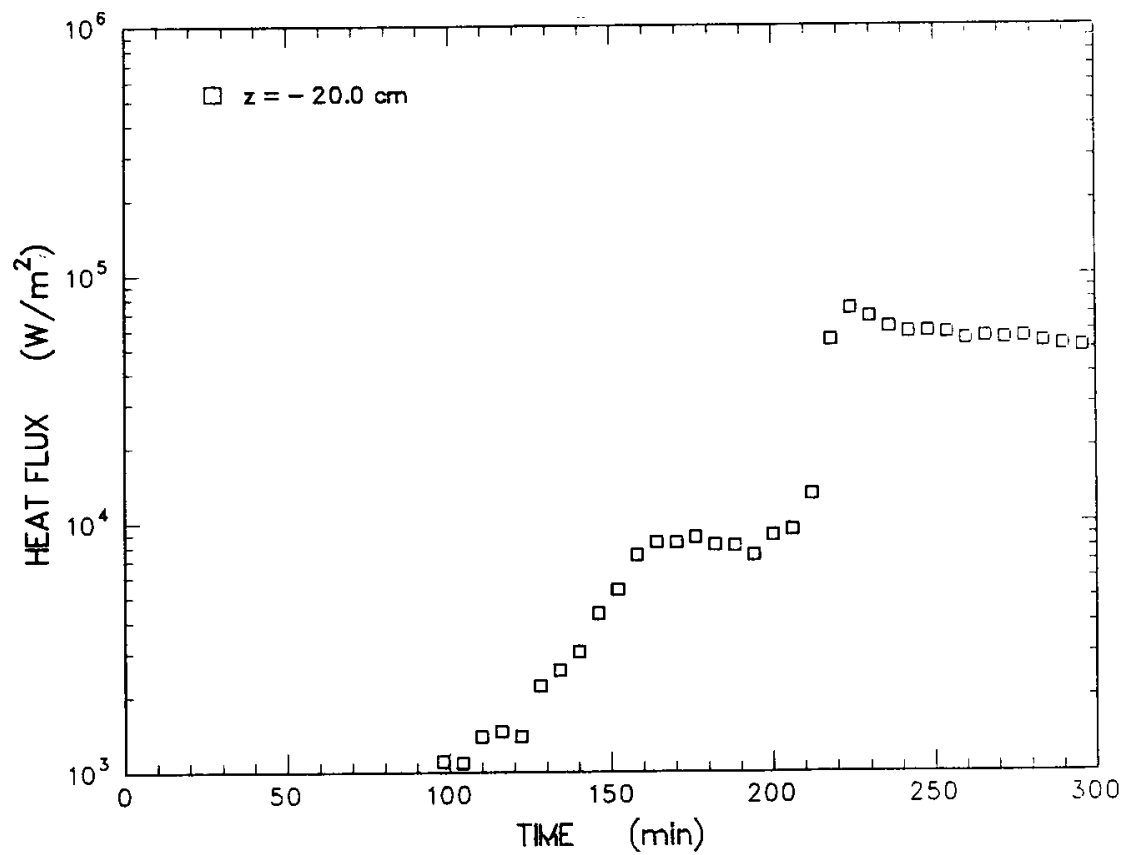

Figure E-1 MgO sidewall heat flux calculated from thermocouple data for the array located at $\mathrm{z}=-20.0 \mathrm{~cm}$

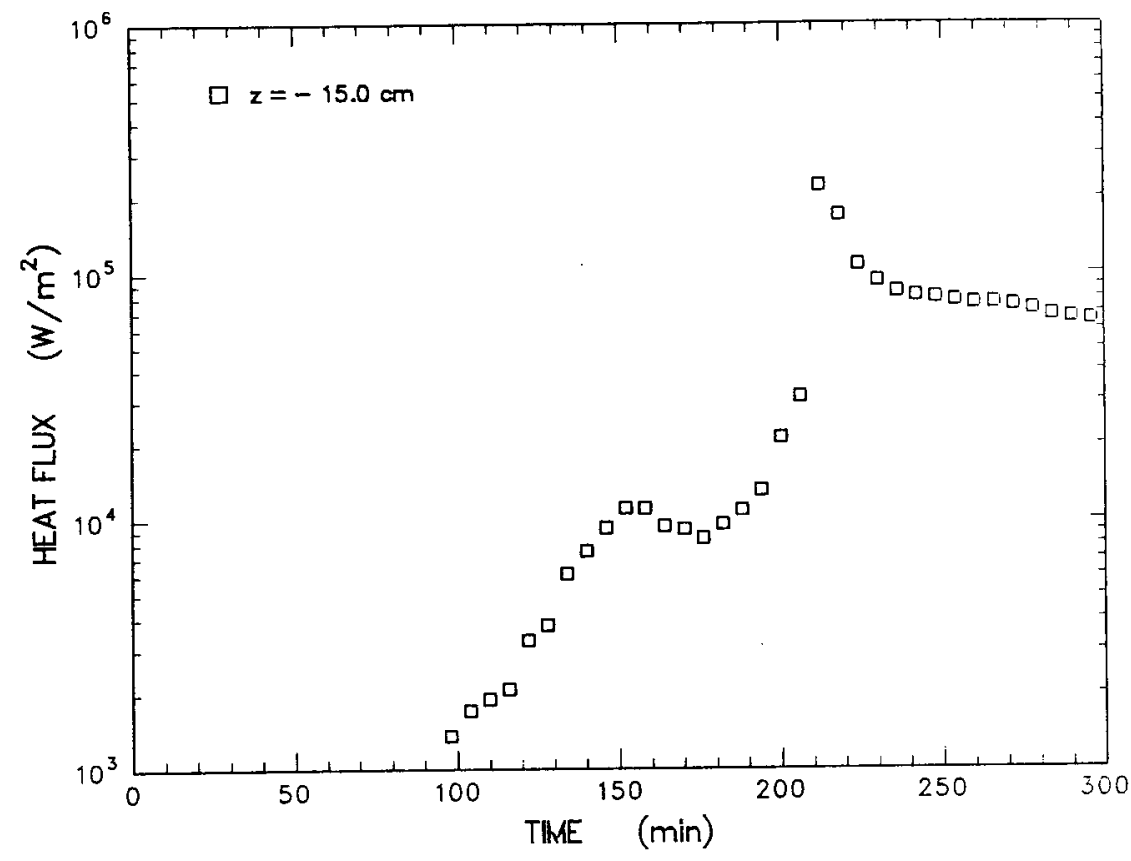

Figure E-2 MgO sidewall heat flux calculated from thermocouple data for the array located at $\mathrm{z}=-15.0 \mathrm{~cm}$ 
Appendix E

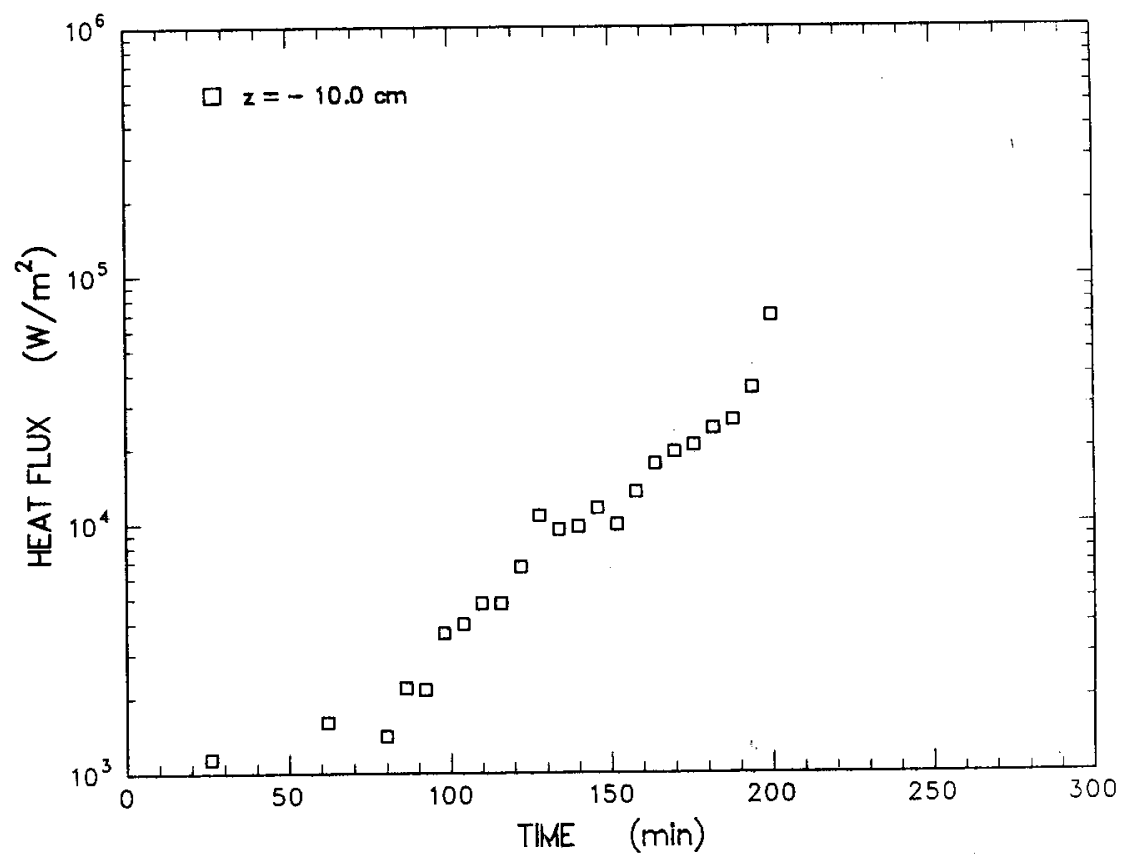

Figure E-3 MgO sidewall heat flux calculated from thermocouple data for the array located at $\mathrm{z}=-10.0 \mathrm{~cm}$

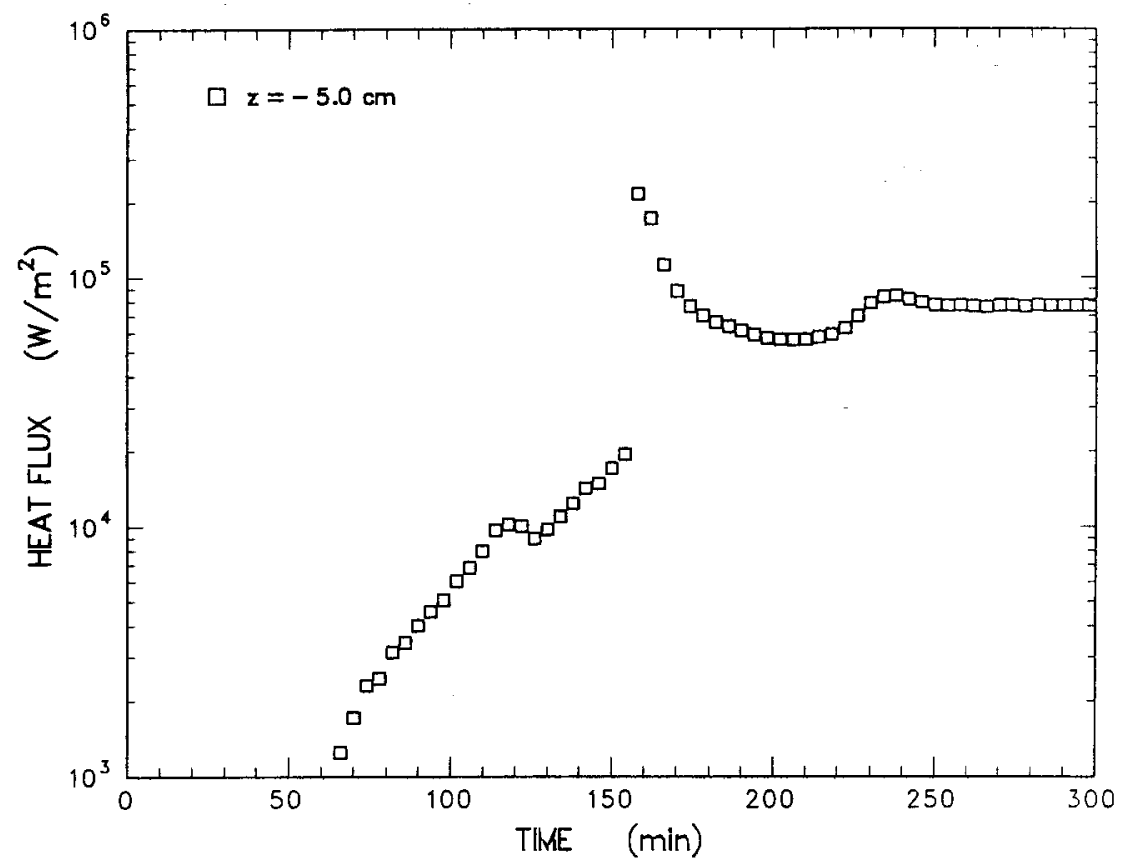

Figure E-4 MgO sidewall heat flux calculated from thermocouple data for the array located at $\mathrm{z}=-5.0 \mathrm{~cm}$ 
Appendix E

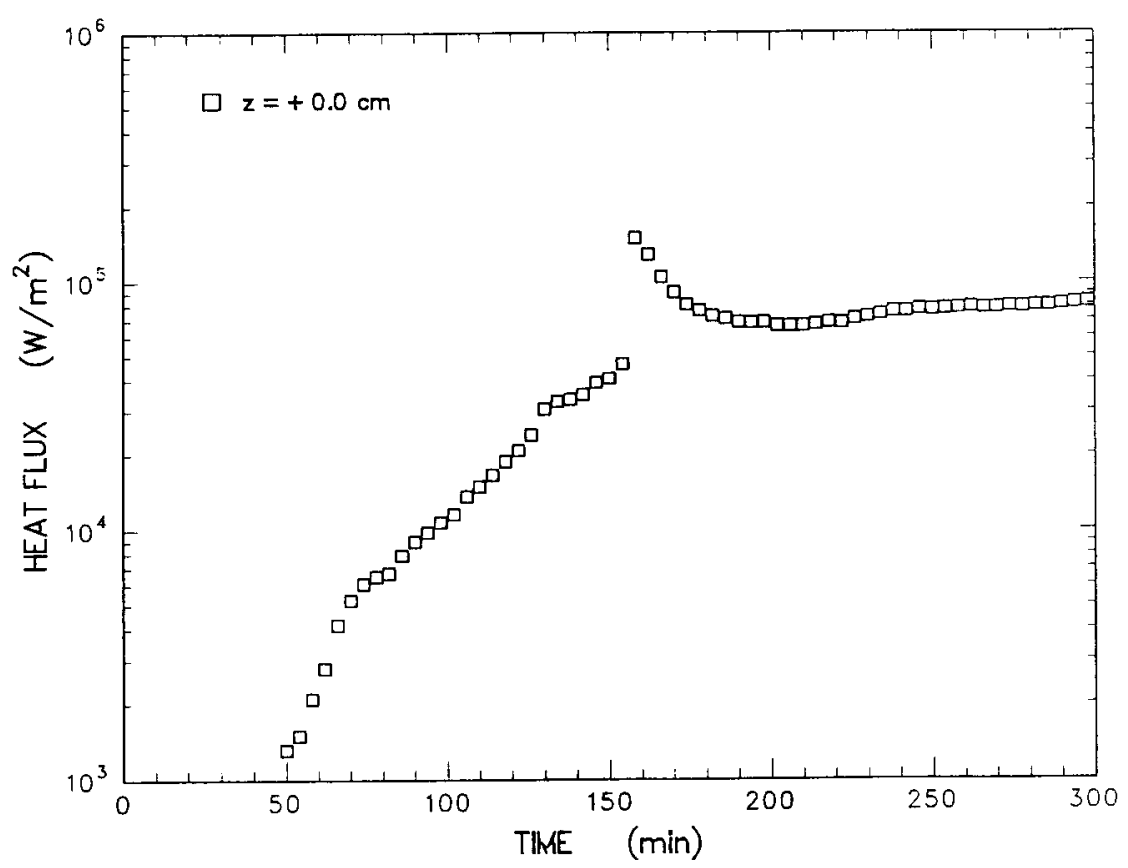

Figure E-5 MgO sidewall heat flux calculated from thermocouple data for the array located at $\mathrm{z}=0.0 \mathrm{~cm}$

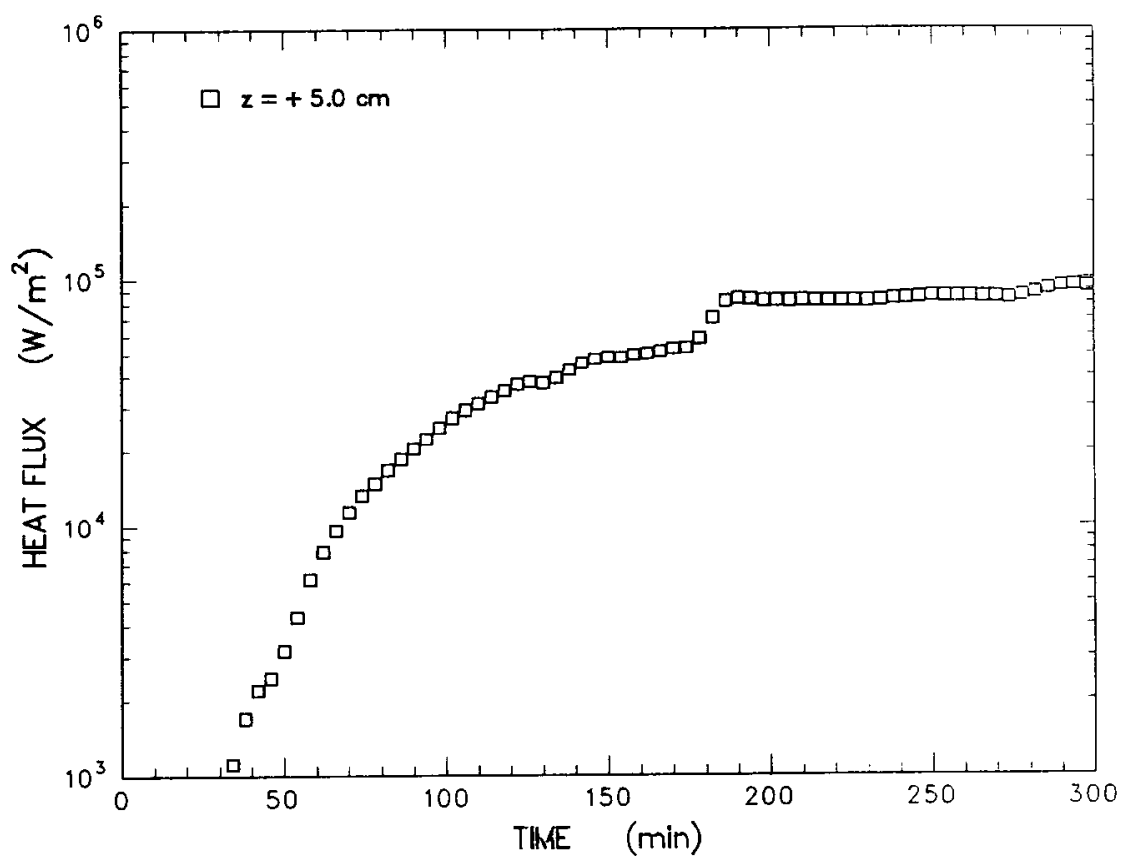

Figure E-6 MgO sidewall heat flux calculated from thermocouple data for the array located at $\mathrm{z}=+5.0 \mathrm{~cm}$ 
Appendix E

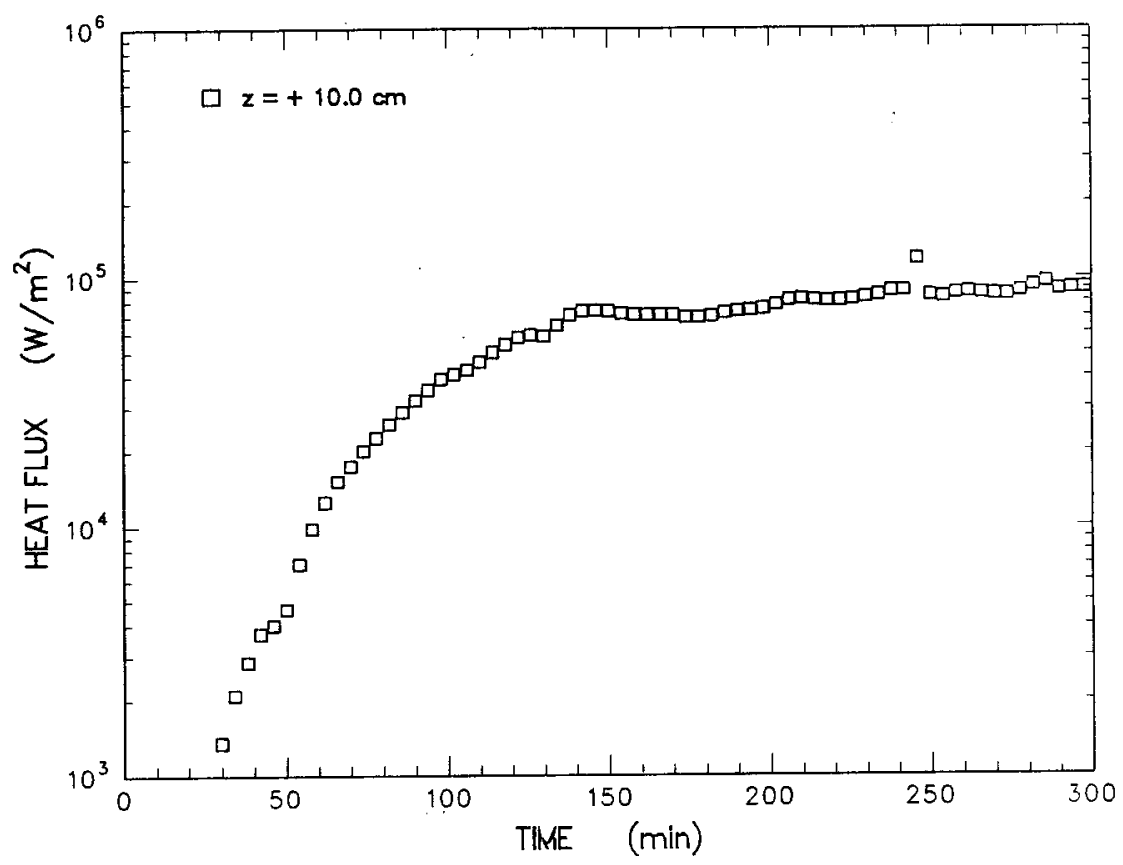

Figure E-7 MgO sidewall heat flux calculated from thermocouple data for the array located at $z=+10.0 \mathrm{~cm}$

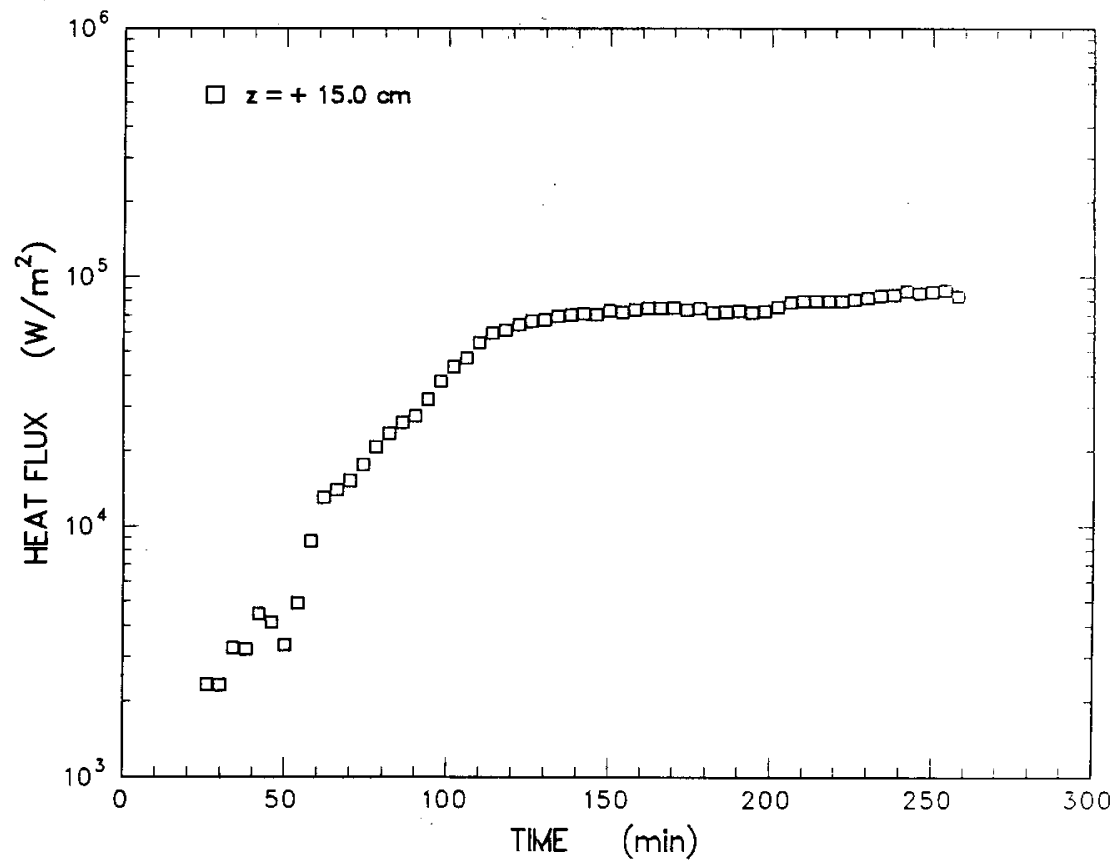

Figure E-8 MgO sidewall heat flux calculated from thermocouple data for the array located at $\mathrm{z}=+15.0 \mathrm{~cm}$ 
Appendix E

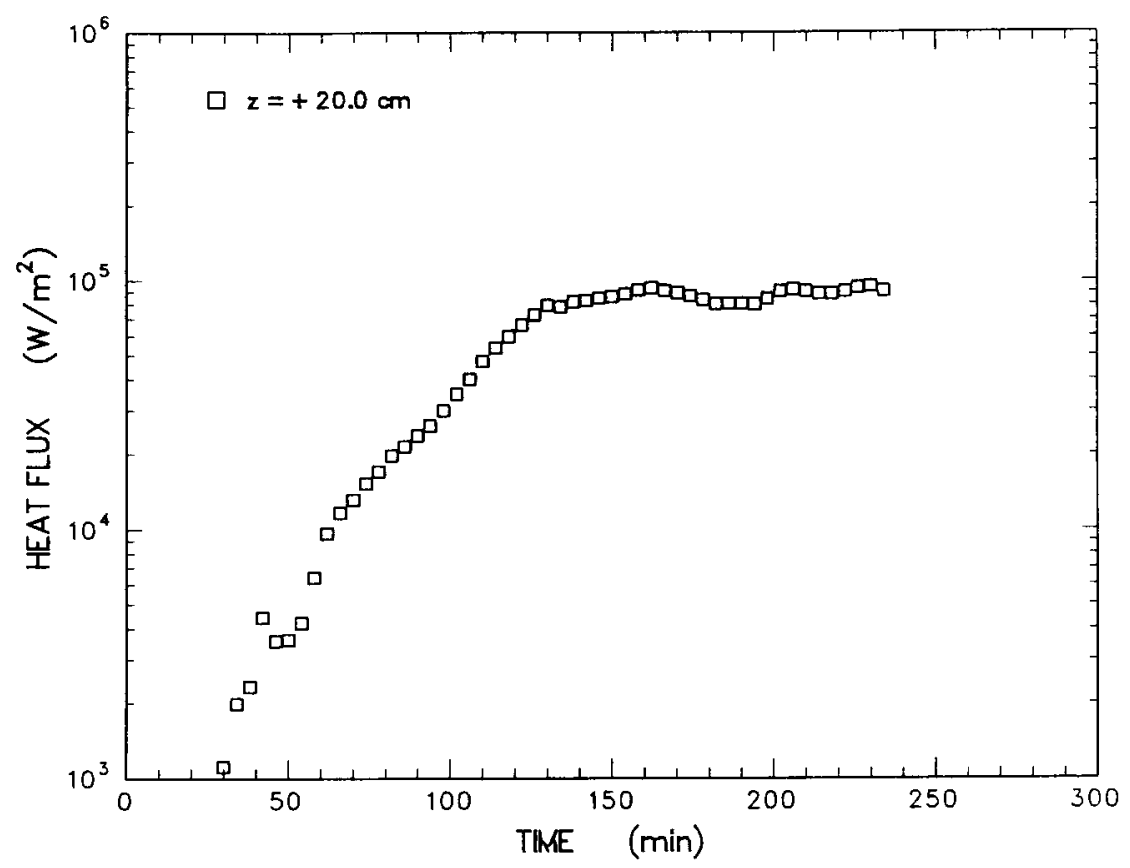

Figure E-9 MgO sidewall heat flux calculated from thermocouple data for the array located at $\mathrm{z}=+20.0 \mathrm{~cm}$

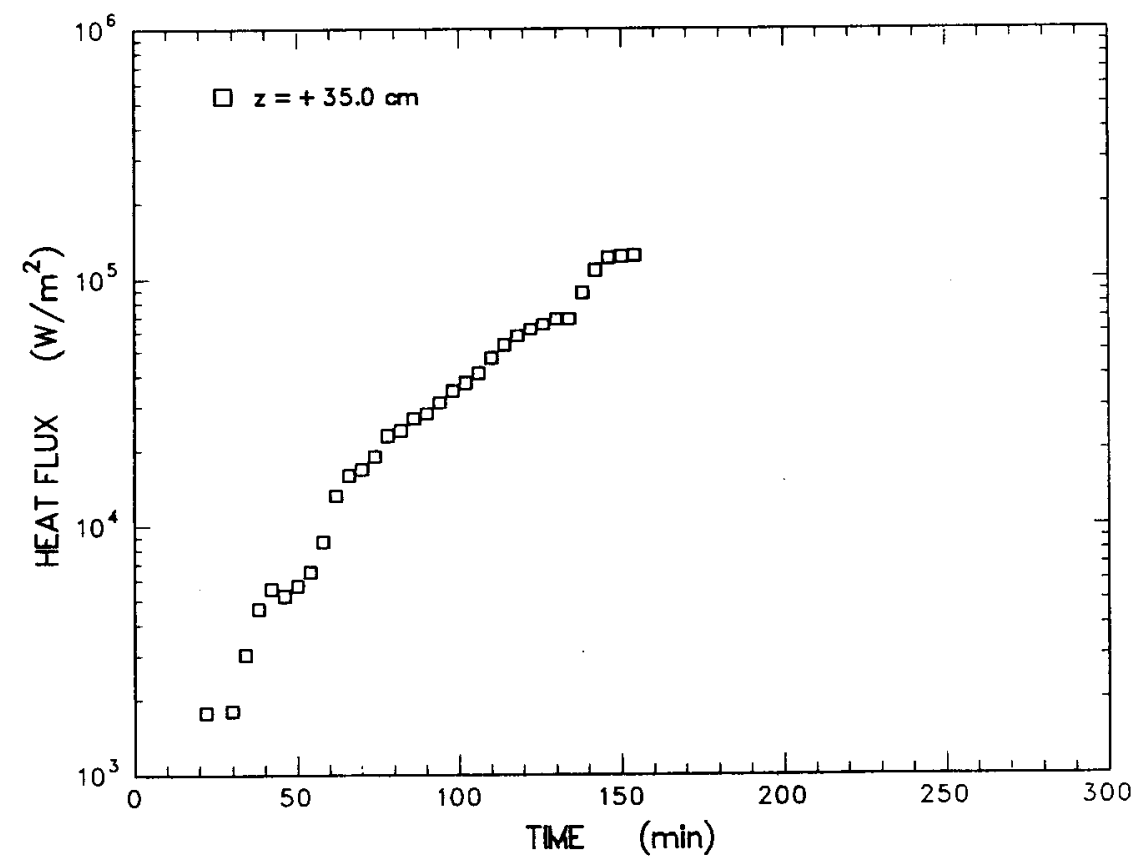

Figure E-10 MgO sidewall heat flux calculated from thermocouple data for the array located at $\mathrm{z}=+35.0 \mathrm{~cm}$ 
Appendix E

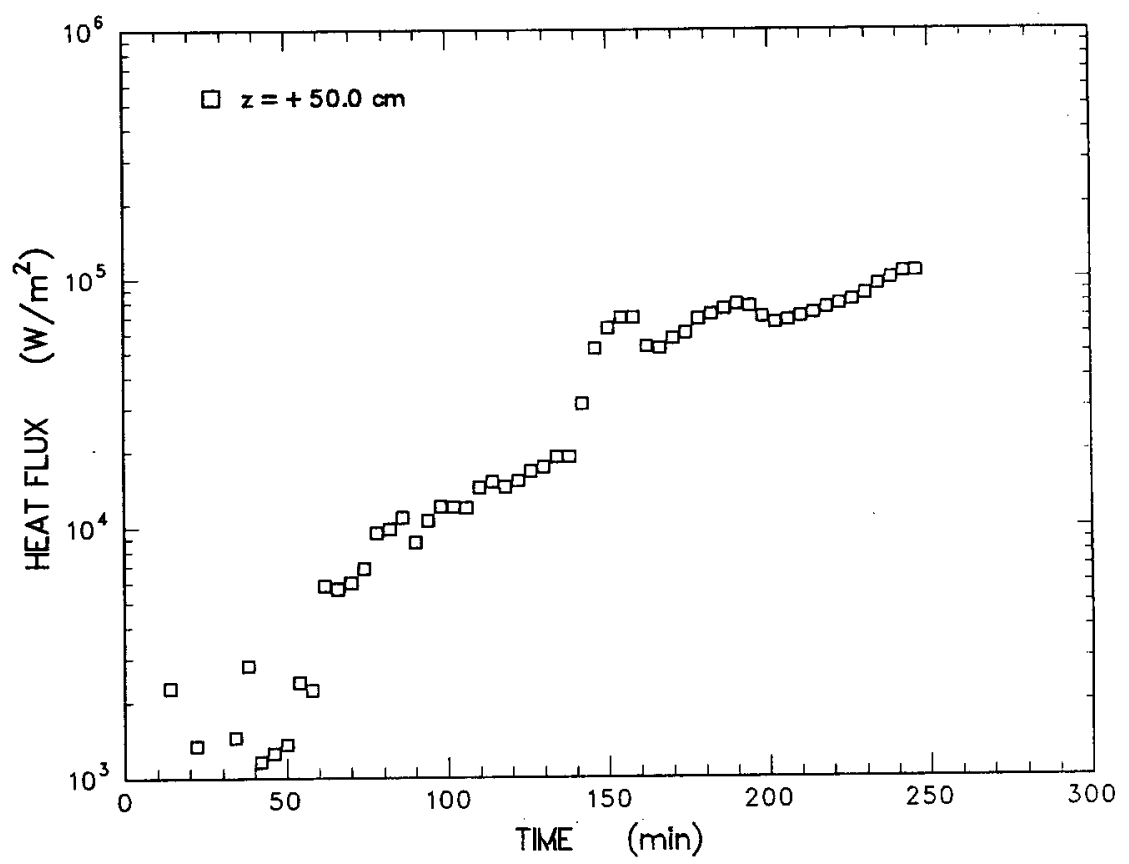

Figure E-11 MgO sidewall heat flux calculated from thermocouple data for the array located at $\mathrm{z}=$ $+50.0 \mathrm{~cm}$

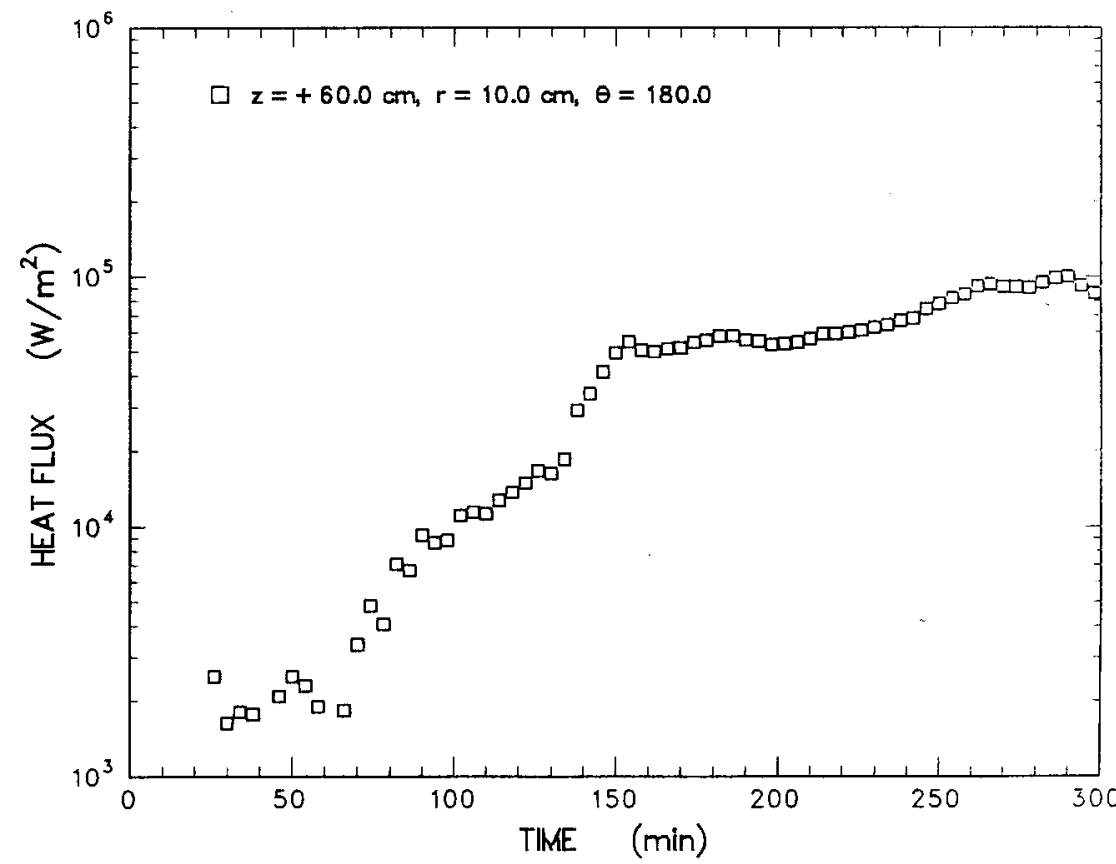

Figure E-12 MgO cover heat flux calculated from thermocouple data for the array located at $\mathrm{r}=10.0 \mathrm{~cm}, \theta=0$, and $\mathrm{z}=+60.0 \mathrm{~cm}$ 
Appendix E

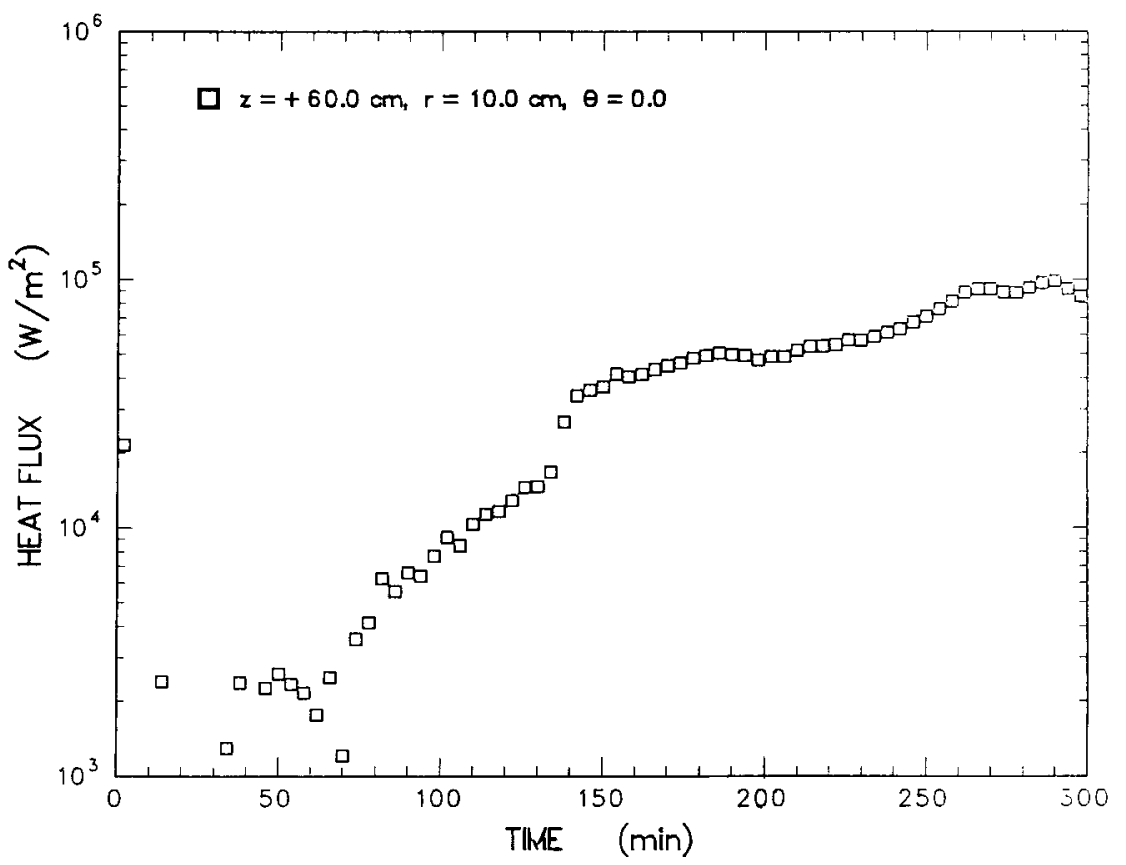

Figure E-13 MgO cover heat flux calculated from thermocouple data for the array located at $r=10.0 \mathrm{~cm}, \theta=180$, and $\mathrm{z}=+60.0 \mathrm{~cm}$

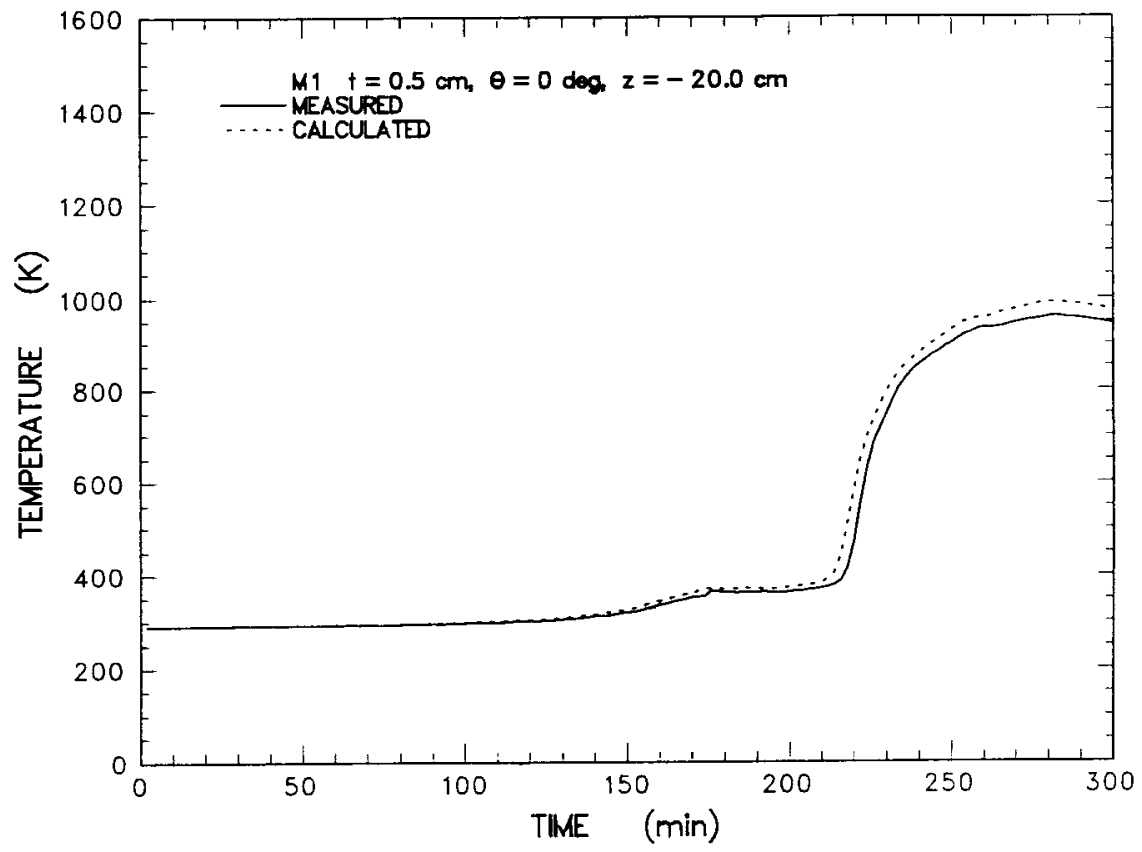

Figure E-14 Comparison of sidewall temperatures measured during the experiment and calculated from the heat flux code for the thermocouple located at $\mathrm{z}=-20.0 \mathrm{~cm}$ and $\mathrm{t}=0.5 \mathrm{~cm}$ 
Appendix E

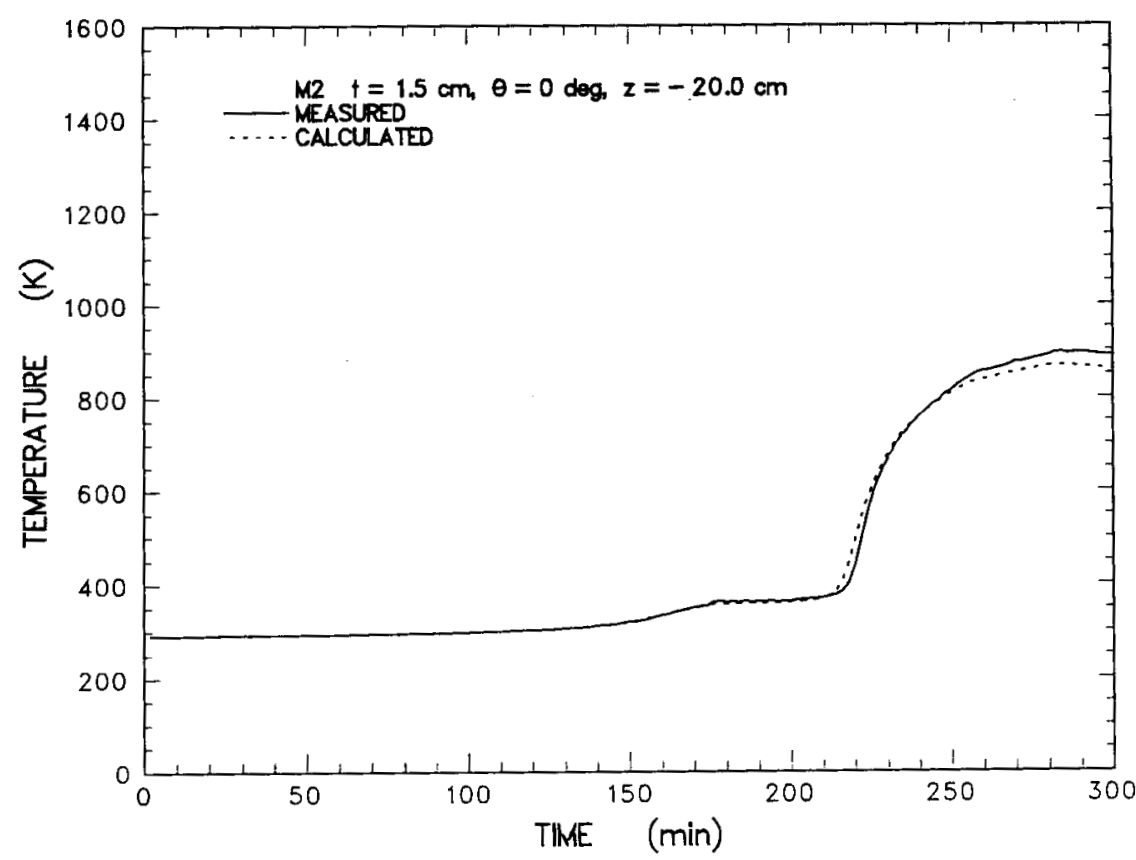

Figure E-15 Comparison of sidewall: temperatures measured during the experiment and calculated from the heat flux code for the thermocouple located at $\mathrm{z}=-20.0 \mathrm{~cm}$ and $\mathrm{t}=1.5 \mathrm{~cm}$

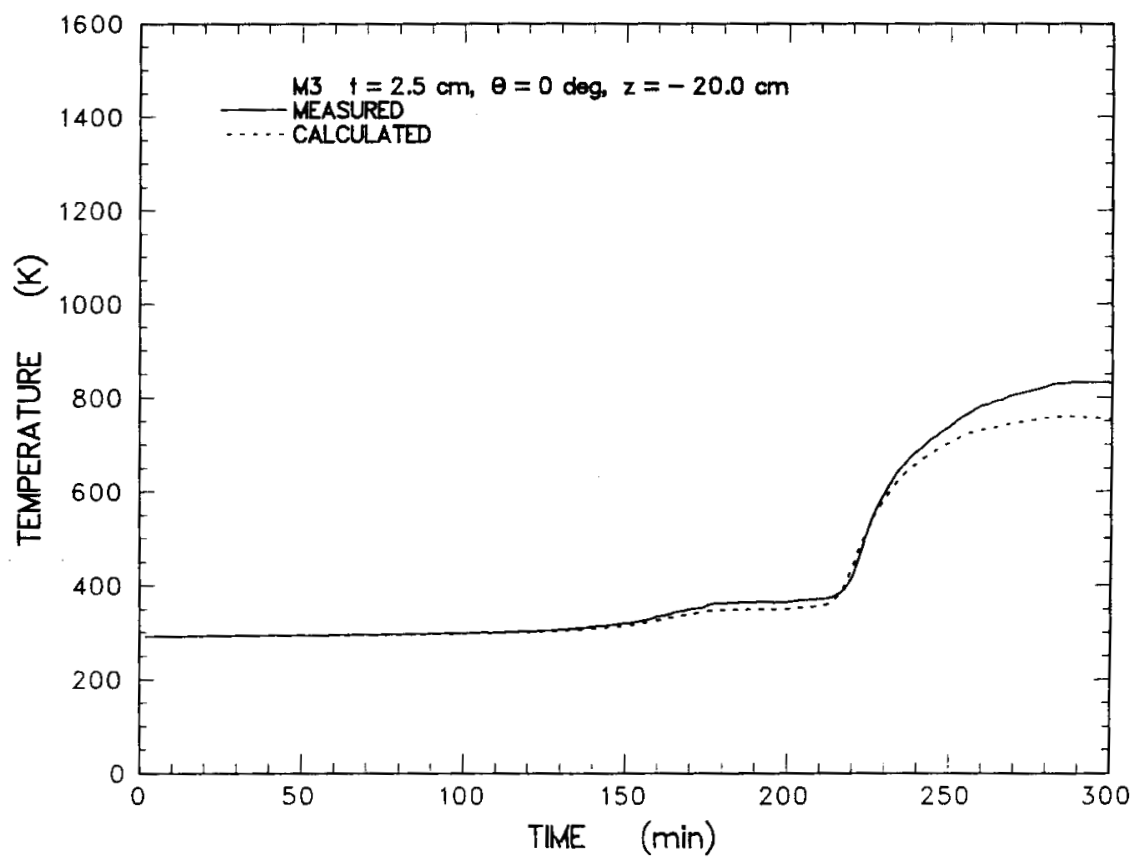

Figure E-16 Comparison of sidewall temperatures measured during the experiment and calculated from the heat flux code for the thermocouple located at $\mathrm{z}=-20.0 \mathrm{~cm}$ and $\mathrm{t}=2.5 \mathrm{~cm}$ 
Appendix E

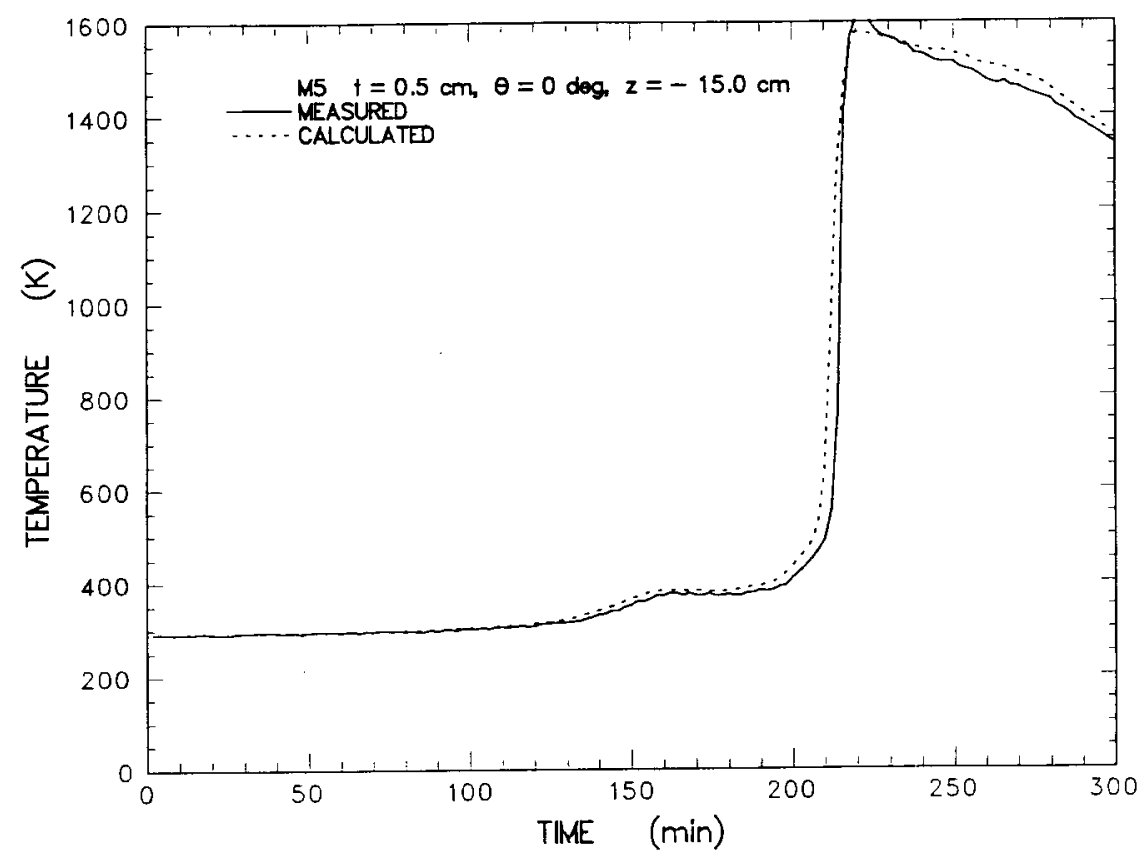

Figure E-17 Comparison of sidewall temperatures measured during the experiment and calculated from the heat flux code for the thermocouple located at $\mathrm{z}=-15.0 \mathrm{~cm}$ and $\mathrm{t}=0.5 \mathrm{~cm}$

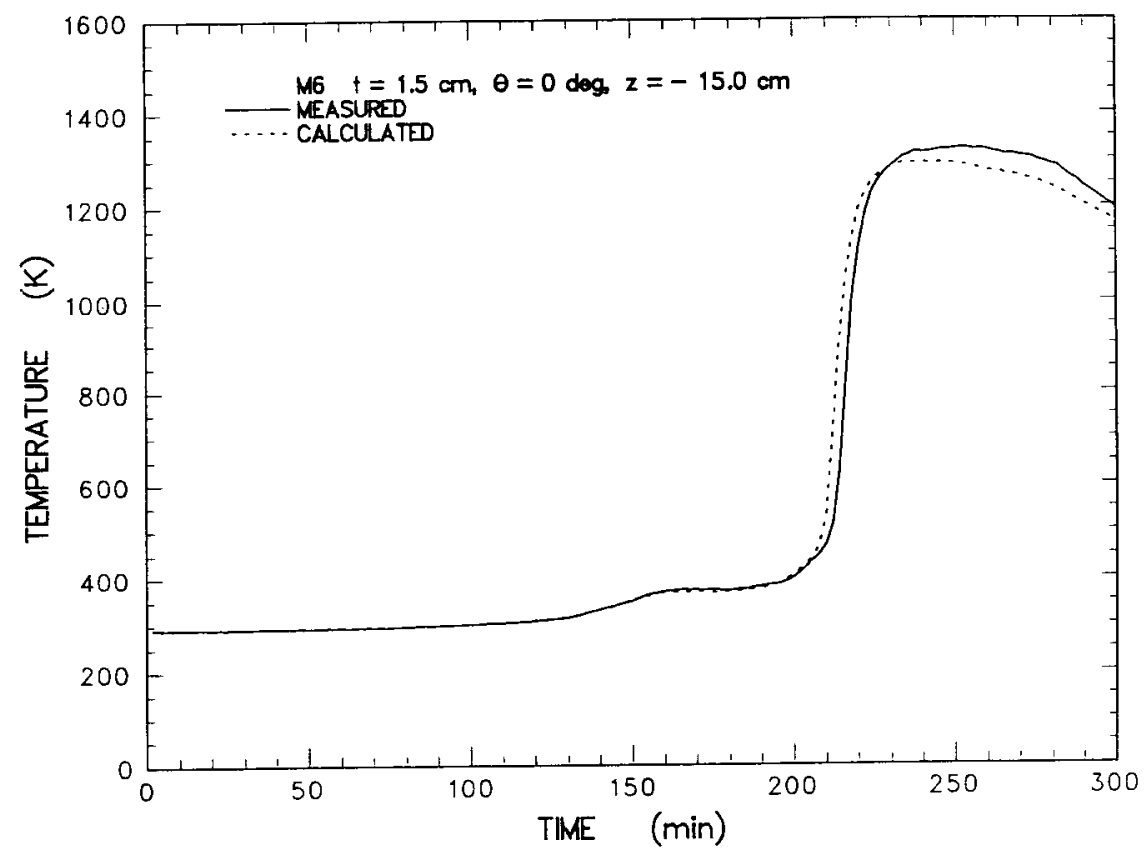

Figure E-18 Comparison of sidewall temperatures measured during the experiment and calculated from the heat flux code for the thermocouple located at $\mathrm{z}=-15.0 \mathrm{~cm}$ and $\mathrm{t}=1.5 \mathrm{~cm}$ 
Appendix E

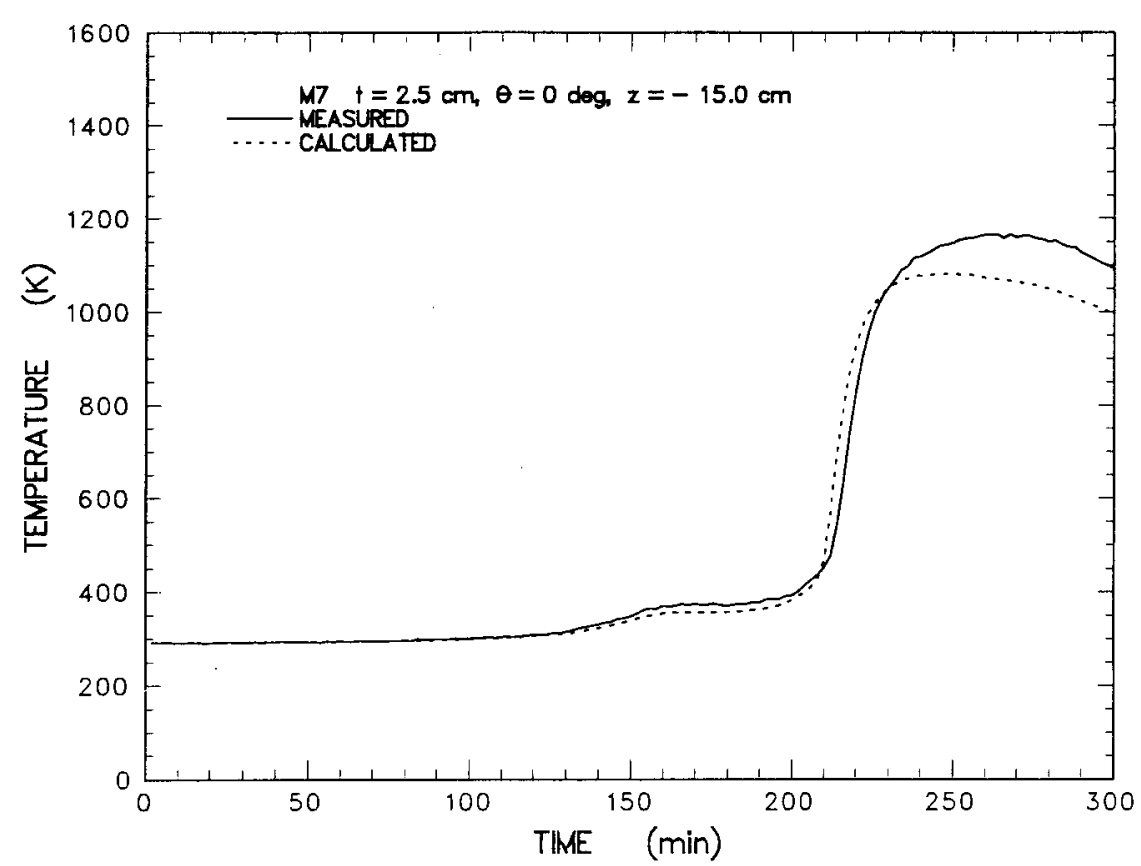

Figure E-19 Comparison of sidewall temperatures measured during the experiment and calculated from the heat flux code for the thermocouple located at $\mathrm{z}=-15.0 \mathrm{~cm}$ and $\mathrm{t}=2.5 \mathrm{~cm}$

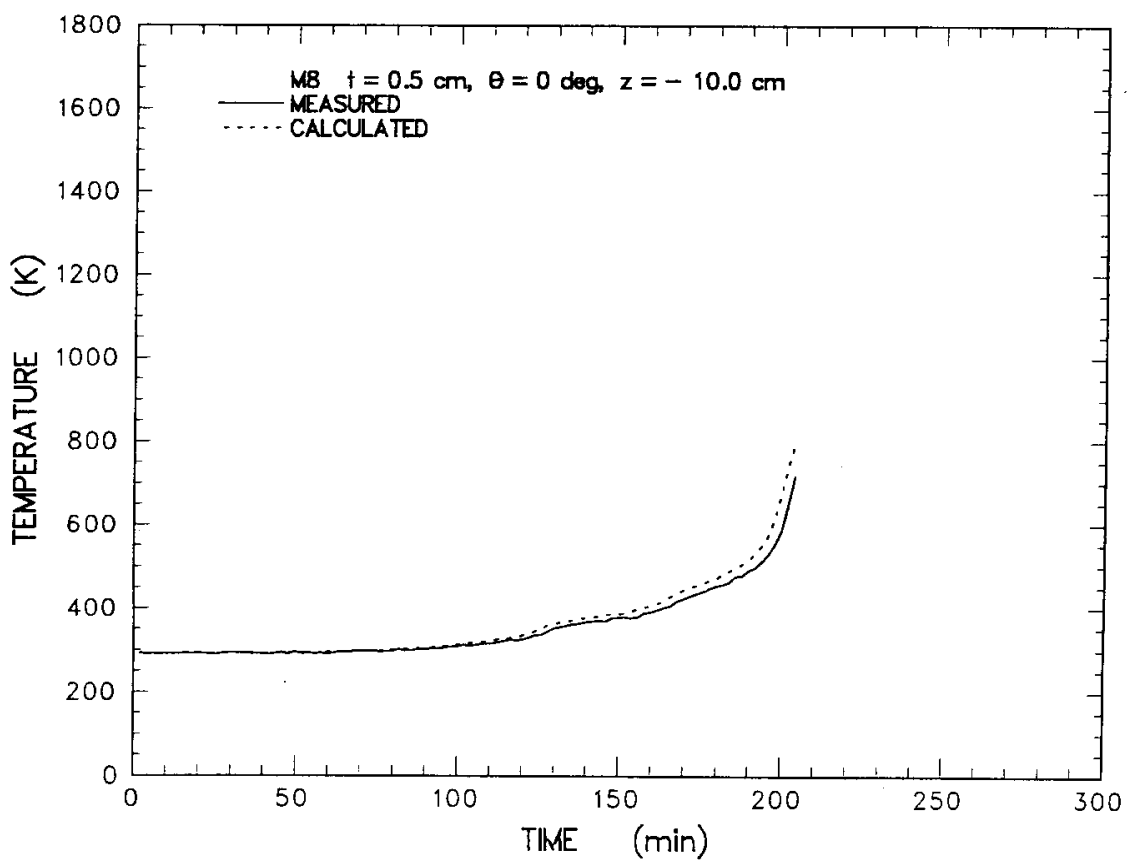

Figure E-20 Comparison of sidewall temperatures measured during the experiment and calculated from the heat flux code for the thermocouple located at $\mathrm{z}=-10.0 \mathrm{~cm}$ and $\mathrm{t}=0.5 \mathrm{~cm}$ 
Appendix E

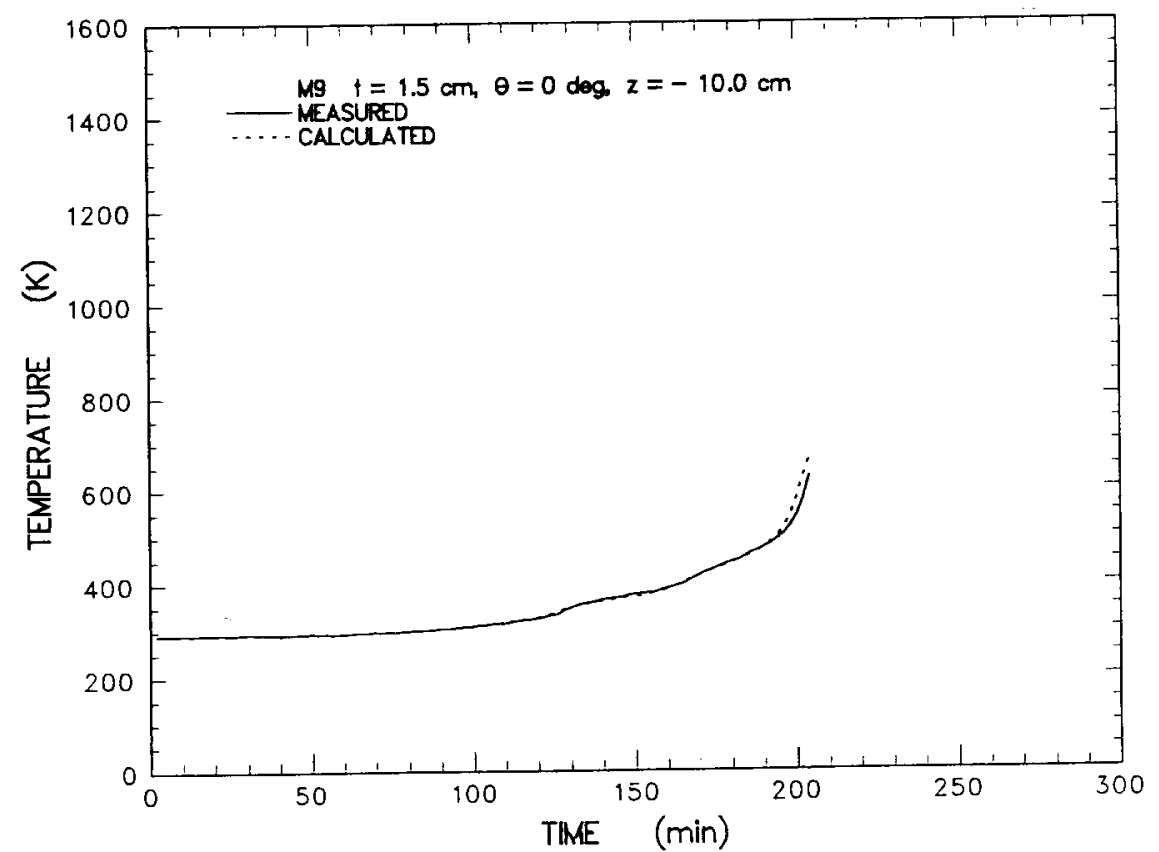

Figure E-21 Comparison of sidewall temperatures measured during the experiment and calculated from the heat flux code for the thermocouple located at $\mathrm{z}=-10.0 \mathrm{~cm}$ and $\mathrm{t}=1.5 \mathrm{~cm}$

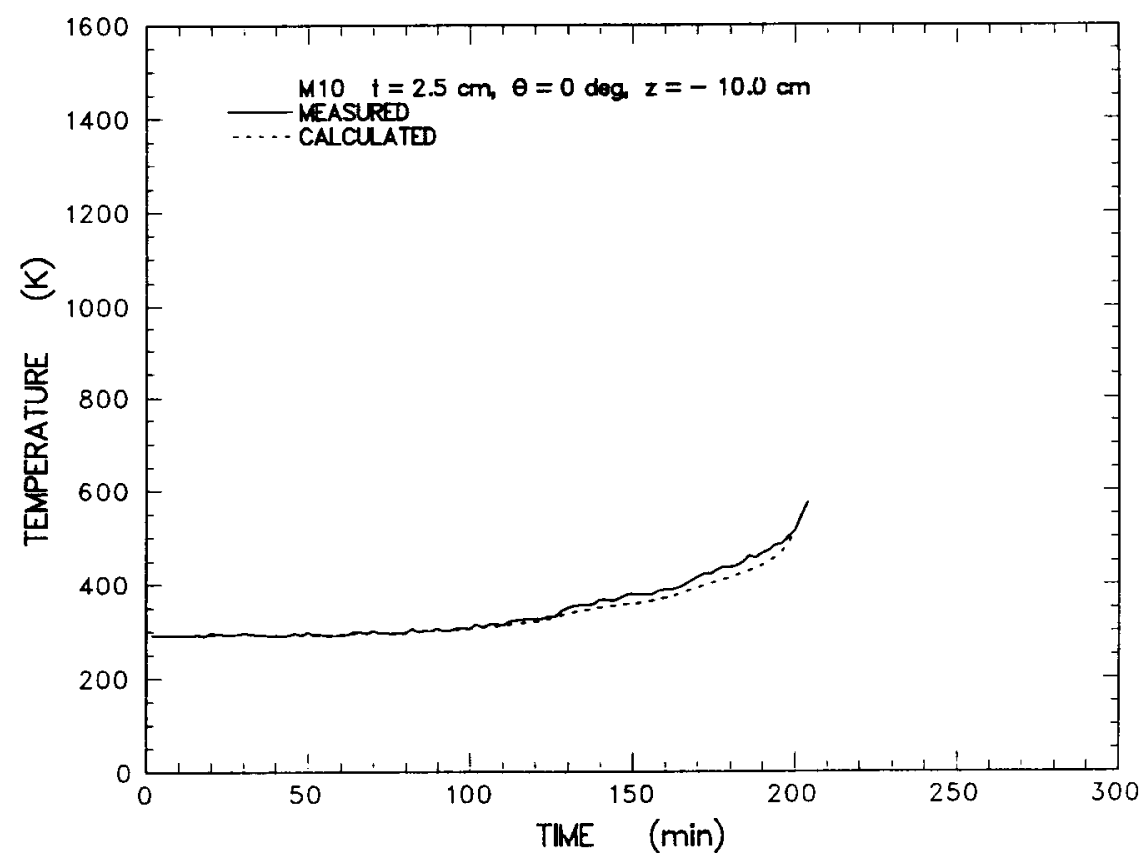

Figure E-22 Comparison of sidewall temperatures measured during the experiment and calculated from the heat flux code for the thermocouple located at $\mathrm{z}=-10.0 \mathrm{~cm}$ and $\mathrm{t}=2.5 \mathrm{~cm}$ 
Appendix E

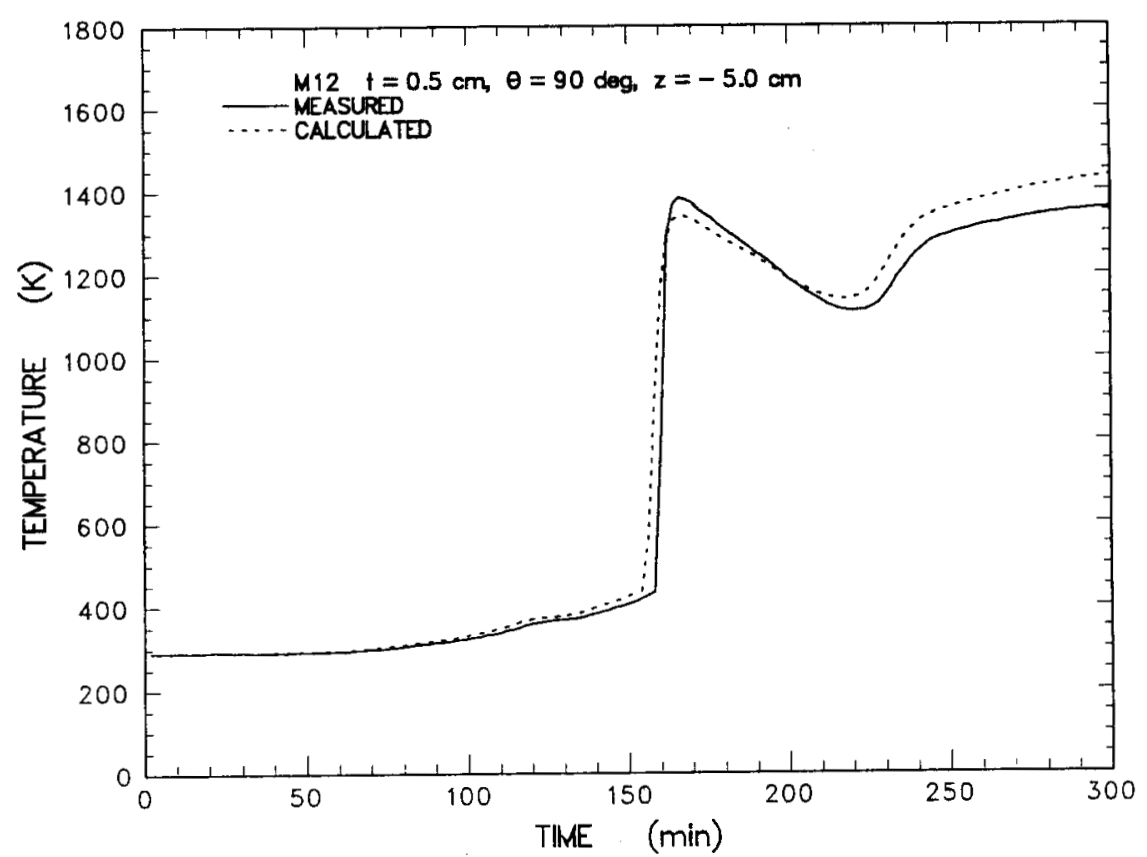

Figure E-23 Comparison of sidewall temperatures measured during the experiment and calculated from the heat flux code for the thermocouple located at $z=-5.0 \mathrm{~cm}$ and $\mathrm{t}=0.5 \mathrm{~cm}$

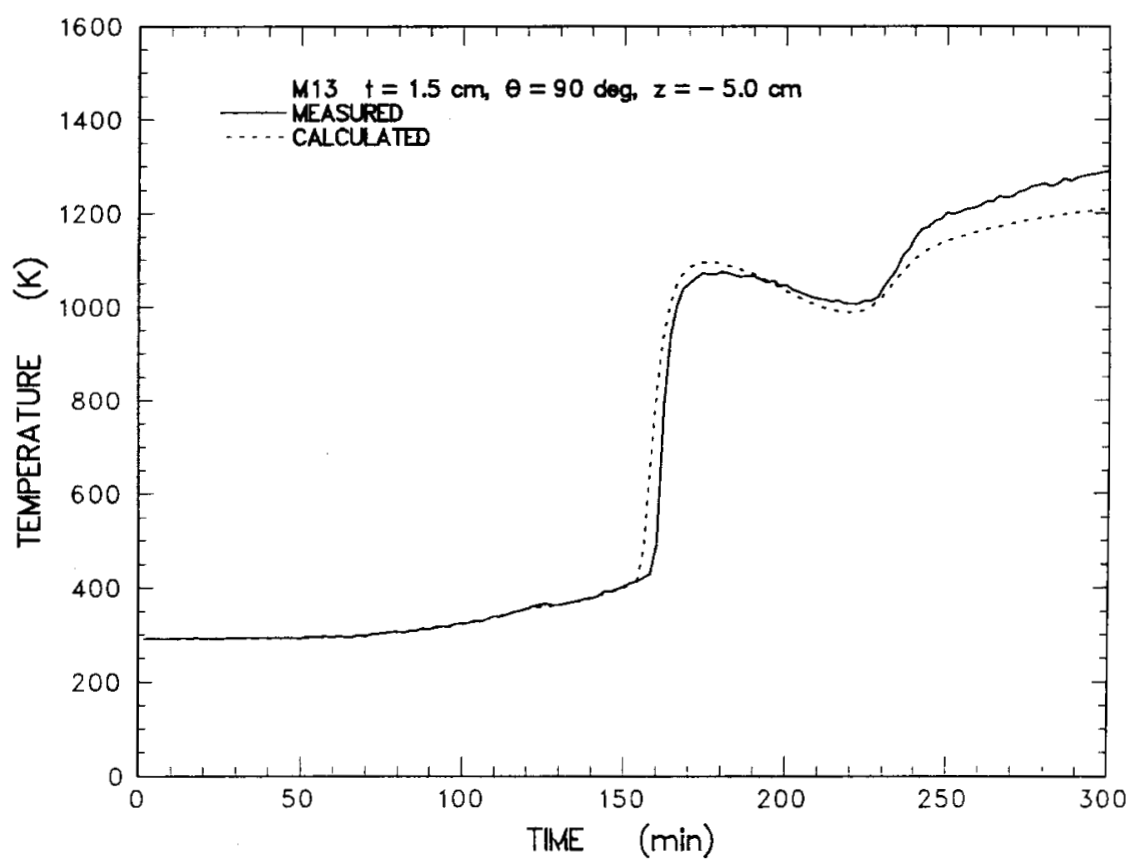

Figure E-24 Comparison of sidewall temperatures measured during the experiment and calculated from the heat flux code for the thermocouple located at $\mathrm{z}=-5.0 \mathrm{~cm}$ and $\mathrm{t}=1.5 \mathrm{~cm}$ 
Appendix E

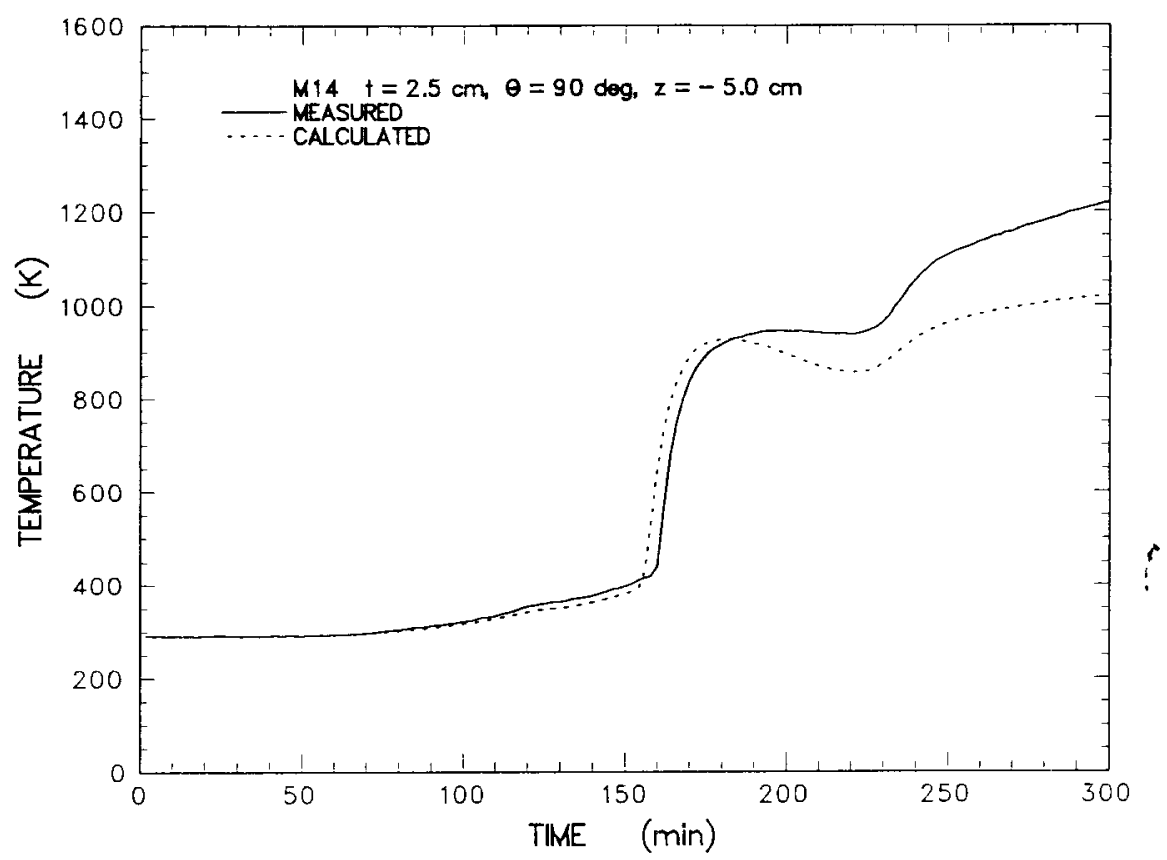

Figure E-25 Comparison of sidewall temperatures measured during the experiment and calculated from the heat flux code for the thermocouple located at $\mathrm{z}=-5.0 \mathrm{~cm}$ and $\mathrm{t}=2.5 \mathrm{~cm}$

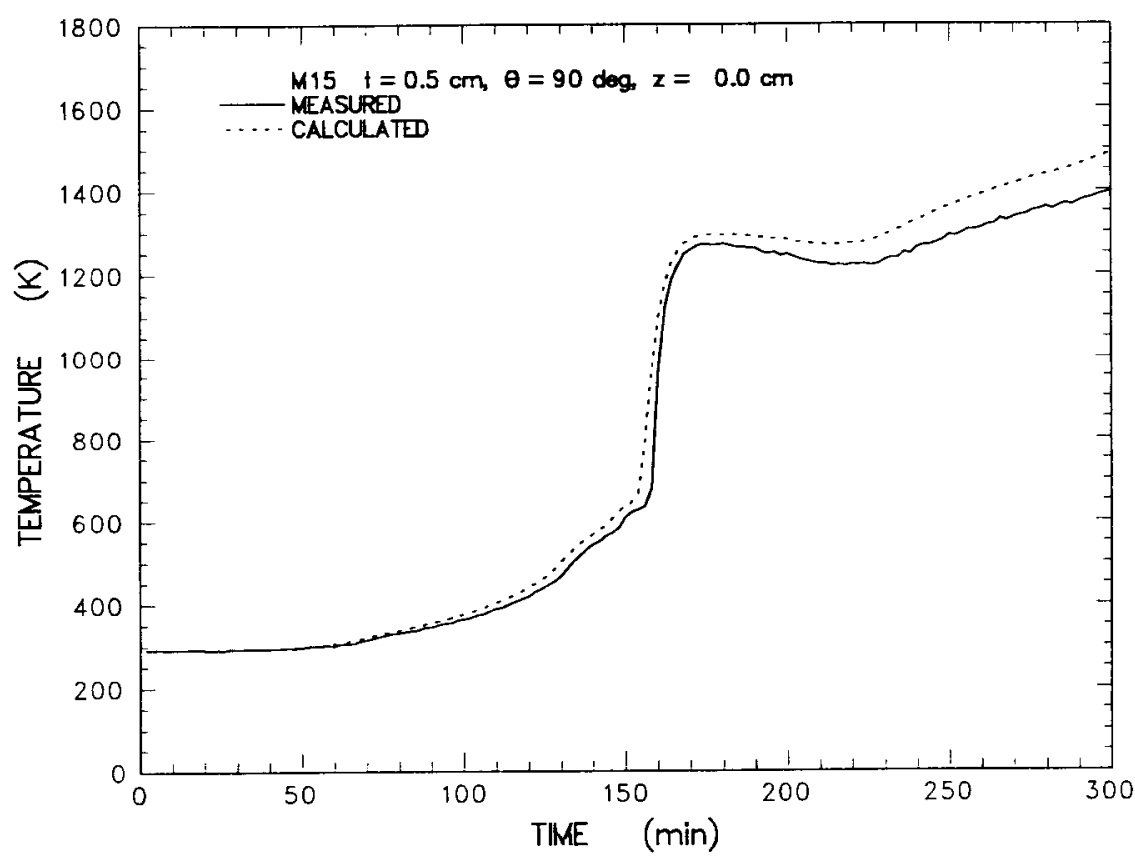

Figure E-26 Comparison of sidewall temperatures measured during the experiment and calculated from the heat flux code for the thermocouple located at $\mathrm{z}=0.0 \mathrm{~cm}$ and $\mathrm{t}=0.5 \mathrm{~cm}$ 
Appendix E

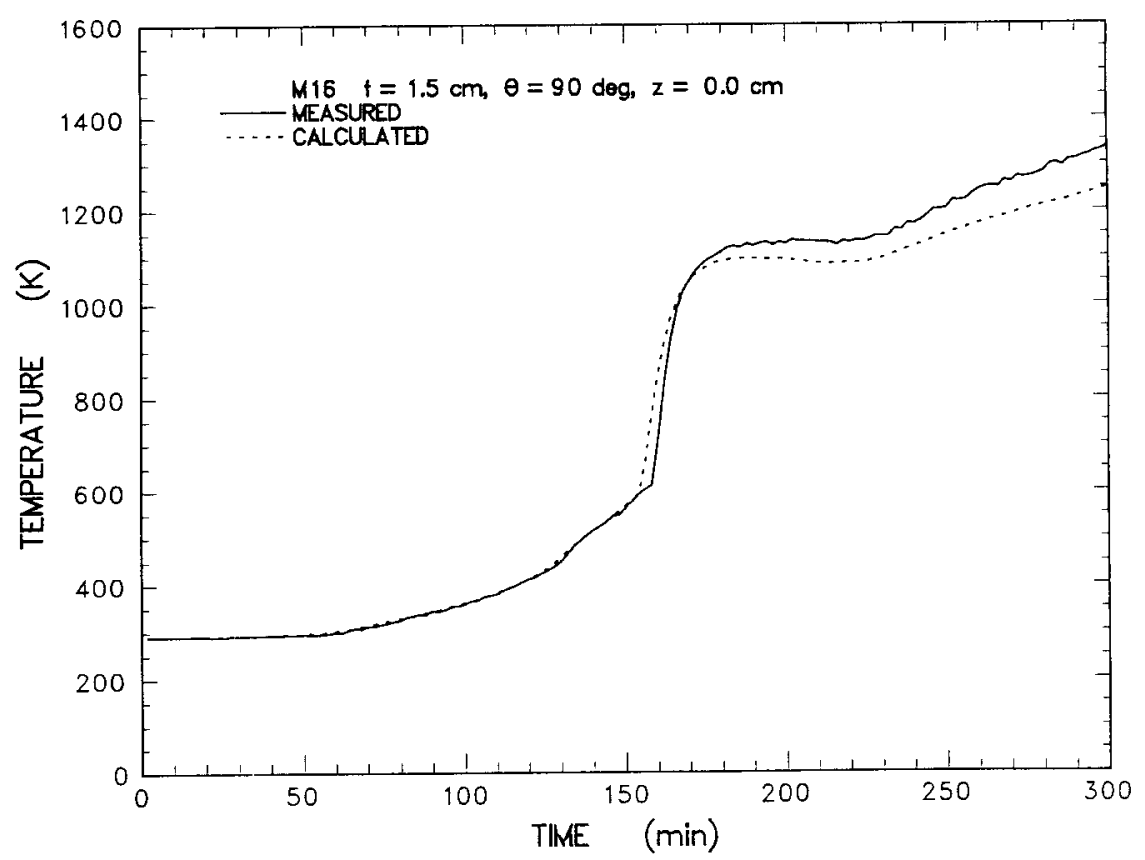

Figure E-27 Comparison of sidewall temperatures measured during the experiment and calculated from the heat flux code for the thermocouple located at $\mathrm{z}=0.0 \mathrm{~cm}$ and $\mathrm{t}=1.5 \mathrm{~cm}$

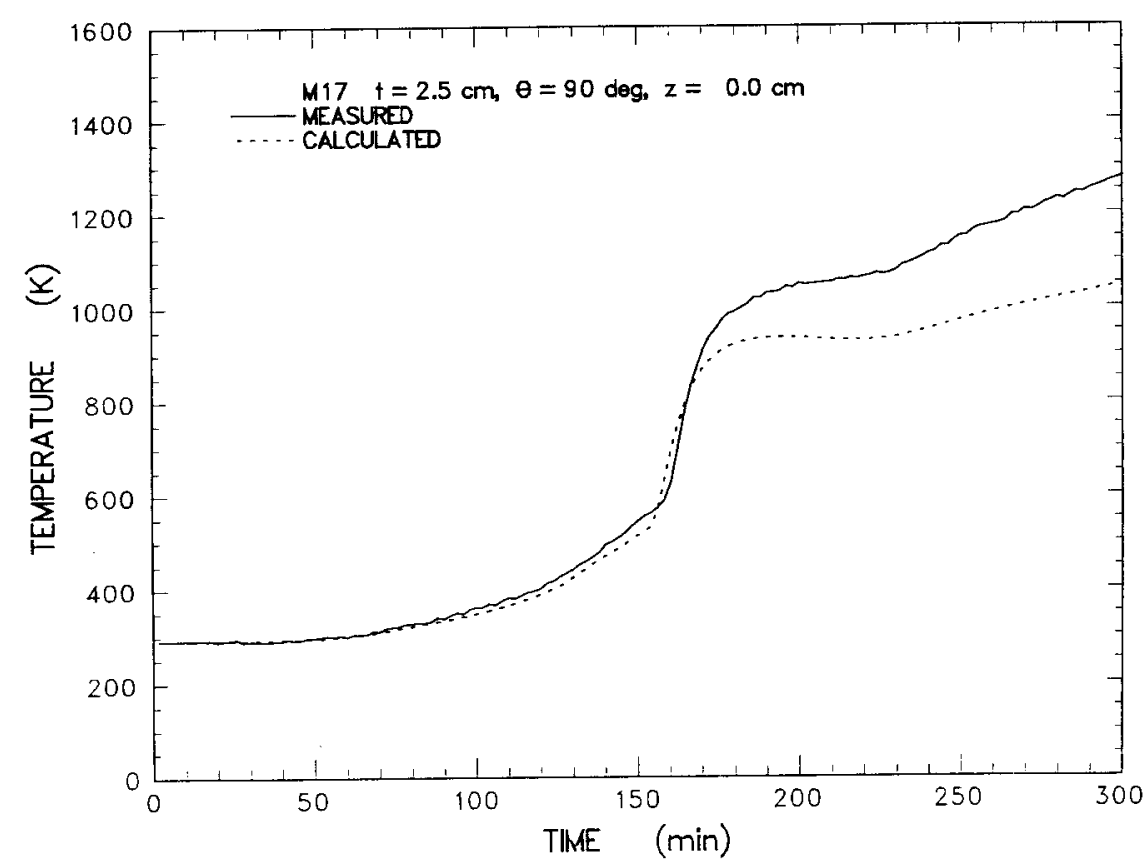

Figure E-28 Comparison of sidewall temperatures measured during the experiment and calculated from the heat flux code for the thermocouple located at $\mathrm{z}=0.0 \mathrm{~cm}$ and $\mathrm{t}=2.5 \mathrm{~cm}$ 
Appendix E

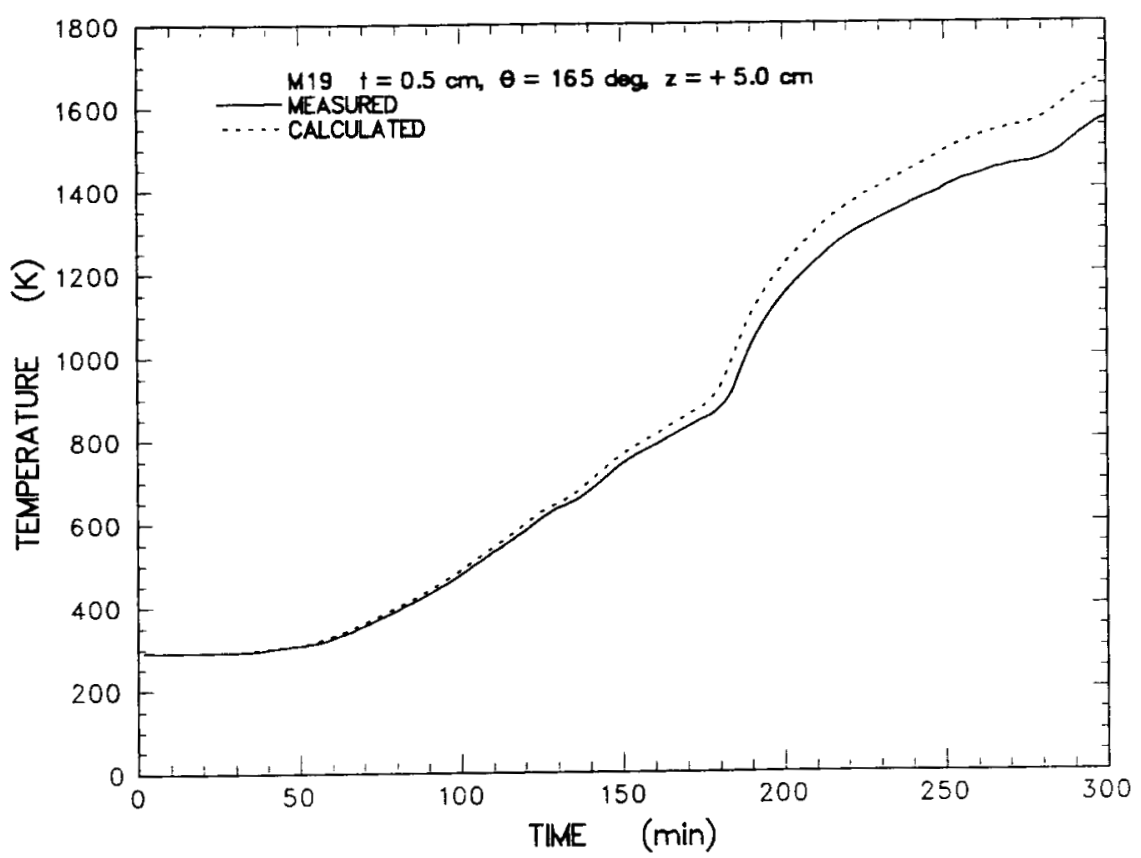

Figure E-29 Comparison of sidewall temperatures measured during the experiment and calculated from the heat flux code for the thermocouple located at $\mathrm{z}=+5.0 \mathrm{~cm}$ and $\mathrm{t}=0.5 \mathrm{~cm}$

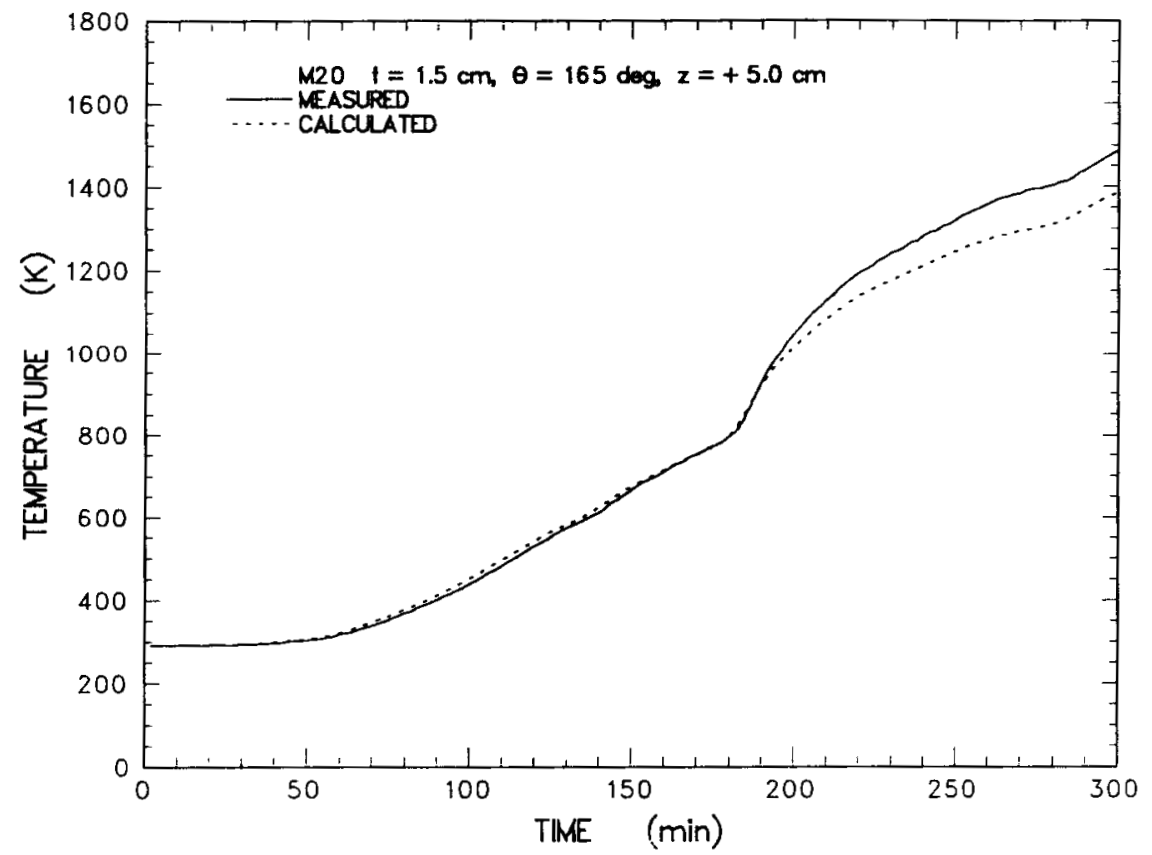

Figure E-30 Comparison of sidewall temperatures measured during the experiment and calculated from the heat flux code for the thermocouple located at $\mathrm{z}=+5.0 \mathrm{~cm}$ and $\mathrm{t}=1.5 \mathrm{~cm}$ 


\section{Appendix E}

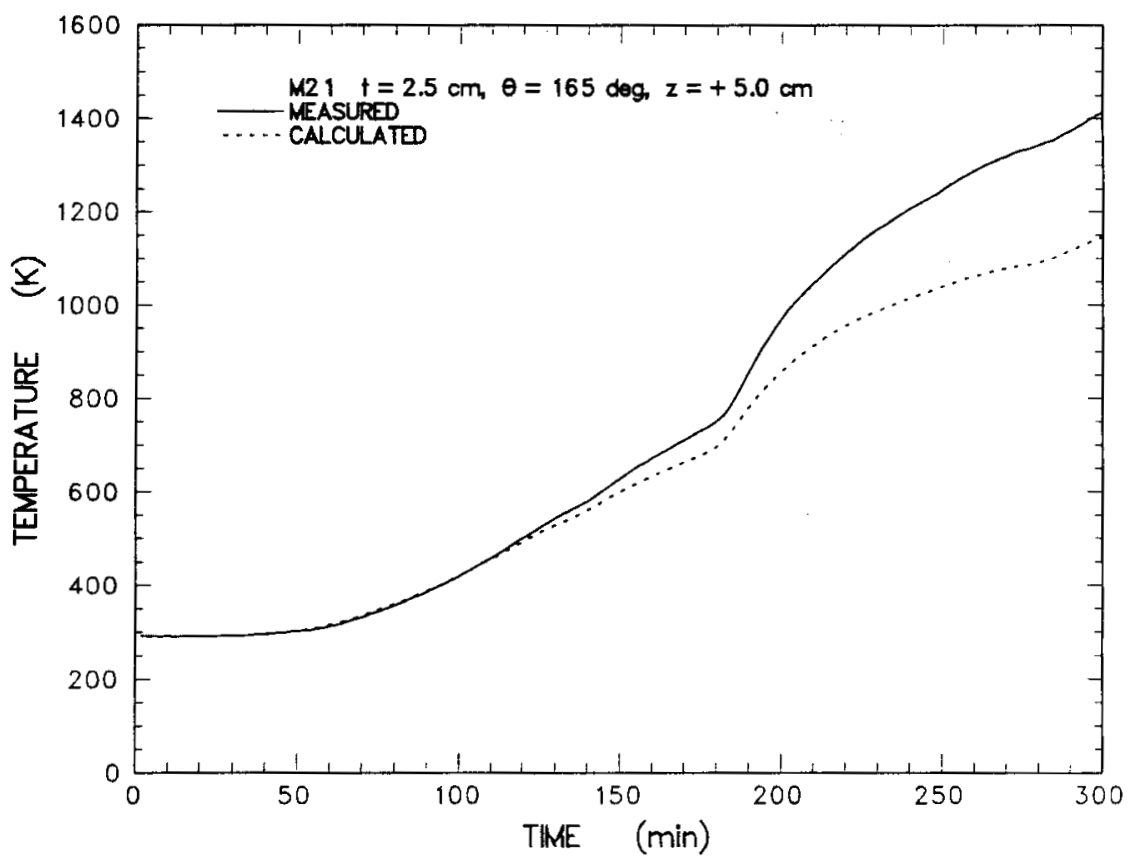

Figure E-31 Comparison of sidewall temperatures measured during the experiment and calculated from the heat flux code for the thermocouple located at $\mathrm{z}=+5.0 \mathrm{~cm}$ and $\mathrm{t}=2.5 \mathrm{~cm}$

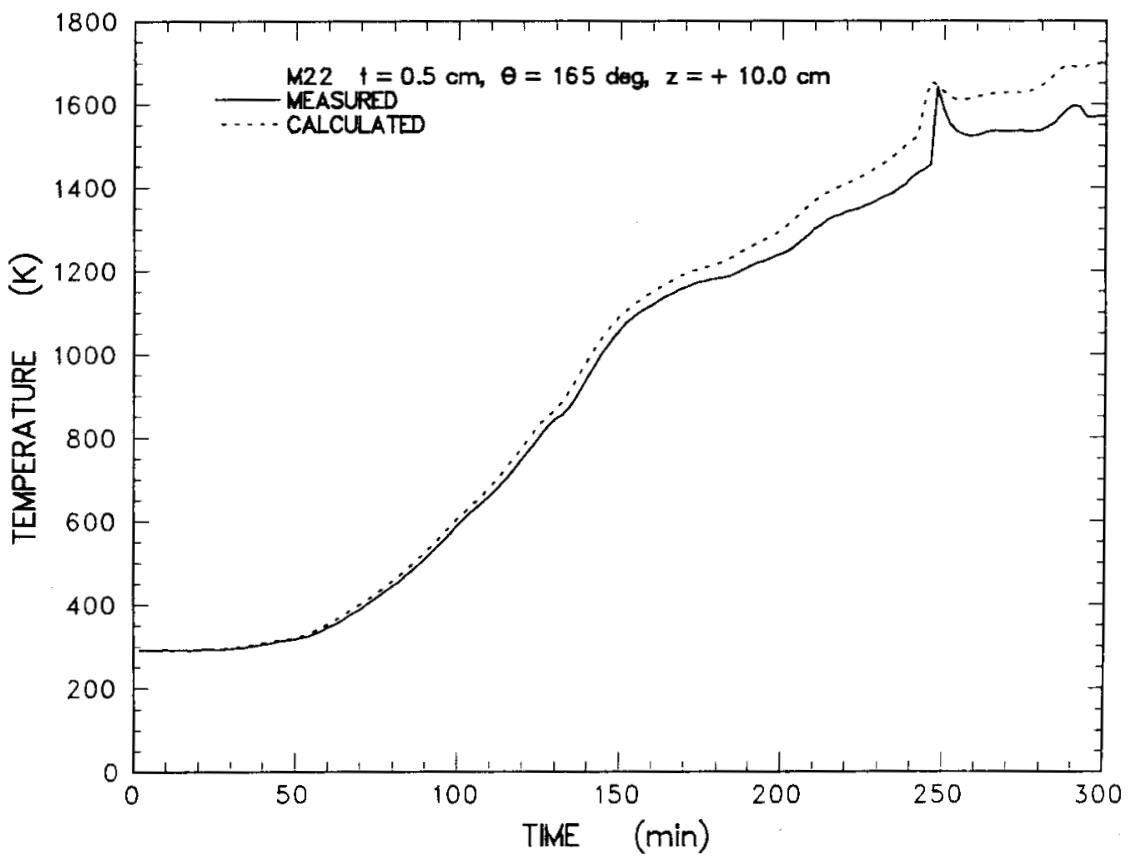

Figure E-32 Comparison of sidewall temperatures measured during the experiment and calculated from the heat flux code for the thermocouple located at $z=+10.0 \mathrm{~cm}$ and $\mathrm{t}=0.5 \mathrm{~cm}$ 


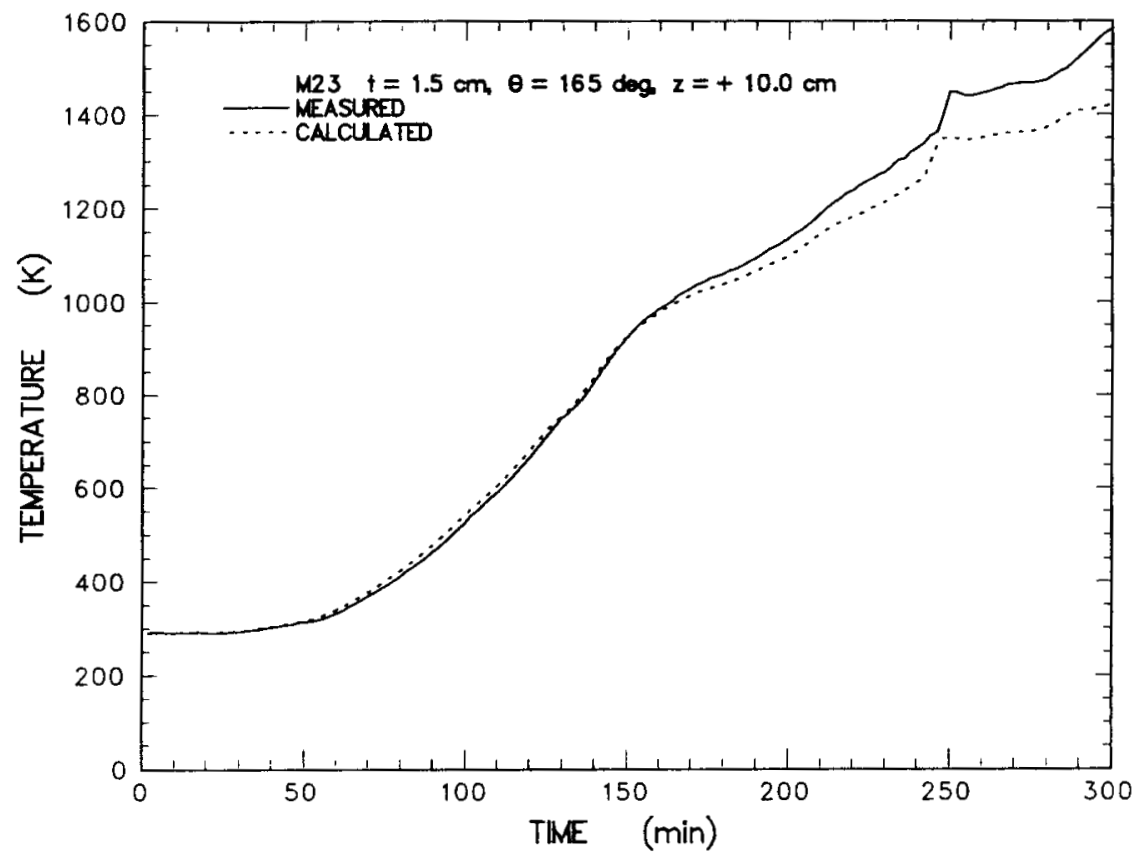

Figure E-33 Comparison of sidewall temperatures measured during the experiment and calculated from the heat flux code for the thermocouple located at $\mathrm{z}=+10.0 \mathrm{~cm}$ and $\mathrm{t}=1.5 \mathrm{~cm}$

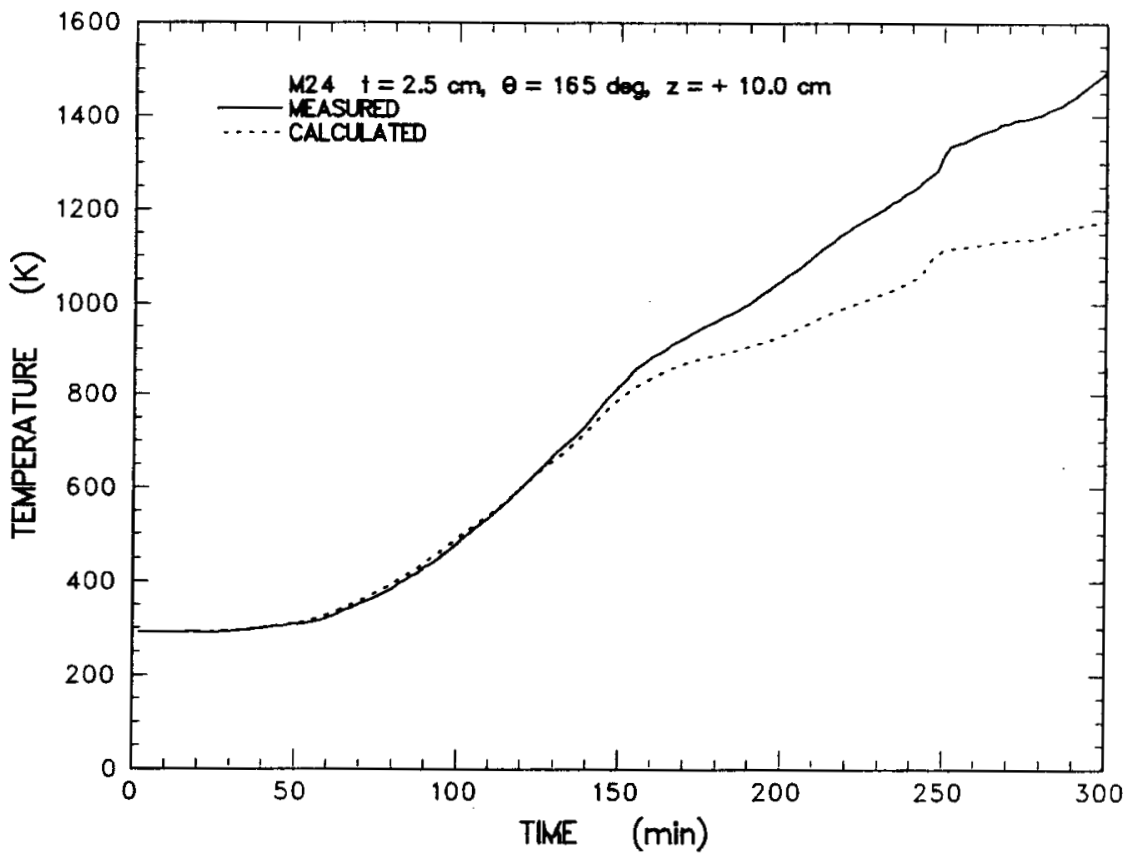

Figure E-34 Comparison of sidewall temperatures measured during the experiment and calculated from the heat flux code for the thermocouple located at $\mathrm{z}=+10.0 \mathrm{~cm}$ and $\mathrm{t}=2.5 \mathrm{~cm}$ 
Appendix E

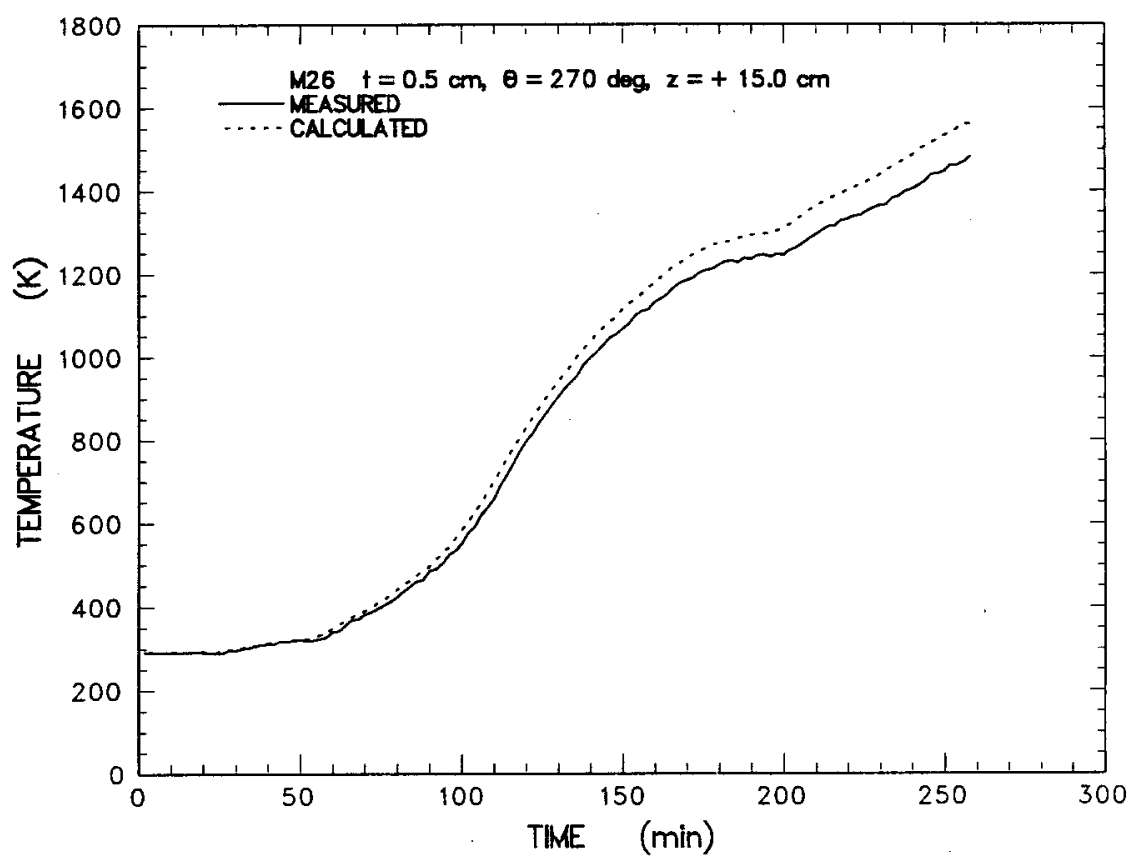

Figure E-35 Comparison of sidewall temperatures measured during the experiment and calculated from the heat flux code for the thermocouple located at $z=+15.0 \mathrm{~cm}$ and $\mathrm{t}=0.5 \mathrm{~cm}$

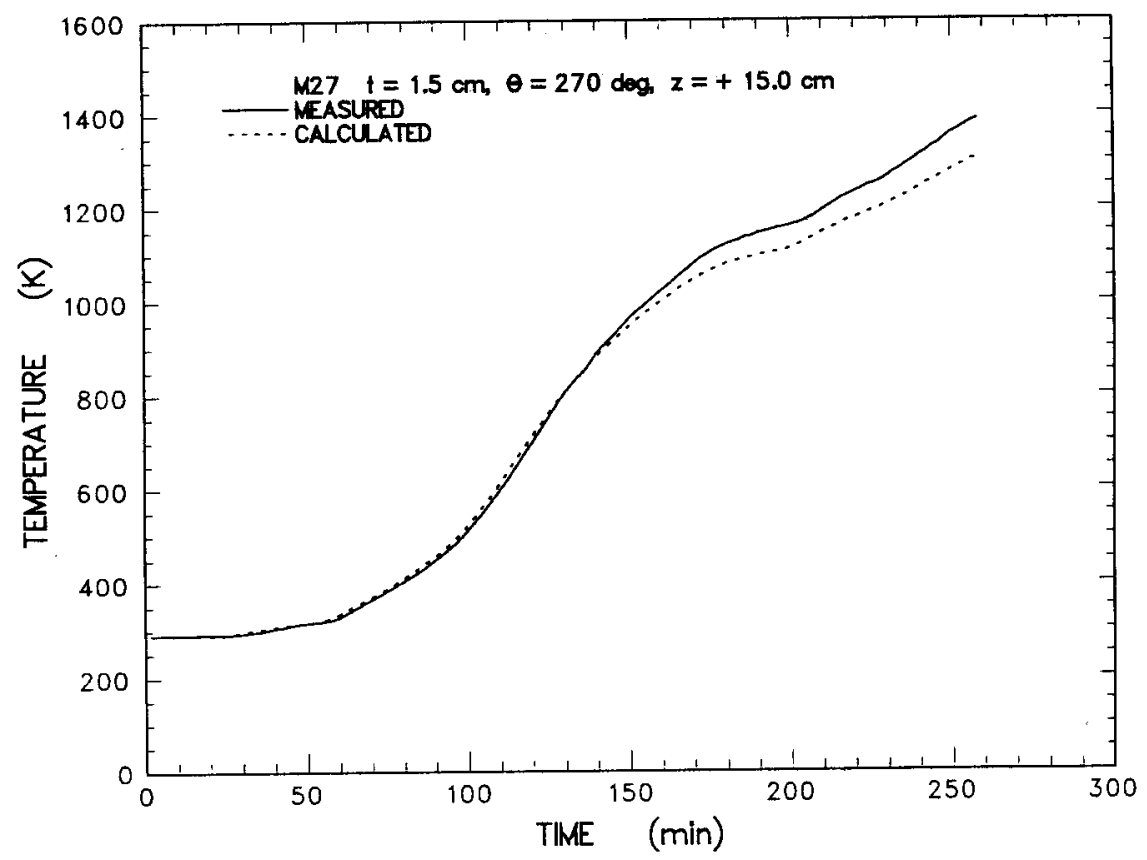

Figure E-36 Comparison of sidewall temperatures measured during the experiment and calculated from the heat flux code for the thermocouple located at $\mathrm{z}=+15.0 \mathrm{~cm}$ and $\mathrm{t}=1.5 \mathrm{~cm}$ 
Appendix E

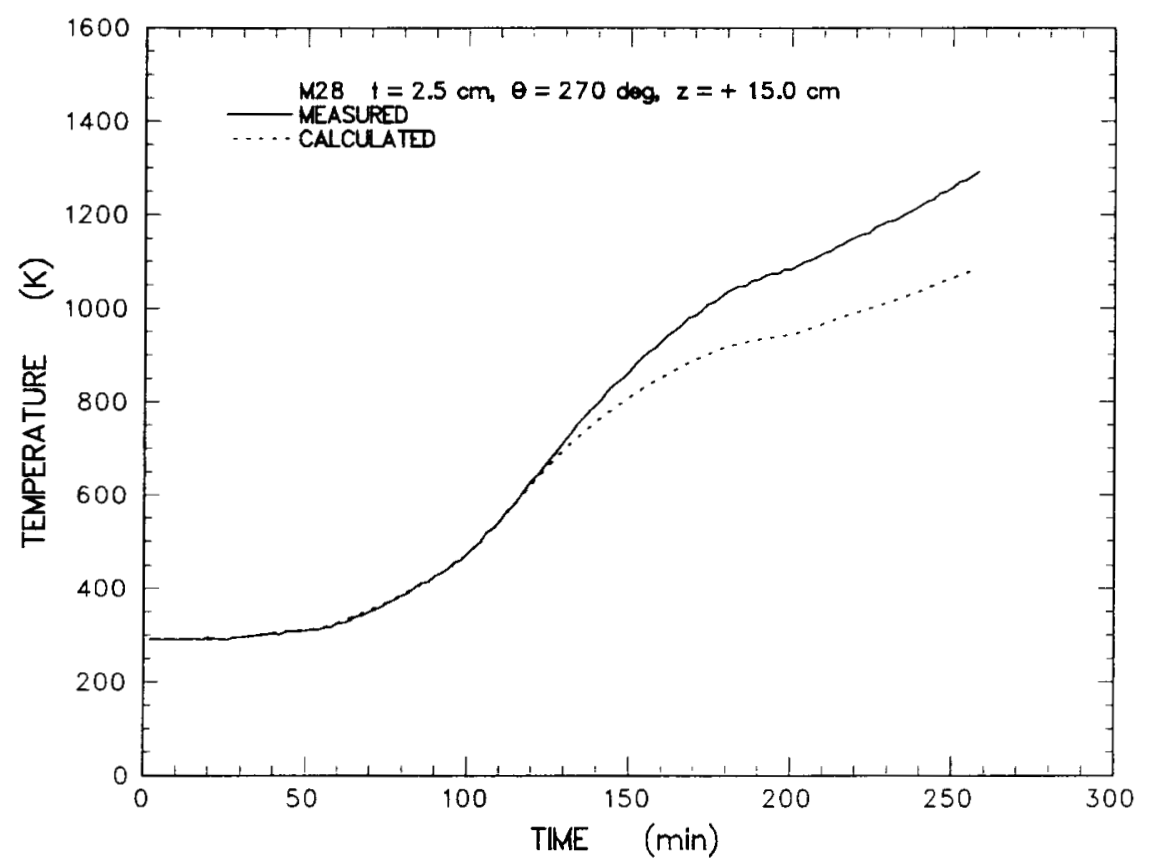

Figure E-37 Comparison of sidewall temperatures measured during the experiment and calculated from the heat flux code for the thermocouple located at $\mathrm{z}=+15.0 \mathrm{~cm}$ and $\mathrm{t}=2.5 \mathrm{~cm}$

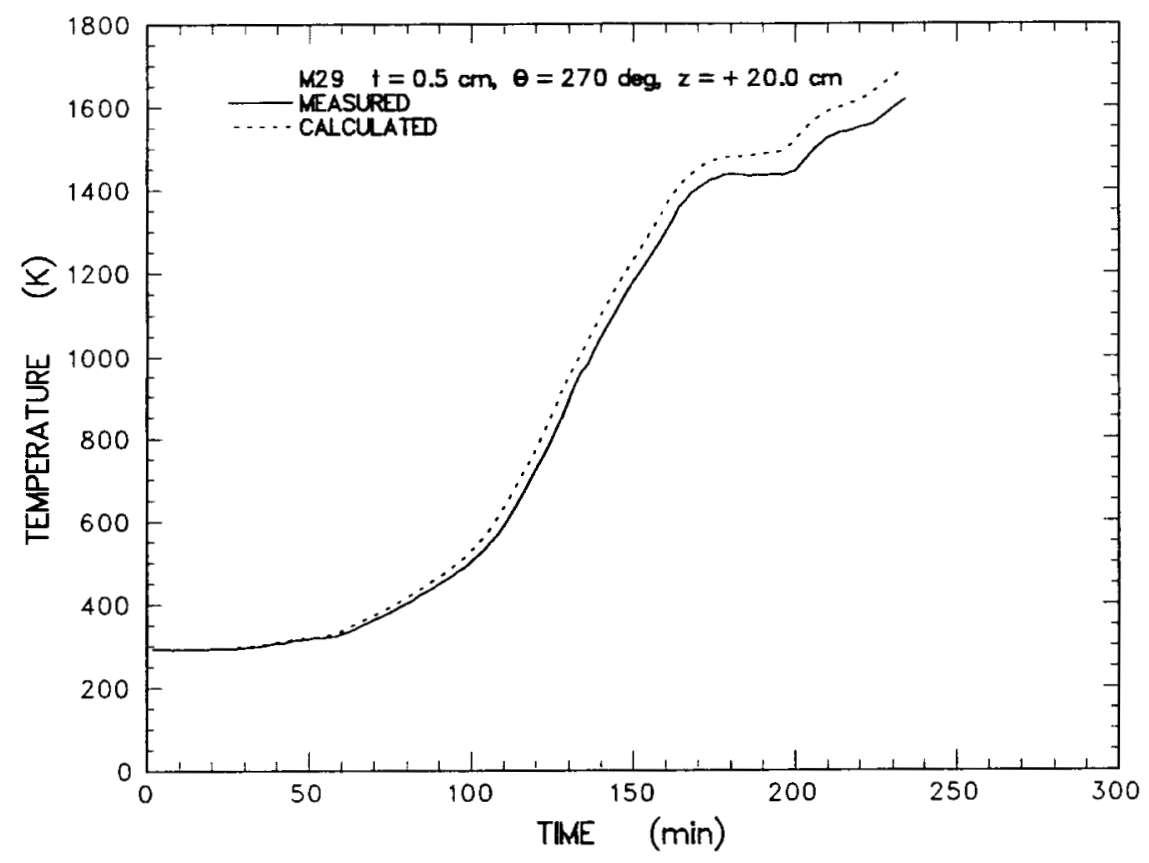

Figure E-38 Comparison of sidewall temperatures measured during the experiment and calculated from the heat flux code for the thermocouple located at $\mathrm{z}=+20.0 \mathrm{~cm}$ and $\mathrm{t}=0.5 \mathrm{~cm}$ 
Appendix E

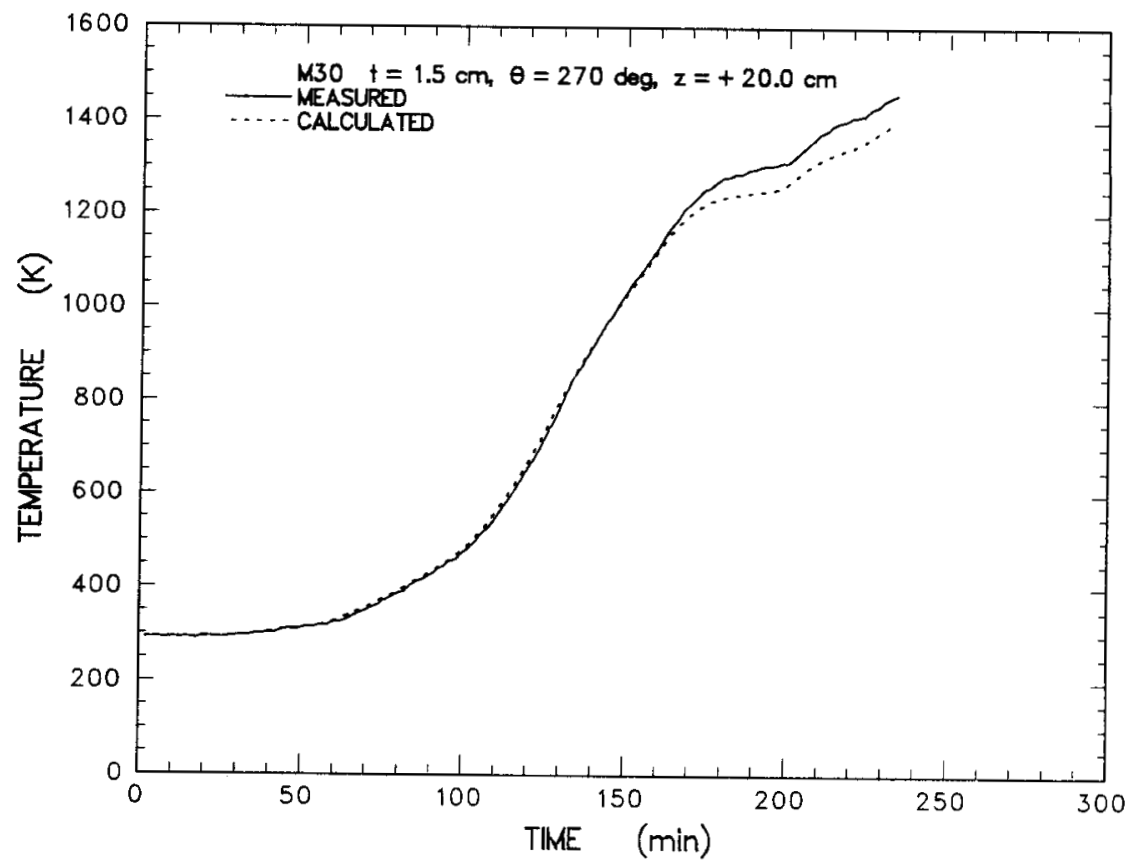

Figure E-39 Comparison of sidewall temperatures measured during the experiment and calculated from the heat flux code for the thermocouple located at $\mathrm{z}=+20.0 \mathrm{~cm}$ and $\mathrm{t}=1.5 \mathrm{~cm}$

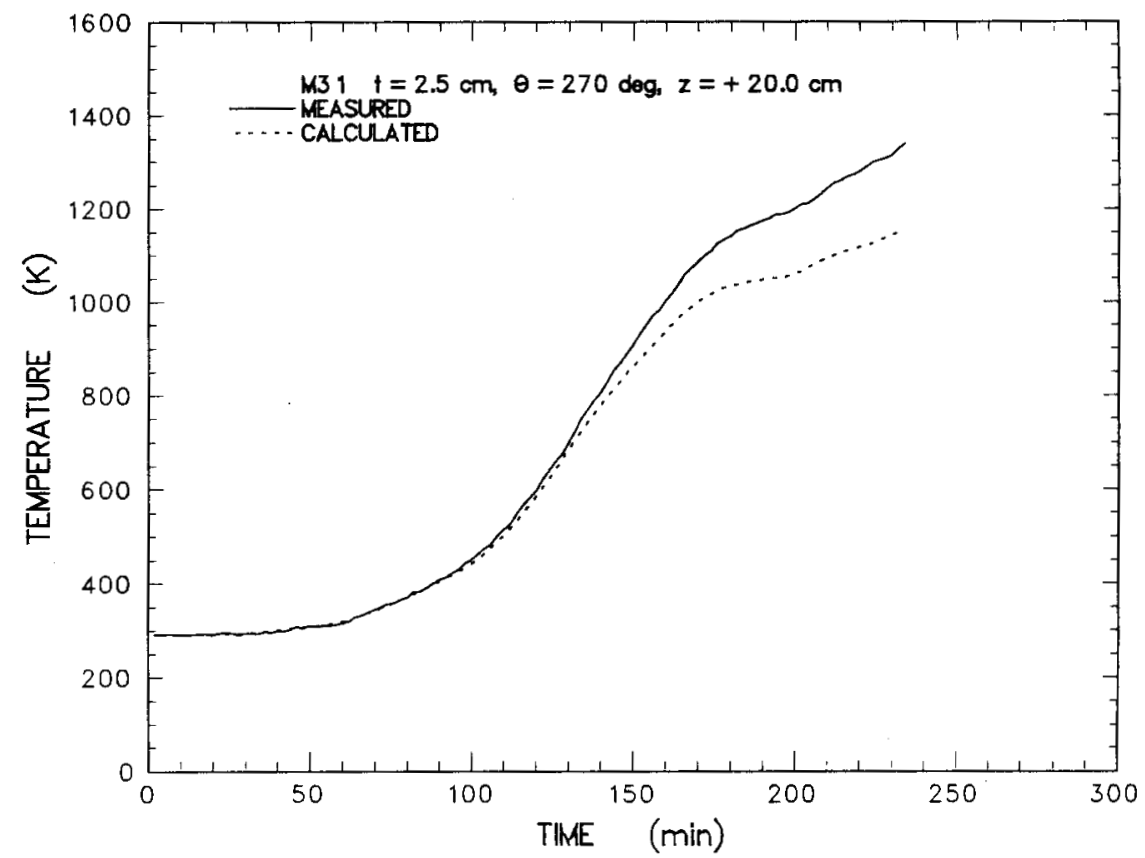

Figure E-40 Comparison of sidewall temperatures measured during the experiment and calculated from the heat flux code for the thermocouple located at $\mathrm{z}=+20.0 \mathrm{~cm}$ and $\mathrm{t}=2.5 \mathrm{~cm}$ 


\section{Appendix E}

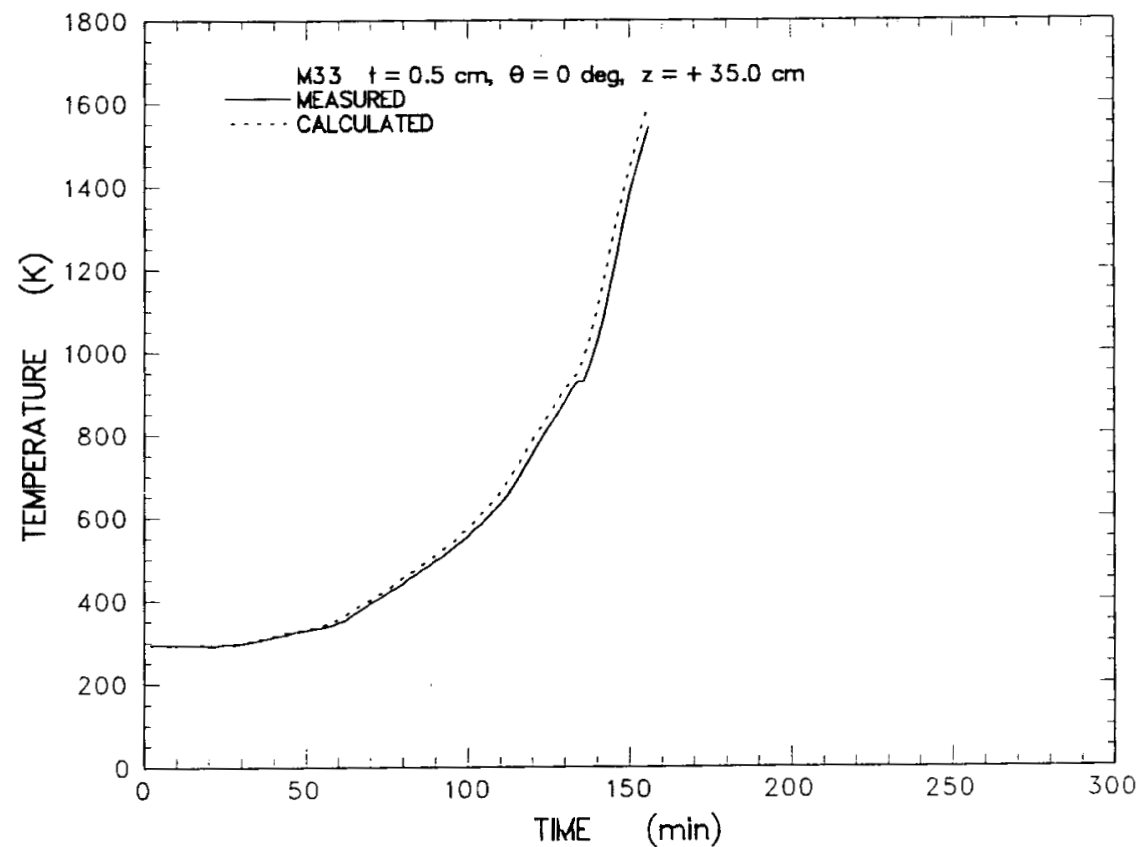

Figure E-41 Comparison of sidewall temperatures measured during the experiment and calculated from the heat flux code for the thermocouple located at $z=+35.0 \mathrm{~cm}$ and $t=0.5 \mathrm{~cm}$

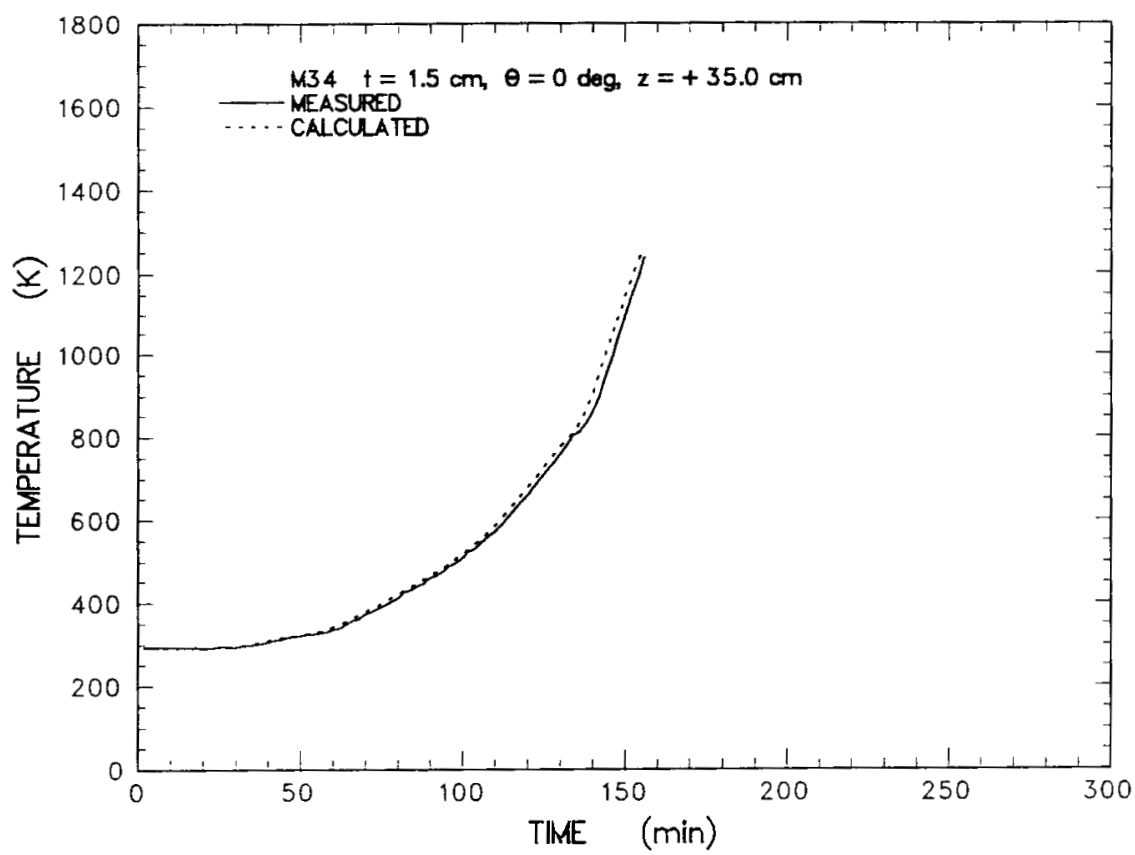

Figure E-42 Comparison of sidewall temperatures measured during the experiment and calculated from the heat flux code for the thermocouple located at $\mathrm{z}=+35.0 \mathrm{~cm}$ and $\mathrm{t}=1.5 \mathrm{~cm}$ 
Appendix E

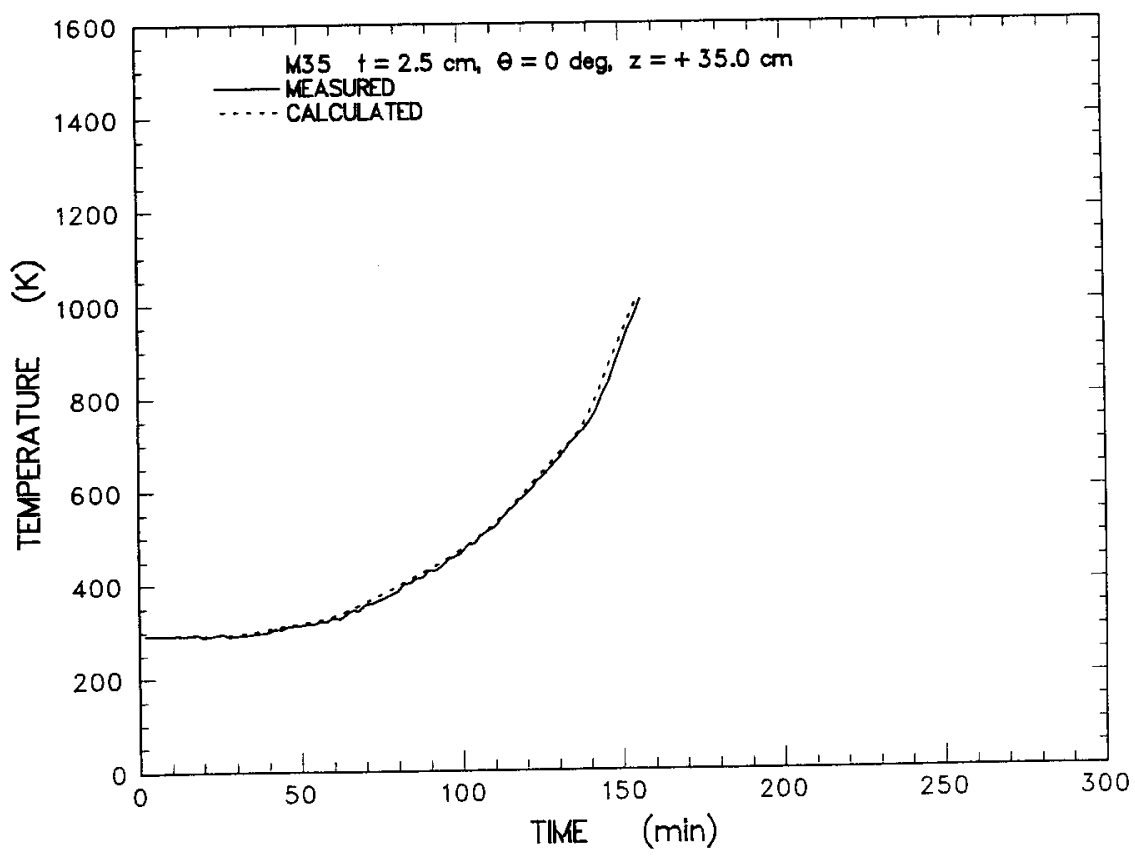

Figure E-43 Comparison of sidewall temperatures measured during the experiment and calculated from the heat flux code for the thermocouple located at $z=+35.0 \mathrm{~cm}$ and $\mathrm{t}=2.5 \mathrm{~cm}$

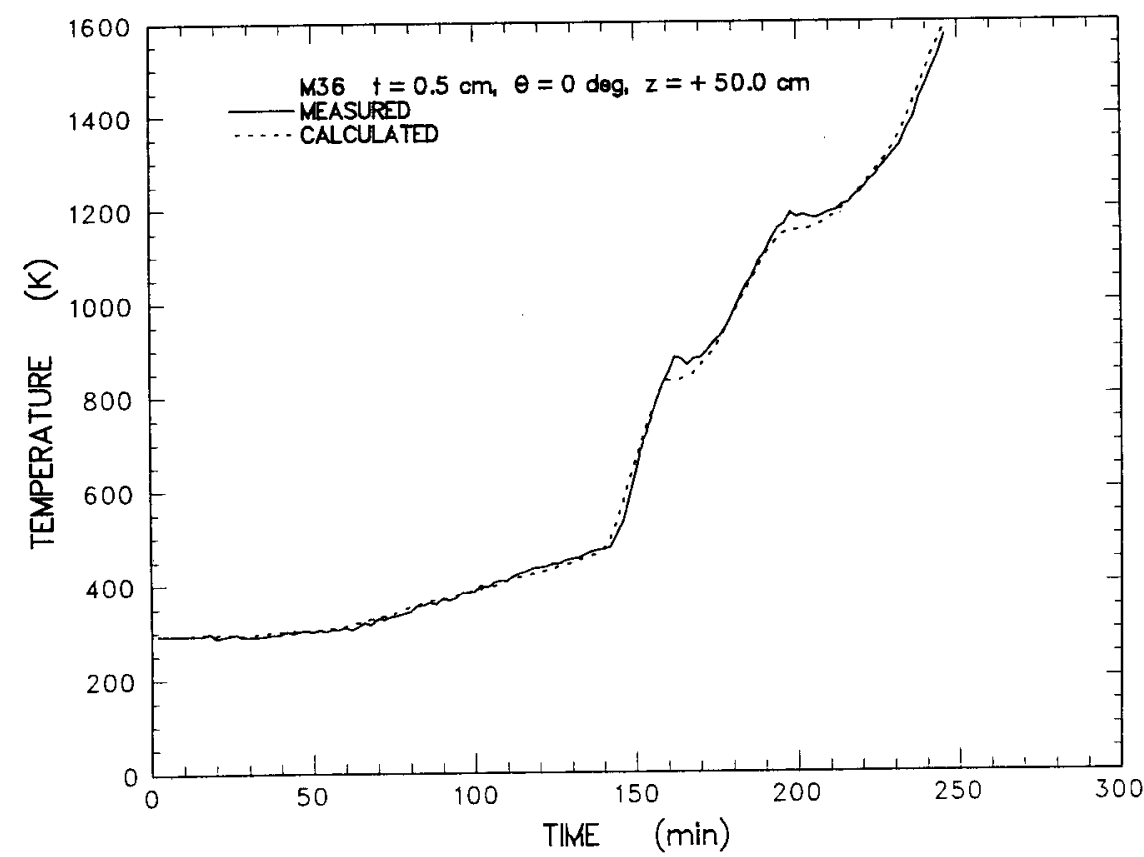

Figure E-44 Comparison of sidewall temperatures measured during the experiment and calculated from the heat flux code for the thermocouple located at $\mathrm{z}=+50.0 \mathrm{~cm}$ and $\mathrm{t}=0.5 \mathrm{~cm}$ 
Appendix E

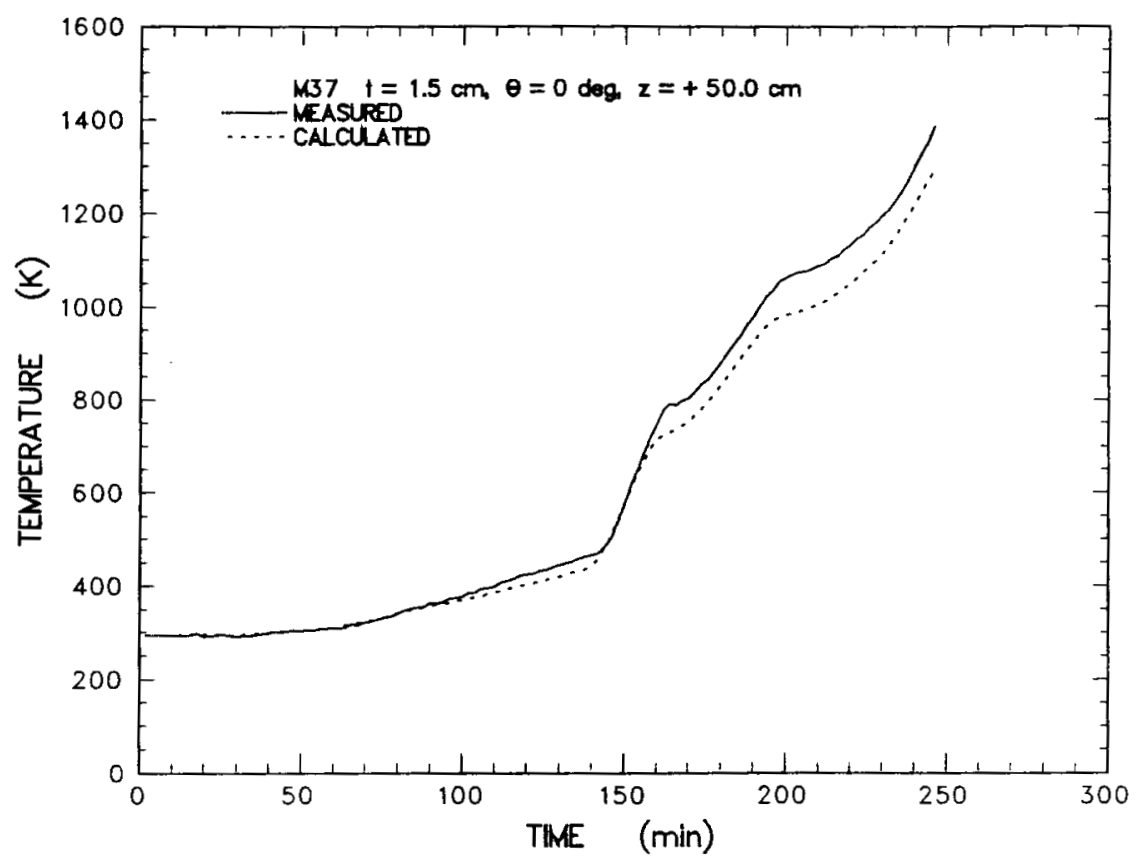

Figure E-45 Comparison of sidewall temperatures measured during the experiment and calculated from the heat flux code for the thermocouple located at $\mathrm{z}=+50.0 \mathrm{~cm}$ and $\mathrm{t}=1.5 \mathrm{~cm}$

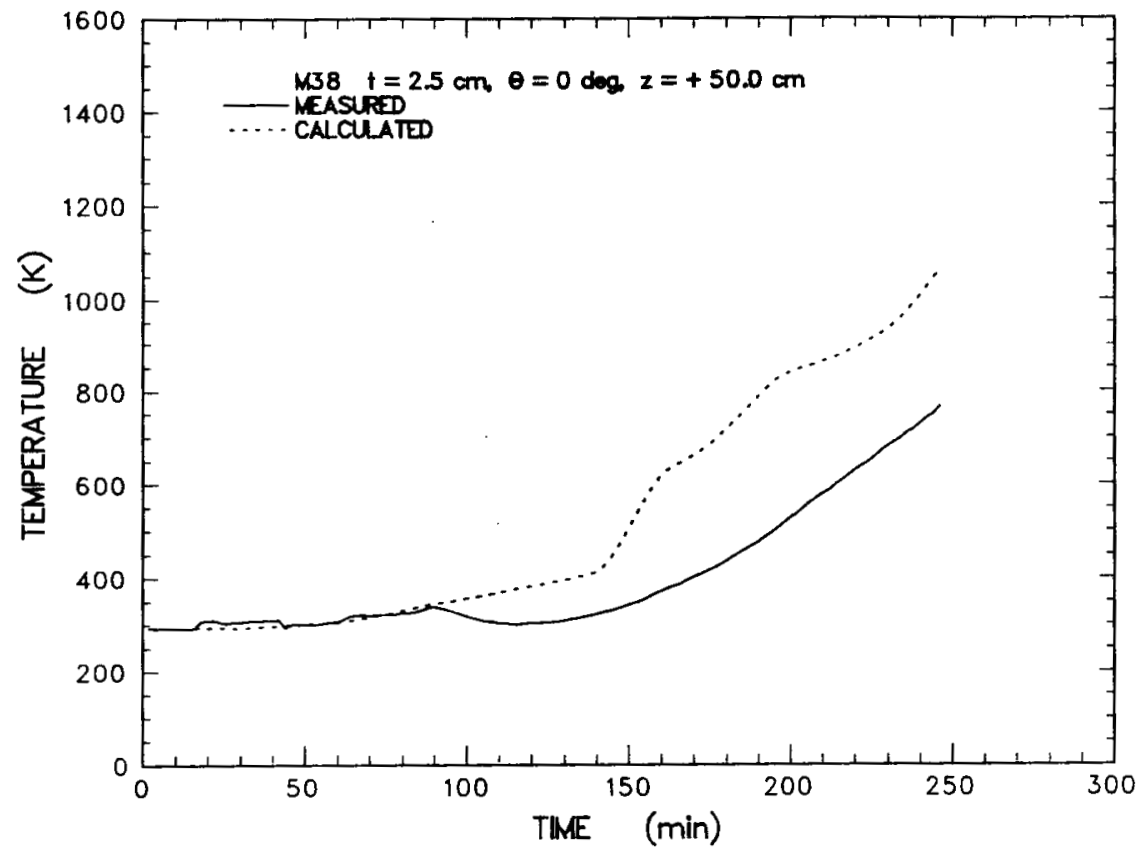

Figure E-46 Comparison of sidewall temperatures measured during the experiment and calculated from the heat flux code for the thermocouple located at $\mathrm{z}=+50.0 \mathrm{~cm}$ and $\mathrm{t}=2.5 \mathrm{~cm}$ 
Appendix E

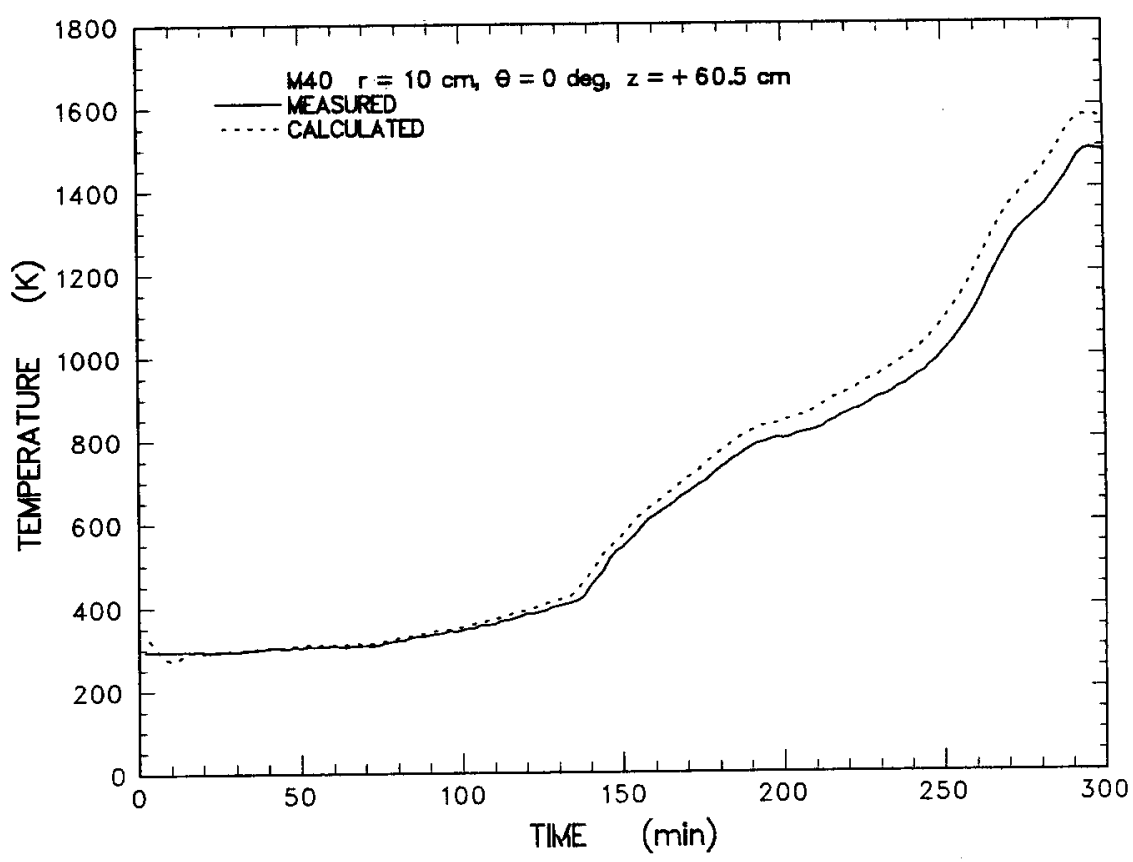

Figure E-47 Comparison of sidewall temperatures measured during the experiment and calculated from the heat flux code for the thermocouple located at $\mathrm{r}=10.0 \mathrm{~cm}, \theta=0, \mathrm{z}=$ $+60.0 \mathrm{~cm}$ and $\mathrm{t}=0.5 \mathrm{~cm}$

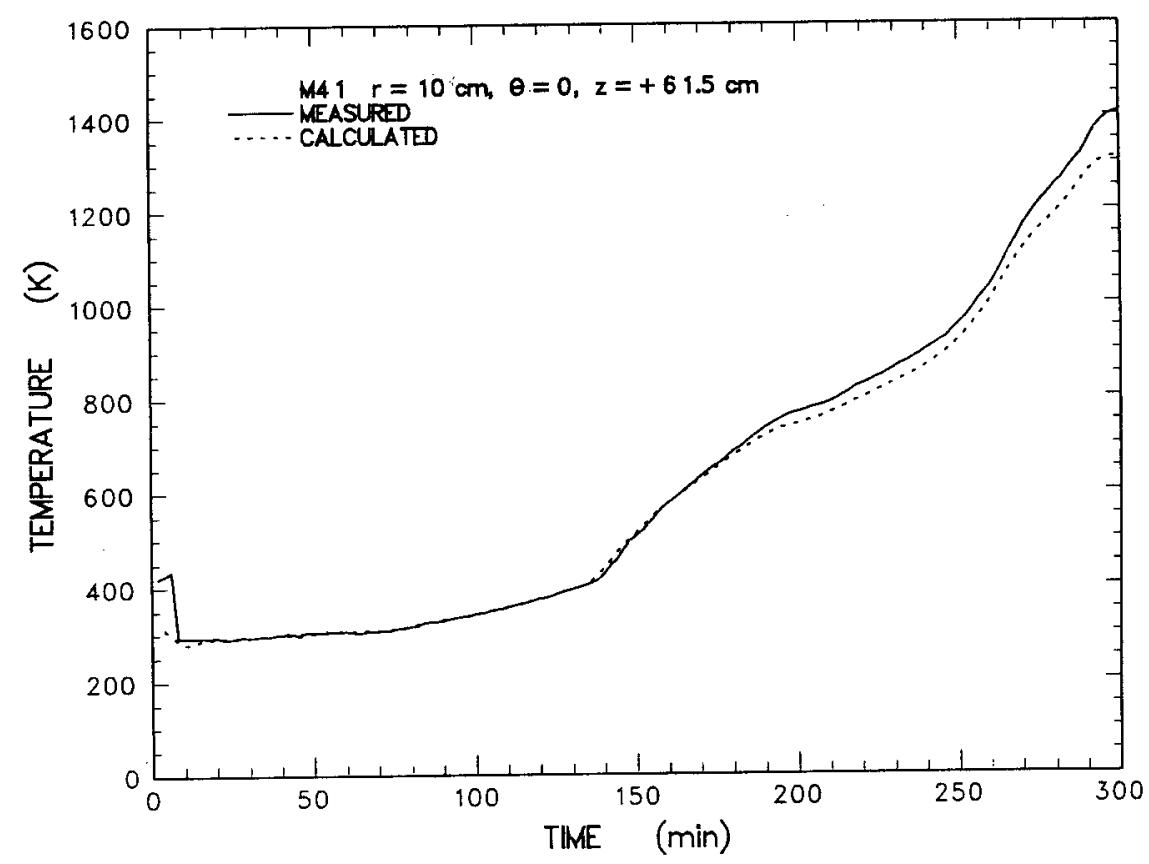

Figure E-48 Comparison of sidewall temperatures measured during the experiment and calculated from the heat flux code for the thermocouple located at $\mathrm{r}=10.0 \mathrm{~cm}, \theta=0, \mathrm{z}=$ $+60.0 \mathrm{~cm}$ and $\mathrm{t}=1.5 \mathrm{~cm}$ 
Appendix E

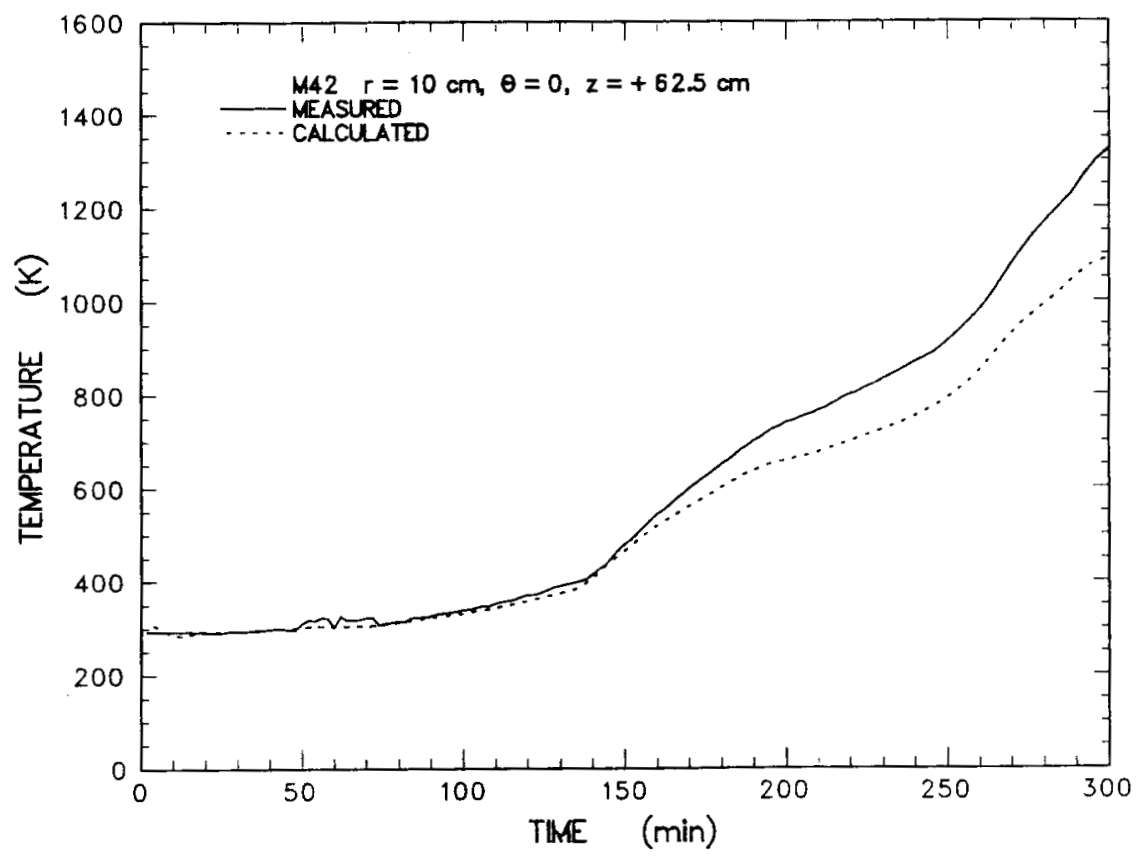

Figure E-49 Comparison of sidewall temperatures measured during the experiment and calculated from the heat flux code for the thermocouple located at $\mathrm{r}=10.0 \mathrm{~cm}, \theta=0, \mathrm{z}=$ $+60.0 \mathrm{~cm}$, and $\mathrm{t}=2.5 \mathrm{~cm}$

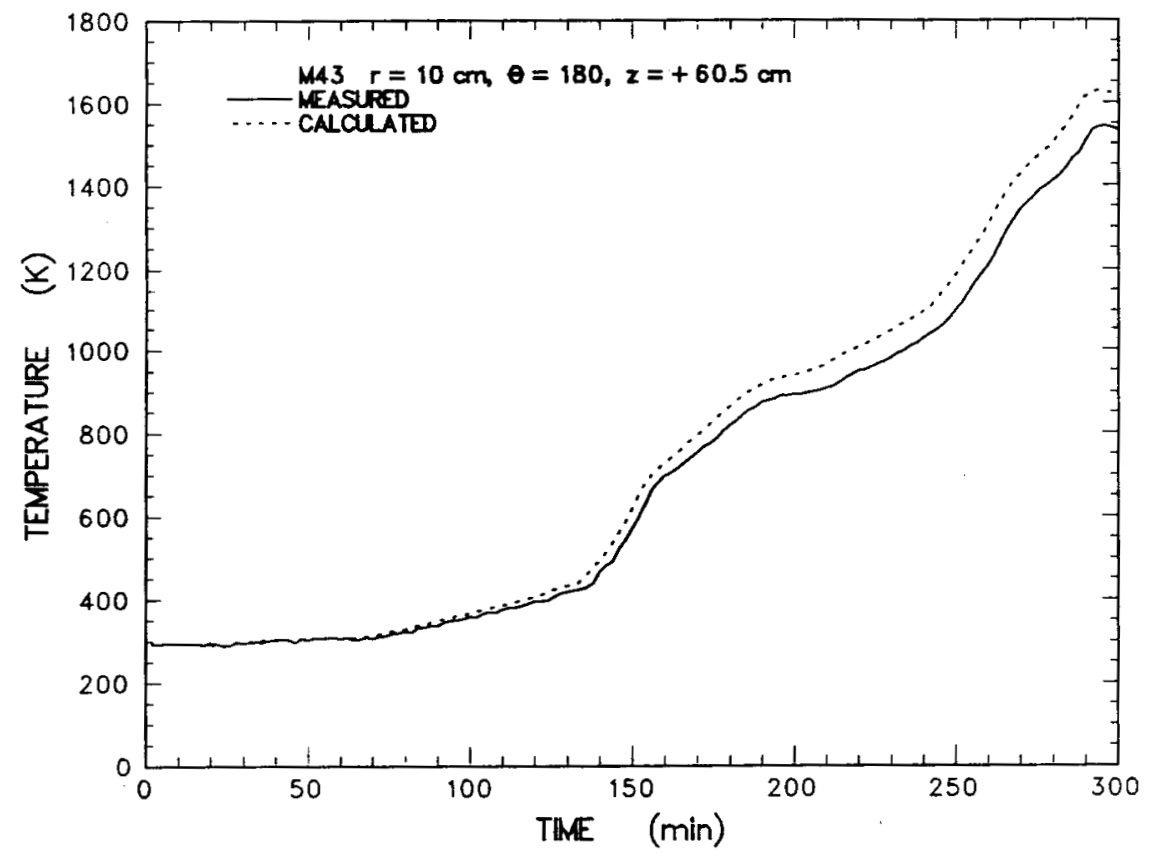

Figure E-50 Comparison of sidewall temperatures measured during the experiment and calculated from the heat flux code for the thermocouple located at $\mathrm{r}=10.0 \mathrm{~cm}, \theta=180, \mathrm{z}=$ $+60.0 \mathrm{~cm}$ and $\mathrm{t}=0.5 \mathrm{~cm}$ 


\section{Appendix E}

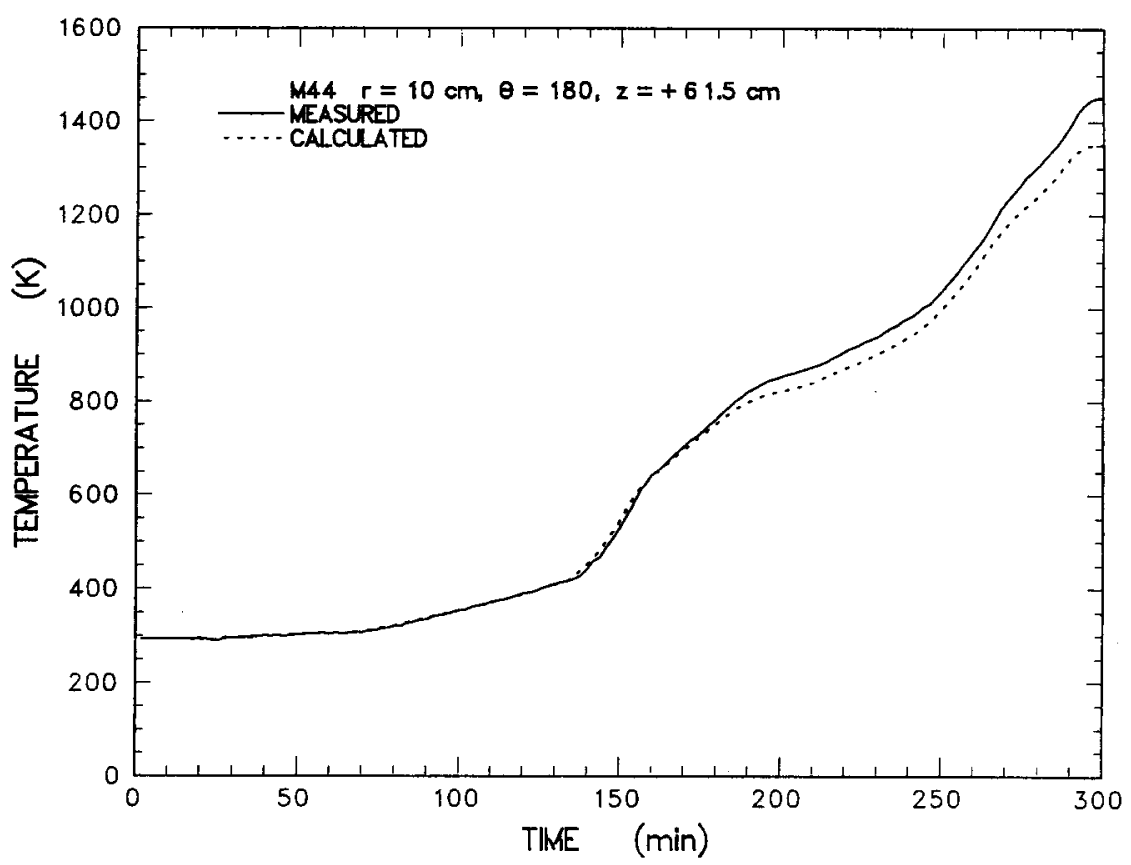

Figure E-51 Comparison of sidewall temperatures measured during the experiment and calculated from the heat flux code for the thermocouple located at $r=10.0 \mathrm{~cm}, \theta=180, \mathrm{z}=$ $+60.0 \mathrm{~cm}$ and $\mathrm{t}=1.5 \mathrm{~cm}$

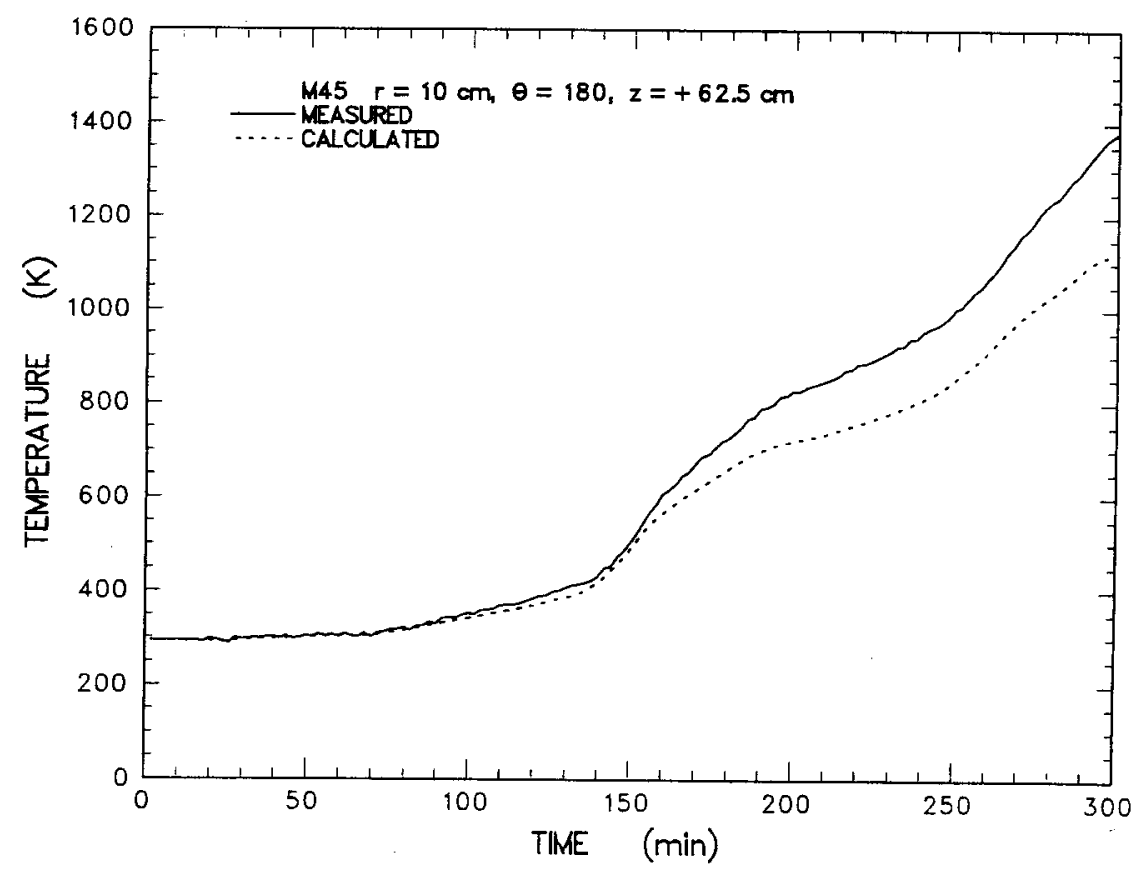

Figure:E-52 Comparison of sidewall temperatures measured during the experiment and calculated from the heat flux code for the thermocouple located at $\mathrm{r}=10.0 \mathrm{~cm}, \theta=180, \mathrm{z}=$ $+60.0 \mathrm{~cm}$ and $\mathrm{t}=2.5 \mathrm{~cm}$ 


\section{APPENDIX F}

PRESSURE TRANSDUCER AND FLOW DEVICE CALIBRATION DATA 


\section{Appendix F}

Enclosed in this appendix are the calibration data for the pressure transducers used in the flow system and calibration plots of the flow devices used in the experiment. 


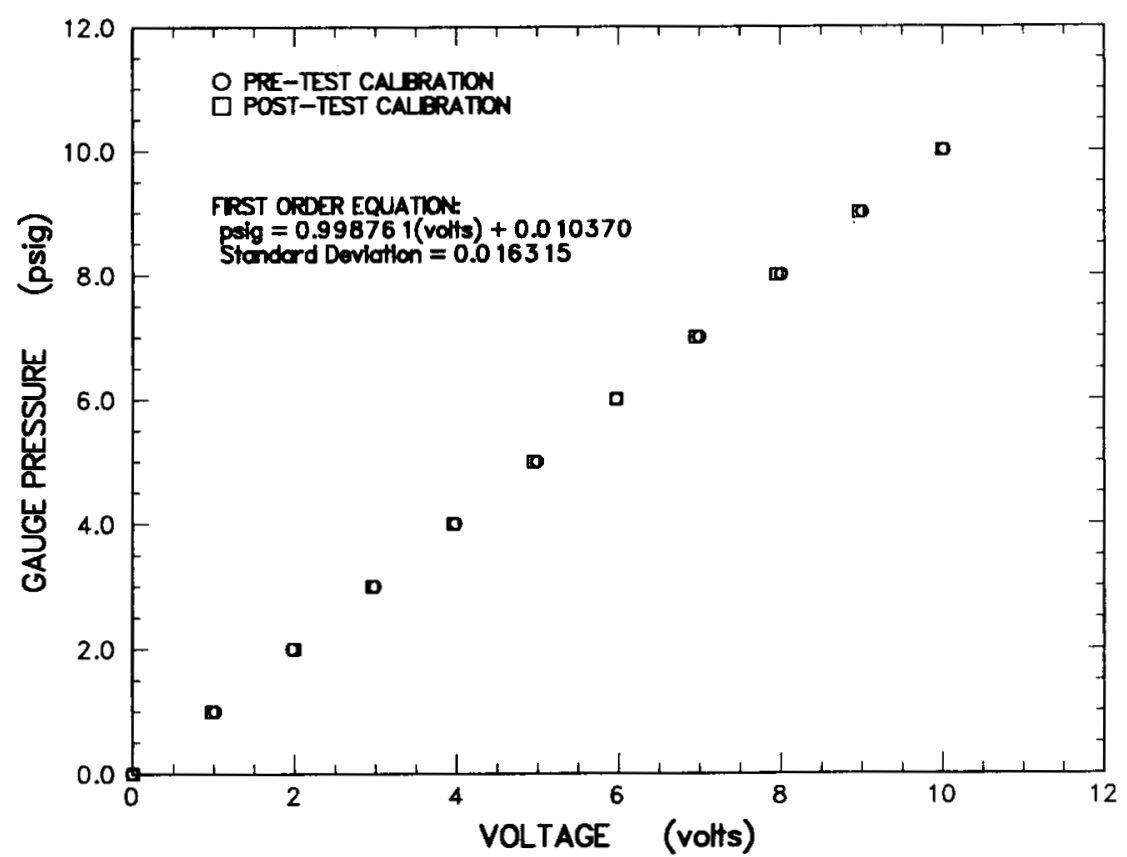

Figure F-1 Gauge pressure transducer (10 psig) calibration installed on the containment vessel

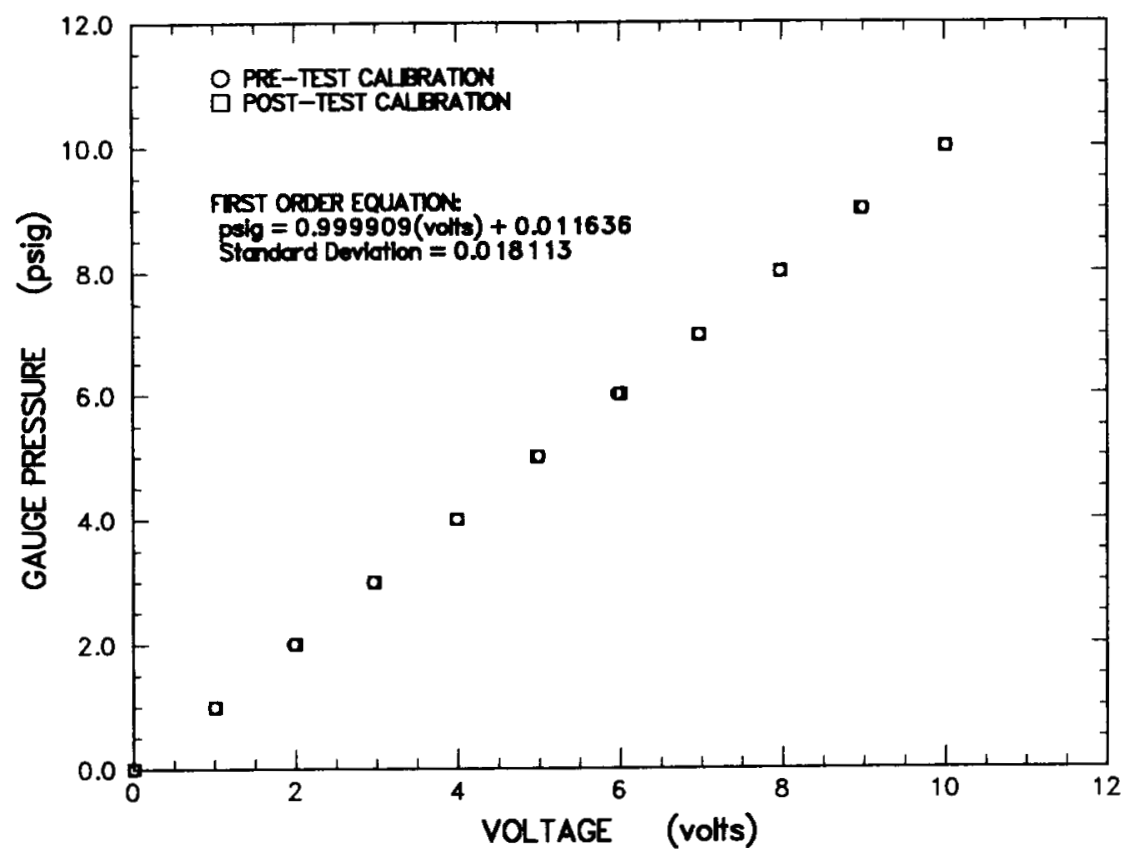

Figure F-2 Gauge pressure transducer (10 psid) calibration installed upstream of the ASME orifice 
Appendix F

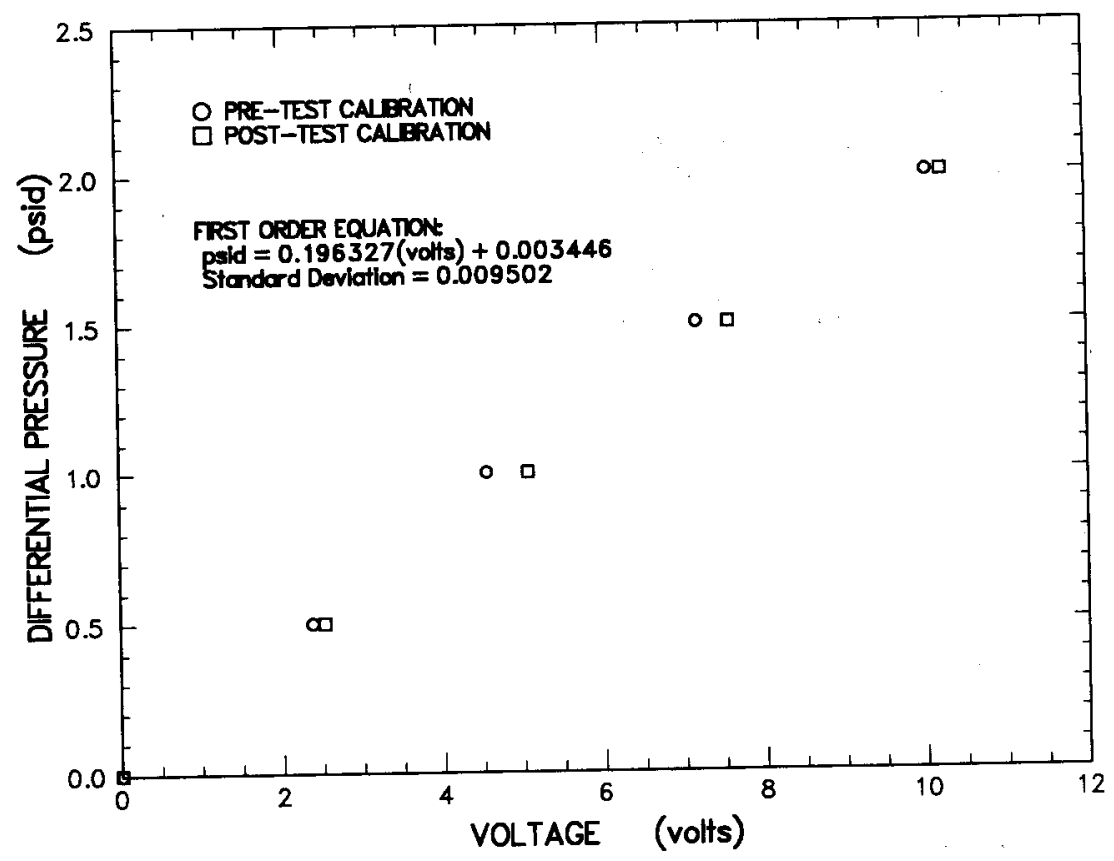

Figure F-3 Differential pressure transducer ( 2 psid) calibration installed across the ASME sharp edge orifice

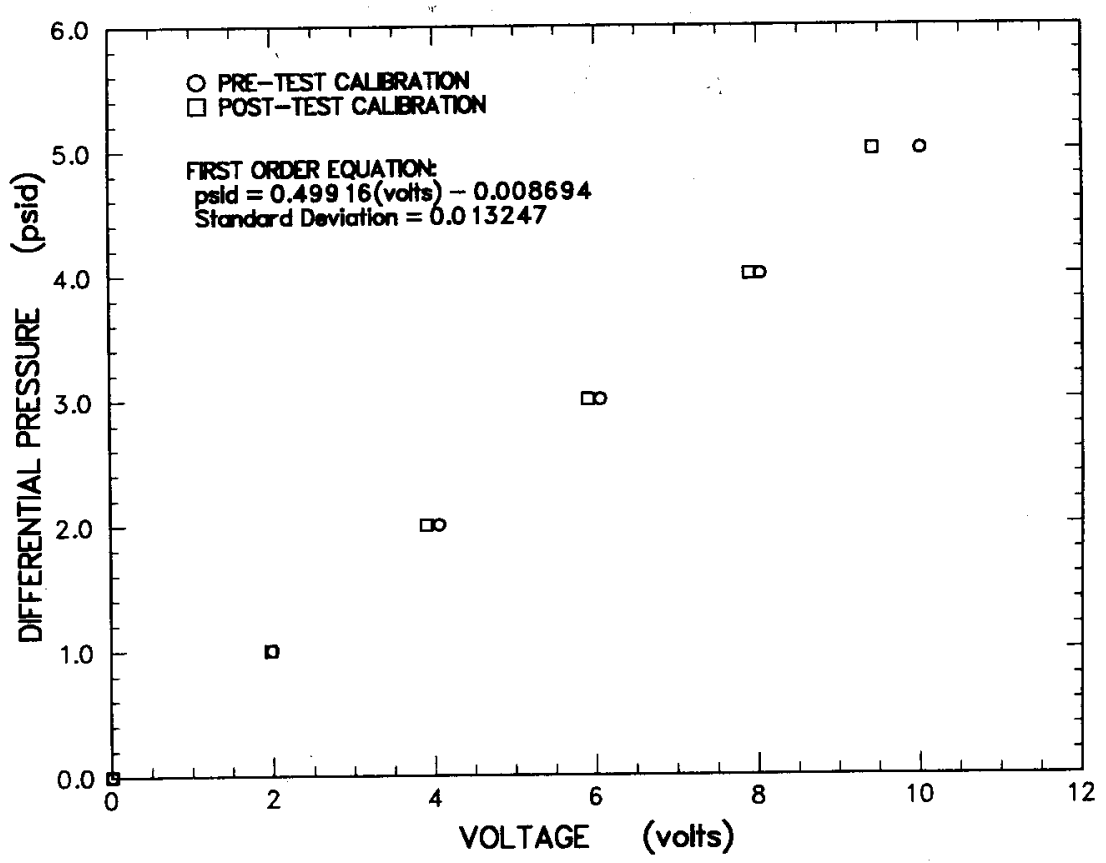

Figure F-4. Differential pressure transducer (5 psid) calibration installed across the ASME sharp edge orifice 
Appendix F

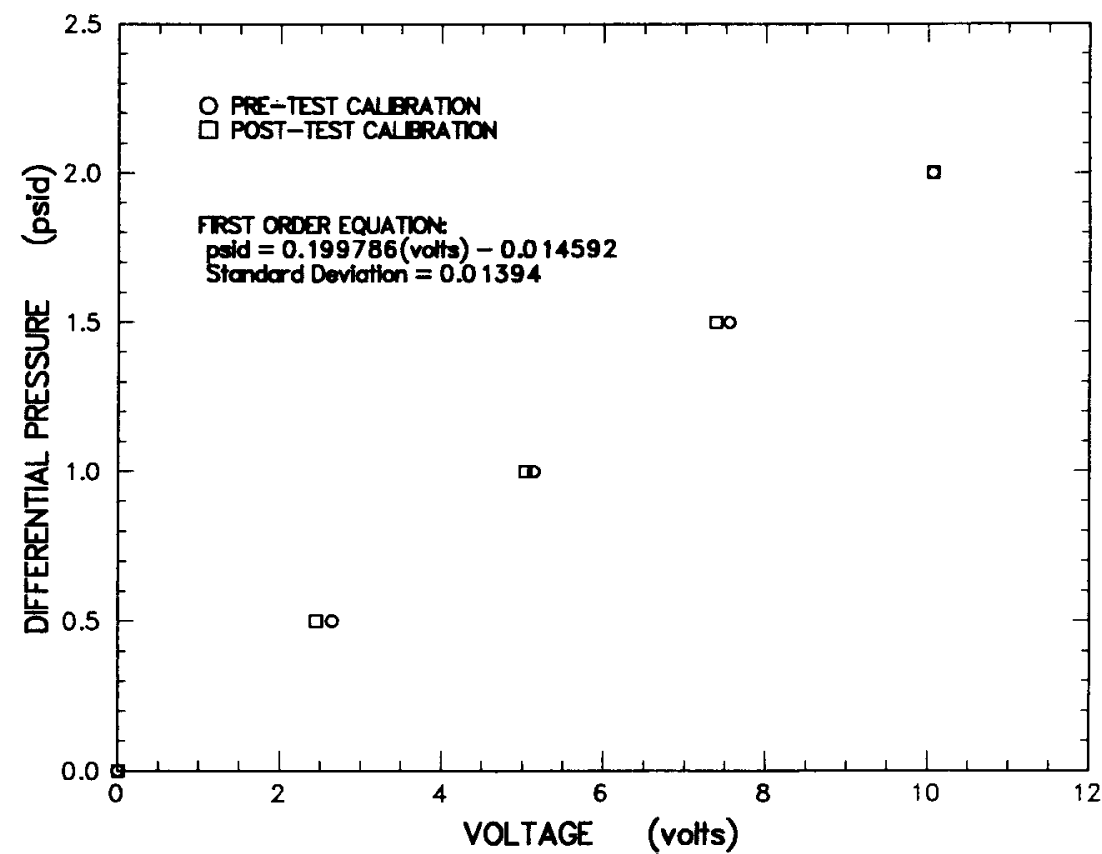

Figure F-5 Differential pressure transducer (2 psid) calibration installed across the laminar flow element

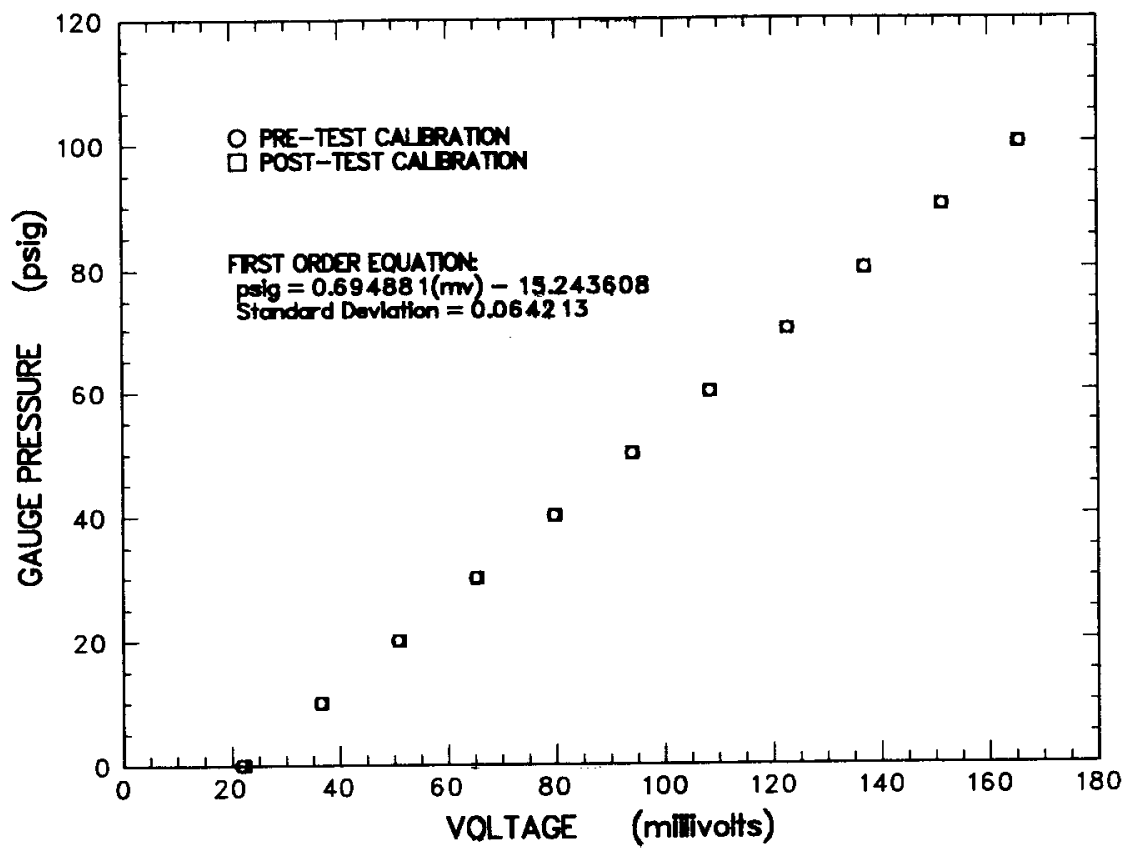

Figure F-6 Gauge pressure transducer (100 psig) calibration installed upstream of the 14 lpm critical orifice to meter the flow of argon purge gas flowing into the containment vessel 


\section{Appendix F}

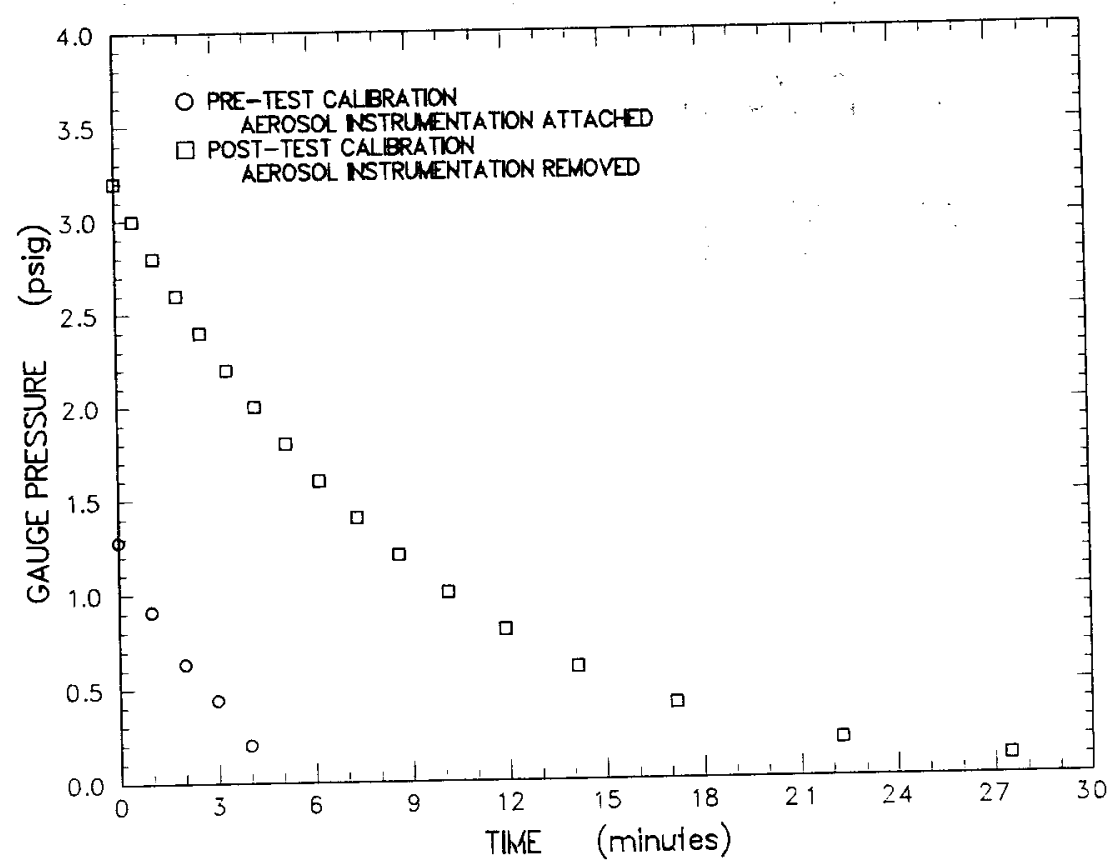

Figure F-7 Plot of pressure decay as a function of time for the containment vessel and flow circuit

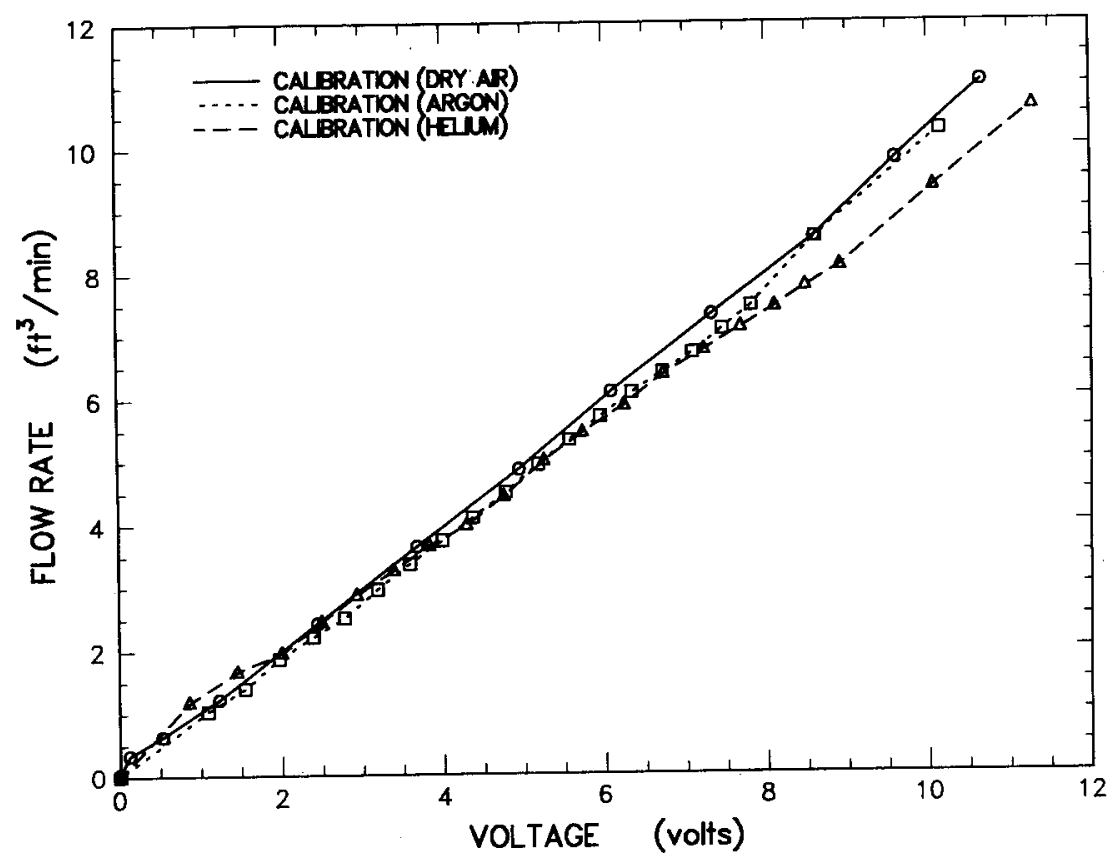

Figure F-8 Turbine meter calibration installed at the inlet of the argon purge to the containment vessel 


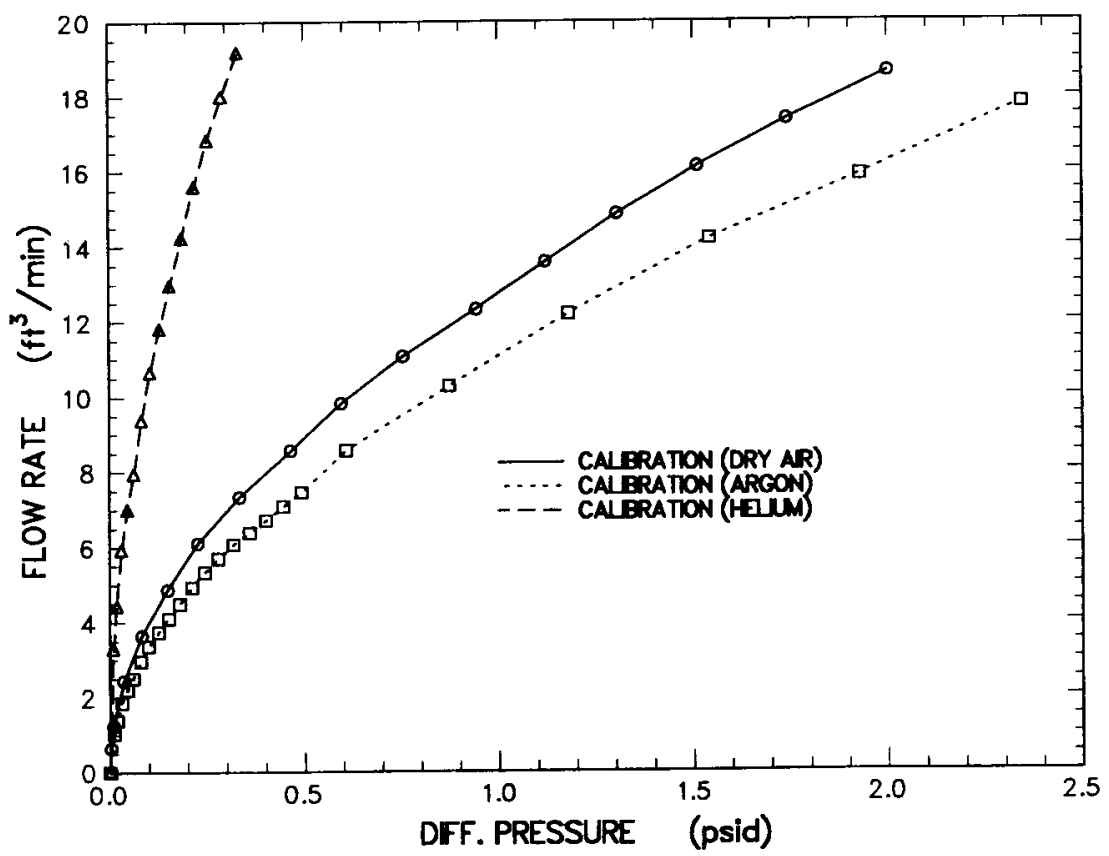

Figure F-9 Calibration of the ASME sharp edge orifice installed in the flow circuit

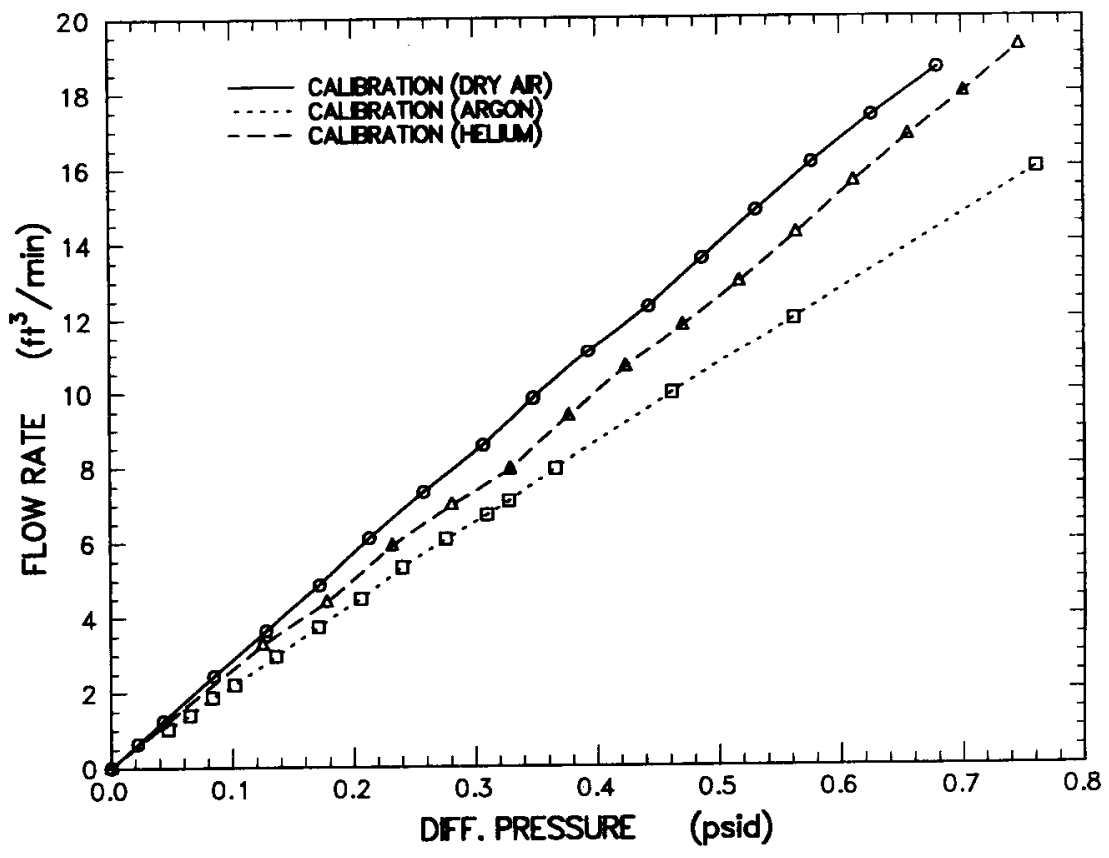

Figure F-10 Calibration of the laminar flow element installed downstream of the gravel filter and near the exit of the flow circuit 
Appendix F

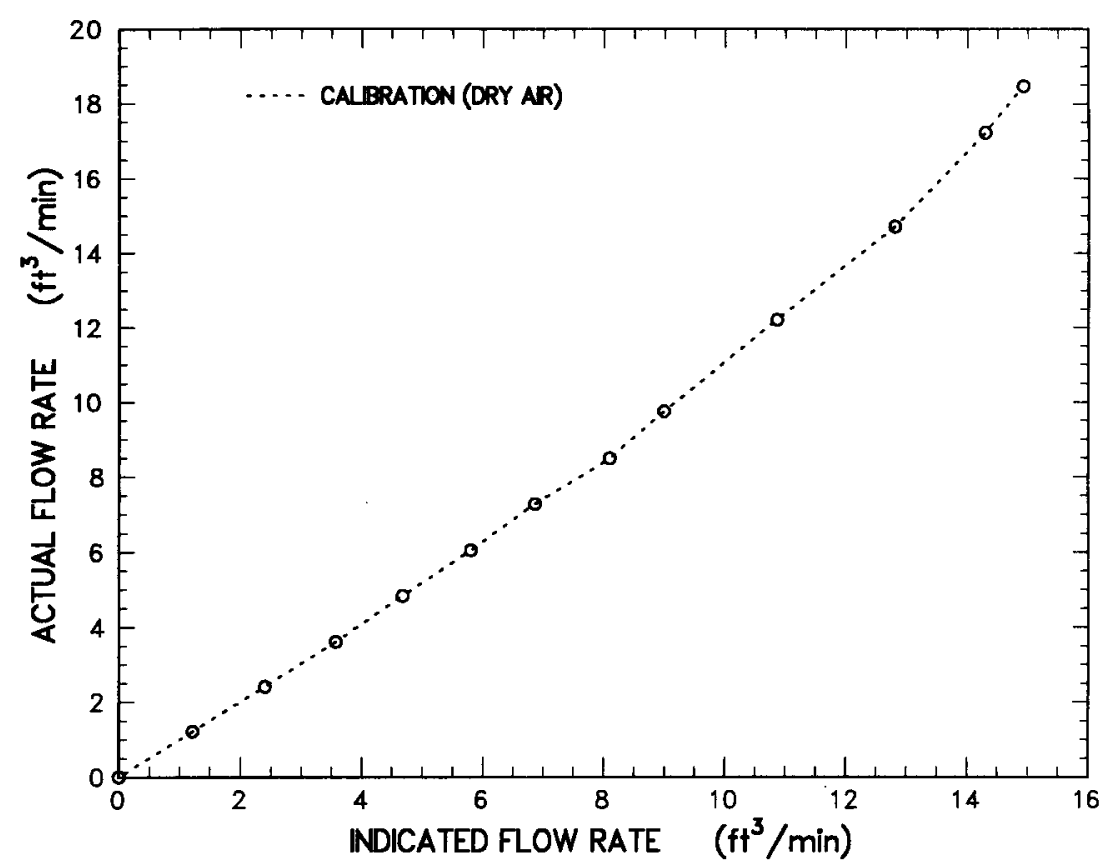

Figure F-11 Calibration of the Rockwell 415 positive displacement gas clock (meter)

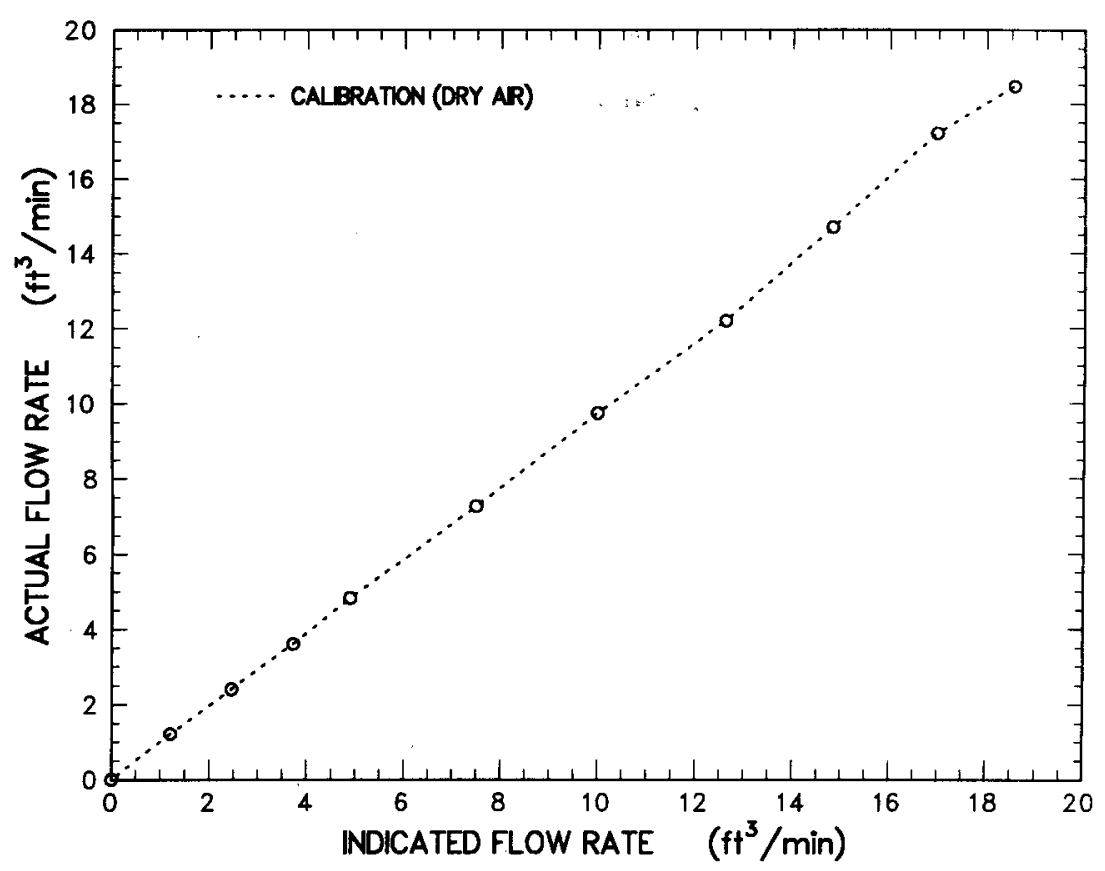

Figure F-12 Calibration of the Rockwell 750 positive displacement gas clock (meter) 
APPENDIX G

GAS COMPOSITION, FLOW RATE, AND AEROSOL DATA 


\section{Appendix G}

In this appendix data is presented for pressure, and recorded using instrumentation installed on temperature, flow, and gas composition measured the gas and aerosol sampling systems. 


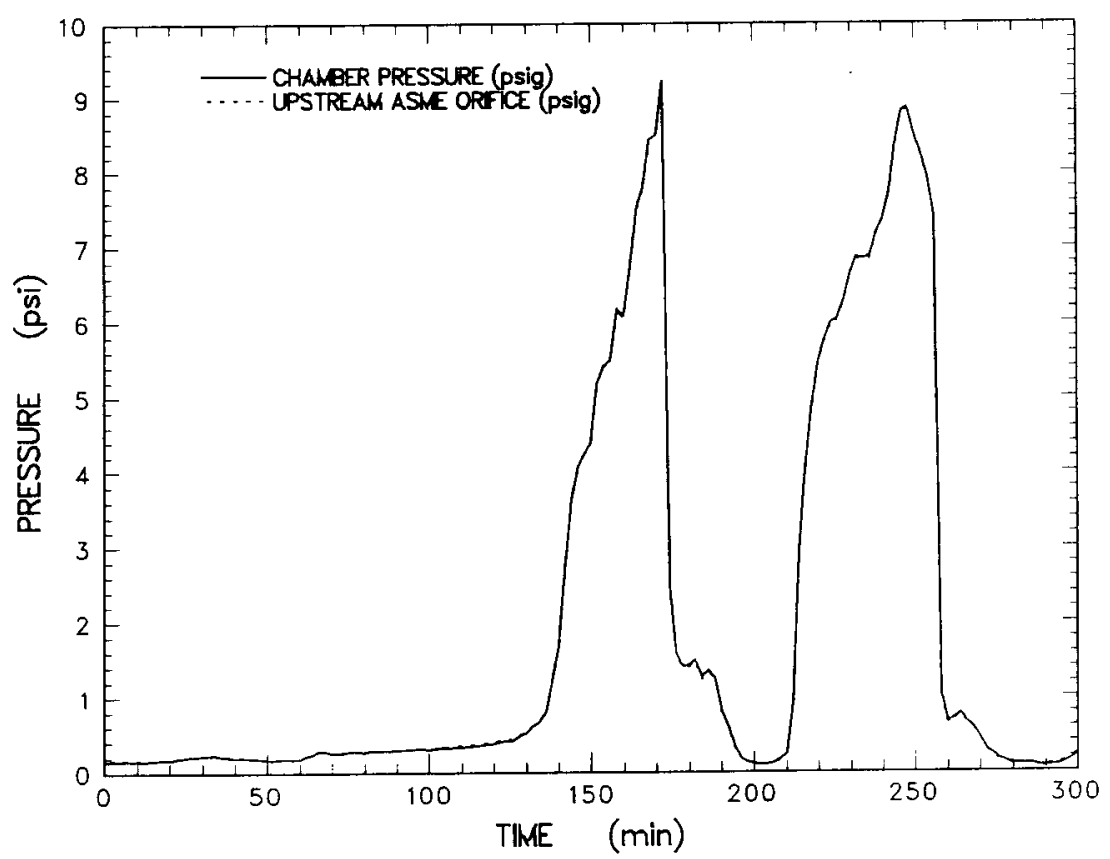

Figure G-1 Gauge pressure measured in the containment vessel and upstream of the ASME sharp edge orifice

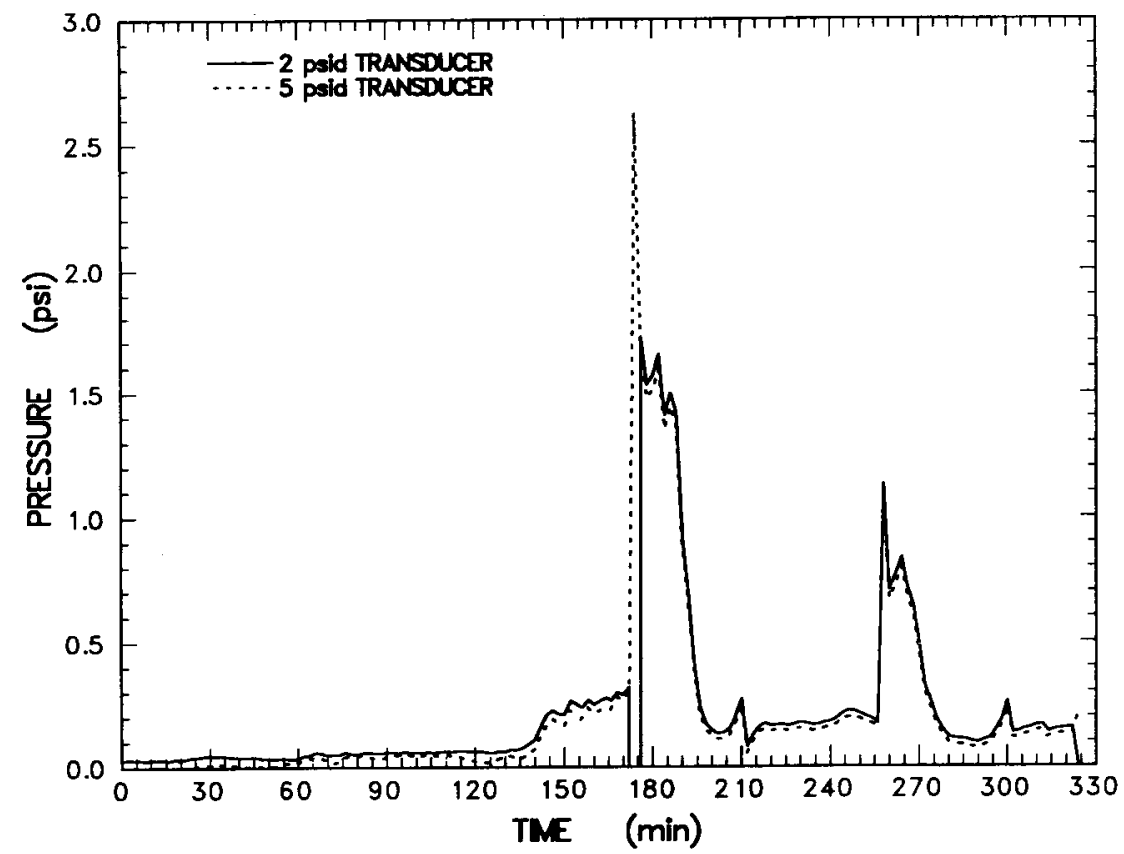

Figure G-2 Differential pressure measured by two transducers installed across the ASME sharp edge orifice 
Appendix G

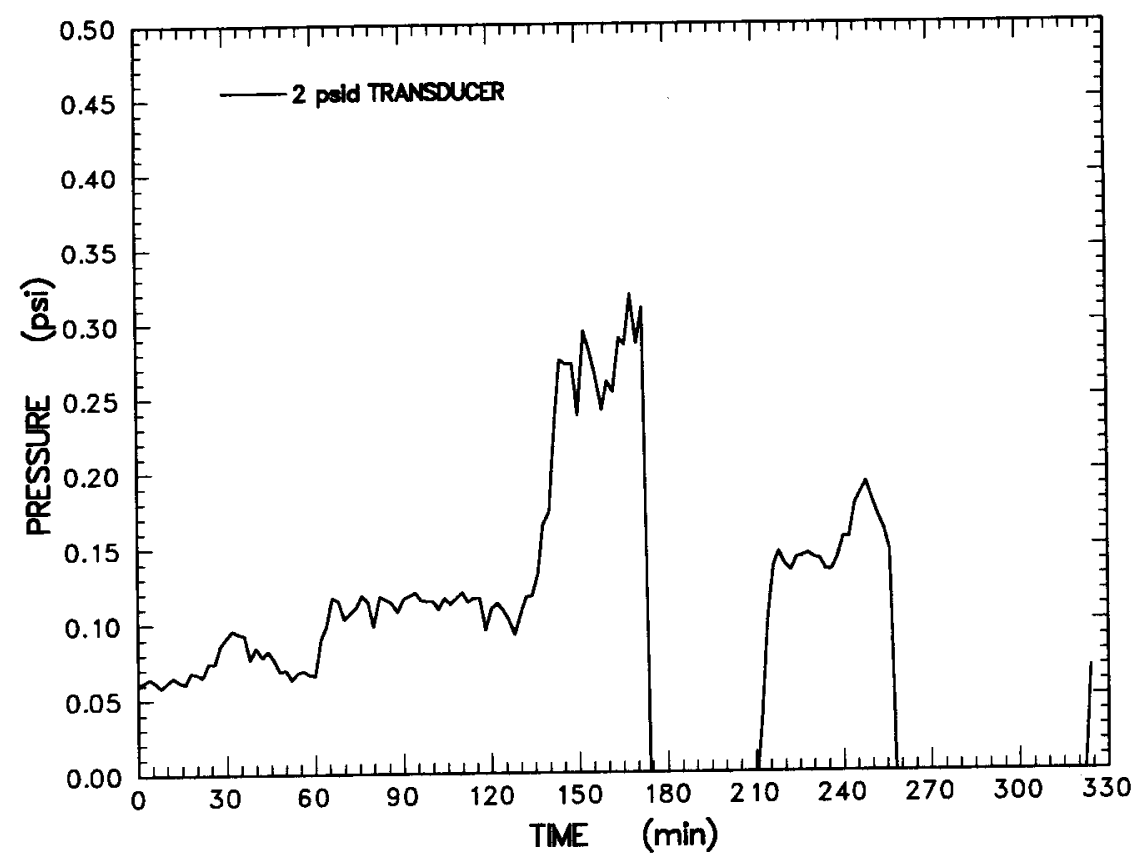

Figure G-3 Differential pressure measured across the laminar flow element

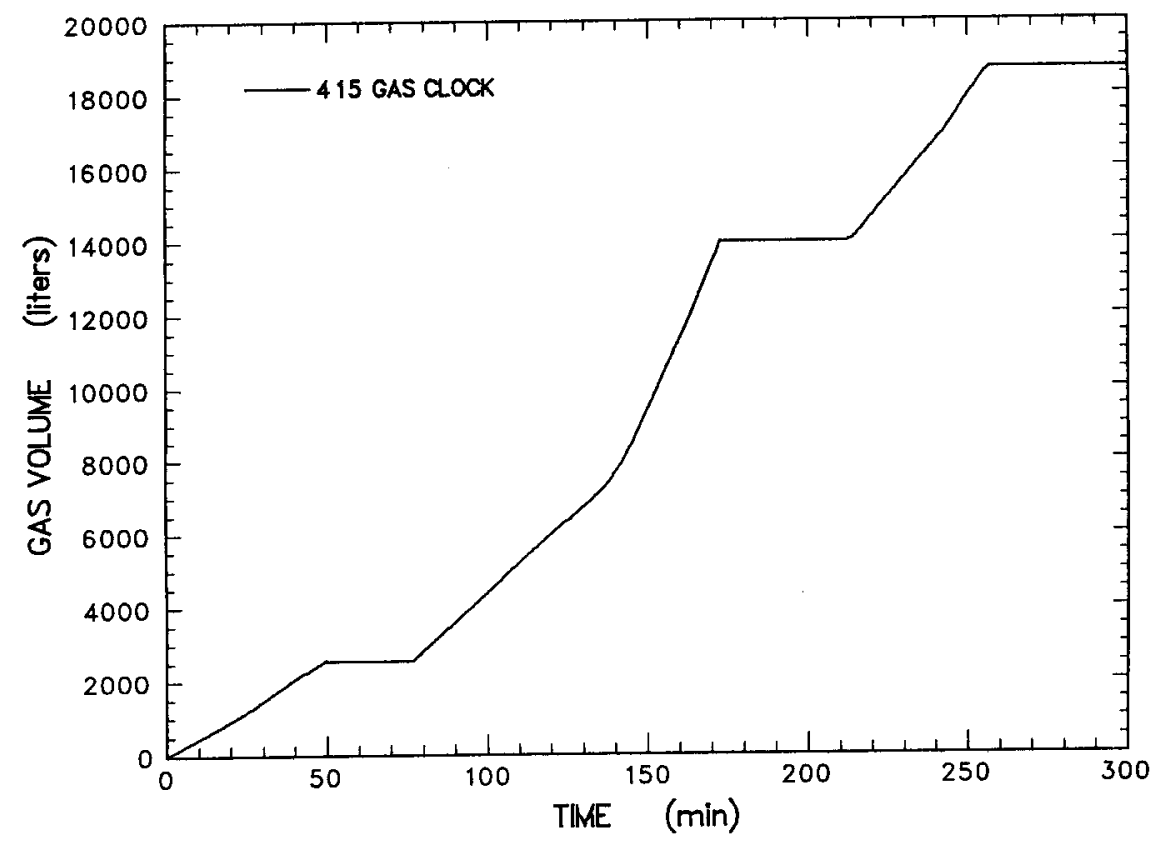

Figure G-4 Volume of gas measured during the experiment by the Rockwell 415 positive displacement gas clocks (meter) 


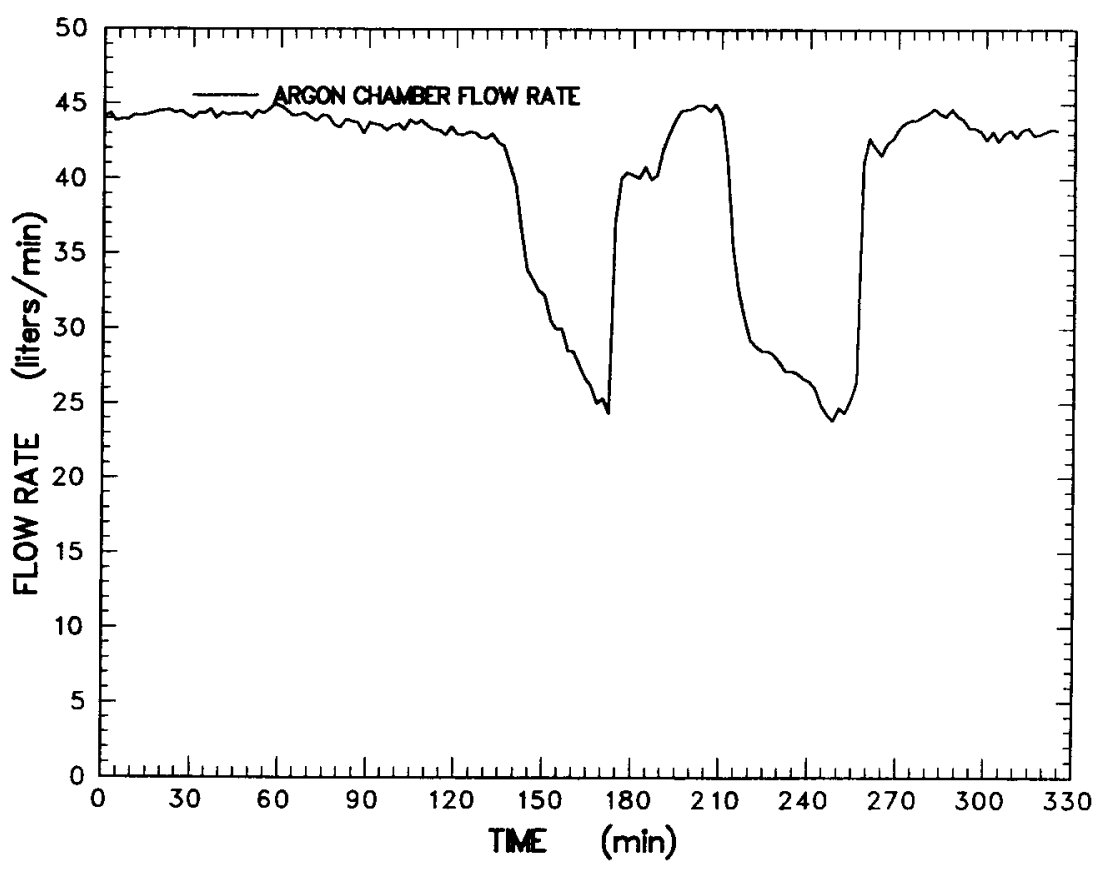

Figure G-5 Flow rate indicated by the turbine meter installed at the inlet of the argon purge to the containment vessel

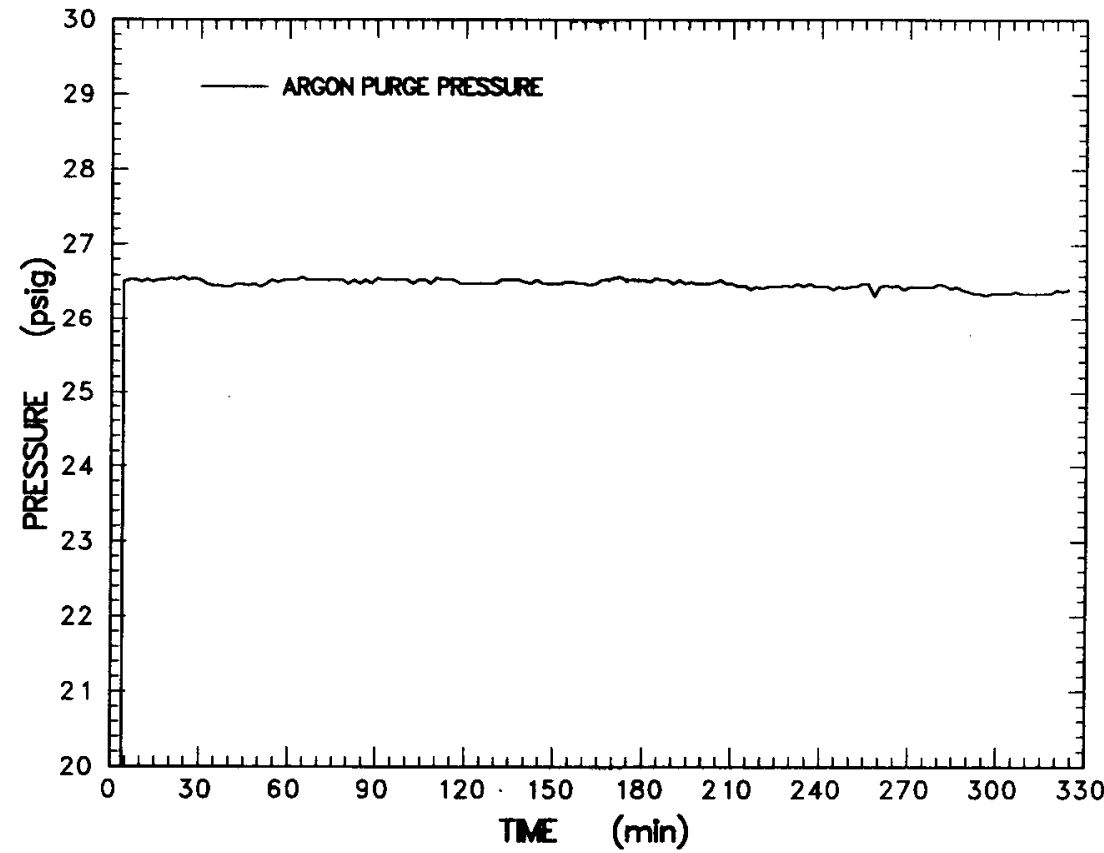

Figure G-6 Absolute pressure measured upstream of a 14 lpm critical orifice used to measure the flow rate of argon purge gas 


\section{Appendix G}

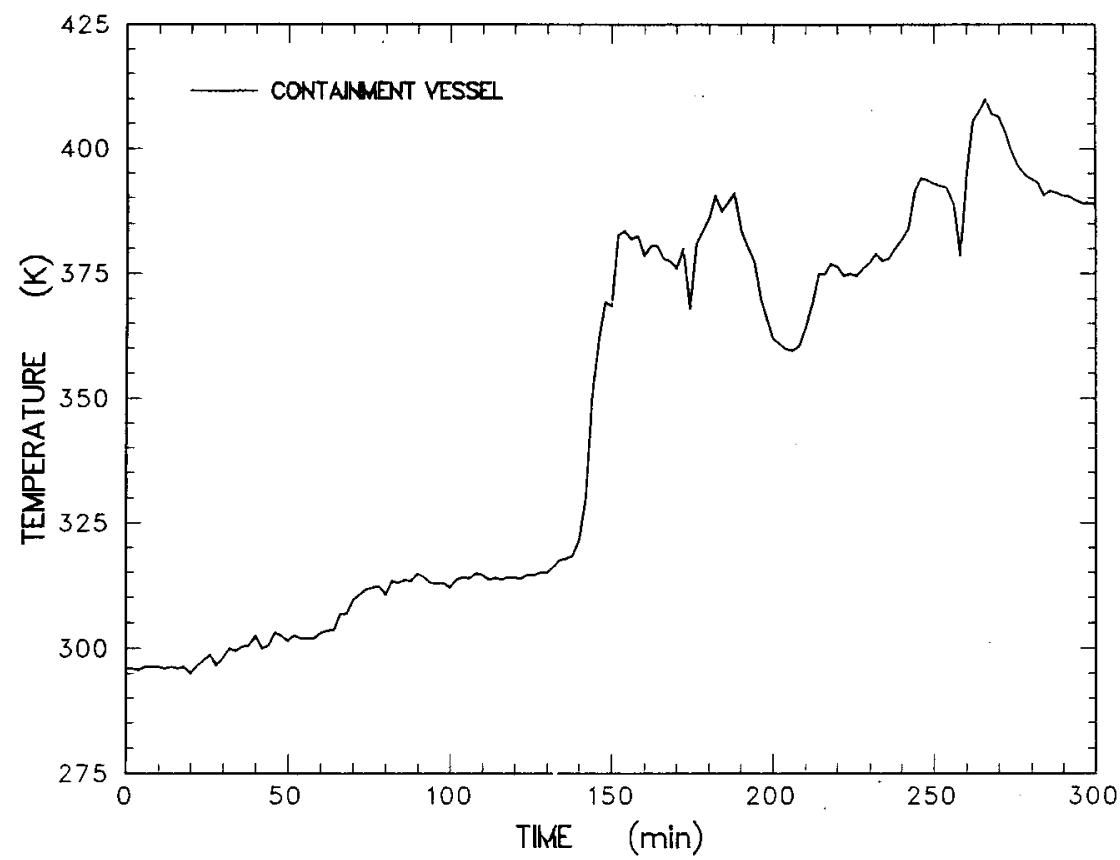

Figure G-7 Atmosphere temperature inside the containment vessel

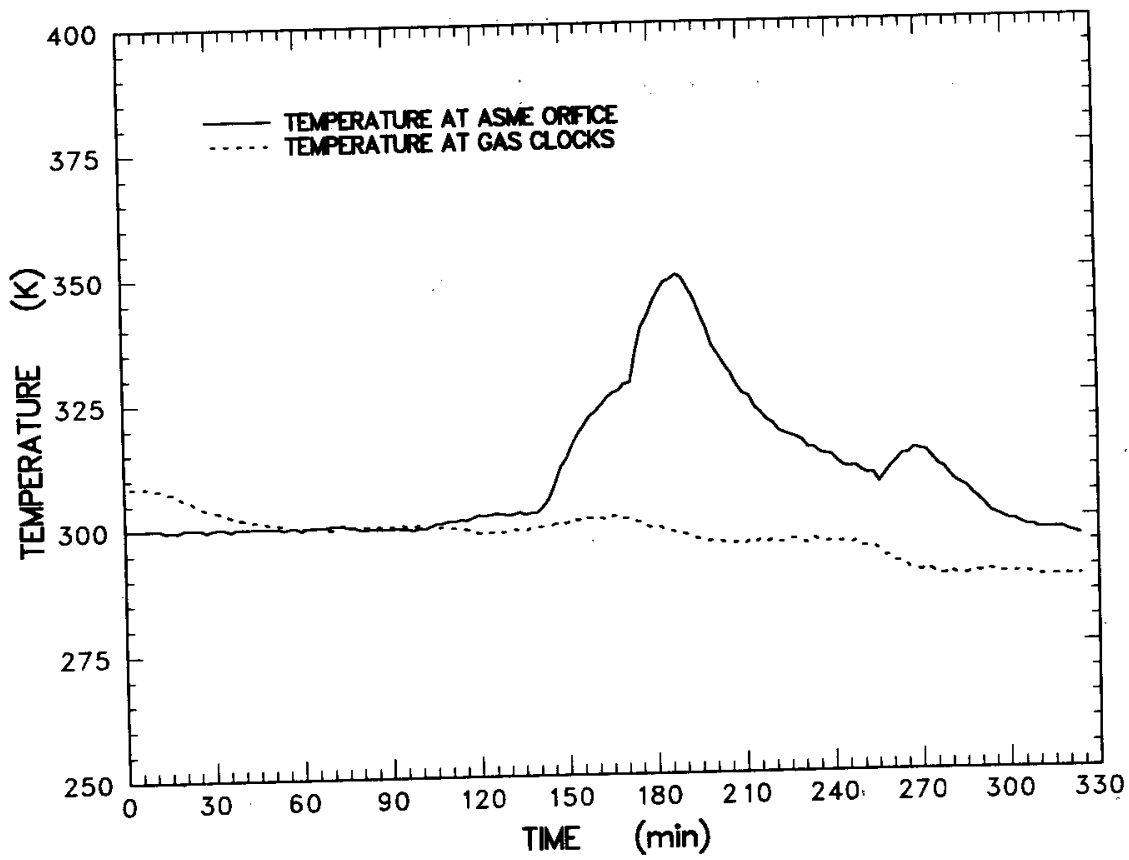

Figure G-8 Temperatures measured in the flow circuit 


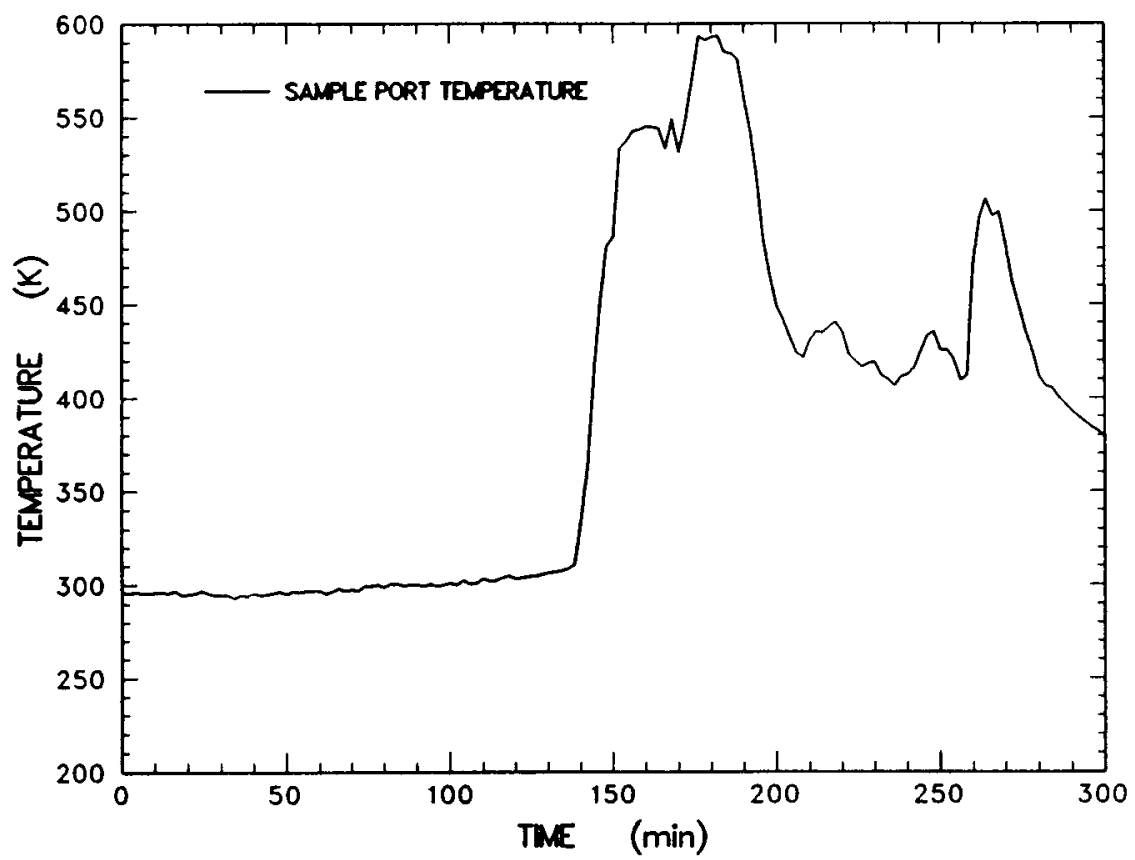

Figure G-9 Gas sample port temperature

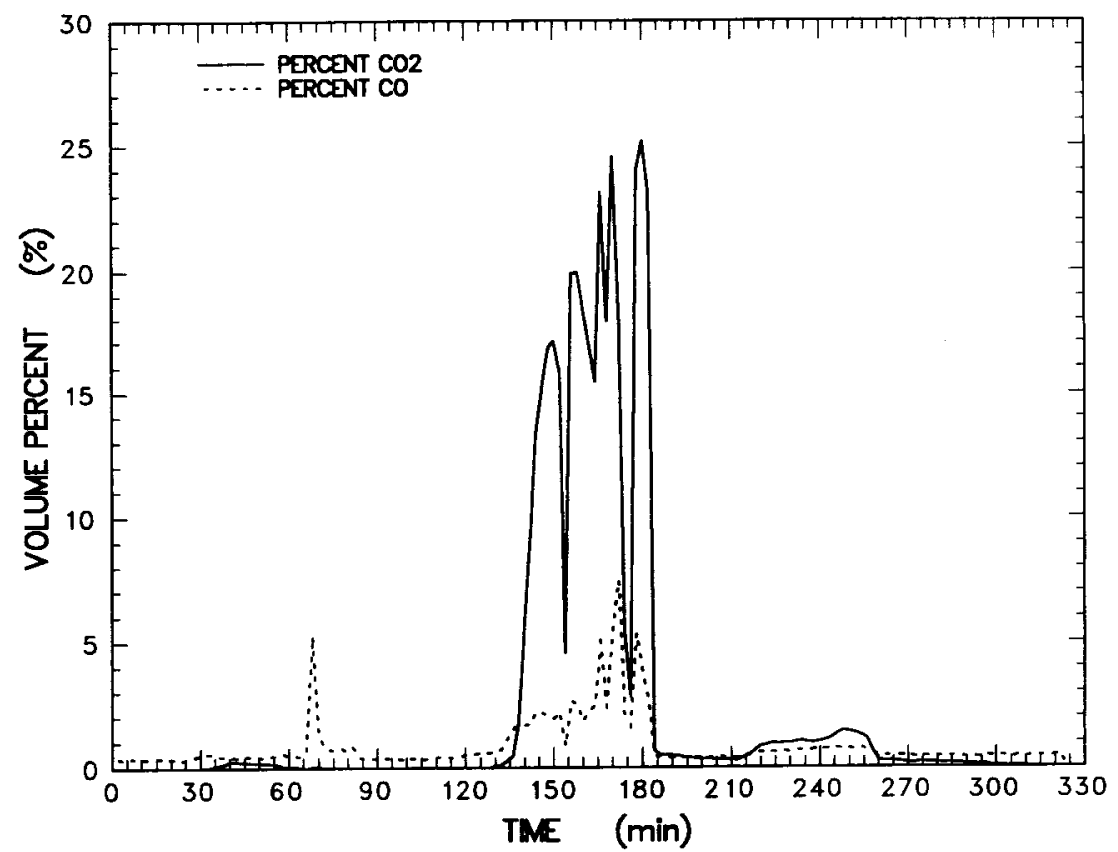

Figure G-10 Volume percent $\mathrm{CO}$ and $\mathrm{CO}_{2}$ measured with the infrared monitor 


\section{Appendix G}

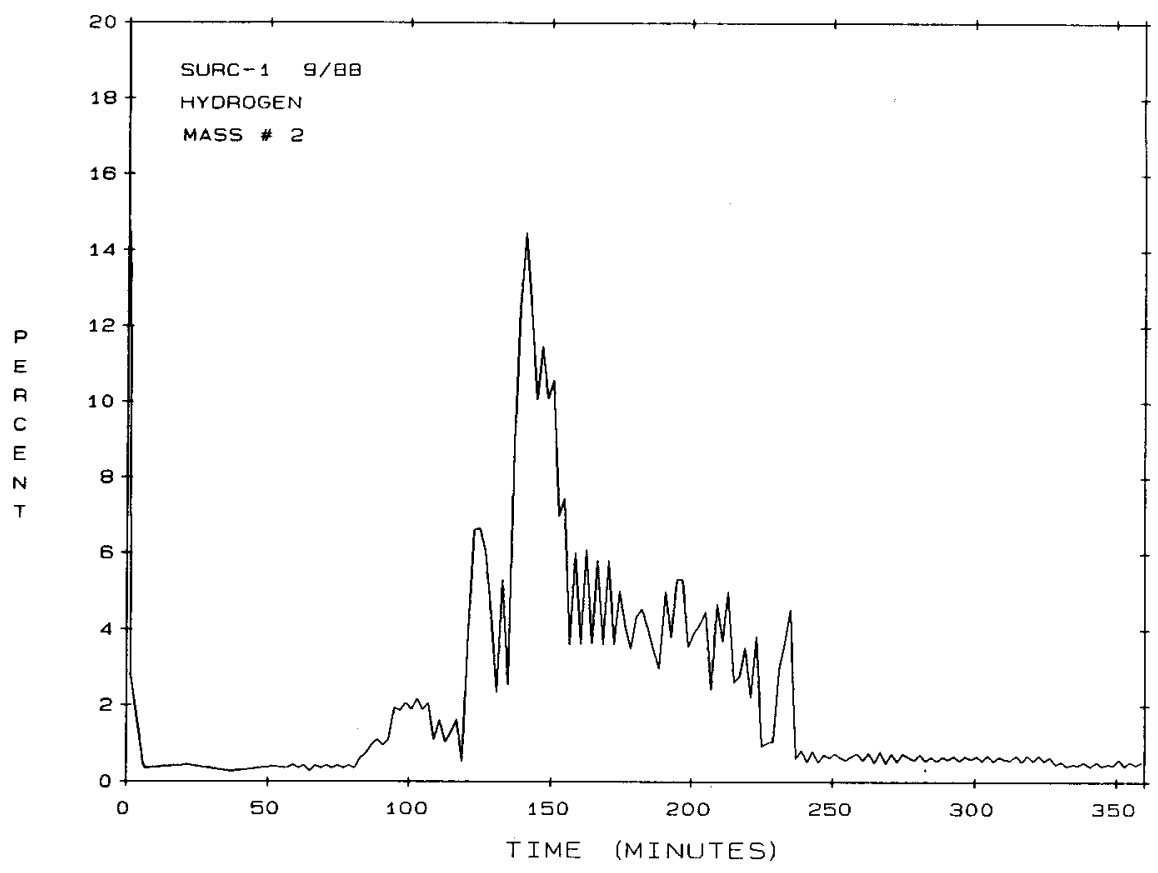

Figure G-11 Volume percent of hydrogen measured by the mass spectrometer

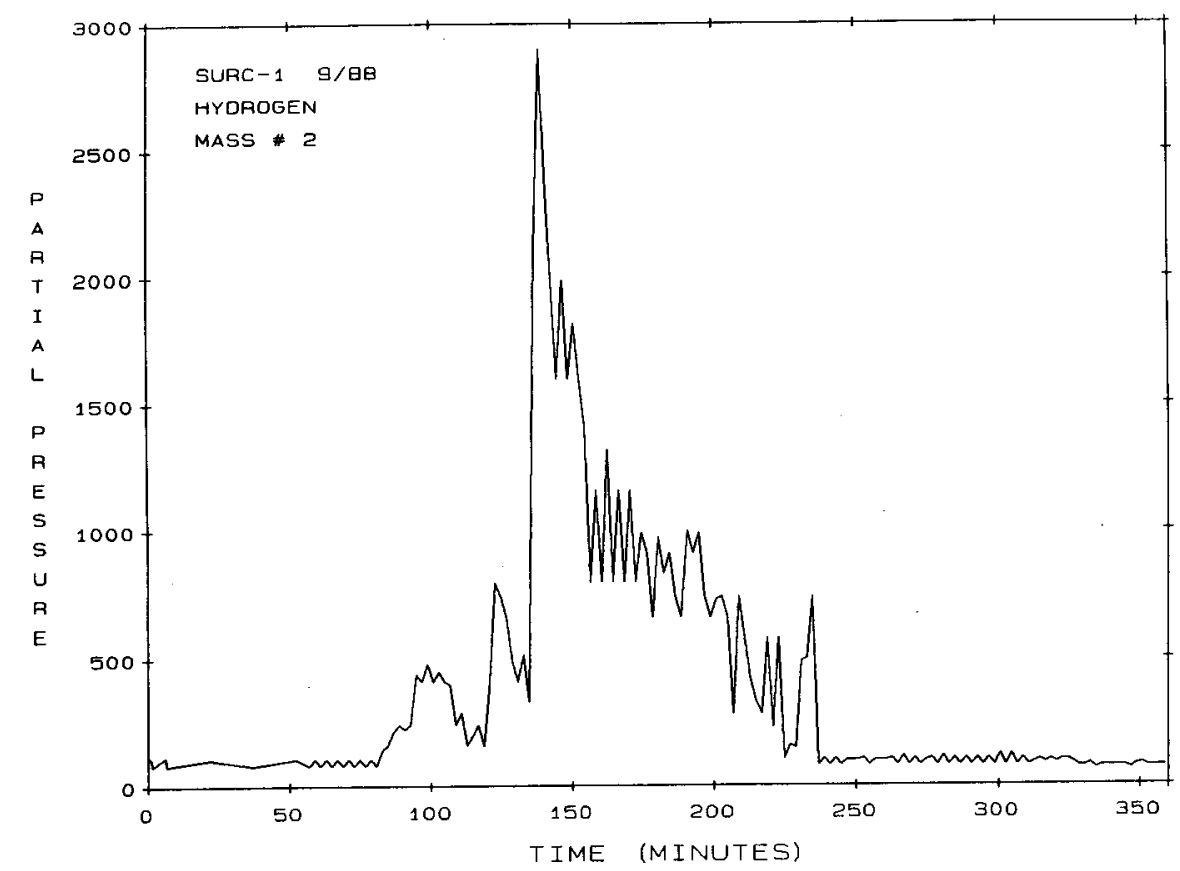

Figure G-12 Partial pressure of hydrogen sampled by the mass spectrometer : 


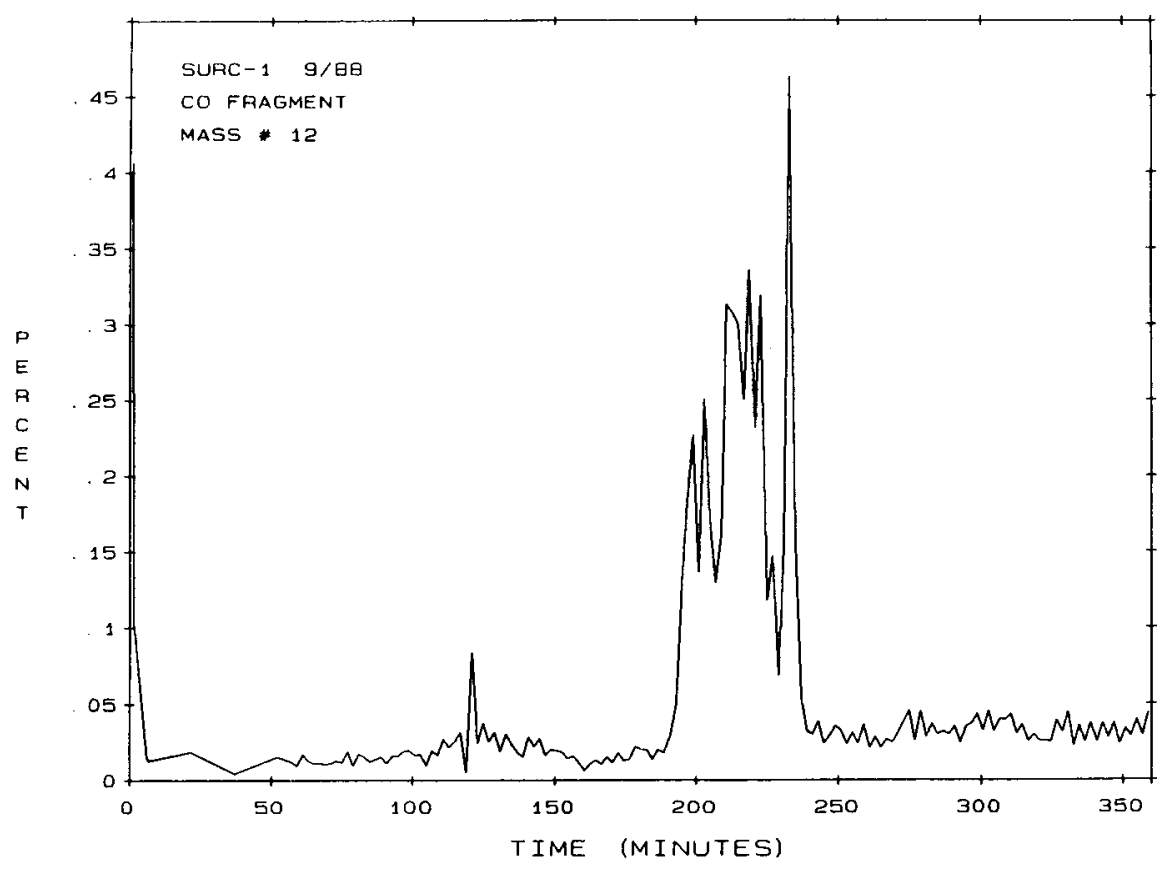

Figure G-13 Volume fragment of carbon monoxide measured by the mass spectrometer

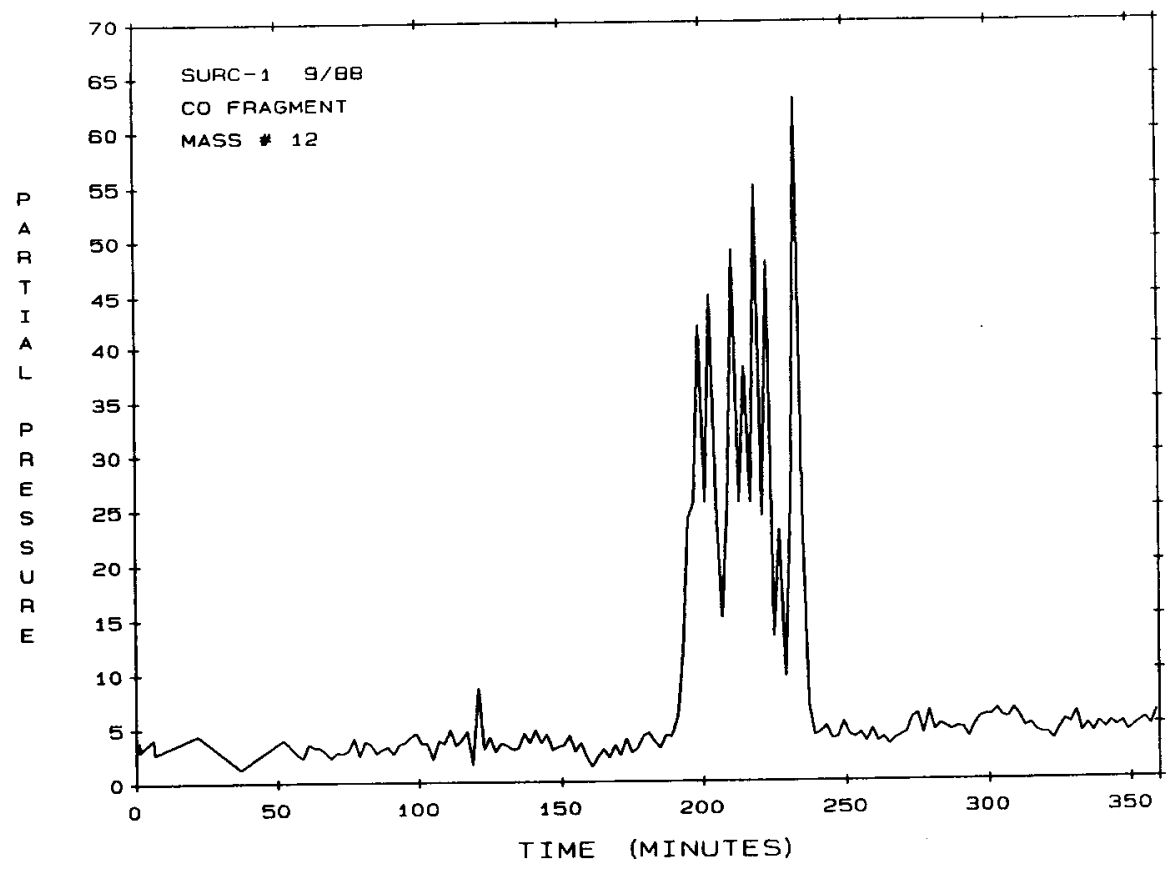

Figure G-14 Partial pressure of carbon monoxide fragment measured by the mass spectrometer 
Appendix G

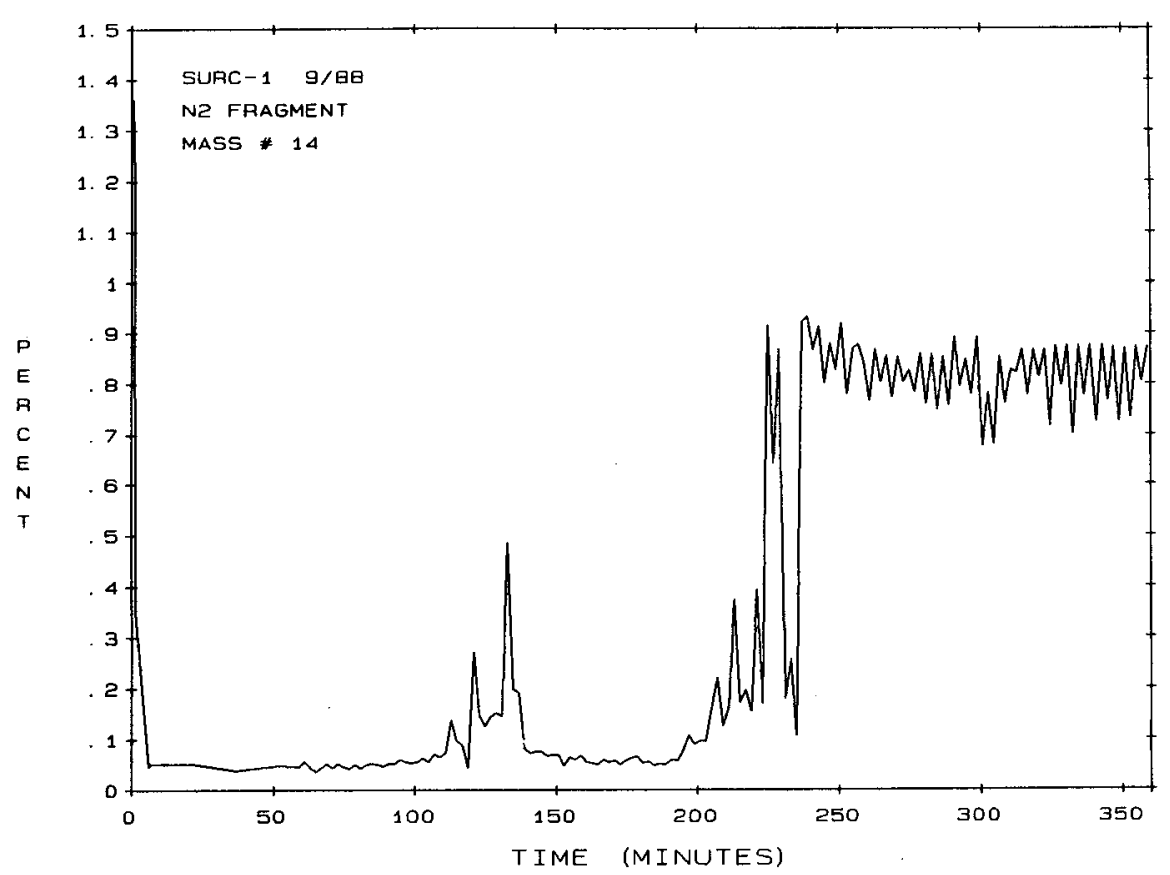

Figure G-15 Volume fragment of nitrogen measured by the mass spectrometer

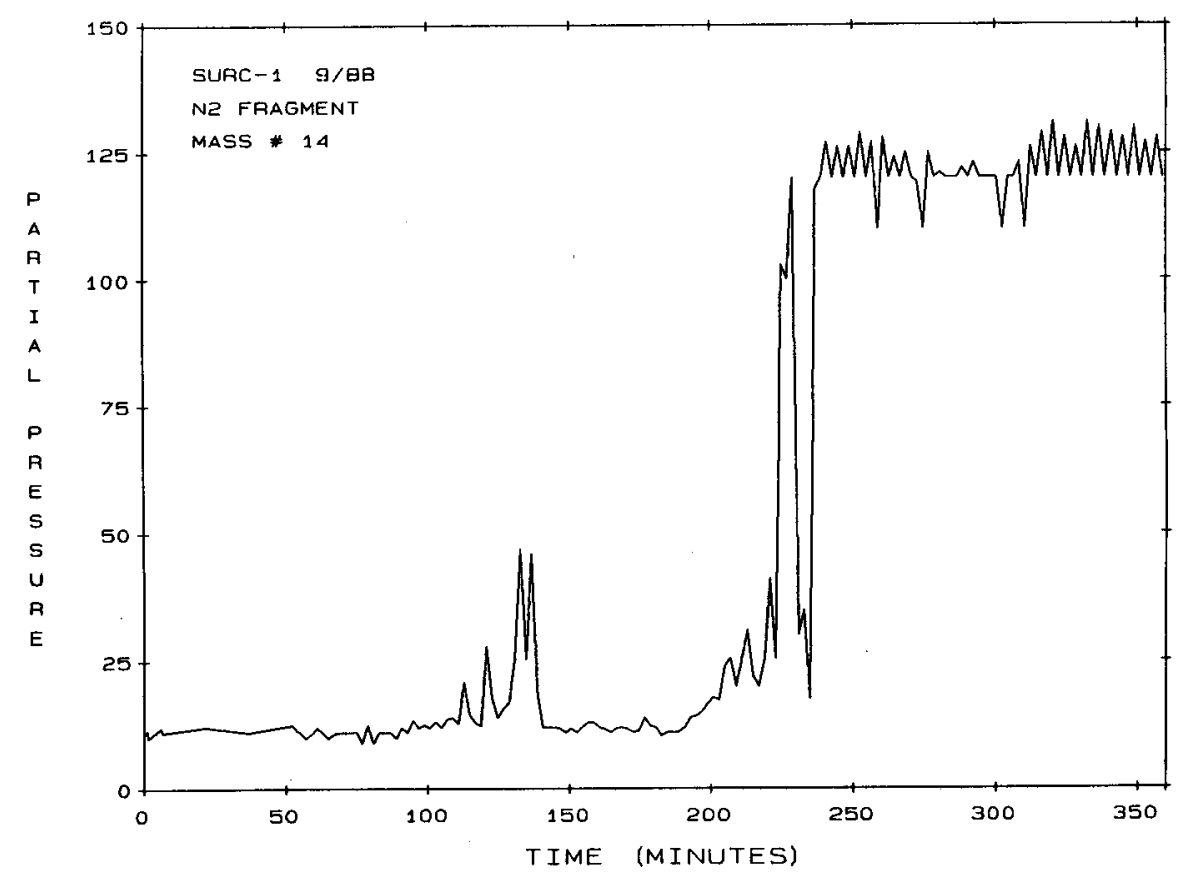

Figure G-16 Partial pressure of nitrogen fragment measured by the mass spectrometer 
Appendix G

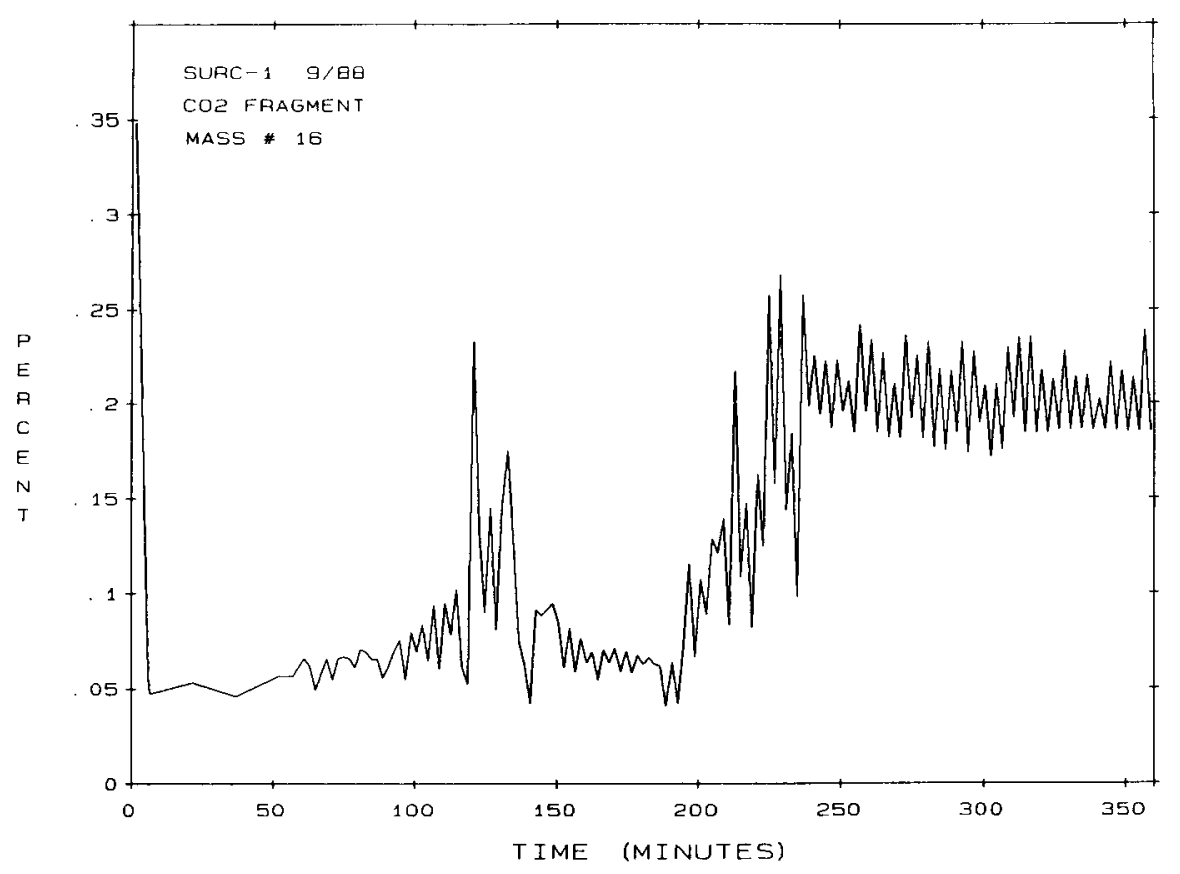

Figure G-17 Volume fragment of carbon dioxide measured by the mass spectrometer

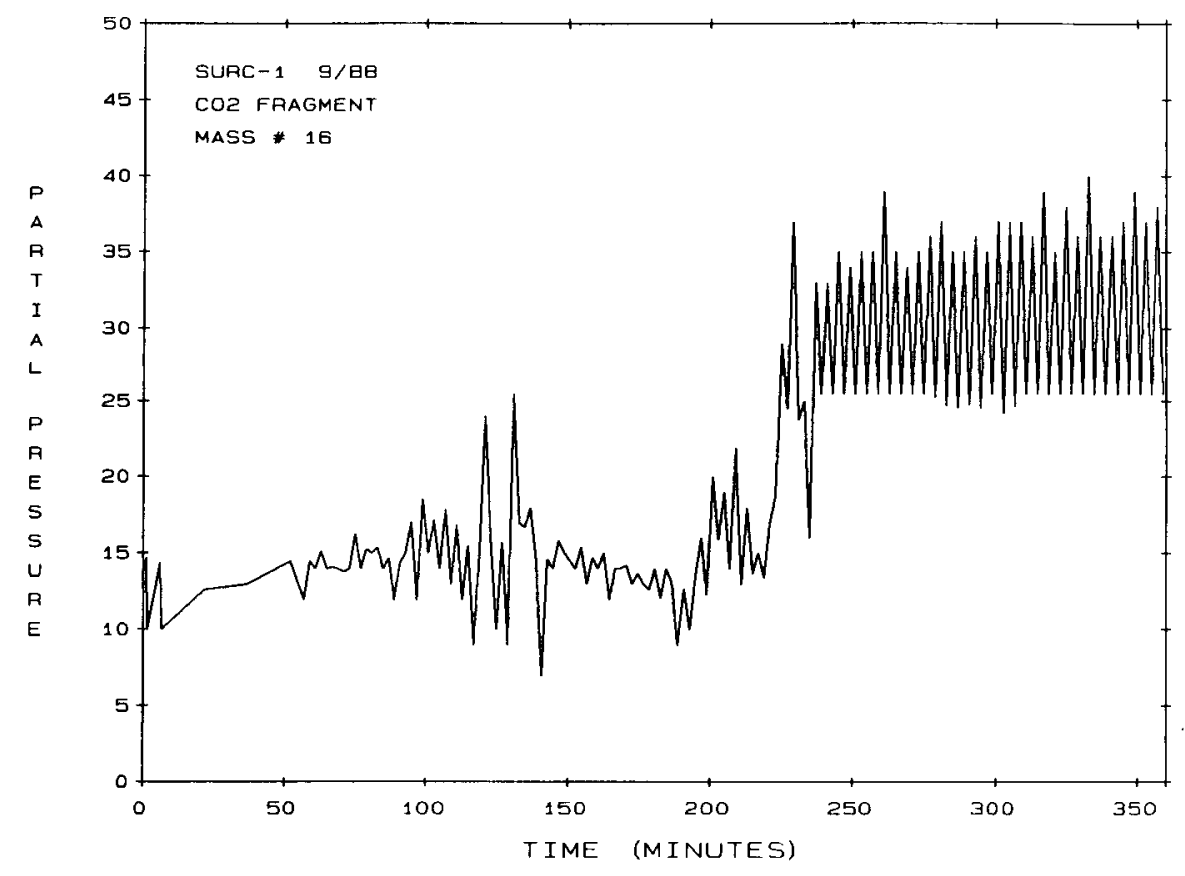

Figure G-18 Partial pressure of carbon dioxide fragment measured by the mass spectrometer 
Appendix G

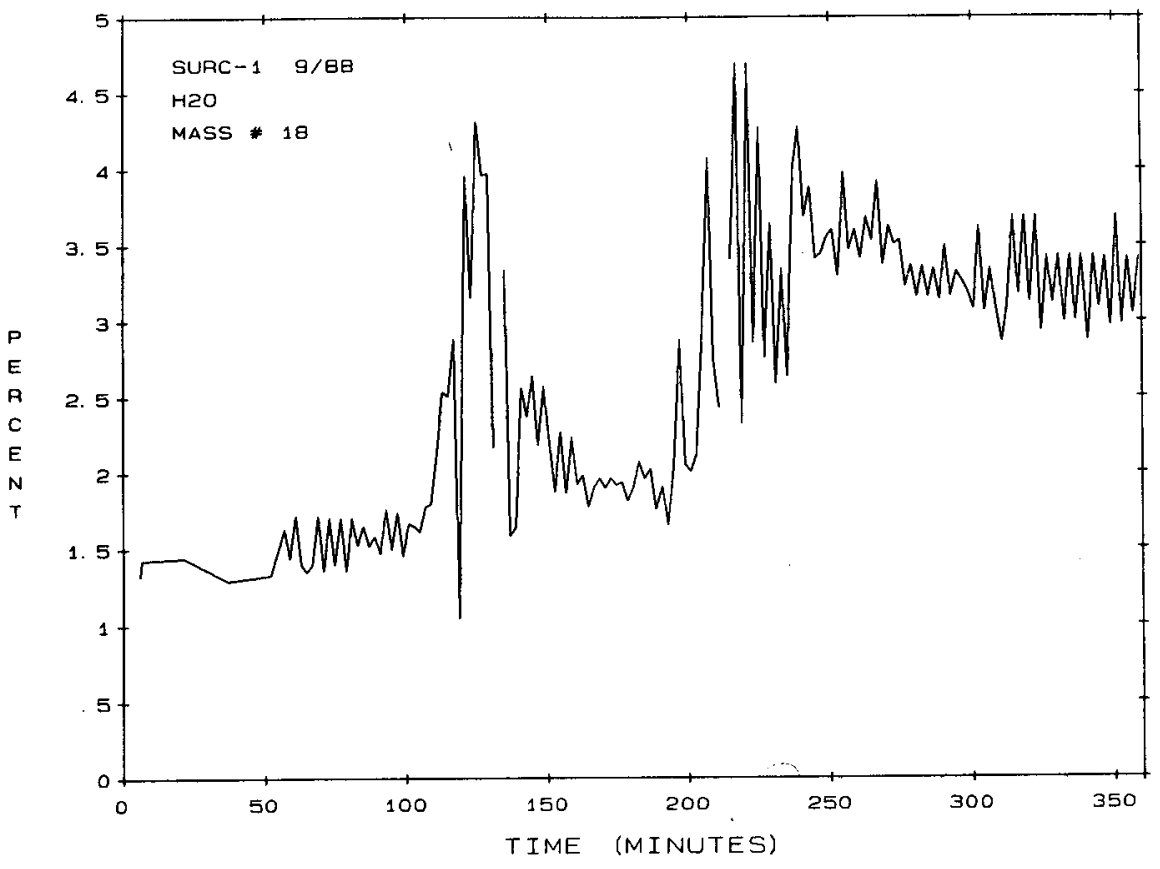

Figure G-19 Volume percent of water vapor measured by the mass spectrometer

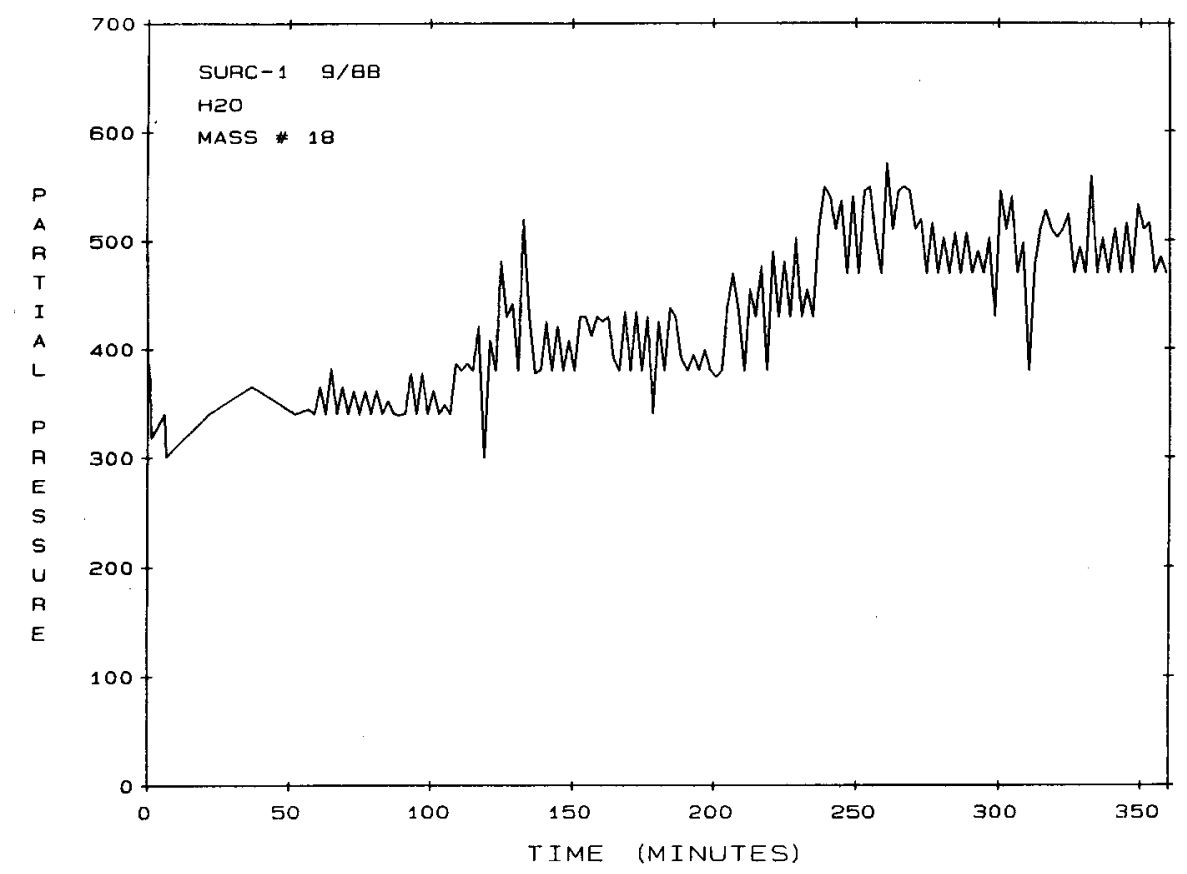

Figure G-20 Partial pressure of water vapor measured by the mass spectrometer 


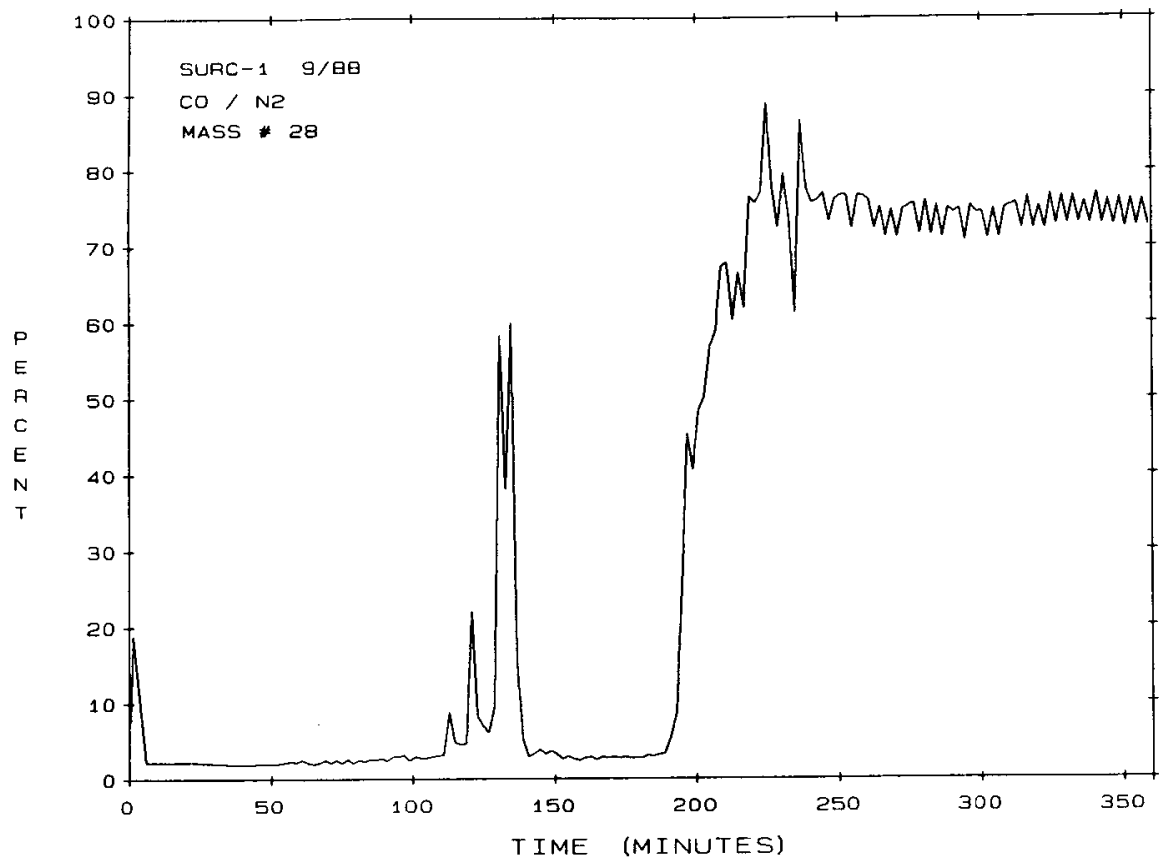

Figure G-21 Volume percent of carbon monoxide and nitrogen measured by the mass spectrometer

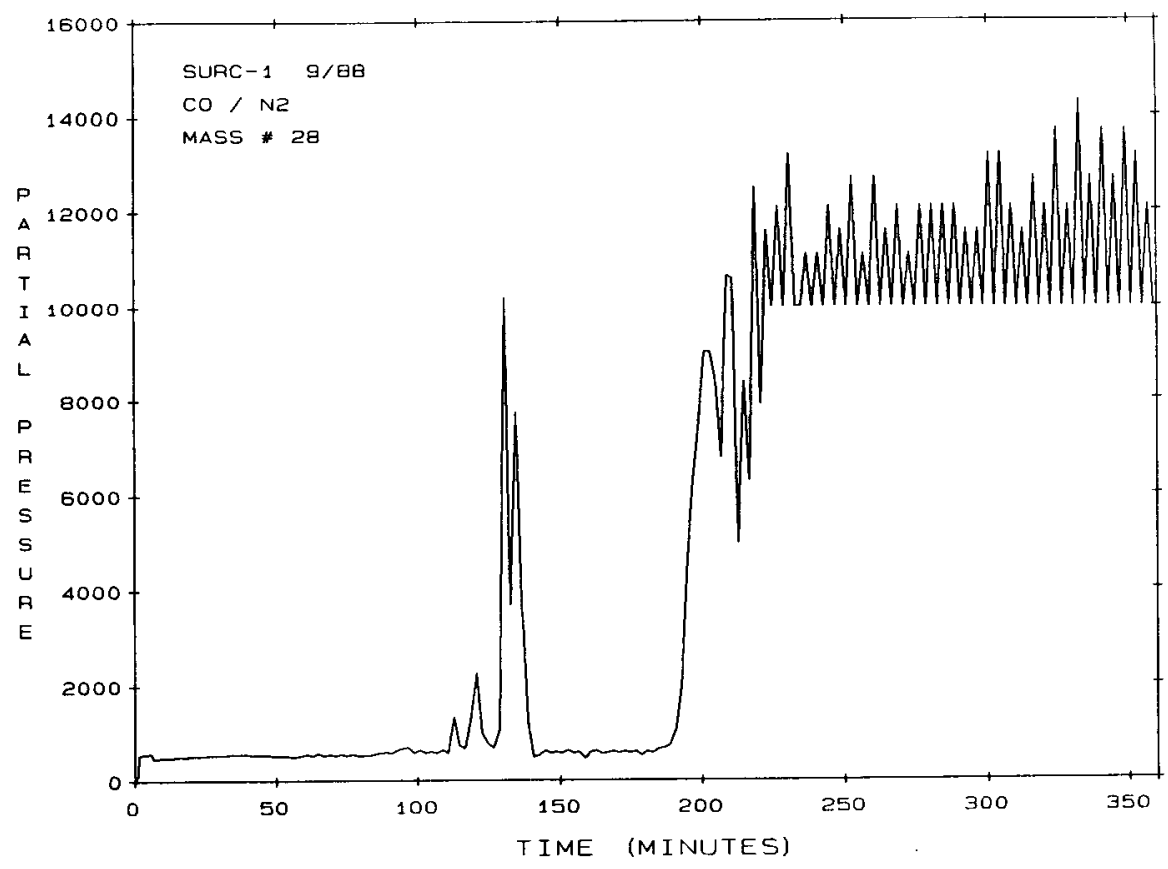

Figure G-22 Partial pressure of carbon monoxide and nitrogen measured by the mass spectrometer 
Appendix G

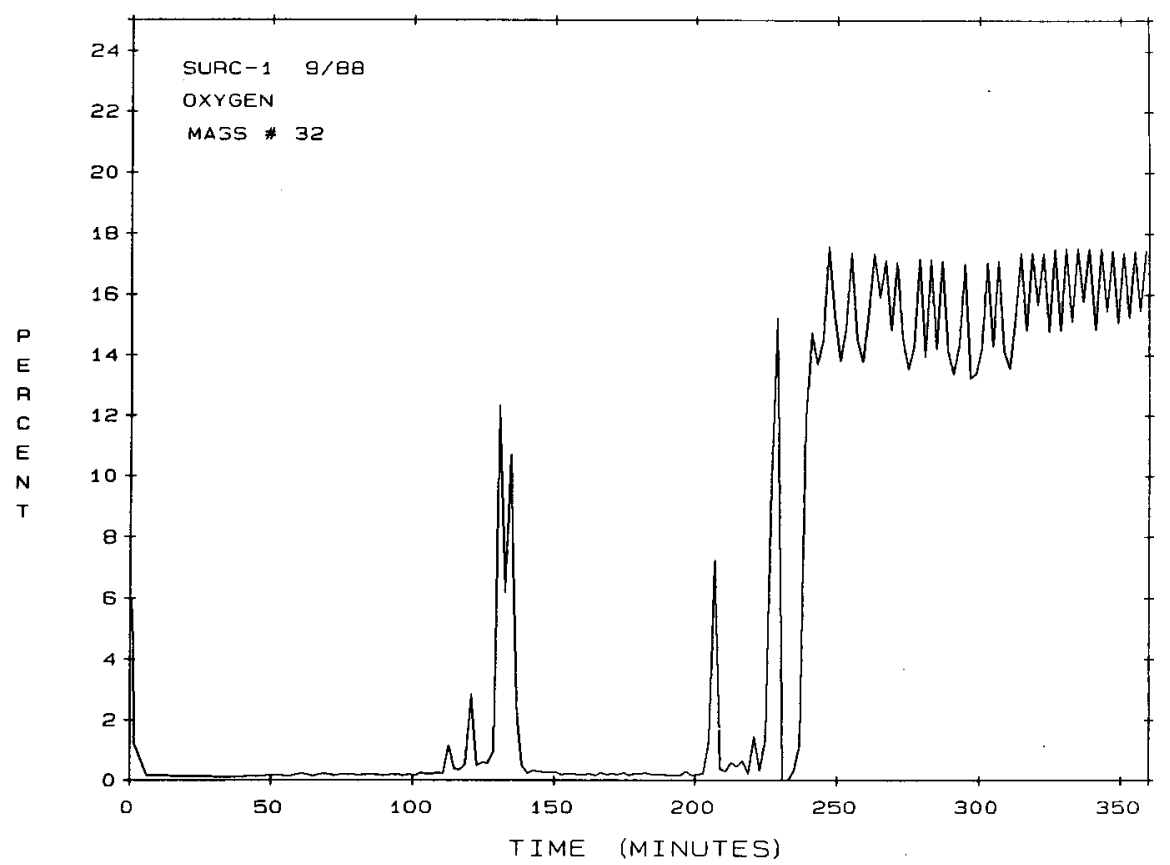

Figure G-23 Volume percent of oxygen measured by the mass spectrometer

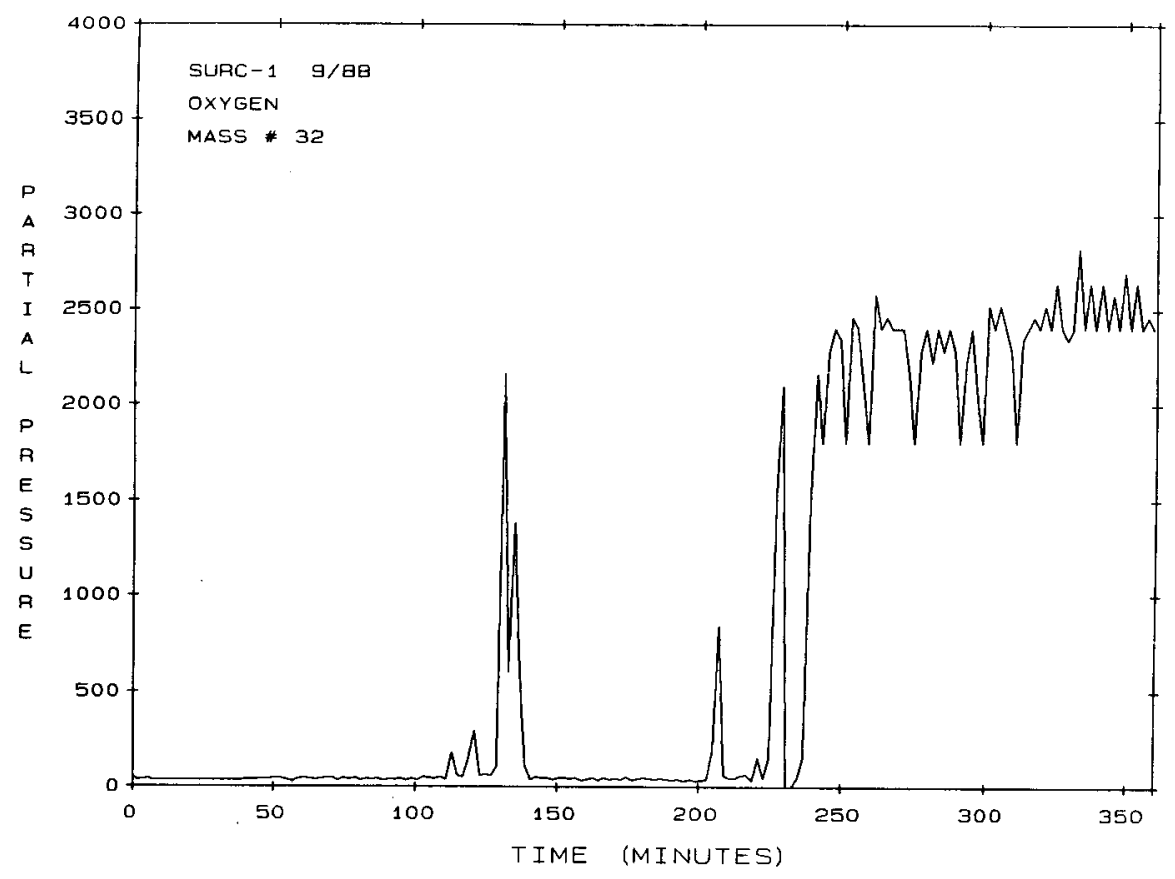

Figure G-24 Partial pressure of oxygen measured by the mass spectrometer 


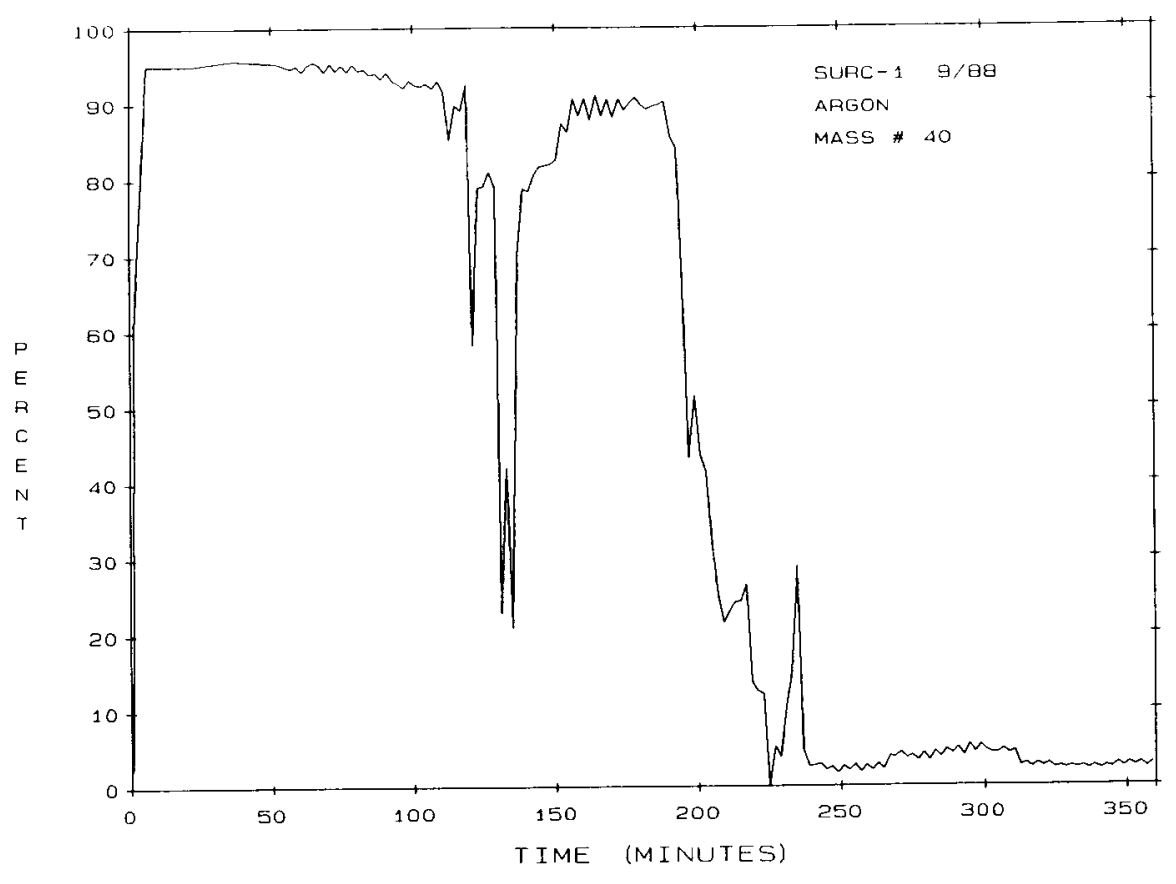

Figure G-25 Volume percent of argon measured by the mass spectrometer

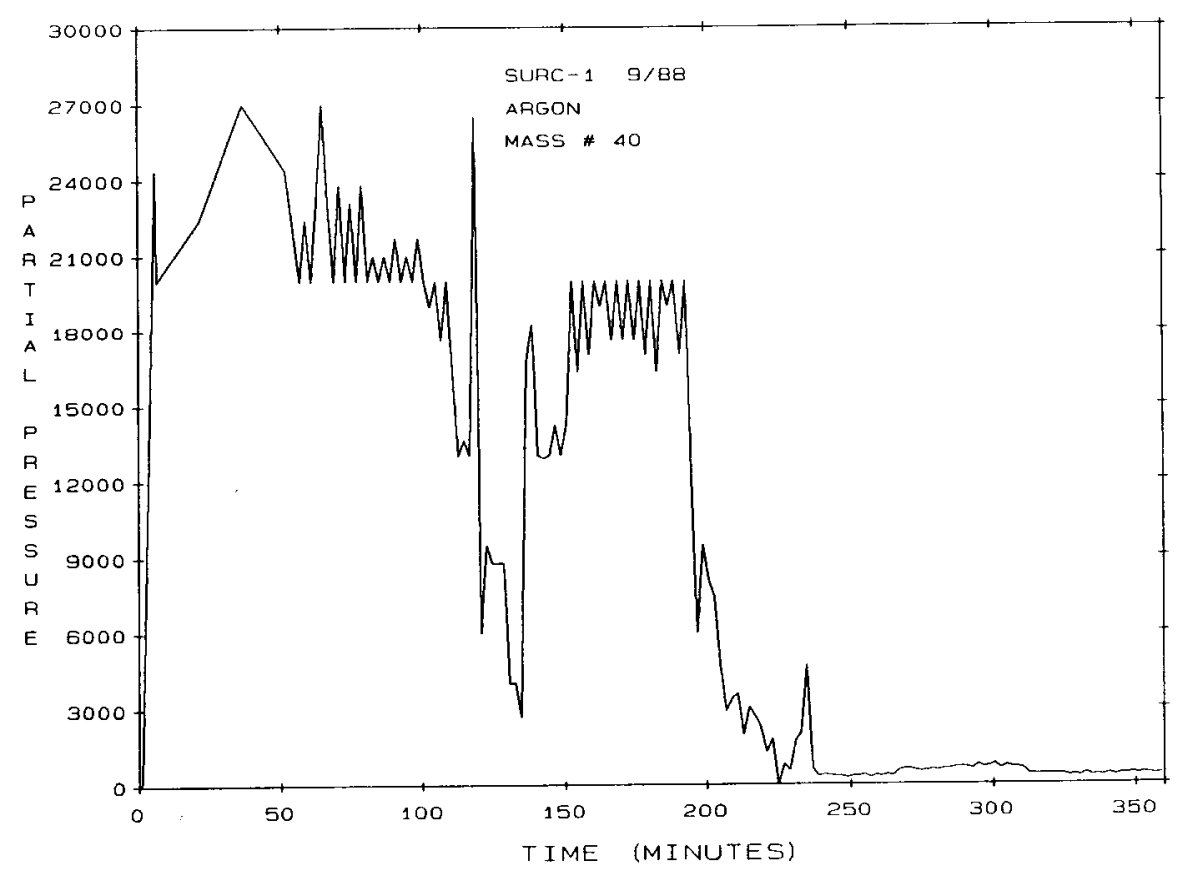

Figure G-26 Partial pressure of argon measured by the mass spectrometer 
Appendix G

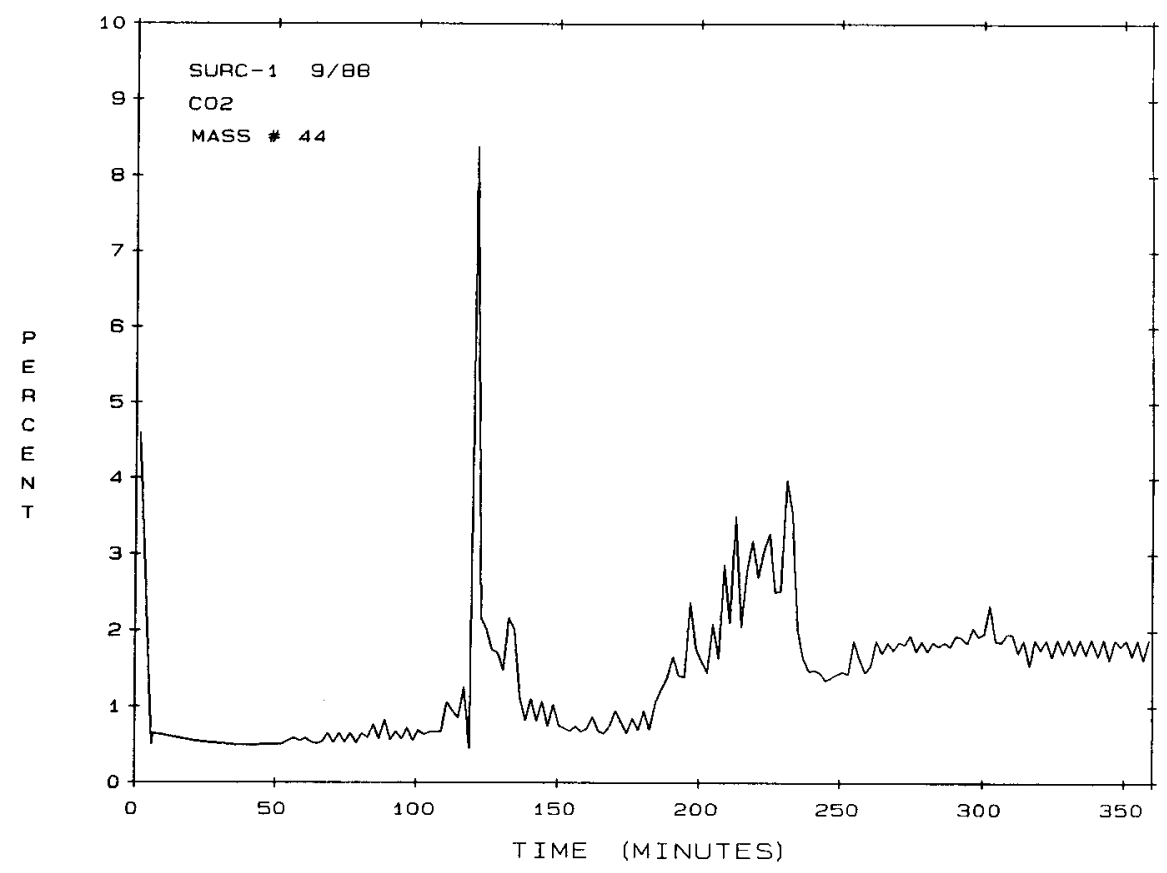

Figure G-27 Volume percent of carbon dioxide measured by the mass spectrometer

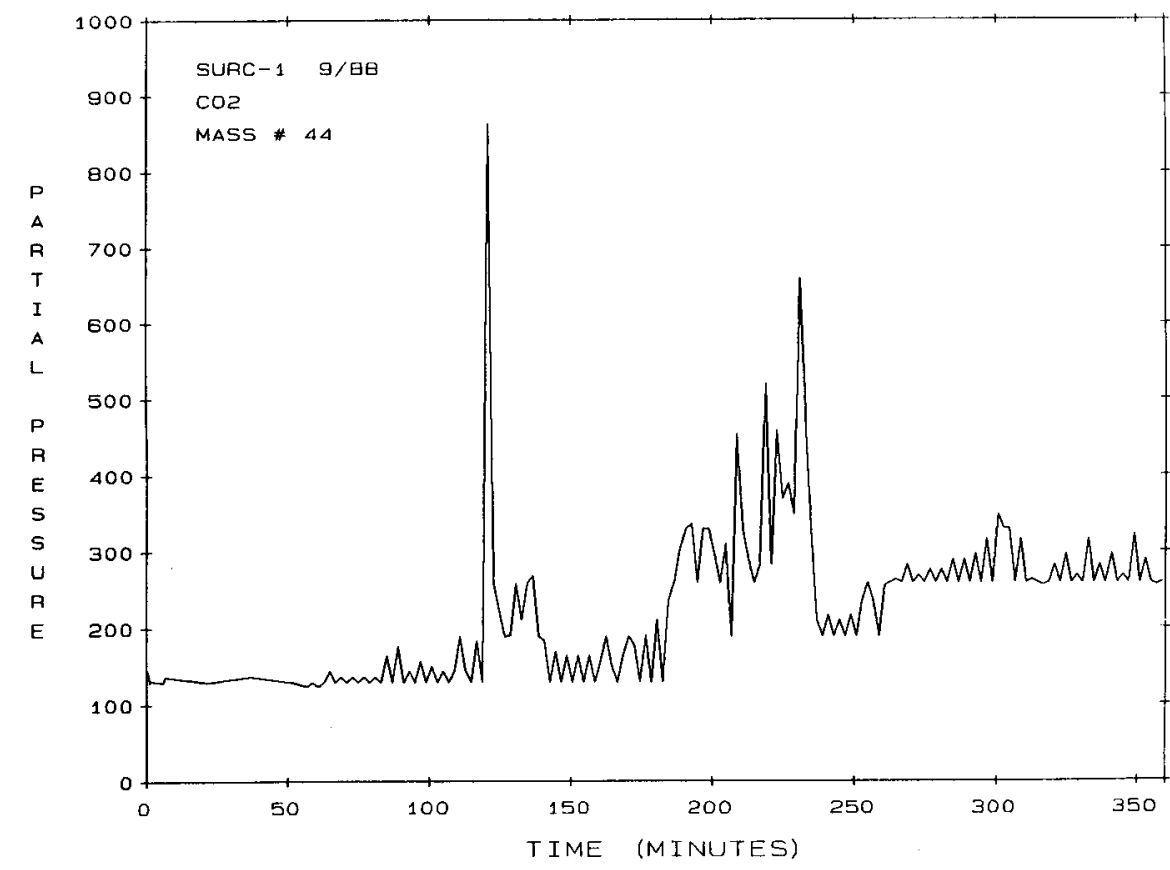

Figure G-28 Partial pressure of carbon dioxide measured by the mass spectrometer 


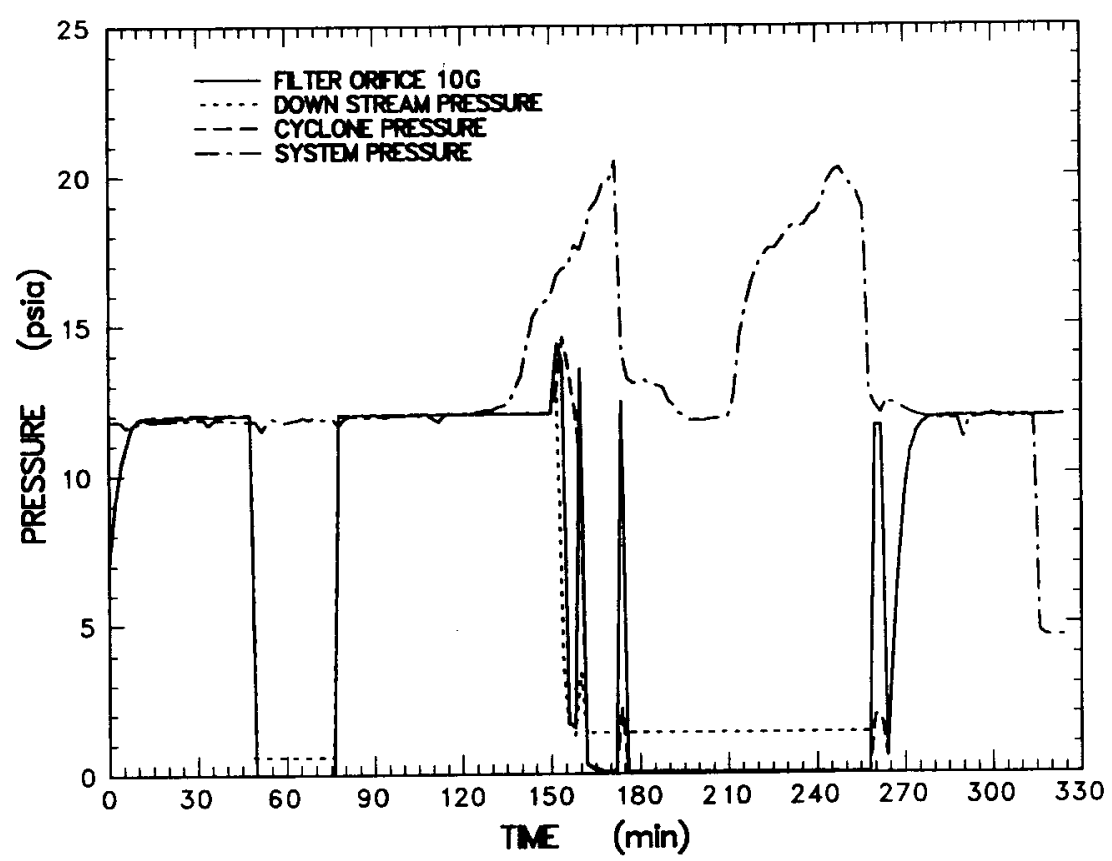

Figure G-29 Absolute pressure measured upstream of critical orifices installed in the aerosol sample lines for the filters and cyclone

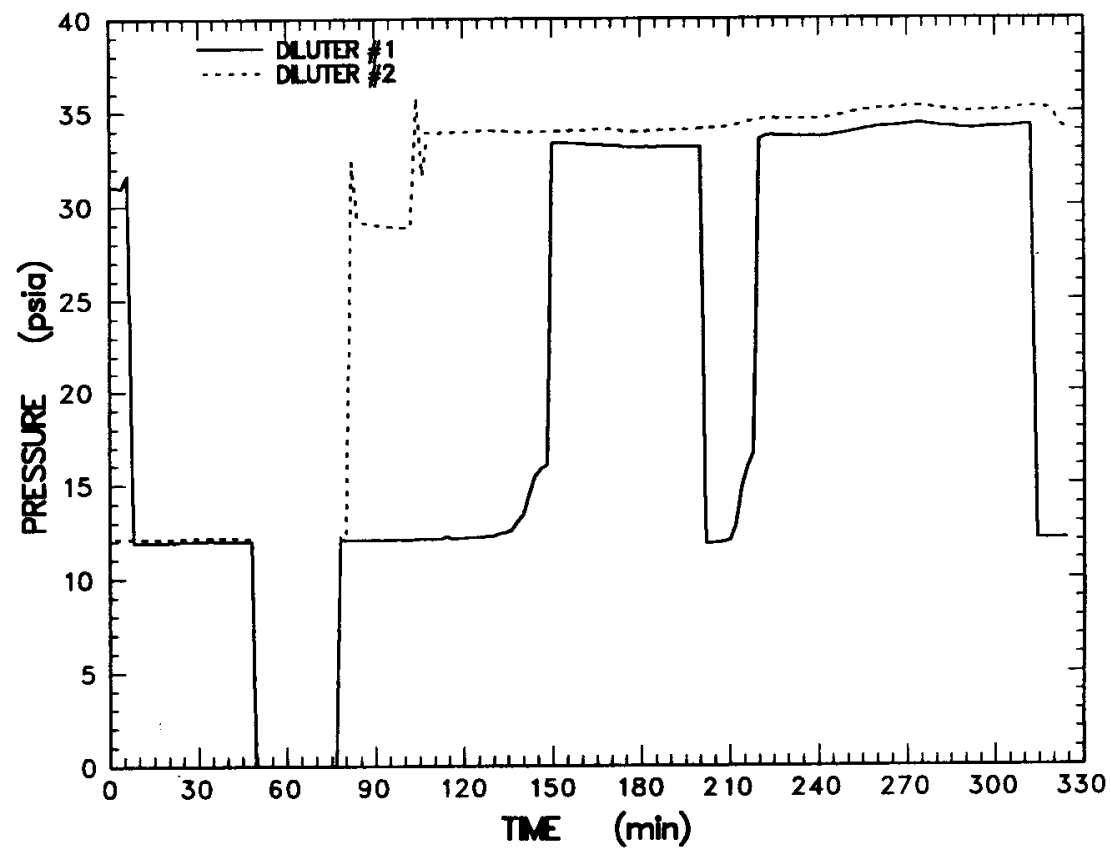

Figure G-30 Absolute pressure measured upstream of critical orifice installed in the aerosol sample line for the diluters 
Appendix G

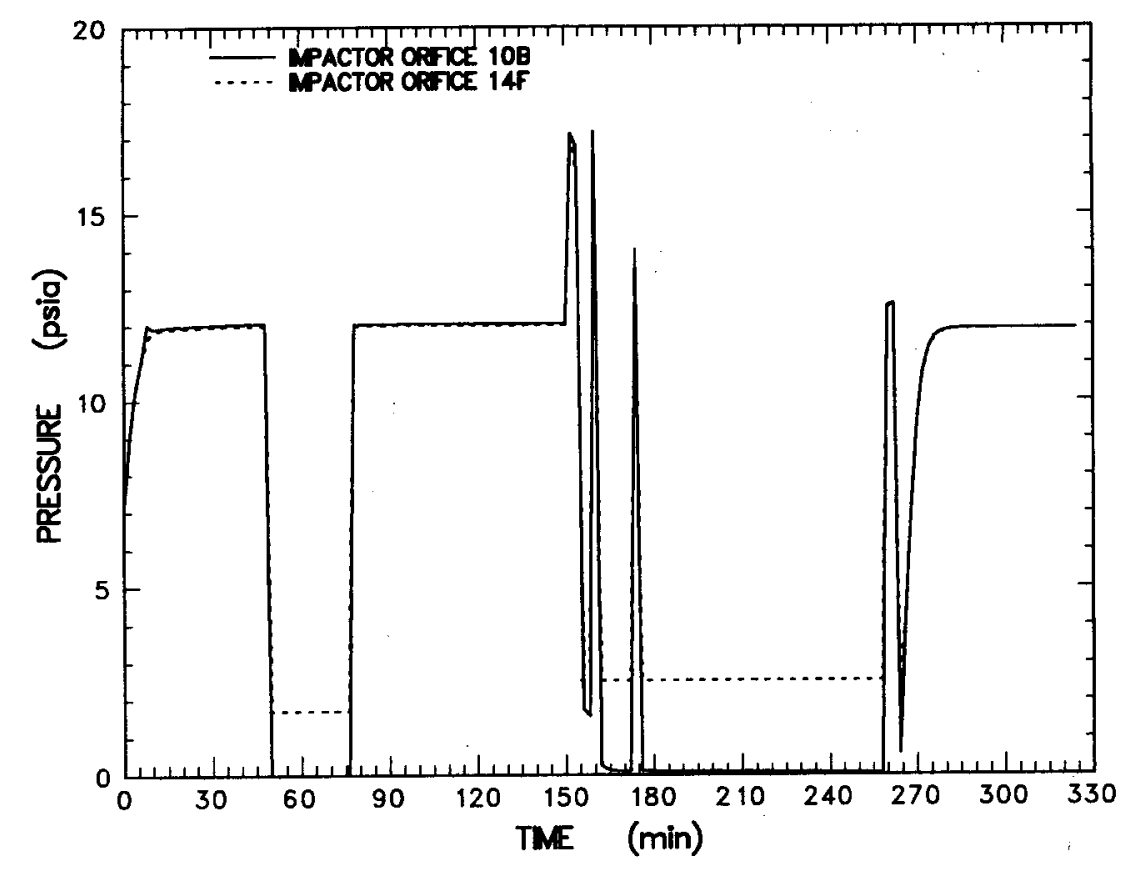

Figure G-31 Absolute pressure measured upstream of critical orifice installed in the aerosol sample line for the impactors

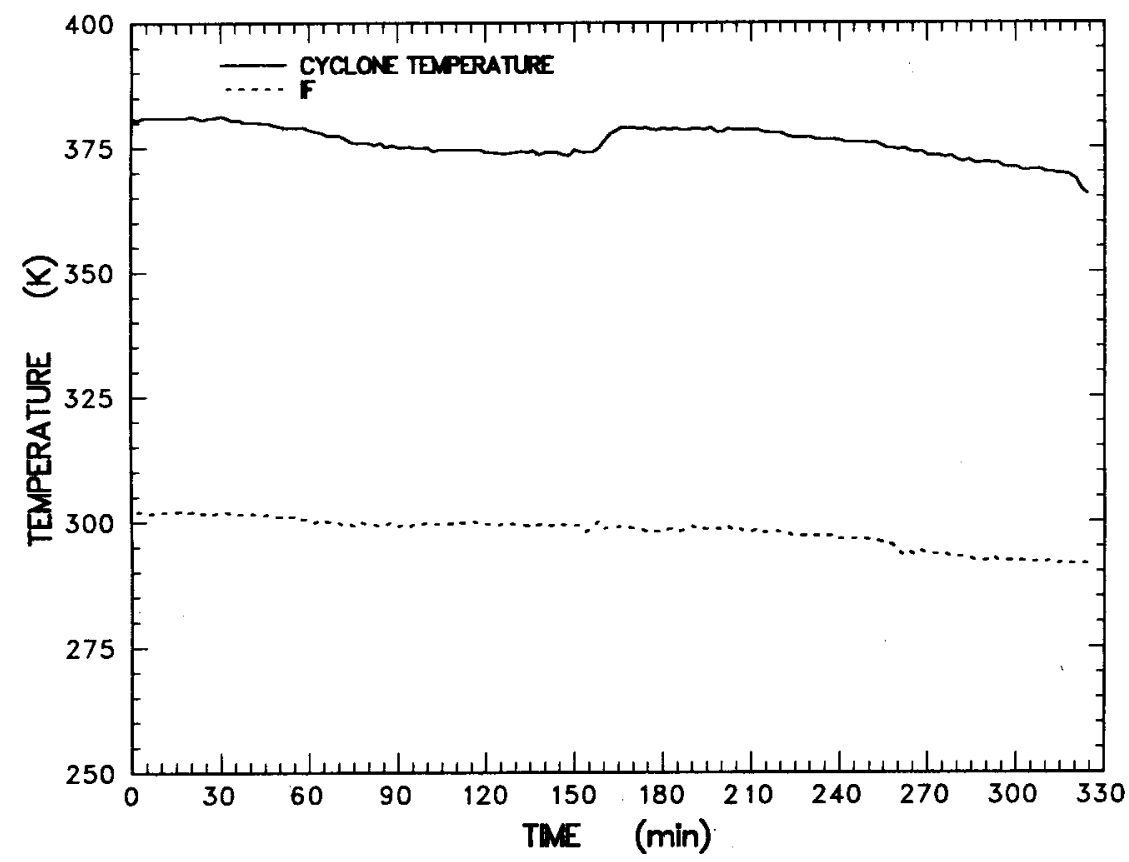

Figure G-32 Temperatures measured at the filter and impactor banks and at the cyclone 


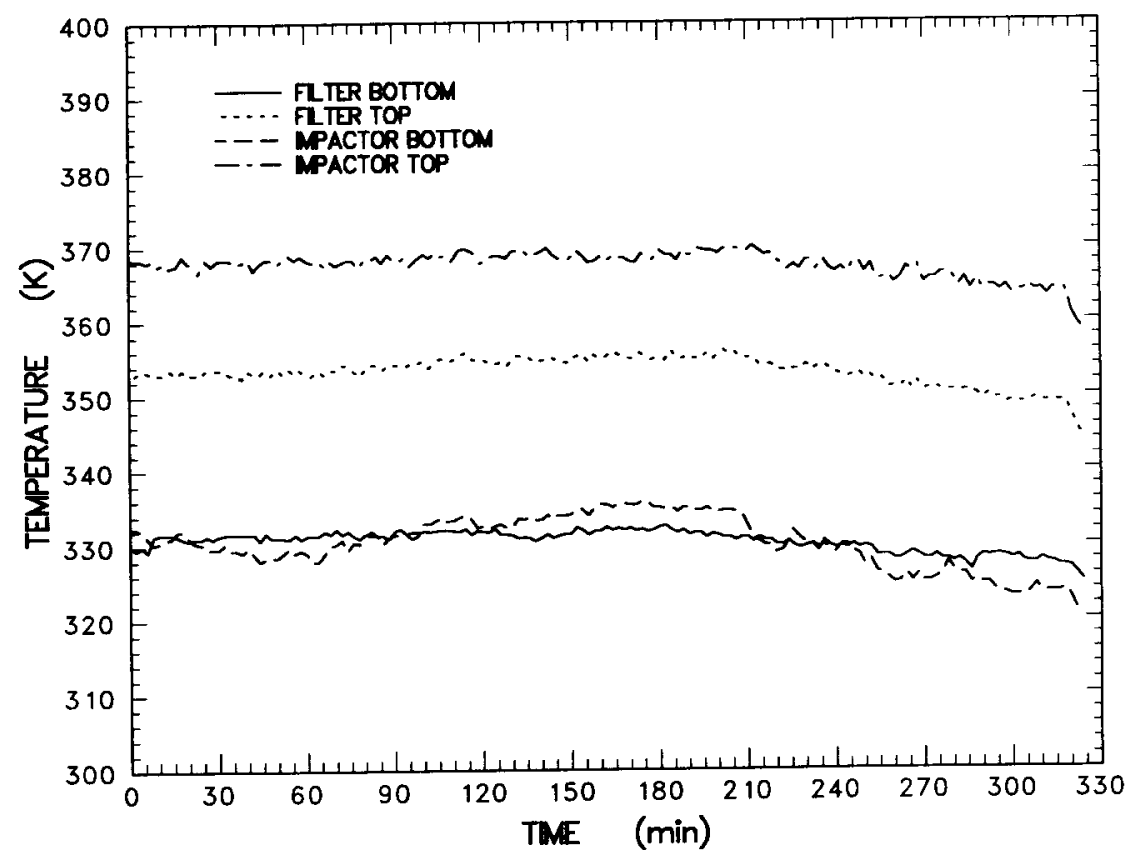

Figure G-33 Temperature of the sample gas exiting the filter and impactor bank circuit

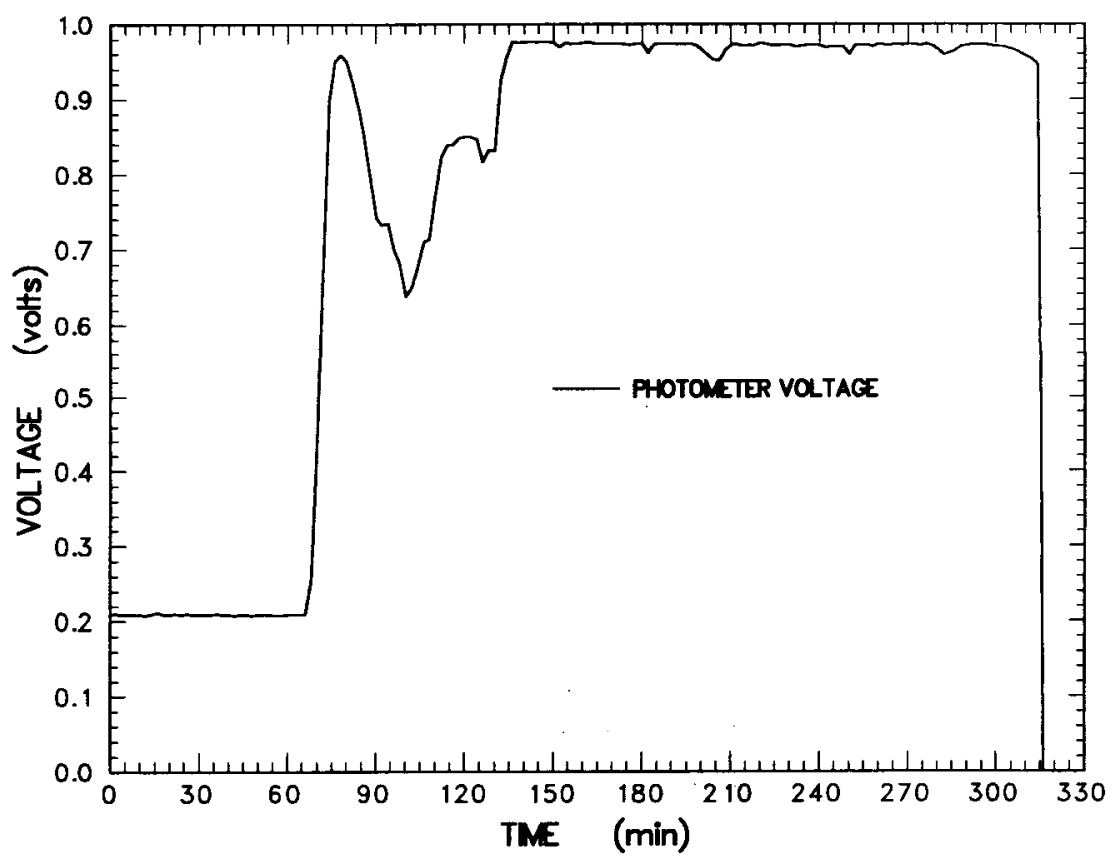

Figure G-34 Photometer output - voltage level is directly proportional to aerosol concentration 
Appendix G

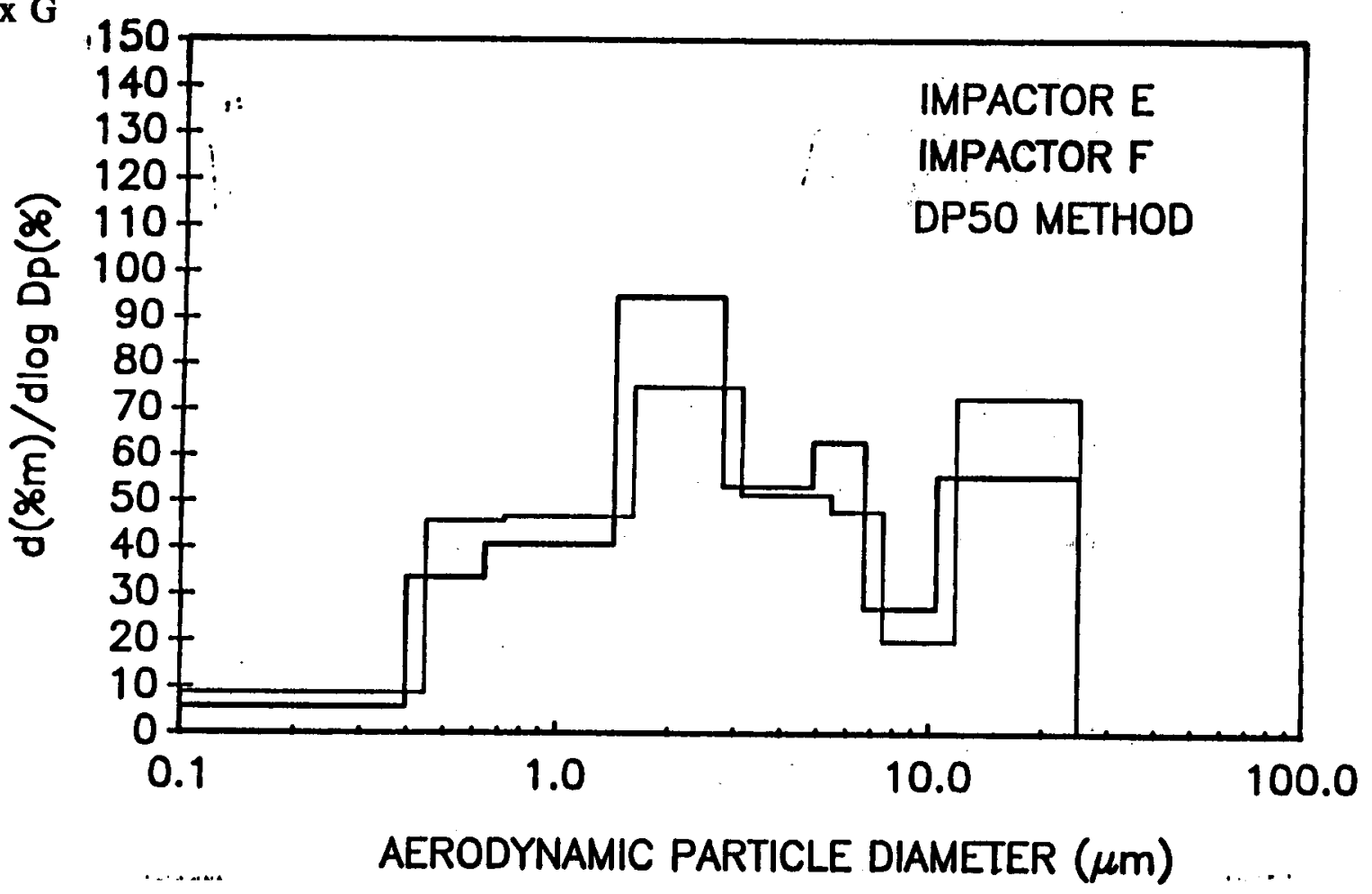

Figure G-35 Normalized aerosol mass distribution from Impactors $E$ and $F$ taken between 154.0 and 155.5 minutes

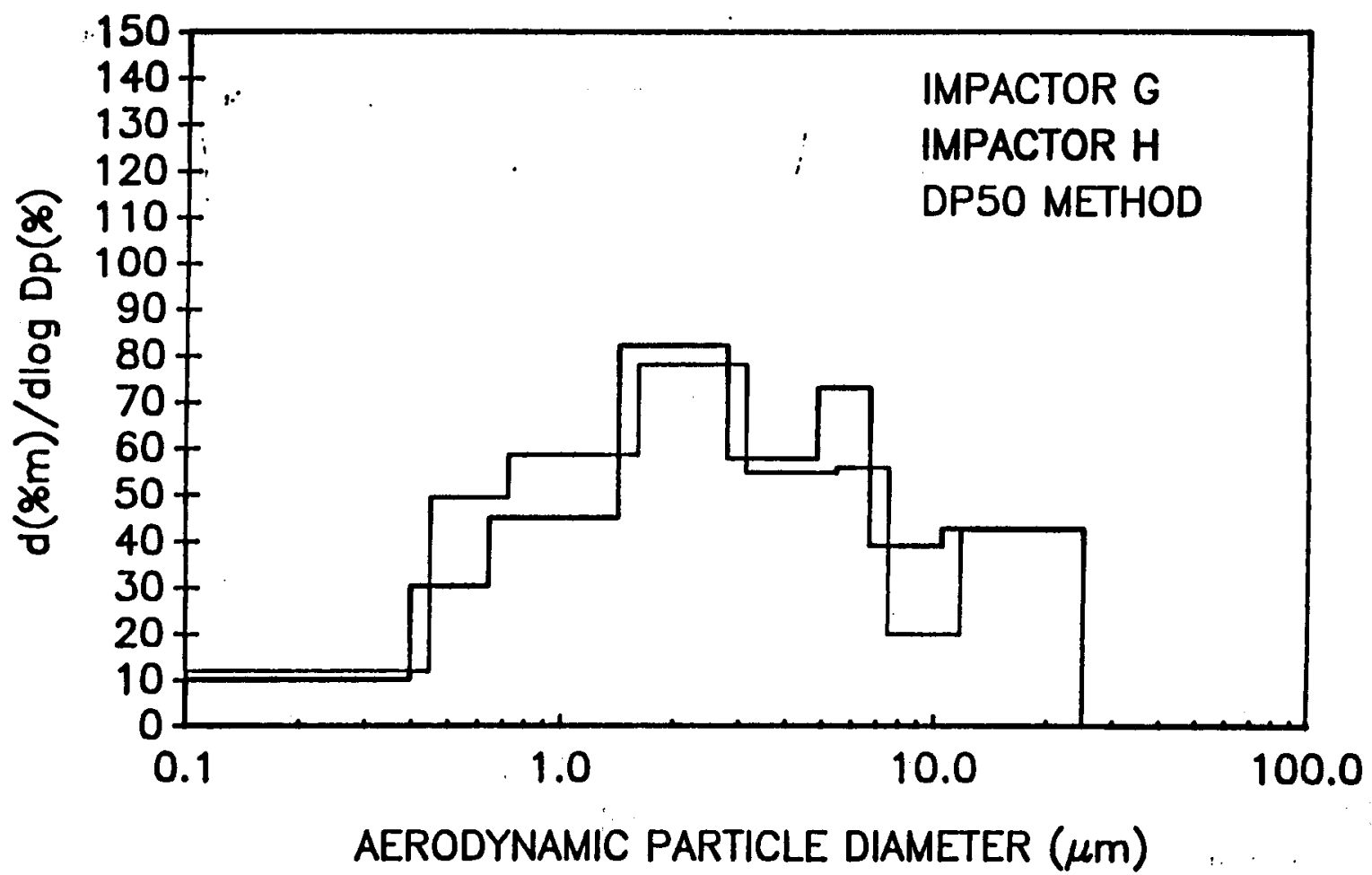

Figure G-36 Normalized aerosol mass distribution from Impactors $G$ and $H$ taken between 159.0 and 160.0 minutes 


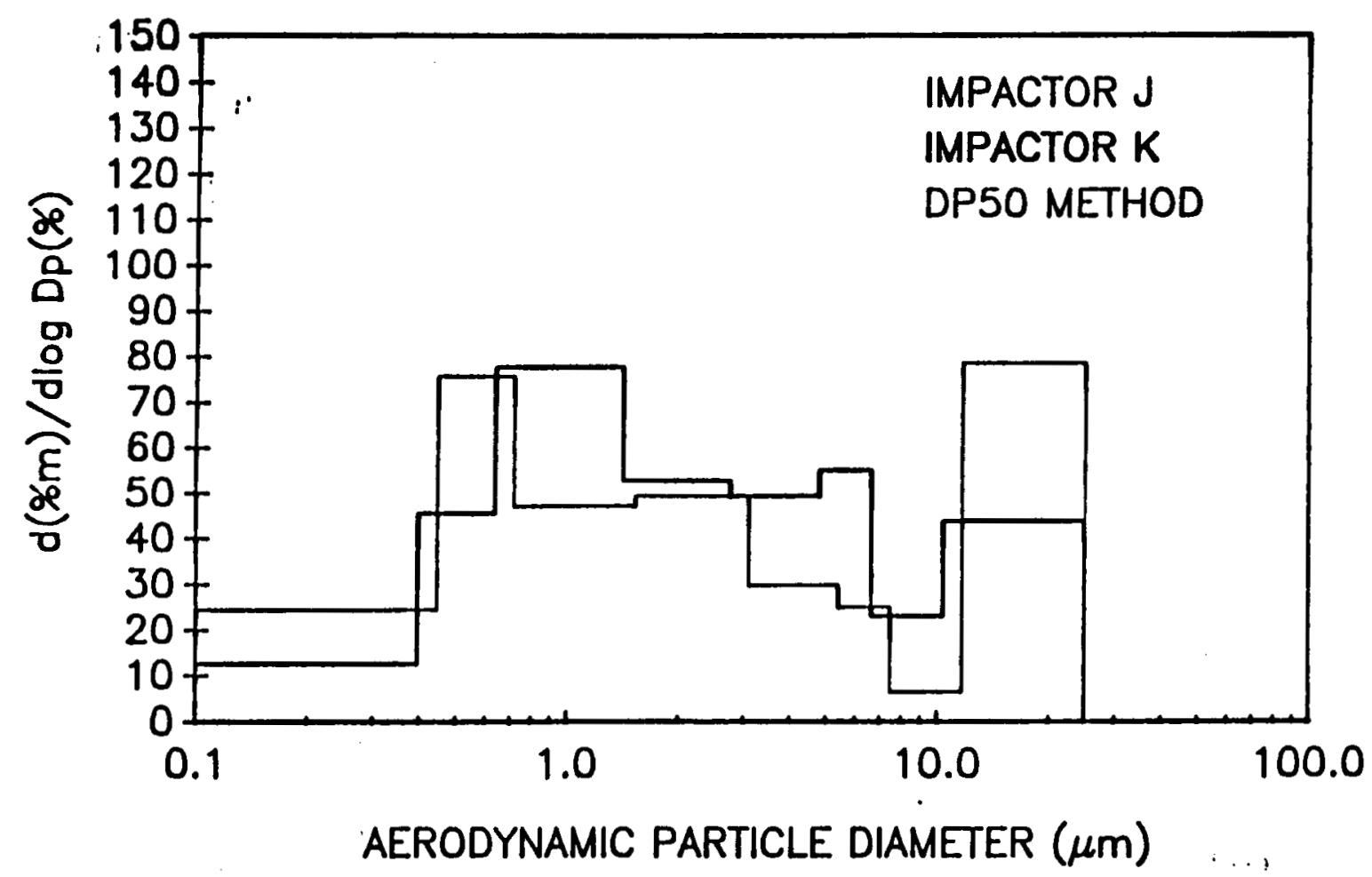

Appendix G

Figure G-37 Normalized aerosol mass distribution from Impactors $J$ and $K$ taken between 173.5 and 174.5 minutes

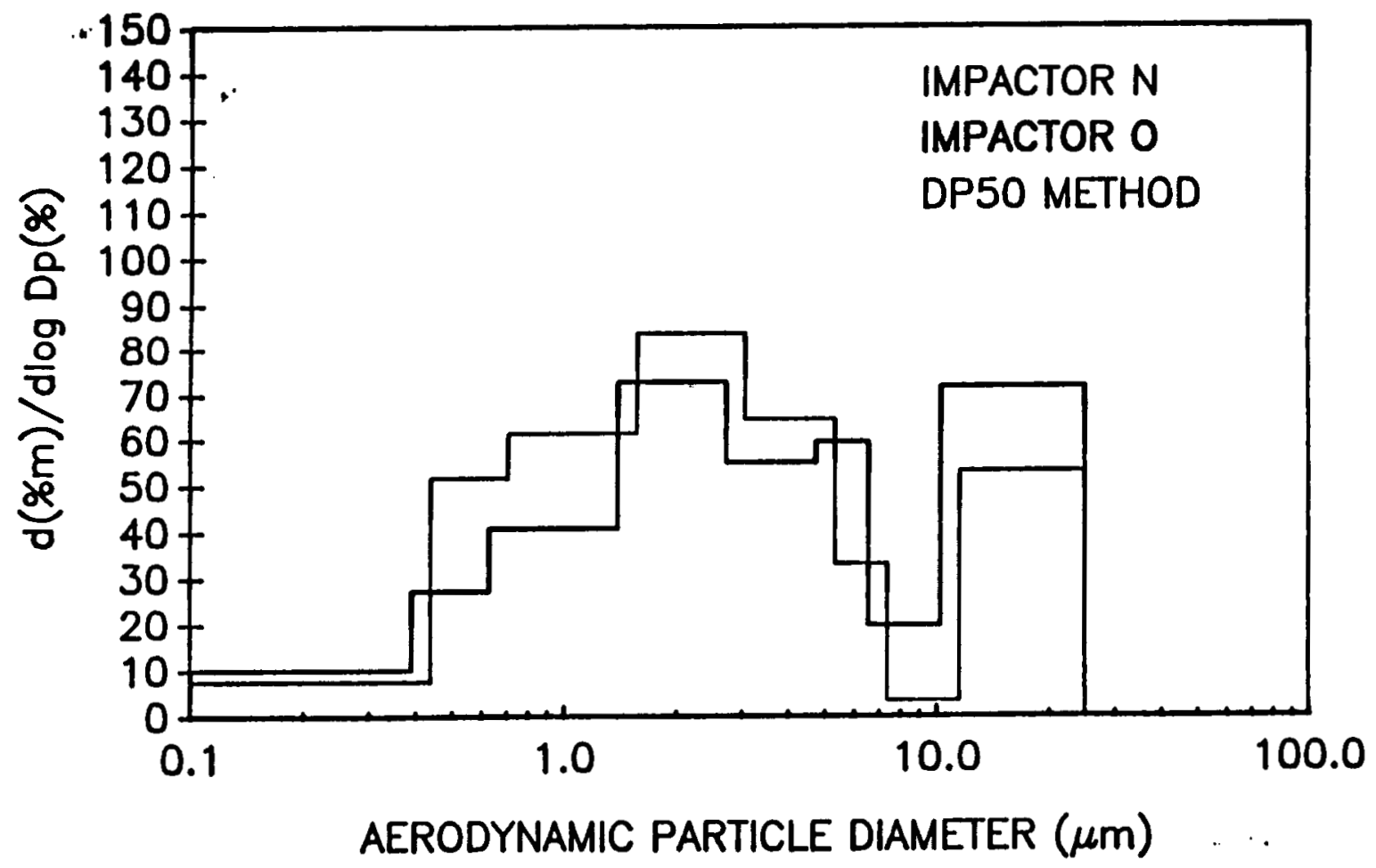

Figure G-38 Normalized aerosol mass distribution from Impactors $N$ and $O$ taken between 260.5 and 261.5 minutes 
Appendix G

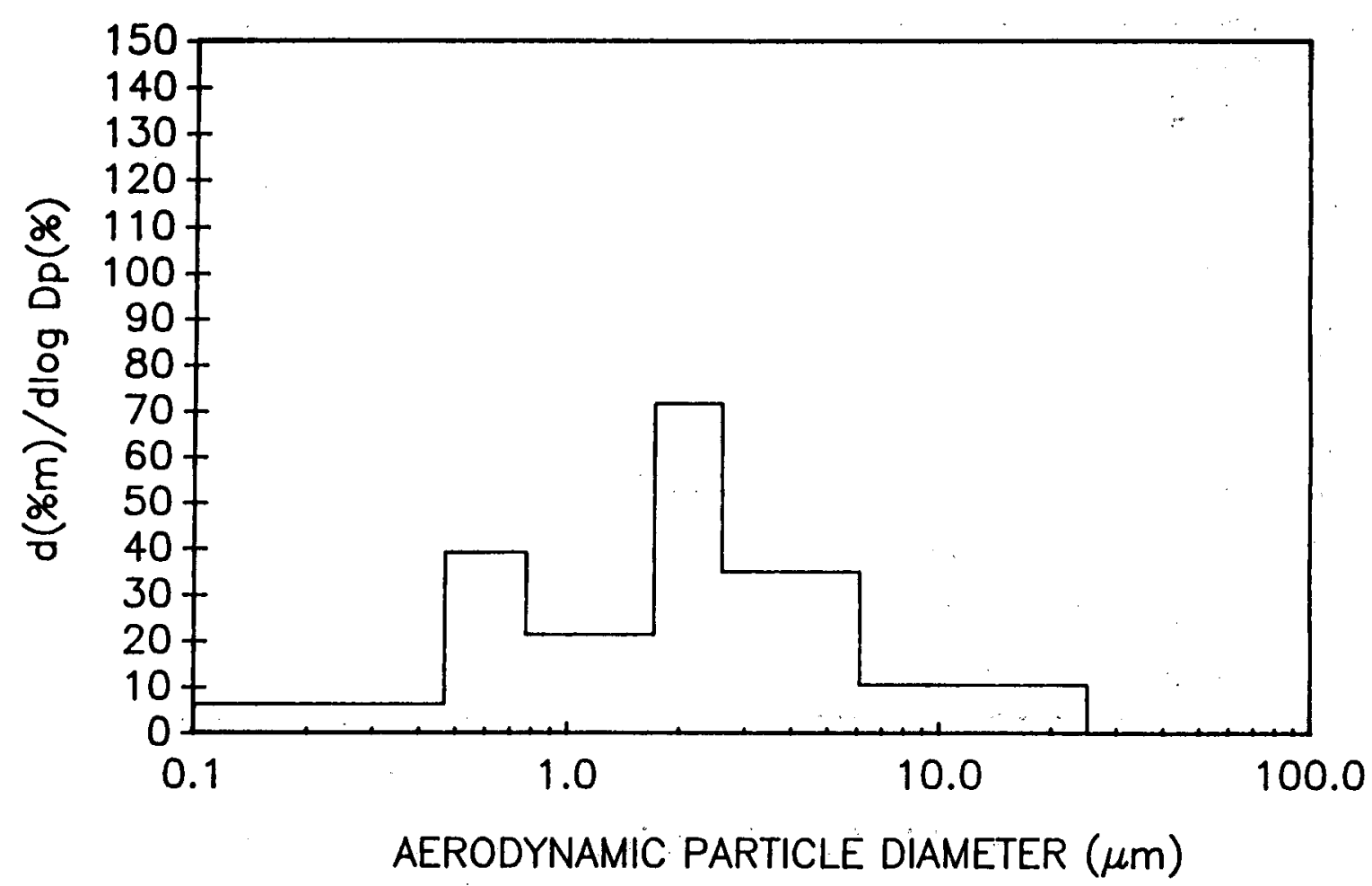

Figure G-39 Normalized aerosol mass distribution from cascade cyclone taken between 153.0 and 159.0 minutes 
Dist

\section{DISTRIBUTION LIST}

No. of

Copies

25 U.S. Nuclear Regulatory Commission Office of Nuclear Regulatory Research Washington, DC 20555

Attn: B. W. Sheron, NLS007

C.G. Tinkler, Jr, NLN344

G.R. Marino, NLS007

A.M. Rubin, NLN344

R.B. Foulds, NLN344

J.A. Murphy, NLS007

S. Basu, NLN344 (15)

E.S. Beckjord, NLS007

F. Eltawila, NLN 344

Z. Rosztoczy, NLS169

T.P. Speis, NLS007

5 U.S. Nuclear Regulatory Commission Office of Nuclear Reactor Regulation Washington, DC 20555

Attn: T.C. Murley, $12 \mathrm{G} 18$

F.P. Gillespie, $12 \mathrm{G} 18$

A.C. Thadani, 8E2 (3)

$2 \quad$ U.S. Department of Energy

Albuquerque Operations Office

P.O. Box 5400

Albuquerque, NM 87185

Attn: C.E. Garcia, Director

2 Electric Power Research Institute

3412 Hillview Avenue

Palo Alto, CA 94303

Attn: A. Machiels
No. of

Copies

3 Brookhaven National Laboratory $130 \mathrm{BNL}$

Upton, NY 11973

Attn: T. Pratt

3 Oak Ridge National Laboratory

P.O. Box Y

Oak Ridge, TN 37830

Attn: T. Kress

3 Argonne National Laboratory

9700 S. Cass Avenue

Argonne, IL 60439

Attn: B. Spencer

1 Nuclear Safety Oversight Commission 1133 15th Street, NW

Room 307

Washington, D.C. 20005

Attn: Cathy Anderson

$1 \quad$ Battelle Columbus Laboratory

505 King Avenue

Columbus, OH 43201

Attn: P. Cybulskis

1 Los Alamos National Laboratories

P.O. Box 1663

Los Alamos, NM 87545

Attn: M. Stevenson

1 UCLA

Nuclear Energy Laboratory

405 Hilgaard Avenue

Los Angeles, CA 90024

Attn: I. Catton 
Dist

\section{DISTRIBUTION LIST (Continued)}

No of

Copies

1 University of Wisconsin

Nuclear Engineering Department

1500 Johnson Drive

Madison, WI 53706

Attn: M.L. Corradini

1 EG\&G Idaho

Willo Creek Building, W-3

P.O. Box 1625

Idaho Falls, ID 83415

Attn: R. Hobbins

1 Battelle Pacific Northwest Laboratory

P.O. Box 999

Richland, WA 99352

Attn: M. Freshley

1 Department of Energy

Scientific and Tech. Info. Center

P.O. Box 62

Oak Ridge, TN 37831

$1 \quad$ Fauske and Associates, Inc.

16W070 West 83rd Street

Burr Ridge, IL 60952

Attn: R. Henry

1 IAEA

Division of Nuclear Reactor Safety

Wagranesrstrasse 5

P.O. Box 100

A/1400 Vienna

Austria

Attn: M. Jankowski
No of

Copies

1 Department LWR Fuel

Belgonucleaire

Rue de Champde Mars. 25

B-1050 Brussels

Belgium

Attn: Mr. H. Bairiot, Chief

1 U.S. Nuclear Regulatory Commission Advising Comm. on Reactor Safeguard Washington, D.C. 20555

Attn: M.D. Houston, P-315

2 Atomic Energy Canada, Ltd.

Chalk River, Ontario

Canada KOJ IJO

Attn: R.D. MacDonald

1 Institute of Nuclear Energy Research

P.O. Box 3

Lungtan

Taiwan 325

Republic of China

Attn: Sen-I Chang

1 Department of Nuclear Safety

Finnish Center for Radiation

and Nuclear Safety

P.O. Box 268

SF-00181 Helsinki

Finland

Attn: Jorma V. Sandberg

1 CEN Cadarache

18108 Saint Paul Lez Durance

France

Attn: A. Meyer-Heine 


\section{DISTRIBUTION LIST (Continued)}

No of

Copies

1 Centre d'Estudes Nuclearies (IPSN-DAS)

Commisariat a l'Energie Atomique

Boite Postale No. 6

F-92265 Fontenay-aux-Roses Cedex

France

Attn: Jacques Duco

1 Gesellschaft fur Reaktorsicherheit (GRS)

Postfach 101650

Glockengrasse 2

5000 Koeln 1

Federal Rebulic of Germany

$1 \quad$ Kraftwerk Union

Hammerbacher Strasse 1214

Postfach 3220

D-8520 Erlangen 2

Federal Rebulic of Germany

Attn: Dr. M. Peeks

2 Kernforschungszentrum Karlsruhe

Postfach 3640

75 Karlsruhe

Federal Republic of Germany

Attn: S. Hagen

1 Nucleare e della Protezione

Sanitaria (DISP)

Ente Nazionnle Energie

Alternative 7(ENEA)

Viale Regina Margherita, 125

Casella Postale M. 2358

I-00100 Roma A.D.

Italy

Attn: Mr. G. Petrangeli

1 Thermodynamics \& Rad. Physics

CEC Joint Research Center, Ispra

I-21020 Ispra (Varese)

Italy

Attn: Alan V. Jones
No of

Copies

2 Japan Atomic Energy Research Institute Tokai-Mura, Naka-Gun

Ibaraki-Ken 319-11

Japan

Attn: K. Soda

1 Reactor Centrum Nederland

1755 ZG Petten

The Netherlands

Attn: Dr. K.J. Brinkman

1 I. V. Kurchatov Institute of Atomic Energy

Nuclear Safety Department

Moscow, 123182

Russia

Attn: V. Asmalov

1 Sub. Emplazamientos y Programas

Consejo de Seguridad Nuclear

Justo Dorado II

28040 Madrid

Spain

Attn: Jose Angel Martinez

1 Consejo de Seguridad Nuckan

SOR Angela de la Cruz No. 3

Madrid

Spain

Attn: Juan Bagues

$1 \quad$ E.T.S. Ingenieros Industriales

Jost Gutierrez Abascal, 2

28006 Madrid

Spain

Attn: Professor Agustin Alonso

1 Department of Nuclear Power Safety

Royal Institute of Technology

S-100 44 Stockholm

Sweden

Attn: B. Raj Sehgal 
Dist

\section{DISTRIBUTION LIST (Concluded)}

No of

Copies

2. Statens Karnkraftinspektion

P.O. Box 27106

S-10252 Stockholm

Sweden

Attn: W. Frid

1 Light Water Reactor Safety Program

Paul Scherrer Institute

CH-5232 Villigen PSI

Switerzerland

Attn: J. Peter Hosemann

1 Swiss Federal Nuclear Safety Directorate

CH-5303 Wurenlingen

Switzerland

Attn: S. Chakraborty

1 Korea Atomic Energy Research Inst.

Korea Adv Energy Research Inst.

PO Box 7

Daeduk-Danji

Taejan 305-353

Attn: C.K. Park

2 UKAEA

Winfrith, Dorchester

Dorset DT2 8DH

United Kingdom

Attn: A. Nichols 102/A50

S. Kinnersly 204/A32
No of

Copies

1 UKAEA Culham Laboratory

Abingdon

Oxfordshire OX14 3DB

United Kingdom

Attn: B.D. Turland E5.157

40

Sandia National Laboratories

P.O. Box 5800

Albuquerque, NM 87185

Attn: D.W. Schaeffer $/ 1810$

S.A. Landenberger/3141 (5)

Document Processing for

DOE-OSTI/3145 (8)

G.C. Claycomb/3151(3)

N.R. Ortiz/6400

D.A. Powers $/ 6404$

M.D. Allen/6422 (5)

F.E. Arellano/6422

N. Bixler $/ 6422$

T.K. Blanchat/6422

R.E. Blose $/ 6422$

J.E. Brockmann/6422

R.M. Elrick/ 6422

T. Heames $/ 6422$

M. Pilch/6422

K.O. Reil/6423

K.E. Washington/6429

E.R. Copus/7725

Central Technical Files/8523-2 


\begin{tabular}{|c|c|}
\hline $\begin{array}{l}\text { US. NUCLEAR REGULATORY COMMISSION } \\
\text { BIBLIOGRAPHIC DATA SHEET } \\
\text { (See instructions on the neverse) }\end{array}$ & \multirow[t]{2}{*}{ 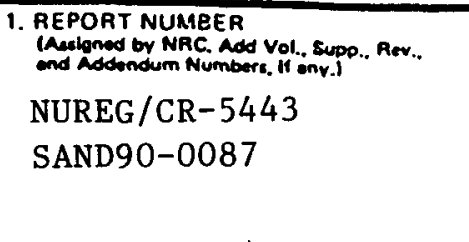 } \\
\hline \multirow{3}{*}{$\begin{array}{l}\text { 2. TITLE AND SUBTITLE } \\
\text { Core-Concrete Interactions Using Molten Urania With } \\
\text { Zirconium on a Limestone Concrete Basemat } \\
\text { The SURC-1 Experiment }\end{array}$} & \\
\hline & \begin{tabular}{c|c} 
3. & DATE REPORT PUBLISHED \\
MONTH & YEAF \\
September & 1992
\end{tabular} \\
\hline & $\begin{array}{l}\text { 4. FIN OR GRANT NUMBEA } \\
\text { A1218 }\end{array}$ \\
\hline \multirow{3}{*}{$\begin{array}{l}\text { 5. AUTHOR(S) } \\
\text { E. R. Copus, R. E. Blose*, J. E. Brockmann, } \\
\text { R. B. Simpson, and D. A. Lucero }\end{array}$} & 6. TYPE OF AEPORT \\
\hline & Technical \\
\hline & $\begin{array}{l}\text { 7. PERIOD COVERED Inclusure Dsis' } \\
\text { Oct } 86 \text { - Aug } 92\end{array}$ \\
\hline \multirow{2}{*}{\multicolumn{2}{|c|}{ 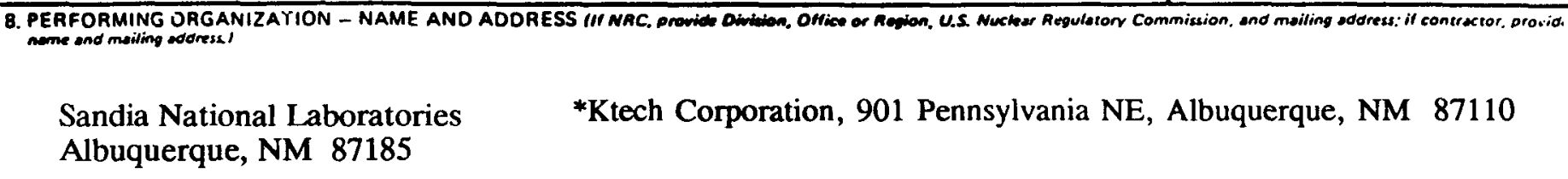 }} \\
\hline & \\
\hline \multicolumn{2}{|l|}{ 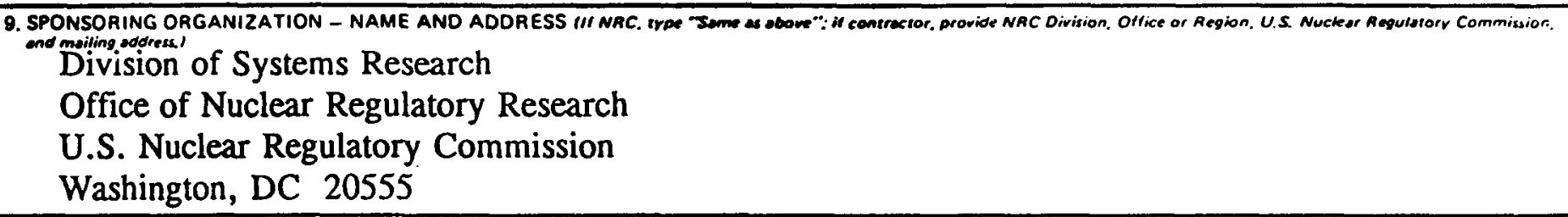 } \\
\hline \multicolumn{2}{|l|}{ 10. SUPPLEMENTARY NOTES } \\
\hline \multicolumn{2}{|l|}{ 11. ABSTRACT (200 worot or kess) } \\
\hline \multicolumn{2}{|c|}{$\begin{array}{l}\text { An inductively heated experiment, SURC-1, was executed as part of the Integral Core-Concrete } \\
\text { Interactions Experiments Program. The purpose of this experiment was to measure and assess the } \\
\text { variety of source terms produced during core debris/concrete interactions. These source terms include } \\
\text { thermal energy released to both the reactor basemat and the containment environment, as well as } \\
\text { flammable gas, condensable vapor and toxic or radioactive aerosols generated during the course of a } \\
\text { severe reactor accident. }\end{array}$} \\
\hline \multicolumn{2}{|c|}{$\begin{array}{l}\text { The SURC-1 experiment used } 204 \mathrm{~kg} \text { of prototypic } \mathrm{UO}_{2}-\mathrm{ZrO}_{2} \text { materials to study the interactions } \\
\text { between core debris and a limestone basement. The experiment eroded } 27 \mathrm{~cm} \text { of concrete during } 130 \\
\text { minutes of sustained interaction at temperatures which ranged from } 2650 \text { to } 2200 \mathrm{~K} \text {. Comprehensive } \\
\text { gas flow rates, gas compositions, and aerosol release rates from the interaction were also measured. }\end{array}$} \\
\hline \multirow{5}{*}{$\begin{array}{l}\text { Molten core interactions, ex-vessel interactions, reactor } \\
\text { containment safety studies, melt-concrete heat transfer, } \\
\text { core debris-concrete interactions, ex-vessel aerosol source } \\
\text { terms, zirconium oxidation }\end{array}$} & 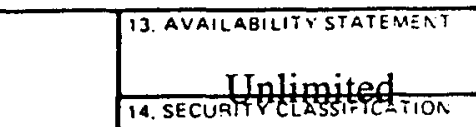 \\
\hline & $\begin{array}{l}\text { Untis Paget } \\
\text { Unclassified }\end{array}$ \\
\hline & $\begin{array}{l}\text { Trhis Reoorul } \\
\text { Unclassified }\end{array}$ \\
\hline & 15. NUMBER OF PAGES \\
\hline & 16. PRICE \\
\hline
\end{tabular}




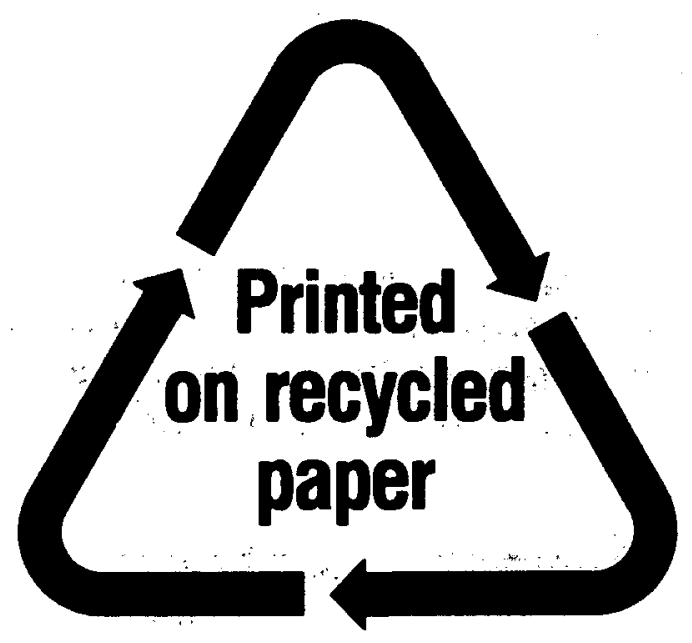

Federal Recycling Program 